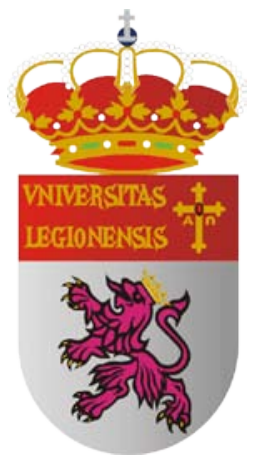

UNIVERSIDAD DE LEÓN

Departamento de Dirección y Economía de la Empresa

\title{
LA RESPONSABILIDAD DE LAS
}

\section{Organizaciones desde la Perspectiva DE LA DEMANDA}

Tesis Doctoral presentada por:

JESÚS GARCÍA GONZÁLEZ

Dirigida por los Profesores

Dr. D. José LuIS VÁzQuez BURGUETE

Dra. Da MARÍA PURIFICACIÓN GARCÍA MIGUÉLEZ 



\title{
LA RESPONSABILIDAD DE LAS
}

\section{Organizaciones desde la Perspectiva de}

\author{
LA DEMANDA
}





\section{AGRADECIMIE NTOS}

Quisiera dedicar unas líneas de agradecimiento a todas aquellas personas que, de una forma u otra, han contribuido y hecho posible la realización de esta Tesis.

Muy especialmente a mis directores de tesis, el profesor Dr. José Luis Vázquez Burguete y la profesora Dra. María Purificación García Miguélez, por su amistad, constante apoyo, disposición y el tiempo que me han dedicado, ya que sin sus consejos y su eficaz trabajo no hubiera podido llevar a cabo este proyecto.

A la profesora Dra. Ana Lanero, por la importante ayuda recibida tanto en el tratamiento de los datos como en los aspectos metodológicos, así como al profesor Dr. Pablo Gutiérrez, y en general al grupo de trabajo de Marketing e Investigación Operativa (MIO) y a otros compañeros de la Universidad de León, por sus palabras de interés y apoyo.

Al personal del Departamento de Gestão e Economia de la Universidade da Beira Interior (Portugal), principalmente a la profesora Dra. Helena Alves, por su extraordinaria acogida durante la realización de la Tesis.

A los miembros de la Asociación Internacional de Marketing Público y No Lucrativo (AIMPN), por haber podido participar en sus foros de debate y contactar con investigadores de esta temática en los diferentes congresos y jornadas que se vienen organizando desde hace una década.

Y por supuesto a mi familia, especialmente a mi esposa Luisa María y a mis hijas Miriam y Sonia, que han compartido el día a día de este trabajo y me han apoyado de manera incondicional. 


\section{ACRónIMOS}

AECA: $\quad$ Asociación Española de Contabilidad y Administración de Empresas

AENOR: $\quad$ Asociación Española de Normalización y Certificación

ASEPAN: $\quad$ Red Española del Pacto Mundial de las Naciones Unidas

AVE: $\quad$ Average Variance Extracted (varianza extraída media)

BSR: $\quad$ Business for Social Responsibility

CECU: $\quad$ Confederación de Consumidores y Usuarios

CED: $\quad$ Committee for Economic Development

CEPAA: $\quad$ Agencia de Acreditación del Consejo de Prioridades Económicas

CEPES: $\quad$ Confederación Empresarial Española de Economía Social

CERES: $\quad$ Coalition for Environmentally Responsible Economies

CERSE: $\quad$ Consejo Estatal de Responsabilidad Social de las Empresas

CSP: $\quad$ Corporate Social Performance

CSR: $\quad$ Corporate Social Responsibility

CRM: $\quad$ Cause Related Marketing

DJSI: $\quad$ Dow Jones Sustainability Indexes

DT: $\quad$ Desviación Típica

ECIDES: $\quad$ Fundación Ecología y Desarrollo

EPA: $\quad$ Encuesta de Población Activa

ERSE: $\quad$ Fundación Étnor

FTSE: $\quad$ Financial Times Stock Exchange

GRI: Global Reporting Initiative

GT.IIIa Subgrupo de Trabajo de Consumo Socialmente Responsable 
IAPNM: International Asotiation on Public and Nonprofit Marketing

IDEAS: Iniciativas de Economía Alternativa y Solidaria

INE: $\quad$ Instituto Nacional de Estadística

ISO: $\quad$ Organización Internacional para la Estandarización

IVAJ: $\quad$ Instituto Valenciano de la Juventud

KMO: $\quad$ Kaiser-Meyer-Olkin

MCC: $\quad$ Marketing Con Causa

MEE: $\quad$ Modelos de ecuaciones estructurales

MERCO: $\quad$ Monitor Español de Reputación Corporativa

ML: $\quad$ maximun likelihood (mínimos cuadrados generalizados)

NHBPEP: $\quad$ Programa Nacional de Educación sobre la Hipertensión Arterial

UE: $\quad$ Unión Europea

OCDE: $\quad$ Organización para la Cooperación y el Desarrollo Económico

OLS: $\quad$ ordinary least squares (mínimos cuadrados ordinarios)

OIT: $\quad$ Organización Internacional del Trabajo

ONG's: $\quad$ Organizaciones no Gubernamentales

ONU: $\quad$ Organización de las Naciones Unidas

OSE: $\quad$ Observatorio de la Sostenibilidad en España

PLS: $\quad$ Partial Least Squares (mínimos cuadrados parciales)

PNC: $\quad$ Puntos Nacionales de Contacto

PNUMA: $\quad$ Programa de las Naciones Unidas para el Medio Ambiente

RS: $\quad$ Responsabilidad Social

RSC: Responsabilidad Social Corporativa

RSE: Responsabilidad Social de las Empresas

SAI: Social Accountability International

SAM: $\quad$ Sustainability Asset Management

SGP: $\quad$ Sistema General de Preferencias 
SID: $\quad$ Social Involvement Disclosure

SPANSIF: $\quad$ Foro de Inversión Socialmente Responsable

UE: $\quad$ Unión Europea

UNED: $\quad$ Universidad de Educación a Distancia

VD: $\quad$ Variable Dependiente

VI: $\quad$ Variable Independiente 


\section{ÍNDICE GeneraL}

INTRODUCCIÓN

CAPítulo 1. ReVISIÓN HISTÓRICo-EConómica de LA RESPONSABILIDAD DE LAS ORGANIZACIONES..................... 11

1.1. Los antecedentes (hasta 1950) ........................................ 15

1.2. Primeros debates y posicionamientos (1951-1960) ....................... 18

1.3. Formalización y consolidación (1961-1980) ................................ 19

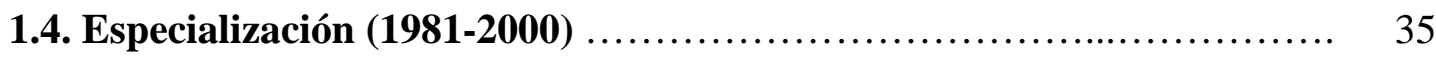

1.5. Nuevos planteamientos y reconceptualización (desde 2001).............. 44

1.6. Estudios bibliométricos ................................................ 50

1.7. Consecuencias de la revisión histórico-económica ......................... 52

Capítulo 2. Planteamientos Normativos y Regulatorios Sobre la Responsabilidad de Las Organizaciones en el Contexto

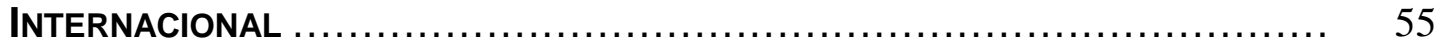

2.1. La regulación de la responsabilidad por la Administración Pública .... 58

2.1.1. Las Políticas Públicas sobre responsabilidad .......................... 59

2.1.2. Posturas sobre la regulación de la responsabilidad .................... 61

2.2. Normativa y regulación internacional ................................... 67

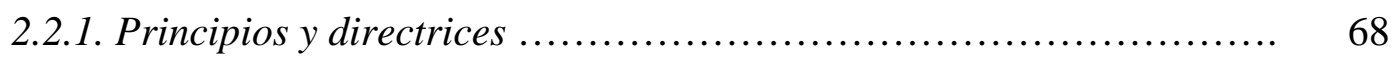

2.2.2. Certificaciones y estándares técnicos ............................... 80

2.2.3. Los indicadores de sostenibilidad .................................... 88

2.3. Normativa y regulación de la responsabilidad en la Unión Europea .... 92

2.3.1. Antecedentes en la UE en cuanto a responsabilidad en las organizaciones ....................................................... 93

2.3.2. La formalización de los planteamientos sobre responsabilidad en la

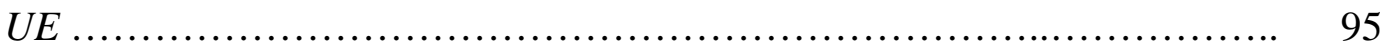


2.3.3. El desarrollo del marco normativo-regulador de la responsabilidad en la UE

\section{Capítulo 3. Regulación y ARTiculación de LA Responsabilidad en}

ESPAÑA

3.1. Primeras iniciativas y debates.

3.1.1. La Subcomisión Parlamentaria para potenciar y promover la responsabilidad social empresarial

3.1.2. El Foro de Expertos en responsabilidad social empresarial

3.1.3. La Mesa de Diálogo Social

3.2. El Consejo Estatal de Responsabilidad Social de las Empresas (CERSE)

3.2.1. Funciones del CERSE

3.2.2. Grupos de Trabajo del CERSE

130

3.3. Otras iniciativas e instituciones relevantes en responsabilidad

3.3.1. Otras iniciativas públicas estatales 136

3.3.2. Iniciativas públicas regionales 138

3.3.3. Otras iniciativas relevantes fuera del ámbito público 140

3.3.4. Datos y resultados a partir de los estudios e investigaciones realizados fuera del ámbito público

3.4 Hacia una visión actual de la responsabilidad

\section{Capítulo 4. La Perspectiva del Consumidor en la Responsabilidad}

DE LAS ORGANIZACIONES

4.1. Una nueva perspectiva de la responsabilidad 162

4.1.1. Los grupos de interés de la empresa: la teoría de los stakeholders ..... 164

4.1.2. Enfoques integradores en la definición de la responsabilidad 173

4.2. La responsabilidad en el proceso de intención de compra

4.2.1. El proceso de decisión de compra y la modelización del comportamiento del consumidor 180

4.2.2. Etapas en el proceso de decisión de pre-compra responsable 186 
4.3. La percepción de la responsabilidad por el consumidor

4.3.1. El concepto de la responsabilidad desde el punto de vista del consumidor

4.3.2. La percepción por el consumidor de la conducta empresarial responsable

4.4. Otros determinantes de la responsabilidad desde la óptica del consumidor

4.4.1. La utilidad esperada

4.4.2. La influencia social

4.5. Propuesta de un modelo de consideración y valoración de la responsabilidad en los procesos de intención de compra

\section{Capítulo 5. Aspectos Metodológicos para la InVestigación}

EMPÍRICA

5.1. Descripción de la muestra

5.2. Procedimiento de recogida de datos

5.2.1. Construcción y administración del cuestionario

5.2.2. Escalas de medición de las variables

5.3. Procedimiento de análisis de datos

5.3.1. Validación del instrumento de medida y análisis preliminares

5.3.2. Validación del modelo predictivo

Capítulo 6. Resultados del Estudio Empírico

6.1. Análisis Factorial

6.2. Análisis correlacionales y descriptivos ............................ 259

6.3. Análisis predictivos con PLS ................................... 262

6.3.1. Evaluación del modelo inicial (Modelo 1) ........................ 262

6.3.2. Reespecificación del modelo de medida (Modelo 2) .................. 278

6.3.3. Reespecificación del modelo estructural (Modelo 3) .................. 288

CONCLUSIONES Y CONSIDERACIONES.................................... 301

Implicaciones teórico-prácticas .................................. 312

Limitaciones y futuras líneas de investigación ......................... 314 
Bibliografía

319

ANEXo

351

RÉSUMÉ

Conclusions

365 


\section{ÍNDICE DE CuADROS}

Cuadro

Pág.

1.1 Principales aspectos señalados en cuanto a la responsabilidad social corporativa durante la etapa de primeros debates y posicionamientos (1951-1960)

1.2 Principales aspectos señalados en cuanto a la responsabilidad social corporativa durante la etapa de formalización y consolidación (1961-1980)

1.3 Principales aspectos señalados en cuanto a la responsabilidad social corporativa durante la etapa de especialización (1981-2000)

1.4 Principales aspectos señalados en cuanto a la responsabilidad social corporativa durante la etapa de nuevos planteamientos y reconceptualización (desde 2001) ....

1.5 Artículos académicos más citados sobre Corporate Social Responsibility (CSR) y Corporate Social Performance (CSP)

2.1 Planteamientos y principios orientadores comparados de las primeras políticas públicas sobre responsabilidad en algunos países occidentales

2.2 Principios del Pacto Mundial de Naciones Unidas (2000)

3.1 Grupos de Trabajo del CERSE

3.2 Agrupaciones empresariales con actuaciones destacadas en materia de responsabilidad en España

3.3 Organizaciones de la sociedad civil con actuaciones destacadas en materia de responsabilidad en España

3.4 Ejemplos de instituciones académicas con actuaciones destacadas en materia de responsabilidad en España

4.1 Clasificación de los grupos de interés de la empresa en función de su relación con la entidad

4.2 Clasificación de las contribuciones sobre responsabilidad desde la perspectiva del Marketing 
4.3 Aportaciones representativas en cuanto a la percepción por parte del consumidor y la respuesta de éste a las iniciativas responsables de las empresas

4.4 Hipótesis para la investigación empírica

5.1 Resumen comparativo entre PLS y los métodos basados en la covarianza

6.1 Resumen de las hipótesis de investigación del Modelo 1

266

6.2 Resumen de las hipótesis de investigación del Modelo 3 


\section{ÍNDICE DE FIGURAS}

Figura

Pág.

1.1 Propuesta de esquema metodológico en relación con los períodos en la evolución histórica y el desarrollo conceptual sobre la responsabilidad de las organizaciones

1.2 La responsabilidad social como "constructo” según los postulados de Harold L. Johnson (1971)

1.3 Los tres círculos concéntricos en la definición de la responsabilidad social de las corporaciones empresariales del Comité para el Desarrollo Económico de EEUU. (1971)

1.4 Las dimensiones en desempeño social corporativo de acuerdo con Sethi (1975) ....

1.5 La pirámide de la responsabilidad social corporativa de Archie B. Carroll (1991)

2.1 Fases contempladas en el proceso de implantación de los principios del Pacto Mundial de Naciones Unidas (2000)

2.2 Proceso para la elaboración de memorias de sostenibilidad conforme a la Global Reporting Initiative

2.3 Proceso de selección de integrantes de la serie de índices FTSE4Good

4.1 Tipología de los stakeholders conforme a su situación respecto a los atributos de poder, urgencia y legitimidad

4.2 Una propuesta metodológica para el análisis de los stakeholders

4.3 Etapas en el proceso de toma de decisiones del consumidor

4.4 Etapas en el proceso de toma decisiones de decisión del consumidor responsable

4.5 Actitudes de consumo responsable

4.6 El proceso de pre-compra responsable

4.7 La generación de la demanda responsable 
4.8 La valoración de la responsabilidad de la oferta

4.9 El proceso de compra responsable

4.10 Modelo de influencia de las asociaciones de RSC en el valor percibido y la satisfacción del consumidor

4.11 Modelo teórico e hipótesis de investigación

5.1 Diagrama de paso teórico genérico con constructos y medidas

6.1 Representación del modelo teórico (Modelo1)

6.2 Modelo de investigación sometido a PLS

6.3 Ajuste global y coeficientes $\beta$ y $\gamma$ del Modelo 1

273

6.4 Representación de las relaciones significativas del Modelo 1

6.5 Segunda versión del modelo sometido a PLS (Modelo 2)

6.6 Representación de las relaciones significativas del Modelo 2

6.7 Tercera versión del modelo sometido a PLS (Modelo 3)

6.8 Representación de las relaciones significativas del Modelo 3 


\section{ÍnDICE DE GRÁFICOS}

Gráfico

Pág.

5.1 Distribución de la muestra del estudio según las características de sexo, edad y nivel de estudios de los encuestados .............................................

6.1 Distribución de frecuencias para variables del modelo 


\section{ÍNDICE DE TABLAS}

Tabla

Pág.

6.1 Estructura factorial de las variables conceptuales ........................... 251

6.2 Estructura factorial de las variables de comportamiento empresarial ............. 253

6.3 Estructura factorial de las variables de generación de demanda responsable ........ 255

6.4 Estructura factorial de las variables de componentes de consumo derivados de criterios de responsabilidad .............................................. 256

6.5 Estructura factorial de las variables utilidad esperada .......................... 257

6.6 Estructura factorial de las variables influencia social .......................... 258

6.7 Correlaciones, medias y desviaciones típicas (DT) .......................... 259

6.8 Parámetros de medida de variables perceptivas del consumidor (Modelo 1) ........ 268

6.9 Parámetros de medida de variables decisión del consumidor (Modelo 1) ........... 270

6.10 Parámetros de medida de variables otros determinantes (Modelo 1) ............... 271

6.11 Matriz de correlaciones y raíz cuadrada de AVE (Modelo 1) ..................... 272

6.12 Índices de ajuste global del Modelo 1 ........................................ 273

6.13 Efectos directos en el Modelo 1 ............................................ 275

6.14 Efectos totales en el Modelo 1 ................................................. 276

6.15 Parámetros de medida de variables perceptivas del consumidor (Modelo 2) ........ 279

6.16 Parámetros de medida de las variables decisión del consumidor y de otros determinantes (Modelo 2) ........................................................ 281

6.17 Matriz de correlaciones y raíz cuadrada de AVE (Modelo 2) ..................... 281 
6.18 Índices de ajuste global del Modelo 2 ..................................... 283

6.19 Efectos directos en el Modelo 2 ................................................ 285

6.20 Efectos totales en el Modelo 2 ......................................... 286

6.21 Parámetros de medida de las variables (Modelo 3) ................................. 291

6.22 Matriz de correlaciones y raíz cuadrada de AVE (Modelo 3) ....................... 292

6.23 Índices de ajuste global del Modelo 3 ........................................ 293

6.24 Efectos directos en el Modelo 3 ............................................... 294

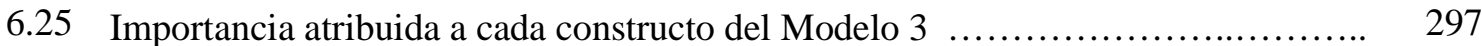

6.26 Efectos totales en el Modelo 3 ................................................ 299 
INTRODUCCIÓN 



\section{INTRODUCCIÓN}

El cada vez mayor dinamismo de los mercados y la actividad económica en general ha dado lugar a la creciente preocupación de todo tipo de entidades por mantener su reputación y hacer patente su implicación con las demandas y cambios sociales. Incluso las empresas privadas son conscientes de la necesidad de responder a las inquietudes de otros públicos objetivo más allá de sus inversores y clientes, concibiendo su actividad de una forma mucho más amplia e integradora.

Aspectos tales como la comprensión de las necesidades del cliente, la colaboración con causas de interés social, las relaciones con proveedores y distribuidores que garanticen unas condiciones adecuadas, el comercio justo, la conciencia medioambiental y de desarrollo sostenible, la integración laboral de discapacitados y otros colectivos de difícil empleabilidad, la conciliación de la vida familiar y laboral, la seguridad en el trabajo y otros muchos, constituyen otros tantos ejemplos de aspectos relevantes para unas entidades, públicas y privadas, convencidas de que la mejora del entorno social a través de sus actuaciones ha de redundar en una mejor consecución de sus objetivos.

Es un hecho que la aceptación, la confianza y el respaldo a una organización por parte de la sociedad depende del cumplimiento de las expectativas (ERSE 2010), no sólo de sus propietarios, sino también de los trabajadores que demandan derechos sociales y económicos, de los clientes cuando exigen productos de calidad, de las comunidades y una sociedad en general preocupada por un desarrollo más sostenible.

La reflexión acerca de la responsabilidad de las organizaciones (principalmente empresas), "ha protagonizado a lo largo del siglo pasado, de una forma más o menos intermitente, distintos debates tanto en el mundo académico como en el organizacional” (Unceta 2005:122). Casos como los de Enron, Worldcom, Arthur Andersen...”donde las entidades tenían como único y exclusivo objetivo de su actividad la rentabilidad inmediata, pone de nuevo sobre el tapete $y$, de una forma bien visible, que la ética resulta imprescindible en el mundo empresarial” (Cortina 2003:34). 
El debate trasciende el marco académico y profesional, para irse materializando con el tiempo en un conjunto de iniciativas que toman cuerpo a finales del siglo pasado y principios del presente. A escala internacional, el Pacto Mundial de las Naciones Unidas propone un debate entre empresas privadas y públicas, gobiernos, organizaciones del trabajo, ONGs y otros agentes de la sociedad civil sobre la necesidad de adoptar una serie de medidas con la intención de propiciar una economía global, responsable y sostenible. En ese contexto, con la intención de fomentar un marco europeo de responsabilidad social de las empresas, la Comisión de la Comunidad Europea presentó en Bruselas el Libro Verde (2001), abriendo una amplia discusión sobre el fomento de los comportamientos responsables en las organizaciones europeas y en todo el mundo.

Este proyecto pretende contribuir al desarrollo del conocimiento científico en el comportamiento responsable de las entidades productivas, enfocando el análisis desde la perspectiva de la demanda y viendo cómo pueden percibirse la responsabilidad de las organizaciones y las implicaciones que la subsecuente confirmación o desaprobación de expectativas pueden tener en sus futuras pautas de actuación, en tanto que las entidades puedan estar más o menos preocupadas por incluir en sus planes estratégicos las apreciaciones de quienes se verán influidos en última instancia, ya sea de forma directa o indirecta, por su actuación.

Los distintos enfoques, tanto de académicos como de otras instituciones que han participado en los debates, difusión teórica e implementación práctica de la responsabilidad asumible e imputable a las organizaciones, han mantenido generalmente una orientación encaminada a definir y medir el alcance que tiene la actividad desarrollada por la organización sobre la sociedad. No obstante, también se puede contemplar la organización desde fuera como ciudadanos-consumidores, como administración, como comunidad, como redes sociales, como universidad, como entorno para delinear y plantear la responsabilidad de aquella desde la óptica de la sociedad en que desarrolla su actividad (De la Cruz et al. 2007).

A pesar de que en los últimos años han aparecido más publicaciones sobre cómo el consumidor percibe este comportamiento responsable, este fenómeno no es aún lo suficientemente conocido ni analizado (Creyer y Ross 1997, Mohr et al. 2001, Sen y Bhattacharya 2001, García de los Salmones et al. 2005, Fernández y Merino 2005, 
Pérez et al. 2008) y, por supuesto, tampoco se han alcanzado resultados definitivos que expliquen cómo es la percepción de los demandantes de los productos y los servicios de las organizaciones es que lleven a cabo conductas responsables, y cómo estas apreciaciones pueden incidir decididamente sobre un comportamiento más responsable de las mismas.

Varios trabajos demuestran que el consumidor evalúa positivamente a la organización cuando esta actúa responsablemente e incluso modifica su comportamiento hacia la misma (Creyer y Ross 1997, Sen y Bhattacharya 2001, Bigné et al. 2005, Fernández y Merino 2005, Forética 2006, Bigné y Currás 2008). Sin embargo, otros contradicen esa conclusión y consideran que la actuación del consumidor al apreciar comportamientos responsables sólo se modifica en determinadas circunstancias (Anderson y Cunningham 1972, Andreu et al. 2004). Incluso otros estudios mantienen que aunque el consumidor advierta un comportamiento responsable, esto no es un criterio que vaya a influir de forma significativa y, mucho menos definitiva, en sus decisiones de compra (Carrigan 1997, Boulstridge y Carrigan 2000).

Es precisamente esta divergencia que se produce al analizar las consecuencias y efectos sobre el comportamiento del consumidor de una actuación más o menos responsable por parte de la organización (y que en parte puede venir condicionada por la falta de consenso sobre la definición y las variables determinantes de la responsabilidad) lo que justifica la necesidad de contar con nuevas teorías que den explicaciones más precisas sobre cómo son esas percepciones y valoraciones (Marín y Rubio 2008).

En su trabajo, Alvarado y Schlesinger (2008), concluyen que la responsabilidad tiene un papel clave en el proceso de formación de la imagen y, por tanto, los empresarios deben saber que sus acciones tendrán un impacto directo en la reputación que los consumidores atribuyen a su negocio, lo cual debe motivar a las empresas y todo tipo de organizaciones a dedicar recursos y esfuerzos a fortalecer los vínculos con sus consumidores para conseguir que éstos lleguen a un mejor estado de identificación con la propia organización.

La percepción social es, por otro lado, una de las dimensiones menos exploradas de la responsabilidad de las organizaciones, motivo por el cual son necesarios nuevos estudios que pongan de manifiesto cómo son valoradas por los distintos públicos- 
objetivo y cuál es la actuación de los mismos ante la forma de gestionar e implementar las actuaciones responsables que les son demandas. Todo ello por cuanto resulta de interés no sólo para la entidad, sino para los diversos agentes interesados en conocer estas opiniones y sus consecuencias (Valor 2006).

Así, y en primer lugar, interesa a las empresas, que deben tomar conciencia de la opinión que sobre su comportamiento tiene el público, pues se trata de una información que les resulta de máxima utilidad, permitiendo orientar sus prioridades y definir objetivos en base a los resultados observados, además de facilitar su diálogo con la sociedad en beneficio de todas las partes.

Igualmente es de utilidad para organizaciones sectoriales y agrupaciones empresariales, puesto que con estos trabajos podrían contar con unos resultados y unas valoraciones que sirven de apoyo empírico y al mismo tiempo para impulsar políticas de promoción de responsabilidad entre sus asociados.

Especialmente relevante es para legisladores y para la Administración Pública saber qué demandan los ciudadanos del Estado, y hacia dónde se orientan sus demandas a la empresa, conociendo de esta forma más datos y valoraciones que pueda guiar la realización de las políticas públicas.

También es de interés para los interlocutores sociales como sindicatos, organizaciones de consumidores, ONGs y organizaciones medioambientales que necesitan tener una información que les sirva como base para la realización de campañas públicas de sensibilización y de información ciudadana.

Es, pues, importante para una gran cantidad de destinos conocer la información con la que cuentan los ciudadanos sobre los resultados no sólo económicos, sino también en otros ámbitos de responsabilidad de la empresa, cuando toman sus decisiones de compra y de inversión. Pero además de información (Valor 2006), es necesario que el ciudadano esté formado es estos aspectos si realmente se quieren trasladar al mercado sus preocupaciones sociales con la finalidad de fortalecer el argumento económico a favor de la responsabilidad.

En tal sentido, el propósito de la presente tesis es contribuir a clarificar el concepto de la responsabilidad de las organizaciones, tanto desde la perspectiva de las 
argumentaciones académicas que han sido objeto de controversia durante las últimas décadas, como de la contextualización que dicho concepto se hace desde un punto de vista normativo-regulatorio y que pone de relieve la práctica institucional del término para posteriormente centrar el estudio en la percepción que hace el consumidor del comportamiento responsable de la empresa, presentando y analizando para ello un modelo que permita poner en orden las variables determinantes de esa visión particular que tiene el consumidor sobre lo responsable que puede llegar a ser una organización. Más concretamente, los objetivos que se pretenden son los siguientes:

i) Realizar un análisis historio-económico de la evolución del concepto de responsabilidad de las organizaciones.

ii) Contextualizar la responsabilidad desde la práctica institucional que condiciona o impone el marco normativo regulatorio.

iii) Conocer cuál es la visión o perspectiva del consumidor hacia el comportamiento responsable que tienen o deben tener las entidades.

iv) Identificar los determinantes de la percepción responsable del consumidor mediante el diseño de un modelo conceptual que sea útil, por un lado, en la explicación de cómo el público percibe la responsabilidad de las organizaciones y cuál es la importancia que le da a ese comportamiento $y$, por otro, analizar las variables que determinan la valoración y adquisición de información de responsabilidad por el consumidor, cuando éste toma en consideración la inclusión de criterios de responsabilidad por parte de la organización.

Con vistas a la consecución del objetivo general y los objetivos específicos el esquema seguido en el trabajo es el que se detalla a continuación.

En el primer capítulo se realiza una valoración y análisis crítico de la pluralidad de puntos de vista bajo los cuales ha venido contemplando la responsabilidad de las organizaciones, revisando los antecedentes científicos, desde la óptica históricoeconómica en que se ha fundamentado su estudio, y a fin de determinar la posición más extendida en la actualidad e este respecto.

Posteriormente, en el segundo y en el tercer capítulo se identifican los diferentes planteamientos regulatorios y normativos que han pretendido delimitar la 
responsabilidad de las organizaciones, haciendo referencia a la función que deben desempeñar las Administraciones Públicas, a la descripción del entorno normativo, en cuanto que un elemento más que han de tener en cuenta las organizaciones en su toma de decisiones sobre acciones responsables, no sólo a nivel nacional o supranacional, sino también a escala internacional, siendo en todos los ámbitos objeto de debate entre empresas privadas y públicas, gobiernos, organizaciones del trabajo, ONGs y otros agentes de la sociedad civil, en el que se pone una y otra vez de manifiesto la necesidad de adoptar una serie de medidas con el propósito de propiciar una economía global, responsable y sostenible. Para ello se hace hincapié no sólo en aspectos normativos, sino también en aquellos otros que, de alguna manera, han incidido en ese tipo de regulaciones y en los comportamientos responsables por parte de las organizaciones.

Todo ello con la certeza de que uno de los factores que más ha impulsado en los últimos años el desarrollo de la responsabilidad social es la presión de los mercados de consumo (Nieto y Fernández 2004), donde un número creciente de consumidores elige un consumo más responsable, busca productos ecológicos o producidos según criterios de responsabilidad. A tal fin en el cuarto capítulo se exploran los planteamientos que suponen una perspectiva o mirada desde fuera hacia las entidades, esquematizando un nuevo enfoque a través del cual las decisiones del consumidor se pueden explicar como una forma de comprender y valorar la actuación de las organizaciones empresariales, examinándose con este propósito las diferentes variables que sirven de base al modelo de estudio.

La parte empírica de la Tesis se estructura en tres capítulos, a los que se hace sucinta referencia al procedimiento empleado, los resultados obtenidos y las conclusiones derivadas del estudio. Para ello se propone un modelo teórico con el que avanzar en la investigación sobre la responsabilidad percibida en las distintas etapas en el proceso de intención de compra del consumidor. En tal sentido se estudia la relación secuencial establecida entre la generación de demanda de responsabilidad, junto con la adquisición información y la valoración de ofertas responsables, en cuanto etapas que describen el núcleo central del modelo, el cual se completa, en primer lugar, analizando el papel determinante de los motivos atribuidos a la responsabilidad empresarial, junto con el concepto de responsabilidad percibido por el consumidor para, en segundo lugar, pasar a integrar otros determinantes que también influyen en el proceso de intención de compra responsable, como son la utilidad esperada y la influencia social. 
Previo al listado de referencias bibliográficas, el apartado de conclusiones, tanto de la parte teórica como de la parte empírica del trabajo, incluye también consideraciones en cuanto a las limitaciones de éste, así como en relación a posibles líneas futuras de investigación derivadas del mismo. 


\title{
CAPítulo 1
}

\author{
Revisión HISTÓRICO-ECONÓMICA DE LA \\ RESPONSABILIDAD DE LAS ORGANIZACIONES
}





\section{CAPÍTULO 1. REVISIÓN HISTÓRICO-ECONÓMICA DE LA RESPONSABILIDAD DE LAS ORGANIZACIONES}

La creciente preocupación de todo tipo de entidades por mantener su reputación y hacer patente su implicación con las demandas y cambios sociales es consecuencia del mayor dinamismo de los mercados y de la actividad económica en general, que se ha generado en los últimos años. Las empresas privadas (paradigma organizativo de la búsqueda "egoísta" del propio beneficio) son conscientes de la necesidad de responder a las inquietudes de otros públicos-objetivo más allá de sus inversores y clientes (sustitución de la teoría o enfoque de los shareholders por el de los stakeholders), concibiendo su actividad de forma mucho más amplia e integradora.

Tomemos como ejemplo ilustrativo una cita de Michael J. Baker (2006): "Ia distinción entre éxito y fracaso en mercados competitivos puede reducirse a dos aspectos básicos: primero, una comprensión de las necesidades del cliente, y, segundo, la habilidad para proporcionar valor añadido”. Dicha filosofía enlaza claramente con lo que se había venido considerando connatural a las entidades del sector público y del Tercer Sector o de Economía Social, dadas su naturaleza y su finalidad.

En tal sentido, aspectos tales como la colaboración con causas de interés social, unas relaciones con proveedores y distribuidores que garanticen unas condiciones adecuadas de trabajo, el comercio justo, la conciencia medioambiental y de desarrollo sostenible (trasladada a los productos ofrecidos y a los procesos desarrollados), la integración laboral de discapacitados y otros colectivos de difícil inserción, la conciliación de la vida familiar y laboral, la seguridad en el trabajo y otros muchos, constituyen otros tantos ejemplos de aspectos de interés para unas entidades públicas y privadas convencidas de que la mejora del entorno social a través de sus actuaciones ha de redundar en una mejor consecución de sus objetivos.

Todo ello forma parte del concepto de Responsabilidad de las Organizaciones, pero no es algo nuevo, o incluso podría decirse que ni tan siquiera novedoso, por cuanto que con idénticos o similares términos ya ha sido objeto de debate y consideración en 
uno u otro momento temporal -eso sí, quizá de una forma algo desestructurada si se compara con los modernos planteamientos-, particularmente desde mediados del siglo XX, tal y como será puesto de manifiesto a lo largo de las páginas siguientes.

No obstante lo anterior, y aunque también han sido muchos los autores que han dedicado específicamente sus esfuerzos al desarrollo teórico de conceptos vinculados a la responsabilidad de las organizaciones hacia el entorno en que se encuentran ubicadas, o bien que han desarrollado sus investigaciones empíricas en conexión con alguno de los aspectos concernientes, lo cierto es que son muy raras (podría decirse incluso que casi inexistentes) las referencias en la literatura académica cuyo planteamiento haya sido el de estructurar o sistematizar las diferentes fases sucedidas en el correspondiente proceso.

Más aún, tales aportaciones no solamente resultan escasas, sino que además puede constatarse cómo en su gran mayoría resultan claramente sesgadas en función del campo de especialización de sus autores, lo que limita su valor frente al punto de vista interdisciplinar que, a juicio de una gran mayoría y asimismo de quien esto suscribe, debería caracterizar cualquier análisis de este tipo.

Partiendo de estos antecedentes, en el presente Capítulo del trabajo se presenta y desarrolla una propuesta de esquema cronológico cuyo objetivo es tratar de arrojar algo de luz sobre la materia, a los efectos de mejor apreciar la evolución de la concepción de la gestión y promoción de las cuestiones de interés público y/o general en los negocios hasta nuestros días.

Según cabe apreciar en la Figura 1.1, en dicho esquema se considera la existencia de cinco etapas o períodos principales que, a efectos pedagógicos para su mejor delimitación temporal, se han hecho coincidir con décadas dentro del período de referencia considerado:

- antecedentes (hasta 1950);

- primeros debates y posicionamientos (1951-1960);

- formalización y consolidación (1961-1980);

- especialización (1981-2000); y

- nuevos planteamientos y reconceptualización (desde 2001). 
Figura 1.1. Propuesta de esquema metodológico en relación con los períodos en la evolución histórica y el desarrollo conceptual sobre la responsabilidad de las organizaciones

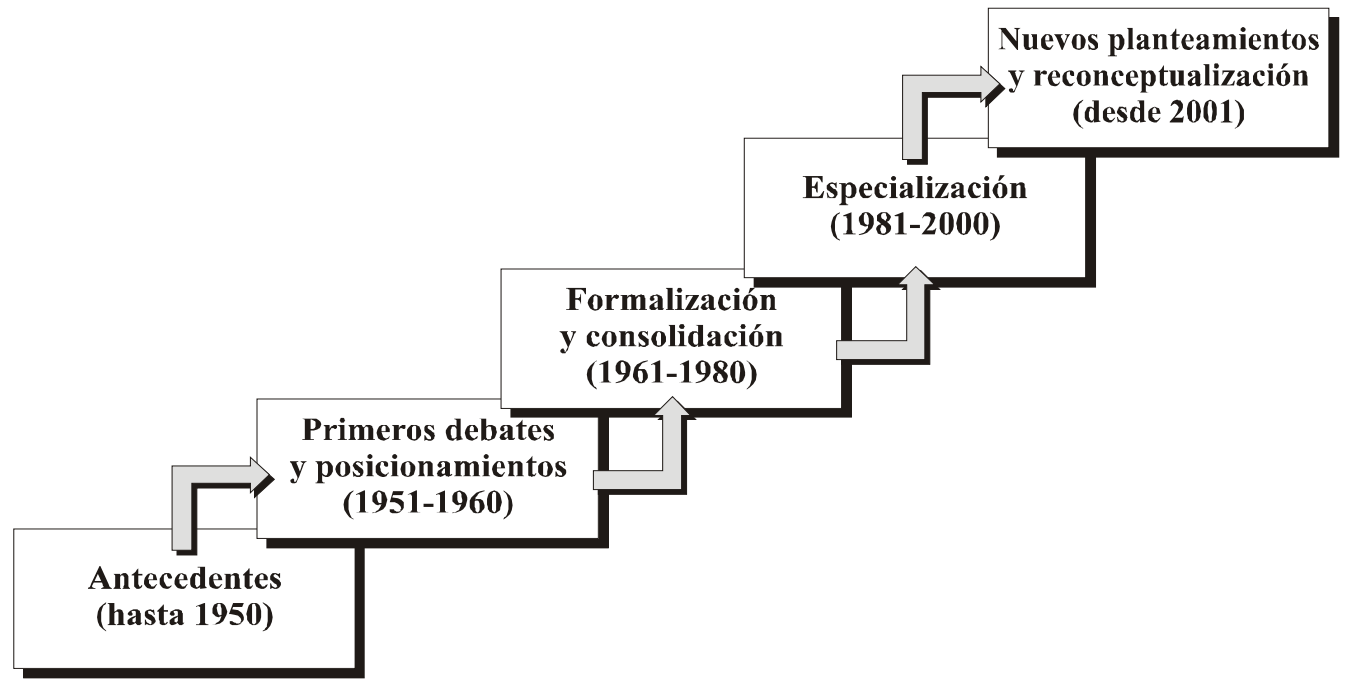

Fuente: Elaboración propia.

\subsection{Antecedentes (hasta 1950)}

Si bien los antecedentes formales -tanto desde la perspectiva académica como, incluso, desde un punto de vista práctico- de la responsabilidad organizativa se sitúan hacia la mitad del siglo XX, es posible identificar otros antecedentes más remotos coincidiendo con los propios de la gestión y promoción de las cuestiones sociales y de interés público y/o general, previos a su sistematización y tratamiento profesionalizado. Cosa distinta es el uso planificado y consciente de este tipo de causas con otra finalidad (lucrativa en última instancia), lo cual sí se corresponde con épocas mucho más recientes.

En este orden de cosas, y partiendo del actual consenso generalizado sobre el papel del intercambio (de bienes, servicios, valores, ideas...) como eje en torno al cual giran las actividades de las diferentes entidades que conforman el tejido socioeconómico, cabe afirmar que éste es casi tan antiguo como la raza humana.

En concreto, Lambin (1995:17) considera que "incluso en un sistema autárquico, basado en la más rudimentaria forma de intercambio, el trueque, los flujos de intercambio y de comunicación existen, aunque su manifestación sea espontánea y 
no exija la asignación de recursos específicos ni formas de organización para garantizar su funcionamiento”. En igual sentido se manifiesta Kotler (1989), al relacionar el nacimiento del marketing con la eclosión de las primeras manifestaciones comerciales plasmadas en el trueque de mercancías. Y otro tanto cabe postular bajo el prisma de las demás disciplinas organizativas.

Siguiendo esta línea de razonamiento, cabe también aventurar la presencia implícita de aspectos sociales y públicos en la base de los intercambios: la primera, en los beneficios o repercusiones no sólo para quienes los realizan, sino también, y por extensión, para las familias u otros grupos sociales de referencia de dichos individuos; la segunda, en la existencia de jerarquías en todo grupo tribal o social susceptibles de ejercer una posición de privilegio (tributos monetarios o en especie, reserva en exclusiva de la actividad comercial o la legitimación para llevarla a cabo, etc.), antecedente fáctico de la actividad económica del sector público o del control de éste sobre la iniciativa privada.

Ratificando esta postura, hay quienes encuentran indicios de una incipiente gestión sistematizada en prácticas en el Israel de la época del Talmud (hace unos 1500 años), en la China de la época de la Dinastía Han (206 a.C. a 220 d.C.) o en los mercados medievales. También hay quien identifica antecedentes relevantes en los escritos sobre el intercambio de los clásicos Platón y Aristóteles o las disquisiciones medievales sobre el precio justo y el interés de autores como Santo Tomás de Aquino o Duns Escoto, posteriormente reflejadas en las aportaciones de una Escuela de Salamanca que, en el siglo XVI, refrendaría la “justicia” de las actividades de los comerciantes, así como -lo que resulta más interesante a los efectos aquí consideradossu contribución al bienestar común por medio de la consecución de los objetivos materiales de la sociedad.

Continuación de los anteriores, son incluso más específicos los antecedentes en los primeros grandes tratados de Economía aparecidos a partir del siglo XVIII, de autores como Smith, Stuart Mill y Marx, quienes incluyeron abundantes reflexiones sobre el consumo y la utilidad del comercio y del intercambio.

Superadas otras cuestiones previas, la cuestión mayor del laissez-faire vs. la supervisión del gobierno en el campo de los negocios fue acrecentando su importancia como tópico social y económico, poniendo en tela de juicio la legitimidad de la actuación pública y llevando a establecer todo un corpus legislativo que sentaría las 
bases para una regulación gubernamental de los negocios y su incidencia sobre el progreso social. Por su parte, lo no lucrativo se vio más bien vinculado a reivindicaciones de índole social (como las de los campesinos sobre la tierra o los movimientos de defensa de los intereses del proletariado) o cuestiones filantrópicas (con un trasfondo religioso o humanitario, sin olvidar otras posibilidades, como el mecenazgo artístico o el patrocinio cultural), en todo caso complemento necesario para paliar las injusticias del funcionamiento del mercado.

Una vez que las disciplinas de gestión empresarial iban tomando carta de naturaleza a nivel docente y profesional (principios del siglo XX), convirtiéndose de manera gradual en campos de estudio independientes y con personalidad propia, cuestiones antes consideradas propias de la esfera pública (como la distribución de productos agrícolas y de primera necesidad) fueron sucesivamente objeto de debate, distinguiéndose actividades distintas a la producción (análisis del mercado, ventas, intermediación, publicidad, financiación, etc.), a la vez que se postulaba una vinculación connatural entre las prácticas de los negocios y la sociedad en términos de aplicación de un sistema agregado de gestión, concebido como un amplio, poderoso e intrincado complejo operativo al servicio de las necesidades de aquélla en la que éstos se hospedan.

En tal contexto, pronto se hizo patente la necesidad de añadir a los tres conjuntos primarios tradicionales de agentes económicos que venían siendo hasta entonces considerados (esto es, los consumidores, los productores y las entidades gubernamentales) dos categorías más, integradas respectivamente por otros grupos de interés y por la sociedad en su conjunto.

Entre las primeras referencias explícitas en la literatura académica cabe mencionar las de los textos de Barnard (1938) sobre las funciones a desempeñar in extenso por parte del ejecutivo “ideal”, de Clark (1939) sobre el control social de los negocios, o de Kreps (1940) sobre la pertinencia de la medida de sus resultados también desde una óptica social. Todo ello configuraría el caldo de cultivo adecuado para que publicaciones señeras, en lo tocante a la opinión del sector, se decidieran a preguntar a los ejecutivos sobre sus responsabilidades sociales (caso del barómetro de Fortune aparecido en 1946). 


\subsection{Primeros debates y posicionamientos (1951-1960)}

No obstante las referencias anteriores, el inicio de la "era moderna” en cuanto al tratamiento y gestión de las actividades de responsabilidad empresarial se sitúa en la década comprendida entre los años 1951 y 1960 (Carroll 1999), coincidiendo con la aparición de las primeras definiciones y los primeros textos específicamente dedicados a este concepto.

Entre éstos destaca, sin duda alguna, el libro de Howard R. Bowen (1953) sobre las responsabilidades sociales del hombre de negocios. Dicho autor, a quien es reservado el apelativo de "padre de la responsabilidad social corporativa", parte en sus planteamientos de la idea de que las grandes compañías son centros de poder cuyas decisiones y actuaciones afectan a las vidas de muchas personas y de muy diversas formas, lo que le lleva a concluir que resulta razonable esperar que los encargados de su gestión asuman algún tipo de responsabilidad al respecto.

En tal sentido, el propio Bowen evocaba los resultados de la encuesta de Fortune de 1946, según los cuales un 93’5\% de los ejecutivos sostuvieron estar de acuerdo con la afirmación de que "los hombres de negocios eran responsables de las consecuencias de sus acciones en una esfera que superaba la de sus balances de beneficios y pérdidas”.

Tras definir la responsabilidad social como algo que "se refiere a las obligaciones de los hombres de negocios de seguir aquellas políticas, tomar aquellas decisiones, o seguir aquellas líneas de actuación que son deseables en términos de los objetivos y valores de nuestra sociedad” (Bowen 1953:6), indica que ésta no es ninguna panacea, pero sí un importante elemento de verdad que ha de guiar las actuaciones de las empresas en el futuro.

Junto a la obra de Bowen, también merece la pena reseñar en esta misma década la inclusión de un apartado dedicado a la responsabilidad social de las empresas en el manual sobre prácticas de gestión de Peter Drucker (1954), o la aparición de los libros de Eells (1956) sobre las donaciones corporativas (planteando dicha responsabilidad a modo de continuum operando en una escala de nivel mínimo a nivel máximo), Heald (1957) sobre la responsabilidad de los gestores hacia la sociedad, o Selekman (1959) sobre la filosofía moral que debía guiar las decisiones de aquéllos. 
Debe notarse asimismo la nula o anecdótica utilización del término “corporativa" al referirse a la "conciencia" o "responsabilidad social” de los hombres de negocios, muy probablemente a causa del menor peso relativo de lo que hoy se conoce como “corporaciones” en el tejido empresarial de la época.

A modo de síntesis, en este período de los primeros debates y posicionamientos son cuatro los aspectos que los diferentes autores señalan como características principales del comportamiento de las entidades empresariales y/o de los encargados de su gestión (Cuadro 1.1): la atención en sus decisiones a las expectativas y valores sociales, las donaciones corporativas, el sentimiento de compromiso con la sociedad, y una filosofía moral que sirva como guía o pauta de actuación a la hora de tomar dichas decisiones. La responsabilidad organizativa no se contempla, en consecuencia, tanto como un programa colectivo de actuación, sino antes bien se trata básicamente de una cuestión de índole e iniciativa personal, tratando de adecuar la función directiva a los valores sociales y de impregnar a los responsables empresariales de una cierta conciencia social a la hora de tomar sus decisiones (Lozano 2009).

Cuadro 1.1. Principales aspectos señalados en cuanto a la responsabilidad social corporativa durante la etapa de primeros debates y posicionamientos (1951-1960)

\begin{tabular}{|c|l|}
\hline Autor & \multicolumn{1}{c|}{ Aspecto/s señalado/s } \\
\hline Bowen (1953) & Atención de los gestores a las expectativas y valores sociales \\
\hline Eells (1956) & Realización de donaciones corporativas \\
\hline Heald (1957) & Implicación (compromiso) con la sociedad \\
\hline Selekman (1959) & Filosofía moral como pauta de decisión en la toma de decisiones \\
\hline
\end{tabular}

Fuente: Elaboración propia.

\subsection{Formalización y consolidación (1961-1980)}

En los años 60 tuvo lugar un significativo incremento de los esfuerzos académicos por concretar el significado de los conceptos acuñados en la década anterior, lo cual supuso la aparición de un buen número de definiciones, que después proliferarían en los años 70, dando así lugar a una etapa conjunta de formalización y consolidación en referencia a lo que ya se denominaba de forma habitual "responsabilidad social corporativa". 
Una de las contribuciones más destacadas se sitúa muy al principio del período, siendo el artículo de Keith Davis (1960), en el que se cuestionaba si las empresas podían permitirse ignorar sus responsabilidades sociales, para él consideradas una especie de "nebulosa” difícil de precisar -pero de indudable transcendencia en el contexto de la gestión-, relacionada con "las decisiones y acciones de los hombres de negocios debidas a razones al menos en parte más allá del interés económico directo o técnico de la empresa” (Davis 1960:70). No obstante la importancia de haber formulado esta incipiente definición, este autor es, con todo, más conocido por haber formulado su famosa "ley de hierro de la responsabilidad", de acuerdo con la cual "las responsabilidades sociales de los empresarios deben corresponderse con su poder [y preeminencia] social”, en tanto que "evitar asumirla lleva a una erosión gradual del poder social” (Davis 1960:71:73).

Algunos años más tarde, Davis llevaría a cabo junto con Robert Bloomstrom una nueva aproximación al concepto de responsabilidad social, en este caso derivada de la más amplia y general "obligación de una persona de considerar los efectos de sus decisiones y de sus acciones sobre el conjunto del sistema social. [De ahí que] los hombres de negocios aplican la responsabilidad social cuando tienen en cuenta las necesidades e intereses de otros que pueden verse afectados por sus acciones. Haciendo esto, miran más allá de la estrechez de los intereses económicos y técnicos de sus empresas” (Davis y Bloomstrom 1966:12) Y este mismo autor completaría después su definición, al añadir que "la sustancia de la responsabilidad social surge de la preocupación por las consecuencias éticas de los propios actos, dado que éstos pueden afectar a los intereses de otros [y] supone un paso de gigante al poner énfasis en las acciones institucionales y su efecto sobre el sistema social en su conjunto” (Davis 1967:46).

Coincidiendo con las primeras aportaciones de Davis, William Frederick (1960:60) aludía a la responsabilidad social como algo que "significa que los empresarios deberían supervisar la operación de un sistema económico que responda a las expectativas del público. Y esto supone como contrapartida que los medios de producción de la economía deberían ser empleados de tal forma que la producción y la distribución debieran alcanzar el bienestar socioeconómico total [...;] implica una postura pública hacia los recursos económicos y humanos de la sociedad, y la voluntad de ver que esos recursos son utilizados para fines sociales amplios y no se 
circunscriben a los estrechos intereses privados de personas y empresas". Aunque de una forma implícita, es interesante apreciar en esta definición la idea subyacente de “sostenibilidad” en el uso de los recursos conforme a los fines sociales.

Del mismo modo, Richard Eells continuaría incidiendo en su idea del continuum o gradación de la responsabilidad social (estableciéndose así los primeros postulados que después cristalizarían en las investigaciones empíricas orientadas a la concreción de escalas de medida) en la primera edición de su manual sobre fundamentos conceptuales de los negocios, publicada en 1961 junto con Clarence Walton, y reservando el concepto para la tercera edición, de 1974, según la cual, “en su sentido más amplio, la responsabilidad social corporativa supone una preocupación por las necesidades y objetivos de la sociedad que va más allá de lo meramente económico [... y] por el papel de las empresas de cara a apoyar y mejorar el orden social” (Eells y Walton 1974:247).

Entre medias, el propio Walton había introducido una definición en un libro, cuyo título literal era, precisamente, el de "Responsabilidades sociales corporativas" (1967:18), indicando que "en resumen, el nuevo concepto de responsabilidad social reconoce el carácter íntimo de las relaciones entre la corporación y la sociedad y comprende que tales relaciones deben ser tenidas en mente por los altos directivos en tanto la corporación y los grupos con ella relacionados alcanzan sus respectivos objetivos”. Dicho autor también presentaba diferentes variantes o modelos, en los que hacía hincapié en la necesidad de una cierta nota de voluntariedad en este tipo de acciones (en contraste con la idea de obligar a las empresas a realizarlas), aceptando que suponen un coste que no es posible enlazar con un beneficio económico directamente mensurable.

Algo posterior a las primeras aportaciones de Davis y a las de Frederick es la definición de Joseph McGuire (1963:144), para quien “la idea de responsabilidades sociales supone que la corporación no tiene sólo obligaciones económicas y legales, sino también ciertas responsabilidades hacia la sociedad que van más allá de estas obligaciones”. Es interesante ver cómo aparecen aquí tanto el término “corporación”, como el concepto de “obligación”, en referencia al ámbito económico y también al legal.

En cuanto a las responsabilidades, éstas son concretadas posteriormente por el autor, al indicar que la entidad debería interesarse por aspectos tales como la política, el 
bienestar comunitario, la educación, o la felicidad de sus empleados, del mismo modo que lo haría un ciudadano ejemplar (constituyendo, de acuerdo con Carroll -1999-, un claro antecedente de las nociones de ética en los negocios y ciudadanía corporativa).

Coincidiendo con el final de la década, en 1970 vería la luz un libro de Morrell Heald, cuyo interés no se debe tanto a sus planteamientos conceptuales (en realidad no proporciona en ningún momento una definición de la responsabilidad social, tan solo indicando que "se trata de algo que los hombres de negocios han experimentado por sí mismos" y cuyo significado debe ser visto en el contexto de las "políticas con las cuales se encuentran asociados" -Heald 1970:xi-) como a la recopilación de ejemplos prácticos y antecedentes acontecidos entre 1900 y 1960.

Mucho más relevante desde un punto de vista teórico y conceptual, por cuanto en ella se puede encontrar un antecedente de la posterior etapa de especialización iniciada en los años 80, es la obra de Harold Johnson (1971), en la que el autor plantea, critica y analiza diferentes puntos de vista sobre la responsabilidad social y las correspondientes definiciones, para después converger en la elaboración de un único constructo. Así:

- Bajo un enfoque "convencional”, una empresa socialmente responsable es aquélla “cuyo personal directivo equilibra una multiplicidad de intereses. En vez de luchar sólo por lograr mayores beneficios para sus accionistas, una empresa responsable también tiene en cuenta a los empleados, a los proveedores, a los distribuidores, a las comunidades locales, y a la nación” (Johnson 1971:51). Aparece aquí un claro precedente de la multiplicidad de intereses propia de la teoría de los stakeholders.

- Desde el punto de vista de la “maximización de los beneficios a largo plazo”, la responsabilidad social supone que "los negocios llevan a cabo programas sociales para añadir beneficios a su organización” (Johnson 1971: 54).

- De acuerdo con una óptica de "maximización de la utilidad”, y asumida ésta como finalidad última y esencial de las empresas, "un empresario o directivo socialmente responsable es uno que tiene una función de utilidad del segundo tipo, de modo que está interesado no sólo en su propio bienestar, sino también en el de los otros miembros de la empresa y en el de sus compañeros conciudadanos” (Johnson 1971:68). 
- Y desde un punto de vista "lexicográfico", se sugiere que "las empresas fuertemente motivadas por los beneficios pueden involucrarse en un comportamiento socialmente responsable. Una vez que logran sus objetivos de beneficio, éstas actúan como si la responsabilidad social fuera un objetivo importante-incluso cuando no lo es-” (Johnson 1971:75).

Siguiendo lo indicado por este mismo autor, cabe asimismo señalar que, aun cuando estos cuatro enfoques pudieran a veces parecer contradictorios, en realidad forman parte de un mismo "constructo", en tanto son modos esencialmente complementarios de ver una misma realidad (Figura 1.2).

Figura 1.2. La responsabilidad social como "constructo" según los postulados de Harold L. Johnson (1971)

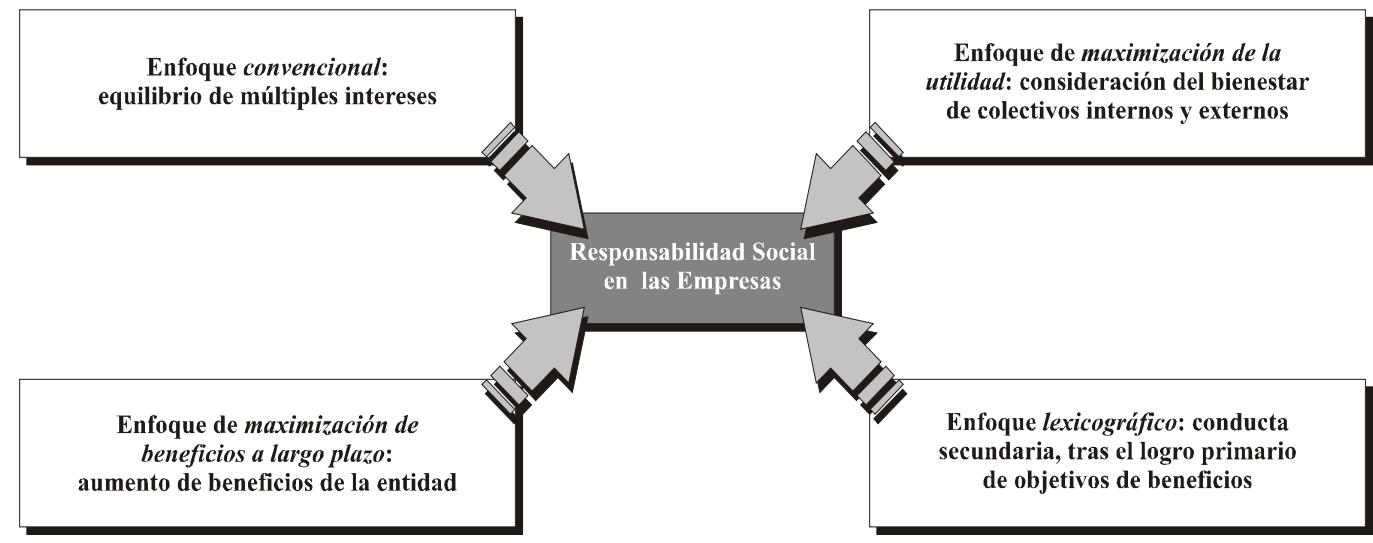

Fuente: Elaboración propia en base a Johnson (1971).

Igualmente relevante es la contribución del Comité para el Desarrollo Económico de EE.UU. (Committee for Economic Development, CED), por cuanto supuso un respaldo explícito a los nuevos postulados desde instancias oficiales. Encontrando su justificación en los resultados de una encuesta de opinión llevada a cabo en 1970 por la Opinion Research Corporation, en la que dos terceras partes de los individuos entendían que las empresas tenían la obligación moral de ayudar a otras instituciones de cara al logro de objetivos de progreso social, y ello aún a expensas de sus beneficios, el CED publicaba en 1971 un documento sobre las responsabilidades sociales de las corporaciones empresariales, en el que decía que a éstas "se les pide asumir más responsabilidades que nunca hacia la sociedad y estar al servicio de una 
amplia gama de valores humanos [...,] contribuir más a la calidad de vida de los norteamericanos que sólo proporcionarles bienes y servicios. En tanto las empresas existen para servir a la sociedad, su futuro depende de la calidad de la respuesta de sus directivos a las cambiantes expectativas del público” (CED 1971:16).

Con estas premisas como punto de partida, para este organismo, la definición de la responsabilidad social se articulaba en tres círculos concéntricos, a modo de niveles con objetivos para el sucesivo cumplimiento (cada nivel se afronta una vez cumplidos los objetivos del previo) tal y como se muestra en la Figura 1.3 (CED 1971:15):

- Un “círculo interno”, incluyendo "las responsabilidades básicas para la eficiente realización de la función económica: productos, empleo y crecimiento económico”.

Figura 1.3. Los tres círculos concéntricos en la definición de la responsabilidad social de las corporaciones empresariales del Comité para el Desarrollo Económico de EEUU.

(1971)

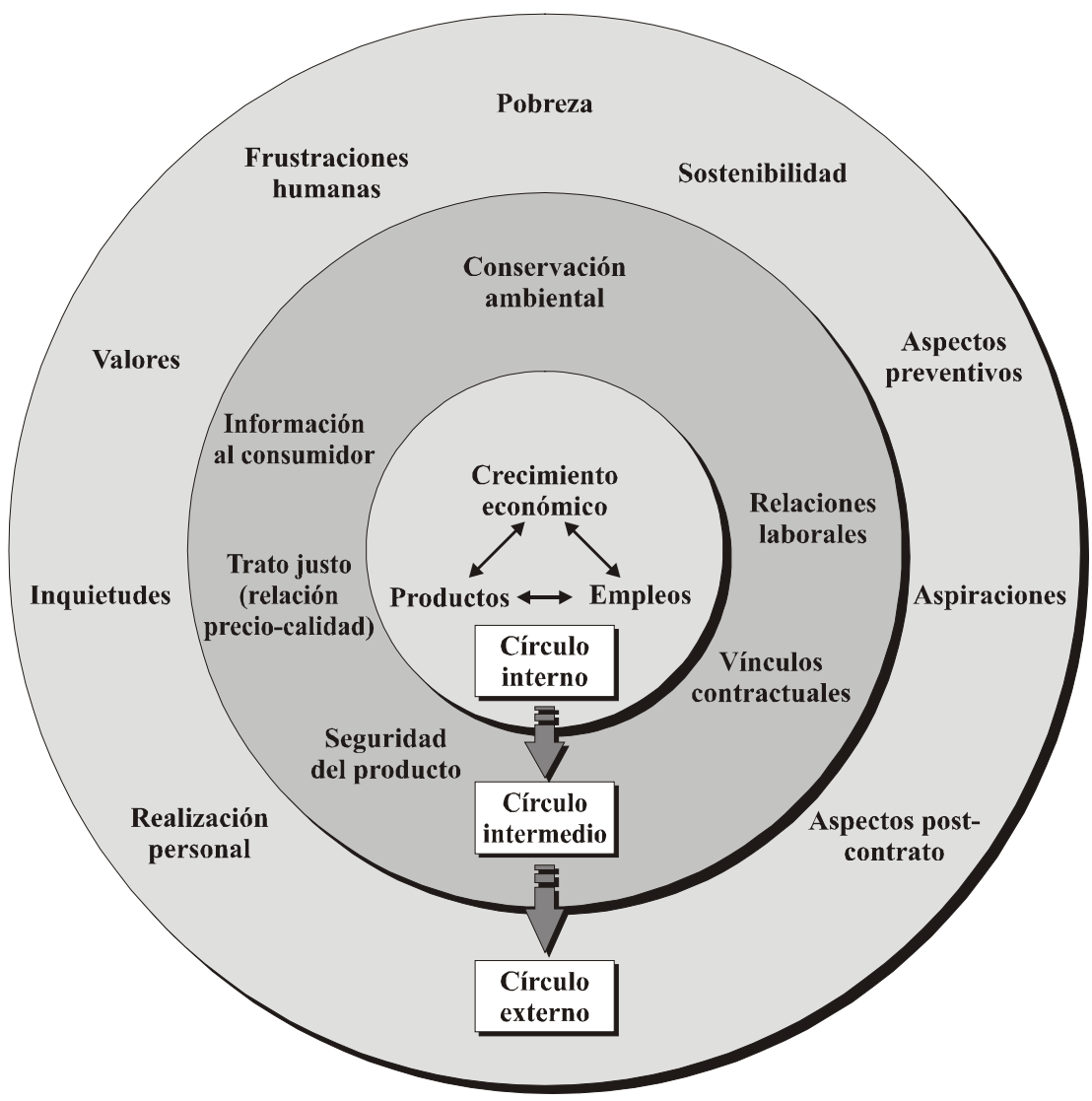

Fuente: Elaboración propia en base a CED (1971). 
- Un “círculo intermedio”, que “acompasa la responsabilidad para ejercer tal función económica con una sensible preocupación por los cambiantes valores y las prioridades sociales: por ejemplo, respecto a la conservación del medio ambiente; los contratos y las relaciones con los empleados; y unas expectativas más rigurosas de los clientes en cuanto a información, trato justo, y protección de daños”.

- Un "círculo externo", donde se van situando las "emergentes y aún amorfas responsabilidades que [en cada momento] las empresas deberían asumir para estar más fuertemente implicadas en la mejora activa del entorno social (por ejemplo, la pobreza y la frustración urbana)”.

Otro aspecto a recalcar en el documento del CED es el concerniente a la necesidad de que no sólo los hombres de negocios, sino también los educadores estuviesen implicados en la consecución de los correspondientes objetivos. Como señala Carroll (1999:275), en el sentido de que la respuesta del CED era acorde con las inquietudes de su época. “los últimos 60 y los primeros 70, un período durante el cual los movimientos sociales relacionados con el medio ambiente, la seguridad en el trabajo, los consumidores, y los empleados confiaban en la transición de un estatus de interés especial a una regulación gubernamental”.

Ese mismo año, George Steiner, en la primera edición de su libro sobre los negocios y la sociedad matizaba la “ley de hierro" de Davis, al afirmar que "cuanto mayor es una compañía, mayores son sus responsabilidades, pero todas las empresas pueden asumir alguna cuota de responsabilidad sin coste, y con frecuencia con un beneficio tanto a corto como a largo plazo” (Steiner 1971:164). También avanzaría otros conceptos recurrentes en definiciones de posteriores autores, como que "asumir responsabilidades sociales es más una actitud, el modo en que un gestor afronta sus tareas de decisión, que un gran cambio en la economía de la toma de decisiones. Es una filosofía que mira al interés social y al ponderado interés de las empresas a largo plazo frente al viejo, estrecho y limitado interés a corto plazo” (Steiner 1971:164). Asimismo interesantes son sus modelos para determinar la responsabilidad social de los negocios a través de la aplicación de los correspondientes criterios, al constituir un antecedente en la búsqueda de escalas de medida.

Resumiendo todo lo anterior, a comienzos de los 70 se percibía claramente el carácter explícito de la dimensión social en unos planteamientos empresariales que hacían hincapié en el diseño y puesta en práctica de métodos eficientes de gestión, lo 
cual estimulaba la exploración de los papeles y relaciones entre los empresarios, el gobierno y los diferentes grupos y colectivos sociales, destinatarios o no de la oferta productiva. En ausencia de una teoría conjunta elaborada, datos o estructura, diferentes autores trataron desde la perspectiva de sus distintas especialidades (como la teoría económica, la organización, el marketing o la gestión) de proporcionar respuestas no empíricas, pero sí relativamente objetivas, a las preguntas relacionadas con los aspectos emergentes a medida que se iba desarrollando un cuerpo conceptual de las distintas disciplinas empresariales.

Más en concreto, los partidarios de ampliar el campo de aplicación del marketing (un aspecto ampliamente debatido en décadas precedentes), encontraron un respaldo definitivo a su postura, proporcionado por una serie de artículos de Kotler, Levy, Zaltman, y Shapiro, publicados entre 1969 y 1973. El más conocido y citado de éstos es el primero, de Philip Kotler y Sidney Levy, titulado "Broadening the concept of Marketing” y aparecido en el Journal of Marketing de enero de 1969. A éste le seguiría otro más específico (julio de 1971), de Philip Kotler y Gerald Zaltman, titulado "Social marketing: an aproach to planned social change”. Por su parte, Benson Shapiro publicaría “Marketing for nonprofit organizations” en 1973 en la Harvard Business Review.

En dichas páginas podemos encontrar afirmaciones como que "el marketing es una actividad social de persuasión que va considerablemente más allá de la venta de pasta de dientes, jabón y acero. Las elecciones nos recuerdan que los candidatos se venden como el jabón; el reclutamiento de estudiantes en las universidades nos recuerda que la educación superior está comercializada; y la captación de fondos nos recuerda que las ‘causas’ también lo están” (Kotler y Levy 1969:10).

Todo ello resulta particularmente interesante por cuanto supuso la acuñación de facto del término "marketing social”, algunas de cuyas variantes, como "marketing de causas sociales” o "Marketing Con Causa” (o MCC, por traducción del inglés “Cause Related Marketing”-CRM-) se han venido planteando desde entonces como denominaciones alternativas para la "Responsabilidad Social Corporativa" (o RSC, en inglés “Corporate Social Responsibility”-CSR-).

Como antecedentes explícitos en la práctica del entonces incipiente marketing social, Alan R. Andreasen -uno de los pioneros y reconocidos expertos a nivel mundial en este campo- menciona dos experiencias concretas que, con algunos cambios, aún 
perviven en la actualidad ${ }^{1}$ : se trata de la cooperación público-privada en la promoción del Programa Nirodh de control de la natalidad en India (en 1968), y de la acción conjunta de entidades públicas y no gubernamentales en el desarrollo del Programa Nacional de Educación sobre la Hipertensión Arterial (NHBPEP) en Estados Unidos (1972).

En uno y otro caso, el hecho de que tuviera y siga teniendo lugar una implicación expresa de empresas privadas en las correspondientes causas hace que sean ejemplos igualmente buenos a efectos ilustrativos de actuaciones de responsabilidad social $^{2}$.

En la teoría económica también se hacía patente la preocupación por este mismo tipo de cuestiones. Así, a la previa afirmación de Milton Friedman (1962:133) de que “pocas tendencias podrían poner en entredicho los fundamentos de la libre sociedad como la aceptación por los mandos corporativos de otra responsabilidad que lograr todo el dinero posible para sus accionistas”, recalcada en otro artículo aparecido en 1970, Paul Samuelson replicaba un año más tarde que "una gran corporación [...] no sólo debe involucrarse con la responsabilidad social, habría hecho mucho mejor en haberlo intentado” (Samuelson 1971:24).

Jules Backman lo ratificaría en 1975, argumentando que la responsabilidad social, como la contabilidad social, los indicadores y las auditorías sociales eran en realidad términos que cubrían diferentes facetas de una misma discusión, claramente decantada, en referencia a "los objetivos o motivos que deberían pesar en las empresas además de los concernientes a su desempeño económico (p.e., beneficios)” (Backman 1975:2).

Volviendo de nuevo atrás, en tanto que George Steiner publicaba un nuevo artículo en 1972 sobre las políticas sociales de las empresas en el que incidía en los mejores resultados obtenidos por éstas al sustituir el carácter eventual y esporádico de las acciones responsables por un procedimiento más riguroso y sistemático en su

\footnotetext{
1 Conferencia inaugural del $8^{\text {th }}$ AIMPN/IAPNM International Congress on Public and Nonprofit Marketing, celebrado en Valencia, e impartida el 18 de Junio de 2009.

2 En otras palabras, es absurdo postular que son acciones de marketing social corporativo o de responsabilidad social corporativa, como algo mutuamente excluyente. Se trata -una vez más- de aproximaciones desde distintas disciplinas a una misma realidad. En aras de la deseable multidisciplinariedad en el estudio de la responsabilidad de las organizaciones, en el presente trabajo las posturas de quienes aún reclaman la exclusividad de los ámbitos de estudio se consideran claramente obsoletas.
} 
planteamiento, Henry Manne y Henry Wallich participaban en un interesante debate auspiciado por el Instituto Americano de Empresa, plasmando sus principales conclusiones en un volumen publicado conjuntamente.

Así, para Manne, un gasto o actividad de una empresa sería socialmente responsable si “los beneficios marginales para la corporación son menores que los que se obtendrían con un gasto alternativo, es algo puramente voluntario, y se trata de un gasto corporativo corriente más que de un cauce para la generosidad individual” (Manne y Wallich 1972:4-6).

Por su parte, Wallich preferiría una definición en un sentido más amplio, como "una condición en la que la corporación es al menos en alguna medida un agente libre. Llegado el extremo de que algunos de los objetivos sociales que se pretenden sean impuestos por Ley a la corporación, ésta no ejerce responsabilidad cuando los implementa. [...] Tres actividades básicas parecen estar implicadas en el ejercicio de la responsabilidad corporativa: 1) el establecimiento de objetivos, 2) la decisión de perseguir los objetivos dados, y 3) la financiación de estos objetivos” (Manne y Wallich 1972:40-41).

Cabe resaltar en la última de estas definiciones la referencia a las discusiones sobre la utilidad -e incluso legitimidad- de la emergente regulación legal en la materia, algo también presente en una nueva aportación de Keith Davis. Éste planteaba en 1973 que la responsabilidad social corporativa "se refiere a la consideración y respuesta por parte de la empresa a aspectos más allá de la estrechez de los requisitos económicos, técnicos y legales de la misma [..., siendo su obligación] evaluar en su proceso decisional los efectos de sus decisiones sobre el sistema social externo de un modo que alcanzará los beneficios sociales a la vez que las tradicionales ganancias económicas que la empresa persigue. [...] Esto significa que la responsabilidad social empieza donde acaba la Ley. Una empresa no es socialmente responsable si simplemente cumple los requisitos legales mínimos, pues esto es algo que cualquier buen ciudadano haría” (Davis 1973:312-313).

De este modo, Davis parecía plantear un antagonismo entre el cumplimiento o la obediencia legal (parte de la ciudadanía corporativa) y la responsabilidad social, para después postular diferentes argumentos a fin de comprobar si una entidad era o no socialmente responsable (en un nuevo intento de escala de medida). 
Otra interesante aportación en ese mismo año es la de Henry Eilbert y Robert Parket, para quienes “quizá la mejor forma de entender la responsabilidad social es pensar en ella como una 'buena vecindad'. El concepto implica dos fases: por un lado, significa no hacer cosas que dañen a los vecinos; por otro, puede expresarse como la asunción voluntaria de la obligación de ayudar a resolver los problemas de los vecinos. [...] Significa el compromiso de una empresa, o de los negocios en general, con un papel activo en la resolución de los grandes problemas sociales, como la discriminación racial, la polución, el transporte, o la decadencia urbana” (Eilbert y Parket 1973:7).

Estos mismos autores también aportaban datos empíricos acerca de la forma en que la responsabilidad social había afectado a los presupuestos de las empresas, qué actividades eran llevadas a cabo por éstas dentro de este apartado, o cuáles de esas actividades eran percibidas como más importantes, en lo que constituía uno de los primeros intentos por asociar la responsabilidad con variables organizacionales.

Asimismo en 1973, Dow Votaw señalaba que la responsabilidad social "es un término brillante; significa algo, pero no siempre lo mismo para todo el mundo. Para algunos conlleva la idea de responsabilidad legal; para otros, significa conducta socialmente responsable en un sentido ético; aún para otros el significado que transmite es el de 'ser responsable', de un modo causal; muchos simplemente lo equiparan con una contribución caritativa; algunos lo hacen significar conciencia social; muchos de quienes lo abrazan más fervientemente lo ven como un simple sinónimo de 'legitimación', en el contexto de 'pertenecer' o ser propio o válido; unos pocos lo ven como un tipo de deber fiduciario que impone unos estándares de comportamiento más elevados a los empresarios que a los ciudadanos en general" (Votaw 1973:11).

Algo después, en 1975, S. Pakrash Sethi publicaba su artículo "Dimensions of social corporate performance: an analytical framework” en la California Management Review, considerado todo un “clásico” en nuestros días. En él proponía el término "desempeño social corporativo" (Corporate Social Performance -CSP-) como alternativa más precisa a la responsabilidad social corporativa, distinguiendo tres dimensiones dentro del mismo, las cuales si bien resultaban complementarias en la definición del constructo -y eran postuladas como tales-, no por eso dejaban de estar hasta cierto punto planteadas a modo de etapas sucesivas dentro de un proceso 
secuencial (esto es, cada una de las cuales suponiendo “un paso más allá” en relación con la precedente). Dichas dimensiones eran (Figura 1.4):

- La “obligación social”, una conducta corporativa de naturaleza prescriptiva, “en respuesta a las fuerzas del mercado o coacciones legales” (Sethi 1975:70).

- La “responsabilidad social”, de naturaleza prescriptiva, que va más allá y "lleva la conducta corporativa a un nivel superior, en que resulta congruente con las normas sociales prevalentes, los valores y las expectativas de desempeño" (Sethi 1975:62). En otras palabras, donde acaba la Ley (Stone 1975).

- La “concienciación social”, concebida como la "adaptación del comportamiento corporativo a las necesidades sociales”, un estadio anticipatorio y preventivo cuya noción ya había avanzado Robert Ackerman en 1973 (quien la retomaría en 1976, junto con Raymond Bauer).

Figura 1.4. Las dimensiones en desempeño social corporativo de acuerdo con Sethi (1975)

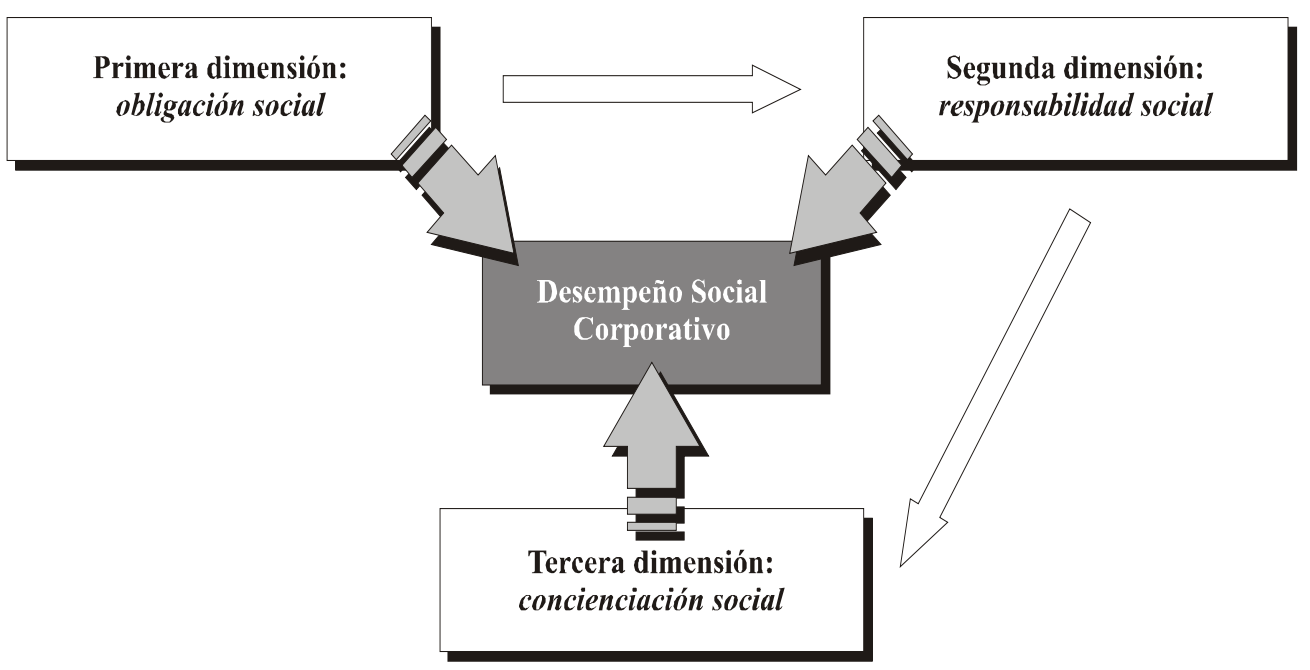

Fuente: Elaboración propia en base a Sethi (1975).

Siguiendo a Votaw, Lee Preston y James Post mostraban, por su parte, su preferencia por el término “responsabilidad pública”, para así "enfatizar la importancia del proceso de las políticas públicas, más que la opinión o consciencia individual, como fuente de objetivos y criterios de valoración” (Preston y Post 
1975:102). En su opinión, en tanto este término alternativo resultaba adecuado al hacer referencia a aquellas funciones y/o actividades de la gestión organizativa que tenían que ver con el contexto específico de la vida pública, consideraban, por el contrario, que hablar de responsabilidad social era hacerlo de "un vago y generalizado sentido de preocupación social que aparece para agrupar una amplia variedad de políticas y prácticas de gestión ad hoc” (Preston y Post 1975:9-10), apostillado por el propio Preston como simples intuiciones en la búsqueda de un "paradigma” que vincule a empresas y sociedad (Preston 1975).

Mediada la década de los 70 fueron publicados los resultados de dos de los primeros antecedentes en cuanto a investigación empírica relacionada con la responsabilidad social corporativa. En el caso del trabajo de Edward Bowman y Mason Haire (1975), el propósito era saber hasta qué punto las empresas estaban involucradas con la responsabilidad social corporativa o si se trataba simplemente de un tópico de estudio que había atraído el interés de los académicos. Para ello, estos autores analizaron una muestra de entidades, distinguiendo entre aquéllas que se consideraban “negocios” en un sentido estricto y las que realizaban actividades de carácter social, a la vez que en este último caso establecían qué tipo de actividades eran las más realizadas y cómo eran reflejadas en las correspondientes memorias y balances anuales (Bowman y Haire 1975:50). Tal y como pudieron comprobar, una amplia terminología era utilizada en la práctica para referirse a una misma cosa: responsabilidad corporativa, responsabilidad social, acción social, servicio público, ciudadanía corporativa, responsabilidad pública, concienciación social...

Por su parte, y tratando de determinar qué hacía que los ejecutivos se interesasen por los problemas sociales, Sandra Holmes procedió a clasificar los “objetivos” o "resultados" positivos que aquéllos esperaban obtener a corto y largo plazo sobre los beneficios de sus entidades, a la vez que los “factores" que utilizaban a la hora de seleccionar aquellas acciones o tipos de actividades en los que involucrarse (Holmes 1976:36-38). Paralelamente, autores como Medawar (1976) disertaban sobre los aspectos técnicos a la hora de reflejar dichos beneficios en las cuentas de resultados y auditorías sociales.

Ese mismo año, Gordon Fitch aportaba una nueva definición en esa misma línea. Para él, las empresas socialmente responsables llevaban a cabo un proceso en dos fases: primero identificaban las cuestiones sociales con las que querían verse relacionadas (en 
función del interés que suscitaban entre los diferentes públicos objetivo, y diferenciándolas así de las “cuestiones no sociales” y de las “cuestiones sociales de menor interés"); después, analizaban los métodos para involucrarse con dichas cuestiones y seleccionaban los más adecuados a sus recursos e intereses, De acuerdo con este planteamiento, Fitch (1976:38) definía la responsabilidad social corporativa como "un serio intento por resolver los problemas sociales causados total o parcialmente por la corporación”.

Casi al mismo tiempo, diferentes autores retomaban el concepto de “desempeño social corporativo" introducido por Sethi, atraídos por un concepto más amplio y que iba "más allá" de la "simple” responsabilidad. Éste fue el caso de autores que iniciaban su andadura en este campo, como Archie Carroll (1977), y de otros que ya llevaban algún tiempo dedicándole sus esfuerzos, como Lee Preston (1978) o Joseph Post (1978a y 1978b).

Los resultados de un nuevo estudio empírico vieron la luz en 1979 cuando Walter Abbott y Joseph Monsen, a partir del análisis de las memorias anuales de las 500 empresas del ranking de Fortune propusieron 28 ítems para ver la "revelación del compromiso social" (Social Involvement Disclosure -SID-) de las mismas. Estos ítems estaban agrupados en seis categorías: medio ambiente, igualdad de oportunidades, personal, compromiso con la comunidad, productos y otros aspectos. En el estudio subyace que la composición de cada categoría (o incluso el número y el nombre de éstas) podía resultar variable, en función de la dirección (temas de interés social) y el alcance (nivel de implicación) del compromiso social en cada momento, así como del efecto de éste en las cuentas de resultados.

Por su parte, Thomas Zenisek, tras realizar una amplia revisión de la literatura preexistente, expresaba su preocupación por el hecho de que las contribuciones previas se habían realizado tradicionalmente sobre una base teórica, a lo que ahora se unían otras contribuciones cuya base era sólo o eminentemente empírica. Como alternativa, y partiendo de la idea de “continuum” planteada por Eells y Walton (Eells 1956, Walton 1967, Eells y Walton 1974), procedió a elaborar un modelo que planteaba una evolución secuencial en la concienciación social de las empresas a lo largo de cuatro fases o etapas, transcurridas entre 1960 y 1979. En la última de dichas fases, la etapa "social” se habría alcanzado el mayor nivel de congruencia entre la "ética de los negocios" 
(comprendiendo aspectos ideológicos y operacionales) y las "demandas/expectativas sociales” (Zenisek 1979:365-366).

Finalmente, dos de las contribuciones más significativas con las que concluían la década de los $70 \mathrm{y}$, con ella, la “edad de oro" de las definiciones sobre la responsabilidad social corporativa (la que aquí ha sido denominada etapa de “formalización y consolidación” conceptual), se deben a los ya mencionados Sethi y Carroll. En tanto el primero planteaba un modelo conceptual para el análisis de la responsabilidad medioambiental de las empresas (Sethi 1979) -un claro precedente en la especialización que caracterizaría la etapa posterior-, Archie Carroll sentaba las bases conceptuales de la "pirámide” que propondría años más tarde.

Concretamente, Carroll (1979:499) partiría de la base de que los directivos precisaban disponer de: i) un concepto claro de qué es la responsabilidad social corporativa; ii) una lista de razones para su existencia (o bien una relación de aquellos stakeholders hacia los que la empresa tiene una responsabilidad, relación o dependencia); y iii) una especificación de la filosofía de la responsabilidad hacia los tópicos correspondientes. Seguidamente, definiría la responsabilidad social corporativa como la actividad empresarial que “armoniza las expectativas económicas, legales, éticas y discrecionales que la sociedad tiene sobre las organizaciones en un momento de tiempo dado" (Carroll 1979:500).

En dicha definición cabe apreciar de nuevo la referencia “adaptativa” que subyacía en la aportación de Abbott y Monsen, al contemplar la posibilidad de que las expectativas sociales sean distintas en cada momento temporal. Por otro lado, un buen número de ideas previas resultan sistematizadas en forma de un modelo conceptual con cuatro grandes “componentes” o “responsabilidades” (Carroll 1979:500): económica (producir bienes y/o servicios para venderlos a cambio de un beneficio, esencia en sí del sistema económico capitalista), legal (como expresión de las “reglas del juego” bajo las cuales se espera que funcione el sistema), ética (pautas de comportamiento que, "por encima y más allá” de las obligaciones legales, la sociedad espera de los negocios), y discrecional (papeles voluntarios estratégicamente asumidos a juicio y elección de directivos y responsables empresariales, en función de las tendencias sociales vigentes y tratando de "sorprender" o superar las expectativas de los stakeholders sobre la implicación de la entidad con la sociedad). 
A modo de síntesis de lo acontecido en esta prolífica etapa de formalización y consolidación, puede decirse que los diferentes postulados vienen caracterizados por el hincapié de los diferentes autores de la época en una serie de aspectos fundamentales sobre los que, a su entender, debería fundamentarse la responsabilidad de las organizaciones y, que sin lugar a dudas, estarán presentes en el desarrollo futuro del concepto, destacando características tales como (Cuadro 1.2): su naturaleza voluntaria, que va más allá de la Ley y de los resultados económicos; el compromiso en la solución de los problemas sociales; la incorporación de valores y expectativas sociales en la gestión empresarial; un enfoque basado en consideraciones de largo plazo; y la consideración de expectativas sociales en lo económico, legal, ético y filantrópico.

Es una etapa en la que se empieza a habar de responsabilidad a partir de la valoración del lugar que ocupa la empresa en la sociedad (Lozano 2009:24), ampliándose la visión de lo que debería comportar una correcta relación con ésta, lo que condujo a enfocar la responsabilidad como una manera de aumentar los vínculos y las contribuciones de las entidades en su entorno más inmediato.

\section{Cuadro 1.2. Principales aspectos señalados en cuanto a la responsabilidad social corporativa durante la etapa de formalización y consolidación (1961-1980)}

\begin{tabular}{|c|c|}
\hline Autor & Aspecto/s señalado/s \\
\hline $\begin{array}{c}\text { Frederick (1960), Davis } \\
\text { (1960), Walton (1967), } \\
\text { Steiner (1971), Manne y } \\
\text { Wallich (1972), Davis } \\
\text { (1973), Eells y Walton } \\
\text { (1974) }\end{array}$ & Voluntariedad, más allá de la Ley y de los resultados económicos \\
\hline $\begin{array}{c}\text { Davis (1973), Eilbert y } \\
\text { Parker (1973), Fitch } \\
\text { (1976) }\end{array}$ & Consideración y compromiso en la solución de los problemas sociales \\
\hline $\begin{array}{c}\text { Steiner (1971), Manne y } \\
\text { Wallich (1972), Eilbert y } \\
\text { Parker (1973), Sethi } \\
\text { (1975) }\end{array}$ & Incorporación de valores y expectativas sociales en la gestión empresarial \\
\hline $\begin{array}{c}\text { Davis (1973), Eilbert y } \\
\text { Parker (1973) }\end{array}$ & Enfoque más centrado en largo plazo \\
\hline $\begin{array}{c}\text { Carroll (1979) } \\
\text { (19) }\end{array}$ & $\begin{array}{c}\text { Consideración de las expectativas sociales en lo económico, legal, ético y } \\
\text { filantrópico }\end{array}$ \\
\hline
\end{tabular}

Fuente: Elaboración propia. 


\subsection{Especialización (1981-2000)}

En los 80 se iniciaría una nueva etapa en relación con la evolución histórica del concepto de responsabilidad social corporativa. Su consolidación como tópico de estudio y la profusión de trabajos aparecidos a lo largo de las dos décadas precedentes traería como resultado la proliferación de estudios empíricos, al tiempo que las nuevas definiciones resultarían relativamente escasas, por cuanto los diferentes autores solían recurrir a las ya existentes. Por otra parte, y podría decirse que como consecuencia, si no lógica, al menos esperable del mayor número de trabajos de campo, tuvo lugar una concreción de los temas de interés/investigación, hasta el punto de poder referirnos a esta nueva fase con el calificativo de etapa de “especialización”.

No obstante, también es posible señalar destacadas aportaciones en el ámbito conceptual, la primera de las cuales, aunque cronológicamente ubicada en el último año de la etapa anterior, es la de Thomas Jones, para quien la responsabilidad social corporativa es una noción que refleja que "las corporaciones tienen una obligación hacia grupos constitutivos de la sociedad distintos de los accionistas y más allá de lo prescrito por la Ley y los convenios colectivos. Dos facetas de esta definición son críticas. Primero, la obligación debe ser adoptada voluntariamente [...]. Segundo, la obligación es extensa, yendo más allá del tradicional deber de incluir como shareholders a otros grupos sociales como clientes, empleados, proveedores $y$ comunidades vecinas” (Jones 1980:59-60).

En este mismo trabajo, Jones haría hincapié en la necesidad de considerar la RSC como un "proceso" integrado por dos subprocesos: uno, de tipo "conductual” o “corpontamental”, consecuencia de un previo de carácter “decisional” (Jones 1980:6566). Sobre este aspecto, así como sobre el carácter dinámico que, en términos generales, preside las relaciones entre los negocios y la sociedad, incidiría en trabajos posteriores (p.e. Jones 1983).

Casi al mismo tiempo, una idea propuesta cerca de treinta años antes por Abraham Maslow, como era la posibilidad de jerarquizar las necesidades de los individuos $^{3}$, daba pie a Frank Tuzzolino y Barry Armandi para complementar la antes

\footnotetext{
3 Aportación que formaba parte de su “teoría de la motivación de los individuos”, y plasmada en su celebérrima "pirámide", de sobra conocida por cualquier experto en Psicología Conductual o en Marketing (Maslow 1954). Aunque con los oportunos matices -a los que se hará referencia más adelante en estas mismas páginas-, constituiría también la base de la posterior "pirámide de la responsabilidad social corporativa” de Carroll (1991).
} 
mencionada definición de Carroll (1979) postulando unas necesidades análogas en las organizaciones (fisiológicas, de seguridad, de pertenencia o afiliativas, de estima, y de autorrealización) igualmente estructuradas. Para estos autores, asumir tal jerarquía en las empresas suponía disponer de "una herramienta conceptual a través del cual una conducta organizacional socialmente responsable podría ser razonablemente valorada” (Tuzzolino y Armandi 1981:24).

Otro planteamiento novedoso corresponde a Dan Dalton y Richard Cosier, quienes a través de un modelo en forma de matriz 2x2 procedieron a clasificar las organizaciones en base a su comportamiento y de acuerdo con la doble dicotomía “legal/ilegal” y "responsable/irresponsable”, con vistas a su ubicación en una u otra de las "cuatro caras de la responsabilidad social” representadas por las cuatro celdas correspondientes. Completando el planteamiento, los autores señalaron -tal y como cabría poder esperar- las conductas “legales-responsables” como las más apropiadas para las empresas a la hora de diseñar su estrategia de RSC (Dalton y Cosier 1982:27).

Aunque sin incluir definiciones en un sentido estricto, contribuciones como las de Melvin Anshen, Richard Strand o Henry Mintzberg se unían a la antedicha de Jones en 1983 resultando también significativas en el ámbito teórico-conceptual. En tanto el primero proponía un nuevo papel de las empresas en el "contrato social” (Anshen 1983), el segundo relacionaba los conceptos de “responsabilidad social”, “conciencia social” y "respuestas sociales” en el interfaz entre la empresa y su entorno (Strand 1983).

Sí sería, por el contrario, introducida una nueva definición por Archie Carroll, quien, partiendo de la previa de 1979, ahora matizaba diciendo que "la RSC supone la conducta de una empresa para ser económicamente rentable, respetuosa con la Ley, ética y apoyar a la sociedad. Para ser socialmente responsable [...] la rentabilidad y la obediencia de la Ley son condiciones primordiales para discutir la ética de la entidad y hasta qué punto apoya a la sociedad en la que existe contribuyendo con dinero, tiempo y talento. De ahí que la RSC esté compuesta por cuatro partes: económica, legal, ética y voluntaria o filantrópica” (Carroll 1983:604).

Por su parte, Peter Drucker dotaba al concepto de responsabilidad en las organizaciones de una nueva dimensión, al introducir una perspectiva claramente estratégica, subrayando la conveniencia o, incluso, la necesidad de convertir las responsabilidades sociales en oportunidades de negocio para las empresas. En concreto, 
y para este autor, "lo propio de la responsabilidad social de las empresas es domar el dragón, esto es, convertir un problema social en una oportunidad económica y en beneficio económico, capacidad productiva, competencia humana, empleos bien retribuidos, y salud” (Drucker 1984:62), en consonancia con los planteamientos de la teoría de los stakeholders que estaba siendo popularizada de forma simultánea por Edward Freeman (1984).

A la vista del creciente interés de los investigadores por interrelacionar la conducta socialmente responsable de las empresas y sus resultados económicos, Philip Cochran y Robert Wood realizaron en 1984 un estudio empírico en el que postulaban la necesidad de vincular el concepto de responsabilidad social corporativa a escalas de medida. Si bien en su estudio estos autores utilizaron el índice de reputación de Moskowitz, reclamaban nuevas escalas que permitiesen contemplar un mayor número de aspectos y una mayor concreción a la hora de clasificar a las diferentes entidades ${ }^{4}$.

Similar en su planteamiento, el también estudio empírico de Kenneth Aupperle, Archie Carroll y John Hatfield en 1985 sometía la definición del segundo a la consideración de una muestra de ejecutivos, concluyendo la validez de los cuatro componentes de la RSC, si bien estableciendo una cierta distinción entre el económico y los tres restantes y retomando para el último de ellos la denominación original de 1979 (“discrecional”). De este modo, “la orientación social de una organización puede ser apropiadamente valorada mediante la importancia que da a los tres componentes no económicos en comparación con el económico” (Aupperle et al. 1985:458).

También en 1985 se publicaría el trabajo de Steven Wartick y Philip Cochran, propugnando una "evolución del modelo de desempeño social corporativo" a partir de las definiciones de Carroll $(1979,1983)$, al reformular los tres aspectos habituales de las definiciones (responsabilidad social corporativa, concienciación, y aspectos sociales)

\footnotetext{
${ }^{4}$ Milton Moskowitz, un autor cuya principal actividad profesional ha estado vinculada al periodismo económico, ideó un "índice de reputación" de las empresas relacionado con su responsabilidad social (ver, p.e., Moskowitz 1972 y 1975). A pesar de las críticas de Cochran y Wood, su utilidad ha sido claramente puesta de manifiesto (sirviendo esto como ejemplo de la "falta de practicidad" o de "operatividad" tantas veces reclamada a las contribuciones del mundo académico), pues sería posteriormente refinado en coautoría con Robert Levering como parte del denominado "índice de confianza".

Versiones sucesivamente actualizadas de la escala de Moskowitz y Levering (la cual cuenta actualmente con 58 ítems, que cubren las cinco dimensiones de credibilidad, respeto, imparcialidad, orgullo y camaradería) vienen siendo asiduamente utilizadas por el Great Place to Work Institute (fundado por el propio Robert Levering y Amy Lyman) desde que éste inició sus actividades en 1980 (incluyendo la elaboración de rankings de las mejores empresas para trabajar para Fortune y otros medios y/o entidades en más de 40 países).
} 
en un marco de principios, procesos y políticas, haciendo hincapié de este modo en los aspectos operacionales de su implementación. En concreto, Wartick y Cochran (1985:767) argumentaban que las definiciones de la RSC debían enfatizar el componente ético de la responsabilidad social y "deberían verse como un conjunto de principios, la concienciación social debería verse como un conjunto de procesos, y la gestión de los aspectos sociales debería verse como un conjunto de políticas”.

Llegados a este punto del repaso histórico, es preciso realizar un inciso para dar cuenta, entre 1982 y 1986, de las consideradas primeras experiencias de materialización de campañas de marketing con causa, llevadas a cabo por American Express y otras entidades en los Estados Unidos. Al igual que ocurría con las experiencias de campañas de marketing social, cabe entender que constituyen ejemplos igualmente reseñables como muestras de acciones de responsabilidad social corporativa, puesto que de facto, no son sino visiones de una misma realidad desde distintas perspectivas ${ }^{5}$.

Y en ese mismo 1986, William Frederick retomaba sus postulados de 1960 a la luz de las numerosas contribuciones llevadas a cabo por otros muchos autores desde entonces. En su definición de la RSC planteaba el "componente ético" como aspecto “indispensable” y que las empresas no podían permitirse evitar en la formulación de sus estrategias, sobre lo cual incidiría al plantear su visión de las teorías del desempeño social corporativo (1987) y, algunos años después, al hablar de la llegada al "estado de madurez” en las relaciones entre las entidades de negocios y la sociedad (1994).

Edwin Epstein postulaba en 1987 una nueva definición de RSC como parte de una teoría de alcance superior. Para él, la responsabilidad social corporativa, la concienciación de las entidades y la ética en los negocios eran tres conceptos íntimamente relacionados, cuyos aspectos y tópicos de interés se solapaban en la práctica. En particular, "la responsabilidad social corporativa se refiere primeramente a lograr resultados a partir de decisiones organizacionales concernientes a aspectos o problemas concretos, los cuales (por algún estándar normativo) tienen efectos más beneficiosos que adversos en los pertinentes stakeholders corporativos. La corrección normativa de los productos de la acción corporativa han constituido el centro de atención de la responsabilidad social corporativa” (Epstein 1987:104).

\footnotetext{
${ }^{5}$ Hasta el punto de llegarse a plantear los términos "responsabilidad social corporativa” y "marketing con causa" como sinónimos o alternativos. Un interesante desarrollo a este respecto puede verse, por ejemplo, en Currás (2007:65-83).
} 
No obstante, la RSC debería integrarse, a juicio de este mismo autor, en un concepto superior, al cual aludió con el nombre de "proceso de política social corporativa”. En concreto, "la esencia del proceso de política social corporativa consiste en la institucionalización dentro de las organizaciones empresariales de los siguientes tres elementos [...:] ética empresarial, responsabilidad social corporativa y concienciación social corporativa” (Epstein 1987:106).

Nada más comenzar la década de los 90 vieron la luz dos aportaciones significativas a partir de la reformulación de ideas anteriores. Por un lado, Donna Wood plantearía un modelo alternativo de desempeño social corporativo y, por otro, Archie Carroll elaboraría una nueva versión -la más conocida y difundida- de su concepto de responsabilidad social corporativa.

Específicamente, el nuevo modelo de Wood (1991b), elaborado tras una revisión y exposición previa de las contribuciones más significativamente utilizadas en la literatura (Wood 1991a), se basaba fundamentalmente en la adaptación de la primera versión del modelo tridimensional de Carroll (1979) realizada por Wartick y Cochran (1985), procediendo a reformular los principios, procesos y políticas de estos últimos en tres principios, de la manera siguiente (Wood 1991b:694 y ss.):

- En primer lugar, el principio de la responsabilidad social corporativa, que comprendía los cuatro niveles de Carroll (económico, legal, ético, y discrecional), en clara relación con las cuestiones relativas a la legitimación social (a nivel institucional), la responsabilidad pública (a nivel organizativo), y la discrecionalidad de la dirección (a nivel individual).

- En segundo lugar, el principio de la concienciación social, en términos tanto de responsabilidad medioambiental como de gestión de stakeholders (lo que suponía un desarrollo de las categorías o actitudes hacia la concienciación de Carroll -reactiva, defensiva, acomodativa y proactiva-, que Wartick y Cochran habían conceptualizado como sus políticas).

- Y, en tercer lugar, el principio de los aspectos sociales, incluyendo tanto las preocupaciones (tópicos de interés) como explícitamente los resultados (beneficios) de las conductas corporativas (algo que únicamente estaba implícito en los modelos de Carroll y de Wartick y Cochran). 
Por su parte, el nuevo concepto de Carroll sobre la RSC partía de la consideración de cuatro componentes o niveles de responsabilidad (al igual que en las versiones anteriores), representados gráficamente en forma de pirámide ${ }^{6}$ (Figura 1.5):

- La responsabilidad económica, o de rentabilidad hacia el accionista (shareholder), finalidad esencial de las entidades de negocios.

- La responsabilidad legal, traducida en el cumplimiento por parte de la empresa de todas aquellas normas legales que le sean de aplicación.

- La responsabilidad ética, entendida como hacer lo correcto, justo y deseable en las distintas vertientes de negocio de la entidad (relaciones con proveedores, empleados, etc.).

- La responsabilidad filantrópica, en virtud de la cual la empresa contribuye al bienestar de la sociedad en la que está ubicada (patrocinando eventos o causas, concediendo becas o llevando a cabo programas formativos y de concienciación, etc.).

Figura 1.5. La pirámide de la responsabilidad social corporativa de Archie B. Carroll (1991)

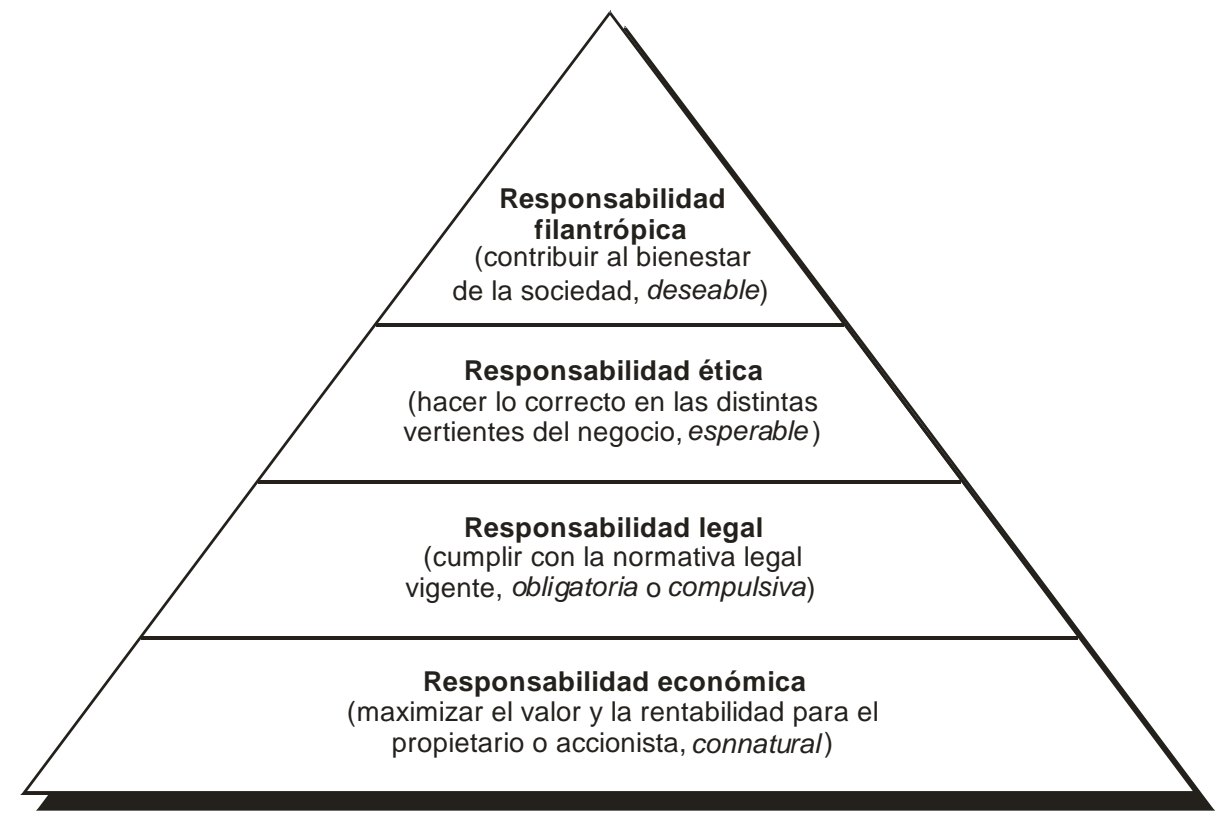

Fuente: Elaboración propia en base a Carroll (1991).

\footnotetext{
${ }^{6} \mathrm{Y}$ tratándose, por tanto, de una aportación análoga en su fundamentación -tal y como ya ha sido avanzado- a la pirámide de Maslow.
} 
De las cuatro, Carroll (1991:40) destacaba la trascendencia de las dos categorías superiores: “[...] todos estos tipos de responsabilidades han existido siempre en alguna medida, pero ha sido únicamente en los años más recientes cuando las funciones ética y filantrópica han adoptado un nivel significativo”. De hecho, una de las novedades más significativas en la nueva reformulación tenía que ver precisamente con el nivel superior o filantrópico (descartando ya la denominación de “discrecional”), que era enlazado con los emergentes postulados de la “ciudadanía corporativa”.

Por otro lado, y aunque el nivel económico estuviese situado en la base de la pirámide (a modo de fundamento para los demás), el propio Carroll aclaraba (1991:42 y ss.) que las empresas no tenían por qué superarlos de forma sucesiva, sino que dedicarían sus esfuerzos en mayor o menor medida a cada uno según las disponibilidades y circunstancias de cada momento ${ }^{7}$. Para ser socialmente responsable, una empresa debería a un mismo tiempo “lograr obtener un beneficio, obedecer la Ley, ser ética, y ser un buen ciudadano corporativo” (Carroll 1991:43).

La formulación de Carroll hace asimismo una referencia integradora a la teoría de los stakeholders, considerándola adecuada al poner "nombres y caras” a los colectivos hacia los cuales las empresas han de ser responsables (Carroll 1991:43).

Finalmente, y cuando menos como curiosidad, cabe señalar que aunque la pirámide de Carroll probablemente sea la contribución más conocida y difundida de este autor, él mismo comentaría años más tarde al referirse a ésta que su formulación "se trataba más de una representación gráfica de la RSC que de un intento de añadir nuevo significado a la definición de cuatro partes” que venía perfeccionando desde sus primeras formulaciones, más de diez años antes (Carroll 1999:289).

Entretanto, otras aportaciones mostraban los tópicos que iban siendo sucesivamente objeto de interés de los investigadores y que, de una u otra manera, estaban presentes en los nuevos planteamientos y definiciones. Entre ellos, los tres “temas estrella” (Carroll 1999:290) fueron el desempeño corporativo o CSP (véase, por ejemplo, Swanson 1995), y el progresivo desarrollo de los principios de la ética en los negocios (entre otros, Freeman y Gilbert 1992, Solomon 1992, Alderson y Kakabadse

\footnotetext{
${ }^{7}$ Radicando aquí, por tanto, la principal diferencia conceptual con el modelo de la pirámide de Maslow. En tanto ésta supone una jerarquía (los individuos no se plantean un nivel de aspiraciones hasta haber concluido o superado los niveles inferiores de la pirámide), no ocurre así en el caso de la pirámide de Carroll (las entidades pueden actuar -y de hecho actúan- con diferentes intensidades en los distintos niveles, sin necesidad de “completar” uno para poder pasar al siguiente).
} 
1994, Litz 1996, Adams 1999 y 2000) y de teoría de los stakeholders (Clarkson 1995, Litz 1996, Gray et al. 1997).

Junto a lo anterior, todo indicaba una acuciante necesidad de reflejar contablemente las actividades de responsabilidad social, de modo que se pudiesen poner de manifiesto sus beneficios -a poder ser cuantitativamente- en los informes elaborados para los diferentes públicos internos y externos a la organización (Puxty 1986 y 1991, Gray et al. 1987 y 1988, Mathews 1993, Gray et al. 1996, Gray et al. 1997, Gray 1998 y 2000, Adams y Harte 2000, Owen et al. 2000). Del mismo modo, captaban la atención aspectos relacionados con el papel regulador a desempeñar por parte del sector público -bien desarrollando el pertinente marco legal o a través de un sistema de control y auditorías- (Bucholz 1987, Harte y Owen 1987, Tinker et al. 1991, Mitnick 1995, McGee 1998, Jones 1999), las distintas particularidades de la responsabilidad medioambiental -resultado de una creciente concienciación social y la subsecuente “presión” derivada para las empresas- (Bucholz 1991, Power 1991, Gray et al. 1995, McGee 1998, Bebbington et al. 1999, Gray 2000), o el desarrollo de un "estilo” o cultura o "especializada” de gestión -con vistas a un cada vez mayor profesionalismo en relación con este tipo de actividades (Alderson y Kakabadse 1994, Murphy 1994 y 1995, Collins 1996, Shepard et al. 1997, Stohs y Brannick 1999), teniendo su correspondiente reflejo en los diseños de los programas educativos y de formación (Bebbington 1997).

Fuera del ámbito académico, las cuestiones que atraían el interés de los directivos y responsables empresariales eran muy similares, tal y como ponían de manifiesto estudios empíricos como el llevado a cabo por Carroll (1994). En definitiva, lo que se percibe en esta etapa es un creciente interés por operativizar el concepto de responsabilidad social corporativa, incorporando los nuevos conceptos colaterales que iban siendo desarrollados.

No obstante, también hubo algunas visiones y planteamientos críticos, aludiendo a la RSC como una moda pasajera, actuaciones diseñadas para captar la atención de los consumidores -incluso comunicando actuaciones o resultados no realizados- o distraer la atención de éstos y otros colectivos respecto a otras acciones "no tan socialmente responsables” llevadas a cabo por las organizaciones (Jones 1996, Owen 1996, Owen et al. 1997, Gray 1998, Bebbington et al. 1999). 
La referencia a dos últimas aportaciones permite concluir el repaso de la etapa de especialización respecto al estudio de la RSC, correspondiendo la primera de ellas a Elkington (1997), quien aportaría el concepto de la "triple bottom line" (o la "triple línea de flotación”), de acuerdo con el cual la supervivencia de una entidad a largo plazo pasa porque ésta sea financieramente segura, elimine o minimice su impacto ambiental negativo y actúe de acuerdo con las expectativas sociales.

Finalmente, Davenport (2000) incluiría una interesante perspectiva integradora, al plantear la ciudadanía corporativa como una aproximación o enfoque de la teoría de los stakeholders para definir el desempeño y sentar las bases para su valoración.

En esta larga etapa de especialización, se recogen los aspectos fundamentales que estarán muy presentes en los nuevos debates, que a lo largo de la primera década de este siglo tutelan los actores y grupos especialmente implicados en la materia. Aun siendo el enfoque de la responsabilidad menos conceptual y más orientado a la investigación práctica y a los procesos organizativos, en el desarrollo y definición del concepto se destacan como aspectos más enfatizados (Cuadro 1.3.): la consideración de un proceso con atención de impactos en los stakeholders, así como de la voluntariedad de las acciones; tener en cuenta las responsabilidades económicas como base de las legales, éticas y filantrópicas, así como las expectativas sociales; la teoría de los stakeholders; la ética de los negocios; el reflejo contable de las actividades de responsabilidad social; los aspectos relacionados con el papel regulador a desempeñar por parte del sector público; las particularidades de la responsabilidad medioambiental; la triple bottom line o triple línea de flotación; y la ciudadanía corporativa como perspectiva integradora.

Cuadro 1.3. Principales aspectos señalados en cuanto a la responsabilidad social corporativa durante la etapa de especialización (1981-2000)

\begin{tabular}{|c|l|}
\hline Autor & \multicolumn{1}{c|}{ Aspecto/s señalado/s } \\
\hline $\begin{array}{c}\text { Jones (1980), Jones } \\
\text { (1983), Epstein (1987) }\end{array}$ & $\begin{array}{l}\text { Proceso y consideración de impactos en los stakeholders } \\
\text { Voluntariedad }\end{array}$ \\
\hline $\begin{array}{c}\text { Carroll (1983), Aupperle } \\
\text { et al. (1985), Wartick y } \\
\begin{array}{c}\text { Cochran (1985), Carroll } \\
\text { (1991), Wood (1991b), } \\
\text { Carroll (1999) }\end{array}\end{array}$ & $\begin{array}{l}\text { Responsabilidades económicas (base), legales, éticas y filantrópicas. } \\
\text { Expectativas sociales }\end{array}$ \\
\hline
\end{tabular}


Cuadro 1.3. Principales aspectos señalados en cuanto a la responsabilidad social corporativa durante la etapa de especialización (1981-2000) (...continuación)

\begin{tabular}{|c|c|}
\hline Autor & Aspecto/s señalado/s \\
\hline $\begin{array}{c}\text { Freeman (1984), } \\
\text { Clarkson (1995), Litz } \\
\text { (1996), Gray et al. (1997) }\end{array}$ & Teoría de los stakeholders \\
\hline $\begin{array}{l}\text { Epstein (1987), Wood } \\
\text { (1991a) Freeman y } \\
\text { Gilbert (1992), Solomon, } \\
\text { (1992), Alderson y } \\
\text { Kakabadse (1994), Litz, } \\
\text { (1996), Adams, (1999), } \\
\text { Adams (2000) }\end{array}$ & Ética de los negocios \\
\hline $\begin{array}{l}\text { Puxty (1986), Gray et al. } \\
\text { (1987), Gray et al. } \\
\text { (1988), Puxty (1991), } \\
\text { Mathews (1993), Gray et } \\
\text { al. (1996), Gray et al. } \\
\text { (1997), Gray (1998), } \\
\text { Adams y Harte (2000), } \\
\text { Gray (2000), Owen et al., } \\
\text { (2000) }\end{array}$ & Reflejo contable de las actividades de responsabilidad social \\
\hline $\begin{array}{c}\text { Bucholz (1987), Harte y } \\
\text { Owen (1987), Tinker et } \\
\text { al (1991), Mitnick } \\
\text { (1995), McGee (1998), } \\
\text { Jones (1999) }\end{array}$ & $\begin{array}{l}\text { Aspectos relacionados con el papel regulador a desempeñar del sector } \\
\text { público }\end{array}$ \\
\hline $\begin{array}{c}\text { Bucholz (1991), Power } \\
\text { (1991), Gray et al. } \\
\text { (1995), Elkington (1997), } \\
\text { McGee (1998), } \\
\text { Bebbington et al. (1999), } \\
\text { Gray (2000) }\end{array}$ & $\begin{array}{l}\text { Particularidades de la responsabilidad medioambiental } \\
\text { Triple bottom line }\end{array}$ \\
\hline Davenport (2000) & Ciudadanía corporativa como perspectiva integradora \\
\hline
\end{tabular}

Fuente: Elaboración propia.

\subsection{Nuevos planteamientos y reconceptualización (desde 2001)}

La quinta y última de las etapas planteadas en el esquema evolutivo, la que ha sido denominada “nuevos planteamientos y reconceptualización” comienza con el nuevo siglo. En consonancia con la diversificación y especialización de los ámbitos de estudio de la etapa anterior, puede decirse que se está desarrollando una “nueva edad de 
oro” en relación con la investigación de la responsabilidad social corporativa por parte del mundo académico ${ }^{8}$.

Particularizando en lo conceptual, para Baron (2001) la responsabilidad de la organización se corresponde con la satisfacción de las necesidades más allá de lo que obliga el mercado y la Ley, excluyendo las acciones sociales que tienen como objetivo el lograr utilidades o que responden a grupos de presión que ponen en riesgo la competitividad de la empresa.

Desde el punto de vista institucional, una de las definiciones surgidas durante esta época más reciente es la incluida en el Libro Verde de la Unión Europea sobre la responsabilidad social empresarial (Comisión Europea 2001): “la integración voluntaria de las preocupaciones sociales y medioambientales en sus operaciones comerciales y sus relaciones con sus interlocutores. De forma amplia es definida como un concepto con arreglo al cual las empresas deciden voluntariamente contribuir al logro de una sociedad mejor y un medio ambiente más limpio”. Dos son las notas que resaltan particularmente en esta definición: la incidencia en el carácter voluntario de las acciones (recalcado) y la mención expresa de una referencia a las cuestiones medioambientales. Destaca asimismo el hecho de que, aunque no se trate de una definición oficialmente adoptada (impuesta), sí ha sido promulgada por un organismo oficial europeo, fruto del consenso de los correspondientes representantes de los Estados miembros, posteriormente refrendada por otros organismos (así, por ejemplo, por parte de la Comisión de las Comunidades Europeas en 2002).

Una alternativa incluso más amplia en la definición del concepto es la del GRI (Global Reporting Initiative), según la cual (Álvarez y Pedreira 2007:21) la responsabilidad social supone "la formalización de políticas y sistemas de gestión en los ámbitos económico, social y medioambiental, también la transparencia informativa respecto de los resultados alcanzados en tales ámbitos y finalmente el escrutinio externo de los mismos”. Es aquí reseñable la equiparación en términos de importancia de tres ámbitos de actuación responsable, así como la referencia a una valoración

\footnotetext{
8 Así, en tanto algunos autores continúan desarrollando sus postulados previos, otros parecen estar "descubriendo" o "redescubriendo" este ámbito de estudio. En tal sentido resultan ilustrativos títulos de artículos como el de Nieto y Fernández (2004): "Responsabilidad social corporativa: la última innovación en management" (el cual puede resultar particularmente llamativo, si bien su contenido indica, no obstante, el conocimiento por parte de los autores de las aportaciones previas en la materia). Otro tanto cabe decir, por ejemplo, del de Reyes, Pinillos y Martín (2005): "La responsabilidad social corporativa: ¿una moda o un nuevo planteamiento de dirección empresarial?”.
} 
externa de los resultados, en clara consonancia con las aproximaciones a este concepto desde la perspectiva del consumidor (como, por ejemplo, Galán et al. 2002, Araque y Montero 2003, Luthy et al. 2003, Maignan y Ferrell 2004, Maignan et al. 2005, Valor 2006, Sorribas 2007).

Así, Araque y Montero (2003:2) al analizar la responsabilidad social empresarial desde esta perspectiva del consumidor y plantear cuáles deben ser las funciones y obligaciones de la empresa en una sociedad plural, consideran que ésta se encuadra "en unas posibilidades de actuación que van más allá del mero cumplimiento de la ley y de la respuesta a presiones sociales acuciantes, y que están condicionadas por las características estructurales de los mercados en los que desarrolle la empresa su actividad”. Esta concepción de la RSE como acto libre y voluntario, es complementada por la idea de "proceso decisional" en el sentido de no dicotomizar la fase de toma de decisiones entre las que son de RSE y de gestión, además de tomar en consideración de los derechos e intereses de todos los stakeholders.

El reflejo contable y en las memorias de resultados de la responsabilidad social en las entidades empresariales ha seguido asimismo estando patente como tópico de interés (entre otros, Gray 2001 y 2002, Larrinaga y Bebbington 2001, Larrinaga et al. 2001, O’Dwyer 2001, Owen y Swift 2001, Owen et al. 2001, Adams 2002, Morimoto et al. 2005), llevando a organismos colegiados como la Asociación Española de Contabilidad y Administración de Empresas (AECA) a elaborar sus propias definiciones. Para esta entidad (AECA 2004), y en una exposición bastante exhaustiva del concepto, la responsabilidad social es "el compromiso voluntario de las empresas con el desarrollo de la sociedad y la preservación del medio ambiente, desde su composición social y un comportamiento responsable hacia las personas y grupos sociales con quienes interactúa [...;] centra su atención en la satisfacción de las necesidades de los grupos de interés a través de determinadas estrategias, cuyos resultados han de ser medidos, verificados y comunicados adecuadamente. Así, la responsabilidad social va más allá del mero cumplimiento de la normativa legal establecida y de la obtención de resultados económicos a corto plazo. Supone un planteamiento de tipo estratégico que afecta a la toma de decisiones y a las operaciones de toda la organización, creando valor en el largo plazo y contribuyendo significativamente a la obtención de ventajas competitivas duraderas”. 
La creciente incorporación de profesionales y expertos del Derecho al estudio de la RSC ha dado igualmente lugar a interesantes puntos de vista que han completado el de las disciplinas económicas. Tal planteamiento se puede ver en definiciones como las de Lizcano (2003), para quien consiste en "asumir la esencia de lo social de las organizaciones empresariales como conjunto de personas que interactúan en el marco de la sociedad, tanto desde un punto de vista de su propia composición elemental (organización igual a la suma de individuos sociales) como desde la óptica del miembro integrante de un sistema social (ciudadano corporativo)" (asimismo refrendado en Esteban et al. 2005, o en Lizcano y Nieto 2006).

Dicha interfaz también ha tenido lugar en la conformación con carácter específico de una dimensión “interna” de la responsabilidad, en la que confluyen expertos de la gestión de recursos humanos y el Derecho Laboral (véase Aragón y Rocha 2004, o Carneiro 2004). En particular, el Foro de Expertos del Ministerio de Trabajo y Asuntos Sociales proponía en 2005 la siguiente definición: “la RSE es, además del cumplimiento estricto de las obligaciones legales vigentes, la integración voluntaria en su gobierno [(el de las empresas)], y gestión, en su estrategia, políticas y procedimientos, de las preocupaciones sociales, laborales, medioambientales y de respeto a los derechos humanos que surgen de la relación y el diálogo transparentes con sus grupos de interés, responsabilizándose así de las consecuencias y los impactos que se derivan de sus acciones” (Álvarez y Pedreira 2007:22).

Éstas y otras aportaciones, muy similares en forma y contenido, han permitido afirmar a autores como Álvarez y Pedreira que una empresa socialmente responsable es aquélla "que adopte voluntariamente un comportamiento ético y socialmente responsable más las de las exigencias legales de cada momento, lo que le permitirá mejorar todos los aspectos internos de funcionamiento, así como su relación con los terceros y el entorno en el que se encuentre operando. Los valores de la RSE deberán estar presentes en la identidad, la misión y la estrategia de la empresa” (Álvarez y Pedreira 2007:23).

En este último orden de cosas, debe tenerse siempre presente no sólo que las prácticas responsables deben ser introducidas voluntariamente, sino también que han de abarcar una amplia gama de acciones, en campos en principio tan dispares como pueden ser el laboral, el social y el medioambiental, sirviendo para mejorar la percepción de la entidad tanto desde el exterior como desde el interior a través de las correspondientes 
acciones de comunicación (Currás 2007). Lograr este objetivo es un reto tanto para empresas como Administraciones, pues aquéllas han de ser socialmente responsables por convencimiento y no por mera imposición normativa (Álvarez y Pedreira 2008).

Vaaland, Heide y Gronhaug, mediante un método de análisis de las definiciones que se han publicado en la literatura sobre RSE, desmontando los aspectos más destacados y por orden de importancia como: beneficios corporativos, stakeholders, preocupación por actos responsables e irresponsables y fenómeno ético, medioambiental y social y, teniendo los aspectos relacionados con el intercambio, la definen como "la gestión de las preocupaciones de los stakeholders por los actos responsables e irresponsables vinculados al medioambiente y a los temas éticos y sociales, de forma que generen beneficios empresariales" (Vaaland et al. 2008:931). Estos autores también reconocen que se trata de un término que engloba múltiples perspectivas y puntos de vista que lo convierten en un concepto ambiguo y complejo.

En la misma dirección y teniendo en cuentas las distintas connotaciones del concepto, Schwalb analiza las frecuencias en las que aparecen aquellos temas identificados como componentes de la $\operatorname{RSE}^{9}$ al consultar las fuentes de la literatura académica, las instituciones latinoamericanas promotoras de la responsabilidad de las organizaciones y las otras instituciones internacionales también promotoras de la materia y, aunque reconoce que no existe una definición, ni un código de conducta único que se ajuste a todas las organizaciones, sugiere una definición integradora de la RSE, entendida como una "filosofía y una forma de gestionar los negocios que implica la incorporación voluntaria, y con visión de largo plazo, de las expectativas económicas, sociales y medioambientales de los distintos stakeholders en las decisiones empresariales. Implica igualmente que estas decisiones deben guiarse por principios éticos y valores que buscan contribuir a la mejora del bienestar de la sociedad en general” (Schwalb 2009:48).

Teniendo en cuenta las contribuciones de diversos autores a lo largo de la última década (Cuadro 1.4), cabe deducir el consenso en cuanto a que la voluntariedad es el

\footnotetext{
${ }^{9}$ Como componentes de la RSE identificadas por la literatura académica y las instituciones promotoras, establece por orden de importancia las siguientes (Schwalb 2009:46): i) consideraciones de las expectativas de los stakeholders en las decisiones empresariales; ii) compromiso con el desarrollo sostenible; iii) voluntariedad: más allá de la Ley y de las obligaciones contractuales; iv) compromiso ético y valores que inspiran las actuaciones contractuales; v) forma de gestionar los negocios; vi) compromiso con la mejora del bienestar de la sociedad; vii) filosofía de negocios; viii) capacidad de respuesta social; ix) compromiso con la mejora de la competitividad empresarial; y x) enfoque de largo plazo.
} 
atributo más destacable de la responsabilidad en la etapa de reconceptualización (Aragón y Rocha 2009:164), la cual viene acompañada por otros calificativos que muestran la forma de entenderla y enfocarla actualmente en las organizaciones. Se trata de aspectos como la inclusión de acciones sociales sin fines lucrativos, la incorporación de las preocupaciones de los stakeholders en la gestión, y la transparencia informativa en los sistemas de gestión de los ámbitos económico, social y medioambiental. También una perspectiva del consumidor condicionada por las características estructurales de los mercados, la satisfacción de las necesidades de los grupos de interés y el reflejo contable en las memorias de sostenibilidad, así como un comportamiento que permita mejorar la percepción tanto interna, como de terceros y del entorno ${ }^{10}$.

Cuadro 1.4. Principales aspectos señalados en cuanto a la responsabilidad social corporativa durante la etapa de nuevos planteamientos y reconceptualización (desde 2001)

\begin{tabular}{|c|c|}
\hline Autor & Aspecto/s señalado/s \\
\hline Baron (2001) & Voluntariedad, con la inclusión de acciones sociales sin fines lucrativos \\
\hline $\begin{array}{l}\text { Comisión Europea } \\
\text { (2001) }\end{array}$ & $\begin{array}{l}\text { Voluntariedad, incorporación de las preocupaciones de los stakeholders } \\
\text { en la gestión empresarial, compromiso con el medioambiente }\end{array}$ \\
\hline $\begin{array}{l}\text { Global Reporting } \\
\text { Initiative (2002) }\end{array}$ & $\begin{array}{l}\text { Sistemas de gestión en los ámbitos económico, social y medioambiental } \\
\text { Transparencia informativa }\end{array}$ \\
\hline $\begin{array}{l}\text { Galán et al. (2002), } \\
\text { Araque y Montero } \\
\text { (2003), Luthy et al. } \\
\text { (2003), Maignan y } \\
\text { Ferrell (2004), Maignan } \\
\text { et al. (2005), Valor } \\
\text { (2006), Sorribas (2007) }\end{array}$ & $\begin{array}{l}\text { Actuación más allá del mero cumplimiento de la Ley, desde una } \\
\text { perspectiva del consumidor y condicionada por las características } \\
\text { estructurales de los mercados }\end{array}$ \\
\hline $\begin{array}{c}\text { Gray (2001), Larrinaga y } \\
\text { Bebbington (2001), } \\
\text { Larrinaga et al. (2001), } \\
\text { O’Dwyer (2001) Owen y } \\
\text { Swift (2001), Owen et al. } \\
\text { (2001), Adams (2002), } \\
\text { Gray (2002), AECA } \\
\text { (2004), Morimoto et al. } \\
\text { (2005) }\end{array}$ & $\begin{array}{l}\text { Voluntariedad, con atención a la satisfacción de las necesidades de los } \\
\text { grupos de interés y reflejo contable en las memorias de sostenibilidad }\end{array}$ \\
\hline $\begin{array}{c}\text { Foro de Expertos (2005), } \\
\text { Currás (2007) Álvarez y } \\
\text { Pedreira (2007), Álvarez } \\
\text { y Pedreira (2008) }\end{array}$ & $\begin{array}{l}\text { Voluntariedad que permita mejorar la percepción en los ámbitos interno, } \\
\text { terceros y entorno }\end{array}$ \\
\hline
\end{tabular}

Fuente: Elaboración propia.

10 Todo ello buscando el bienestar colectivo, tal y como enfatizan algunos de los planteamientos más recientes, como los de la “economía del bien común” (Felber 2012). 


\subsection{Estudios bibliométricos}

El recorrido histórico-económico que acaba de ser realizado en torno al concepto y los planteamientos sobre responsabilidad en las organizaciones resulta más completo si se complementa con una breve mención de algunos estudios bibliométricos que han sido llevados a cabo en este campo, los cuales pueden ser claramente considerados como una fuente más de cara al objetivo de una mejor comprensión de la evolución de los paradigmas y parámetros que han venido guiando las teorías e investigaciones a lo largo del tiempo.

Tal es el caso de los estudios realizados por De Bakker et al. sobre el concepto y los artículos citados con más frecuencia de Corporate Social Responsibility (CSR) y Corporate Social Performance (CSP) en 2005 y 2006, respectivamente.

En tanto el primero de dichos trabajos resulta más limitado, al estar basado en una única base de datos, el segundo es más completo por cuanto también son más las fuentes de datos empleadas por los autores. Con todo, este segundo estudio también plantea el inconveniente de que, al contrario que su predecesor, no establece una clasificación ordenada de las fuentes bibliográficas referenciadas, sino que muestra los artículos únicamente relacionándolos alfabéticamente dentro de una de dos categorías, conforme a sus citas realizadas en cada una de las bases de datos utilizadas como referentes.

En tal sentido, el Cuadro 1.5 sintetiza los resultados del estudio mostrando en la parte superior los artículos más citados ${ }^{11}$, donde se aprecia la gran importancia de los trabajos realizados en la década de los 90 (caso de Wood 1991, Clarkson 1995, Jones 1995, Klasssen y Mc Laughlin 1996, Mitchell et al. 1997, o Waddock y Graves 1997). Junto a ellos aparecen en posiciones destacadas algunas contribuciones publicadas en los 80 (como la de Aupperle et al. 1985, o la de McGuire et al. 1988) o en el momento inmediatamente precedente (el artículo de Carroll de 1979).

Todo ello es una nueva prueba que pone de manifiesto la importancia que en el ámbito académico y profesional tuvieron los debates llevados a cabo durante la que aquí ha sido considerada etapa de especialización, cuya extensión abarca a las dos décadas del período temporal comprendido entre 1981 y 2000.

\footnotetext{
${ }^{11}$ Estableciendo como criterio un índice de citas mayor que 100 en alguna base de datos utilizadas en el estudio, ya sea la Web of Science/Social Citacion Index (WoS/SSCI), el Scopus SCImago Journal \& Country Rank (SJR) y Google Scholar.
} 
Cuadro 1.5. Artículos académicos más citados sobre Corporate Social Responsibility (CSR) y Corporate Social Performance (CSP)

\begin{tabular}{|c|c|c|c|c|c|}
\hline Autor / contribución & $\begin{array}{c}\text { WoS/SSCI } \\
\text { online } \\
03 / 2004\end{array}$ & $\begin{array}{c}\text { WoS/SSCI } \\
\text { online } \\
09 / 2005\end{array}$ & $\begin{array}{c}\text { WoS/SSCI } \\
\text { total refs. } \\
03 / 2004\end{array}$ & $\begin{array}{c}\text { Scopus } \\
\text { SJR } \\
\text { 09/2004 }\end{array}$ & $\begin{array}{c}\text { Google } \\
\text { Scholar } \\
09 / 2005\end{array}$ \\
\hline Aupperle et al. (1985) & 96 & 103 & 108 & n.d. & 89 \\
\hline Carroll (1979) & n.d. & n.d. & 155 & n.d. & 174 \\
\hline Clarkson (1995) & 72 & 92 & 95 & n.d. & 251 \\
\hline Jones (1995) & 119 & 137 & 140 & n.d. & 150 \\
\hline Klasssen y Mc Laughlin (1996) & 61 & 63 & 87 & 118 & 152 \\
\hline McGuire et al. (1988) & 91 & 103 & 103 & n.d. & 132 \\
\hline Mitchell et al. (1997) & 107 & 155 & 258 & 218 & 335 \\
\hline Waddock y Graves (1997) & 48 & 70 & 73 & 82 & 119 \\
\hline Wood (1991b) & 117 & 137 & 140 & n.d. & 215 \\
\hline Abbott y Monsen (1979) & 44 & 47 & 53 & n.d. & 45 \\
\hline Agle et al. (1999) & 21 & 33 & 33 & 46 & 77 \\
\hline Bowman y Haire (1975) & 46 & 46 & 56 & n.d. & 38 \\
\hline Brown y Dacin (1977) & 35 & 60 & 65 & 64 & 88 \\
\hline Carroll (1991) & n.d. & n.d. & 44 & n.d. & 72 \\
\hline Carroll (1999) & n.d. & n.d. & 19 & n.d. & 64 \\
\hline Cochran y Wood (1984) & 64 & 70 & 75 & n.d. & 61 \\
\hline Greening y Gray (1994) & 36 & 41 & 43 & n.d. & 64 \\
\hline Griffin y Mahon (1997) & n.d. & n.d. & 50 & n.d. & 96 \\
\hline McWilliams y Siegel (2001) & 10 & 24 & 25 & 44 & 59 \\
\hline Roberts (1992) & 16 & 20 & 20 & n.d. & 61 \\
\hline Spicer (1978) & 33 & 37 & 54 & n.d. & 53 \\
\hline Swanson (1995) & 19 & 28 & 28 & n.d. & 52 \\
\hline Turban y Greening (1997) & 34 & 38 & 38 & n.d. & 73 \\
\hline Wartick y Cochran (1985) & 63 & 73 & 84 & n.d. & 86 \\
\hline Wood y Jones (1995) & n.d. & n.d. & 32 & n.d. & 59 \\
\hline
\end{tabular}

Fuente: Adaptado de De Bakker et al. (2006:13-14).

Por su parte, en la parte inferior de dicha Tabla aparecen otras contribuciones que, si bien asimismo importantes referentes en la literatura, han tenido menos impacto que las anteriores atendiendo al criterio del número de citas recibidas ${ }^{12}$.

\footnotetext{
${ }^{12}$ Aportaciones con un índice de citas entre 50 y 100 en alguna de las bases de datos utilizadas.
} 
Con todo, al analizar los resultados de estos estudios o de otros análogos que pudieran ser realizados, deben tenerse presentes las potenciales limitaciones de tales investigaciones. De hecho, los propios De Bakker et al. (2006) ya reconocían algunas de ellas, como la posibilidad de que los artículos citados con asiduidad no tengan por qué ser necesariamente los de mayor calidad ${ }^{13}$, la utilización de una única o unas pocas bases de datos ${ }^{14}$, el hecho de que pueda haber otros artículos adicionales que no se hayan incluido en la investigación por no aparecer expresamente caracterizados con el título o palabras clave escogidas (Corporate Social Responsibility, Corporate Social Performance, o sus respectivas siglas) -incluso por restringir la búsqueda a un único idioma-, o la asimismo posibilidad de que existan notables diferencias en los rankings según el momento concreto de búsqueda de citas (por ejemplo, la importancia relativa de un artículo puede decaer a medida que aparezcan contribuciones posteriores, incluso basadas sobre su contenido).

\subsection{Consecuencias de la revisión histórico-económica}

A modo de síntesis tras el recorrido que, con una perspectiva temporal, ha sido realizado a lo largo de las páginas de este capítulo, cabe concluir la pluralidad de términos con la que se ha venido haciendo referencia a una misma realidad, como es el carácter responsable de las actuaciones de los distintos agentes económicos. En concreto, en tanto el concepto de Responsabilidad Social Empresarial (RSE) se ha venido empleando para aludir más expresamente a las actividades de las entidades productivas del sector privado, el término Responsabilidad Social Corporativa (RSC) también se ha aplicado a entidades de este mismo sector, las grandes corporaciones empresariales, lo que en más de una ocasión no ha resultado acorde con el sentido que

\footnotetext{
${ }^{13}$ En concreto, y refiriéndose a la supuesta calidad de los artículos, De Bakker et al. (2006) manifiestan que éstos pueden ser citados únicamente porque un autor o autores quieren indicar que una determinada contribución se ubica en una corriente concreta de pensamiento, convirtiéndose en referentes habituales por ese motivo. En tal sentido, y a título de ejemplo, explicitan incluso que la reiteración de citas al artículo de Mitchell et al. (1997) puede deberse simplemente al hecho de pertenecer a la teoría de los stakeholders.

También objeto de reflexión pueden ser otras posibilidades, como que un artículo se cite por su mala calidad o como exponente de lo que no se debe hacer, o porque sus resultados contradigan a todos los demás (no siendo descartable que eso se deba a la aplicación de un método inadecuado de análisis o a la inapropiada aplicación de un método pertinente). La casuística puede ser, en la práctica, bastante amplia.

${ }^{14}$ Pudiendo deberse, como en el caso del estudio de De Bakker et al., a la no existencia de más fuentes fiables, pero teniendo en cuenta, en todo caso, que la utilización de un número reducido de fuentes limita esa misma fiabilidad y las posibilidades de generalización de los resultados obtenidos.
} 
se quería dar al término, para hacer referencia a un concepto más amplio, cual es la responsabilidad de todo tipo de entidades (no sólo empresariales). Se precisa, por tanto, una clarificación en cuanto a la correcta utilización de unos términos que, no necesariamente y en toda ocasión resultan perfectamente sinónimos.

Así las cosas, recientes planteamientos sostienen que el término RSE resulta en muchos casos preferible, por cuanto éste es el más apropiado a la hora de referirse a todo tipo de entidades productivas del sector privado (grandes, medianas o pequeñas), y no falta incluso quien es partidario de extender su alcance al emprendedor socialmente responsable, dado que éste quien al materializar su proyecto debe poner la actividad empresarial "a disposición de la sociedad, sin olvidar los criterios de rentabilidad económica, como objetivos perfectamente compatibles y unidireccionales” (Muñoz 2012:19), indicando de esta forma que los nuevos emprendedores socialmente responsables tienen la posibilidad de configurar empresas más humanas y sociales, tanto en el ámbito interno como externo al interactuar con la sociedad.

En análogo sentido, y con el claro propósito de lograr una armonización internacional de la teoría y la práctica de la responsabilidad organizativa, organismos e instituciones como la Organización Internacional para la Estandarización (ISO) y los Organismos de Normalización han orientado sus esfuerzos al propósito de consensuar una normativa de estandarización, generalmente con la intervención en este tipo de iniciativas de una pluralidad de actores, considerando así múltiples opiniones y puntos de vista diferentes sobre lo que debe ser y contener el proceso de diseño e implementación de las correspondientes medidas, planes y actuaciones.

Si bien en ocasiones los resultados han quedado inéditos, en casos como el de la ISO 26000 se han dado a conocer tras un largo período de desarrollo y elaboración ${ }^{15}$. La importancia de este estándar internacional es clara (Argandoña e Isea 2011), no sólo como primera norma universal de responsabilidad social, sino también por cuanto cuyo alcance no se limita a las empresas, sino que está pensada para cualquier tipo de entidad, ya sea pública o privada, en base a lo cual ahora se habla, cada vez más generalizadamente, de Responsabilidad Social (RS).

\footnotetext{
${ }^{15}$ La ISO 26000 pretende ayudar a cualquier organización a "incorporar el comportamiento socialmente responsable en su $A D N$ ” (Argandoña e Isea 2011:8), siendo el resultado de un largo y laborioso proceso de diez años de documentación y recogida de opiniones para su posterior debate a fin de llegar a un consenso entre empresas, expertos y otros grupos de interés.
} 
Por otro lado, y también habida cuenta de la manifiesta posibilidad de confusión conceptual y falta de consenso que podría tener la utilización de un término de estas características por parte de académicos de distintas disciplinas (tal y como ha podido comprobarse a lo largo de todo el capítulo), cabe igualmente llegar a la conclusión de que el vocablo "social” puede asimismo ser equívoco o resultar inadecuado, pues tiende a restringir el alcance de la responsabilidad, la cual, por su amplia naturaleza, no debe constreñirse a los aspectos estrictamente "sociales" (particularmente relacionados con actuaciones filantrópicas o “con causa”, así como con determinados comportamientos internos), llevando todo ello a considerar incluso más apropiada la referencia únicamente al término Responsabilidad (R) de las organizaciones.

Todo apunta, pues, en base a tales deducciones y argumentaciones, que a la locución inicial Responsabilidad Social Corporativa (RSC, o CSR según la terminología anglosajona Corporate Social Responsibility) se le han ido cambiando o eliminando las letras: primero, y para hacer no hacer referencia sólo a las grandes corporaciones empresariales, en muchos casos se alude a la Responsabilidad Social Empresarial (RSE o ESR, según esa misma terminología Entrepreneurial Social Responsibility); después, para incluir en su alcance a cualquier tipo de entidad organizativa, se reduce el término a Responsabilidad Social (RS); y, por último, con vistas a la inclusión de aspectos no exclusivamente sociales y de vital transcendencia en el bienhacer de las organizaciones, se ha sugiere la mayor propiedad de reducir el término a, simplemente, Responsabilidad (R).

Por todo ello, y desde un punto de vista terminológico, en la presente Tesis Doctoral, se ha optado por emplear el término Responsabilidad como el más apropiado para hacer referencia al alcance y contenido de aquello a lo que se está haciendo referencia. Ello sin perjuicio del recurso puntual a alguna de las alternativas previamente comentadas. 


\section{CAPítulo 2}

Planteamientos Normativos y Regulatorios

SOBRe LA RESPONSABILIDAD DE LAS ORGANIZACIONES

en el CONTEXto InTERnACional 



\section{CApÍtulo 2. Planteamientos Normativos y REgulatorios SOBRE LA RESPONSABILIDAD DE LAS ORgANIZACIONES EN EL CONTEXTO INTERNACIONAL}

Tal y como ha quedado puesto de manifiesto en el Capítulo 1, el concepto de responsabilidad aplicado al desempeño de las organizaciones comprende un espectro de prácticas y actividades de tal magnitud y disparidad que viene dificultando sobremanera cualquier intento de acuñar una definición homogénea, unitaria y de generalizada aceptación, a la vez que ha derivado con relativa frecuencia -unas veces por necesidad y otras por conveniencia- en la utilización de nociones excesivamente genéricas y/o ambiguas sobre el particular.

Dentro de este gran debate global, un aspecto particular es el concerniente al papel que debe asumir la Administración, no limitándose a una conducta responsable en el diseño y puesta en práctica de sus actuaciones (análogamente a cualquier otra organización, y más aún si cabe, por cuanto su finalidad es -o debe ser- la gestión y procura del bienestar social), sino yendo más allá en su rol de agente activo y regulador (legislador) de tales actividades e iniciativas.

Existen, no obstante, diferentes posturas a este respecto, en algunos casos dando lugar a enconadas discrepancias. Más allá de lo anterior, debatir sobre la conveniencia (o pertinencia) de que la responsabilidad sea promovida por los poderes públicos, por los interlocutores sociales u otras organizaciones, o si, por el contrario, ésta debe quedar en el marco estrictamente privado, supone una dificultad añadida en el debate general (Fernández y Merino 2005), suscitando un gran número de interrogantes: ¿debe existir una Ley o normativa que regule la responsabilidad y, de ser así, debe hacerse a nivel nacional o buscando estándares internacionales?, ¿hasta qué punto cabe pormenorizar en los planteamientos regulatorios con respaldo coercitivo?, ¿se trata de aspectos que deban inscribirse en el marco del diálogo social y de la negociación colectiva?, ¿debe, por contra, encomendarse la responsabilidad a la voluntaria iniciativa de las propias entidades, mediante códigos de conducta y otras iniciativas unilaterales o sectoriales? 
Partiendo de estos planteamientos, el Capítulo 2 comienza por hacer referencia a la función que deben desempeñar las Administraciones Públicas, como agente directamente interesado en mantener y promover un adecuado clima que favorezca un desarrollo apropiado de la responsabilidad, abundando en las características de las políticas correspondientes, así como en hasta qué punto se puede considerar adecuada esa intervención.

Tras lo anterior se procede a describir el contexto normativo, en tanto que un elemento más del entorno organizativo, a tener en cuenta a la hora de tomar las correspondientes decisiones sobre acciones y actuaciones no sólo a nivel nacional o supranacional, sino también a escala internacional, máxime una vez que son cada vez más frecuentes los posicionamientos favorables a la responsabilidad desde empresas privadas y públicas, gobiernos, entidades no lucrativas, organizaciones sindicales, consumidores... conscientes de la necesidad de adoptar lo antes posible cuantas medidas resulten necesarias para propiciar una economía global, responsable y sostenible.

Con este propósito de estudio del contexto normativo-regulatorio se abordan, en primer lugar y desde un punto de vista general las iniciativas internacionales que pretenden establecer un marco global, para después profundizar en la articulación de iniciativas en el marco de la Unión Europea, haciendo hincapié no sólo en aspectos estrictamente normativos, sino también en aquellos otros que de alguna manera han incidido en el tenor de las regulaciones y las políticas de fomento de comportamientos responsables de las organizaciones.

\subsection{La regulación de la responsabilidad por la Administración Pública}

De lo indicado en las páginas del primer capítulo se desprende que gran parte de las contribuciones de la Academia, aunque con importantes diferencias de fondo, sugieren o incluso enfatizan en sus planteamientos conceptuales el carácter voluntario de la responsabilidad en el quehacer diario de las organizaciones, lo que apunta claramente a posicionamientos alejados de cualquier tipo de injerencia o regulación.

No obstante, no es menos cierto que la Administración se encuentra en disposición de facilitar el desarrollo de procesos que favorezcan iniciativas más responsables por parte del conjunto de organizaciones a la vez que ella misma puede predicar con el ejemplo, involucrándose en la práctica de tales actuaciones. 
En otras palabras, y desde un punto de vista más pragmático, las prácticas responsables desarrolladas por las organizaciones se producen en ámbitos que pueden estar más o menos regulado, siendo fácil constatar que el grado de intervención gubernamental no sólo puede promover, facilitar o condicionar las actuaciones responsables en el momento presente, sino también hacerlo significativamente en el futuro como resultado de las políticas adoptadas, como consecuencia de unos variables niveles de regulación, que generalmente parecen estar siendo más perceptibles y notables en los ámbitos medioambiental y laboral (Unceta 2005).

\subsubsection{Las políticas públicas sobre responsabilidad}

La Administración, como agente encargado de velar por el interés general, no sólo desempeña una función importante como órgano regulador y normalizador de las relaciones sociales, sino que también debe adoptar un papel activo y encargarse de propiciar y fomentar la responsabilidad, generando para ello incentivos a fin de que las organizaciones adopten criterios que la favorezcan. Debe, además implementarla dentro de su esfera de actuación como contratista, consumidor, inversor o financiador.

Así las cosas, a la hora de diseñar las políticas públicas, la Administración deberá tener en cuenta los aspectos que se incluyen en el abanico de la responsabilidad social, independientemente de su consideración como cuestiones de interés público o privado, por cuanto las decisiones sobre el uso, consumo y deterioro del capital natural, social y humano afectan a toda la sociedad presente y venidera, siendo necesario que los responsables públicos asuman el gran protagonismo que les corresponde a través del diseño e implementación de políticas de promoción de una forma de gestión más responsable con la sociedad y con el entorno ${ }^{16}$.

Conforme lo indicado en un Informe elaborado por el Foro de Expertos de RSE en España (2007a:12), ésta “contribuye a la mejora integral de la calidad de gestión de la empresa, a desempeñar un papel más positivo con todos sus grupos de interés y con la sociedad”. La generalización de las prácticas responsables puede tener una doble utilidad social: por un lado, potenciar las aportaciones positivas de las empresas a la sociedad; por otro, consolidar un tejido empresarial más consistente, eficiente y

\footnotetext{
${ }^{16}$ Postura defendida en los planteamientos del Documento elaborado tras la VI Sesión de Trabajo del Foro de Expertos de RSE: "Las políticas de fomento y desarrollo de la responsabilidad social de las empresas en España” (For de Expertos de RSE 2007d).
} 
competitivo. En este sentido, parece lógico y positivo que las distintas Administraciones Públicas se planteen el estímulo y la extensión de la responsabilidad por entenderse como algo claramente beneficioso para la economía en sus respectivos ámbitos competenciales y para la sociedad.

Las políticas públicas sobre responsabilidad se suelen clasificar en una doble categoría $^{17}$, distinguiendo de esta forma entre las de fomento y las de incentivos. Mientras las primeras asientan las bases de tipo estratégico para un correcto desarrollo de la responsabilidad, las segundas favorecen su implantación.

De un modo más particular, dentro de las políticas de fomento cabe distinguir acciones de difusión (campañas de información del impacto positivo de las prácticas socialmente responsables), de sensibilización (contribuyendo a la generación de un mayor y más específico conocimiento, así como al fomento de la investigación e innovación en el desarrollo de la responsabilidad en la sociedad), de consolidación de las partes interesadas (fomentando la asociación entre estos grupos para crear instrumentos de deliberación y concertación), así como de influencia en procesos globales (un heterogéneo abanico, integrado, a título de ejemplo, por las orientadas a difundir la responsabilidad en los foros internacionales, a fomentar los mecanismos y organismos internacionales que reclamen incumplimientos en esta materia, o al desarrollo de planes de cooperación bilateral).

Por su parte, y dentro de la categoría de políticas de incentivos se encuentran las orientadas a fomentar la contratación pública sostenible (exigiendo determinados requisitos, en términos de responsabilidad, a las entidades que quieran contratar con la Administración), las ayudas públicas (para la aplicación práctica y efectiva de criterios de responsabilidad, estableciendo los correspondientes mecanismos de control), y el apoyo fiscal (premios para conductas responsables o, por el contrario, en forma de sanciones cuando no lo son). También aquí estarían incluidas las intervenciones en relación con los mecanismos de inversión socialmente responsable (ya sea desarrollando su normativa, premiando la actitud de los inversores, o condicionando la gestión de los intermediarios financieros), y las actuaciones de regulación sobre los procedimientos de reporte y verificación (estableciendo requisitos mínimos para la información que debe ser presentada a los distintos grupos de interés, así como sobre su contrastación).

\footnotetext{
17 Clasificación propugnada, por ejemplo y entre otros, por el Observatorio de Responsabilidad Corporativa en el Módulo II del Documento “La RSC, desafíos y oportunidades” (2011).
} 


\subsubsection{Posturas sobre la regulación de la responsabilidad}

Tal y como ya ha sido avanzado, se han producido y aún hoy en día continúan teniendo lugar debates sobre la conveniencia/pertinencia de regular la responsabilidad y, en su caso, sobre la legitimación y procedimientos para su regulación ${ }^{18}$.

Por un lado, están quienes se oponen a cualquier tipo de intento normativo y opinan que debe ser un sistema basado la voluntariedad donde la Administración debe mantenerse al margen y dejar hacer al mercado. Frente a los defensores de ese "laissezfaire” se encuentran aquellos otros que entienden necesaria y apuestan por una mayor intervención que regule, cuando menos, los aspectos sustantivos en esta materia. En este sentido, y existiendo diferencias de criterio sobre el alcance y profundidad deseable de las iniciativas reguladoras en materia de responsabilidad, la opinión más generalizada se decanta por que "puede resultar de utilidad el que las distintas Administraciones Públicas impulsen un marco promocional y un clima estimulador de la responsabilidad” (Congreso de los Diputados 2006:112).

No obstante lo anterior, también es cierto que al hablar de responsabilidad como sistema de gestión lo más habitual es subrayar el carácter de voluntariedad en lo que realmente puede considerarse valioso (con expresiones en relación con las actuaciones "más allá de lo exigido por la legalidad”, o que comienzan "allí donde acaba la obligatoriedad de la Ley”), con lo que “introducir elementos de obligatoriedad en sus prácticas supondría su desnaturalización. [...] Sin embargo, esa visión también corre el riesgo de ignorar un contexto más amplio de la responsabilidad, como un modelo de gestión que afecta de manera integral y transversal a toda la actividad de la organización, donde se podría circunscribir la acción reguladora a aquellos aspectos de la responsabilidad que, en un momento dado y en función de las circunstancias, puedan necesitarlo” (Congreso de los Diputados 2006:84-85).

\footnotetext{
18 Son varios los documentos donde se pueden constatar evidencias de tal afirmación. A título ilustrativo, en España cabe hacer referencia al apartado dedicado a la contraposición voluntariedad-legislación (págs. 84 y ss.) del "Informe de la Subcomisión para Potenciar y Promover la Responsabilidad Social de las Empresas. Acuerdo de la Comisión de Trabajo y Asuntos Sociales (27/06/2006)”, aprobado por ésta el 27 de junio de 2006 y publicado en el Boletín Oficial de las Cortes Generales el 04/08/2006, más conocido como “Libro Blanco” sobre la RSE en España.

En dicho apartado se da cuenta sobre las posturas defendidas por los principales actores implicados en materia de responsabilidad (Gobiernos y Administraciones Públicas, Academia, empresas, organizaciones y redes empresariales, sindicatos, organizaciones de la sociedad civil, organizaciones de consumidores, instituciones de inversión, consultoras y certificadoras) en este interesante debate.
} 
También existen posturas intermedias (Lozano et al. 2005, Balaguer et al. 2007), considerando que la regulación de la responsabilidad no debería incluir normas de contenido fuerte, sino limitarse a propiciar las condiciones adecuadas para su implantación y posterior desarrollo, utilizando para ello algún tipo de herramienta (política, recomendación o directriz) que permita asegurar aspectos clave, tales como la transparencia en el diseño y articulación de las acciones o la difusión de los resultados, dando a conocer el impacto positivo de las conductas responsables en términos internos (de la propia organización) y externos (hacia fuera de ésta).

En líneas generales, la postura de los partidarios de la no intervención (fundamentalmente determinados ámbitos empresariales ${ }^{19}$ ) encuentra su síntesis en el argumento de que el mercado impondrá los ritmos a los que se desarrollará la responsabilidad, manteniendo, en consecuencia, que la intervención coarta o imposibilita la innovación y la creatividad y con ella se vulneran, en definitiva, las propias leyes del mercado. Según los defensores de esta línea argumental, las empresas y restantes organizaciones llegarían con el tiempo a establecer por propia iniciativa y conveniencia fórmulas de autorregulación basadas en los denominados códigos éticos o de conducta.

Haciendo gala de unos planteamientos diametralmente opuestos, los partidarios de la regulación aducen que, para que las prácticas de responsabilidad sean creíbles, no pueden ser desarrolladas, implementadas y evaluadas unilateralmente por las entidades que las llevan a la práctica, sino que se requiere un marco regulatorio que establezca unos estándares y unas normas básicas (Valor 2010), a modo de “reglas del juego" de generalizado conocimiento y obligado cumplimiento ${ }^{20}$.

Tal y como se aprecia, en cierta manera las distintas opiniones evidencian la diversidad de conceptos que giran en torno al término de la responsabilidad, de los aspectos que contiene, y de cómo se debe aplicar.

\footnotetext{
${ }^{19}$ Véase, por ejemplo, el trabajo de Unceta y Gurrutxaga (2005) sobre el tejido empresarial del País Vasco, concluyendo cómo, por lo general, los gestores y directivos son contrarios a la regulación, especialmente en el caso de las entidades de pequeño y mediano tamaño (más limitadas en sus recursos y posibilidades), entendiendo que lo más adecuado es que el papel a jugar por la Administración en este campo se limite a efectuar recomendaciones. En el mismo sentido se mostraba el sector empresarial cuando se realizó el seguimiento del "Libro Verde" sobre responsabilidad en la UE (COM 2002-347 final).

${ }^{20}$ Yendo incluso más allá en esta línea argumental, Valor (2010:147) sostiene que "muchos afirman que dejar al mercado que controle a las empresas no sólo es técnicamente imposible. El hecho de que sólo se pueda reclamar la responsabilidad a la empresa a través de los mecanismos de mercado supone considerar que ciertos bienes, como los derechos humanos, son bienes privados".
} 
Alternativa, o más bien complementariamente, puede tratarse de responder a la pregunta sobre qué debe ser voluntario y obligatorio en términos de responsabilidad para unas entidades abocadas a operar en un entorno cada vez más global. Para ello, y desde un punto de vista práctico, basta con analizar a nivel de Derecho comparado las normativas reguladoras en distintos países y regiones económicas, constatándose la gran disparidad existente: en una parte significativa de los casos, algo que en un país es estrictamente obligatorio, se plantea como voluntario en otras regiones del mundo, y viceversa. Esto no es sino una nueva prueba de la evidente contradicción en la que se incurre en muchas definiciones de la responsabilidad, y más si el objetivo último es caracterizar una organización y sus actuaciones como responsables cuando "van más allá de la propia Ley”.

Pormenorizando en este análisis pueden apreciarse, con todo, también ciertas analogías o similitudes en los marcos reguladores. Así, al considerar el contenido de las principales iniciativas a nivel global en materia de responsabilidad puede comprobarse cómo todas ellas incluyen aspectos que tienen qué ver con derechos fundamentales del ser humano. Desde los principios del Global Compact hasta el proyecto de normas de Naciones Unidas, pasando por las líneas directrices para empresas multinacionales de la OCDE, se trata de establecer un marco regulador de las actuaciones en relación con aspectos como la libertad sindical, el trabajo infantil, lo derechos de los consumidores, los conflictos armados, las empresas de seguridad, las contribuciones políticas, la corrupción... Debe recordarse, no obstante, el carácter voluntario que impregna a todas estas iniciativas, no tanto relacionado con la importancia de los derechos que protege (pues esto sería bastante incongruente), sino antes bien con la imposibilidad material de regular unitariamente la actuación de personas jurídicas a nivel global (dadas las disparidades de planteamientos y marcos reguladores particulares que antes han sido mencionadas).

En este mismo orden de cosas, un problema de orden mayor puesto de manifiesto a raíz de la utilización de códigos de conducta propios o sectoriales por parte de grandes empresas multinacionales en ausencia de normas globales y mecanismos de supervisión y sanción generalmente aceptados (o en sustitución de éstos) ha sido y está siendo la dificultad para regular a nivel global y con normativa vinculante no la actuación de Estados o los parámetros para dicha actuación, sino directamente para el cumplimiento por parte de personas jurídicas. Parece evidente que es necesario un 
mayor control de las entidades cuando éstas actúan en un marco internacional en el que existen debilidad institucional, un alto grado de corrupción, regímenes dictatoriales y/o conflictos armados. Aún hoy en día hay países que no han ratificado los convenios fundamentales de la OIT u otros acuerdos y normativas de carácter internacional sobre derechos humanos, o que permiten la vulneración sistemática de los mismos en sus respectivos territorios (Tascón 2008) ${ }^{21}$.

En cierta manera, lo que se ha generado en torno a la responsabilidad es un amplio debate que pretende dilucidar qué herramientas son las más adecuadas para generar marcos de comportamiento apropiados y aceptables para unas organizaciones, en algunos casos con un enorme poder, que actúan en un sistema global fruto de la conjunción de muy diversas realidades. En este sentido es necesario hacer una diferenciación de los impactos que pueden tener las distintas actuaciones en base a diversos criterios tales como el tamaño de la entidad, el sector de actividad al que pertenece, y el contexto geográfico y geopolítico donde esté operando.

Como complemento propiciatorio de la generación de un marco regulatorio que favorezca la transparencia son varios los Gobiernos y Administraciones que por propia iniciativa están aplicando políticas de incentivo de la responsabilidad -materializadas básicamente a través de la contratación pública- y políticas de fomento -como la formación de responsables y funcionarios públicos, directivos y trabajadores-. Tales medidas generan confianza. Para que los mercados funcionen correctamente, los agentes que intervienen en ellos deben contar con suficiente información en tiempo y en forma, y ésta debe ser accesible, homogénea, comparable y suponer un coste razonable.

En ese sentido (Andreu et al. 2004), si se recurre de nuevo al análisis de Derecho comparado, en este caso de lo que ocurría en algunos de los países más desarrollados con las primeras políticas públicas sobre responsabilidad (Cuadro 2.1), puede verse cómo éstas trataban de establecer determinados planteamientos regulatorios tendentes fundamentalmente a promover o a obligar sobre determinados aspectos (generalmente medioambientales) que debían incluir los informes de responsabilidad de determinadas empresas y, en algún caso, de la propia a la propia Administración (Nueva Zelanda).

\footnotetext{
${ }^{21}$ Tal cual ocurre en países en desarrollo cuyas legislaciones nacionales en la materia no son aceptables en las sociedades occidentales por no cumplir unos mínimos estándares de protección y derechos de los trabajadores, dando lugar a múltiples interrogantes: ¿cuál es o cuál debería ser en este caso la responsabilidad de una empresa multinacional sobre lo que ocurre en sus subcontratas?, ¿qué sucede cuando una empresa tiene subcontratado todo su proceso productivo?, etc.
} 


\section{Cuadro 2.1. Planteamientos y principios orientadores comparados de las primeras políticas públicas sobre responsabilidad en algunos países occidentales}

\begin{tabular}{|c|c|}
\hline País & Planteamientos / principios orientadores \\
\hline Dinamarca & $\begin{array}{l}\text { Primer país en legislar sobre información medioambiental de las } \\
\text { compañías en 1995. Cada año crece el número de empresas que se suman } \\
\text { al mandato. La calidad de los informes es evaluada desde las agencias } \\
\text { gubernamentales. El Ministerio de Comercio e Industria se encarga de } \\
\text { promover la incorporación de medidas de fomento de la elaboración de } \\
\text { informes o memorias empresariales sobre responsabilidad }\end{array}$ \\
\hline Noruega & $\begin{array}{l}\text { La vigente Ley sobre Contabilidad incluye una serie de medidas que } \\
\text { obliga a las compañías a incluir información medioambiental en los } \\
\text { informes financieros anuales }\end{array}$ \\
\hline Suecia & $\begin{array}{l}\text { Los informes financieros anuales deben incluir información } \\
\text { medioambiental. Desde } 1997 \text { todas las agencias gubernamentales han } \\
\text { implantado sistemas de gestión medioambiental y deben informar } \\
\text { anualmente sobre sus progresos }\end{array}$ \\
\hline Alemania & $\begin{array}{l}\text { El Gobierno promueve y guía la información medioambiental, sin que } \\
\text { esta sea requerida por Ley. En febrero de } 2002 \text { se publicaron una serie de } \\
\text { directrices para la información voluntaria, en línea con la Global } \\
\text { Reporting Initiative (GRI), pero menos ambiciosas }\end{array}$ \\
\hline Francia & $\begin{array}{l}\text { La Ley de Regulación Económica (LOI 116) obliga desde enero de } 2002 \\
\text { a las empresas cotizadas a publicar informes de sostenibilidad. Esta Ley } \\
\text { divide, además, las acciones de comunicación sobre RSC en cuatro } \\
\text { ámbitos: comunidad, recursos humanos, estándares laborales y gestión } \\
\text { del medioambiente }\end{array}$ \\
\hline Reino Unido & $\begin{array}{l}\text { La iniciativa de la Cámara de los Comunes en junio de 2002, en el } \\
\text { ámbito de la promoción de la transparencia informativa en materia de } \\
\text { responsabilidad dio lugar a un Programa Interministerial para coordinar } \\
\text { la acción gubernamental en este campo, incluyendo el uso de las políticas } \\
\text { públicas como orientación e incentivo para las mejores prácticas } \\
\text { empresariales, la promoción del consenso sobre códigos de actuación, y } \\
\text { la generación de un marco adecuado para la comunicación y el escrutinio } \\
\text { público de las acciones responsables }\end{array}$ \\
\hline Estados Unidos & $\begin{array}{l}\text { La Agencia de Protección Medioambiental (Environmental Protection } \\
\text { Agency, EPA) establece un directorio de sustancias tóxicas, de las cuales } \\
\text { todas las compañías están obligadas a facilitar datos relativos en cuanto a } \\
\text { posibles emisiones, que son públicos. Se exige a las compañías cotizadas } \\
\text { información acerca de posibles procedimientos judiciales abiertos por } \\
\text { motivos medioambientales }\end{array}$ \\
\hline Japón & $\begin{array}{l}\text { El Ministerio de Medio Ambiente publica una serie de directrices sobre } \\
\text { información medioambiental, así como un listado de indicadores sobre la } \\
\text { misma materia que, básicamente siguen el modelo propuesto por el GRI }\end{array}$ \\
\hline Nueva Zelanda & $\begin{array}{l}\text { El Gobierno ha promovido un proceso de información en materia de } \\
\text { responsabilidad dirigido al personal de todas las Administraciones } \\
\text { Públicas, a modo de demostración para el sector privado, introduciendo } \\
\text { al mismo tiempo diferentes medidas orientadas a incrementar la } \\
\text { transparencia }\end{array}$ \\
\hline
\end{tabular}


Cuadro 2.1. Planteamientos y principios orientadores comparados de las primeras políticas públicas sobre responsabilidad en algunos países occidentales (...continuación)

\begin{tabular}{|c|l|}
\hline País & \multicolumn{1}{c|}{ Planteamientos / principios orientadores } \\
\hline Canadá & $\begin{array}{l}\text { La Securities Commission pide a las empresas que faciliten información } \\
\text { acerca de posibles incidencias futuras, operativas y financieras, } \\
\text { vinculadas a las prácticas medioambientales de las compañías }\end{array}$ \\
\hline Australia & $\begin{array}{l}\text { Se exige a las compañías información pública detallada acerca de cómo } \\
\text { se aplica, en el seno de cada empresa, la legislación medioambiental }\end{array}$ \\
\hline Sudáfrica & $\begin{array}{l}\text { El Informe King sobre Gobierno Corporativo (marzo, 2002) se refiere a } \\
\text { la necesidad de publicar informes de sostenibilidad, incluyendo aspectos } \\
\text { sociales y medioambientales, que resulte fiable, clara, relevante, } \\
\text { comparable y verificable, de acuerdo con el modelo propuesto por GRI }\end{array}$ \\
\hline España & $\begin{array}{l}\text { Se requiere información medioambiental a las empresas del sector } \\
\text { eléctrico desde 1998 (RD 457/1998), y desde 2002 a las del resto de } \\
\text { sectores de actividad (Resolución ICAC 25/03/2002), a efectos del } \\
\text { reconocimiento, valoración e información de los aspectos } \\
\text { medioambientales en las cuentas anuales. Desde 1990 existe la } \\
\text { obligación de emitir información sobre empleados (muy escasa) en los } \\
\text { informes anuales obligatorios }\end{array}$ \\
\hline
\end{tabular}

Fuente: Elaboración propia en base a Andreu et al. (2004).

Respecto a dichos informes, son muchas las instancias partidarias de su adecuada regulación, incluyendo inversores, consumidores, empresas e instituciones académicas. A título ilustrativo, un reciente estudio de la Universidad de Harvard (Ioannis y Serafeim 2011) sobre las consecuencias derivadas de un marco regulatorio del contenido de los informes de responsabilidad, concluía que la difusión obligatoria de información contribuye a priorizar el desarrollo sostenible, la formación del personal, la inclusión de criterios éticos en las prácticas empresariales, la disminución del soborno y la corrupción, o la mejora de la credibilidad, entre otras ${ }^{22}$, siendo estos efectos mayores en aquellos países donde dicha regulación se aplica con mayor intensidad.

En todo caso, reconocer un cierto papel a la reglamentación no es contradictorio con el carácter esencialmente voluntario de la responsabilidad que mantienen muchos de los actores implicados en el debate. La Unión Europea (también otras instituciones nacionales o internacionales) puede igualmente contribuir a la difusión de buenas prácticas y animar a las empresas a desarrollar su propia estrategia en esta materia ${ }^{23}$.

\footnotetext{
${ }^{22}$ Cuyo listado completo puede verse en http://www.hbs.edu/research/pdf/11-100.pdf.

${ }^{23}$ En palabras de Michel Barnier (Comisario Europeo de Mercado Interior y Servicios) en una entrevista publicada en Solidaridad Digital el 7/05/2012 (Domínguez 2012).
} 


\subsection{Normativa y regulación internacional}

Los debates sobre la responsabilidad en las organizaciones trascienden, pues, al mundo académico y profesional para dar lugar a iniciativas en otros ámbitos, particularmente en la última década del siglo pasado y en los primeros años del presente (Unceta 2005), y hasta la actualidad.

Numerosas entidades y organizaciones públicas y no lucrativas, ya se trate de organizaciones sin fines de lucro, centros de investigación, sindicatos o asociaciones empresariales vienen realizando también interesantes aportaciones, al tiempo que han desarrollado un buen número de instrumentos o herramientas cuya finalidad es servir de punto de referencia para la aplicación de la responsabilidad, guiando y ayudando de este modo a las empresas a gestionar la integración de criterios y parámetros responsables en sus distintos ámbitos de negocio.

Específicamente, la mayoría de los organismos internacionales relacionados con la materia se han implicado, de una u otra forma y en mayor o menor medida, en iniciativas que tienen que ver con la responsabilidad, dada tanto la amplitud del concepto como la creciente concienciación y social que se está experimentado en la etapa más reciente sobre el comportamiento responsable, hasta convertirse en una auténtica demanda social, fuera y dentro del ámbito organizativo (Fernández 2012).

Las estrategias y las políticas de apoyo a las conductas responsables emanadas de las instituciones internacionales constituyen, de hecho, uno de los instrumentos más significativos con los que cuentan las distintas organizaciones interesadas para diseñar e implementar sus estrategias al respecto en el día a día, si bien -tal y como ocurría con buena parte de las normativas a que se hacía referencia en el apartado precedente- debe tenerse presente que en ningún caso se trata de legislaciones o medidas coercitivas, y ello por dos razones (Fernández y Martínez 2003): i) la coercitividad no resulta acorde con el espíritu de la responsabilidad social; y ii) la mayoría de estas instituciones carecen de la atribución de legislar, limitándose en sus actuaciones a debatir y proponer documentos y directrices para su generalizada aceptación, en forma de acuerdos, tratados o programas internacionales que puedan dar lugar a posteriores políticas, actuaciones o normativas.

En tal sentido, y aunque existen algunos tratados de aplicación obligatoria por parte de los Estados nacionales, que inciden y condicionan significativa y decisivamente 
el contexto en el que se desarrolla la responsabilidad organizativa ${ }^{24}$, con lo que es fácil deducir el interés de su estudio, la inmensa amplitud de contenidos justifica centrar el análisis llevado a cabo en este apartado en aquellos principios, directrices e iniciativas internacionales más directa y estrechamente relacionados con la capacidad de influir y definir en la práctica en las actuaciones.

A tal fin, en los siguientes epígrafes se distinguirá entre:

- Principios y directrices.

- Certificaciones y estándares técnicos.

- Indicadores de sostenibilidad.

\subsubsection{Principios y directrices}

Los principios y directrices son iniciativas promovidas a nivel internacional y que están encaminadas a establecer los valores básicos y fundamentales inherentes a todo compromiso responsable de cualquier organización. Aunque aún a día de hoy no existen ni un consenso, ni una armonización a nivel internacional sobre cuáles deben ser éstos -recuérdese que tampoco hay acuerdos unánimes ni siquiera sobre la definición de responsabilidad-, no es menos cierto que algunos pronunciamientos son de referencia universal. A ellos se hace referencia a continuación.

a) La Declaración Universal de los Derechos Humanos:

El 10 de diciembre de 1948, la Asamblea General de las Naciones Unidas aprobó y proclamó la Declaración Universal de Derechos Humanos. Tras este acto histórico, pidió a todos los países miembros que publicaran el texto de la Declaración y dispusieran que fuera “distribuido, expuesto, leído y comentado en las escuelas y otros

\footnotetext{
${ }^{24}$ Además de la Declaración Universal de los Derechos Humanos, condicionante directo y obligado de toda acción que pretenda ser caracterizada como responsable, existen otros pactos, declaraciones, tratados o convenios que también son de aplicación obligatoria, pero con una relación no tan estrecha en sus contenidos o en la práctica no tan vinculantes.

Entre éstos, y por orden cronológico, cabe destacar el Convenio número 87 de la OIT sobre Libertad Sindical y Protección del Derecho a la Sindicación (1948), el Pacto Internacional de los Derechos Civiles y Políticos y la Convención Internacional sobre Eliminación de todas las Formas de Discriminación Racial (ambos de 1966), la Convención sobre la Eliminación de todas las Formas de Discriminación de la Mujer (1979), la Declaración sobre el Derecho de los Pueblos a la Paz y la Convención contra la Tortura y Otros Tratos o Penas Crueles, Inhumanos y Degradantes (ambas de 1984), la Declaración sobre el Derecho al Desarrollo de la ONU (1986), la Convención sobre los Derechos del Niño (1989), la Declaración de la Cumbre de la Tierra de Río de Janeiro (1992), la Carta de la Tierra (1997), o la Convención de la OCDE sobre la Lucha contra la Corrupción de Agentes Públicos Extranjeros en las Transacciones Comerciales Internacionales (también de 1997, con una Recomendación revisada de 2009).
} 
establecimientos de enseñanza, sin distinción fundada en la condición política de los países o de los territorios $" 25$.

Este documento proclama la protección internacional de los derechos humanos dentro del ámbito de influencia de las Naciones Unidas, asegurando que sus organizaciones no sean cómplices de abusos de los citados derechos. La Declaración Universal es uno de los documentos más importantes del siglo $\mathrm{XX}$, siendo traducida a 337 idiomas y habiéndose convertido en un documento fundamental en la orientación de las acciones de Gobiernos y Administraciones, empresas y otras organizaciones, e individuos. Ha sido ratificada por todos los países del mundo, lo no ocurre con ningún otro documento de estas características ${ }^{26}$.

La Declaración Universal de los Derechos Humanos se considera un derecho de primera generación y la mayor parte de sus principios son consuetudinarios, esto es, tienen valor jurídico vinculante para todo Estado que no se haya opuesto a los mismos. En algunos casos, tal vinculación se recoge de forma expresa en normas nacionales, tal y como ocurre en España, conforme al tenor del art. 10.2 de la Constitución de 1978.

b) Las Convenciones de la Organización Internacional del Trabajo:

La Organización Internacional del Trabajo (OIT) es un organismo de la ONU con estructura tripartita (gobiernos, trabajadores y empleadores) con la finalidad de establecer normas técnicas internacionales en el ámbito laboral. Estas normas de mínimos son instrumentos legales que establecen principios y derechos básicos universales en el trabajo, siendo de aplicación a los trabajadores de todo el mundo, con independencia de la organización en que presten sus servicios. Su propósito es evitar la competencia desleal basada en la explotación y el abuso. Las normas de la OIT tienen una buena base técnica y cuentan con el apoyo de empleadores, trabajadores y gobiernos, cuya negociación tripartita a nivel global conduce a la adopción de las

\footnotetext{
25 El Preámbulo de la Declaración (http://www.un.org/es/documents/udhr) resalta la importancia del contenido del documento "como ideal común por el que todos los pueblos y naciones deben esforzarse, a fin de que tanto los individuos como las instituciones, inspirándose constantemente en ella, promuevan, mediante la enseñanza y la educación, el respeto a estos derechos y libertades, y aseguren, por medidas progresivas de carácter nacional e internacional, su reconocimiento y aplicación universales y efectivos, tanto entre los pueblos de los Estados miembros como entre los de los territorios colocados bajo su jurisdicción”.

${ }^{26}$ En un monográfico del Journal USA dedicado a los 60 primeros años de la Declaración de los Derechos Humanos se incluyen diferentes artículos en los que se hace referencia a diferentes aspectos que ponen de manifiesto tanto la importancia del documento, como su influencia y su trascendencia (http://www.america.gov/esp/publications/ejournalusa/1108.html).
} 
normas. Los instrumentos de la OIT se mantienen al día a través de un proceso de revisión y con la jurisprudencia de un mecanismo supervisor de carácter formal que interpreta el significado y la correcta aplicación de las normas de este organismo.

Entre las convenciones y recomendaciones de la OIT, y junto con la Declaración sobre los Principios y Derechos Fundamentales en el Trabajo de 1998, destaca como documento elaborado exitosamente y de aplicación universal la Declaración Tripartita de Principios sobre Empresas Multinacionales y Política Social (ILO). Este documento, tal y como cabe deducir de su propio título, tiene como objetivo minimizar o resolver aquellas dificultades que las empresas multinacionales puedan provocar o experimentar en relación con el progreso económico o social a escala particular (en territorios y/o regiones concretos) y global.

Esta Declaración Tripartita fue adoptada por el Consejo de Administración de la OIT el 16 de noviembre de 1977 y se revisa periódicamente (la última vez en 2006), e invita a los Gobiernos de los Estados miembros, a las organizaciones de trabajadores y de empleadores interesados, y a las empresas multinacionales que operan en los territorios de dichos Estados a que observen los principios en ella contenidos, promoviendo leyes, políticas, medidas y disposiciones apropiadas a este fin ${ }^{27}$.

c) El Pacto Mundial (Global Compact) de Naciones Unidas:

El Pacto Mundial ${ }^{28}$ es una iniciativa internacional promovida por las Naciones Unidas, operativa desde julio de 2000. Su propósito es estimular una conciencia de civismo empresarial, como base propiciadora del desarrollo de una economía mundial más sostenible e integradora, viniendo a suponer un enfoque de fomento de la responsabilidad de las entidades a través de la adopción de compromisos voluntarios (Rodríguez-Piñero 2006). La finalidad última es involucrar a las empresas en la gestión de algunos de los principales retos sociales y medioambientales que son consecuencia de la creciente globalización.

Con todo, el Pacto Mundial se limita a su papel como plataforma global para la promoción de un adecuado comportamiento empresarial en responsabilidad, a modo de estándar sin certificación que no prevé formas de control ni sistemas de penalización en caso de incumplimiento.

\footnotetext{
${ }^{27}$ El texto completo de la Declaración Tripartita está disponible en http://www.oit.org.

${ }^{28}$ Cuyo texto está disponible en http://www.unglobalcompact.org.
} 
Uno de sus objetivos particulares es llegar a establecer una red mundial en la que se fomente el buen comportamiento en las prácticas empresariales ${ }^{29}$, siendo ya multitud las entidades de todo el mundo que se han adherido voluntariamente ${ }^{30}$.

El Pacto Mundial promueve la adopción de diez principios básicos, solicitando a las organizaciones que los adopten e integren en su funcionamiento, y al tiempo apoyen las políticas públicas coherentes con ellos (Cuadro 2.2): dos del ámbito de los derechos humanos (inspirados en la previa Declaración Universal), cuatro en el área del trabajo (inspirados, por su parte, en los asimismo previos Principios Fundamentales de la OIT), tres en el terreno medioambiental (en clara consonancia con los Principios de Río sobre Desarrollo y Medio Ambiente), y un décimo relativo a la lucha contra la corrupción.

\section{Cuadro 2.2. Principios del Pacto Mundial de Naciones Unidas (2000)}

\begin{tabular}{|c|c|}
\hline Ámbito & \multicolumn{1}{c|}{ Principio/s } \\
\hline Derechos humanos & $\begin{array}{c}\text { 1.- Las empresas deben apoyar y respetar la protección de los derechos } \\
\text { humanos proclamados en el ámbito internacional } \\
\text { 2.- Las empresas deben asegurarse de no ser cómplices en abusos a los } \\
\text { derechos humanos }\end{array}$ \\
\hline \multirow{2}{*}{ Normativa laboral } & $\begin{array}{c}\text { 3.- Las empresas deben respetar la libertad de asociación y el } \\
\text { reconocimiento efectivo del derecho a la negociación colectiva } \\
\text { 4.- Las empresas deben eliminar todas las formas de trabajo forzoso u } \\
\text { obligatorio } \\
\text { 5.- Las empresas deben abolir de forma efectiva el trabajo infantil } \\
\text { 6.- Las empresas deben eliminar la discriminación con respecto al } \\
\text { empleo y la ocupación }\end{array}$ \\
\hline Medio ambiente & $\begin{array}{c}\text { 7.- Las empresas deben apoyar los métodos preventivos con respecto a } \\
\text { problemas ambientales }\end{array}$ \\
8.- Las empresas deben adoptar iniciativas para promover una mayor \\
responsabilidad ambiental \\
9.- Las empresas deben fomentar el desarrollo y la difusión de \\
tecnologías inofensivas para el medio ambiente
\end{tabular}

Fuente: http://www.unglobalcompact.org (consultado en junio de 2012).

\footnotetext{
${ }^{29}$ La Red Española del Pacto Mundial de Naciones Unidas (ASEPAM) comenzó a ser operativa en 2004.

${ }^{30}$ En 2008 el Pacto Mundial ya se había convertido en la iniciativa global con más adhesiones, un total de 6.500, de las que 5.000 correspondían a empresas, en tanto que 1.500 lo hacían a organizaciones de la sociedad civil y otras organizaciones no empresariales (Valor 2010). Lejos de detenerse o ralentizarse, el incremento en las cifras de adhesión sigue siendo espectacular, puesto que cuatro años después (septiembre de 2012) en el portal de la organización (www.unglobalcompact.org) podía apreciarse cómo ya lo habían hecho más de 8.000 entidades de 135 países diferentes. Entre ellas, cabe destacar el número de entidades españolas, las más numerosas, por encima del millar.
} 
A nivel operativo, la adhesión al Pacto Mundial supone tres obligaciones para una organización, como son: i) incluir los principios en cualquier forma de comunicación corporativa; ii) informar de los pasos dados incluyendo otros actores; y iii) unirse a los proyectos de la ONU beneficiosos para países en desarrollo. A mayores de lo anterior, debe procederse a la elaboración y envío de un informe corporativo anual en el que se ponga de manifiesto la aplicación práctica de los principios y se reflejen las experiencias o avances conseguidos en dicha aplicación.

Varios son los puntos fuertes que cabe destacar en esta iniciativa. Entre ellos (Valor 2010), su carácter global y voluntario (puede adherirse y participar cualquier tipo de organización), gracias a la naturaleza de la ONU, así como haber puesto de acuerdo a gran número de países en la concreción de unos principios básicos. También ha servido para acelerar el cambio en las empresas (implicándolas en proyectos más globales), ha permitido reforzar la colaboración de las Naciones Unidas con el sector privado, y ha abierto posibilidades para la interacción entre organizaciones no gubernamentales y empresas y otros agentes socioeconómicos, a través de las redes locales. Por el contrario, y como puntos débiles, puede aludirse a que siempre será un estándar de mínimos, vago en cuanto a su ejecución, puesto que no se contempla mecanismo válido de control alguno que permita verificar si las organizaciones adheridas están cumpliendo o no con las obligaciones asumidas.

Más aún, cuando dicho cumplimiento no debe ser traumático, puesto que se contempla un proceso de implantación para las entidades firmantes basado en un proceso de mejora continua, diseñado en cuatro fases o etapas, a fin de favorecer la implantación progresiva de cada uno de los principios del Pacto de acuerdo con los recursos y la realidad particular de cada entidad. Dichas fases programadas (Figura 2.1.) son las de diagnóstico, políticas, acciones, y seguimiento y medición de impactos.

En este mismo orden de cosas, y pese a la mencionada ausencia de mecanismos válidos de control (particularmente en lo que se refiere a la inexistencia del respaldo de instrumentos coercitivos o sancionadores), la ONU siempre ha tenido un especial interés en conseguir que la adhesión suponga una adopción real de los principios y no una mera cuestión de imagen, para lo que procedió al establecimiento de un Comité de Seguimiento del Pacto Mundial, al que se pueden enviar queja y denuncias, con el fin de poder analizar los casos controvertidos y salvaguardar en todo momento la reputación del programa. 


\section{Figura 2.1. Fases contempladas en el proceso de implantación de los principios del} Pacto Mundial de Naciones Unidas (2000)

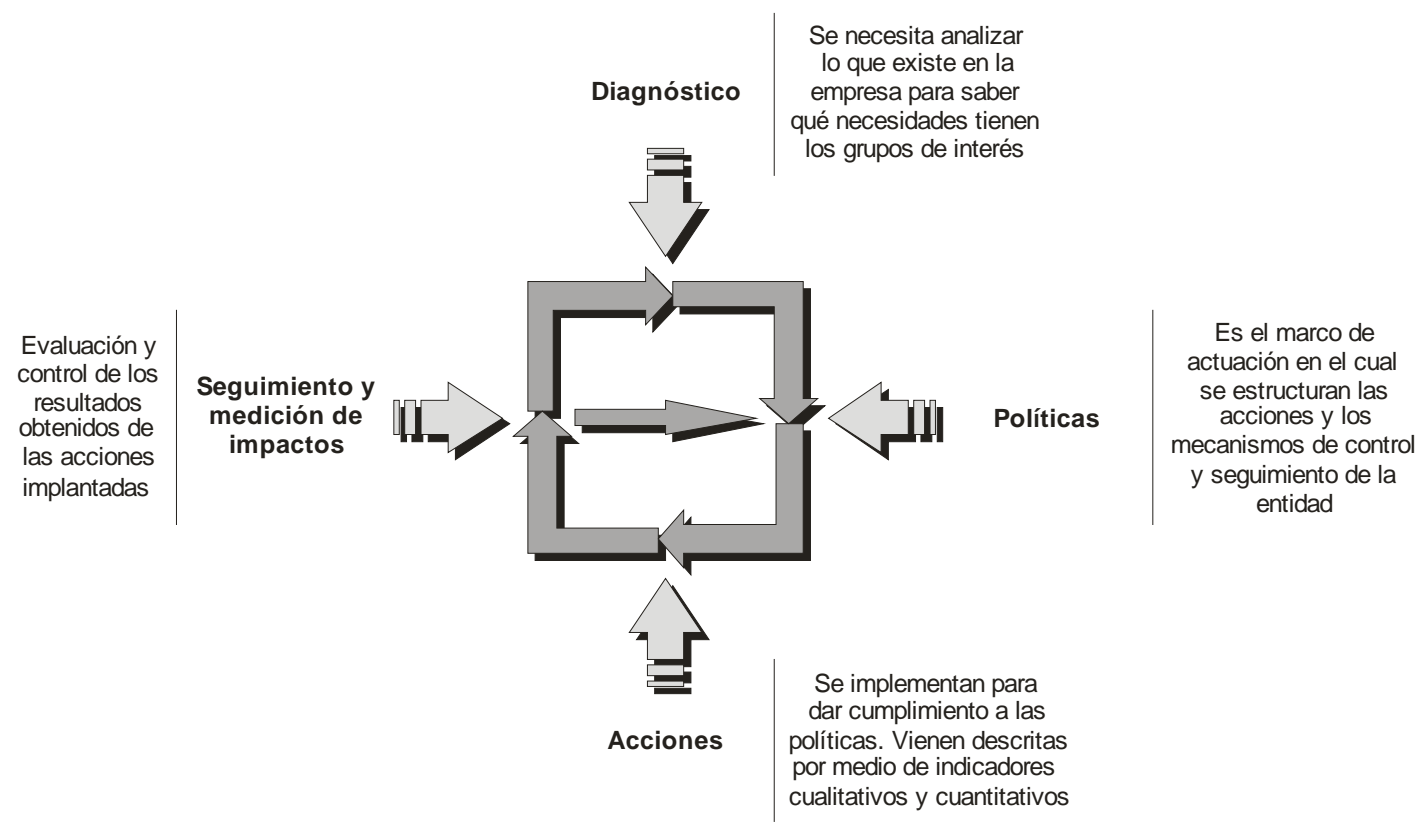

Fuente: Elaboración propia a partir de http://www.pactomundial.org (consultado en junio de 2012).

Enfatizando la importancia de este documento, algunos estudios, como el llevado a cabo por Ayuso y Mutis (2010) se preguntan si puede ser el Pacto Mundial de las Naciones Unidas una herramienta válida para asegurar la responsabilidad de las empresas en un entorno global.

Tras efectuar el correspondiente análisis, la conclusión a la que llegan ambos autores sólo es parcialmente alentadora: por una parte, constatando que las empresas declaran estar procediendo a un alto nivel de cumplimiento en sus actuaciones de todos y cada uno de los indicadores de las cuatro áreas del Pacto Mundial.

Por otra parte, constatando asimismo que la información ofrecida por las empresas en sus Informes de Progreso no está demasiado en consonancia con tal afirmación, puesto que suele ser muy genérica y, por lo general, los correspondientes contenidos no son específicos sobre las actuaciones emprendidas en las actividades de la entidad o con los proveedores situados en países en desarrollo (ni en cuanto a su individualización ni en lo tocante a los datos aportados). 
d) Otras normas, directrices y convenios:

Adicionalmente, la ONU también ha promulgado otras disposiciones que sirven de referencia en el ámbito internacional para el diseño e implantación de conductas responsables en las organizaciones.

Entre ellas, se encuentran las Normas de las Naciones Unidas sobre las Responsabilidades de las Empresas Trasnacionales y otras Empresas Comerciales en la Esfera de los Derechos Humanos, aprobadas por la Subcomisión para la Protección y la Promoción de los Derechos Humanos en 2003. Este documento está constituido por un conjunto de pautas relativas a la observancia de los derechos humanos en las empresas, reuniendo en un solo texto normas internacionales aplicables a este respecto y en lo tocante a cuestiones laborales, de salud y medioambientales, de discriminación, de seguridad, etc.

Junto a las anteriores, las previamente aprobadas Directrices para la Protección del Consumidor $(1999)^{31}$, ya planteaban una serie de principios generales en relación con la percepción que pueden tener los integrantes de este colectivo sobre el carácter más o menos responsable de la conducta de las entidades productivas (lo cual será objeto de consideración específica en posteriores capítulos de este mismo trabajo), contemplando aspectos como su protección frente a los riesgos para su salud y su seguridad, la garantía de sus intereses económicos, el acceso a una información adecuada que les posibilite realizar elecciones bien fundadas, las acciones formativas en campos como la repercusión ambiental, social y económica de sus elecciones y decisiones, la posibilidad de obtener compensaciones por conductas no responsables, la posibilidad de constituir libremente grupos u otras organizaciones para hacer oír sus opiniones en los procesos de adopción de decisiones que les afecten, y la promoción de modalidades sostenibles de consumo.

Más recientes son las Normas de Seguridad y Calidad de los Productos Alimentarios contenidas en el Código Alimentario (Codex Alimentarius), conjunto de pautas sectoriales internacionales adoptadas por la correspondiente Comisión, con el objetivo fundamental de proteger la salud de los consumidores y asegurar prácticas equitativas en el comercio de los alimentos, a la vez que coordinando los trabajos sobre normas alimentarias emprendidos por organismos internacionales.

\footnotetext{
${ }^{31}$ Texto consultable en http://www.un.org/esa/sustdev/publications/consumption_sp.pdf.
} 
También existen diferentes Convenios Relativos al Medioambiente y a los Principios de Buen Gobierno, que cualquier país puede ratificar libremente (continúa, pues, apreciándose aquí el carácter voluntario común a la mayor parte de normas y estándares), pero que ocasionalmente se convierten en requisitos o son valorados positivamente en caso de efectivo cumplimiento ${ }^{32}$, cual es el caso de las Medidas SPG+ de la Unión Europea ${ }^{33}$. Entre estos Convenios cabe destacar (cronológicamente):

- El Convenio Único de las Naciones Unidas sobre los Estupefacientes (1961).

- El Convenio de las Naciones Unidas sobre Sustancias Psicotrópicas (1971).

- La Convención sobre el Comercio Internacional de las Especies Amenazadas de Fauna y Flora Silvestres (1975).

- El Convenio de las Naciones Unidas contra el Tráfico Ilícito de Estupefacientes y Sustancias Psicotrópicas (1988).

- El Protocolo de Montreal, relativo a las sustancias que agotan la capa de ozono (1989).

- El Convenio de Basilea, sobre el control de los movimientos transfronterizos de residuos peligrosos y su eliminación (1992).

- El Convenio sobre la Diversidad Biológica (1992).

- El Protocolo de Kioto (1997), sucesor de la Convención Marco de las Naciones Unidas sobre el Cambio Climático (1994).

- El Protocolo de Cartagena, sobre la prevención de los riesgos biotecnológicos (2000).

- La Convención de las Naciones Unidas (o Convenio de México) contra la corrupción (2003).

- El Convenio de Estocolmo, sobre los contaminantes orgánicos persistentes (2004).

- El Dictamen del Comité Económico y Social Europeo CESE 132/2005, de 9 de febrero, sobre el Sistema de Preferencias Arancelarias Generalizadas.

\footnotetext{
32 A efectos de una enumeración exhaustiva de los más representativos de estos Convenios puede recurrirse a los citados en el Dictamen del Comité Económico y Social Europeo sobre Instrumentos de Información y Evaluación de la Responsabilidad Social de las Empresas en una Economía Globalizada, de 8 de julio de 2005 (SOC/192).

33 El Sistema de Preferencias Generalizadas (SPG) es un instrumento por el cual la UE concede ventajas comerciales a los países en desarrollo, facilitando el comercio internacional mediante un acceso más fácil de los productos de éstos al mercado europeo. En su versión SPG+ se trata de un régimen especial de estímulo al desarrollo sostenible y el buen gobierno, conforme al cual, los países que quieran ser beneficiarios deben cumplir distintos requisitos, entre los que se encuentran ratificar y aplicar de manera efectiva una serie de convenios de la ONU y de la OIT relativos a los derechos humanos, aspectos laborales, aspectos medioambientales, y a los principios de buen gobierno.
} 
e) Las Líneas Directrices para Empresas Multinacionales de la Organización para la Cooperación y el Desarrollo Económico:

La Organización para la Cooperación y el Desarrollo Económico (OCDE) procedió a la aprobación en 1976 de las denominadas Líneas Directrices para Empresas Multinacionales, habiendo sido desde entonces objeto de revisión en diferentes ocasiones, la última de ellas en 2000.

Se trata en origen de una iniciativa específica, por cuanto venía diseñada para un tipo concreto de empresas con una problemática particular derivada de su actuación en el ámbito internacional. No obstante, también son susceptibles de aplicación a empresas nacionales, tanto en éste como en el caso anterior, con carácter voluntario. En todo caso, las Líneas Directrices conforman el conjunto más exhaustivo de pautas acordadas internacionalmente sobre las actividades empresariales, incluyendo recomendaciones sobre la publicación de información, el empleo y las relaciones laborales, el medio ambiente, la lucha contra la corrupción, los intereses de los consumidores, la ciencia y la tecnología, la competencia y la fiscalidad. Su formulación se realiza en base a principios y normas de responsabilidad social que representan valores compartidos por los países miembros de la OCDE y algunos otros que no pertenecen a esta organización.

En cuanto a su objetivo, persiguen fomentar la confianza de aquellos lugares en los que la correspondiente entidad productiva desarrolle su actividad, un adecuado clima de relaciones laborales, la lucha contra la corrupción, el respeto a los intereses de los consumidores, la difusión de la ciencia y la tecnología, el fomento de la competencia, el respeto de la fiscalidad, la defensa del medio ambiente y, en definitiva, contribuir al desarrollo sostenible.

Aunque las Líneas Directrices no los obligatorias, las empresas que las suscriben deben aplicarlas en todos los países en que operan, encomendándose a los Estados que las han firmado la tarea de promover y fomentar su uso, para lo cual deben proceder a establecer Puntos Nacionales de Contacto (PNC) ${ }^{34}$. Estos PNC, además de ayudar a poner en práctica las Directrices, actúan como foro de discusión de los asuntos relacionados con las mismas y también participan en los procedimientos de examen y consulta que permitan abordar cuestiones relativas a su interpretación.

\footnotetext{
${ }^{34}$ En el caso de España, el Punto Nacional de Contacto fue establecido en la Secretaría General de Comercio Exterior del Ministerio de Industria, Turismo y Comercio.
} 
f) La Global Reporting Inititative:

La Global Reporting Initiative (GRI) es un acuerdo de alcance internacional suscrito en 1997 a instancias y como iniciativa conjunta de la organización no gubernamental estadounidense CERES (Coalition for Environmentally Responsible Economies) y el PNUMA (Programa de las Naciones Unidas para el Medio Ambiente), al objeto de fomentar la calidad, el rigor y la utilidad de las memorias sociales o de sostenibilidad (GRI 2002), particularizando en la triple bottom-line, esto es, en la triple dimensión económica, medioambiental y social.

Una de las principales ventajas de la GRI es contar con el respaldo de un comité multistakeholder, lo que le asegura el compromiso por parte de representantes de empresas, de organizaciones asesoras no lucrativas, de auditorías, de sociedades de inversión o de sindicatos, entre muchos otros colectivos. Todos estos grupos han trabajado para consensuar un marco fiable, creíble y unificado, a modo de guía unificada para la elaboración de memorias de sostenibilidad, que pueda ser utilizada por organizaciones de cualquier tamaño, sector o ubicación en cualquier lugar del mundo.

Esta “Guía para la Elaboración de Memorias de Sostenibilidad” se propone como documento de uso voluntario para las organizaciones que deseen informar sobre el carácter sostenible de su desempeño, y está complementada por otros documentos de ayuda que pueden ser utilizados como apoyo por las organizaciones y partes interesadas en su articulación y compresión.

Hasta el momento presente, se han difundido dos versiones de la Guía ${ }^{35}$. La primera de ellas (G.2) se divulgó como borrador en 1999 y como texto final en 2000, al tiempo que, con clara consciencia de las posibles limitaciones, se articulaba un proceso de corrección y propuesta de mejoras en los años posteriores. Resultado de dicho proceso, una nueva versión actualizada y corregida veía la luz en 2006 (la G.3.0), en la que se habían revisado tanto las directrices básicas como los suplementos específicos de cada sector y los protocolos técnicos.

\footnotetext{
35 Encontrándose la tercera versión en el proceso inmediatamente previo a su difusión, tal y como se desprende de lo publicado a este respecto el 28/02/2011 en el "Intelligence \& Capital News Report" (disponible en http://www.icnr.es/articulo.php?n=110328001420). La nueva versión de la Guía estará unida al Protocolo Técnico para ayudar a las compañías a determinar sobre qué aspectos de su actividad informar.

En palabras de Nelmara Arbex (Vicepresidenta de la GRI), recogidas por Media Responsable, los responsables de esta iniciativa se muestran "muy orgullosos de estrenar la guía GRI G3.1. Juntos, el Protocolo y la nueva guía G3.1 harán posible que las organizaciones sean transparentes sobre una amplia gama de cuestiones importantes, pero muchas veces olvidadas”.
} 
Desde un punto de vista práctico, las memorias de sostenibilidad que han sido elaboradas conforme a los principios y orientaciones de la GRI presentan varias ventajas con respecto a aquéllas para las que no han sido tenidos en cuenta. Entre ellas, y específicamente, cabe destacar la de poder utilizarse, entre otros, con los siguientes propósitos (GRI 2006):

i) el estudio comparativo y la valoración del desempeño en materia de sostenibilidad con respecto a leyes, normas, códigos y pautas e iniciativas voluntarias;

ii) la demostración del modo en que una organización influye y se ve influida por las expectativas creadas en materia de sostenibilidad (a modo de prueba fehaciente); $y$

iii) la comparación de las características del desempeño de una organización y entre distintas organizaciones a lo largo del tiempo.

Tal y como se puede apreciar en la Figura 2.2, la Guía de la GRI incluye unos principios y orientaciones, seguidos por unos contenidos básicos.

Figura 2.2. Proceso para la elaboración de memorias de sostenibilidad conforme a la Global Reporting Initiative

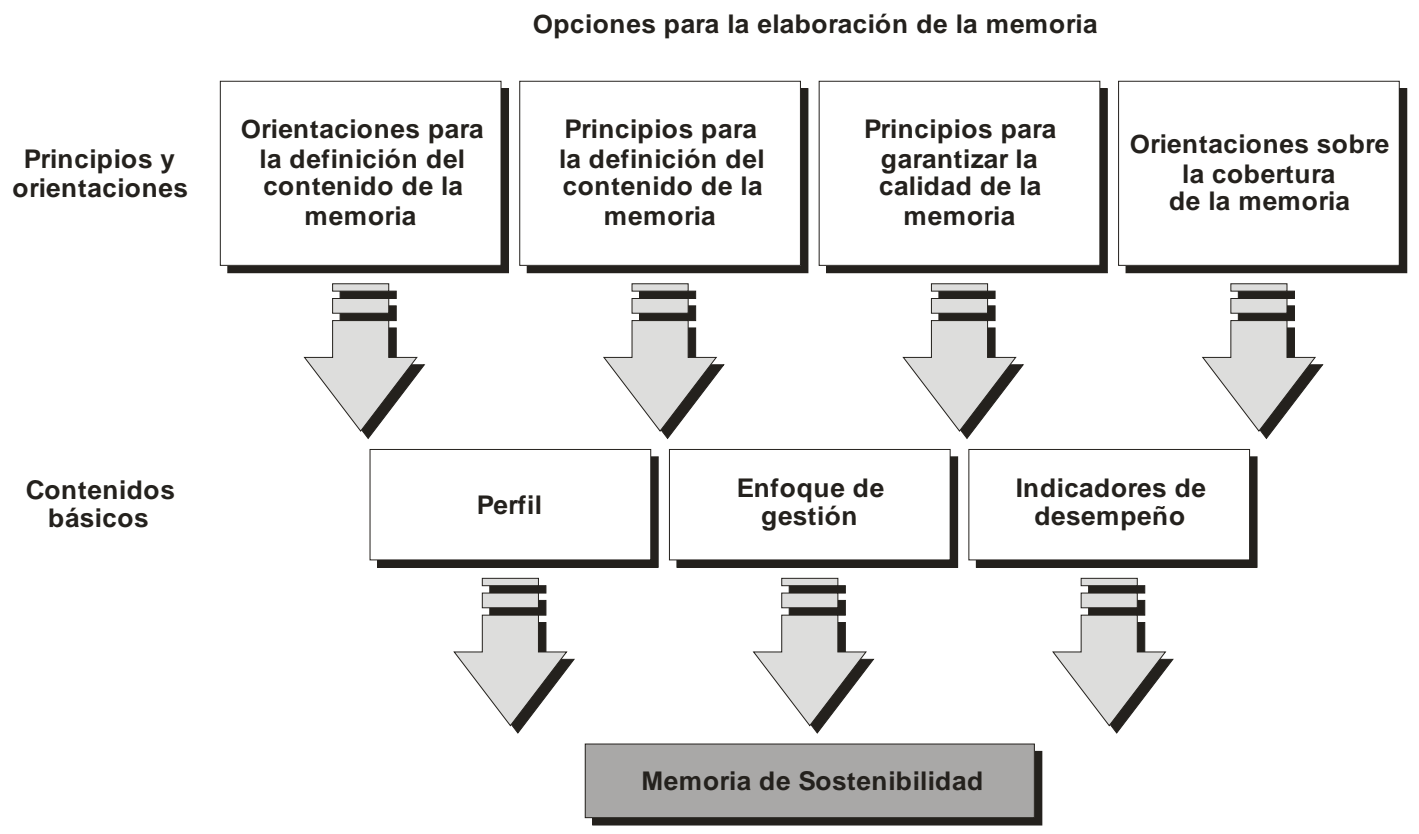

Fuente: Elaboración propia a partir de GRI (2006:6). 
Los principios y orientaciones sirven para determinar qué incluir en la memoria, tocando aspectos fundamentales para ayudar a conseguir la transparencia en el proceso, tanto en lo concerniente a la definición de la memoria (materialidad, participación de grupos de interés, contexto de sostenibilidad y exhaustividad) como en cuanto a su calidad (equilibrio, comparabilidad, precisión, periodicidad, claridad y fiabilidad). También se incluye en este apartado la necesidad de indicar la cobertura de la memoria, especificando las entidades sobre las que la organización informante ejerce un control o una influencia significativa.

Como contenidos básicos, se indica que las memorias deben incluir información sobre el contexto general para comprender el desempeño de la organización (estrategia y perfil) y su estilo de gestión al abordar aspectos específicos (enfoque de la dirección), así como indicadores para disponer de información comparable respecto al desempeño económico, ambiental y social (indicadores de desempeño).

Las memorias de sostenibilidad se califican principalmente en función del número de indicadores que reportan de y si han sido verificadas externamente ${ }^{36}$. Con todo, sigue sin verificarse que la información aportada para cada indicador se reporte de forma completa y exhaustiva y, en consecuencia, la calificación obtenida en base al contenido de la memoria no siempre se corresponde con la realidad (Valor 2010:166).

En la web de la $\mathrm{GRI}^{37}$ se incluyen datos actualizados en cuanto a las memorias de sostenibilidad recibidas tras su elaboración por distintas compañías y recibidas y a su contenido, desde el comienzo de la iniciativa en 1999, clasificándolas por entidades, países y continentes, para que puedan ser consultadas libremente por quienes lo deseen. En tal sentido, y más allá de lo meramente anecdótico, cabe comentar que, si bien EEUU era el país con más memorias elaboradas hasta 2003, la situación cambiaría a partir de 2004, momento en que las organizaciones españolas han tomado la delantera, ocupando el primer lugar hasta la actualidad ${ }^{38}$.

\footnotetext{
${ }^{36}$ En la tercera versión de la Guía GRI se califican las memorias en diferentes categorías (C, C+, B, B+, $\mathrm{A}, \mathrm{A}+$ ), conforme a sus niveles de aplicación y teniendo además en cuenta en qué medida incorporan el enfoque de gestión y los indicadores de desempeño sectoriales.

${ }^{37}$ http://www.globalreporting.org/ReportServices/GRIReportsList/.

${ }^{38}$ En concreto, de las 1837 memoras confeccionadas en 2010 en todo el mundo conforme a las pautas de la GRI, 169 correspondían a entidades españolas, lo que venía a constituir un significativo porcentaje del 9.20\%. Este dato pone de manifiesto la impresionante acogida y compromiso de las entidades del país con esta iniciativa, planteando y comunicando los resultados de sus actuaciones más allá de lo estrictamente financiero.
} 
g) La Alianza Mundial para la Responsabilidad Social del Banco Mundial:

En el momento de concluir estas páginas, desde el Banco Mundial se está promoviendo una Alianza Mundial para el fomento de una mayor responsabilidad social, con el objetivo de intensificar el suministro de opiniones, potenciando la capacidad de la sociedad civil de interactuar con los gobiernos en materia de desarrollo y responsabilidad. La Alianza se ocupará de dar respaldo a las organizaciones de la sociedad civil que se ocupan de la responsabilidad y transparencia, aprovechando una plataforma de conocimientos para intercambiar experiencias, así como propiciando más oportunidades de participación y colaboración con los Gobiernos en aras de la consecución de objetivos de desarrollo conforme a ideales compartidos.

Aunque aún no esté operativa, esta iniciativa resulta reseñable dada la actividad y trascendencia de las actuaciones de su organismo promotor. Entre los primeros pasos para el desarrollo de la misma se ha programado un proceso de consultas, con la triple finalidad $\mathrm{de}^{39}:$ i) establecer un espacio de diálogo entre distintas partes que permita considerar y aprovechar diferentes perspectivas; ii) solicitar y recibir informaciones y comentarios tanto de organizaciones de la sociedad civil, como de entidades bilaterales y multilaterales, gobiernos, sector privado... sobre la buena gestión, alcance y detalles operativos de la Alianza; iii) ampliar y profundizar en los posibles canales de continua participación con partes interesadas clave, incluso en la fase de implementación.

\subsubsection{Certificaciones y estándares técnicos}

Con la finalidad de definir de forma más precisa los principios inspiradores de la actuación responsable de las organizaciones, la incorporación efectiva de éstos en su gestión conforme a los compromisos por ellas adquiridos y la comunicación de los resultados conseguidos a las partes interesadas, diferentes organizaciones tanto públicas como privadas han promovido iniciativas dentro del apartado de certificaciones y estándares técnicos, tendentes a la definición y articulación de criterios armonizados con los que no sólo incentivar conductas responsables, sino también -y lo que es más relevante- poder disponer de herramientas fiables para valorar hasta qué punto es responsable el comportamiento de una entidad.

\footnotetext{
${ }^{39}$ Entre enero y junio de 2012. Éste y otros pormenores en cuanto al desarrollo del proceso constitutivo de la Alianza Mundial (calendario y programas de reuniones, listas de participantes, resumen de opiniones, etc.) pueden consultarse en la web del Banco Mundial (http://www.worldbank.org/).
} 
Entre dichas herramientas, que representan a la vez unos mecanismos de coordinación y unos instrumentos de regulación (Heras 2011), pueden considerarse como más significativas a escala global las reseñadas a continuación.

a) Business for Social Responsibility:

La Business for Social Responsibility (BSR) es una asociación de empresas de carácter no lucrativo y establecida en 1992 con sede en San Francisco (EEUU).

El objetivo del BSR es ayudar a todo tipo de empresas a desarrollar su actividad respetando los valores éticos, al medioambiente y a la comunidad. Para ello se encarga de proporcionar a sus miembros información, asesoría jurídica y herramientas para convertir la responsabilidad social en una parte integral de sus operaciones cotidianas.

b) Las Normas ISO 14000:

Los diferentes esfuerzos unilaterales de los países ante las demandas derivadas de la creciente concienciación medioambiental de los 90 pusieron de manifiesto la necesidad de un sistema universal que permitiese evaluar el desempeño medioambiental de las organizaciones, en cualquier ámbito geográfico, con mayores garantías (Clements 1995). En respuesta al requerimiento, la Organización Nacional para la Estandarización (ISO) se comprometió al diseño de estándares medioambientales de aceptación internacional, las ISO 14000.

Como primeras de esta familia de normas ${ }^{40}$, en un claro intento de establecer un referente voluntario internacional para una gestión medioambiental entendida como control de los elementos y fuerzas que rodean a una entidad, las ISO 14001 y 14004 aparecieron en septiembre de 1996. Posteriores series se ocuparían, respectivamente, de las auditorías medioambientales (ISO 14010 a 14012), la evaluación del rendimiento en este campo (ISO 14031 y 14032), el análisis del ciclo de vida (ISO 14040 a 14048), las etiquetas ambientales (ISO 14020 a 14025), y la medición de la emisión de gases de efecto invernadero (ISO 14064 y 14065).

Ninguna de las Normas ISO 14000 está concebida para ser aplicada a acciones aisladas (aunque pueda entenderse que así es como operan en la práctica), sino que comparten el objetivo de llegar a implantar en las entidades unos planteamientos de concienciación y responsabilidad medioambiental en los sistemas de gestión, a modo de

\footnotetext{
${ }^{40}$ Cuyo listado completo puede consultarse en http://www.iso.org/.
} 
una auténtica filosofía inspiradora en la que todos los grupos estén implicados de forma participativa, colaborando en base a intereses comunes y al firme compromiso con la preservación de la vida en el planeta, en línea con lo exigido a las entidades productivas. Por tanto, las ISO 14000 no fijan unas metas medioambientales, sino que lo que hacen es establecer unos requisitos sobre la sistemática de trabajo a cumplir por parte de las empresas respecto a las actividades que generan el impacto ambiental. Tal circunstancia ha dado lugar a críticas ocasionales a estos estándares, argumentando para ello su rigidez y su tendencia a la burocratización (Heras 2011).

Como ejemplo ilustrativo de los mecanismos que cada uno de estos estándares contempla para su puesta en funcionamiento, cabe aludir al mecanismo en cuatro fases de la ISO 1400141: i) planificación, análisis y evaluación a partir de la previa identificación de los elementos y factores de impacto medioambiental; ii) implantación, definiendo responsabilidades, plan de acción y documentación; iii) comprobación y desarrollo de un sistema de auditorías internas; y iv) revisiones periódicas del sistema por parte de la dirección.

c) La Norma SA 8000:

La Norma SA 8000 es un estándar establecido en 1997 por la SAI (Social Accountability International), contando en su elaboración con la participación, además de otros grupos, de expertos de Naciones Unidas y de la Organización Internacional del Trabajo. La Comisión encargada de su elaboración se completaba con integrantes de organizaciones representantes del amplio espectro de partes interesadas (sindicatos, fabricantes, minoristas, organismos académicos, ONGs y empresas de consultoría y certificación). Se trata de una norma internacional sobre responsabilidad formulada con el fin de proveer normas para la producción ética de bienes y servicios.

La SA 8000 se centra en los derechos laborales, contemplando en cuanto a contenido un alcance más allá de los derechos fundamentales reconocidos por la OIT, y estableciendo normas básicas en cuestiones sobre trabajo infantil, trabajo forzado, salud y seguridad, libertad de asociación y derecho de negociación colectiva, discriminación, prácticas disciplinarias, horas de trabajo, retribuciones, y sistemas de gestión.

\footnotetext{
${ }^{41}$ El numero de certificaciones de la norma ISO 14001 ya alcanzaba a finales de 2008 la cifra de 188.815, destacando por su número las de las entidades chinas (39.195) y japonesas (35.573), seguidas, aunque a distancia, por las españolas (16.443). No obstante, ya en aquel entonces comenzaba a constatarse que, tras el fuerte aumento inicial, las tasas de crecimiento anuales en el número de certificaciones parecían haber comenzado a reducirse (Heras 2011).
} 
En tal sentido, indica que las entidades certificadas deben acatar en sus actuaciones no sólo la legislación nacional, sino también cualquier otro derecho aplicable, como las normas laborales internacionales (OIT, Declaración Universal de Derechos Humanos, y Carta de los Derechos del Niño), cumpliendo con las obligaciones correspondientes conforme a lo que la organización se somete voluntariamente, así como -por descontadocon lo establecido al respecto en el propio estándar.

La adhesión a los planteamientos de la SA 8000 requiere, por otro lado, acciones de comunicación externa, en el sentido de que toda organización certificada habrá de establecer y mantener procedimientos para dar a conocer regularmente datos y otras informaciones relativas al cumplimiento de los requerimientos establecidos. Asimismo se reconoce disponer de la posibilidad de acceso a las partes interesadas con la finalidad de verificar que la información facilitada por la compañía es razonable y adecuada al cumplimiento de los requerimientos del estándar, cuando exista un contrato en el que así se estipule. A pesar de la limitación en cuanto a este último aspecto (debe existir un contrato, y debe ser especificado en éste), debe tenerse en cuenta que la SA 8000 es, en todo caso, un estándar verificable, pues contempla la realización de auditorías por parte de un organismo autónomo acreditado (Caballero y Balaguer 2005a).

Aunque diseñado como un complemento a los estándares ISO 9000 e ISO 14000 (relativos, respectivamente, a la calidad y al medio ambiente), la aplicación del SA 8000 se ha revelado significativamente inferior ${ }^{42}$, con tres posibles formas complementarias de utilización (Fuentes et al. 2005): i) como referencia útil en auditorías internas a la propia organización acreditada; ii) cuando dicha entidad sea auditada por otra o a instancias de otra con ella relacionada, a fin de comprobar el cumplimiento de los requisitos del estándar; y iii) cuando por alguna razón la entidad sea auditada por alguna organización externa independiente que no sea un cliente directo, ni proveedor, ni tenga una relación directa. En este último caso, la auditoría será realizada por un organismo de certificación, una empresa especializada en auditorías financieras, o una ONG, siempre que haya sido acreditada para ello por parte de la CEPAA (Agencia de Acreditación del Consejo de Prioridades Económicas).

\footnotetext{
42 Estudios como el realizado por Heras (2011) ponen de manifiesto que el número de certificaciones conforme al estándar SA 8000 en 2009 fue de 2.103, lejos de las correspondientes a los ISO. Por países, destacaban las 827 correspondientes a entidades italianas, las 458 de entidades indias, y las 270 de entidades chinas. En su conjunto, esas certificaciones de 2009 correspondían a centros productivos o fabriles en 64 países y con más de un millón de empleados (Valor 2010).
} 
d) La Norma AA 1000:

En 1999 el Institute of Social and Ethical AccountAbility (ISEAA) establecía la Norma AA 1000 como instrumento auditor y de certificación de la información sobre la responsabilidad organizativa. Se trata de un método de evaluación que usa un conjunto específico de principios y referentes para evaluar la calidad de los informes elaborados por las distintas entidades y los primordiales sistemas, procesos y competencias que sustentan sus resultados (Cohen et al. 2003, Zadek y Raynard 2004). El procedimiento abarca también las acciones de comunicación de resultados que han sido llevadas a cabo con el fin de generar credibilidad en los públicos usuarios (ISEAA 2008).

La AA 1000 especifica los procesos que debe llevar a cabo una organización para responder por sus acciones, tratando de explicar o justificar las acciones $u$ omisiones por las cuales la organización resulta responsable ante las partes interesadas. El sistema incluye métodos y un conjunto de pautas sobre principios y procesos para la rendición transparente de cuentas, mediante una norma de auditoría que confiere mayor credibilidad a los informes, siendo ésta la razón por la cual se considera como una herramienta complementaria de la Guía de la Global Reporting Initiative.

En cuanto a sus principales características, la AA 1000 destaca por cuanto (ISEAA 2003): i) resulta exhaustiva, al tener en cuenta todos los aspectos del resultado organizacional; ii) examina de manera exhaustiva cómo la entidad alcanza sus propios resultados, cuál es su impacto, cuáles los puntos de vista de las partes interesadas, cómo responde a sus demandas y cómo realiza el informe; iii) está dotada de un enfoque previsor, al indicar la habilidad de una organización para ejecutar las políticas y metas establecidas, así como para cumplir futuras normas y expectativas; iv) establece, apoya e integra enfoques de aseguramiento; v) se puede aplicar a diferentes tipos y tamaños de organizaciones; y vi) requiere la asesoría de los expertos en aseguramiento para cubrir sus competencias y relaciones con la organización informante.

Un elemento clave en el proceso es el diálogo con los stakeholders, quienes colaboran para definir los indicadores y determinar los asuntos a debate. Ello contribuye a reforzar sus puntos fuertes, tales como (Valor 2010) el constante perfeccionamiento, la actualización de las pautas para evaluar la calidad de los informes éticos y sociales, el hecho de que cualquier organización pueda utilizar esta herramienta, el carácter complementario de las memorias GRI, la interdependencia entre la calidad de los resultados y del proceso, y el compromiso significativo de gestión que requiere. 
e) Los Indicadores ETHOS:

Los indicadores Ethos fueron desarrollados por el Instituto brasileño del mismo nombre en 2000. Se trata de una herramienta inicialmente concebida para su uso a nivel interno en una organización, si bien son asimismo susceptibles de utilización como instrumento auxiliar en la gestión de las relaciones con proveedores y otros grupos, en la gestión de riesgos y oportunidades, o -y en particular- de cara así como fortalecer el compromiso de la entidad con la responsabilidad social empresarial y el desarrollo sostenible.

La batería de indicadores ha experimentado varias revisiones desde su propuesta inicial, lo cual da una clara idea de su dinamismo o propósito de constante actualización. En todo caso, se han estructurado en forma de cuestionario y dispuesto en cuadros contiguos para facilitar la planificación de las acciones, a modo de escala evolutiva, la cual actúa como referente o inspiración en los parámetros de políticas y actuaciones.

En función de su contenido, los sindicadores se agrupan en un total de siete grupos o categorías: i) valores, transparencia y gobierno corporativo; ii) público interno; iii) medioambiente; iv) proveedores; v) consumidores y clientes; vi) comunidad; y vii) gobierno y sociedad. Dentro de su grupo, cada indicador tiene la finalidad concreta de mostrar cómo puede la entidad mejorar la gestión del aspecto específico que valora.

\section{f) La Norma ISO 26000:}

Mucho más reciente, la redacción final de la norma internacional ISO 26000 vio la luz el 1 de noviembre de 2010, culminando de esta forma un largo proceso que la Organización Internacional para la Estandarización y los Organismos de Normalización iniciaban en 2003. Tras varios borradores, el texto de la norma supone el desarrollo de la primera guía consensuada a nivel internacional sobre responsabilidad social en las organizaciones, estableciendo directrices sobre principios, materias fundamentales y otros asuntos relacionados, así como cuestiones referentes a su puesta en práctica por todo tipo de entidades, ya sean privadas, públicas, o no gubernamentales, y con independencia de su tamaño, su localización, la naturaleza de sus actividades y de sus productos, o de otros factores socioculturales o medioambientales del entorno en el que lleva a cabo sus actividades. 
En su contenido se aprecia un claro enfoque transversal de la responsabilidad, en la línea de las declaraciones de las Naciones Unidas y sus organismos. Con todo, no debe perderse de vista el hecho de que se trata de una norma de lineamientos o de recomendaciones y no de requisitos (esto es, no es una norma jurídica). Resulta de aplicación voluntaria y su propósito, al menos en principio y a diferencia de otras normas ISO, no es la certificación, sino disponer de un documento que refleje un entendimiento común en cuanto a la definición de la responsabilidad en las organizaciones, los principios en los que se fundamenta, y las materias, subtemas o asuntos que comprende. Por otro lado, no pretende ser ninguna barrera (técnica o limitadora del comercio internacional), ni de desarrollo de normas nacionales más específicas o de otro tipo.

Aunque antes de la publicación de la ISO 26000 ya existía una amplia gama de códigos de responsabilidad, la mayor parte tenían un claro enfoque sectorial o de actividad, o bien estaban orientadas a un ámbito territorial o económico concreto. De ahí que entre sus virtudes se enfatice el consenso global plasmado en una norma internacional que sintetiza una gran diversidad de criterios en un texto coherente y al alcance de todos, a la vez que útil y práctico de cara a su implementación en cualquier tipo de organización.

No obstante, esta iniciativa internacional también ha sido objeto de críticas (Argandoña e Isea 2011), señalándose a este respecto aspectos tales como su capacidad relativa para brindar directrices universales en materia de responsabilidad y la dificultad de homogeneizar criterios de actuación responsable para un amplísimo y heterogéneo espectro de organizaciones, lo cual hace que su contenido deba ser al fin generalista y poco sensible a las peculiaridades socioculturales de cada país o ámbito territorial. Junto a ellas, otras críticas menores hacen referencia a problemas hipotéticos ${ }^{43}$ que, en opinión de Argandoña (2011) no tienen por qué darse (de ahí su relatividad) y, en todo caso, dependerán en gran medida de la eficiencia de la norma, aspecto éste que deberá comprobarse en la práctica, a partir de su uso.

\footnotetext{
${ }^{43}$ Entre tales eventuales contratiempos, Argandoña (2011a) indica los siguientes: el enfoque a priori o preventivo, más que correctivo, de la norma, que en la práctica puede restarle potencia; el hecho de que, pese a la voluntariedad de su implantación, pueda llegar a convertirse en un obstáculo o amenaza para la libre competencia (si, por ejemplo, los Estados exigen su cumplimiento como condición para que las empresas sean admitidas en concursos para concesiones o contratos); o que no está claro cómo se puede llegar a compaginar con futuros estándares que se puedan proponer sobre la materia.
} 
Pormenorizando en cuanto a su contenido, la ISO 26000 tiene cuatro objetivos concretos, como son: asistir o ayudar a las organizaciones a establecer, implementar, mantener y mejorar los marcos o estructuras de responsabilidad; apoyar a las organizaciones a demostrar su responsabilidad mediante una buena respuesta y un efectivo cumplimiento de compromisos de todos los stakeholders, incluyendo los empleadores; facilitar una comunicación confiable de los compromisos y actividades; así como promover y potenciar una máxima transparencia en todas las actuaciones.

Para su mejor consecución, son consideradas las siguientes siete facetas de la responsabilidad: i) gobernanza organizativa; ii) derechos humanos; iii), prácticas laborales; iv) medioambiente; v) prácticas justas de operación; vi) asuntos relacionados con los consumidores; y vii) participación activa y desarrollo de la comunidad.

Asimismo, y conforme a las directrices de la Conferencia ISO de Bangkok, la norma tiene una estructura secuencial con diez apartados: i) introducción; ii) alcance; iii) referencias normativas; iv) términos y definiciones; v) contexto de responsabilidad en el que opera la organización; vi) principios de responsabilidad importantes para las organizaciones; vii) orientación sobre los temas/materias centrales de responsabilidad; viii) orientaciones prácticas para la implementación de la responsabilidad; ix) anexos de orientación; y x) bibliografía.

En dicha estructura se aprecia claramente la orientación práctica de la norma, señalando los elementos que una organización debe considerar si desea implementar sus políticas de responsabilidad aplicando el estándar. Para ello, lo primero que deberá hacer es tener presentes e interiorizar los principios sustanciales de responsabilidad (como el Pacto Global, las convenciones, regulaciones y requerimientos legales, o los asuntos o aspectos propios derivados de principios, convenciones u otros asuntos identificados en la materia). Una vez reestructurada en razón de los principios o asuntos descritos, la entidad deberá establecer su compromiso y políticas de responsabilidad, lo cual sólo podrá hacer de manera exitosa cuando contraste la situación real en que se encuentra con los principios y asuntos definidos, debiendo establecer cuáles son relevantes y cómo actuar sobre ellos, teniendo siempre presente el punto de vista de los stakeholders, mediante un proceso interactivo y participativo.

Sólo tras lo anterior, una organización estará en condiciones de establecer los objetivos y programas necesarios para cumplir con su compromiso social a través de actividades monitorizadas y con resultados contrastados, evaluados y revisados. 


\subsubsection{Indicadores de sostenibilidad}

La diversidad de principios, directrices, códigos, certificaciones y estándares técnicos propuestos por distintos organismos e instituciones para orientar y/o valorar el carácter más o menos responsable de las actuaciones de las organizaciones, unida a la evidencia de los diferentes grados de desarrollo y la heterogeneidad de los entornos en que éstas desarrollan su actividad resulta argumento justificativo a la vez que complica sobremanera la tarea de establecer algún tipo de indicador que tengan en cuenta, para cada organización, aspectos muy variados de su comportamiento y que pueden ir desde la aceptación de principios o directrices, hasta la aplicación de estándares, prácticas de buen gobierno corporativo, o difusión y elaboración de memorias de responsabilidad. En definitiva, se trata de disponer de algún tipo de referente que permita señalar qué entidades son mejor gobernadas y gestionadas ${ }^{44}$.

Los indicadores de sostenibilidad han surgido con el propósito de dar respuesta a esta demanda. Son constructos desarrollados a partir de diferentes metodologías, y cuyo objetivo es comparar y clasificar las entidades en función de su grado de incorporación o cumplimiento de determinados criterios sobre comportamientos responsables. Pueden agruparse en tres grandes categorías, como son (Fuentes et al. 2005) ${ }^{45}$ :

i) Las listas de empresas socialmente responsables: cuyo objeto es distinguir a las entidades productivas que destacan por desarrollar mejores prácticas éticas y sociales. A las ventajas de un amplio eco en la opinión pública y un coste relativamente reducido, unen el inconveniente de estar en muchas ocasiones más relacionados con la notoriedad (lo que favorece a las grandes empresas) que con las prácticas sociales de las entidades.

Dentro de esta categoría, y a título de ejemplo, cabe aludir a las listas de las 10 empresas más admiradas por los lectores de EE.UU. elaborada por Fortune, o “The 100 Best Corporate Citizens” (valorando esfuerzos de creación de empleo y relaciones laborales). En España, el Monitor Español de Reputación Corporativa (MERCO)

\footnotetext{
${ }^{44}$ Necesidad en la que desde diferentes ámbitos, tanto académicos como institucionales y profesionales, viene haciéndose hincapié desde las primeras etapas del desarrollo conceptual de la responsabilidad, tal y como era puesto de manifiesto en el capítulo precedente.

45 Junto a estas tres categorías, Fuentes et al (2005) indican, como vías alternativas para afrontar las obligaciones en cuanto a responsabilidad: la adhesión/ratificación a/de declaraciones o normas internacionales; la emisión de informes sociales; y la certificación del respeto a determinadas normas de gestión ética (esto es, las que aquí han sido incluidas dentro del apartado dedicado a otros planteamientos normativos y regulatorios de la responsabilidad de las organizaciones a nivel internacional).
} 
ii) Los códigos de conducta: son declaraciones de valores y prácticas empresariales establecidos para servir de referencia a los directivos en sus actuaciones diarias, conectando la misión y los valores organizativos con el comportamiento cotidiano. Presentan varias ventajas, como son su capacidad para mejorar la imagen de la organización, la facilidad de su implantación, su flexibilidad y un coste reducido. Frente a ellas, cuentan con el inconveniente del escaso control externo en cuanto a su cumplimiento efectivo.

iii) Los índices de sostenibilidad: que pretenden orientar a los inversores con mayor sensibilidad hacia las entidades que desarrollan prácticas sociales y de desarrollo sostenible, caracterizándose por seleccionar (para formar parte del índice) a aquellas organizaciones que acreditan determinadas prácticas en el ámbito de la responsabilidad decididas por el proveedor del índice, y que exceden los parámetros exclusivamente financieros o de estricta rentabilidad económica, para incluir un amplio abanico de criterios (Lozano 2009), que se adaptan a las circunstancias y al contexto en el que operan las entidades.

Asimismo, una ventaja adicional de los índices es que no son exclusivos de los mercados de inversión, sino que pueden proveer información no sólo a quien dirige la empresa o a quien espera un rendimiento de los fondos que ha aportado a la misma, sino también a otros posibles públicos interesados (tales como clientes, proveedores, trabajadores, medios de comunicación, gobierno, o la sociedad en general), que con su actuación pueden premiar o castigar el desempeño de la entidad.

De estas tres categorías, los índices de sostenibilidad son los que resultan más fiables en cuanto a su metodología de elaboración. No obstante, y dado que existen varios organismos que los confeccionan, sus planteamientos metodológicos pueden ser dispares, lo cual debe ser tenido en cuenta a efectos de comparación y valoración de los correspondientes resultados y rankings.

Entre ellos, a continuación se hace referencia a los dos índices -o series de índices- más reputados y globales en cuanto a la cobertura de su análisis ${ }^{46}$.

\footnotetext{
${ }^{46}$ Tanto en el Informe del Foro de Expertos en Responsabilidad Social de las Empresas correspondiente a 2007 y elaborado a instancias del Ministerio de Trabajo y Asuntos Sociales (disponible en http://www.mtin.es/), como en el documento subsecuente dedicado al "Desarrollo de la Responsabilidad Social de las Empresas en España” son los que se citan precisa y exclusivamente como aquéllos que desde 2001 incluyen cada año a mayor número de empresas españolas.
} 
a) Los Índices de Sostenibilidad Dow Jones:

Los Índices de Sostenibilidad Dow Jones (Dow Jones Sustainability Indexes, DJSI) surgieron en 1999 como resultado de la colaboración entre los encargados de la elaboración del índice Dow Jones y la Sustainability Asset Management (SAM), que aportaba su dilatada experiencia en la elaboración de indicadores de sostenibilidad.

Se trata de una de las primeras experiencias globales para mostrar el desempeño financiero de las empresas líderes en sostenibilidad. Para la elaboración del índice a nivel global ${ }^{47}$, el Dow Jones Sustainability World Index, se procede a contactar con las aproximadamente 2500 mayores compañías integrantes del Dow Jones Global Total Stock Market Index, las cuales pueden participar en el proceso de evaluación cumplimentando un extenso cuestionario adaptado sectorialmente y que incluye aspectos referidos a buenas prácticas, gobierno corporativo, integridad, gestión de riesgos, ecoeficiencia, atracción y retención de talento. Estos criterios son elegidos y actualizados en base al informe sobre evaluación de sostenibilidad empresarial que elabora periódicamente el departamento de investigación de la SAM.

Las compañías seleccionadas para el índice de sostenibilidad serán las que se consideren más sostenibles en función de su valoración (el 10\% del total) ${ }^{48}$. Para ello no sólo se tiene en cuenta la información de la encuesta, sino también la transparencia en la información de la propia entidad, la información aportada por los medios de comunicación, y posibles informes de partes interesadas, todo lo cual se utiliza para evaluar el desempeño económico, social y medioambiental y decidir si finalmente una compañía puede ser incluida en el DJSI,

Con posterioridad se realiza un seguimiento diario de las cuestiones críticas que puedan ir surgiendo, que puede conducir a la exclusión de la empresa si la situación se considera lo suficientemente crítica (por ejemplo, casos de abuso de los derechos humanos, despidos o mala gestión de conflictos con los trabajadores, o los desastres catastróficos).

En todo caso, las informaciones obtenidas son analizadas y verificadas por un observador independiente y mediante las pertinentes ponderaciones se establece el correspondiente ranking.

\footnotetext{
${ }^{47}$ La serie de índices Dow Jones Sustainability Indexes se establecen a nivel mundial (índice global), de Europa, de América del Norte y de Corea.

${ }^{48}$ Este procedimiento puede verse de forma detallada en http://www.sustainability--index.com/.
} 
b) La Serie de Índices FTSE4Good:

El grupo Finantial Times Stock Exchange (FTSE) desarrolló en 2001 la Serie de Índices FTSE4Good (FTSE4Good Index Series), para identificar y medir la rentabilidad de las empresas en los ámbitos de la sostenibilidad medioambiental, protección y apoyo de los derechos humanos, y relaciones con sus grupos de interés.

Cuando una entidad quiere convertirse en miembro consultivo, hay un proceso de selección (Figura 2.3) ${ }^{49}$, del que están excluidas las entidades de determinados sectores (como productores de tabaco y uranio, centrales nucleares o fabricantes de armamento), a la espera de criterios específicos para ellos. Dicho proceso contempla el cumplimiento obligatorio de estándares en relación con los ámbitos antes reseñados.

Figura 2.3. Proceso de selección de integrantes de la serie de índices FTSE4Good

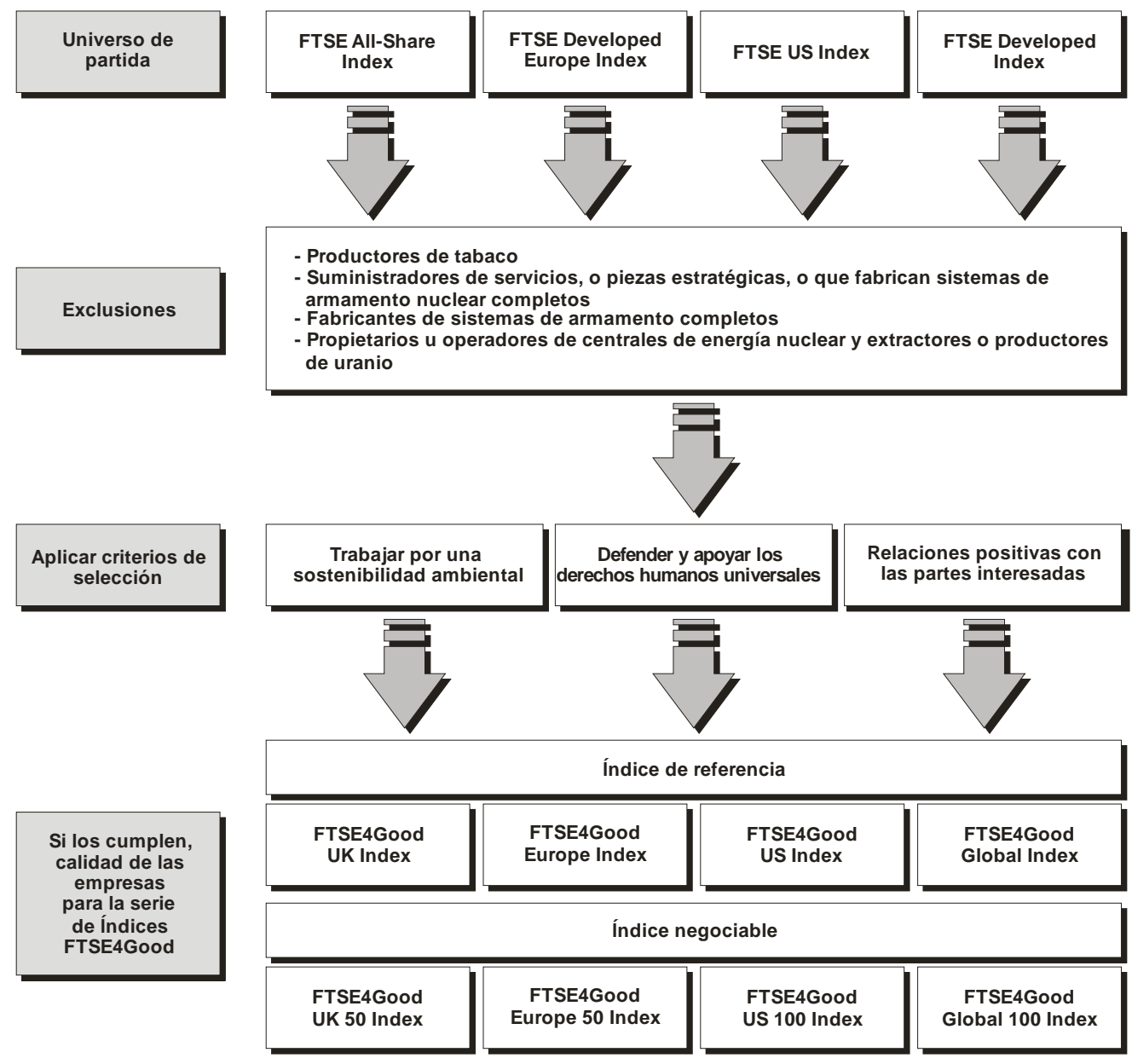

Fuente: Elaboración propia a partir de http://www.ftse.com (consultado en junio de 2012).

${ }^{49}$ Información más detallada sobre el cual puede verse en http://www.ftse.com/. 
Para verificar el cumplimiento en cada uno de dichos ámbitos se contemplan diferentes criterios de inclusión, derivados de las recomendaciones establecidas al respecto en los códigos de conducta mundialmente reconocidos, y revisados de forma regular mediante un proceso consultivo que culmina en propuesta para su aprobación por parte del Comité de Asesoramiento del FTSE4Good, integrado por expertos en responsabilidad social, en gestión de fondos, en inversión socialmente responsable, todos ellos independientes del FTSE. En estas revisiones, también se tiene en cuenta que el desarrollo a nivel mundial de cuanto atañe a la responsabilidad social no es uniforme, haciéndose eco de los diferentes grados de concienciación en distintos países o áreas geográficas, así como de las diferencias en los marcos legislativos y contextos particulares de actuación.

Cuando una entidad cumple con los criterios requeridos y se convierte en un miembro constitutivo de FTSE4Good, significa que está transmitiendo un conocimiento más profundo y un mensaje claro hacia sus empleados, accionistas, clientes, proveedores y demás grupos de interés, de cómo sus operaciones se acercan a un comportamiento más responsable y transparente comprometido con el medioambiente y con las comunidades en las que operan.

\subsection{Normativa y regulación de la responsabilidad en la Unión Europea}

El desarrollo en Europa de la normativa y regulación de la responsabilidad en las organizaciones venía presentando un cierto retraso con respecto a países como EE.UU., donde ya existía tiempo atrás una importante tradición y tenían lugar intensos debates (Fernández y Martínez 2003), si bien los avances de los últimos años tienden hacia una progresiva equiparación.

No obstante, tampoco es menos cierto que dentro del contexto europeo coexisten notables diferencias entre países, no sólo en base a su pertenencia o no a un marco supranacional como es la Unión Europea, sino incluso dentro de ésta. Este hecho, unido a la toma de conciencia tanto de los ciudadanos, como de las empresas, los poderes públicos y otros grupos de interés, ha llevado a plantear la necesidad ineludible de acometer e implantar estrategias más responsables, para lo cual resulta requisito indispensable disponer de un modelo social a escala europea que dé adecuada respuesta a esas demandas. 
En tal sentido, y además de los tratados internacionales de aplicación obligatoria, a nivel comunitario también existen otros de obligado cumplimiento para los países miembros de la UE y que establecen reglas básicas de comportamiento responsable, algunos de ellos de larga tradición, como el Convenio Europeo para la Protección de los Derechos Humanos y de las Libertades (1950), o la Carta Social Europea (1961).

Partiendo de esta base, y tras hacer referencia a lo que suponen antecedentes en esta materia, se analizan diferentes aspectos en cuanto a la formalización de un marco normativo-regulador de la responsabilidad en la UE y su posterior desarrollo.

\subsubsection{Antecedentes en la UE en cuanto a responsabilidad en las organizaciones}

Antes de que la responsabilidad social corporativa -o, en sentido más amplio, la responsabilidad en las organizaciones- fuese objeto de referencia explícita en cualquier documento o directriz comunitaria, existieron algunas iniciativas que constituyen los antecedentes necesarios y propiciadores que abrieron el camino para posteriormente debatir y perfilar las líneas maestras definitorias de los múltiples matices que, hoy en día y en el contexto europeo, se considera que debe dicho concepto. Entre éstas, destacan la Recomendación de la Comisión CEE proponiendo un Código de Conducta Europeo sobre Transacciones con Valores Mobiliarios de 1977, y el Libro Blanco sobre Crecimiento, Competitividad y Empleo de 1993.

a) La Recomendación de la Comisión CEE proponiendo un Código de Conducta Europeo sobre Transacciones con Valores Mobiliarios:

El 25 de julio de 1977 la Comisión de la CEE realizó una Recomendación proponiendo un Código de Conducta Europeo sobre Transacciones con Valores Mobiliarios (Recomendación 77/534/CEE), a fin de favorecer la dinámica del mercado financiero y de la vida de los negocios, tratando de mejorar los mecanismos del libre mercado y su eficacia.

Dicha Recomendación estaba dirigida a los Estados miembros, con el fin de que fuesen éstos quienes velasen por el respeto de los principios contenidos en el correspondiente Código de Conducta, al estar en la situación más propicia para ejercer su influencia sobre el funcionamiento de los mercados de valores mobiliarios. 
En tal sentido, el objetivo específico del Código era plantear las normas propiciadoras de un comportamiento leal que contribuyese al funcionamiento eficaz de los mercados de valores mobiliarios en el ámbito europeo, asegurando una adecuada protección de los intereses del público.

Para ello, se basaba en los siguientes principios inspiradores: i) respeto del espíritu de las disposiciones legales o reglamentarias en vigor en cada Estado, así como de los principios de buena conducta existentes; ii) difusión entre el público, y a su debido tiempo (sin que nadie pueda resultar privilegiado) de una información leal, correcta, clara y suficiente; iii) igualdad de trato asegurada a todo tenedor de valores mobiliarios de la misma naturaleza y emitidos por la misma sociedad; iv) garantía de un comportamiento leal por parte de los miembros de los órganos de vigilancia, de administración y de dirección de una sociedad cuyos valores mobiliarios se negocien en el mercado, así como de quienes la controlen de hecho o de derecho; v) igual garantía (deber) en cuanto a la conducta de quienes operen habitualmente en los mercados de valores inmobiliarios, aun cuando ello pueda privarles en algunos casos o situaciones de ventajas financieras inmediatas; y vi) esfuerzo de los intermediarios financieros por evitar todo conflicto de intereses, ya sea entre ellos mismos, con sus clientes o con otras personas o entidades con las que tengan relación profesional.

b) El Libro Blanco sobre Crecimiento, Competitividad y Empleo:

Años más tarde, el Consejo Europeo, bajo la presidencia de Jacques Delors, aprobaría en diciembre de 1993 el Libro Blanco sobre Crecimiento, Competitividad y Empleo. Con este documento se hacía un llamamiento para luchar contra la exclusión social, planteando las líneas para una estrategia europea para desarrollar el empleo y la creación de empresas, e invitando a que éstas se involucrasen más activamente en la integración social, lo que auspiciaría las posteriores redes europeas de estas entidades.

De algún modo, el Libro Blanco pretendía colaborar en la reflexión y toma de decisiones para sentar las bases de un desarrollo sostenible en las economías europeas, a fin de hacer frente mejor a la competencia internacional. Las líneas de acción que plantea pasan por aportar "soluciones que deberían orientarnos hacia un modelo de desarrollo sostenible, tanto desde el punto de vista de la eficacia del triángulo crecimiento-competitividad-empleo, como en relación con el medio ambiente y la mejora de la calidad de vida” (CCE 1993). 


\subsubsection{La formalización de los planteamientos sobre responsabilidad en la UE}

La primera referencia explícita a la responsabilidad social que se puede ver en los documentos comunitarios se produjo en marzo de 2000, cuando el Consejo Europeo de Lisboa destacó la necesidad de establecer buenas prácticas en cuanto a organización del trabajo, educación, formación continua, igualdad de oportunidades, inserción social y desarrollo sostenible, con el objetivo de que la economía europea fuese capaz de crecer económicamente de manera sostenible con más y mejores empleos y con mayor cohesión social (Fernández y Martínez 2003).

Tras ello, se han desarrollado diferentes iniciativas y documentos, constituidos referentes de primera entidad, dentro e incluso fuera de la UE, entre los que destacan los indicados a continuación.

a) La Estrategia Europea de Desarrollo Sostenible:

En junio de 2001 el Consejo Europeo de Gotemburgo aprobó la Estrategia Europea de Desarrollo Sostenible ${ }^{50}$, con la que se completaban, en materia de responsabilidad social, las recomendaciones del Consejo Europeo de Lisboa (marzo de 2000) ${ }^{51}$ y de la Agenda Social Europea (mayo de 2001) ${ }^{52}$, ésta última aprobada en el Consejo Europeo de Niza (diciembre de 2000). El propósito fundamental de dicha Estrategia es el avance paralelo en términos de crecimiento económico, cohesión social y protección del medioambiente, con una visión a largo plazo de una sociedad más próspera que cuente con un medioambiente más limpio, seguro y sano.

Para ello, propone una serie de medidas encaminadas tanto a mejorar los procesos políticos para que sean más abiertos y transparentes, como a animar a las empresas a adoptar un enfoque proactivo en materia de desarrollo sostenible integrándolo en sus operaciones. En tal sentido, se plantea para el sistema educativo un

\footnotetext{
${ }^{50}$ Comunicación de la Comisión "Desarrollo sostenible en Europa para un mejor mundo: Estrategia de la Unión Europea para un desarrollo sostenible” (propuesta de la Comisión ante el Consejo Europeo de Gotemburgo, COM 2001-264 final).

${ }^{51}$ Con el propósito de convertir a la UE en la economía basada en el conocimiento más competitiva y dinámica del mundo, capaz de crecer económicamente de manera sostenible con más y mejores empleos y con mayor cohesión social, y con el objetivo de pleno empleo en Europa, en el contexto de una sociedad que se adapte mejor a las opciones personales de mujeres y hombres.

52 Sugiriendo la adopción de unas orientaciones de política social, basadas en: un mayor número y mejor calidad de los puestos de trabajo; el desarrollo en el entorno laboral de un nuevo equilibrio entre flexibilidad y seguridad; la lucha contra cualquier forma de exclusión y de discriminación para favorecer la integración social; la modernización de la protección social; el fomento de la igualdad entre hombres y mujeres; y el refuerzo de la dimensión social en las actuaciones organizativas.
} 
papel vital, impulsando la sensación de responsabilidad individual y colectiva de una población que se sienta partícipe del objetivo del desarrollo sostenible.

Como medidas concretas, las propuestas de la Estrategia Europea de Desarrollo Sostenible se especifican en los siguientes extremos (COM 2001-264 final:9):

- “Un Libro Blanco de la Comisión sobre la gobernanza, [el cual] incluirá propuestas para una amplia consulta de las partes interesadas, tanto de dentro como de fuera de la Unión, que consistirá en una consulta pública previa a cualquier propuesta política importante.

- Todas las empresas que cotizan en bolsa y con una plantilla de al menos 500 empleados deberán publicar la «triple línea de fondo» en sus informes anuales a los accionistas que mida sus resultados en materia económica, medioambiental y social. [En tal sentido] se insta a las empresas comunitarias a demostrar y publicar su adhesión a las directrices de la OCDE para las empresas multinacionales u otras directrices equiparables.

- [Y] los Estados miembros deberán examinar en qué medida sus sistemas educativos pueden contribuir a una mayor comprensión del desarrollo sostenible”.

b) El Libro Verde de la Comisión Europea sobre Responsabilidad Social:

En plena consonancia con la Estrategia Europea de Desarrollo Sostenible, la Comisión Europea elaboró en julio de ese mismo 2001 un Libro Verde para “Fomentar un Marco Europeo para la Responsabilidad Social de las Empresas” ${ }^{53}$. En su texto se plantea un amplio debate sobre el modo en que la Unión Europea podría promover las actuaciones responsables, tanto a nivel europeo como internacional y, en particular, acerca del modo de aprovechar al máximo las experiencias existentes, de fomentar el desarrollo de prácticas innovadoras, de aumentar la transparencia de las actuaciones, y de incrementar la fiabilidad de la evaluación y de la validación de las diversas iniciativas realizadas en Europa.

En tal sentido, destaca por ser la primera iniciativa que, a escala europea, ha dado lugar a una reflexión abierta acerca de la materia (Fernández y Merino 2005), entendiendo ésta como “la integración voluntaria, por parte de las empresas, de las

\footnotetext{
${ }^{53}$ COM 2001-366 final. Más popularmente conocido como “Libro Verde de la Unión Europea sobre la Responsabilidad”, y al que ya se ha hecho mención en el capítulo precedente, por contener una de las muy escasas definiciones sobre el particular propuesta por una institución internacional.
} 
preocupaciones sociales y medioambientales en sus operaciones comerciales y sus relaciones con sus interlocutores" (COM 2001-366 final:7), por considerar que se trata de la definición más ampliamente aceptada, proporcionando la necesaria base de partida para destacar la idea de que ser socialmente responsable no sólo implica cumplir en su totalidad las obligaciones jurídicas, sino ir más allá del mero cumplimiento e invertir en capital humano, en el entorno y en las relaciones con los interlocutores. A este mismo planteamiento se llega a partir de la experiencia adquirida con la inversión en tecnologías y prácticas comerciales respetuosas con el medio ambiente, sugiriendo que ir más allá del cumplimiento legislativo permite aumentar la competitividad de las empresas, además de tener un impacto directo y positivo en la productividad.

Otra idea a destacar en el Libro Verde es la concerniente a considerar que las actuaciones y prácticas responsables, aunque tradicionalmente se venían llevando a cabo por parte de grandes empresas, en su gran mayoría multinacionales, revisten gran importancia para todo tipo de entidades, independientemente del tipo de empresa, tamaño y sector de actividad ${ }^{54}$.

Junto a lo anterior, en el texto del documento se establece una clara distinción entre una dimensión interna y una dimensión externa de las prácticas socialmente responsables. Dentro de las primeras se encuentran tanto inversiones en capital humano, salud y seguridad y gestión del cambio, como las prácticas respetuosas con el medio ambiente vinculadas a la gestión de los recursos naturales empleados en la producción. En el ámbito externo, las empresas deben colaborar con la comunidad local, a la que proporcionan, fundamentalmente, puestos de trabajo, salarios, servicios e ingresos fiscales. Por otro lado, las empresas dependen de la buena salud, de la estabilidad y de la prosperidad de las comunidades donde operan, extendiéndose sus prácticas de responsabilidad social hasta considerar una amplia variedad de partes interesadas que incluye a socios comerciales y proveedores, consumidores, autoridades públicas y ONG defensoras de la comunidad local y del medio ambiente. En tal sentido, la dimensión externa incluye, entre otros aspectos y en particular, el respeto a los derechos humanos, principalmente en lo que respecta a las cadenas de producción a escala mundial.

\footnotetext{
54 Tal afirmación conviene ser matizada, por cuanto no es sinónimo de que las pequeñas y medianas empresas no sean responsables en sus actuaciones. Más bien se trata de hacer hincapié en que también pueden y deben serlo, redundando en su propio beneficio. Cosa bien distinta es que la difusión y/o el alcance mediático de estas campañas y actividades no tengan, salvo excepcionalmente, el impacto de las grandes corporaciones.
} 
Asimismo se plantea la conveniencia de la gestión integrada, diseñando, organizando e implementando las actuaciones y relaciones de las entidades con las distintas partes interesadas en función de particularidades sectoriales y culturales. A tal fin, deberá adoptarse una declaración de principios, un código de conducta o un manifiesto donde se indiquen objetivos, valores fundamentales y alcance de las responsabilidades respecto a las partes interesadas. Eso se reflejará posteriormente en las medidas y actuaciones, añadiendo una dimensión social o ecológica a los programas y presupuestos con el fin de realizar auditorías sociales o medioambientales.

Casi un año después de la aprobación del Libro Verde, en la Resolución del Consejo Europeo de 10 de abril de 2002, relativa a su seguimiento ${ }^{55}$, se reflejaban tanto la buena acogida del documento como la afirmación de que la responsabilidad podía contribuir de forma efectiva a lograr los objetivos de los Consejos Europeos de Lisboa (23-24/03/2000), Estocolmo (23-24/03/2001) y Gotemburgo (15-16/06/2001), a fin de que la Unión Europea sea la economía basada en el conocimiento más competitiva y dinámica del mundo, fomentando la integración social y el desarrollo sostenible.

En dicha Resolución se aprecia también cómo el Consejo Europeo es consciente de los distintos aspectos subrayados en el texto previo del Libro Verde, reafirmándose en la utilidad de promover "las iniciativas dirigidas a intercambiar buenas prácticas e ideas innovadoras [...], un mayor conocimiento y análisis de la repercusión de las prácticas socialmente responsables sobre los resultados económicos de las empresas, [... así como] las iniciativas dirigidas a incluir la responsabilidad social de las empresas en la formación de directivos y trabajadores”. Para ello, invita a las autoridades públicas de todos los niveles -incluidos organismos e instituciones internacionales-, las empresas, los interlocutores sociales, las organizaciones no gubernamentales y cualquier otra parte o persona interesada, a expresar su opinión sobre el modo de establecer una cooperación dirigida a crear un nuevo marco que fomente la responsabilidad social de las empresas, teniendo en cuenta los intereses tanto de las empresas como de las diversas partes interesadas. En definitiva, no se trataba sino de estimular el debate y definir los medios para desarrollar una asociación que permita instaurar un marco europeo para la promoción de la responsabilidad ${ }^{56}$.

\footnotetext{
${ }^{55}$ Resolución del Consejo 2002/C86/03, de 10 de abril.

${ }^{56}$ En la Comunicación de la Comisión Europea COM 2002-347 final, relativa a la responsabilidad social de las empresas y su contribución al desarrollo sostenible se muestra un resumen del proceso de consulta, a la vez que se describen la estrategia europea destinada a promover la responsabilidad (definición, lugar
} 
c) La Comunicación de la Comisión Europea sobre responsabilidad social de las empresas: una contribución empresarial al desarrollo sostenible:

Una vez planteado el debate con el Libro Verde, la Comunicación de la Comisión Europea de 2 de julio de $2002^{57}$ tenía como objeto realizar un seguimiento del mismo, sintetizando para ello las principales propuestas de los distintos colectivos. Tal y como se puede apreciar en la misma, aunque todos ellos coinciden en la ya señalada acogida favorable del documento y la utilidad del debate sobre la responsabilidad, mantienen algunas significativas diferencias en sus posiciones, mayormente debidas a la defensa de intereses particulares. Así, por ejemplo (COM 2002-347 final:4-5):

- “Las empresas subrayan la naturaleza voluntaria de la responsabilidad social, su integración en el contexto del desarrollo sostenible y la necesidad de definir su contenido a escala global. Destacan que no cabe esperar soluciones «únicas y universales» y que cualquier tentativa de regular la responsabilidad social de las empresas a nivel europeo sería contraproducente, en la medida en que anularía la creatividad y el carácter innovador de las empresas, que constituyen el motor del desarrollo con éxito de la RSE. Además, podría generar conflictos de prioridades para las empresas que operan en distintas áreas geográficas.

- Los sindicatos y las organizaciones de la sociedad civil advierten de que las iniciativas voluntarias no son suficientes para salvaguardar los derechos de los trabajadores y los ciudadanos y propugnan el desarrollo de un marco reglamentario que establezca normas mínimas y garantice unas reglas de juego equitativas. Insisten además en que, para ser creíbles, las prácticas de responsabilidad social no pueden ser definidas, aplicadas y evaluadas de manera unilateral por las propias empresas y que es necesaria la participación de todas las partes interesadas. Exigen, además, la introducción de mecanismos eficaces que obliguen a las empresas a responsabilizarse de las consecuencias sociales y medioambientales de sus actividades.

- Los inversores señalan la necesidad de mejorar la divulgación de la información y la transparencia de las prácticas empresariales, así como la

${ }^{57}$ COM 2002-347 final, a la que ya se viene haciendo mención. 
metodología utilizada por las agencias de calificación y la gestión de los fondos de inversión socialmente responsable (ISR) y de los fondos de pensiones.

- Las organizaciones de consumidores insisten en la importancia de disponer de información exhaustiva y fiable sobre las condiciones éticas, sociales y ecológicas de producción y comercialización de los bienes y los servicios, que les oriente en sus decisiones de compra.

- [Por su parte,] en su Resolución de 3 de diciembre de 2001, el Consejo señaló que un enfoque europeo de la responsabilidad social de las empresas podría servir para desarrollar el concepto y para completar las medidas existentes a nivel local y nacional, aportándoles un valor añadido. El Consejo mencionó asimismo que la responsabilidad social podría contribuir no sólo a fomentar un elevado nivel de cohesión social, de protección del medio ambiente y de respeto de los derechos fundamentales, sino también a mejorar la competitividad para todos los tipos de empresas, desde PYME a multinacionales, $y$ en todos los sectores de actividad.

- El Comité Económico y Social ha subrayado que los principios de acción voluntaria y de sostenibilidad medioambiental, económica y social, junto con las orientaciones incluidas en los acuerdos suscritos en el ámbito de las organizaciones internacionales, deben servir de marco de referencia para las nuevas iniciativas europeas destinadas a apoyar los esfuerzos de las empresas en el ámbito de la responsabilidad social.

- El Comité de las Regiones considera que la acción a nivel europeo debe proporcionar un marco que permita aumentar la sensibilización, promover principios responsables y ayudar a las empresas y autoridades públicas a integrar la responsabilidad social en sus actividades.

- [Y,] por último, el Parlamento Europeo ha propuesto integrar el concepto de responsabilidad social de las empresas en todos los ámbitos de competencia de la UE, en particular en la financiación de las medidas sociales y regionales, y establecer una plataforma multilateral sobre este tema. Aboga por que las empresas incluyan en sus informes un triple balance que mida sus resultados en materia social y medioambiental, incluida la dimensión de los derechos humanos". 
Tal y como cabe apreciar, se trata de posturas en mayor o menor medida encontradas, llevando a la Comisión a reconocer la coexistencia de una amplia gama de enfoques relativos a la responsabilidad. En todo caso, ello no es obstáculo para exponer su visión de las tres características en que se debe basar cualquier estrategia de promoción de actuaciones responsables (COM 2002-347 final:6):

- "Consiste en un comportamiento que adoptan las empresas voluntariamente, más allá de sus obligaciones jurídicas, por considerar que redunda a largo plazo en su propio interés;

- [está] vinculada al concepto de desarrollo sostenible: las empresas deben integrar en sus operaciones las consecuencias económicas, sociales y medioambientales;

- [Y,] no es algo que pueda «añadirse» optativamente a las actividades principales de la empresa, sino que afecta a su propia gestión”.

Junto a lo anterior, la Resolución reconoce la presencia de una serie de factores negativos de cara a la consecución de avances y la armonización de posturas, como son la falta de información sobre la correlación entre responsabilidad y resultados económicos, la falta de consenso en torno a una definición adecuada de responsabilidad, la escasa educación y formación en la materia, la insuficiente sensibilización en las Pymes, la falta de transparencia (por la inexistencia de instrumentos ampliamente reconocidos para diseñar, administrar y divulgar las políticas de responsabilidad), el escaso conocimiento y el poco apoyo tanto de consumidores como de inversores, así como la falta de coherencia de las políticas públicas.

Tales deficiencias suponen en muchas ocasiones auténticos desafíos a la hora de llevar a cabo las necesarias actuaciones de sensibilización y divulgación, así como para plantear la adopción generalizada de las prácticas socialmente responsables por parte de las empresas, la cual deberá estar fundamentada en los principios de: i) reconocimiento de la naturaleza voluntaria de la responsabilidad; ii) desarrollo de prácticas creíbles y transparentes; iii) focalización de actividades en aquéllas en que la intervención de la comunidad aporte un valor añadido; iv) utilización de un enfoque equilibrado y global de la responsabilidad que incluya los aspectos económicos, sociales y ecológicos, así como los intereses de los consumidores; v) atención a las necesidades y características de las pequeñas y medianas empresas; y vi) apoyo y coherencia con los acuerdos internacionales existentes. 
Esos seis principios muestran claramente el posicionamiento de la Comisión Europea en materia de responsabilidad. A partir de ahí, su estrategia se centra y concreta en acciones como, por ejemplo: dar a conocer mejor el impacto positivo de la responsabilidad en las empresas y en la sociedad; fomentar el intercambio de experiencias y buenas prácticas; promover el desarrollo de las capacidades de gestión en este ámbito con carácter general y, en particular, entre las pequeñas y medianas entidades productivas; facilitar la convergencia y la transparencia de las prácticas y los instrumentos de responsabilidad (códigos de conducta, normas de gestión, contabilidad, auditoría y elaboración de informes, etiquetas e inversión socialmente responsable); crear a nivel de la UE un foro multilateral en este ámbito; e integrar la responsabilidad social en las políticas comunitarias.

d) El Foro Multilateral Europeo sobre Responsabilidad Social de las Empresas:

Actuando en consecuencia con lo indicado en la previa Comunicación, en octubre de 2002, la Comisión Europea promovió el establecimiento del Foro Multilateral Europeo sobre Responsabilidad Social de las Empresas sobre una base multistakeholder, al convocar una representación equilibrada de las organizaciones a nivel europeo de representantes de empresarios, trabajadores, consumidores y sociedad civil, así como de asociaciones profesionales y redes de empresas, bajo la Presidencia de la propia Comisión, y con presencia de otras instituciones de la UE invitadas en calidad de observadoras. Su objetivo era triple, incluyendo tanto la promoción del intercambio de experiencias, como el acercamiento de posturas e iniciativas, y la detección de aquellos ámbitos en los que pudiera ser conveniente una actuación a escala comunitaria.

Las funciones encomendadas al Foro se estructuraron en dos niveles de reunión y actuación, el primero de los cuales contemplaba la celebración anual de dos reuniones plenarias a nivel político para adoptar orientaciones generales, normas de procedimiento y programas de trabajo, procediéndose asimismo a evaluar los progresos realizados. Por su parte, el segundo nivel contemplaba la organización de mesas redondas temáticas de composición más restringida y definida en el primer nivel, para ejecutar los programas de trabajo. En concreto, se constituyeron cuatro mesas redondas que estudiaron la mejora de conocimientos y facilitación de intercambios y experiencias; las vías para promover la responsabilidad en pymes; la diversidad, la convergencia y la trasparencia de las prácticas; y los instrumentos de la responsabilidad y su desarrollo. 
La actividad desarrollada a uno y otro nivel dio como resultado la publicación de un Informe Final en $2004^{58}$, con el que quedaban finalizadas las tareas del Foro y en el que se disponían recomendaciones agrupadas en tres grandes áreas:

i) la conveniencia de continuar llevando a cabo acciones y campañas encaminadas a la sensibilización y a la mejora de los conocimientos sobre responsabilidad, aumentando la conciencia sobre los valores y los principios fundamentales, a la vez que dando a conocer textos de referencia y contribuyendo a la recopilación, intercambio y difusión de información, desarrollando prácticas, herramientas e iniciativas que mejoren las condiciones sociales, económicas y el impacto ambiental, y la investigación y mejora del conocimiento en materia de responsabilidad;

ii) la necesidad de contribuir al desarrollo de capacidades y competencias para integrar la responsabilidad en la actuación de las empresas, aumentando su capacidad para ello con la cooperación de todas las partes interesadas, reconociendo que muchas organizaciones pueden desempeñar un papel catalizador y de apoyo para las empresas en la materia (como organizaciones de consumidores, asesores de empresas, inversores, sindicatos, medios de comunicación), y promoviendo la inclusión en la educación institucional de formación sobre estos aspectos, no sólo para los futuros directivos y empleadores, sino también para los ciudadanos en general, teniendo en cuenta que cualquier individuo es consumidor y puede ser también trabajador, socio de una compañía o integrante de otras partes interesadas en el comportamiento empresarial; y

iii) la pertinencia en cuanto a la necesidad de garantizar un entorno favorable para la responsabilidad, intensificando por parte de las instituciones de la UE y de los Gobiernos de los Estados miembros los esfuerzos para logar una mayor coordinación de sus políticas en aras de asegurar un marco jurídico, económico y social que permita a las empresas ir más allá de lo estrictamente coercitivo, una mayor transparencia y comunicación que dé confianza y credibilidad a la responsabilidad (teniendo en cuenta la naturaleza, el tamaño, las actividades, los costes, la capacidad, la competencia, las expectativas y las

\footnotetext{
58 Se trata del informe "Final results \& recommendations", del European Multistakeholder Forum on CSR celebrado el 29 de julio de 2004. Dicho documento se encuentra disponible en está disponible en http://www.observatoriorsc.org.
} 
demás circunstancias de la entidad), una mayor disposición de información sobre la inversión socialmente responsable y otros fondos, y un desarrollo del diálogo entre las partes interesadas que permita entender con mayor claridad sus funciones y expectativas, a la vez que recomendando que tanto las instituciones de la UE como los gobiernos nacionales ayuden y animen a todos los países a ratificar y aplicar convenios internacionales de protección de los derechos socioeconómicos de los ciudadanos, y un clima favorable al desarrollo económico, ambiental y el progreso social.

A la vista de los resultados de su actividad, la actuación del Foro Multilateral Europeo sobre Responsabilidad Social de las Empresas puede considerarse positiva, al haber logrado fomentar con éxito el debate europeo sobre la responsabilidad en las empresas. No obstante, también hay quien señala (Howitt 2006) que no ha sido tan eficaz en cuanto a conseguir poner en marcha un proceso dinámico en relación con dicho debate, y por cuanto tampoco logró que se llegasen a adoptar medidas concretas para permitir fomentar un entorno empresarial más responsable.

Pormenorizando asimismo en los aspectos positivos, debe señalarse que el debate promovido por el Foro también ha dado lugar a interesantes aportaciones en el ámbito académico, donde no sólo están presentes los puntos de vista de las disciplinas tradicionalmente más asociadas al mundo de la empresa. Así, por ejemplo, y desde un enfoque jurídico, Rodríguez-Piñero (2006) indica que debe destacarse particularmente su papel por cuanto éste fue capaz de sacar a la luz diferencias de opinión significativas entre empresas y otras partes interesadas, pero también al servir para lograr un cierto grado de consenso entre los participantes y, sobre todo, propiciar un estado de toma de conciencia común sobre el significado y alcance de la responsabilidad, con la subsecuente necesidad de progresar en cuanto a una adecuada y armonizada regulación a este respecto.

Finalmente, cabe asimismo reseñar que en febrero de 2009 el Foro Multilateral volvería a ser convocado, en esta ocasión con el propósito de realizar una revisión de los avances acaecidos en materia de responsabilidad tanto en Europa como en el resto del mundo en el tiempo transcurrido desde su primer período de actividad, así como para debatir posibles iniciativas futuras a este respecto. Esta nueva fase de trabajo daría lugar al establecimiento de diversos Grupos de Trabajo multistakeholder de expertos en responsabilidad empresarial. 


\subsubsection{El desarrollo del marco normativo-regulador de la responsabilidad en la UE}

La progresiva formalización de planteamientos en la UE sobre responsabilidad se ha visto acompañada de un paralelo desarrollo de un marco normativo-regulador a escala comunitaria. Fruto de dicho desarrollo han visto la luz distintas Resoluciones y Comunicaciones, tal y como se indica a continuación.

a) La Resolución del Consejo, de 6 de febrero de 2003, relativa a la responsabilidad social de las empresas:

Tras acoger favorablemente las propuestas de la Comisión, el Consejo Europeo explicitó su estrategia de fomento de la responsabilidad por medio de su Resolución de 6 de febrero de 2003, relativa a la responsabilidad social de las empresas ${ }^{59}$. En ella, sostiene que ha de ser planteada en base a seis pilares fundamentales, los cuales deberán ser, a su vez, objeto de posterior desarrollo, a la vez que fundamentar el debate sobre la responsabilidad en el ámbito de la UE:

i) reconocimiento explícito de la naturaleza voluntaria de las actuaciones, que supera las obligaciones legales;

ii) necesaria credibilidad y transparencia de las prácticas responsables;

iii) focalización en actividades para las cuales la participación de la Comunidad suponga una ventaja añadida;

iv) planteamiento conceptual equilibrado y amplio, incluyendo los aspectos económico, social y medioambiental de la responsabilidad, así como teniendo en cuenta los intereses de los consumidores;

v) atención a las necesidades específicas y a las peculiaridades de las pequeñas y medianas empresas; y

vi) apoyo a los instrumentos y acuerdos internacionales existentes, buscando la compatibilidad con los mismos.

La Resolución del Consejo también recalca asimismo la idea de que las estrategias responsables que se lleven a cabo deberán estar respaldadas por una explicitación de su previsible impacto positivo. Para ello será necesario incrementar el nivel de conocimientos, los intercambios de experiencias y buenas prácticas (también en pro de una mayor transparencia y convergencia), el desarrollo de aptitudes de gestión en esta materia, así como la integración de la responsabilidad en las políticas comunitarias.

\footnotetext{
${ }^{59}$ Resolución del Consejo 2003/C39/02, de 6 de febrero.
} 
Por otro lado, también se hace una referencia explícita a la labor positiva del Foro Multilateral (cuya primera etapa de actividad estaba teniendo lugar en esos momentos), señalando el compromiso de la Comisión de implicar a los Estados miembros, instándoles a fomentar, a su vez, la responsabilidad a escala nacional y de forma paralela al desarrollo de la estrategia comunitaria, entendida ésta última en términos de beneficios añadidos para las empresas, mejores condiciones para el diálogo entre los interlocutores sociales y civiles, y como aspecto a incorporar progresivamente tanto en la actividades empresariales como en las políticas nacionales y en la actuación de la propia Administración a todos sus niveles.

b) La Comunicación de la Comisión al Consejo y al Parlamento Europeo relativa a la revisión de la Estrategia para un desarrollo sostenible (2005):

En una posterior Comunicación ${ }^{60}$, la Comisión procedía a revisar las primeras medidas adoptadas dentro de la estrategia comunitaria para un desarrollo sostenible, trasladando al Consejo y al Parlamento Europeo su conclusión en cuanto a la existencia de posibilidades reales de mejorar con ella las condiciones de vida de los ciudadanos, lograr una mayor justicia social y propiciar nuevas industrias innovadoras en las que Europa podría detentar el liderazgo mundial en caso de abordar rápidamente el problema de las amenazas del modo de vida de la etapa reciente para el desarrollo sostenible. Para ello, invertir las tendencias y factores negativos es un reto no sólo factible, sino indispensable, que requiere de la Comisión reunir a las instituciones comunitarias, los Estados miembros, las empresas, los ciudadanos y sus organizaciones representativas en torno a una perspectiva clara y un marco de acción político.

Entre los principios rectores que deben inspirar las políticas de la UE, este mismo documento establece en lo relativo a la participación de las empresas y de los interlocutores sociales, su orientación a la mejora del diálogo social, el aumento de la responsabilidad empresarial y el fomento de las asociaciones entre el sector público y el privado, para así lograr unos mayores niveles de cooperación y el establecimiento de responsabilidades comunes para conseguir una producción y consumo sostenibles.

c) La Comunicación de la Comisión al Parlamento Europeo, al Consejo y al Comité Económico y Social Europeo “poner en práctica la Asociación para el Crecimiento y el Empleo: hacer de Europa un polo de excelencia” (2006):

\footnotetext{
${ }^{60}$ COM 2005-658 final.
} 
A partir de las conclusiones contenidas en el Informe Final del Foro Multilateral, vio la luz una nueva Comunicación de la Comisión sobre responsabilidad, dirigida al Parlamento Europeo, al Consejo y al Comité Económico y Social Europeo ${ }^{61}$, en la cual hacía hincapié expresamente su postura en cuanto a que “Europa necesita empresarios activos, actitudes positivas hacia el espíritu empresarial y confianza en las empresas, precisa un clima público en el que se aprecie a los empresarios no sólo por generar grandes beneficios, sino también por su contribución justa al tratamiento de determinados desafíos de la sociedad”.

Tal aseveración suponía además un nuevo argumento justificativo para dotar de mayor visibilidad a las políticas europeas sobre responsabilidad, reconociendo cuanto ya se venía realizando hasta el momento en las empresas, así como animándolas a ir más allá en sus actuaciones.

En tal sentido, la nueva Comunicación supone un reconocimiento explícito de la labor y el trabajo llevados a cabo en el transcurso de las reuniones del Foro Multilateral y, particularmente, la utilidad del contenido de su Informe de junio de 2004. El texto de dicho documento subraya concretamente y de forma expresa lo que de positivo supone llegar a alcanzar una definición de consenso, así como el propósito de seguir profundizando en el alcance y los límites de la responsabilidad, con el apoyo de las correspondientes medidas de sensibilización.

No obstante, también pone de manifiesto que en su primera etapa de trabajo el Foro no fue capaz de lograr consenso en aspectos tales como los requisitos de información de las empresas o la necesidad de una normativa europea sobre responsabilidad.

Asimismo, y al considerar que las organizaciones empresariales son las que han de desempeñar un papel protagonista en materia de responsabilidad social, hay también un reconocimiento de la importancia de que tenga lugar una mayor colaboración con las empresas europeas y de éstas entre sí, para lo cual propone crear una Alianza Europea donde tendrían cabida las contribuciones de empresas activas - de todos los tamaños y sectores- a la promoción de la responsabilidad, a fin de posibilitar un mayor número de prácticas responsables entre las empresas europeas.

\footnotetext{
${ }^{61}$ COM 2006-136 final.
} 
d) La Resolución del Parlamento Europeo, de 13 de marzo de 2007, sobre la responsabilidad social de las empresas: una nueva asociación:

El entonces portavoz del Parlamento Europeo sobre RSC, Richard Howitt, procedió a la elaboración de un "Informe sobre la Responsabilidad Social de las Empresas: una nueva asociación” en diciembre de $2006^{62}$, el cual sería posteriormente aprobado como Resolución del Parlamento Europeo el 13 de marzo de $2007^{63}$. En su texto se encuentran diferentes recomendaciones a tener en cuenta tanto por parte de las instituciones europeas como de los Gobiernos y Administraciones de los Estados de la UE, en buena medida para dotar de un mayor dinamismo al debate europeo sobre la responsabilidad, animando a adoptar medidas concretas para propiciar un entorno empresarial más responsable.

El documento incluye duras críticas en cuanto a la labor que venía siendo realizada en los años precedentes, señalando, entre otras cosas, que "se produjeron sucesivas demoras de la Comisión en dar respuesta a aquellas partes interesadas que desean que la RSE estuviera sujeta a requisitos de transparencia establecidos mediante un proceso de verificación externa y/o medidas legislativas en las que tuvieran un papel explicito las partes interesadas y las que querían ver la RSE como un ejercicio dirigido exclusivamente por las empresas que evolucionase sin ninguna intervención publica al margen de las declaraciones, conferencias de prensa y ceremonias de entrega de premios”.

Además, pone de manifiesto que la Comisión decidió en su momento excluirse del debate para, finalmente, presentar una Comunicación en la que indicaba su firme respaldo a un enfoque contrario a todo tipo de regulación.

Tras repasar toda la normativa europea relacionada con la responsabilidad hasta el momento, el Parlamento sostiene, como consideración de partida, que "las empresas no pueden sustituir a los poderes públicos cuando éstos dejan de asumir el control del respeto de las normas sociales y medioambientales”, lo que pone viene a poner de manifiesto el límite que la institución quiere dar al ámbito de actuación de las empresas o, lo que es lo mismo, en cuanto a la determinación de las competencias o acciones que les son atribuibles.

\footnotetext{
${ }^{62}$ Documento de Sesión del Parlamento Europeo de 20/12/2006 (A6-0471/2006 final).

${ }^{63}$ Resolución del Parlamento Europeo 2006/2133 (INI), de 13 de marzo de 2007.
} 
La Resolución también reconocía que el debate entre las partes interesadas con vistas a lograr una definición apropiada de la responsabilidad continuaba abierto. En concreto, señalando que, dentro de la actual definición operativa, la expresión “ir más allá en el cumplimiento” puede dar lugar a situaciones paradójicas, merced a lo cual algunas empresas pueden estar manifestando una probada responsabilidad social cuando en realidad están violando la legislación local o internacional.

Por otro lado, la pluralidad y la diversidad que acompañan al carácter voluntario de las iniciativas puede en la práctica llegar a convertirse en un obstáculo de cara a que más empresas adopten prácticas responsables, o incluso en un desincentivo para las que ya llevan a cabo este tipo de actuaciones por lo difuso del marco contextual. Todo ello, si bien esa misma diversidad y amplia libertad de actuación puede ser fuente de inspiración para las empresas en su creciente compromiso por incorporar las normas y principios acordados internacionalmente a través de un enfoque multilateral.

En cuanto a la credibilidad de las acciones que se realizan de forma voluntaria, se incide en la conveniencia de que éstas sean mensurables y transparentes, haciendo posible su seguimiento a efectos de verificación independiente

Del mismo modo se destaca el hecho de que los mercados y las empresas en Europa no se encuentran todos en una misma fase de desarrollo, y de ahí que cualquier plan de trabajo tendente a la imposición de un modelo único de responsabilidad no resulte adecuado ni conduzca a una aceptación significativa de la responsabilidad. Antes bien, se deben tener presentes los aspectos contextuales, remarcando la importancia del comportamiento de la sociedad civil, y particularmente, de las campañas y actuaciones encaminadas a sensibilizar a los consumidores para que éstos adquieran productos provenientes de procesos de producción responsable y, por ende, promuevan la mayor implantación de prácticas responsables en las empresas.

Otro aspecto importante en el que hace hincapié la Resolución es la necesaria ampliación de los ámbitos de responsabilidad, abarcando progresivamente nuevos aspectos, tales como el aprendizaje a lo largo de la vida, la organización del trabajo, la igualdad de oportunidades, la inclusión social, el desarrollo sostenible y la ética. En tal sentido, son analizadas seis cuestiones de particular transcendencia: i) el debate en la UE sobre la responsabilidad; ii) su vínculo con la competitividad; iii) sus instrumentos; iv) la mejora de su reglamentación; v) su integración en las políticas y programas de la UE; y vi) la contribución de Europa en esta materia. 
Así, y en cuanto al debate activo sobre la responsabilidad que tiene lugar en la UE, el Parlamento consideraba adecuada la decisión de la Comisión de promover una Alianza Europea, siempre y cuando se establezcan unos objetivos claros y unos calendarios adecuados, todo ello desde una perspectiva estratégica. También consideraba positiva la actividad desarrollada durante los dos años de funcionamiento del Foro Multilateral, respaldando los esfuerzos de la Comisión por ampliar la participación e incluir inversores, representantes del sector educativo y autoridades públicas, sin olvidar que es "necesario adoptar medidas para generar la confianza de las diferentes partes interesadas en que se llevará a cabo un verdadero diálogo que conduzca a un impacto real de las políticas y los programas de la UE para incentivar y aplicar la RSE en las empresas”.

Por lo que respecta a la relación entre responsabilidad y competitividad, se reconocía la conveniencia de introducir más normas eficaces en cuanto a ésta última como aspecto fundamental para garantizar las prácticas responsables, subrayándose que las empresas responsables, además de integrar cuestiones de política social (como el respeto de los derechos de los trabajadores, una política salarial justa, o la formación a lo largo de toda la vida) deben contribuir a eliminar las desigualdades de género y las barreras a las personas con discapacidad.

A la hora de valorar los instrumentos de la responsabilidad, el Parlamento apoyaba los esfuerzos realizados por el Eurostat y la Comisión en pro del desarrollo de indicadores, reconociendo las limitaciones en la medición de la conducta empresarial, la auditoría social y la certificación. Asimismo subrayaba que “los consumidores desempeñan un importante papel en la creación de incentivos para la producción y una práctica comercial responsables”, y ello aunque la situación del momento era “poco transparente para los consumidores, entre otras cosas, debido a la confusión que existe entre las diferentes normas nacionales de producción y los diversos sistemas de etiquetado de productos”.

En relación con los instrumentos jurídicos, se enfatiza la necesidad de una mejora del conocimiento de los mismos y sus cauces de aplicación, recomendando en tal sentido la utilización de un lenguaje sencillo y fácilmente comprensible que pueda reforzar las políticas de responsabilidad. A efectos de lograr este propósito, tanto la Comisión como los Gobiernos de los Estados miembros, deberán realizar nuevos esfuerzos en la contratación pública para apoyar a la responsabilidad. 
Refiriéndose a la integración de la responsabilidad en las políticas y programas de la UE, el Parlamento mantenía que los compromisos manifestados por la Comisión en el sentido de apoyarla y promoverla en todos los campos de actividad, debían traducirse en acciones concretas. De forma análoga recalcaba que la investigación futura en la materia debería centrar su atención en el vínculo existente entre competitividad y desarrollo sostenible (tanto a nivel macro como micro) y en el impacto de las iniciativas y posibles violaciones de sus principios. Además, pedía a la Comisión que publicase un informe anual sobre responsabilidad, el cual estuviera elaborado por investigadores y expertos independientes.

Por último, en su Resolución el Parlamento Europeo reconocía la importancia y la madurez alcanzada por iniciativas internacionales como la Global Reporting Iniciative, solicitando para su desarrollo el apoyo y la participación de las empresas líderes de la UE en nuevos enfoques sectoriales. En igual sentido pedía que se apoye y promueva el respeto a las normas y principios internacionales, que se desarrollen más iniciativas internacionales a favor de la transparencia total, así como que en los debates de la Organización Internacional de Normalización la representación europea garantice cualquier resultado coherente con las normas y acuerdos internacionales, métodos de evaluación y certificaciones externas.

e) La Comunicación de la Comisión Europea “estrategia renovada de la UE para 2011-2014 sobre la responsabilidad social de las empresas” (2011):

La respuesta de la Comisión a las peticiones del Consejo y del Parlamento Europeo para que desarrollase más su política en materia de responsabilidad ha dado lugar a una más reciente Comunicación, titulada "estrategia renovada de la UE para 2011-2014 sobre la responsabilidad social de las empresas” ${ }^{64}$, en la que se ponen de manifiesto los avances realizados desde el inicio de las políticas europeas sobre la materia, es decir, en el período 2006-2011 ${ }^{65}$. Con ello se trataba igualmente de apoyar la

\footnotetext{
${ }^{64}$ COM 2011-681 final.

${ }^{65}$ En las Comunicación se relacionan y describen los indicadores utilizados para valorar el progreso de las políticas de responsabilidad en dicho período 2006-2011. Así, por ejemplo: el número de empresas que suscribieron los diez principios de responsabilidad del Pacto Mundial de las Naciones Unidas aumentó de 600 a 1900 en dicho período; el número de organizaciones con sitios registrados pasó de 3300 a 4600; las empresas que suscribieron acuerdos de empresas transnacionales con organizaciones empresariales pasaron de 79 a 140; las entidades adheridas a la Iniciativa de Cumplimiento Social de las Empresas (para mejorar las condiciones de trabajo en sus cadenas de suministro) pasaron de ser 69 (en 2007) a 700; y las empresas que publicaron informes sobre sostenibilidad siguiendo las directrices de la Iniciativa Global se incrementaron igualmente, pasando de 270 a 850 entidades.
} 
iniciativa promovida por la Alianza Europea para la RSE, si bien reconociendo que seguía habiendo importantes retos pendientes.

En este texto se determinan los factores que deberán contribuir a la mayor eficacia de las decisiones en materia de responsabilidad, esto es: i) un planteamiento multilateral equilibrado (teniendo en cuenta la opinión de las empresas, de las otras partes interesadas y de los Estados); ii) la adopción de una definición europea de responsabilidad coherente con los principios y directrices internacionales actualizados; iii) la promoción de la recompensa que tiene en el mercado una conducta responsable de las empresas; iv) la consideración de sistemas de autorregulación y corregulación; v) la transparencia; vi) una mayor atención a los derechos humanos; y vii) la propiciación de un entorno más favorable para que las empresas asuman voluntariamente la parte que les corresponde de la responsabilidad social.

En relación con este último aspecto, y de cara a determinar más claramente qué es lo que se espera de las empresas, la Comisión presenta una nueva definición, basada en el impacto que la responsabilidad de aquéllas puede tener en la sociedad, y entendiendo que "el respeto de la legislación aplicable y de los convenios colectivos entre los interlocutores sociales es un requisito previo al cumplimiento de dicha responsabilidad. Para asumir plenamente su responsabilidad social, las empresas deben aplicar, en estrecha colaboración con las partes interesadas, un proceso destinado a integrar las preocupaciones sociales, medioambientales y éticas, el respeto de los derechos humanos y las preocupaciones de los consumidores en sus operaciones empresariales y su estrategia básica”.

Este nuevo intento conceptual hace hincapié en que la responsabilidad no debe ser considerada un resultado, sino que en realidad se trata de un proceso en el que han de ser tenidas en cuenta todas las cuestiones objeto de preocupación -tal y como las habitualmente incluidas en la triple bottom line-, haciendo referencia explícita a las de tipo ético y a las propias de los consumidores, evidenciando de este modo un giro en el enfoque de la responsabilidad hacia aquellos aspectos perceptivos de la parte que otorga la capacidad de operar a la organización en el mercado.

Este proceso, según continúa reconociendo la Comunicación, no tiene por qué ser igual en todas las entidades, pues depende en buena medida de factores como la naturaleza de las operaciones y el tamaño empresarial. Su finalidad es, por un lado, maximizar la creación de valor compartido, lo cual viene a consistir en la práctica en 
adoptar un comportamiento estratégico a largo plazo (teniendo presentes las oportunidades para desarrollar productos, servicios y modelos empresariales innovadores); por otro, identificar, prevenir y atenuar los posibles efectos adversos, llevando para ello a cabo medidas de diligencia debida basadas en el riesgo (así como en sus cadenas de suministro).

Como orientación para un planteamiento formal de la responsabilidad se remite a su marco global evolutivo, con el que la política europea para la promoción de la responsabilidad debe ser totalmente coherente, y que viene determinado por los principios y directrices reconocidos internacionalmente al respecto, con una mención explícita a las Líneas Directrices de la OCDE para las empresas multinacionales, los diez principios de la iniciativa del Pacto Mundial de Naciones Unidas, la ISO 26000, la Declaración Tripartita de Principios sobre Empresas Multinacionales y Política Social de la OIT y los Principios Rectores de las Naciones Unidas sobre Empresas y Derechos Humanos.

Al hacer referencia a la naturaleza pluridimensional de la responsabilidad, se recalca la labor de apoyo que han de llevar a cabo los poderes públicos (los cuales deben estar en condiciones de ofrecer una combinación inteligente de medidas voluntarias y de acciones regulatorias) y otras partes interesadas, estableciendo que la responsabilidad se debe aplicar a todas las empresas y reconociendo que contribuye al diálogo social y lo complementa. Tras ello se establece un programa de actuación para el período 2011-2014 con el que también se pretende evitar la aparición de cargas administrativas innecesarias.

El conjunto de medidas propuestas incluye compromisos asumidos por la propia Comisión Europea, así como sugerencias para las empresas, para los Estados miembros y para otros colectivos interesados, destacando las siguientes líneas:

- Creación y desarrollo de plataformas multilaterales sobre responsabilidad en diversos sectores industriales.

- Puesta en marcha a partir de 2012 de un sistema de premio europeo que fomente las asociaciones entre empresas y otras partes interesadas en cuestiones relacionadas con la responsabilidad.

- Inicio de un debate abierto sobre el papel potencial de las empresas y realización de encuestas periódicas sobre la confianza de los ciudadanos en las empresas y sus actuaciones, así como sobre sus actitudes en lo tocante a la responsabilidad. 
- Puesta en marcha de un proceso para la elaboración de un código de buenas prácticas sobre auto y corregulación.

- Facilitación de una mejor integración de las consideraciones sociales y medioambientales en la contratación pública.

- Estudio del requisito de que todos los fondos de inversión o instituciones financieras informen sobre cualquier criterio de inversión ético o responsable que apliquen o cualquier norma o código al que se adhieran.

- Ofrecimiento de más apoyo financiero a proyectos de educación y formación sobre responsabilidad y puesta en marcha en 2012 de acciones para sensibilizar a los profesionales de la educación y de la empresa sobre la importancia de la colaboración en este ámbito.

- Invitación a los Estados miembros para elaborar sus propios planes de acciones prioritarias que promuevan la responsabilidad.

- Seguimiento del compromiso adquirido por las empresas europeas con más de 1000 trabajadores en plantilla en cuanto a tomar en consideración los principios y directrices sobre responsabilidad y la norma de orientación ISO 26000, pues con el límite de 2014 deberán comprometerse con al menos uno de los principios o directrices siguientes: el Pacto Mundial, las Líneas Directrices de la OCDE, o la norma-guía ISO 26000. Además todas las empresas europeas multinacionales deberán comprometerse a respetar la Declaración Tripartita de Principios sobre Empresas Multinacionales y Política Social de la OIT.

- Invitación a los Estados miembros para elaborar planes nacionales orientados a la implementación de los Principios Rectores de las Naciones Unidas y que, de este modo, las empresas europeas asuman la responsabilidad de respetar los derechos humanos, tal y como se define en los citados Principios.

\subsubsection{Perspectivas de futuro en la UE en materia de responsabilidad}

Tal y como cabe, pues, apreciar a partir del contenido de los epígrafes precedentes de este apartado, el modelo asumido por la Comisión Europea insiste en la idea de asunción y aceptación voluntaria por parte de las empresas de la necesidad y/o conveniencia de llevar a cabo buenas prácticas y de tener en cuenta las preocupaciones sociales y medioambientales en sus operaciones económicas y en las relaciones con sus interlocutores, esto es, sin que ello suponga la existencia de mandatos jurídicos 
vinculantes (Rodríguez-Piñero 2006:124). Conforme a este punto de vista, el desarrollo futuro de acciones sobre responsabilidad en la UE no demanda nuevos instrumentos normativos, sino instrumentos alternativos a las soluciones jurídicas y judiciales ya existentes, esto es, nuevas técnicas de regulación social que promuevan la asunción voluntaria de compromisos por parte de las organizaciones.

En todo el camino recorrido hasta el momento, el Libro Verde tuvo la virtud de abrir un debate en torno a la responsabilidad (sobre todo empresarial) que aún sigue vivo, intentando definir sus contenidos y sus límites (Marín 2012:274), aun cuando los argumentos de las partes no son siempre coincidentes: por un lado, las empresas reivindican una y otra vez la naturaleza exclusivamente voluntaria de la responsabilidad, tratando de evitar una regulación, sobre todo en el ámbito jurídico, que frenaría la creatividad y el carácter innovador de sus actuaciones; por otro lado, los sindicatos, organizaciones no gubernamentales y otros grupos y colectivos de interés social defienden que las iniciativas voluntarias y autorregulaciones no son suficientes -tal y como queda suficientemente demostrado por la experiencia- y sostienen en consecuencia la necesidad de elaborar un marco reglamentario con normas de mínimos, así como, para las iniciativas de autorregulación, la necesidad de que éstas incorporen mecanismos de control y verificación externa.

Sin embargo, no es menos cierto que en la Unión Europea, aunque persistan desacuerdos notables en algunas cuestiones importantes, sí existe un consenso generalizado sobre cuáles son las características más sobresalientes que ha de tener la responsabilidad. De este modo, la responsabilidad (Marín 2012):

- viene a consistir en la adopción de una serie de compromisos y de pautas de conducta por parte de las empresas, en principio de forma voluntaria, además del cumplimiento por parte de éstas de las obligaciones jurídicas que les son propias (como las leyes de sociedades o códigos mercantiles), lo cual conlleva determinados compromisos y comportamientos que redundan a largo plazo en el propio interés de las organizaciones;

- está vinculada al concepto de desarrollo sostenible, el cual debe ser integrado en las decisiones que tome la entidad y en la valoración de las consecuencias de las mismas, tanto en el orden económico, como en el social y medioambiental (si bien hoy por hoy aún existe bastante falta de precisión en cuanto a posibles matices); 
- es un concepto que tiene naturaleza estratégica y que ha de ser integrado en las decisiones operativas habituales de la corporación (conformando un elemento transversal dentro de su estrategia); y

- tiene una dimensión global, puesto que si las actividades económicas tienen lugar en un escenario global, la responsabilidad asociada a las mismas ha de estar igualmente inmersa, de forma consustancial e inevitable, en ese mismo sistema global de relaciones internacionales, vinculada a la deseable, aunque hoy por hoy inexistente, gobernanza global. 


\title{
CAPítulo 3
}

Regulación y ARTiculación de LA ResponsabiLidad

\author{
EN ESPAÑA
}





\section{CAPÍtUlo 3. REgUlación y ARTICUlACión de LA RESPONSABILIDAD EN} ESPAÑA

Aunque no con la misma importancia que en otros países del entorno desarrollado, los aspectos relacionados con la responsabilidad de las organizaciones han estado también presentes en mayor o menor medida en la realidad española. Con todo, el verdadero auge del debate público a este respecto puede situarse a principios del presente siglo, tras la publicación del Libro Verde de la Comisión Europea en 2001, por lo que aún es relativamente joven ${ }^{66}$, si bien en ocasiones se reclaman en esta materia unos niveles de madurez impropios del tiempo transcurrido, lo cual, no obstante, resulta comprensibles debido a la dinámica vivida en la etapa más reciente (Lozano 2009).

La evolución del proceso tendente a la progresiva regulación y articulación de la responsabilidad organizativa en España debe, en consecuencia, contextualizarse en el marco de los principios y directrices internacionales, así como, y en especial, de las recomendaciones de la Unión Europea. Todo ello, sin olvidar las peculiaridades de empresas, mercados y otros actores a nivel nacional. Como resultado, a lo largo del último decenio han venido teniendo lugar diferentes y diversas actuaciones encaminadas a establecer un sistema propicio a la implementación de modelos de conducta responsable en todo tipo de entidades, adecuado a las características propias de cada una de ellas y conducente a tasas significativas de aceptación de la responsabilidad como filosofía o pauta básica de actuación por parte de las organizaciones.

Tomando como punto de partida dichos postulados, y en consonancia con su espíritu impulsor, los sucesivos Gobiernos de los países comunitarios en general, y los

\footnotetext{
${ }^{66}$ El Foro de Expertos en Responsabilidad Social de las Empresas, constituido en 2005 por iniciativa del Ministerio de Trabajo y Asuntos Sociales -y al que se hará posterior referencia en el capítulo- se hacía eco de esta situación en un posterior informe (2007c), señalando que el debate sobre los aspectos relacionados con la responsabilidad en España se encontraba en estado incipiente y embrionario hasta 2003. No obstante, el mismo Informe puntualizaba que a partir de ese momento el número de iniciativas promovidas por empresas, instituciones y otras organizaciones pasaba a ser extraordinario. Más aún, el incremento era significativo no sólo en términos absolutos, sino también en comparación con países que venían haciendo gala de cierta “tradición” en este campo, según ha sido indicado en páginas precedentes. En esa misma línea se situaba la Mesa de Diálogo Social, en un Informe paralelo (2007).
} 
de España en particular, se han decantado por el carácter voluntario de las prácticas responsables, no imponiendo obligaciones al respecto (Lozano et al. 2005). Lejos de ello, las distintas políticas y actuaciones se han encaminado a la dinamización, facilitación y promoción de las prácticas responsables, el desarrollo de estándares, la difusión de información y buenas prácticas, y la creación de espacios de diálogo. Se trata de un proceso abierto, que subraya la importancia de la participación activa de todos los grupos de interés implicados, no sólo en las primeras iniciativas y como consecuencia de la preocupación por analizar la situación, sino también posteriormente, por medio de turnos de debate abiertos y encaminados al diseño de un marco regulador sobre la responsabilidad ajustado a los intereses del país.

Resultado de lo expuesto, en los últimos años se viene dando un espectacular incremento de jornadas temáticas, charlas, conferencias y debates especializados, a la vez que proliferan fundaciones, redes $\mathrm{y}$ asociaciones específicas. Igualmente se multiplican las memorias de responsabilidad y sostenibilidad de las empresas en un buen número de las cuales se asignan tareas específicas o, incluso, se crean los correspondientes departamentos. Los Gobiernos y las Administraciones Públicas en todos los niveles han llevado a cabo sus primeras iniciativas en cuanto a responsabilidad propia, y se han impulsado medidas políticas de gran repercusión para promover la responsabilidad de todo tipo de organizaciones. Todo este tipo de actuaciones viene facilitado por la sensibilización de la opinión pública, la presencia en los medios de comunicación y las posibilidades que ofrecen las nuevas tecnologías.

\subsection{Primeras iniciativas y debates}

Antes de la publicación del Libro Verde, en España ya se habían desarrollado algunas iniciativas responsables, promovidas sobre todo por empresas, sindicatos y otros agentes de la sociedad civil, en tanto que la actuación pública se limitaba a regular algunos aspectos en relación con los informes medioambientales de las empresas.

Dentro del sector privado (que prácticamente monopolizaba todo el espacio y el discurso en cuanto a análisis situacional, promoción y difusión de la responsabilidad), las empresas transnacionales eran en esta etapa inicial las más activas a la hora de adoptar prácticas responsables en sus modelos de gestión, así como a reportar sobre sus actuaciones, lo que impulsó la constitución de diversas fundaciones y asociaciones cuya 
finalidad era analizar, promover y divulgar los modelos de responsabilidad social en el conjunto de las empresas (Melé 2004, Lozano et al. 2005, Archel y Husillos 2009).

Entre 1992 y principios del año 2000, tuvieron lugar iniciativas particularmente destacadas para debatir, analizar, implementar y promocionar aspectos de la responsabilidad (Archel y Husillos 2009). Entre ellas, cabe mencionar la constitución en 1995 de la Fundación Empresa y Sociedad (para promover que sus socios sean agentes activos en la integración de empresas desfavorecidas), en 2002 del Foro de Reputación Corporativa (por grandes empresas, con el propósito de analizar y divulgar tendencias y modelos de reputación corporativa en la gestión empresarial), o también en 2002 del Club de Excelencia en Sostenibilidad (con el propósito de propiciar un foro empresarial de debate y constituirse en referencia para aquellas entidades que quieran progresar en el desarrollo sostenible).

Esa labor se vio secundada por otras iniciativas promovidas desde un dinámico Tercer Sector, y así, por ejemplo, en 1992 iniciaban su andadura la Fundación Economía y Desarrollo (para promover prácticas de consumo responsable) y la Confederación Empresarial Española de Economía Social (CEPES, con la finalidad de solucionar problemas locales de empleo, integración y cohesión), y después lo harían otras surgidas en el ámbito universitario.

Otros interlocutores ya activos en esta época eran organismos públicos, agentes económicos y sociales, la propia sociedad civil, otras fundaciones, otros expertos independientes, entidades de gestión y auditoría en responsabilidad, medios de comunicación, etc., todos los cuales iban a estar presentes en los primeros debates específicos sobre las tendencias y medidas para fomentar la responsabilidad, desempeñando un importante papel en la difusión de los documentos consensuados y aprobados, así como de cara a la interpretación y matización de su contenido y de cara a posteriores desarrollos en materia de responsabilidad.

Esta amplia red social trabajaría desde diversos ángulos y perspectivas, siendo determinante para el proceso de diálogo multistakeholder en España entre 2005 y 2007, debatiendo sobre la responsabilidad y haciendo propuestas sobre el papel gubernamental y los instrumentos de fomento y apoyo necesarios (Archel y Husillos 2009). En aras de lograr el mayor nivel de consenso posible entre los distintos grupos de interés, se establecieron tres foros de debate: la Subcomisión Parlamentaria para potenciar y promover la RSE, el Foro de Expertos en RSE, y la Mesa de Diálogo Social. 


\subsubsection{La Subcomisión Parlamentaria para potenciar y promover la responsabilidad} social empresarial

Al objeto de proveer un foro para proponer al Gobierno las correspondientes medidas a adoptar, la Comisión de Trabajo y Asuntos Sociales acordó solicitar al Pleno del Congreso de los Diputados la creación de una Subcomisión Parlamentaria para potenciar y promover la responsabilidad social de las empresas, la cual fue constituida el 9 de febrero de 2005 bajo la presidencia del diputado Ramón Jáuregui, quien programó la comparecencia de 59 especialistas procedentes de una amplia pluralidad de ámbitos: administraciones públicas y organismos públicos, agentes económicos y sociales, representantes de la sociedad civil, fundaciones, otros expertos, empresas y organismos singulares, entidades de gestión y auditoría en responsabilidad, medios de comunicación y fondos éticos.

La Subcomisión estuvo trabajando durante diecisiete meses, entre febrero de 2005 y junio de 2006. El 27 de junio de 2006 fueron aprobadas por unanimidad las conclusiones y recomendaciones finales, contenidas en un Informe final, conocido como Libro Blanco de la RSE, y que, como tal, contenía un conjunto oficial de propuestas en este ámbito, a la vez que resultaba una guía para su puesta en práctica.

Una vez aprobado por la Comisión de Trabajo y Asuntos Sociales, y publicado en el Boletín Oficial de las Cortes Generales el 4 de agosto de 2006, el Libro Blanco de la RSE se convertía en el primer documento de estas características aprobado por un parlamento nacional de un país de la Unión Europea.

En síntesis, el Libro Blanco recomienda que las políticas públicas de desarrollo de la responsabilidad social de las empresas estén compuesta por normas orientadas a fomentar iniciativas de prácticas empresariales responsables adoptadas voluntariamente, así como por acuerdos y medidas legislativas tendentes a favorecer las conductas responsables de los actores económicos.

Se encuentra estructurado en tres grandes capítulos o apartados, el primero de ellos dedicado al análisis de los antecedentes, la descripción de los trabajos y la relación de la documentación aportada por la Subcomisión. A continuación, el segundo capítulo resume las 59 comparecencias, agrupadas por temas y exponiendo los puntos de vista de los grupos de interés sobre los aspectos de la RSE acerca de los que fueron consultados: definición, contenidos, legislación, prácticas, reporte, verificación, etc. 
A continuación, el tercer capítulo contiene las conclusiones, en tres apartados:

i) Constataciones (30): conclusiones de carácter más general consensuadas por los grupos de interés consultados y que mostraban el estado de la RSE en aquel momento en España, con sus debilidades y fortalezas.

ii) Directrices generales (5): criterios y/o enfoques que pueden ayudar a entender mejor las recomendaciones enumeradas en la última sección.

iii) Recomendaciones (57): principios orientadores para lograr una actuación responsable, algunos de los cuales dirigidos a las empresas y asociaciones empresariales, en tanto otros lo estaban a las administraciones públicas, a los consumidores, a los inversores (como actores demandantes de la RSE) y a otros grupos de interés. Son formulados a partir del análisis de experiencias previas y de documentos en el seno de la Subcomisión, y su propósito es contribuir a desarrollar la RSE con acciones de sensibilización, unificación de criterios de gestión, informes de sostenibilidad, estímulos fiscales, etc.

Como uno de los puntos más destacables del trabajo de la Subcomisión, destaca el esfuerzo realizado en el plano conceptual, entendiendo la RSE como un proceso de mejora continua que constituye un nuevo modelo de gestión y presupone una ampliación de los grupos de interés a los que se dirige la actividad de la empresa, incidiendo su carácter activo y voluntario. En tal sentido era aceptada la definición que en aquellos momentos ya había elaborado el Foro de Expertos en $\mathrm{RSE}^{67}$, en los términos siguientes (Congreso de los Diputados 2006:110): “la Responsabilidad de las Empresas es, además del cumplimiento estricto de las obligaciones legales vigentes, la integración voluntaria en su gobierno y su gestión, en sus estrategia políticas y procedimientos, de las preocupaciones sociales, laborales, medioambientales y de respeto de los derechos humanos que surgen de la relación y dialogo trasparentes de los grupos de interés, responsabilizándose así de las consecuencias y de los impactos que se derivan de sus acciones. Una empresa es socialmente responsable cuando responde satisfactoriamente a las expectativas que sobre su funcionamiento tienen los distintos grupos de interés”.

Tal y como cabe apreciar, esta definición no es sino un desarrollo de la acuñada en su momento en el Libro Verde de la UE. Aunque quizá con el inconveniente de ser

${ }^{67}$ Aunque cronológicamente constituido después (razón por la que asimismo es objeto de posterior consideración en este trabajo), el Foro de Expertos en responsabilidad social empresarial ya había realizado una parte importante de su trabajo al tiempo de redactar el Libro Blanco. 
más larga de lo que pudiera considerarse habitual, cuenta con la ventaja de ser prolija al referirse a los aspectos más importantes que debe abarcar la responsabilidad. En tal sentido, y a mayores de las recomendaciones ya reiteradas (mejora continua, ampliación de los grupos de interés, carácter activo y voluntario de la responsabilidad), se hace también énfasis en la importancia de la transparencia y comunicación de las acciones de las empresas a la sociedad, habida cuenta de la posibilidad por parte de ésta de recompensar a las entidades responsables y castigar a las que no lo son (considerando así el consumo responsable como un importante potenciador de la responsabilidad).

El Libro Blanco también señala que las posibilidades reales de desarrollar la responsabilidad en España “dependen tanto de las iniciativas de las administraciones públicas como de las acciones de las empresas, consumidores e inversores, medios de comunicación, sindicatos, ONGs, etc.” (Congreso de los Diputados 2006:112). Esas posibilidades se verían incrementadas si, de algún modo, todos esos grupos aunasen energías y esfuerzos para promocionar conjuntamente la RSE.

Asimismo -y tal y como ha sido anticipado- se exhorta a llevar a cabo unas políticas públicas para el desarrollo de la responsabilidad mediante normas que fomenten iniciativas voluntarias en cuanto a prácticas empresariales responsables, así como a través de acuerdos y medidas legislativas que contribuyan a favorecer las conductas responsables de los actores económicos. Entre otras, impulsar la inversión socialmente responsable, las reducciones fiscales, las bonificaciones en las cuotas a la Seguridad Social, establecer un marco fiscal favorable para las empresas responsables, regular los procesos de elaboración y verificación de memorias de sostenibilidad, así como recomendar a las comunidades autónomas la creación en cada una de ellas de una secretaría destinada a fomentar medidas de responsabilidad, al tiempo que también se pedía la creación de un Consejo que permitiese mantener el diálogo con los grupos de interés para orientar la actuación política en esta materia, mejorarla y estimularla.

Finalmente, las recomendaciones también van encaminadas a estimular la investigación sobre determinados aspectos que se entendían aún poco desarrollados, así como la realización de campañas de difusión del consumo responsable, indicando a este respecto que "las asociaciones de consumidores, junto a otras organizaciones de la sociedad civil, pueden desarrollar un papel fundamental en la promoción del consumo responsable” (Congreso de los Diputados 2006:119) al brindar información clara y suficiente a los consumidores sobre productos y empresas socialmente responsables. 


\subsubsection{El Foro de Expertos en responsabilidad social empresarial}

Convocado por el Ministerio de Trabajo y Asuntos Sociales, el Foro de Expertos en responsabilidad social empresarial fue constituido formalmente el 17 de marzo de 2005, con la finalidad de conocer las demandas e iniciativas surgidas en cuanto a responsabilidad, para así poder asesorar al Gobierno acerca de esta materia. En él participaron representantes de varios ministerios, así como expertos provenientes de distintos ámbitos ${ }^{68}$.

Los trabajos del Foro se organizaban en sesiones temáticas en las que se abordaban diferentes aspectos de la responsabilidad. El resultado conjunto de esas reuniones fue la aprobación por unanimidad de un único documento o Informe del Foro de Expertos en Responsabilidad Social Empresarial, el cual permitió avanzar en la definición de las relaciones y actuaciones necesarias para fomentar la RSE, y su contenido se estructuró en cuatro secciones o apartados:

i) la definición y el ámbito de la RSE;

ii) el informe de RSE como motor de la responsabilidad social;

iii) el desarrollo de la RSE en España; y

iv) las políticas públicas de fomento y desarrollo de la RSE en España.

Tal y como ha sido indicado, la definición del Foro de Expertos transcendería desde un primer momento al ser inmediatamente adoptada por la Subcomisión Parlamentaria para potenciar y promover la RSE a efectos de su inclusión en el Libro Blanco. Al entender de los miembros del Foro (Foro de Expertos en RSE 2007a), resulta útil por cuanto explica el carácter global de la responsabilidad (señalando esferas de actuación tanto en el ámbito interno como en el externo), a la vez que alude a sus actores sociales (en su sentido más amplio), a su naturaleza (tridimensional, y con responsabilidad ante la sociedad), y a la necesidad de un proceso de diálogo y acuerdo social (con todas las partes interesadas), de políticas públicas (adoptando una posición positiva y activa de apoyo al desarrollo responsable) e inversiones socialmente responsables (como palanca de cambio).

La segunda sección del Informe fue dedicada a explicar el papel que podía jugar la elaboración de informes de RSE como motor impulsor de conductas responsables en las empresas (Foro de Expertos en RSE 2007b), así como los objetivos de este tipo de

\footnotetext{
68 Sin embargo, las organizaciones sindicales y empresariales se autoexcluyeron de participar en los trabajos del Foro, reclamando un espacio que resultase más propio para ellos.
} 
documentos (asumir un compromiso público con las partes interesadas, responder a los requerimientos de los mercados -de consumidores e inversores-, avances en cuanto a transparencia interna y externa, materialidad y relevancia de la información, necesidad de mostrar los avances en la materia, e integración de la responsabilidad en la gestión empresarial), y el porqué de la necesidad de estimular su elaboración en España.

Se analizan en la tercera parte del documento datos definitorios del desarrollo de la RSE a escala nacional (Foro de Expertos en RSE 2007c), utilizando para ello los indicadores que se entendían más relevantes como, por ejemplo, el número de informes de sostenibilidad publicados por las empresas, destacando el elevado número de empresas que ya en esas fechas elaboraba sus informes social en conformidad con las guías de la Global Reporting Initiative. Asimismo era objeto de mención destacada la creación de organizaciones dinamizadoras del debate público y de las prácticas innovadoras de responsabilidad, la creación a finales del 2004 de la Asociación Española del Pacto Mundial de Naciones Unidas (ASEPAM), la aprobación de normas y leyes como las de transparencia (Código Conthe), igualdad, etc., así como la notoriedad que venían alcanzando en los últimos años los índices de sostenibilidad.

En la última parte del informe, y en relación a las políticas públicas de fomento y desarrollo de la RSE en España (Foro de Expertos en RSE 2007d), se procedía a explicar la necesidad de las mismas, incluyendo 29 recomendaciones de cara a la información y sensibilización de los actores; al estímulo de la participación, el conocimiento, la implantación y la corresponsabilidad; a la relación con el desarrollo sostenible; al fomento de la responsabilidad en las Pymes; y a la relación con el dialogo y la cooperación. Por último, se proponía la creación de un Consejo Estatal de RSE (al igual que lo hacía la Subcomisión Parlamentaria en su informe de conclusiones), indicando los objetivos que debería proponerse, su composición y funcionamiento, todo ello facilitando el diálogo multilateral permanente entre los distintos grupos de interés.

Durante el tiempo en que estuvo activo el Foro de Expertos, varios de sus miembros lo abandonaron, por disconformidad con el rumbo y la orientación de las sesiones de trabajo (Archel y Husillos 2009). Por otro lado, algunos de sus integrantes, organizaciones de la sociedad civil, suscribirían un texto con 17 puntos, publicado en el anexo del documento principal, en el que reclamaban un papel más activo para la Administración y un mayor compromiso de ésta para establecer marcos legales, y hacían algunas matizaciones sobre el funcionamiento y equilibrio del Consejo Estatal. 


\subsubsection{La Mesa de Diálogo Social}

La Mesa de Diálogo Social vino a conformarse en el tercer escenario para el análisis y debate en torno a las prácticas responsables en las empresas. En tal sentido, la Comisión de Seguimiento y Evaluación del Diálogo Social acordó en su sesión de 2 de marzo de 2005 que la responsabilidad debía ser considerada dentro del marco de la Declaración para el Diálogo Social de 2004.

Sobre la base de dicho acuerdo, el Gobierno y las organizaciones empresariales y sindicales decidieron incorporar la responsabilidad al temario de su agenda y con ese fin constituyeron la Comisión de Seguimiento y Evaluación del Diálogo Social, o Mesa de Diálogo Social, como foro tripartito e integrado por representantes del Gobierno, de los empresarios (a través de las asociaciones CEOE y CEPYME) y de los trabajadores (UGT y CCOO, como sindicatos más representativos).

El objetivo concreto de la Mesa de Diálogo Social (2007:2) era “alcanzar unos mayores niveles de desarrollo económico y competitividad empresarial de calidad en el empleo, de bienestar social, de cohesión territorial y de sostenibilidad ambiental”.

El 20 de marzo de 2007 tuvo lugar la primera de las reuniones para profundizar en las medidas a adoptar en materia de responsabilidad y elaborar propuestas para impulsarla y difundirla, teniéndose en cuenta como referente para las sesiones de trabajo los documentos hasta entonces aprobados en el ámbito institucional europeo (desde la Cumbre de Lisboa, hasta la Resolución del Parlamento Europeo de marzo de 2007, pasando por el Libro Verde), así como las iniciativas y debates que esta materia se habían producido en España.

Tras varias reuniones, el 19 de diciembre del propio año 2007 fue aprobado el documento titulado “La Responsabilidad Social de las Empresas. Diálogo Social”, señalando el alcance y definiendo el concepto de RSE, a la vez que incluyendo las premisas, objetivos y los principios generales de la misma. Desde el punto de vista de las partes implicadas (Mesa de Diálogo Social 2007:3), la responsabilidad se constituía así en "un conjunto de compromisos de diverso orden económico, social y medioambiental adoptados por las empresas, las organizaciones e instituciones públicas y privadas y que constituyen un valor añadido al cumplimiento de sus obligaciones legales, contribuyendo a la vez al progreso social y económico en el marco de un desarrollo sostenible”. 
En consonancia con estos planteamientos, desde la Mesa de Diálogo Social se entendía que los principios generales rectores de la responsabilidad debían ser los relacionados con la voluntariedad, la ayuda a la generación de valor añadido, y la integración progresiva de las prácticas y actuaciones en las distintas políticas de empresa.

Junto a los anteriores, se señalaba la conveniencia y/o necesidad de que también fuese objeto de consideración a la hora de valorar los diferentes programas y actuaciones lo concerniente a su viabilidad económica, a la adaptabilidad y flexibilidad de cara a su implementación (dependiendo de particularidades y/o de la naturaleza del negocio, su ámbito geográfico, su tamaño y otras especificaciones), la credibilidad de unos y otras (entendiendo la transparencia como un componente de éxito esencial), la globalidad (en cuanto a la orientación de algunas actuaciones a paliar situaciones de debilidad institucional y legal en determinados países), la dimensión y naturaleza social (con la finalidad de reforzar la función social de la empresa), la dimensión y naturaleza medioambiental (vinculada al concepto de desarrollo sostenible), así como la implicación y participación de los trabajadores (prácticas propiciadoras de la mejora de la competitividad, la creación de empleo, la mejora en las condiciones de trabajo y el desarrollo sostenible).

$\mathrm{Al}$ igual que en los dos precedentes análogos en cuanto a propósito y contenido, en el texto elaborado por la Mesa de Diálogo Social se incluyó un apartado en el que se recogían propuestas en relación a las políticas públicas que debían desarrollarse para apoyar la responsabilidad. En este caso se trataba de diez, entre las cuales cabe mencionar la mejora del conocimiento respecto a la responsabilidad, particularmente empresarial; su vinculación a los factores de competitividad, creación de empleo y cohesión social y medioambiental; el análisis y difusión de buenas prácticas; el estímulo a las empresas para que presenten informes de responsabilidad y de un modo particular en lo que se refiere a las Pymes; o el consumo responsable (integración de principios de responsabilidad en los modelos y patrones de consumo, procediendo para ello a la elaboración y difusión de información dirigida a los consumidores).

Por último, y siguiendo una vez más la pauta marcada por el Libro Blanco de la RSE y por el Informe del Foro de Expertos en Responsabilidad Social Empresarial, en el documento de la Mesa de Diálogo Social también se incluyó la propuesta relativa a la creación de un Consejo Estatal de responsabilidad social. 


\subsection{El Consejo Estatal de Responsabilidad Social de las Empresas (CERSE)}

Los documentos elaborados por la Subcomisión Parlamentaria para potenciar y promover la RSE, el Foro de Expertos en RSE, y la Mesa de Diálogo Social presentaban, tal y como cabía esperar, varios puntos en común, entre los que figuraba la propuesta de creación de un Consejo Estatal. Estas recomendaciones dieron pie a que el Ejecutivo elaborara el Real Decreto 221/2008, de 15 de febrero, por el que se crea y regula el Consejo Estatal de Responsabilidad Social de las Empresas (CERSE) ${ }^{69}$.

El CERSE, de ámbito estatal y adscrito al entonces Ministerio de Trabajo y Asuntos Sociales (hoy Ministerio de Empleo y Seguridad Social), siendo un órgano paritario presidido por el Ministro e integrado por 56 vocales representando a la Administración, organizaciones sindicales, organizaciones empresariales e instituciones de prestigio en el ámbito de la responsabilidad social.

\subsubsection{Funciones del CERSE}

El CERSE fue constituido como órgano asesor y consultivo del Gobierno (careciendo, por tanto, de carácter ejecutivo), a fin de identificar y promover mejores prácticas en materia de responsabilidad social, en forma de propuestas al Ejecutivo.

Por una parte, venía a constituir un nuevo foro de debate abierto a todas las partes interesadas en las cuestiones relacionadas con la responsabilidad ${ }^{70}$. Por otro, y derivado de lo anterior, debía identificar y promover aquellas iniciativas y regulaciones que pudieran resultar de algún modo favorables (aplicación de estándares, características de informes o memorias, etc.).

Para cumplir sus objetivos, el CERSE debe proceder a llevar a cabo una serie de actividades o actuaciones, entre las que se encuentran la realización de una memoria anual, la emisión de informes, la realización de estudios, y la actuación como observatorio de la RSE en España, promoviendo y fomentando iniciativas en la materia, así como colaborando, cooperando y participando en otros foros análogos a nivel nacional e internacional.

\footnotetext{
${ }^{69}$ Posteriormente objeto de modificación por el Real Decreto 1469/2008, de 5 de septiembre, en cuanto a su composición.

${ }^{70}$ No sólo empresarios, sindicatos y Gobierno, como, por ejemplo, ocurría en la Mesa de Diálogo Social, sino incluyendo también representantes de otros colectivos igualmente interesados, análogamente a como había ocurrido en el Foro de Expertos.
} 
En cuanto a su funcionamiento, el CERSE puede actuar como Pleno, mediante la Comisión Permanente o a través de Grupos de Trabajo. El Pleno es el encargado de la emisión de informes, la realización de estudios y consultas, así como de formular las correspondientes propuestas, además de aprobar la memoria anual. Por su parte, la Comisión Permanente se encarga de aquellos informes, consultas o estudios que, de forma expresa, le haya encomendado el Pleno. Por último, los Grupos de Trabajo deben ser paritarios, y se encargan de realizar estudios o informes en temas que afecten a los cometidos del Consejo.

\subsubsection{Grupos de Trabajo del CERSE}

Los primeros vocales del CERSE fueron nombrados el 13 de enero de 2009, y el proceso de constitución de este órgano culminaría una semana después, el 20 de enero, con la celebración de la primera reunión del Pleno, en la que asimismo se propuso la creación de distintos Grupos de Trabajo.

En consonancia con dicha propuesta, el 6 de mayo de 2009 la Comisión Permanente estableció la creación de cinco Grupos de Trabajo, en los que cada uno de los grupos integrantes del Consejo (Administraciones Públicas, organizaciones empresariales más representativas, organizaciones sindicales más representativas, y organizaciones e instituciones de reconocida representatividad e interés en el ámbito de la responsabilidad social de las empresas) tiene, como máximo, cinco representantes.

Cada uno de los cinco Grupos de Trabajo formados fue encargado de ahondar y debatir y abordar en relación con aspectos concretos que fueron considerados de gran transcendencia, con la finalidad de elaborar los correspondientes documentos, en los que se sentasen las bases para promocionar la responsabilidad en España. En concreto, dichos grupos estaban referidos a los siguientes aspectos (véase también el Cuadro 3.1):

- Grupo 1: el papel de la RSE ante la crisis económica: su contribución al nuevo modelo productivo, la competitividad y el desarrollo sostenible.

- Grupo 2: transparencia, comunicación y estándares de los informes y memorias de sostenibilidad.

- Grupo 3: consumo e inversión socialmente responsable (dos subgrupos)

- Grupo 4: la RSE y la educación.

- Grupo 5: gestión de la diversidad, cohesión social y cooperación al desarrollo. 
Cuadro 3.1. Grupos de Trabajo del CERSE

\begin{tabular}{|c|c|c|}
\hline $\begin{array}{l}\text { Grupo de } \\
\text { trabajo }\end{array}$ & Objetivos & Contenidos de trabajo \\
\hline $\begin{array}{l}\text { 1. El papel de la } \\
\text { RSE ante la crisis } \\
\text { económica: su } \\
\text { contribución al } \\
\text { nuevo modelo } \\
\text { productivo, la } \\
\text { competitividad y } \\
\text { el desarrollo } \\
\text { sostenible }\end{array}$ & $\begin{array}{l}\text { Analizar la crisis económica a } \\
\text { fin de dar con un nuevo } \\
\text { modelo productivo en el que la } \\
\text { transparencia en la gestión, la } \\
\text { cohesión social, la igualdad de } \\
\text { oportunidades y de género, el } \\
\text { medioambiente y la } \\
\text { participación de todas las } \\
\text { partes implicadas sean } \\
\text { prioritarios }\end{array}$ & $\begin{array}{l}\text { Selección de buenas prácticas sobre: } \\
\text { a) empleados, gestión de talento, } \\
\text { conciliación, medidas de igualdad y } \\
\text { mejora de la productividad; } \\
\text { b) clientes y consumidores, desde la } \\
\text { perspectiva de la mejora de la } \\
\text { competitividad y la RSE; y } \\
\text { c) Administración, en su doble faceta como } \\
\text { fuente reguladora y como empleadora y } \\
\text { perceptora de dichas políticas. }\end{array}$ \\
\hline $\begin{array}{l}\text { 2. Transparencia, } \\
\text { comunicación y } \\
\text { estándares de los } \\
\text { informes y } \\
\text { memorias de } \\
\text { sostenibilidad }\end{array}$ & $\begin{array}{l}\text { Fomentar los informes de } \\
\text { sostenibilidad y su verificación } \\
\text { para lograr la transparencia de } \\
\text { las empresas, organizaciones y } \\
\text { Administraciones Públicas }\end{array}$ & $\begin{array}{l}\text { Debate sobre diagnóstico de la RSE en } \\
\text { España, los grupos de interés, la esfera de } \\
\text { influencia de una organización, los modelos } \\
\text { de referencia para informar, indicadores, } \\
\text { comparabilidad, verificación, y el papel de la } \\
\text { Administración en la generalización de la } \\
\text { RSE y verificación de la información no } \\
\text { financiera }\end{array}$ \\
\hline $\begin{array}{l}\text { 3. Consumo e } \\
\text { inversión } \\
\text { socialmente } \\
\text { responsable }\end{array}$ & $\begin{array}{l}\text { Analizar la utilización del } \\
\text { etiquetado (de comercio justo, } \\
\text { y otras posibles simbologías } \\
\text { análogas) como herramienta } \\
\text { distintiva del cumplimiento de } \\
\text { criterios sociales y en relación } \\
\text { con el medio ambiente, } \\
\text { además de la actuación de la } \\
\text { Administración Pública como } \\
\text { consumidor de bienes y } \\
\text { servicios }\end{array}$ & $\begin{array}{l}\text { Para el subgrupo de consumo socialmente } \\
\text { responsable, estudio del marco conceptual, la } \\
\text { información al consumidor, garantías y } \\
\text { buenas prácticas, la experiencia } \\
\text { internacional, buenas prácticas, y patrones de } \\
\text { consumo } \\
\text { Para el subgrupo de inversión socialmente } \\
\text { responsable, abordaje de temas referentes a } \\
\text { la definición de ISR, análisis, situación y } \\
\text { experiencias internacionales, privadas y } \\
\text { públicas según tipos de productos y } \\
\text { servicios, y desarrollo de capacidades, } \\
\text { informando y fomentando la ISR }\end{array}$ \\
\hline $\begin{array}{l}\text { 4. La RSE y la } \\
\text { educación }\end{array}$ & $\begin{array}{l}\text { Informar, divulgar, sensibilizar } \\
\text { y formar en materia de } \\
\text { Responsabilidad Social y } \\
\text { extender el conocimiento al } \\
\text { conjunto de la ciudadanía }\end{array}$ & $\begin{array}{l}\text { Debate sobre temas relacionados con la } \\
\text { incorporación de la RSE en el sistema } \\
\text { educativo, la difusión, formación e } \\
\text { información en RSE, la RSE en las } \\
\text { universidades y escuelas de negocio y la } \\
\text { innovación curricular y la investigación }\end{array}$ \\
\hline $\begin{array}{l}\text { 5. Gestión de la } \\
\text { diversidad, } \\
\text { cohesión social y } \\
\text { cooperación al } \\
\text { desarrollo }\end{array}$ & $\begin{array}{l}\text { Analizar la gestión de la } \\
\text { diversidad, la cohesión social y } \\
\text { la cooperación al desarrollo, la } \\
\text { incorporación de cláusulas } \\
\text { sociales en las contrataciones } \\
\text { públicas, la integración de } \\
\text { colectivos en riesgo de } \\
\text { inclusión para facilitar su } \\
\text { incorporación al mercado de } \\
\text { trabajo, temas de igualdad, } \\
\text { derechos humanos y } \\
\text { diversidad }\end{array}$ & $\begin{array}{l}\text { Consenso sobre materias relacionadas con la } \\
\text { definición conceptual de la gestión de la } \\
\text { diversidad, la cohesión social y la } \\
\text { cooperación al desarrollo, la incorporación } \\
\text { de cláusulas sociales en las contrataciones } \\
\text { públicas, la integración de colectivos en } \\
\text { riesgo de inclusión para su incorporación al } \\
\text { mercado de trabajo, temas de igualdad y de } \\
\text { derechos humanos }\end{array}$ \\
\hline
\end{tabular}

Fuente: Elaboración propia en base a documentos de trabajo del CERSE. 
La labor de los Grupos de Trabajo se plasma en documentos base elaborados a partir del análisis de las propuestas realizadas por sus componentes, conteniendo recomendaciones, orientaciones y conclusiones a fin de ser sometidas al Pleno para su aprobación y posterior remisión al Gobierno.

Entre dichos documentos, todos ellos aprobados por el Pleno del CERSE el 3 de mayo de $2011^{71}$, y habida cuenta de su particular relación con la presente Tesis, cabe destacar el elaborado por el Subgrupo de consumo socialmente responsable ${ }^{72}$.

En la introducción al mismo (CERSE-GT.IIIa 2011), y de forma descriptiva, se hace referencia a los distintos aspectos que deben contemplar las políticas y actuaciones de responsabilidad en todas las organizaciones (públicas o privadas), así como su potencial contribución al objetivo de desarrollo sostenible. Se trata de una exposición general cuyo planteamiento parte del postulado de que tanto el desempeño organizativo como la percepción de sus actuaciones va a poder influir, cuando menos, en términos de ventajas competitivas en numerosos ámbitos de actuación ${ }^{73}$ : reputación; capacidad de atracción de y retención de trabajadores; grado de fidelización de clientes; motivación, compromiso y productividad de los empleados; percepción de inversores, donantes, patrocinadores y de la comunidad financiera en general; relaciones con empresas, Gobiernos, proveedores, clientes y con la comunidad donde opera, etc. Sobre esta base se plantea el objetivo a alcanzar, que no es otro que la delimitación de los aspectos que conforman la responsabilidad desde el punto de vista del consumo, para después avanzar en posibles líneas de desarrollo.

Así (y análogamente a otros documentos en la materia), la responsabilidad se ve (CERSE-GT.IIIa 2011:2) como "el conjunto de actitudes, medidas y comportamientos que realizan las organizaciones con carácter voluntario y más allá de lo que exige la legislación para contribuir a un mejor servicio y a una mayor calidad de vida del

\footnotetext{
${ }^{71}$ La relación completa de documentos se encuentra disponible en http://www.empleo.gob.es/es/sec trabajo/autonomos/economia-soc/resposocempresas/consejo_rse/index.htm (consultada en junio de 2012).

72 En este caso aprobado con dos votos particulares, uno del grupo empresarial (mostrando sus discrepancias en cuanto a la actuación de las Administraciones Públicas, la verificación de los informes referentes al etiquetado y manual de instrucciones, así como al distintivo de organizaciones responsables), y el otro de la Secretaría de Estado de Comercio (referido exclusivamente a la verificación de los informes, por considerar que se trata de una limitación excesiva al comercio). Por tal motivo se produjo un cierto retraso en la publicación del documento.

${ }^{73}$ Todo ello, derivado de la percepción por parte de distintos grupo de interés, cuya influencia será más o menos intensa y/o determinante en los resultados de la entidad, pero en todo caso -conforme se señala en la página 1 del documento de referencia- relacionada con las expectativas crecientes que tienen sobre el comportamiento responsable de la misma.
} 
consumidor y de la sociedad en su conjunto", bien entendido que recalcando en esta ocasión la capacidad que tienen los consumidores para influir mediante su elección de compra en la conducta en las modificaciones de la conducta organizativa, haciendo de este modo del consumo "un motor de justicia social y equilibrio ambiental”.

En tal contexto, consumo responsable es “la elección de los productos no sólo en base a la relación calidad/precio, sino también en base a las implicaciones sociales y medioambientales de los productos o servicios mismos y al buen gobierno de las organizaciones que los ofrecen”. Con estas connotaciones "es uno de los motores de la responsabilidad de las organizaciones, puesto que de alguna manera fomenta la creación de productos y de organizaciones innovadoras, faculta a los consumidores a tener en consideración estos aspectos a la hora de escoger los productos e incita a las organizaciones a que sean socialmente responsables” (CERSE-GT.IIIa 2011:2-3).

Establecido el marco teórico referencial, el documento pasa a abordar el papel de la Administraciones como impulsoras de políticas de coordinación administrativa y fomento del consumo responsable, así como con su propia actuación en el mercado (por ejemplo, incluyendo en los contratos cláusulas de responsabilidad en las compras públicas $^{74}$, realizando acciones formativas, y con la generación y difusión de herramientas clarificadoras de la inclusión de condiciones sociales o medioambientales.

Refiriéndose a los principios orientadores de las prácticas responsables hacia los consumidores y la sociedad, el documento enfatiza el reconocimiento de los derechos de aquéllos a la seguridad (minimizando el riesgo por el uso de bienes y servicios), a recibir información (incluyendo la relacionada con aspectos responsables, como los procesos de contratación justos, transparentes y eficientes, las medidas de protección de la salud y seguridad de los trabajadores en los procesos productivos y de distribución, o la promoción de la educación para el consumo responsable y sostenible), a poder escoger, a ser escuchados en sus reclamaciones ( $y$, si fuese el caso, a ser compensados o indemnizados), a un entorno social adecuado y un medioambiente saludable, y al respeto de sus datos personales y su privacidad, También se incluirían aquí la adopción de enfoque preventivos, y la promoción de la igualdad de género, la responsabilidad, el diseño universal y la accesibilidad global.

\footnotetext{
74 Si bien el grupo empresarial señaló en su voto particular (página 5 de dicho documento) la conveniencia de excluir la frase “igualmente impulsaran [(referido a las Administraciones Públicas)] políticas de fomento del consumo responsable a través de su actuación en el mercado".
} 
En cuanto a los elementos cuya implementación resulta clave para el fomento del consumo responsable, pueden sintetizarse en los dos siguientes:

i) facilitar la información al consumidor ${ }^{75}$ y contribuir a su libre elección por medio de un etiquetado más sencillo, accesible, comprensible y homogéneo, al tiempo que pertinente, claro y veraz para comunicar las características sociales y ambientales de los productos; y

ii) ofertar bienes y servicios beneficiosos desde el punto de vista tanto social como medioambiental (no sólo reduciendo o minorando efectos negativos, sino también mejorando aspectos de producción y distribución), así como informando a los consumidores (en consonancia con el punto previo) acerca de los pertinentes aspectos en cuanto a desempeño, origen, eficiencia energética, impactos para la salud, cumplimiento de convenios y normativas, etc. de dichos bienes y servicios.

En referencia a los procedimientos de verificación y distintivos de acreditación, cabe señalar que es la parte del documento donde las opiniones de los integrantes del Subgrupo resultan más dispares ${ }^{76}$. Con todo, el acuerdo mayoritario apunta a que, para estimular los avances en el proceso de información, sería deseable que las entidades se sometiesen a procedimientos de verificación por terceros independientes, así como diseñar un distintivo -a modo de señal para los consumidores- identificador de las que son socialmente responsables, eliminando de este modo asimetrías de información y como prueba de la fiabilidad de los datos aportados.

El acuerdo sí es unánime, en cambio, en cuanto a los restantes contenidos del documentos, referidos a los siguientes puntos:

- La gestión de reclamaciones y sugerencias de consumidores y usuarios, siendo la información a este respecto uno de los factores importantes a tener en cuenta de cara a considerar o no socialmente responsables a las entidades que se adhieran al Sistema Arbitral de Consumo.

\footnotetext{
${ }^{75}$ Constatado el hecho de que la falta de información es un problema para el ejercicio del consumo responsable (el consumidor no podría discriminar los productos), así como teniendo en cuenta que el derecho a la información es uno de los derechos básicos de los consumidores, tal y como se recoge en la legislación nacional, y en las directrices de la OCDE y de Naciones Unidas.

${ }^{76}$ Por entender la Secretaría de Estado de Comercio Exterior en ambos casos que se trata de una limitación excesiva al comercio. Por su parte, el grupo empresarial no está a favor de la verificación de los informes argumentando que impide una visión de conjunto de transparencia, porque aquéllos deben ir dirigidos a todos los grupos de interés. Tampoco está de acuerdo en lo tocante al distintivo, sosteniendo que la acreditación de los criterios sociales y medioambientales contiene componentes subjetivos.
} 
- La formación para el consumo, que no deberá perseguir únicamente el objetivo de transferir conocimientos (aspectos de consumo responsable), sino también el de proporcionar conocimientos de la responsabilidad de las organizaciones (permitiendo de esta forma desarrollar habilidades para evaluar y hacer comparaciones).

- Las garantías de calidad, origen y procesos, en referencia a salud y seguridad, reglamentaciones, etiquetado de productos, y otras informaciones sobre características y riesgos de los productos y acerca de otras condiciones socio y medioambientales.

- La accesibilidad y el apoyo a las personas con discapacidad, impulsando el interés por la accesibilidad universal de los entornos, y de los bienes y servicios.

- La política medioambiental y la política social, que han de estar presentes en los planteamientos estratégicos de todo tipo de organizaciones.

- La protección y privacidad de datos, debiéndose comprometer aquellas entidades que disponen de ellos a cumplir la legislación al respecto, y en concreto a especificar el propósito para el que fueron recopilados, a no revelarlos si no existe consentimiento de la persona a quien corresponden, y a identificar a la persona o personas encargadas de implementar y verificar los procedimientos de protección.

- La responsabilidad de los consumidores y los comportamientos individuales de los mismos, asumiendo que pueden contribuir al desarrollo y puesta en práctica de patrones más sostenibles de producción y de consumo.

- La comparación con otros países y entornos, a efectos de difusión de buenas prácticas y comunicación de las acciones de responsabilidad y que puedan servir de ejemplo o como referente para actuaciones futuras.

Por último, el informe elaborado por el Subgrupo de consumo socialmente responsable incluye, a modo de conclusión, una serie de recomendaciones en cuanto a: i) los objetivos a tener en cuenta por las políticas gubernamentales de fomento del consumo responsable (erradicación de la pobreza, satisfacción de las necesidades básicas de los miembros de la sociedad, reducción de la desigualdad); ii) la deseabilidad de que las organizaciones adopten sistemas de verificación de sus informes o memorias de responsabilidad (mejor por terceros independiente); y iii) la también deseabilidad, con el fin de eliminar asimetrías de información, de establecer un sistema identificativo de las organizaciones responsables derivado de esos mismos sistemas de verificación, que incluya un distintivo como referente para los consumidores. 


\subsection{Otras iniciativas e instituciones relevantes en responsabilidad}

Junto a las anteriores, hay toda otra serie de iniciativas encaminadas a promover la responsabilidad, ya sea a nivel estatal o regional, promovidas por distintas instancias e instituciones, alguna de las cuales cuenta, incluso, con respaldo normativo.

\subsubsection{Otras iniciativas públicas estatales}

La progresiva importancia de la responsabilidad ha propiciado un desarrollo normativo paralelo que, en el caso español, ha dado lugar a disposiciones tanto a nivel estatal como regional, entre las que cabe destacar las indicadas a continuación.

a) La Proposición no de Ley sobre Responsabilidad Social de las Empresas, aprobada por el Congreso de los Diputados el 23 de junio de $2009^{77}$, instando al Gobierno a promover la responsabilidad mediante una serie de recomendaciones, como son las de impulsar una gestión socialmente responsable de las Administraciones Públicas, fortalecer la cultura de consumo responsable, incorporar en las actuaciones internacionales de las empresas españolas las prácticas socialmente responsables, favorecer la inversión socialmente responsable, fomentar la transparencia empresarial, potenciar el diálogo de todos los grupos de interés, favorecer la expansión cultural, educativa y formativa en materia de responsabilidad, así como favorecer y coordinar las políticas autonómicas en la materia.

b) La Ley 2/2011, de 4 de marzo, de Economía Sostenible, precepto normativo que, de forma comprensiva, hace referencia a distintos aspectos de las tres facetas de la responsabilidad ${ }^{78}$ : económica (lucha contra el fraude, fomento de la innovación y la competitividad, y de la inversión responsable), medioambiental (desarrollo de un modelo estratégico sostenible, régimen de comercio de derechos de emisión, movilidad sostenible y protección ambiental) y social (necesaria reforma del sistema educativo, del mercado laboral y renovación del modelo productivo, así como fortalecimiento del estado de bienestar en cuanto a dependencia e integración laboral).

\footnotetext{
${ }^{77}$ Presentada por el Grupo Parlamentario Socialista, el texto completo de este documento se encuentra disponible en http://www.congreso.es (consultada en junio de 2012). Se contextualiza en el conjunto de informes y documentos redactados al objeto de sentar las bases o principios de actuación de las Administraciones Públicas, en línea tanto con las recomendaciones del Libro Verde de la Comisión Europea como del Informe de la Subcomisión para Potenciar y Promover la RSE.

${ }^{78}$ En algunos casos planteando cambios sustanciales con respecto a lo que podrían considerarse prácticas habituales hasta ese momento (Ibisate 2011).
} 
Además de lo anterior, la Ley 2/2011 incorpora asimismo algunos artículos que afectan directamente a aspectos concretos de la responsabilidad:

- La sostenibilidad en la gestión de las empresas públicas (art. 35), haciendo hincapié en la labor de fomento de la responsabilidad en el ámbito público, no sólo mediante la elaboración de informes y memorias de sostenibilidad por parte de las sociedades mercantiles estatales y sociedades públicas, para su autoevaluación de acuerdo con los principales estándares internacionales, sino también aplicando medidas de responsabilidad en los procesos de producción, en la cadena de valor, y en los sistemas de contratación pública y consumo energético. Asimismo desarrollando líneas de investigación, desarrollo e innovación que contribuyan a la mejora de los procesos productivos, así como a facilitar la movilidad de los trabajadores y su adaptación a las nuevas tecnología y a la cultura de la sostenibilidad.

- El impulso a la eficiencia en la contratación pública y la financiación de la colaboración público-privada (art. 37) bajo principios de transparencia y buen gobierno corporativo, en los términos previstos en la Ley 30/2007, de 30 de octubre, de Contratos del Sector Público (a la que modifica). En particular, en referencia a los mercados financieros, y derivado de los acuerdos con organismos internacionales respecto a la elaboración de informes anuales y el suministro de información adicional, así como la obligación de realizar un informe detallado sobre las remuneraciones de los miembros de los consejos. Asimismo contemplando partidas específicas para la contratación de actividades innovadoras con pequeñas y medianas empresas responsables (art. 38).

- La promoción de la responsabilidad social de las empresas es objeto de particular consideración en el art. 39, al objeto de difundir el conocimiento y las mejores prácticas existentes, a la vez que de estimular su estudio y análisis. Para ello, se encarga al Consejo Estatal de Responsabilidad Social de las Empresas la elaboración de las recomendaciones necesarias sobre características, indicadores y modelos de reporte necesarios para la autoevaluación de las empresas en materia de responsabilidad, debiendo las sociedades anónimas de más de 1000 trabajadores comunicar expresamente sus informes anuales de responsabilidad (con la finalidad de que el CERSE pueda efectuar un seguimiento adecuado del grado de implantación de las correspondientes políticas en las grandes empresas). Asimismo se incluye la posibilidad de que cualquier empresa solicite ser reconocida como socialmente responsable (art. 39.3), conforme las condiciones determinadas por el CERSE. 


\subsubsection{Iniciativas públicas regionales}

Las Administraciones Regionales y Locales no son ajenas a toda esta situación, sino que, antes al contrario, vienen desempeñando también un papel de primer orden en el desarrollo normativo y en las políticas de promoción de la responsabilidad. Entre tales iniciativas, cabe aludir a las promovidas por distintas Comunidades Autónomas ${ }^{79}$.

a) La Ley 15/2010, de 9 de diciembre, de responsabilidad social empresarial en Extremadura, al objeto de fomentar la actuación responsable de las empresas y las Administraciones Públicas que desarrollen su actividad en esa región. Según se indica en su exposición de motivos, por entender que las iniciativas previas de Gobiernos, instituciones y entidades no habían tenido traducción normativa, si bien "nunca los esfuerzos, las reflexiones y las nobles ideas cayeron en terreno baldío”.

Partiendo de una definición en línea con los pronunciamientos establecidos en el Libro Verde de la Comisión Europea y, a nivel nacional, por el Foro de Expertos en $\mathrm{RSE}^{80}$, la norma precisa las características que debe tener una empresa socialmente responsable ${ }^{81}$. Como principal herramienta para medir el grado de responsabilidad de una entidad, se utilizan sus informes, elaborados conforme a las directrices marcadas por la Global Reporting Initiative, y verificados por entidades especializadas externas (modelo simplificado para las Pymes).

Conforme a ello, podrá ser calificada como "empresa socialmente responsable de la Comunidad Autónoma de Extremadura” por la Consejería competente en materia de trabajo cualquier empresa que voluntariamente lo desee (art. 7) ${ }^{82}$, estableciéndose asimismo precisiones en cuanto a duración, prórroga y revocación de tal calificación

\footnotetext{
79 También se han llevado a cabo numerosas actuaciones en materia de responsabilidad en el ámbito municipal, lo cual determina que no sean aquí relacionadas ni se abunde en cuanto a su amplio y variado contenido. No obstante, procede al menos reconocer su existencia e importancia.

${ }^{80}$ Aunque, ciertamente, con algún matiz propio. En concreto, el art. 3 define las empresas socialmente responsables como aquéllas que "además del cumplimiento estricto de las obligaciones legales vigentes, hayan adoptado la integración voluntaria en su gobierno y gestión, en su estrategia, y en sus políticas y procedimientos, los valores y códigos éticos de las preocupaciones sociales, laborales, medioambientales y de respeto de los derechos humanos que surjan de la relación y el diálogo transparente con sus grupos de interés, responsabilizándose así de las consecuencias y de los impactos que derivan de sus acciones”.

${ }^{81}$ A diferencia de lo que sucede en otros marcos normativos más abstractos, si bien es asimismo cierto que sin indicar los estándares en los que se basa dicha especificación de características.

${ }^{82}$ En tal sentido, y con la finalidad de promover condiciones favorables a la incorporación de principios responsables en las prácticas de gestión de pequeñas y medianas empresas, se constituiría el Observatorio de Responsabilidad Social de Extremadura, cuyo portal web (http://www.rsextremdura.es/) fue concebido como herramienta de ayuda, consulta e intercambio de experiencias, así como instrumento para el análisis, difusión y sensibilización sobre los valores de la responsabilidad, entre la ciudadanía, empresas y el conjunto de agentes sociales de la Comunidad Autónoma.
} 
(art. 8), la creación de un premio para la entidad más destacada (art. 8) ${ }^{83}$, y un Registro de estas entidades (art. 10).

Cabe asimismo señalar que el texto legal extremeño no sólo se refiere a la responsabilidad de las empresas, sino que dedica el título II de su articulado (arts. 13 y ss.) a la responsabilidad en el sector público en el correspondiente ámbito territorial, en cuanto a políticas y actuaciones de fomento de la RSE, información y sensibilización a este respecto, impulso de medidas favorecedoras de la participación, el conocimiento, la mayor implicación y la corresponsabilidad, y el desarrollo sostenible, con particular hincapié en el caso de las pequeñas y medianas entidades empresariales.

Con carácter particular, se hace también referencia al papel y actuaciones de la Junta de Extremadura y sus organismos públicos dependientes (arts. 20 y ss.), como contratantes, consumidores, inversores, empleadores y prestadores de servicios.

b) Aunque sin reflejo normativo, algunas actuaciones en materia de responsabilidad llevadas a cabo por parte de otras Comunidades Autónomas resultan igualmente relevantes ${ }^{84}$. Entre ellas:

- El Gobierno de la Comunidad Balear estableció en 2008 una Dirección General de RSE, primera de estas características en una Comunidad Autónoma española, con el objetivo de impulsar y desarrollar un sistema de responsabilidad social corporativa de empresas en el territorio balear, haciendo especial hincapié en la puesta en marcha de políticas de igualdad en el ámbito laboral. Este organismo fue el anfitrión, en el marco de la Presidencia española de la UE durante el primer semestre de 2010, de la Conferencia Europea de Responsabilidad Social de las Empresas, promovida conjuntamente por la Comisión Europea, el Gobierno de España y el Gobierno Balear.

- La Generalidad de Cataluña aprobó en octubre de 2009 un plan 2009-2012 de medidas de responsabilidad (RSGENCAT) para impulsarla tanto en el ámbito de la propia Administración (a modo de nexo de unión de las actuaciones llevadas a cabo por los diferentes Departamentos), como en las empresas y entidades financieras catalanas. Las medidas contenidas en este plan se encuentran estructuradas en cuatro grandes ejes,

${ }^{83} \mathrm{Al}$ margen de los beneficios en cuanto a concesión de ayudas, incentivos fiscales, prioridad en la adjudicación de contratos y publicidad, contemplados con carácter general para todas las empresas a las que se otorgue dicha calificación (art. 12).

${ }^{84}$ Pudiendo tomarse como referencia a este respecto los datos en cuanto a iniciativas desarrolladas en España de Forética, disponibles en http://www.foretica.org (consultada en junio de 2012). 
como son: i) potenciar la educación, el conocimiento y la difusión de los valores de la responsabilidad social; ii) incrementar el número de acciones emprendidas por las empresas catalanas en esta materia (incluyendo el asesoramiento externo y ayudas directas); iii) fomentar las buenas prácticas en el campo de las finanzas; y iv) mejorar las buenas prácticas en las distintas Administraciones Públicas catalanas.

- Más recientemente, en 2010 la Generalidad de Valencia ha promovido junto con otras entidades la Red Valenciana del Emprendedor y La Economía Social (Red Emprendes), con presencia de los principales organismos que actúan en el campo de la economía social y el emprendimiento en el territorio valenciano. Además, cuenta con la colaboración de otras entidades autonómicas, como el Instituto Valenciano de la Juventud (IVAJ), a efectos de proponer a los jóvenes el modelo de la Economía Social como una opción empresarial alternativa, a través de su red territorial.

\subsubsection{Otras iniciativas relevantes fuera del ámbito público}

Tal y como ya fue previamente señalado, en España también se han producido iniciativas en materia de responsabilidad promovidas por agentes del sector privado o del Tercer Sector (principalmente empresas, sindicatos y sociedad civil), anteriores en el tiempo al inicio propiamente de los recientes e intensos debates a este respecto, e incluso a la actuación pública. Se trata de un amplio y heterogéneo catálogo de iniciativas referidas al análisis, promoción y difusión de la responsabilidad, donde el sector privado prácticamente monopoliza todo el espacio y discurso.

De hecho, tales iniciativas sentarían las bases para que estos agentes pudiesen desempeñar un papel preponderante en los posteriores debates con los representantes de las entidades estatales, sin lo cual los procesos descritos en páginas precedentes hubieran resultado imposibles o, al menos, incompletos. Más aún, estos grupos siguen colaborando activamente en la actualidad en los foros de debate y de discusión sobre la responsabilidad, así como en la realización de informes ${ }^{85}$, documentos, estudios, tareas formativas, etc. Todo ello encaminado a dar respuesta a muchos aspectos en los que, aún hoy en día, se está lejos de alcanzar el deseado consenso.

\footnotetext{
${ }^{85}$ En las páginas 35 y 36 del Informe del Foro de Expertos en Responsabilidad Social Empresarial, y dentro del correspondiente anexo, se enumeran las organizaciones que elaboran regularmente informes sobre la situación de las empresas españolas en materia de responsabilidad.
} 
El impacto de la actuación de estas instancias privadas y sociales crece en la medida que se integran en redes de conocimiento y de buenas prácticas compartidas que permiten un acercamiento y aprendizaje mutuo, puesto que la solución a problemas colectivos pasa en muchos casos -si no en todos- por la colaboración multisectorial (Viñuales y Eguiagaray 2006:32).

Como en tantas otras ocasiones, la pluralidad y heterogeneidad del contenido de estas iniciativas dificulta su clasificación, razón por la que se recurre a alternativas como su procedencia (o principal impulsor) ${ }^{86}$, lo que permite distinguir entre aquellas promovidas por agrupaciones empresariales, por organizaciones de la sociedad civil, y por instituciones académicas.

a) Iniciativas promovidas por agrupaciones empresariales:

Entre las muchas y variadas actuaciones de las agrupaciones empresariales que han contribuido al desarrollo de la responsabilidad en España, cabe mencionar las de la Asociación Española de Contabilidad y Administración de Empresas (AECA), la Asociación Española de Normalización y Certificación (AENOR), la Asociación Española del Pacto Mundial de las Naciones Unidas (ASEPAM), el Club de Excelencia en Sostenibilidad, la Confederación Empresarial Española de Economía Social (CEPES), la sección nacional de la European Business Ethics Network (EBEN España), Forética, la Fundación Empresa y Sociedad, y la Fundación Entorno.

En el Cuadro 3.2 se incluye una relación alfabética de estas entidades, indicándose asimismo las principales características y los aspectos más destacables de sus iniciativas.

b) Iniciativas promovidas por organizaciones de la sociedad civil:

En idéntico sentido al anterior cabe reseñar la labor de diferentes organizaciones de la sociedad civil. Como muestra el Cuadro 3.3, entre ellas, y por orden alfabético, se encuentran el Foro de Inversión Socialmente Responsable (SpainSif), el Foro RSE Navarra, la Fundación Ecología y Desarrollo (ECODES), la Fundación Ética de los Negocios y de las Organizaciones (ÉTNOR), la Fundación SERES, Iniciativas de Economía Alternativa y Solidaria (IDEAS), el Observatorio de la RSE de UGT, el Observatorio de RSC, y el Observatorio de la Sostenibilidad en España (OSE).

\footnotetext{
${ }^{86}$ Por ejemplo, conforme a las indicaciones para la agrupación de las mimas en los Anuarios sobre Responsabilidad Social Empresarial en España elaborados por la Fundación Ecología y Desarrollo y por la Fundación Alternativas.
} 
c) Iniciativas promovidas por instituciones académicas:

Un tercer grupo de iniciativas son las que han sido promovidas desde el ámbito académico, ya sea a nivel institucional (como filosofía o pauta de actuación en sus procedimientos de gestión), o ya sea impartiendo los correspondiente estudios o por medio de la constitución y actuación de las correspondientes cátedras especializadas.

Conforme se muestra en el Cuadro 3.4, y a título de ejemplo ${ }^{87}$, entre estas iniciativas se encuentran las de ESADE, IE Business School, IESE Business School, la Universidad de Alcalá de Henares, la Universidad de Málaga, la Universidad de Murcia, la Universidad Nacional de Educación a Distancia (UNED), la Universidad Politécnica de Cartagena, y la Universidad Pontificia de Comillas.

\section{Cuadro 3.2. Agrupaciones empresariales con actuaciones destacadas en materia de responsabilidad en España}

\begin{tabular}{|c|c|c|}
\hline Entidad & Perfil / carácter & Aspectos destacables de su actuación \\
\hline $\begin{array}{c}\text { Asociación } \\
\text { Española de } \\
\text { Contabilidad y } \\
\text { Administración } \\
\text { de Empresas } \\
\text { (AECA) } \\
\text { http://www.aeca.es/ }\end{array}$ & $\begin{array}{l}\text { En línea con su objetivo de } \\
\text { mejora continua del nivel de } \\
\text { competencia y conocimientos } \\
\text { de los profesionales de la } \\
\text { empresa, asume como área de } \\
\text { estudio e investigación todos } \\
\text { los aspectos relacionados con } \\
\text { la responsabilidad social } \\
\text { corporativa }\end{array}$ & $\begin{array}{l}\text { Creación de una Comisión de Estudio para } \\
\text { promover el comportamiento socialmente } \\
\text { responsable de las organizaciones, desde el } \\
\text { estudio y la investigación científica, así } \\
\text { como un foro cualificado de primer nivel, en } \\
\text { el que poder debatir sobre los temas } \\
\text { fundamentales de la misma, impulsando su } \\
\text { desarrollo conceptual y su implantación } \\
\text { generalizada en las organizaciones, todo ello } \\
\text { con la vocación de alcanzar la categoría de } \\
\text { referencia obligada en la materia, tanto a } \\
\text { nivel nacional como internacional }\end{array}$ \\
\hline $\begin{array}{l}\text { Asociación } \\
\text { Española de } \\
\text { Normalización y } \\
\text { Certificación } \\
\text { (AENOR) } \\
\text { http://www.aenor.es/ }\end{array}$ & $\begin{array}{c}\text { Constituida en 1986, para } \\
\text { contribuir a la mejora de la } \\
\text { calidad y la competitividad de } \\
\text { las empresas, sus bienes y } \\
\text { servicios. Aporta su } \\
\text { experiencia e información en } \\
\text { materia de normalización. } \\
\text { Tiene } 21 \text { sedes en España, y } \\
\text { otras } 13 \text { en Iberoamérica y } \\
\text { Europa }\end{array}$ & $\begin{array}{l}\text { Elaboración del documento técnico en el que } \\
\text { se contiene el desarrollo de la especificación } \\
\text { RS 10, estableciendo los requisitos para la } \\
\text { implantación de un sistema integrado de } \\
\text { gestión de la Responsabilidad Social (RS) en } \\
\text { las organizaciones empresariales. Destaca } \\
\text { por ser una herramienta pionera en materia } \\
\text { de responsabilidad, compatible e integrable } \\
\text { con otras herramientas y sistemas de gestión } \\
\text { de la calidad -como la norma ISO 9001-, de } \\
\text { gestión medioambiental -como la norma ISO } \\
\text { 14001-, a la vez que incorpora indicaciones } \\
\text { de textos aceptados mundialmente, como la } \\
\text { norma ISO } 26000\end{array}$ \\
\hline
\end{tabular}

(continúa...)

\footnotetext{
${ }^{87}$ Pues hoy en día rara es la institución académica (podría decirse que ninguna) que no incorpora en mayor o menor medida cuestiones relacionadas con la responsabilidad y la sostenibilidad en sus planes de estudios y/o no las incluye en las competencias de alguna de sus unidades estructurales.
} 


\section{Cuadro 3.2. Agrupaciones empresariales con actuaciones destacadas en materia de responsabilidad en España (...continuación)}

\begin{tabular}{|c|c|c|}
\hline Entidad & Perfil / carácter & Aspectos destacables de su actuación \\
\hline $\begin{array}{c}\text { Asociación } \\
\text { Española del } \\
\text { Pacto Mundial de } \\
\text { Naciones Unidas } \\
\text { (ASEPAM) } \\
\text { http://www.pactomun } \\
\text { dial.org/ }\end{array}$ & $\begin{array}{l}\text { Constituida en 2004, es una de } \\
\text { las primeras plataformas } \\
\text { nacionales del Pacto Mundial, } \\
\text { así como una de las más } \\
\text { activas. Agrupa a empresas, } \\
\text { ONGs, sindicatos, } \\
\text { instituciones académicas y } \\
\text { organismos sociales. Desde } \\
2008 \text { ha pasado a denominarse } \\
\text { Red Española del Pacto } \\
\text { Mundial de Naciones Unidas }\end{array}$ & $\begin{array}{l}\text { Desarrollo de actividades orientadas a } \\
\text { apoyar, promover y difundir conductas } \\
\text { responsables y, específicamente, la } \\
\text { incorporación de los diez principios que } \\
\text { integran el Pacto Mundial de Naciones } \\
\text { Unidas en la visión estratégica de las } \\
\text { empresas españolas y su práctica diaria. En } \\
\text { el primer año desde la constitución de la } \\
\text { Asociación, el número de instituciones } \\
\text { firmantes del Pacto Mundial paso de } 270 \text { a } \\
\text { 360, siendo ya más de } 1000 \text { en la actualidad }\end{array}$ \\
\hline $\begin{array}{c}\text { Club de } \\
\text { Excelencia en } \\
\text { Sostenibilidad } \\
\text { http://www.clubsoste } \\
\text { nibilidad.org/ }\end{array}$ & $\begin{array}{l}\text { Constituido por grandes } \\
\text { empresas que apuestan por el } \\
\text { crecimiento sostenible desde el } \\
\text { punto de vista económico, } \\
\text { social y medioambiental, como } \\
\text { foro de diálogo con } \\
\text { stakeholders, plataforma de } \\
\text { becnhmarking y difusión de } \\
\text { buenas prácticas en materia de } \\
\text { responsabilidad y desarrollo } \\
\text { sostenible }\end{array}$ & $\begin{array}{l}\text { Desarrollo conjunto, con KPMG y la GRI, y } \\
\text { con el apoyo del Ministerio de Trabajo e } \\
\text { Inmigración, de una plataforma web que } \\
\text { recoge los informes de responsabilidad } \\
\text { corporativa y sostenibilidad de las empresas } \\
\text { españolas, permitiendo analizar el nivel de } \\
\text { transparencia y realizar comparaciones según } \\
\text { criterios de sector, tamaño y/o ubicación. } \\
\text { Elaboración de estudios y publicaciones, } \\
\text { como dos informes sobre la situación y } \\
\text { tendencias del consumo responsable en } \\
\text { España, en } 2008 \text { y 2012, respectivamente }\end{array}$ \\
\hline $\begin{array}{l}\text { Confederación } \\
\text { Empresarial } \\
\text { Española de } \\
\text { Economía Social } \\
\text { (CEPES) } \\
\text { http://www.cepes.es/ }\end{array}$ & $\begin{array}{l}\text { Constituida en } 1992 \text { como } \\
\text { confederación empresarial de } \\
\text { ámbito nacional, su } \\
\text { composición multisectorial la } \\
\text { convierte en la institución más } \\
\text { representativa de la Economía } \\
\text { Social en España. En base a } \\
\text { ello, actúa como plataforma de } \\
\text { diálogo institucional con los } \\
\text { poderes públicos }\end{array}$ & $\begin{array}{l}\text { Realización de numerosas actividades con el } \\
\text { objetivo o denominador fundamental de } \\
\text { fomentar y defender la Economía Social y } \\
\text { los movimientos y sectores que la integran, } \\
\text { así como de trasladar al conjunto de la } \\
\text { sociedad -en general- y al mundo } \\
\text { empresarial -en particular- la necesidad de } \\
\text { adoptar formas de hacer empresa que sean } \\
\text { socialmente responsables y con valores } \\
\text { específicos }\end{array}$ \\
\hline $\begin{array}{l}\text { EBEN España } \\
\text { http://www.eben- } \\
\text { spain.org/ }\end{array}$ & $\begin{array}{l}\text { Es la rama española de la } \\
\text { European Business Ethics } \\
\text { Network (EBEN), asociación } \\
\text { de ámbito europeo establecida } \\
\text { en } 1987 \text { para fomentar el } \\
\text { estudio y la aplicación de la } \\
\text { ética en las organizaciones, los } \\
\text { negocios y la economía }\end{array}$ & $\begin{array}{l}\text { Materialización de acciones y actividades } \\
\text { dirigidas a sus miembros, y participando de } \\
\text { la común aspiración de reconocer la } \\
\text { necesidad de implementar aspectos éticos en } \\
\text { la sociedad y la empresa. A tal fin, se han } \\
\text { elaborado estudios y publicaciones, así como } \\
\text { realizado congresos y otros eventos } \\
\text { vinculados a la responsabilidad }\end{array}$ \\
\hline $\begin{array}{c}\text { Forética } \\
\text { http://www.foretica. } \\
\text { org/ }\end{array}$ & $\begin{array}{l}\text { Desde su constitución en } 1999 \\
\text { tiene un papel clave en la } \\
\text { difusión de la RSE, aportando } \\
\text { soluciones innovadoras ante } \\
\text { los retos de la gestión ética en } \\
\text { foros de decisión a nivel tanto } \\
\text { nacional como internacional }\end{array}$ & $\begin{array}{l}\text { Autoría de la Norma de Empresa SGE21, } \\
\text { primer sistema gestor de la responsabilidad } \\
\text { social europeo, que permite auditar procesos } \\
\text { y lograr una certificación en Gestión Ética y } \\
\text { Responsabilidad Social. Participación en el } \\
\text { Comité Técnico de la Norma ISO } 26000 . \\
\text { Publicación de informes sobre la evolución } \\
\text { de la responsabilidad social de las empresas } \\
\text { en España }\end{array}$ \\
\hline
\end{tabular}




\section{Cuadro 3.2. Agrupaciones empresariales con actuaciones destacadas en materia de responsabilidad en España (...continuación)}

\begin{tabular}{|c|c|l|}
\hline Entidad & Perfil / carácter & \multicolumn{1}{c|}{ Aspectos destacables de su actuación } \\
\hline $\begin{array}{c}\text { Fundación } \\
\text { Empresa y } \\
\text { Sociedad } \\
\text { http://www.empresay } \\
\text { sociedad.org/ }\end{array}$ & $\begin{array}{c}\text { Constituida como fundación } \\
\text { en 1995, tiene la misión de } \\
\text { promover la integración de la } \\
\text { acción social en las estrategias } \\
\text { de las empresas }\end{array}$ & $\begin{array}{l}\text { Realización de actividades de fomento y } \\
\text { apoyo a la canalización de recursos de las } \\
\text { empresas para la puesta en marcha de } \\
\text { proyectos relacionados con la mejora del } \\
\text { bienestar social de individuos o colectivos } \\
\text { desfavorecidos }\end{array}$ \\
\hline $\begin{array}{c}\text { Fundación } \\
\text { Entorno - Consejo } \\
\text { Social Español } \\
\text { para el Desarrollo } \\
\text { Sostenible } \\
\text { http://www.fundacion } \\
\text { entorno.org/ }\end{array}$ & $\begin{array}{c}\text { Organización privada sin } \\
\text { las empresas a afrontar el reto } \\
\text { del desarrollo sostenible como } \\
\text { oportunidad de negocio, } \\
\text { compartiendo conocimientos y } \\
\text { haciendo llegar el mensaje a } \\
\text { Gobiernos y otras entidades }\end{array}$ & $\begin{array}{l}\text { Actuación desde 2006 como Punto Regional } \\
\text { del Consejo Empresarial Mundial para el } \\
\text { Desarrollo Sostenible (WBCSD), pasando a } \\
\text { denominarse Fundación Entorno-BCSD } \\
\text { España. Participación activa en varios clubs } \\
\text { de debate y publicación de 5 ediciones del } \\
\text { "Informe Entorno sobre la gestión de la } \\
\text { sostenibilidad en la empresa española” }\end{array}$ \\
\hline
\end{tabular}

Fuente: Elaboración propia en base a los contenidos de las páginas web.

\section{Cuadro 3.3. Organizaciones de la sociedad civil con actuaciones destacadas en materia de responsabilidad en España}

\begin{tabular}{|c|c|c|}
\hline Entidad & Perfil / carácter & Aspectos destacables de su actuación \\
\hline $\begin{array}{c}\text { Foro de Inversión } \\
\text { Socialmente } \\
\text { Responsable } \\
\text { (SPAINSIF) } \\
\text { http://www.spainsif. } \\
\text { es/ }\end{array}$ & $\begin{array}{l}\text { Asociación sin ánimo de lucro } \\
\text { fundada como plataforma por } \\
32 \text { entidades interesadas en } \\
\text { promover la inversión } \\
\text { socialmente responsable en } \\
\text { España. Agrupa entidades } \\
\text { financieras y gestoras, } \\
\text { proveedores de servicios ISR, } \\
\text { organizaciones sin ánimo de } \\
\text { lucro y sindicatos }\end{array}$ & $\begin{array}{l}\text { Realización de actividades de difusión de los } \\
\text { principios orientadores de la inversión } \\
\text { socialmente responsable, entre las que } \\
\text { destacan diferentes campañas educativas y/o } \\
\text { informativas. Elaboración de publicaciones y } \\
\text { prestación de servicios relacionados con la } \\
\text { ISR, así como desarrollo de proyectos de } \\
\text { investigación con universidades, escuelas de } \\
\text { negocios y otras instituciones educativas. } \\
\text { Fomento de la cooperación con la red } \\
\text { internacional de SIF }\end{array}$ \\
\hline $\begin{array}{c}\text { Foro RSE } \\
\text { Navarra } \\
\text { http://www.portalso } \\
\text { cialnavarra.org/ }\end{array}$ & $\begin{array}{l}\text { Resultado de la colaboración } \\
\text { de tres organizaciones } \\
\text { coordinadoras (Fundación } \\
\text { Centro de Recursos } \\
\text { Ambientales de Navarra, } \\
\text { Fundación Gaztelan, y } \\
\text { Departamento de Gestión de } \\
\text { Empresas de la Universidad } \\
\text { Pública de Navarra) }\end{array}$ & $\begin{array}{l}\text { Difusión de los principios orientadores de la } \\
\text { inversión socialmente responsable y de las } \\
\text { prácticas asociadas a los mismos, así como } \\
\text { prestación de servicios e impulso de } \\
\text { proyectos de investigación en la materia } \\
\text { (llevados a cabo en particular por medio del } \\
\text { Departamento que participa en la } \\
\text { coordinación del Foro), resultado de los } \\
\text { cuales son diversas publicaciones } \\
\text { especializadas en la materia }\end{array}$ \\
\hline
\end{tabular}




\section{Cuadro 3.3. Organizaciones de la sociedad civil con actuaciones destacadas en materia de responsabilidad en España (...continuación)}

\begin{tabular}{|c|c|c|}
\hline Entidad & Perfil / carácter & Aspectos destacables de su actuación \\
\hline $\begin{array}{c}\text { Fundación } \\
\text { Ecología y } \\
\text { Desarrollo } \\
\text { (ECODES) } \\
\text { http://www.ecodes. } \\
\text { org/ }\end{array}$ & $\begin{array}{l}\text { Organización independiente } \\
\text { que actúa en favor del } \\
\text { desarrollo sostenible en su } \\
\text { triple dimensión económica, } \\
\text { social y medioambiental } \\
\text { promoviendo un papel activo } \\
\text { de las empresas }\end{array}$ & $\begin{array}{l}\text { Colaboración con otros actores sociales en } \\
\text { acciones de promoción del desarrollo } \\
\text { sostenible y cambio social. Elaboración de } \\
\text { diferentes publicaciones en las que se ponen } \\
\text { de manifiesto los incentivos no sólo éticos, } \\
\text { sino también económicos, a la actuación } \\
\text { responsable de las empresas }\end{array}$ \\
\hline $\begin{array}{l}\text { Fundación Ética } \\
\text { de los Negocios y } \\
\text { de las } \\
\text { Organizaciones } \\
\text { (ÉTNOR) } \\
\text { http://www.etnor.org/ }\end{array}$ & $\begin{array}{l}\text { Organización sin ánimo de } \\
\text { lucro que surge en } 1991 \text { para } \\
\text { promover el reconocimiento, } \\
\text { la difusión y el respeto de los } \\
\text { valores éticos implícitos en la } \\
\text { actividad económica y la } \\
\text { realidad de las organizaciones } \\
\text { de todos los sectores }\end{array}$ & $\begin{array}{l}\text { Autoría de un buen número de publicaciones } \\
\text { sobre ética y responsabilidad social. Ha } \\
\text { promovido la primera red wiki especializada } \\
\text { en ética y responsabilidad social de la } \\
\text { empresa, implementada con el fin de } \\
\text { elaborar una enciclopedia temática básica } \\
\text { que constituya un referente a disposición de } \\
\text { empresas, entidades públicas y del tercer } \\
\text { sector, y, en general, de cualquier agente } \\
\text { interesado }\end{array}$ \\
\hline $\begin{array}{c}\text { Fundación } \\
\text { SERES } \\
\text { http://www.fundacion } \\
\text { seres.org/ }\end{array}$ & $\begin{array}{l}\text { Constituida en } 2009 \text { al objeto } \\
\text { de consolidarse como } \\
\text { plataforma de acción social } \\
\text { para empresas y otros actores, } \\
\text { a través de la innovación, } \\
\text { transmisión de conocimientos } \\
\text { y buenas prácticas }\end{array}$ & $\begin{array}{l}\text { Realización, en colaboración con } \\
\text { McKinsey\&Co, de una herramienta de } \\
\text { gestión para que las organizaciones puedan } \\
\text { clasificar y valorar proyectos de RSC, } \\
\text { permitiendo una mejor selección de } \\
\text { actividades, en función de su impacto } \\
\text { positivo en el crecimiento, la gestión del } \\
\text { riesgo y el retorno de capital }\end{array}$ \\
\hline $\begin{array}{l}\text { Iniciativas de } \\
\text { Economía } \\
\text { Alternativa y } \\
\text { Solidaria } \\
\text { (IDEAS) } \\
\text { http://www.ideas. } \\
\text { coop/ }\end{array}$ & $\begin{array}{l}\text { Organización cooperativa de } \\
\text { comercio justo cuyo objetivo } \\
\text { es transformar el entorno } \\
\text { económico y social a fin de } \\
\text { construir un mundo más justo } \\
\text { y sostenible, mediante la } \\
\text { promoción del comercio justo, } \\
\text { la economía solidaria y el } \\
\text { consumo responsable, a nivel } \\
\text { nacional e internacional }\end{array}$ & $\begin{array}{l}\text { Elaboración de herramientas de análisis de la } \\
\text { conducta organizativa mediante la difusión } \\
\text { pública de investigaciones sobre diferentes } \\
\text { sectores económicos y marcas comerciales } \\
\text { llevadas a cabo a través de su Observatorio } \\
\text { para un Comercio Justo. Realización de } \\
\text { actividades de consultoría, formación y } \\
\text { asistencia técnica para el desarrollo de } \\
\text { nuevos productos y la mejora de la calidad } \\
\text { mediante talleres y cursos de capacitación en } \\
\text { países del Sur }\end{array}$ \\
\hline $\begin{array}{l}\text { Observatorio de la } \\
\text { RSE de UGT } \\
\text { http://www.observato } \\
\text { rio-rse.org.es/ }\end{array}$ & $\begin{array}{l}\text { Entidad constituida con el } \\
\text { propósito de llevar a cabo el } \\
\text { seguimiento sistemático y el } \\
\text { análisis de las estrategias, } \\
\text { políticas y prácticas } \\
\text { relacionadas con la } \\
\text { responsabilidad en las } \\
\text { empresas españolas }\end{array}$ & $\begin{array}{l}\text { Realización de estudios en cuanto a } \\
\text { evaluación y análisis comparado de prácticas } \\
\text { responsables en las empresas, al objeto de } \\
\text { facilitar la labor de los investigadores y la } \\
\text { difusión de datos e informaciones relevantes } \\
\text { sobre la forma en que las empresas } \\
\text { incorporan los principios de responsabilidad, } \\
\text { tanto de cara aquéllos como a la opinión } \\
\text { pública en general }\end{array}$ \\
\hline
\end{tabular}


Cuadro 3.3. Organizaciones de la sociedad civil con actuaciones destacadas en materia de responsabilidad en España (...continuación)

\begin{tabular}{|c|c|c|}
\hline Entidad & Perfil / carácter & Aspectos destacables de su actuación \\
\hline $\begin{array}{l}\text { Observatorio de } \\
\text { RSC } \\
\text { http://www.observato } \\
\text { riorsc. org/ }\end{array}$ & $\begin{array}{l}\text { Asociación integrada por } 15 \\
\text { organizaciones de la sociedad } \\
\text { civil (ONGs, sindicatos y } \\
\text { organizaciones de } \\
\text { consumidores), como } \\
\text { plataforma de sensibilización } \\
\text { para fomentar la participación } \\
\text { y cooperación entre } \\
\text { organizaciones }\end{array}$ & $\begin{array}{l}\text { Elaboración de publicaciones por parte de } \\
\text { sus miembros, como el informe “La opinión } \\
\text { y valoración de los consumidores de la } \\
\text { responsabilidad social de la empresa en } \\
\text { España” (2004, 2006, 2008 y 2010) de la } \\
\text { Confederación Española de Consumidores y } \\
\text { Usuarios (CECU), o directamente por el } \\
\text { Observatorio, como el estudio “La } \\
\text { responsabilidad social corporativa en las } \\
\text { memorias anuales de las empresas del IBEX } \\
35 \text { ” (siete ediciones hasta 2011). Autoría de } \\
\text { la norma SGE21, sistema de gestión ética y } \\
\text { socialmente responsable. Otro de sus } \\
\text { miembros, la Fundación Luis Vives, } \\
\text { promueve desde 2009 la Revista de } \\
\text { Responsabilidad Social de la Empresa }\end{array}$ \\
\hline $\begin{array}{l}\text { Observatorio de la } \\
\text { Responsabilidad } \\
\text { en España (OSE) } \\
\text { http://www.sostenibili } \\
\text { dad-es.org/ }\end{array}$ & $\begin{array}{c}\text { Organismo independiente } \\
\text { constituido en } 2005 \text { mediante } \\
\text { un convenio de colaboración } \\
\text { entre el Ministerio de Medio } \\
\text { Ambiente y Medio Rural y } \\
\text { Marino, la Fundación } \\
\text { Biodiversidad y la Fundación } \\
\text { General de la Universidad de } \\
\text { Alcalá }\end{array}$ & $\begin{array}{l}\text { Elaboración del “Informe anual de } \\
\text { sostenibilidad en España”, así como de uno } \\
\text { o más informes temáticos anuales sobre } \\
\text { cuestiones de especial relevancia en relación } \\
\text { con la sostenibilidad en cualquiera de sus } \\
\text { dimensiones medioambiental, económica, } \\
\text { social, territorial, institucional, global y/o } \\
\text { cultural (como los cambios de ocupación del } \\
\text { suelo en España, calidad del aire y del agua, } \\
\text { o la sostenibilidad local) }\end{array}$ \\
\hline
\end{tabular}

Fuente: Elaboración propia en base a los contenidos de las páginas web.

\section{Cuadro 3.4. Ejemplos de instituciones académicas con actuaciones destacadas en materia de responsabilidad en España}

\begin{tabular}{|c|c|l|}
\hline Entidad & \multicolumn{1}{|c|}{ Perfil / carácter } & \multicolumn{1}{c|}{ Aspectos destacables de su actuación } \\
\hline ESADE & $\begin{array}{c}\text { Escuela de negocios de la } \\
\text { Universidad Ramón Llull, en } \\
\text { cuyo ideario figura la } \\
\text { formación de personas con alto } \\
\text { nivel de competencia } \\
\text { profesional y plena } \\
\text { consciencia de la } \\
\text { responsabilidad social }\end{array}$ & $\begin{array}{l}\text { Entre sus unidades de investigación se } \\
\text { encuentra el Instituto de Innovación Social, } \\
\text { cuyo trabajo se centra fundamentalmente en } \\
\text { las relaciones y prácticas de cooperación } \\
\text { entre ONGs y empresas. A través del mismo } \\
\text { realiza una amplia actividad de formación, } \\
\text { investigación y divulgación en los campos de } \\
\text { la responsabilidad social empresarial y de la } \\
\text { ética en los negocios }\end{array}$ \\
\hline
\end{tabular}




\section{Cuadro 3.4. Ejemplos de instituciones académicas con actuaciones destacadas en materia de responsabilidad en España (...continuación)}

\begin{tabular}{|c|c|c|}
\hline Entidad & Perfil / carácter & Aspectos destacables de su actuación \\
\hline $\begin{array}{l}\text { IE Business } \\
\text { School } \\
\text { http://www.ie.edu/ }\end{array}$ & $\begin{array}{l}\text { Escuela de negocios } \\
\text { especializada en las áreas de } \\
\text { gestión y jurídica de la } \\
\text { empresa, la cual integra } \\
\text { criterios de RSE tanto en las } \\
\text { tareas de enseñanza e } \\
\text { investigación como en la } \\
\text { propia gestión de la entidad }\end{array}$ & $\begin{array}{l}\text { Al margen de la integración de principios } \\
\text { responsables en su gestión, cuenta con una } \\
\text { Cátedra de Ética Corporativa, y con un } \\
\text { Departamento de Gestión del Impacto } \\
\text { Social. Sus líneas de conocimiento incluyen } \\
\text { responsabilidad corporativa, creación de } \\
\text { empresas de economía social, inversión } \\
\text { social, filantropía estratégica/efectiva, y } \\
\text { desarrollo sostenible }\end{array}$ \\
\hline $\begin{array}{l}\text { IESE Business } \\
\text { School } \\
\text { http://www.iese.edu/ }\end{array}$ & $\begin{array}{l}\text { Escuela de dirección de } \\
\text { empresas de la Universidad de } \\
\text { Navarra, cuya filosofía de } \\
\text { actuación incluye una } \\
\text { particular atención a las } \\
\text { cuestiones relacionadas con la } \\
\text { responsabilidad social de la } \\
\text { empresa, a fin de proporcionar } \\
\text { respuestas válidas a la } \\
\text { comunidad empresarial }\end{array}$ & $\begin{array}{l}\text { Destacado número de investigaciones y } \\
\text { publicaciones en líneas de trabajo como el } \\
\text { papel de la empresa en la sociedad, la } \\
\text { integración de la responsabilidad social en el } \\
\text { gobierno de las empresas, su difusión a } \\
\text { través de las estructuras organizativas, la } \\
\text { responsabilidad social en las empresas } \\
\text { españolas, los fundamentos de la ética } \\
\text { empresarial y responsabilidad social } \\
\text { corporativa, o las relaciones entre empresas y } \\
\text { otros agentes en esta materia }\end{array}$ \\
\hline $\begin{array}{l}\text { Universidad de } \\
\text { Alcalá de Henares } \\
\text { http://www.csruah.es/ }\end{array}$ & $\begin{array}{l}\text { Universidad pública que } \\
\text { incluye entre sus actividades } \\
\text { de docencia e investigación } \\
\text { cuestiones relacionadas con la } \\
\text { responsabilidad organizativa }\end{array}$ & $\begin{array}{l}\text { La Cátedra de RSC realiza actividades } \\
\text { docentes, de investigación y difusión en el } \\
\text { ámbito de la ética empresarial, tanto desde } \\
\text { una perspectiva básica o general, como } \\
\text { aplicada (estudio de casos y aplicaciones } \\
\text { sectoriales). Desde } 2007 \text { promueve un } \\
\text { máster especializado en RSE }\end{array}$ \\
\hline $\begin{array}{l}\text { Universidad de } \\
\text { León } \\
\text { http://www.unileon.es/ }\end{array}$ & $\begin{array}{l}\text { Universidad pública que } \\
\text { incluye entre sus actividades } \\
\text { de docencia e investigación } \\
\text { cuestiones relacionadas con la } \\
\text { responsabilidad organizativa }\end{array}$ & $\begin{array}{l}\text { Al margen de las actividades de docencia e } \\
\text { investigación en la materia, incluye en su } \\
\text { estructura Áreas cuyas funciones están } \\
\text { directamente relacionadas con diferentes } \\
\text { aspectos de la misma, como la de } \\
\text { Responsabilidad Social e Igualdad, la de } \\
\text { Cooperación al Desarrollo, la de Calidad } \\
\text { Ambiental y Universidad Saludable, y una } \\
\text { Oficina Verde REUS (Red Española de } \\
\text { Universidades Saludables) }\end{array}$ \\
\hline $\begin{array}{l}\text { Universidad de } \\
\text { Málaga } \\
\text { http://www.observato } \\
\text { rio-rse.org.es/ }\end{array}$ & $\begin{array}{l}\text { Universidad pública que } \\
\text { incluye entre sus actividades } \\
\text { de docencia e investigación } \\
\text { cuestiones relacionadas con la } \\
\text { responsabilidad organizativa }\end{array}$ & $\begin{array}{l}\text { En colaboración con la Consejería de } \\
\text { Empleo de la Junta de Andalucía y el } \\
\text { Ayuntamiento de Málaga, dispone de una } \\
\text { Cátedra de Prevención-RSC, cuyas } \\
\text { actividades docentes, de investigación, } \\
\text { difusión y divulgación están vinculadas a la } \\
\text { seguridad y salud en el trabajo y a otros } \\
\text { aspectos de la responsabilidad }\end{array}$ \\
\hline
\end{tabular}




\section{Cuadro 3.4. Ejemplos de instituciones académicas con actuaciones destacadas en materia de responsabilidad en España (...continuación)}

\begin{tabular}{|c|c|c|}
\hline Entidad & Perfil / carácter & Aspectos destacables de su actuación \\
\hline $\begin{array}{l}\text { Universidad de } \\
\text { Murcia } \\
\text { http://www.um.es/ }\end{array}$ & $\begin{array}{l}\text { Universidad pública que } \\
\text { incluye entre sus actividades } \\
\text { de docencia e investigación } \\
\text { cuestiones relacionadas con la } \\
\text { responsabilidad organizativa }\end{array}$ & $\begin{array}{l}\text { Junto a otras actividades de docencia e } \\
\text { investigación, la Cátedra de Responsabilidad } \\
\text { Social Corporativa, cuya constitución fue } \\
\text { fruto de un acuerdo con la Consejería de } \\
\text { Educación, Formación y Empleo de la } \\
\text { Comunidad de Murcia, realiza actividades de } \\
\text { formación, difusión, promoción y } \\
\text { sensibilización, así como de intercambio de } \\
\text { conocimientos y buenas prácticas en la } \\
\text { materia }\end{array}$ \\
\hline $\begin{array}{c}\text { Universidad } \\
\text { Nacional de } \\
\text { Educación a } \\
\text { Distancia } \\
\text { (UNED) } \\
\text { http://www.rsc.uned. } \\
\text { es/ }\end{array}$ & $\begin{array}{l}\text { Universidad pública que } \\
\text { incluye entre sus actividades } \\
\text { de docencia e investigación } \\
\text { cuestiones relacionadas con la } \\
\text { responsabilidad organizativa }\end{array}$ & $\begin{array}{l}\text { Desde 2004, y en colaboración con la } \\
\text { Universidad Jaime I de Castellón, organiza } \\
\text { un máster interuniversitario en sostenibilidad } \\
\text { y RSC, del que es la entidad coordinadora. } \\
\text { Desde } 2012 \text { cuenta además con la Cátedra } \\
\text { UNED-Telefónica de Responsabilidad } \\
\text { Corporativa y Sostenibilidad, que funciona a } \\
\text { modo de laboratorio de ideas y proyectos de } \\
\text { innovación social y generar y transmitir } \\
\text { conocimiento de calidad en la materia, } \\
\text { centrando en gran medida su investigación } \\
\text { en el sector de las tecnologías de la } \\
\text { información y de las comunicaciones, y } \\
\text { abordando temas como la gestión, la } \\
\text { medición o la valoración de responsabilidad }\end{array}$ \\
\hline $\begin{array}{c}\text { Universidad } \\
\text { Politécnica de } \\
\text { Cartagena } \\
\text { http://www.catedrace } \\
\text { de.es/ }\end{array}$ & $\begin{array}{l}\text { Universidad pública que } \\
\text { incluye entre sus actividades } \\
\text { de docencia e investigación } \\
\text { cuestiones relacionadas con la } \\
\text { responsabilidad organizativa }\end{array}$ & $\begin{array}{l}\text { Desde 2010, la Cátedra de Cultura y Ética } \\
\text { Directiva y Empresarial analiza las } \\
\text { relaciones entre ética y economía en el } \\
\text { ámbito organizativo y profundiza en su } \\
\text { aplicación en la empresa desde una } \\
\text { perspectiva teórica y aplicada, desarrollada } \\
\text { sobre cuatro ejes estratégicos fundamentales: } \\
\text { investigación, formación, divulgación y } \\
\text { relaciones externas }\end{array}$ \\
\hline $\begin{array}{l}\text { Universidad } \\
\text { Pontificia de } \\
\text { Comillas } \\
\text { http://www.upcomillas } \\
\text {.es/ }\end{array}$ & $\begin{array}{l}\text { Universidad privada que } \\
\text { incluye entre sus actividades } \\
\text { de docencia e investigación } \\
\text { cuestiones relacionadas con la } \\
\text { responsabilidad organizativa }\end{array}$ & $\begin{array}{l}\text { Desde 2002, la Cátedra de Ética Económica } \\
\text { y Empresarial, dependiente de la Facultad de } \\
\text { Ciencias Económicas y Empresariales } \\
\text { (ICADE) viene llevando a cabo actividades, } \\
\text { actuando como un foro de reflexión, debate e } \\
\text { investigación sobre temas relacionados con } \\
\text { la ética empresarial, la responsabilidad social } \\
\text { de las empresas y la ciudadanía empresarial. } \\
\text { Las actividades de la Cátedra están } \\
\text { encaminadas a servir de punto de encuentro } \\
\text { entre académicos, empresarios, directivos y } \\
\text { otros profesionales }\end{array}$ \\
\hline
\end{tabular}

Fuente: Elaboración propia en base a los contenidos de las páginas web. 
3.3.4. Datos y resultados a partir de los estudios e investigaciones realizados fuera del ámbito público

Siendo ya de por sí harto difícil reflejar de forma exhaustiva a todos los actores que fuera del ámbito público han contribuido al desarrollo de la responsabilidad en España, más vano resulta cualquier intento de poner sobre el papel los resultados de la labor por ellos realizada. No obstante, y habida cuenta del propósito de la presente Tesis Doctoral, sí parece conveniente dar cuenta al menos de ciertos datos y resultados, fruto de los estudios e investigaciones realizados, en cuanto a la responsabilidad de las organizaciones empresariales desde el punto de vista de los consumidores o usuarios.

Así, por ejemplo, entre los estudios llevados a cabo a nivel nacional para conocer y analizar la opinión de aquéllos, cabe mencionar el que la Confederación de Consumidores y Usuarios (CECU) viene realizando con carácter bianual desde 2004. Su objetivo concreto es valorar la percepción de los consumidores españoles respecto al comportamiento responsable de las empresas, la información recibida sobre las mismas y sus actuaciones, y el papel del gobierno y otras instancias públicas, así como profundizar en determinados aspectos de las pautas de conducta de los propios consumidores en cuanto a sus acciones de consumo responsable.

A tal fin, y partiendo de una muestra de 1004 entrevistados mayores de 18 años, el informe correspondiente a 2010 (el más reciente en el momento de redactar estas páginas) pone de manifiesto que el 67,8\% de los ciudadanos no ha oído hablar de RSE, mientras que los aspectos o dimensiones más valorados del desempeño empresarial eran las relaciones con los clientes y con los empleados, y el respeto a los derechos humanos. Además, los entrevistados valoraban mejor el comportamiento de las pequeñas y medianas empresas en esta materia que el de las grandes. La información recibida en cuanto las actuaciones de unas y otras se consideraba, con todo, baja por una gran mayoría de los individuos (de nuevo un 67,8\%), y más creíble y de mayor calidad si procede de medios de comunicación social, ONGs o Internet. Por lo que se refiere a la actuación pública, un porcentaje ligeramente mayoritario de los mismos se posiciona a favor de medidas gubernamentales de estímulo o refuerzo positivo para mejorar la conducta empresarial. Finalmente, y respecto al consumo responsable, un 22,9\% manifiesta su no disposición a asumir mayores costes en sus compras, mientras que el 59,5\% llegaría a pagar hasta un 10\% más en sus adquisiciones, el 10,5\% pagaría un sobrecoste entre el 11\% y el 25\%, y sólo un 3\% pagaría entre un 26\% y un 50\% más. 
La perspectiva del consumidor ha sido también incorporada a partir de 2004 en los estudios e informes de Forética sobre la situación de la RSC en España desde 2004, analizando su grado de conocimiento y percepción sobre el comportamiento de las empresas, y el grado de integración de la responsabilidad en el consumo. En el último informe publicados, correspondiente a 2011, y respecto al previo de 2008, los resultados apuntan a un incremento de la notoriedad de las cuestiones relacionadas con la responsabilidad (más del 50\% de encuestados manifestaron haber oído hablar de ella), siendo mayor la nitidez del concepto a la vez que ganan terreno sus dimensiones social y medioambiental, en detrimento de la económica. Más aún, se trataba de aspectos prioritarios para un $60 \%$ de individuos, ganando peso al hablar de una "buena empresa” los atributos más relacionados con su integración en las pautas de gestión (mayor valoración de los componentes social y laboral), y percibiéndose mejoras en los campos social y medioambiental por parte de 6 de cada 7 integrantes de la muestra.

En lo que respecta al consumo responsable, en ese mismo informe se señala que un 45\% de los ciudadanos reconocía haber dejado de adquirir algún bien o servicio por considerar que la empresa fabricante o distribuidora llevaban a cabo prácticas poco responsables o éticas (porcentaje que sólo era del 37\% en el informe de 2008), sobre todo en el caso de productos alimenticios, textil y calzado, droguería y cosmética, y telefonía. Asimismo se evidencia una creciente discriminación positiva hacia los productos de empresas responsables por parte de los consumidores españoles.

Para el territorio de la Comunidad Valenciana, la Fundación Ética de los Negocios y de las Organizaciones (ÉTNOR) llevó a cabo en 2007 un trabajo de análisis a través del Observatorio de Ética y Responsabilidad Social de la Empresa de la Comunidad Valenciana (ERSE), cuyo propósito era concretar los aspectos y elementos de la dimensión ética de la cultura empresarial en la región, y sobre esa base proponer a la Administración Pública, a las empresas y a la sociedad civil ${ }^{88}$ las claves para diseñar e implementar políticas y planes de acción en este ámbito. Una de las fuentes de información utilizada fue un estudio de campo cualitativo y cuantitativo con 407 entrevistas sobre la percepción de los trabajadores, clientes y la sociedad en general, del que se concluía un elevado grado de desconocimiento sobre lo que es y lo que implica el concepto, así como que la percepción de los ciudadanos tiene más que ver con una dimensión interna centrada en las condiciones laborales.

\footnotetext{
${ }^{88} \mathrm{Al}$ considerar fundamental la participación activa de estos tres pilares.
} 
Un nuevo estudio de la Fundación ÉTNOR en 2010 tomó como referente la opinión de una muestra de 404 individuos para aproximar lo que consideraba perspectiva social (punto de vista de trabajadores, clientes y de la sociedad en general), la cual, junto con la de empresarios y directivos, vendría a constituir el componente perceptivo de las fuentes de información requeridas. Junto a éste, las otras fuentes de datos para el análisis de la RSE eran un índice elaborado en base a las políticas y prácticas concretas de responsabilidad social, y el monitor de la comunicación de RSE de las empresas de mayor facturación de la Comunidad Valenciana (a partir del análisis de contenidos de las páginas web de las mismas).

El informe correspondiente (Fundación ÉTNOR 2010) destaca, entre otros aspectos, un desconocimiento elevado del concepto de responsabilidad por parte de la mayor parte de la sociedad (aunque los individuos sí son capaces de identificar las prácticas que lo componen), la cual se manifiesta más crítica que las empresas a la hora de evaluar la implantación actual de la RSE, exigiendo más trasparencia a las empresas y que comuniquen sus acciones y políticas de forma más clara y unificada. Asimismo se señala que las prácticas empresariales parecen no haber mejorado significativamente en los últimos años. La conclusión no es sino que el ciudadano demanda más información y no dispone de instrumentos adecuados para conocer y valorar adecuadamente hasta qué punto es responsable o no la actuación de las empresas.

Futro de sus hallazgos, la Fundación ÉTNOR realiza en su informe una serie de recomendaciones al ámbito público, al ámbito empresarial y al conjunto de la sociedad: i) a la Administración corresponde desarrollar un modelo responsable de gestión para su propio funcionamiento, así como incorporar cláusulas sociales en su contratación; ii) la empresa debe mejorar la comunicación con los diferentes grupos de interés, siendo precisa la colaboración e implicación de las organizaciones empresariales; y iii) la sociedad ha de sensibilizar y formar a los directivos y empresarios en materia de RSE, así como mejorar las buenas prácticas empresariales para visualizar los compromisos y apuestas que se van poniendo en marcha.

Un estudio de la Cátedra de RSC de la Universidad de Murcia (Marín et al. 2008) analizó la percepción de los consumidores sobre la responsabilidad empresarial recabando datos mediante 350 entrevistas personales, dirigidas a saber el grado de conocimiento sobre aquélla, el papel atribuido a las empresas, y las perspectivas de consumo responsable. Los resultados indicaban que un tercio de los encuestados tenía 
conocimiento del concepto y a otros tantos les sonaba, siendo particularmente valoradas al respecto las medidas encaminadas a lograr mejoras medioambientales, en la situación de los empleados y en la protección de derechos de los clientes. En tanto un 31\% de individuos consideraba que las empresas adoptan pautas responsables por su preocupación por mejorar la sociedad, un 28\% creen que las causas son estratégicas. Respecto a la posibilidad de pagar más por los productos de empresas responsables, un 37,2\% lo harían, mientras un $40 \%$ pagarían lo mismo y un $71 \%$ se manifestaban dispuestos a discriminar la oferta de una empresa que sabe realiza prácticas poco éticas.

Muy similar en sus planteamientos y desarrollo fue el estudio de García, Gibaja y Mújika (2007) sobre una muestra telefónica de 407 consumidores guipuzcoanos. Las conclusiones del mismo se plantearon a partir de la previa constatación de la existencia de un grado relativamente grande de desacuerdo entre empresa y consumidor en lo tocante a la responsabilidad, siendo mayor la importancia que el consumidor otorga a los aspectos vinculados a su dimensión interna. En tal sentido, el perfil del consumidor guipuzcoano puesto de manifiesto en el estudio apuntaba a individuos inclinados a penalizar los comportamientos empresariales socialmente no responsables, e incluso pagar un sobreprecio por los que sí lo son, a la vez que demandan más información sobre la RSC (más creíble si la facilitan las organizaciones de consumidores, pues la mayoría de encuestados intuía intereses comerciales tras los esfuerzos empresariales), quieren que se avance en esta materia, y ven su futuro con optimismo.

Un estudio más reciente de estos mismos autores llevado a cabo conforme a idénticos procedimiento y metodología (García, Gibaja y Mújika 2011) tenía como objetivo determinar el nivel de participación ciudadana de los guipuzcoanos en actuaciones encaminadas a promover comportamientos empresariales socialmente responsables. Sus resultados vuelven a evidenciar que ese consumidor concede más importancia a las actividades relacionadas con la dimensión interna, así como la brecha entre lo que el consumidor piensa y lo que hace en esta materia, constatándose que en 2010 tres de cada cuatro consumidores no habían adoptado (ni se habían planteado) iniciativa alguna para tratar de que una empresa modificase un comportamiento considerado socialmente irresponsable. Asimismo se señalaba que en un porcentaje similar no buscaba nunca o casi nunca en sus compras esta información, considerando, en todo caso, más fiables las informaciones de las organizaciones de consumidores, todo lo contrario que las de las propias empresas. 


\subsection{Hacia una visión actual de la responsabilidad}

La conclusión más evidente a partir del análisis de los distintos planteamientos y debates acaecidos a lo largo de las diferentes etapas en la evolución histórico-económica del concepto de responsabilidad, así como los esfuerzos programáticos a nivel internacional y nacional es la ausencia de un parecer unificado y/o generalmente aceptado a este respecto. Tal y como ha sido expresamente señalado en varias ocasiones (por ejemplo, McWilliams et al. 2005, o Garmendia 2009), no cabe hablar de un marco teórico que albergue el concepto, los instrumentos de medida, o ni tan siquiera los métodos empíricos para la investigación. Antes al contrario, la propia naturaleza abierta y dinámica del fenómeno a describir resulta determinante para que los planteamientos hayan de evolucionar por fuerza con el tiempo y se vean condicionados por la cultura, la ideología y las costumbres de cada sociedad (Carroll 1979, Van Herpen et al. 2003, González 2005, Argandoña et al. 2012), encontrándose aquí explicación a la proliferación de enfoques y teorías en torno a la responsabilidad de las organizaciones.

Con propósito sistematizador, Garriga y Melé (2004) clasifican las teorías y enfoques caracterizando sus posiciones en cuanto a los beneficios, las demandas sociales y los valores éticos, sugiriendo cuatro grupos o categorías:

i) Teorías instrumentales: donde la empresa es vista exclusivamente como un instrumento generador de riqueza (maximización de valor para el accionista, estrategias para lograr ventajas competitivas, marketing con causa).

ii) Teorías políticas: con referencia al poder de las empresas en la sociedad y el ejercicio responsable del mismo en el escenario político (constitucionalismo corporativo, teoría del contrato social integrador, ciudadanía corporativa).

iii) Teorías integradoras: conforme a las cuales la empresa se centra en la captación e identificación de las demandas sociales, para darles una posterior respuesta con la que pretende legitimidad social y una mayor aceptación y prestigio social (gestión de asuntos sociales, principio de responsabilidad pública, gestión de los grupos implicados, la acción social corporativa).

iv) Teorías éticas: basadas en las responsabilidades éticas de las empresas para con la sociedad, fundamentándose en principios que expresan qué se debe y qué no se debe hacer, o la necesidad de construir una sociedad mejor (teoría normativa de los stakeholders, derechos universales, desarrollo sostenible, enfoque del bien común). 
Así las cosas en el plano conceptual y metodológico, difícil resulta plantear y, menos aún consensuar procedimientos y políticas que propicien una mayor eficiencia en el ámbito de la responsabilidad. Conforme indica Melgar (2009), a ello contribuyen asimismo la heterogeneidad interna de las propias organizaciones, el hecho de que los resultados no siempre sean fáciles de apreciar o de medir a corto o medio plazo (se trata de intangibles que se perciben en el largo plazo), la complejidad de aunar la gestión de cuestiones de muy diversa índole y naturaleza (por lo que cualquier enfoque integrado precisa de varios instrumentos de gestión), la debilidad de determinadas instituciones públicas (sobre todo en los países en vías de desarrollo) que hace imposible en muchas ocasiones hablar de responsabilidad compartida o, incluso, las perceptibles carencias persistentes aún hoy en día en cuanto a la difusión de una cultura de responsabilidad en el conjunto de la sociedad, factor de esencial e indispensable para la predisposición a la adopción de comportamientos más sensibles en este ámbito.

Todo ello hace que, al igual que ocurre con otros conceptos de hondo calado social y político, la delimitación de la responsabilidad no sea nítida y un cierto grado de imprecisión pueda aparecer incluso como característica inherente a todo intento de acotar su significado. No obstante, también cabe argumentar que es justamente en este carácter impreciso donde reside una buena parte de su poder activador de procesos y debates (González 2005). La carencia de una definición sólida ha impulsado y continúa impulsando iniciativas, a modo de esfuerzos programáticos que permitan esclarecer los distintos elementos que han de contener y compartir las prácticas responsables.

En tal sentido debe tenerse en cuenta que, si bien en otros momentos no ha sido así, los posicionamientos actuales sobre el significado y contenido de la responsabilidad en las organizaciones no se basan en la realización de acciones filantrópicas con poca o, en ocasiones, ninguna relación con la actividad propia de una entidad (Cancino y Morales 2008). Antes al contrario, la preocupación principal se centra en el diseño, desarrollo y comunicación de resultados de acciones llevadas a cabo durante los procesos productivos, y que deben poner de manifiesto que la entidad se comporta de forma responsable con sus empleados, con sus proveedores, con sus clientes y, en general, con cualquier otro público interesado que participe o se pueda ver afectado por los resultados de la actividad organizativa. En definitiva, y sobrepasado ya el tiempo de las operaciones meramente cosméticas o de lavado de imagen, es la hora de una gestión auténticamente responsable, basada en principios de transparencia y eficacia. 
Con todo, a partir del análisis de las distintas definiciones conceptuales, los principios inspiradores, y la interpretación de unas y otros, pueden concluirse algunos aspectos determinantes de la visión actual de la responsabilidad:

i) Es mayoritaria la opinión de quienes propugnan la voluntariedad como aspecto fundamental a la hora de valorar la responsabilidad en la gestión. En base a ello, las organizaciones habrán de optar, libre y voluntariamente, por alguna fórmula autorreguladora, ya sea basada en los códigos éticos o de conducta existentes o autodiseñada, para corregir los impactos negativos derivados del desarrollo de la actividad que le es propia.

No obstante, hay quien se plantea el interrogante de si tal mecanismo es eficiente por sí solo pues, si bien positivo, no por ello puede dejar de resultar insuficiente, en particular cuando lo que está en juego es algo de alcance tan global como los derechos humanos y medioambientales. En consecuencia, se plantea la conveniencia de activar cuando menos un marco jurídico regulador de la responsabilidad, entendido éste como conjunto de políticas públicas que incluyan unos mínimos a cumplir por parte de las organizaciones que adopten voluntariamente la decisión de ser socialmente responsables e integrar elementos de seguridad y de impulso de la responsabilidad en su actuación (Aparicio y Valdés 2009).

ii) Ya no sólo la definición, sino los aspectos prioritarios de la responsabilidad no son únicos e inalterables, sino que varían con el tiempo ${ }^{89}$ (al igual que, y en consonancia con las preocupaciones sociales de cada momento), el marco territorial y otras circunstancias, tales como el sector de actividad de la entidad, su dimensión y las características del entorno socioeconómico (Garmendia 2009).

De este modo, el impacto y la repercusión de una misma conducta o actuación pueden diferir sustancialmente según el momento y el entorno en el que se contextualicen ${ }^{90}$. Por ello, no cabe hablar en términos prácticos de un modelo específico y universalmente consensuado que establezca la manera en

\footnotetext{
89 Evidencia que constata, por ejemplo, el texto de la norma ISO 26000, recomendando seguidamente adoptar como pauta de conducta la revisión y actualización periódica de dichas prioridades por parte de cada entidad usuaria.

${ }^{90}$ Tal y como específicamente se indica en el Cuaderno de conclusiones del Primer Foro de Investigación y Debate sobre la Responsabilidad Social de las Empresas, promovido por la Fundación Luis Vives en 2011.
} 
que debe desarrollarse el comportamiento responsable de las empresas o, lo que es lo mismo, "asumiendo la inexistencia de un catálogo general de buenas prácticas, son los comportamientos que las empresas observan en los distintos ámbitos los que suelen tomarse en consideración a la hora de valorar su compromiso social” (Unceta y Gurrutxaga 2005:90). Antes bien, dependerán de multitud de factores, tales como quién o quiénes son el interlocutor o interlocutores, el papel que desempeñan, el contexto geográfico, la actividad de la organización o su grado de implicación con las cuestiones sociales y medioambientales.

iii) Hablar de responsabilidad supone necesariamente tener en cuenta las expectativas de los stakeholders sobre las decisiones y actuaciones de una organización $^{91}$, en términos económicos, medioambientales y sociales.

Si bien la concepción de la responsabilidad de los administradores -o, por extensión, de los directivos o responsables, para así hacer referencia a todo tipo de entidades- era inicialmente mucho más monista (enfocada a la maximización del beneficio de la propiedad), hoy en día se ha tornado mucho más pluralista, habiendo de responder ante los distintos grupos de interés, lo que viene a suponer un punto de vista mucho más amplio con respecto a sus orígenes.

iv) Aunque no unánime, y a falta de estándares delimitados (Unceta 2005), sí es bastante amplio el acuerdo al menos en cuanto a las grandes áreas o grandes líneas de conducta responsable: económica, medioambiental y social.

Con todo, no deja de tratarse de conceptos igualmente amplios, en especial en cuanto a la temática social, que incluiría un amplio catálogo de aspectos, tales como los derechos humanos, el respeto de la diversidad, la igualdad de género, la lucha contra el fraude y la corrupción, la ayuda a la comunidad, el respeto a las reglas del mercado, las cuestiones relacionadas con la formación, la salud y bienestar de los trabajadores, etc. ${ }^{92}$.

\footnotetext{
${ }^{91}$ Aspecto reiterado en la mayor parte de intentos de establecer una definición que se han realizado en la etapa más reciente (entre otros, Guibert 2007, Garmendia 2009, o Schwalb 2009).

${ }^{92}$ Entre ellos, la ISO 26000 señala en su capítulo 6 como materias interrelacionadas, de igual importancia, y a abordar de modo integral, la gobernanza de la organización, los derechos humanos, las prácticas laborales, el medio ambiente, las prácticas justas de operación (anticorrupción, participación política responsable, competencia justa, promoción de la responsabilidad en la cadena de valor, respeto a los derechos de propiedad), y los asuntos relacionados con los consumidores, así como la participación activa y en el desarrollo de la comunidad.
} 
v) La integración de la responsabilidad debe plantearse con carácter global y transversal, afectando a todas las áreas y actores de la entidad de que se trate, y en todas las áreas y contextos en los que desarrolle sus actividades (Herranz 2010, Marín 2012) ${ }^{93}$. De hecho, y dada la diversidad de aspectos contemplados, cabe incluso argumentar que la responsabilidad "sólo tiene sentido si configura y estructura una visión global de la empresa [o entidad] y una manera de entender su actividad” (Lozano 2004:12).

Una organización, por tanto, será responsable de sus actividades e impactos independientemente del lugar concreto o del área geográfica donde esté actuando o donde el impacto tenga lugar y, por tanto, sin importar lo más o menos laxa que pueda ser la legislación de uno u otro país o territorio, de si ésta cuenta o no con mecanismos de control y supervisión para hacer cumplir la normativa, o de los diferentes grado de exigencia.

vi) Lejos de ser un conjunto descoordinado de actuaciones más o menos puntuales o esporádicas, la responsabilidad debe plantearse como filosofía sistemática de actuación. Se trata de una forma de gestionar los negocios y las organizaciones que afecta a toda la cadena de valor necesaria para el desarrollo de la actividad que le es propia (producción de bienes o prestación de servicios), requiriendo la implicación de todas las áreas funcionales de la misma (Fundación Luis Vives 2011) a fin de operativizar y dinamizar los aspectos que aseguren que la incorporación de criterios responsables tiene lugar a lo largo de todos los procesos.

Este planteamiento va a resultar sumamente valioso particularmente en marcos contextuales como el que caracteriza los tiempos actuales, donde los procesos de producción y servucción son altamente complejos, a la vez que buen número de entidades tienden a subcontratar y externalizar una parte importante de sus actividades.

vii) La adopción de principios de actuación responsables en una organización ha de suponer, en definitiva, la redefinición del papel que a ésta le corresponde,

\footnotetext{
93 Así lo refleja la Comisión Europea tanto en el Libro Verde como en su Comunicación de 2 de julio de 2002, relativa a la responsabilidad social de las empresas y a la contribución de éstas al desarrollo sostenible (COM 2002-347 final), aludiendo al "enfoque equilibrado y global” que ha de tener la RSE. Ya en España, y por ejemplo, la Mesa de Diálogo Social (2007) se hace eco de esos mismos postulados y reconoce expresamente la globalidad como uno de los principios de la responsabilidad, así como que las decisiones y actividades de una organización pueden no estar circunscritas a un solo país.
} 
de un modo más vinculado con la sociedad ${ }^{94}$, asumiendo compromisos a más largo plazo y con todos los grupos de interés, cuyas demandas han de ser respondidas en un entorno global comprometido con los aspectos sociales y medioambientales del desarrollo sostenible. Ello redundará en un mayor grado de reconocimiento de su labor y de su influencia en el desarrollo socioeconómico.

Es, precisamente, este último aspecto el que hace que la reconceptualización de las organizaciones, íntimamente relacionada con el nuevo rol asignado a las mismas, sea consecuencia de los cambios en los sistemas de valores que impregnan la sociedad actual, planteando la necesidad de profundizar en las relaciones entre aquéllas y ésta a través de un conocimiento íntegro de la realidad y una sólida base ética (Garriga y Melé 2004). Asimismo deberá tenerse en cuenta la aparición de múltiples grupos de interés, cuya actuación es capaz de generar una gran presión sobre el entorno competitivo de la entidad (Bigné et al. 2005), y que reaccionarán ante las prácticas responsables. En tal sentido, el análisis de las reacciones de los consumidores se conformará como factor clave a ser tenido en cuenta por las organizaciones empresariales, en la medida en que ello afectará directamente tanto a su comportamiento como a sus resultados.

\footnotetext{
${ }^{94}$ Tal y como sostiene Lozano (2009:22), “una empresa contemporánea gestiona cuatro capitales: el económico, el humano, el social y el medioambiental. [...] Su actuación debe ser valorada a partir de estos cuatro capitales, y no sólo en relación con el primero de ellos. [...] Una empresa es ciudadana en la medida que se valora desde su contribución a la sociedad, y no simplemente desde su capacidad de maniobra en el mercado y ante la legislación".
} 
Capítulo 4

La Perspectiva del Consumidor en la

RESPONSABILIDAD DE LAS ORGANIZACIONES 



\section{Capítulo 4. La Perspectiva del Consumidor en la Responsabilidad DE LAS ORGANIZACIONES}

Si las empresas que ofertan sus bienes y servicios en el mercado parecen estar cada vez más comprometidas con la adopción de pautas de conducta responsable, no es menos cierto que esto se debe en gran medida al progresivo interés y las mayores exigencias de información y veracidad al respecto que, desde el lado de la demanda, realizan los consumidores (Carrigan y Attalla 2001, Maignan 2001). Sin embargo, la mayoría de las investigaciones coinciden en señalar el papel limitado que la responsabilidad parece tener en los comportamientos de compra (Öberseder et al. 2011), y de ahí la pertinencia de comprender mejor el proceso mediante el cual los consumidores integran las percepciones sobre iniciativas de responsabilidad en sus criterios de selección.

En tal sentido, el presente Capitulo de la Tesis se plantea de acuerdo con un enfoque aproximativo, comenzando por una referencia a los diferentes grupos de interés que influyen o son influidos de manera más o menos directa por el desempeño de las organizaciones empresariales (teoría de los stakeholders), para seguidamente centrar el estudio en el análisis de la responsabilidad de la perspectiva del consumidor, y después examinar las diferentes variables que configuran ésta última, las cuales servirán de base al modelo de estudio.

La descripción de los constructos integrantes de dicho modelo explicativo de la forma en que los aspectos de la responsabilidad son tenidos en cuenta en los procesos de decisión de compra de los consumidores parte del análisis de lo que ocurre en los primeros estadios del proceso más amplio de toma de decisiones por parte de éstos, esto es, desde el reconocimiento de una necesidad hasta su transformación en demanda, y el reconocimiento paralelo de la necesidad de disponer de información sobre las conductas y comportamientos responsables de las empresas, como elemento fundamental en la búsqueda de datos y posterior valoración de las ofertas del mercado, centrando así las intenciones de compra en las que se perciben como responsables. 
No obstante, tampoco se debe perder de vista el hecho de que son otras muchas las variables, tanto internas como externas, que asimismo condicionan la toma de decisiones del consumidor. Por esta razón, y tras introducir en el modelo los aspectos relacionados con su percepción de la responsabilidad y las atribuciones que realiza a las empresas en cuanto a comportamiento responsable, son también objeto de consideración otros constructos igualmente condicionantes del resultado de las decisiones, agrupados en las dos grandes categorías de utilidad esperada (de los productos y la oferta responsable) e influencia social (como variable exógena condicionante).

Tomando todo ello como base, y a través de las interrelaciones entre las diferentes variables que han sido establecidas en la literatura, se procede a una primera aproximación del modelo de consideración y valoración de la responsabilidad en los procesos de intención de compra, sometido a validación empírica en la segunda parte del trabajo.

\subsection{Una nueva perspectiva de la responsabilidad}

Las organizaciones no sólo deben dar cuenta de su gestión y de su desempeño ante los propietarios, accionistas o directivos (esto es, lo que vendría a poder considerarse ante sí mismas), sino también ante todos los colectivos internos y externos que de forma directa o indirecta inciden o se ven afectados por ellos (trabajadores, consumidores, proveedores, comunidad local, Administración Pública, otras organizaciones de la sociedad civil, etc.). Los resultados de la actividad organizativa se extienden así al conjunto de la sociedad ${ }^{95}$.

En consonancia, y tal y como se ha puesto de manifiesto en los capítulos precedentes, los distintos enfoques, tanto de académicos como de otras instituciones y organizaciones que han tomado parte en los debates sobre la responsabilidad en la empresa, ya teóricos o ya de cara a la implementación práctica del concepto, están más bien orientados a definir y medir el alcance que tiene la actividad desarrollada por una organización sobre determinados colectivos o la sociedad en su conjunto. En palabras de Guibert (2007:27), con estas iniciativas lo que se hace es "sacar una foto de la

\footnotetext{
${ }^{95}$ Razón por la que autores como Guibert (2007 y 2011) sostienen que el término "social” ha pasado a ser, de manera casi espontánea y natural, el "apellido" connatural de la responsabilidad. Aplicarlo, pues, al hablar de la responsabilidad en el ámbito organizativo viene a resultar, por obvio, reiterativo e innecesario.
} 
empresa a la sociedad". No obstante, tan importante o más es "tomar la foto desde la sociedad”, viéndola desde fuera como ciudadanos-consumidores, Administración, comunidad, redes sociales, universidad, entorno, etc., dejando que sean estos colectivos quienes establezcan las líneas definitorias de lo que, a su entender, debe ser una empresa responsable, La responsabilidad de las empresas sería así planteada desde la perspectiva de los grupos o colectivos en relación con los que opera.

Bajo esta nueva perspectiva, y en palabras de Jáuregui $(2009)^{96}$, la propia sociedad penetra y participa de la empresa como nunca lo había hecho. Surgen con fuerza stakeholders externos que configuran una interrelación con las entidades productivas hasta ahora inexistente, exigiéndoles que no oculten ningún secreto de su actividad: los medios de comunicación informan sobre ellas y, en particular, internet facilita información inmediata a este respecto, la publicidad de sus logos comerciales les compromete, y cada vez es mayor la sensación de que es imprescindible alcanzar ciertos niveles de empatía social para conectar con el mercado. Al mismo tiempo, los consumidores son cada vez más conscientes del poder de su fuerza colectiva.

Por ello, y sin duda, uno de los factores que más han impulsado en los últimos años el desarrollo de la responsabilidad social es la presión de los mercados de consumo (Nieto y Fernández 2004) ${ }^{97}$. Cada vez son más quienes optan por adoptar unas pautas de consumo más responsable, buscando y adquiriendo productos ecológicos o producidos según criterios de responsabilidad, de comercio justo, o vinculados a acciones sociales, elaborados en condiciones laborales justas, sin generar externalidades negativas, etc.

\footnotetext{
96 Según se indicó en el capítulo previo, Ramón Jáuregui fue el diputado que presidió la Subcomisión Parlamentaria para potenciar y promover la responsabilidad social de las empresas, dentro del ámbito de actividad de la Comisión de Trabajo y Asuntos Sociales del Congreso de los Diputados. En su opinión, las empresas no están aumentando sus compromisos en materia de responsabilidad porque los directivos se hayan "convertido" a la ética de los negocios. Antes bien, la clave de la expansión de las actividades responsables está en que, por vez primera en la historia de los mercados, la sostenibilidad se ha convertido en un argumento de competitividad.

De este modo, y en un entorno competitivo global, una estrategia no puede basarse en la devaluación del medio ambiente, ni en el maltrato laboral, ni en el incumplimiento de normas internacionales en materia sindical o de derechos humanos. Todo lo contrario, superar los mínimos en todos esos planos es lo que incrementa la competitividad de una entidad por el plus de excelencia añadido que supone en relación a sus plantillas, a su ambiente laboral, a sus productos, a su productividad, a su empatía social y, por ende, en términos de su reputación corporativa.

97 Junto a éste, y en opinión de estos mismos autores, habría que citar otros dos grandes factores impulsores de la responsabilidad en época reciente: por un lado, el aumento de la regulación, tanto a nivel internacional como nacional; por otro, la presión del mercado financiero, al aumentar el número de inversores que pretenden realizar una inversión socialmente responsable (en fondos y empresas que desarrollen buenas prácticas). Uno y otro están también, y en mayor o menor medida, condicionados por la percepción que tenga el ciudadano-consumidor sobre el comportamiento responsable de las empresas.
} 


\subsubsection{Los grupos de interés de la empresa: la teoría de los stakeholders}

Antes de entrar en el análisis del significado de la responsabilidad empresarial para el consumidor (y más una vez que se es consciente de la extrema dificultad y complejidad de los esfuerzos conceptuales), conviene comenzar por determinar cuáles son los grupos de interés o stakeholders ante los que la empresa ha de responder y cuyas expectativas, demandas e intereses debe satisfacer.

A este respecto, y según se avanzaba en el primer capítulo, los planteamientos actuales sobre la responsabilidad pasan por la consideración de las expectativas de los stakeholders en las decisiones empresariales. Además de los aspectos económicos, deben tenerse en cuenta los posibles impactos medioambientales y otras preocupaciones sociales, lo que supone una clara ampliación de los objetivos de unas entidades que tienen contraída una serie de obligaciones y compromisos con una pluralidad de grupos con los que se relacionan e interactúan porque, de alguna manera, van más allá de lo que establecen normas y contratos.

Estos grupos de interés se pueden clasificar atendiendo a diferentes criterios o consideraciones, siendo dos los más habituales (Maignan et al. 1999 y 2005, Maignan y Ferrell 2000, Maignan et al. 2005, Parmar et al. 2010, Hult et al. 2011), Así, en primer lugar, y según el grado de compromiso con la empresa, cabe hablar de: i) stakeholders primarios, o indispensables para la supervivencia de la empresa (inversores, empleados, clientes, proveedores y el grupo de stakeholders públicos); y ii) stakeholders secundarios, que no tienen obligación contractual con la entidad ni ejercen ninguna autoridad legal sobre ella (competidores, medios de comunicación, asociaciones comerciales, ONGs, etc.). También se puede distinguir entre: i) stakeholders internos (departamentos funcionales, empleados y otras partes internas); y ii) stakeholders externos (competidores, agencias de publicidad, organismos reguladores, etc.).

Una alternativa a lo anterior es la clasificación de Cuervo (2009), en función de la relación de cada colectivo con la entidad (Cuadro 4.1). Así, en un primer grupo estarían los que configuran la propia empresa (empresarios, accionistas, directivos y empleados); en un segundo grupo, los que tienen relaciones directas con ella (clientes, proveedores comerciales, proveedores de recursos financieros, analistas y otros grupos); y, por último, un tercer grupo estaría integrado por los afectados por las externalidades de la empresa (Administraciones, comunidad, partidos políticos, activistas sociales, ecologistas, medios de comunicación, otros grupos y sociedad en general). 
Cuadro 4.1. Clasificación de los grupos de interés de la empresa en función de su relación con la entidad

\begin{tabular}{|c|c|c|}
\hline Grupo & Colectivos & Componentes \\
\hline \multirow{4}{*}{$\begin{array}{l}\text { 1. Agentes } \\
\text { centrales o que } \\
\text { configuran la } \\
\text { empresa }\end{array}$} & Empresario & Individual, corporativo \\
\hline & Accionistas & Accionistas de control, accionistas pasivos \\
\hline & Directivos & Alta dirección, ejecutivos con contrato individual \\
\hline & Trabajadores & Con convenio, con contrato individual, sindicatos \\
\hline \multirow{3}{*}{$\begin{array}{l}\text { 2. Agentes con } \\
\text { relaciones } \\
\text { directas con la } \\
\text { empresa }\end{array}$} & Clientes & $\begin{array}{l}\text { Clientes individuales, organizaciones de defensa de } \\
\text { consumidores, etc. }\end{array}$ \\
\hline & Proveedores & Suministradores principales, de inputs, y de componentes \\
\hline & $\begin{array}{l}\text { Inversores y } \\
\text { mercados } \\
\text { financieros }\end{array}$ & $\begin{array}{l}\text { Bancos y cajas de ahorros, inversores institucionales, } \\
\text { auditores, analistas financieros }\end{array}$ \\
\hline \multirow{3}{*}{$\begin{array}{c}\text { 3. Agentes } \\
\text { afectados por las } \\
\text { externalidades de } \\
\text { la empresa }\end{array}$} & $\begin{array}{l}\text { Administraciones } \\
\text { Públicas }\end{array}$ & $\begin{array}{l}\text { Estado, Administración Autonómica, Administración } \\
\text { Local, Reguladores }\end{array}$ \\
\hline & Sociedad & $\begin{array}{l}\text { Partidos políticos, sociedad civil, activistas sociales, } \\
\text { ONGs, medios de comunicación }\end{array}$ \\
\hline & Competidores & Organizaciones empresariales \\
\hline
\end{tabular}

Fuente: Elaboración propia en base a Cuervo (2009).

Otra posibilidad, cuando la empresa ha de afrontar un proceso de toma de decisiones, es valorar las relaciones que mantiene en ese momento con sus stakeholders y las que querría o debería tener en el futuro (sin perder de vista el hecho de que cada colectivo no tiene por qué ser homogéneo ni estanco). Una de las taxonomías que más útiles pueden resultar para este propósito es la sugerida por Mitchell et al. (1997), basada en la situación de los individuos respecto a tres atributos: i) su poder, o la capacidad que tienen para influir e imponer su punto de vista en la actuación empresarial; ii) su legitimidad, en el sentido valorar hasta qué punto se trata de acciones deseables, adecuadas o apropiadas dentro del sistema social de normas, valores o creencias al que se circunscriben; y iii) la urgencia o perentoriedad de las propuestas que realizan.

En base a este criterio, se distinguen tres grandes grupos o categorías de stakeholders (Figura 4.1): latentes, expectantes, y definitivos. 


\section{Figura 4.1. Tipología de los stakeholders conforme a su situación respecto a los} atributos de poder, urgencia y legitimidad

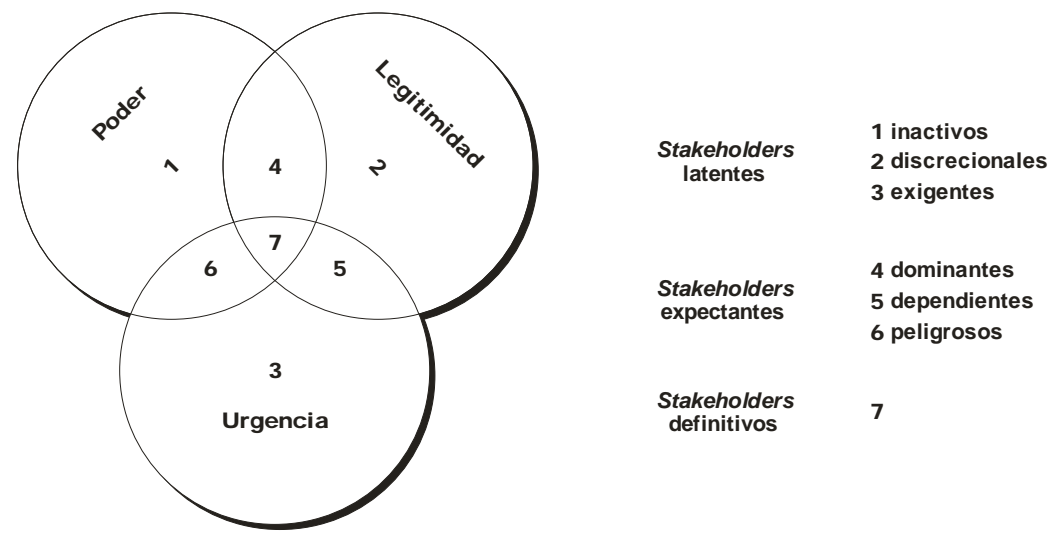

Fuente: Elaboración propia en base a Mitchell et al. (1997).

a) Los stakeholders latentes son aquéllos que sólo poseen uno de los tres atributos. En base a ello, se distingue entre stakeholders latentes inactivos (quienes, aunque tienen poder, sus demandas no son urgentes y carecen de legitimidad), discrecionales (que tienen legitimidad, pero carecen de poder o capacidad de influencia, al tiempo que sus demandas no son urgentes), y exigentes (cuyas demandas son urgentes, pero carecen de poder y de legitimidad).

Aunque en principio son los menos relevantes para una empresa, deben tenerse en cuenta no sólo por el hecho de ser igual grupos de interés, sino también por su potencial relevancia futura en caso de adquirir algún otro atributo.

b) Los stakeholders expectantes poseen dos de los tres atributos de referencia. En función de cuáles sean, unos serán stakeholders expectantes dominantes (con poder y legitimidad, pero con demandas no urgentes), dependientes (con demandas urgentes y legítimas, pero carentes de poder), y peligrosos (con demandas urgentes y poder de actuación, pero sin legitimidad).

La relevancia de este grupo es moderada, pero es importante identificarlos a nivel particular, así como tener en cuenta posibles interrelaciones, pues éstas pueden dar lugar a coaliciones, consolidando su posición ante la entidad.

c) Los stakeholders definitivos son aquéllos en los que concurren los tres atributos, lo que hace que sean objeto directo de atención de la empresa. 
En todo caso, la finalidad de estas y otras clasificaciones es configurar un mapa conforme a los postulados iniciales de Freeman (1984) en su teoría de los stakeholders, basados en la creación de valor, el intercambio y la transmisión de aquél (cómo se alcanza, o para quién se crea y se destruye valor). Considera y se apoya en un concepto moderno de empresa, en tanto que entidad que actúa en un entorno abierto (dinámico y cambiante), a la vez que desarrolla un complejo entramado de relaciones con una amplia pluralidad de interlocutores, los cuales, a su vez, pueden establecer relaciones o coaliciones en función de sus intereses e independientemente de aquélla.

El propio Freeman señalaba el amplio desconocimiento existente en cuanto al funcionamiento de esas redes, dificultando cualquier intento de actuación positiva y proactiva sobre ellas $^{98}$, la cual requeriría formular programas estratégicos específicos e integrados basados en esquemas de pensamiento que consideren todos los stakeholders de la organización y hagan posible una explicación de su comportamiento (Figura 4.2).

Figura 4.2. Una propuesta metodológica para el análisis de los stakeholders

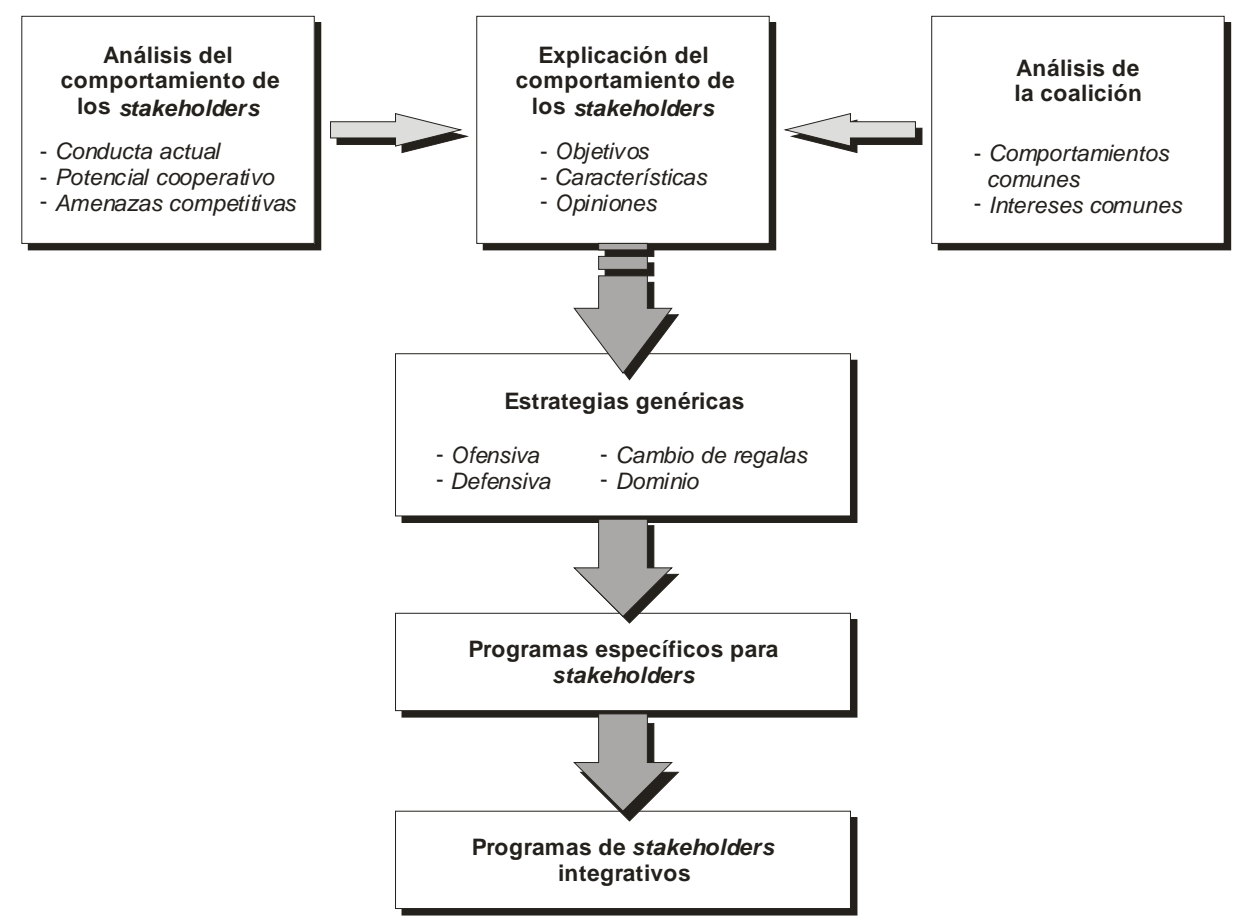

Fuente: Elaboración propia en base a Freeman (1984).

\footnotetext{
${ }^{98}$ Hasta el punto de emplear este desconocimiento (aspecto en el que a día de hoy aún no se ha avanzado significativamente) a la hora de demostrar la utilidad del concepto de stakeholders, tomándolo como base para la formulación de la correspondiente teoría.
} 
Dicha propuesta se realiza bajo una óptica esencialmente gerencial, pues de lo que se trata en última instancia es de gestionar las obligaciones de la empresa para con sus públicos objetivo, sustentadas en la red de relaciones con y entre los mismos. El resultado de la gestión de la organización está directamente vinculado a la forma en que se gestione la red de relaciones y, para que éstas funcionen, se precisa mutua confianza (Arenas 2006).

El argumento justificativo es una concepción multidimensional de la empresa, que implica computar los efectos externos positivos y negativos generados en el proceso de creación de valor y, que no tiene por qué estar en conflicto con las responsabilidades adquiridas con los accionistas. De hecho, los deberes fiduciarios de la empresa hacia sus accionistas son compatibles con otras responsabilidades públicas y privadas que, desde el punto de vista social, la entidad “deseable” pueda también tener hacia ellos (Freeman et al. 2010). Si los conflictos de intereses que se puedan plantear son sistemáticamente resueltos priorizando en demasía o considerando exclusivamente el beneficio de los accionistas en detrimento de otros stakeholders clave, aumentarán las posibilidades de que el proyecto fracase.

Tal razonamiento se enmarca en un "pragmatismo filosófico" (Freeman et al. 2010), conforme al cual teoría y práctica son aspectos igualmente relevantes, además de complementarse en el desarrollo del conocimiento (la práctica indica lo importante que es lo que puede hacerse, en tanto la teoría lleva a explorar otros horizontes), siendo especialmente significativa la formulación de preguntas relevantes y que puedan ser contestadas mediante modelos cualitativos y/o cuantitativos. Explícita o implícitamente, engloba tres enfoques o aspectos (Hult et al. 2011): i) uno descriptivo o empírico, a fin de describir y/o explicar cómo se comportan realmente las empresas y sus directivos como stakeholders; ii) uno instrumental, para ver qué ocurriría si las empresas se comportaran de determinada manera; y iii) uno normativo, referido a la corrección moral del comportamiento de las entidades y/o de sus directivos ${ }^{99}$. A ellos, y en base a la consideración de conceptos normativos relacionados con la responsabilidad y con la ética, cabría añadir un cuarto aspecto, el enfoque directivo, orientado a la determinación y análisis de las necesidades de los profesionales de la gestión (Parmar et al. 2010).

\footnotetext{
${ }^{99} \mathrm{Si}$ bien en la última revisión de la teoría de los stakeholders (Freeman et al. 2010) no se da importancia a esta distinción, por entender que aparecen en realidad interconectadas en un único enfoque complejo, al igual que lo es la actividad económico-financiera, donde muchas ocasiones los datos son limitados o escasos y es relativamente alta la probabilidad de excluir aspectos relevantes de los problemas.
} 
Con todo, la teoría de los stakeholders no puede considerarse únicamente gerencial, dado que su propósito es múltiple y debe ser entendida como un conjunto de ideas compartidas que permiten analizar múltiples cuestiones relevantes y planteadas desde la perspectiva de diferentes disciplinas (Freeman et al. 2010). Sus pilares básicos son el proceso de creación de valor en la empresa (aspecto económico) y el carácter social del mismo (aspecto moral), por lo que la ética se considera central e inseparable de las decisiones empresariales, y de ahí que la "mentalidad” de los directivos resulte como crucial en la gestión del proceso y en la resolución de conflictos y fricciones.

En el contexto de dicha teoría cabe distinguir un doble paradigma en la evolución de la responsabilidad (Freeman et al. 2010). En un primer momento es considerada una actividad residual o no estratégica de la empresa, estando subyacente la idea de devolver a la sociedad parte de lo que de ésta se ha recibido (la filantropía y el patrocinio serían claros exponentes de esta etapa), al tiempo que se mantiene una clara separación entre el valor social y financiero (o entre aspectos económicos y éticos). Por su parte, en un segundo estadio los planteamientos resultarían mucho más próximos a los de la teoría de los stakeholders, integrando las dimensiones social, ética y medioambiental en los criterios gerenciales de la empresa y en sus principios de dirección estratégica, lo que constituye una perspectiva ex ante sobre la creación de valor (no basado, como antes, exclusivamente en la distribución del beneficio).

Independientemente de sus ventajas y poder explicativo, también se han puesto de manifiesto algunas limitaciones de la propuesta stakeholders, bien relacionadas con sus supuestos conceptuales de análisis o con su aplicación, entre las que cabe mencionar las siguientes (González 2001):

i) En cuanto a su uso descriptivo y estratégico, se centra sólo en los efectos o consecuencias de las acciones o estrategias de la empresa y, en caso de conflicto de intereses, ni práctica ni teóricamente es fácil para ella jerarquizarlos o equilibrarlos para saber cuáles deben tener prioridad.

ii) Por lo que se refiere a su uso instrumental, se plantea una paradoja por cuanto si el objetivo estratégico principal es maximizar los intereses de los propietarios o accionistas, y para alcanzarlo se sacrifican en ocasiones los intereses de otros grupos vitales para lograr la maximización de los beneficios, al final los resultados sobre el objetivo principal pueden ser contrarios a los deseados (Bowie y Duska 1990). 
iii) La perspectiva de análisis está limitada a un concepto de interés económico, aun cuando las demandas e intereses de los stakeholders también pueden ser de carácter no económico (como la conciliación de la vida familiar u otros tipos de flexibilidad laboral).

iv) Aunque el planteamiento teórico surgió con conceptos normativos, carece de una justificación filosófica que permita diferenciar entre intereses y responsabilidades morales, económicos, sociales y de otro tipo, o simplemente especificar los principios o criterios morales que deberían regir las conductas humanas y empresariales (Donaldson 1989). Por tanto, carece de unas bases sólidamente afianzadas en la teorías éticas tradicionales (Argandoña 1998).

v) A pesar de haberse dicho mucho sobre las obligaciones y responsabilidades de los directivos hacia otros stakeholders, poco se ha hecho respecto de las obligaciones de otros stakeholders hacia la corporación. Del mismo modo, y siendo una tarea muy importante del enfoque especificar de qué y por qué es responsable la empresa y no sólo ante quién tiene obligaciones, poco se ha avanzado en cuanto a criterios normativos que permitan reflexionar sobre las responsabilidades de aquélla.

No obstante, y pese a las críticas y problemas aún no resueltos (como la forma de minimizar el oportunismo gerencial, o el rol de la comunidad como stakeholder, entre otros), la teoría de los stakeholders sigue siendo el marco conceptual más utilizado para el estudio de la responsabilidad (Phillips et al. 2003, Bigné et al. 2011).

En consonancia con lo señalado por algunos autores (Cuervo 2009), puede verse como una forma de incentivar cambios en las preferencias de los consumidores, introducir nuevas variables de diferenciación, mejorar el clima laboral, generar confianza, legitimidad y apoyo a la empresa. Este enfoque, incluye todos los grupos de interés que buscan la creación de riqueza para los diferentes partícipes, al considerar a la empresa como un lugar de intercambio, de contratos entre agentes que buscan maximizar su función de utilidad, para lo cual el gobierno de la empresa trata de resolver los conflictos de interés más significativos.

Centrándonos en el caso concreto del consumidor, para analizar su papel, importancia e influencia como stakeholder en la toma de decisiones de la organización, resulta de utilidad el modelo de prominencia de Mitchell et al. (1997), en base al cual su 
mayor o menor preponderancia dependerá de su caracterización en cuanto a los atributos de poder, legitimidad y urgencia, en los siguientes términos:

a) el poder, en tanto tengan acceso a medidas coercitivas, utilitarias o normativas para imponer su voluntad:

b) la legitimidad de sus demandas, avalada por la percepción generalizada de que sus acciones son deseables y aprobadas dentro de un sistema social de normas, valores, creencias y definiciones; y

c) la urgencia de las mismas, en términos de inmediatez y sensibilidad al tiempo de las actuaciones pretendidas, además de ser importante o críticas para el consumidor.

En opinión de Schwalb (2009), de estos tres corresponden al consumidor los atributos centrales de poder y legitimidad, mientras que la urgencia dependerá de las circunstancias. Se puede considerar como un stakeholder definitivo, aunque a veces pueda no ejercer el poder, y la legitimidad varíe según el marco social, según exista o no un marco legal que reconozca los derechos del consumidor, o la madurez, la educación y la experiencia de éste en el ejercicio de sus derechos.

Conforme al modelo de prominencia, los directivos perciben la posición de cada grupo de interés en función de la posesión relativa de cada uno de ellos en lo relativo a su poder, legitimidad y urgencia, determinando después cómo destinar los recursos para atender sus demandas (Mitchell et al. 1997). De esta forma, la importancia atribuida por la dirección de la empresa a los intereses del consumidor dependerá de la percepción que tenga sobre su situación respecto a los tres atributos. En función de la concurrencia o carencia de los mismos obtendrá mayor o menor atención por parte de la empresa.

Siendo, pues, el consumidor un stakeholder, como tal grupo de interés debe ser objeto de consideración por parte de la entidad. Ésta, en el diseño e implementación de su estrategia de integración de la responsabilidad, debe contemplar, entre otras materias de singular importancia, los asuntos relacionados con los consumidores y sus deberes para con los mismos ${ }^{100}$.

\footnotetext{
${ }^{100}$ Aspecto específicamente señalado en el cuarto de los capítulos de la norma ISO 26000, en el que se hace relación de las siete materias fundamentales que han de ser tenidas en cuenta por las organizaciones para su integración en las políticas de responsabilidad. Aparte de los asuntos con los consumidores, entre estas materias se encuentran la gobernanza de la organización, los derechos humanos, las prácticas
} 
La identificación de dichos asuntos o responsabilidades hacia los consumidores, puede hacerse en los siguientes términos (Argandoña e Isea 2011):

i) Prácticas justas de marketing, incluyendo datos objetivos e imparciales y principios justos de contratación, que permitan al consumidor contar con toda la información necesaria para decidir si el producto satisface o no sus necesidades.

ii) Protección de la salud y la seguridad de los consumidores, ofreciéndoles productos que sean seguros y saludables.

iii) Promoción de patrones de consumo que sean acordes con el desarrollo sostenible (consumo sostenible), favoreciendo niveles de consumo que garanticen la satisfacción de las necesidades de las generaciones presentes sin comprometer la capacidad de las generaciones futuras para satisfacer las suyas.

iv) Oferta de mecanismos para que los consumidores puedan satisfacer sus necesidades tras haber adquirido un producto o disfrutado del mismo, mediante una serie de disposiciones relacionadas con la devolución, la reparación o el mantenimiento.

v) Reconocimiento (de facto) de la importancia de proteger el derecho a la privacidad y confidencialidad de los datos de los consumidores.

vi) Inclusión de la posibilidad de acceso a servicios esenciales, en el caso de que la organización preste servicios básicos. En tal sentido, y aun cuando el Estado pueda ser incapaz de garantizar el derecho a dichos servicios a una parte de la población, se aconseja contribuir a la garantía de dichos derechos.

vii) Realización de actuaciones de mejora de la educación e incremento de la toma de conciencia por parte del consumidor, proporcionando a éste el conocimiento de sus derechos y responsabilidades y facilitando que pueda proceder a tomar sus decisiones con una mayor libertad.

Todos esos aspectos están relacionados con las expectativas del consumidor sobre el comportamiento responsable de la organización, en estrecha relación con los principios propios de una sociedad económicamente globalizada y permanentemente conectada gracias al extraordinario desarrollo de las tecnologías de la información y la comunicación. En la medida que el consumidor pueda apreciar y valorar las conductas responsables, formarán parte de lo que se espera recibir de la entidad (Sichar 2003).

laborales, el medio ambiente, las práctica justas de operación, y la participación activa y en el desarrollo de la comunidad. 


\subsubsection{Enfoques integradores en la definición de la responsabilidad}

Existe un número relativamente alto de contribuciones en la literatura académica que abordan el tema de la responsabilidad desde la perspectiva de la Organización de Empresas, superior al de las aportaciones desde otras disciplinas de la empresa y del ámbito económico en general, así como desde otras áreas del conocimiento científico (Pérez 2011). En concreto, y desde la disciplina del Marketing, las investigaciones se han centrado generalmente en dimensiones limitadas del concepto, en especial en trabajos de carácter empírico (Vaaland et al. 2008). Conforme indican Maignan y Ferrell (2004), en la literatura comercial se aprecia una gran fragmentación en términos de unidad de análisis considerada y de las dimensiones de responsabilidad estudiadas, lo que lleva a concluir que la investigación no ha conseguido proporcionar una visión integrada y global de la responsabilidad que permita coordinar las distintas actividades sociales de la empresa.

Entrando en un mayor nivel de detalle, las iniciativas en el estudio de la responsabilidad desde la perspectiva del Marketing pueden agruparse en seis grandes categorías (Kotler y Lee 2005, Galán 2011): las promociones de causas, el marketing con causa, el marketing social corporativo, la filantropía corporativa, el voluntariado en la comunidad, y las prácticas empresariales socialmente responsables (Cuadro 4.2) ${ }^{101}$ :

1. Las promociones de causas (cause promotions) son actuaciones sustanciadas mediante la aportación por parte de las entidades de fondos, contribuciones en especie u otros recursos corporativos para sufragar acciones llevadas a cabo con el objetivo de incrementar la conciencia y/o fomentar la preocupación e interés por una causa social, para apoyar la participación de voluntarios en favor de una causa, o en la recaudación de fondos para ésta (en todo caso, ya sea actuando la entidad por sí misma, o como socio colaborador de otras más directamente vinculadas con dicha causa). Dentro de esta categoría es objeto de particular interés el análisis de las prácticas de comunicación de la responsabilidad y el papel de la publicidad con contenido social en la estrategia empresarial.

\footnotetext{
${ }^{101}$ A estas categorías, y habida cuenta de su creciente importancia en la época más reciente, autores como Pérez (2011) sugieren que sería preciso incorporar otras como: el marketing medioambiental (donde se toma el medioambiente como principal dimensión de interés en las políticas sociales de la organización); la actitud directiva hacia la responsabilidad (y en particular de los directivos de marketing); la integración teórica (que aglutinaría los esfuerzos encaminados a incorporar el paradigma de la responsabilidad en la teoría del Marketing); y la respuesta del consumidor (para analizar el efecto que tienen las acciones de responsabilidad en las creencias, actitudes y comportamientos de éste).
} 
2. El marketing con causa (MCC, cause-related marketing o CRM), surge cuando una empresa se compromete a contribuir o a donar un porcentaje de sus ingresos (por uso o por volumen) a una causa específica. La compañía suele estar asociada a una ONG, con lo que se crea una relación mutuamente beneficiosa y diseñada para aumentar las ventas de un producto particular y también para proporcionar fondos a una entidad colaboradora. Las contribuciones dentro de esta categoría se dedican a analizar y definir el efecto de tales actuaciones sobre la rentabilidad empresarial y la conducta del consumidor. Aunque hay quien considera que se trata de una forma más de promoción de ventas, para otros autores estas acciones deben entenderse como filantropía empresarial planificada de acuerdo con objetivos mucho más amplios (Buil et al. 2012), puesto que, además de mejorar la posición de la propia empresa, se pretende contribuir a la mejora de la sociedad (File y Prince 1998, Varadarajan y Menon 1988) ${ }^{102}$.

\section{Cuadro 4.2. Clasificación de las contribuciones sobre responsabilidad desde la perspectiva del Marketing}

\begin{tabular}{|c|l|}
\hline Categoría & \multicolumn{1}{c|}{ Elementos definitorios del enfoque } \\
\hline Promociones de causas & $\begin{array}{l}\text { Análisis de aportaciones de fondos u otros recursos para actuaciones } \\
\text { persuasivas, estimulando la conciencia o fomentando el interés por una } \\
\text { causa social, con un énfasis particular en las estrategias promocionales y } \\
\text { públicos objetivo fuera de la organización }\end{array}$ \\
\hline Marketing con causa & $\begin{array}{l}\text { Estudio de las contribuciones y apoyos, vinculadas con las ventas o } \\
\text { transacciones de productos específicos de la empresa, y que dependen de } \\
\text { la apreciación y las acciones de respuesta del consumidor }\end{array}$ \\
\hline Marketing social & $\begin{array}{l}\text { Estudio de los cambio de comportamiento de los individuos tras acciones } \\
\text { para apoyar la concienciación, la participación en la recaudación de } \\
\text { fondos o el reclutamiento voluntario para una causa }\end{array}$ \\
\hline Filantropía corporativa & $\begin{array}{l}\text { Análisis de las acciones que suponen contribuciones directas a una causa } \\
\text { u ONG, frecuentemente bajo la forma de cantidades en efectivo y/o } \\
\text { dotaciones en especie (siendo la iniciativa más tradicional y discrecional) }\end{array}$ \\
\hline $\begin{array}{c}\text { Voluntariado en la } \\
\text { comunidad }\end{array}$ & $\begin{array}{l}\text { Estudio de las acciones de servicio en el seno de la empresa para que sus } \\
\text { colaboradores dediquen voluntariamente parte de su tiempo (talento, } \\
\text { experiencia, ideas y/o trabajo físico) a apoyar causas y organizaciones de } \\
\text { la comunidad local }\end{array}$ \\
\hline socialmente responsables & $\begin{array}{l}\text { Análisis de las prácticas empresariales discrecionales (o esperadas, según } \\
\text { los estándares éticos o morales) e inversiones que se apoyan en causas } \\
\text { sociales para mejorar el bienestar de la comunidad y proteger el entorno }\end{array}$ \\
\hline
\end{tabular}

Fuente: Elaboración propia en base a Kotler y Lee (2005), y Galán (2011).

\footnotetext{
${ }^{102}$ En este sentido, y al analizar la influencia de las campañas de marketing con causa en la actitud hacia la marca, Buil et al. (2012) concluyen que las campañas más creíbles son las mejor valoradas y las que más la fortalecen. Determinantes de la valoración de la campaña y de la actitud hacia la marca son el ajuste entre el producto y la causa, la familiaridad con la marca, y la implicación con la causa.
} 
3.- Mediante prácticas de marketing social corporativo (MSC, coporate social marketing o CSM), una empresa apoya la implementación de una campaña cuyo objeto es lograr un cambio de comportamiento en los individuos, ya sea por sí misma o en colaboración con agencias del sector público y/o entidades del sector no lucrativo (Penelas et al. 2012). Desde esta perspectiva se estudia la contribución de las actividades de marketing a los comportamientos y a los logros socialmente responsables, para lo cual se diseñan, implementan y controlan los programas sociales. Según Kotler (1989), se trata de las actividades desarrolladas por una empresa o sector con el objetivo de lograr el compromiso de los consumidores hacia un determinado comportamiento de interés social, favoreciendo, al mismo tiempo y de forma directa, los intereses de la/s empresa/s en cuanto a su posición en el mercado y a su imagen.

4. En caso de optar por acciones de filantropía corporativa (corporate philanthropy $)^{103}$, lo que hace la entidad es una contribución directa a una ONG o causa determinada, frecuentemente en forma de cantidades en efectivo y/o donaciones en especie. Se trata, en definitiva, de una transferencia de recursos corporativos a unos destinatarios externos y con una finalidad caritativa. Por otra parte, son donaciones muy institucionalizadas, relacionadas con el Estado del Bienestar, con el apoyo de un instrumento básico en tal sentido como es la figura de las fundaciones, y cuyas prácticas están motivadas por una combinación de altruismo, sentimiento de ciudadanía, prudencia y razones comerciales (Shaw y Post 1993). Son aquí objeto de consideración los programas estratégicos específicos basados en donaciones y obras benéficas.

5. Al llevar a cabo actuaciones de voluntariado en la comunidad (voluntariado comunitario o community volunteering), una organización realiza servicios por medio de sus empleados y otros colaboradores, a los que apoya y anima a dedicar libre y altruistamente parte de su tiempo y sus capacidades a apoyar causas y organizaciones de la comunidad local. Estas personas donan su tiempo y su talento, su experiencia, sus ideas y/o trabajo físico, conectando los esfuerzos voluntarios con las metas y valores básicos de la entidad. Los programas de voluntariado corporativo se pueden definir como aquél conjunto de políticas y prácticas formales e informales que las empresas

\footnotetext{
${ }^{103}$ Debe realizarse, tal y como señala Valor (2010), una precisión en cuanto a la definición conceptual del término "filantropía”, por cuanto en español tiene la connotación de “desinteresado". Ello hace que no resulte muy apropiado, dado que la empresa persigue siempre (directa o indirectamente) un objetivo económico cuando colabora con la comunidad. En el entorno anglosajón, por el contrario, no se plantea esta dificultad, ya que el término "philanthropy" carece de la mencionada connotación y se refiere a las contribuciones de la empresa a actividades de interés general.
} 
usan para estimular y ayudar a los empleados a hacer voluntariado en servicios comunitarios (Tschirhart 2005). Es un tipo de actuaciones que se han desarrollado más en países como Estados Unidos y el Reino Unido, mientras que en otros como España se encuentra en un estado más incipiente, aunque progresivamente se le empieza a prestar cada vez más atención, llevando a las empresas a incorporarlas como una parte integral de sus programas de responsabilidad (González et al. 2008, Dávila 2012).

6. Al realizar prácticas empresariales socialmente responsables (socially responsible business practices), las empresas adoptan y/o reconducen actuaciones discrecionales e inversiones para apoyar causas sociales orientadas a la mejora del bienestar de la comunidad y la protección del entorno. Tales iniciativas pueden ser concebidas e implementadas directamente por la organización, o bien llevarse a cabo en asociación con otras, en todo caso con carácter voluntario o discrecionales (pues no son obligadas por Ley). Antes bien, responden a lo que se espera de la entidad conforme los estándares éticos o morales imperantes.

Siendo, pues, evidente la variedad de aspectos de la responsabilidad a los que se refiere y la fragmentación de las líneas de investigación al respecto desde la disciplina del Marketing, destaca la que analiza la influencia de la información que el consumidor recibe acerca de las actividades sociales de las empresas en sus posteriores decisiones de compra y consumo (Pérez 2011). Con todo, es relativamente reciente (Sen y Bhattacharya 2001, Pérez 2011), pues hasta el año 2000 sólo cuatro trabajos se centraban específicamente en estos aspectos (Brown y Dacin 1997, Murray y Vogel 1997, Creyer y Ross 1997, y Ellen et al. 2000). De hecho, la escasez de estudios sobre la responsabilidad desde la óptica del consumidor llamaba la atención hasta hace poco (Andreu et al. 2004, Bigné et al. 2005), y pese al dinamismo más reciente, el número de aportaciones es muy escaso en comparación con otros estudios sobre responsabilidad en las ciencias empresariales en general (Alvarado 2008).

En cuanto a su contenido, esta línea de investigación centra sus esfuerzos en la mayor comprensión del modo en que cómo son percibidos los comportamientos de una organización desde la perspectiva externa de la demanda, y en qué medida son apreciadas y valoradas las iniciativas de la misma. En el Cuadro 4.3 se incluyen las contribuciones más representativas en las que se analizan el efecto que tienen las acciones de responsabilidad empresarial en las creencias, actitudes y comportamientos de los consumidores. 
Cuadro 4.3. Aportaciones representativas en cuanto a la percepción por parte del consumidor y la respuesta de éste a las iniciativas responsables de las empresas

\begin{tabular}{|c|c|}
\hline Autor & Aspecto/s señalado/s \\
\hline Bowen y Dacin (1997) & $\begin{array}{l}\text { Asociaciones corporativas y respuesta de los consumidores hacia las } \\
\text { compañías percibidas como socialmente responsables }\end{array}$ \\
\hline Creyer y Ross (1997) & $\begin{array}{l}\text { Influencia del comportamiento de la empresa en las intenciones de } \\
\text { compra del consumidor }\end{array}$ \\
\hline Murray y Vogel (1997) & $\begin{array}{l}\text { Efectividad de la responsabilidad para la generación de buena voluntad o } \\
\text { predisposición positiva hacia la empresa }\end{array}$ \\
\hline Folkes y Kamins (1999) & $\begin{array}{l}\text { Influencia de la información corporativa acerca de aspectos éticos sobre } \\
\text { las actitudes del consumidor }\end{array}$ \\
\hline $\begin{array}{l}\text { Lafferty y Goldsmith } \\
\qquad(1999)\end{array}$ & $\begin{array}{l}\text { Influencia de la credibilidad de los personajes que respaldan las acciones } \\
\text { de responsabilidad sobre las actitudes de los consumidores }\end{array}$ \\
\hline Ellen et al. (2000) & $\begin{array}{l}\text { Condiciones que contribuyen a una mejor evaluación de los esfuerzos de } \\
\text { marketing con causa }\end{array}$ \\
\hline $\begin{array}{l}\text { Sen y Bhattacharya } \\
\text { (2001) }\end{array}$ & $\begin{array}{l}\text { Efecto de las iniciativas de responsabilidad en los juicios éticos de los } \\
\text { consumidores acerca de la empresa }\end{array}$ \\
\hline Maignan y Ferrell (2003) & $\begin{array}{l}\text { Diferencias en el significado e importancia de la responsabilidad entre } \\
\text { consumidores de distintos países y su impacto en la evaluación de la } \\
\text { empresa }\end{array}$ \\
\hline $\begin{array}{l}\text { Bhattacharya y Sen } \\
\text { (2004) }\end{array}$ & $\begin{array}{l}\text { Implementación y medición de las iniciativas de responsabilidad } \\
\text { empleando factores resultantes internos y externos del consumidor }\end{array}$ \\
\hline Berens et al. (2005) & $\begin{array}{l}\text { Relación entre la responsabilidad y la estrategia de marca en la respuesta } \\
\text { del consumidor }\end{array}$ \\
\hline $\begin{array}{l}\text { Fernández y Merino } \\
\qquad(2005)\end{array}$ & $\begin{array}{l}\text { Disponibilidad a pagar un sobreprecio asociado a un producto o servicio } \\
\text { socialmente responsable }\end{array}$ \\
\hline $\begin{array}{l}\text { García de los Salmones } \\
\text { et al. (2005) }\end{array}$ & $\begin{array}{l}\text { Influencia de las percepciones sobre aspectos económicos, jurídicos, } \\
\text { éticos y sociales en la evaluación y lealtad de los consumidores de } \\
\text { servicios de telefonía móvil }\end{array}$ \\
\hline Bigné et al. (2006) & $\begin{array}{l}\text { Influencia de la responsabilidad en el comportamiento de compra de los } \\
\text { estudiantes europeos }\end{array}$ \\
\hline Dacin y Brown (2006) & $\begin{array}{l}\text { Asociaciones e identidad corporativas, y respuesta de los consumidores } \\
\text { hacia las compañías percibidas como socialmente responsables }\end{array}$ \\
\hline Ellen et al. (2006) & Atribuciones de los consumidores a los programas de responsabilidad \\
\hline Sen et al. (2006) & $\begin{array}{l}\text { Atención prestada a las acciones responsables, e impacto de las mismas } \\
\text { en intenciones y conductas futuras de consumo, empleo e inversión }\end{array}$ \\
\hline Bigné y Currás (2008) & $\begin{array}{l}\text { Contraste de la influencia de la imagen de RSC y de la habilidad } \\
\text { corporativa de la marca sobre la intención de compra del consumidor a } \\
\text { través de la identificación de la empresa, a través de un modelo }\end{array}$ \\
\hline Webb et al. (2008) & $\begin{array}{l}\text { Reformulación del concepto de consumo socialmente responsable para } \\
\text { incluir nuevas demandas y aspectos, como el rendimiento y el reciclaje }\end{array}$ \\
\hline Vlachos et al. (2009) & $\begin{array}{l}\text { Análisis de los motivos que hacen que los consumidores demanden a las } \\
\text { empresas que se comporten responsablemente, distinguiendo entre } \\
\text { egoístas, estratégicos, impulsados por stakeholders, y de valores }\end{array}$ \\
\hline
\end{tabular}


Cuadro 4.3. Aportaciones representativas en cuanto a la percepción por parte del consumidor y la respuesta de éste a las iniciativas responsables de las empresas (...continuación)

\begin{tabular}{|c|l|}
\hline \multicolumn{1}{|c|}{ Autor } & \multicolumn{1}{c|}{ Aspecto/s señalado/s } \\
\hline Green y Peloza (2011) & $\begin{array}{l}\text { Análisis de la constancia en el apoyo positivo de los consumidores a las } \\
\text { acciones de responsabilidad, utilizando un contexto recesivo como } \\
\text { referente para contrastar la situación en cuanto a distintos tipos de } \\
\text { responsabilidad }\end{array}$ \\
\hline Bigné et al. (2011) & $\begin{array}{l}\text { Determinación del grado en que las asociaciones de responsabilidad } \\
\text { influyen en el valor percibido y en las dimensiones cognitiva y afectiva } \\
\text { de la satisfacción de los consumidores }\end{array}$ \\
\hline de los Ríos et al. (2012) & $\begin{array}{l}\text { Análisis de la relación entre la información sobre responsabilidad social } \\
\text { proporcionada a sus clientes por las entidades financieras y su reputación } \\
\text { corporativa }\end{array}$ \\
\hline Pérez y Rodríguez (2012) & $\begin{array}{l}\text { Análisis de la imagen y la importancia de la responsabilidad para los } \\
\text { usuarios de servicios financieros }\end{array}$ \\
\hline
\end{tabular}

Fuente: Elaboración propia en base a Alvarado (2008) y las contribuciones relacionadas.

Del análisis de estas aportaciones se desprende la existencia de un denominador común, cual es conocer la forma en que se perciben y aprecian los múltiples y variados aspectos con los que las organizaciones quieren poner de manifiesto a sus clientes y consumidores el carácter responsable de sus actuaciones. Cabría, también y no obstante, preguntarse si los consumidores son realmente del poder de sus decisiones y actuaciones en los procesos de compra como herramienta para lograr cambios de comportamiento de las empresas y de los mercados.

\subsection{La responsabilidad en el proceso de intención de compra}

La demanda de comportamientos socialmente responsables por parte de los ciudadanos y de organizaciones de la sociedad civil es uno de los aspectos más significativos del escenario internacional de los últimos años (Doh y Guay 2006). Estos grupos buscan la efectividad de sus demandas empleando para ello diferentes estrategias (García et al. 2011) como pueden ser, entre otras, las de entorpecer, ralentizar o boicotear el ritmo normal de las operaciones de la empresa (aumentando el coste económico para la misma) u otras formas de expresión colectiva utilizadas para denunciar comportamientos empresariales (campañas de recogida de firmas, envío de correos electrónicos, manifestaciones, etc.). 
De entre todas estas posibles actuaciones, las que centran aquí el interés son aquéllas que tienen una gran repercusión (y justificación) económica por concernir a los consumidores y a sus decisiones, debiéndose analizar el modo en que el mercado y el poder de compra pueden actuar como vía de expresión de las preocupaciones sociales, medioambientales y éticas.

Así las cosas, si el consumidor no está obligado a comprar un producto y es libre de adquirirlo o rechazarlo, cabe plantear el interrogante sobre por qué no argumentar que la responsabilidad en cuanto a que las empresas orienten sus actuaciones en la dirección que se considere más apropiada por el conjunto de los stakeholders residirá no sólo en aquéllas, sino tanto y más en sus clientes. Éstos no estarían exentos de cierta carga de responsabilidad, sobre todo bajo una visión clásica de la teoría del libre mercado, con decisiones que repercuten directamente en los resultados empresariales.

Esta línea de razonamiento está relacionada con lo que se ha dado en denominar “doctrina de la advertencia vacía”, fundamentada en el presupuesto de libre participación y elección en las relaciones empresa-cliente (Bowie y Duska 1990, Weiss 1994) ${ }^{104}$. No obstante, tal teoría no está exenta de críticas, derivadas en parte de sus propias hipótesis, como son (Weiss 1994): i) la existencia de empresas que manipulan las necesidades y hábitos de los consumidores; ii) la falta de información sobre condiciones de producción, productos y comportamientos; y iii) que el libre mercado ni mucho menos siempre protege al cliente frente a comunicaciones controvertidas y a productos de baja calidad.

Un análisis pormenorizado de la influencia de las acciones responsables en los procesos de compra deberá tratar de identificar las fases en que las limitaciones anteriores sean reconocidas y tenidas en cuenta. En todo caso, se puede intuir que una responsabilidad compartida empresa-consumidor plantea considerables dificultades en marcos como el actual, con pluralidad de productos y de actividades que los consumidores deben conocer y sobre los que han de tener información al tomar sus decisiones, no cabiendo esperar que en caso de no disponer de ella procedan a investigar antes de decantarse por un producto que cumpla sus expectativas (Valor 2010).

\footnotetext{
${ }^{104}$ Orientada a la salvaguarda de la seguridad y confianza del cliente, sostiene que al consumidor se le debe dar un anuncio del producto "hueco" o vacío de alternativas, para que sea él quien se preocupe y cuide de sí mismo, dado que la relación entre empresa y cliente está regulada por una "mano invisible”, y asumiendo el supuesto de que el cliente tiene libertad y sentido común suficiente para seleccionar lo que quiere o rechazar lo que no quiere (Weiss 1994:137).
} 
4.2.1. El proceso de decisión de compra y la modelización del comportamiento del consumidor

Distintos modelos han tratado de plasmar el proceso seguido en las decisiones de compra del consumidor, todos los cuales comparten una serie de planteamientos o rasgos comunes en las diversas etapas consideradas. De entre las varias posibilidades ${ }^{105}$, aquí se utilizará como referente explicativo el compartido por Blackwell et al. (2006), Solomon (2008) y Santesmases (2012), por ser uno de los más representativos. Tal y como se puede apreciar en la Figura 4.3, dicho modelo sugiere una serie secuencial de actuaciones de los consumidores, que van desde el reconocimiento del "problema" o necesidad, hasta la valoración de los resultados de la decisión de compra.

Conforme a este esquema, y aunque no siempre con la misma intensidad o importancia, lo primero que se plantea es la generación de demanda o reconocimiento de la necesidad por parte del consumidor, unido a un deseo de satisfacerla y una capacidad para hacerlo, en todo lo cual la motivación del individuo y los factores de su entorno influyen de un modo especial.

Figura 4.3. Etapas en el proceso de toma de decisiones del consumidor

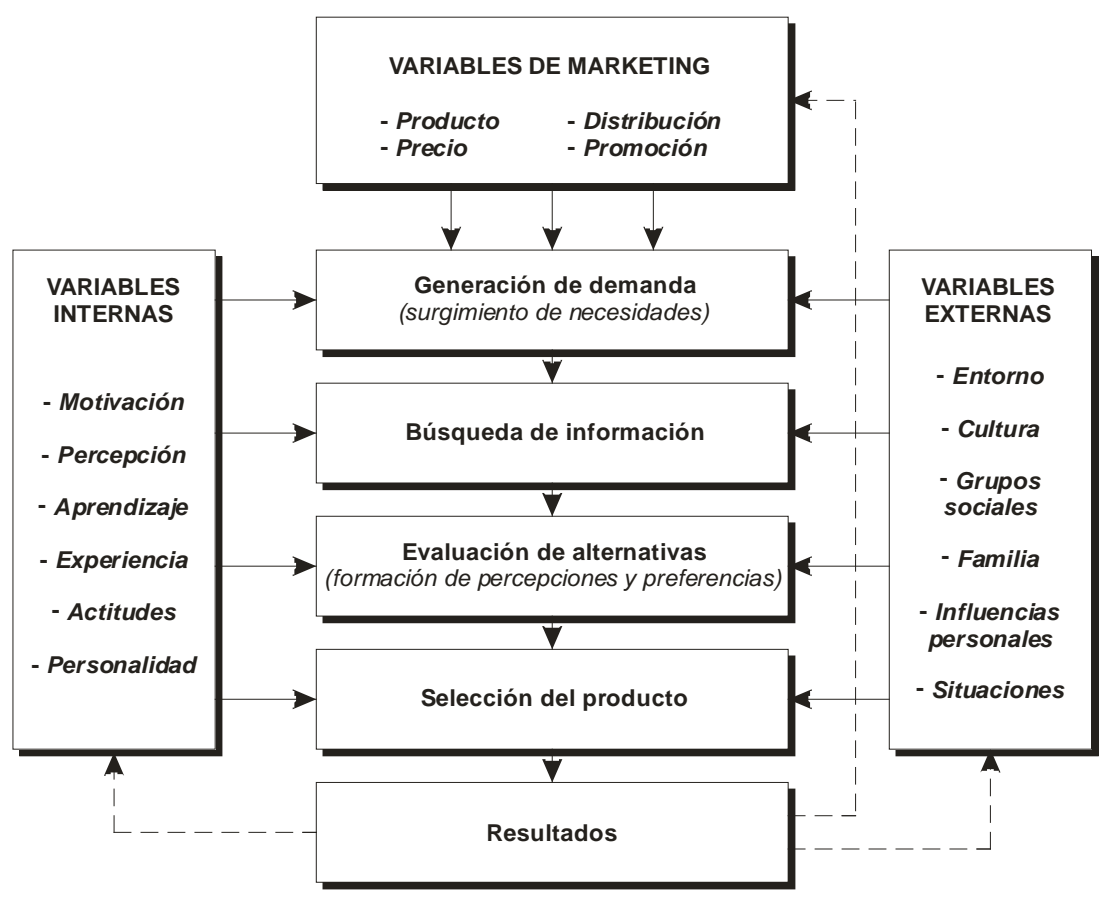

Fuente: Elaboración propia en base a Solomon (2008) y a Santesmases (2012).

\footnotetext{
${ }^{105}$ Entre otros, los de Chatfield y Goodhart (1973), o Cabero y Cebollada (1998).
} 
A continuación se procede a una búsqueda de información, mediante la cual el consumidor explora en el ambiente y puede encontrar los datos apropiados para estar en condiciones de tomar una decisión adecuada. La búsqueda puede ser interna (en su memoria o en sus datos) o externa al individuo (fuentes de información de terceros), y será más o menos laboriosa según la experiencia previa y la complejidad de la compra.

En el momento de evaluar las alternativas para satisfacer su necesidad que le ofrece el mercado, el consumidor percibe los atributos de los distintos productos candidatos a la elección y forman sus preferencias. Es ahora cuando el individuo considera tanto las alternativas conocidas (conjunto evocado) como las realmente tomadas en cuenta en el proceso de selección (conjunto de consideración) para ordenar y evaluar las opciones relevantes conforme a unos criterios de evaluación o dimensiones utilizadas para juzgar los méritos de las opciones competidoras.

La selección de productos se realiza en base a la percepción de sus atributos o características determinantes, optando por comprar o no respecto a cada opción, ya sea de modo definitivo o temporal, hasta que se recabe más información.

Una vez realizada la compra, en una fase de resultados el consumidor experimenta sentimientos o sensaciones de satisfacción o insatisfacción hacia el producto adquirido, predisponiéndole a reiterar o cambiar su elección en el futuro. La satisfacción está determinada por muchos factores (calidad del producto, precio, marca, funcionamiento, etc.) en relación a expectativas previas. Tanto los resultados como toda la experiencia adquirida realimentarán nuevos procesos de decisión de compra.

Según se aprecia asimismo en la Figura 4.3, todo el proceso está influido no sólo por aspectos o variables comerciales (producto, precio, distribución, promoción), sino también por una amplia serie de variables internas y externas al individuo.

Esa misma secuencia también ha servido de base para explicar el proceso de compra desde el punto de vista responsable (Öberseder et al. 2011). En este sentido, Valor (2010) describe el camino que siguen los consumidores (Figura 4.4), a modo de ciclo que incluye los antecedentes de la compra (convicciones personales de valores y eficacia), la adquisición de información (sobre diferentes aspectos de la organización), la valoración de alternativas (desde el punto de vista económico o no económico), y el comportamiento o decisión que, de nuevo, retroalimentará los antecedentes de la compra. 
Figura 4.4. Etapas en el proceso de toma de decisiones del consumidor responsable

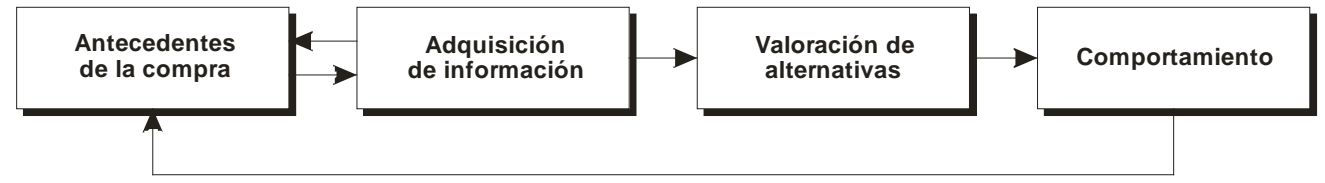

Fuente: elaboración propia a partir de Valor (2010).

De este modo, las tres primeras etapas (a las que está dedicado el subepígrafe siguiente) no serían, así, sino prolegómenos del momento “clave” en que el consumidor ha de tomar una decisión acorde con sus valores personales y otros factores, incluida su percepción sobre la responsabilidad, sus expectativas y su percepción sobre el carácter más o menos responsable de las actuaciones de las empresas, y su percepción respecto a la eficacia de sus actuaciones para incidir en la conducta de éstas.

Esa decisión, con todo, no siempre es ni mucho menos fácil. En ocasiones, ni siquiera los consumidores con predisposición favorable son capaces de encontrar una alternativa en el mercado coherente con sus valores y expectativas, o sus condicionantes presupuestarios pueden hacerles inviable adquirirla. En otros casos pueden considerar que el sacrificio de objetivos de utilidad en pro de otros fines altruistas es demasiado grande, o que no estén dispuestos a sacrificar más allá de unos ciertos niveles de precio o calidad por comprar de forma responsable.

Si, finalmente, los individuos toman decisiones de consumo responsable ${ }^{106}$, lo harán persiguiendo un objetivo fundamentalmente expresivo, principalmente punitivo, o bien lo harán teniendo en mente una mezcla con más o menos peso de alguno de ellos. El fin será expresivo cuando el consumidor entienda su decisión como una forma de declaración pública de valores y creencias personales, y será punitivo cuando se realicen para influir en la toma de decisiones de las entidades (premiándolas o reprobándolas).

En consonancia con lo anterior, se distinguen hasta cuatro tipos o categorías de consumo responsable (Valor 2010): estrategias de salida, estrategias de voz, estrategias de compra inteligente, y estrategias de no compra.

\footnotetext{
${ }^{106}$ Calificativo al que en ocasiones se hace referencia con otros sinónimos, tales como "consumo ético”, “activismo del consumidor”, o “consumo político” (Valor 2010).
} 
a) Las estrategias de salida se materializan en acciones de rechazo de una marca o de un producto a tenor de la disconformidad con las prácticas empresariales, o con los resultados sociales o medioambientales de la entidad. Pueden llegar a plantearse bajo la forma de boicot o abandono real del mercado, dejando de comprar, o bien limitarse al aspecto emocional, como expresión del desacuerdo.

El boicot no sólo consiste en dejar de realizar determinadas compras, pudiendo también tratarse de diversas formas de presión. En tal sentido, quizá la clasificación más completa es la que atiende a la acción solicitada (Friedman 1999, Valor 2010), lo que permite distinguir entre boicots de amenaza (a modo de aviso, sin llegar a realizar el boicot propiamente dicho), de realización (no se amenaza, pero se lleva a cabo), los orientados a los medios de comunicación (iniciados por organizaciones o individuos con alta notoriedad y reconocimiento, tratan de conseguir presencia en los medios), los orientados al mercado (intentan conseguir presencia en el mercado, repercutiendo de forma negativa en la cifra de ventas de la empresa boicoteada), y los obstruccionistas (tratan de ejercer presión directa sobre la empresa, pidiéndola que desista o realice una o varias prácticas o comportamientos).

b) Optar por estrategias de voz supone llevar al mercado valores individuales, apoyando la compra de determinados productos y/o marcas, ya sea por los buenos resultados sociales y/o medioambientales, o por las buenas prácticas de las empresas que los ofrecen. Para tener éxito, conviene contar con el apoyo de certificados o de etiquetas que ayuden al consumidor a elegir productos y marcas de las organizaciones con mejor desempeño en aquellos aspectos que más valora.

c) La categoría de estrategias de compra inteligente agrupan todas las formas de consumo, o no consumo, que persiguen lograr cambios estructurales, de acuerdo con los cuales determinadas necesidades (demandas) pasarían a satisfacerse en mercados alternativos y arraigados en sistemas de valores radicalmente diferentes. Entre las más conocidas de dichas formas se encuentran el comercio justo y la agricultura biológica.

El comercio justo se considera la forma más importante de compra inteligente. Se basa en una alianza comercial que trata de conseguir el desarrollo sostenible de productos excluidos y/o en desventaja. Intenta modificar las estructuras comerciales, al entender que en ellas está una de las raíces de la pobreza, ofreciendo unas condiciones justas a los productores locales de países en desarrollo. 
Por su parte, la agricultura biológica, cada vez más demandada, se caracteriza por una oferta que utiliza en sus etapas productivas, medios y materiales naturales y respetuosos con el medio ambiente, en lugar de compuestos sintéticos. Aunque existen argumentos a favor y en contra de los productos biológicos, lo cierto es que los consumidores, generalmente, los perciben como más sanos y con menos riesgos que los tratados con productos químicos.

d) Las estrategias de no compra derivan de los postulados de un movimiento simplificador o reductor del consumo (simplifying), y apoyado en la puesta en práctica de la denominada “ley de las 3R”: reducir, reciclar y reutilizar (Valor 2010). El objetivo concreto, y según los casos, puede ser asegurar la sostenibilidad del planeta, resolver las necesidades sin acudir al mercado, o conseguir mayor estabilidad y tiempo, entre otras.

Dentro de este apartado están las propuestas de acciones operativas y campañas de menor consumo dirigidas a los ciudadanos, los bancos de tiempo, las redes de intercambio, las comunidades de personas que tratan de vivir de forma sostenible y alejadas del sistema de mercado actual, etc.

En una propuesta análoga, Forética (2011) se refiere a las formas que tienen los individuos de incorporar criterios de responsabilidad en el consumo, conforme a las percepciones de éstos (Figura 4.5). Así, mediante una discriminación negativa van a despreciar determinados productos por considerarlos poco responsables (ya sea en sí mismos, o a causa del proceso de producción o de la reputación del fabricante). Por el contrario, mediante una discriminación positiva mostrarán su preferencia por productos considerados más responsables, ya sea cuando se ofertan en igualdad de condiciones o incluso pagando una prima o sobreprecio por ellos. También cabe la posibilidad, manifiesta en la vida real, de que ambas aproximaciones coexistan, con lo que las actuaciones pueden ser relativas, quedarse en una mera declaración de intenciones por la presencia de determinados condicionantes, o incluso puede darse el caso de que los consumidores digan una cosa y hacer otra ("gap de doble moral”) ${ }^{107}$. Esto es así por cuanto los sujetos tienden a magnificar su conducta en primera persona, mientras que, por regla general y cuando se proyecta la cuestión a un tercer sujeto, los resultados tienden a acercarse más al comportamiento real.

\footnotetext{
${ }^{107}$ Conforme al informe de Forética (2011), este "gap de la doble moral” sería una de las variables menos cíclicas en su estudio, manteniéndose estable entre 2006 y 2010 en torno al 36\% en lo que se refiere a la disposición a premiar o pagar más por un consumo responsable, según se considere la actuación del consumidor en primera o en tercera persona.
} 
Figura 4.5. Actitudes de consumo responsable

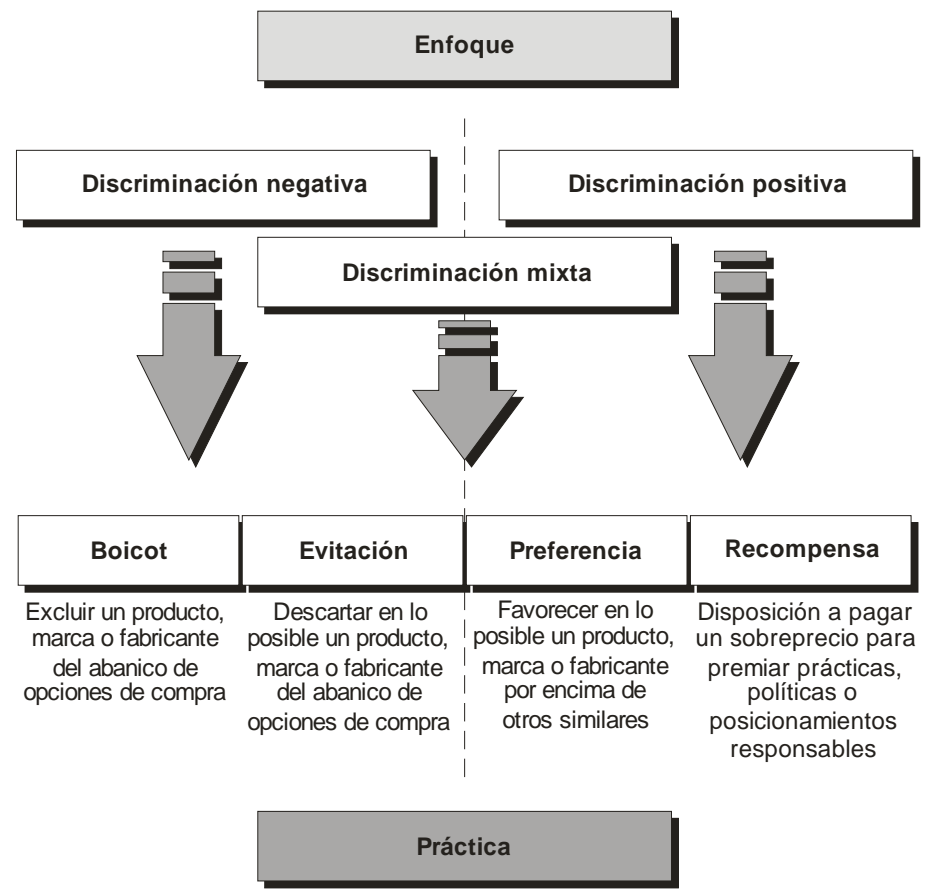

Fuente: Forética 2011.

Los resultados del estudio empírico paralelo de esta organización ponen de manifiesto que la discriminación negativa se revelaba como principal manifestación de consumo responsable en 2010, siendo un 45\% el porcentaje de quienes decían haberla practicado en alguna ocasión (frente al 37\% de 2006), y sugiriéndose un patrón cíclico para esta conducta, como vía de respuesta del consumidor cuando tiene dificultades económicas. Por el contrario, y aunque los consumidores se mostraban favorables a la discriminación positiva, decrecía el número de individuos dispuestos a pagar un plus adicional por una oferta responsable ${ }^{108}$.

En uno y otro caso, se aprecian diferencias sectoriales en cuanto a percepción de la importancia de atributos sociales y ambientales como condicionantes del consumo, evidenciados por un análisis de la elasticidad de la demanda. Los sectores más sensibles serían los de alimentación, farmacia, transporte de viajeros, y energía, mientras que en el otro extremo estarían servicios bancarios y de telefonía, y medios de comunicación.

\footnotetext{
${ }^{108}$ Si bien los autores del estudio sopesaban la posibilidad de que se tratase más de algo coyuntural que de un cambio sustancial en el comportamiento a largo plazo de los consumidores.
} 


\subsubsection{Etapas en el proceso de decisión de pre-compra responsable}

Para el análisis de las etapas previas a la decisión de compra del consumidor, y a efectos de una mayor precisión terminológica, se sugiere una variante de la propuesta de Valor (2010), según se muestra en la Figura 4.6. De acuerdo con este planteamiento, y una vez que se ha generado la demanda, el consumidor iniciará un proceso encaminado a la obtención de información sobre posibles ofertas (o sobre la responsabilidad de las ofertas disponibles), procediendo posteriormente a su valoración conforme a sus estándares o expectativas previas al respecto. En todos estos pasos serán consideradas una serie de variables centrales para la descripción del modelo de consideración y valoración de responsabilidad en el proceso de intención de compra que forma parte del presente trabajo $^{109}$.

Figura 4.6. El proceso de pre-compra responsable

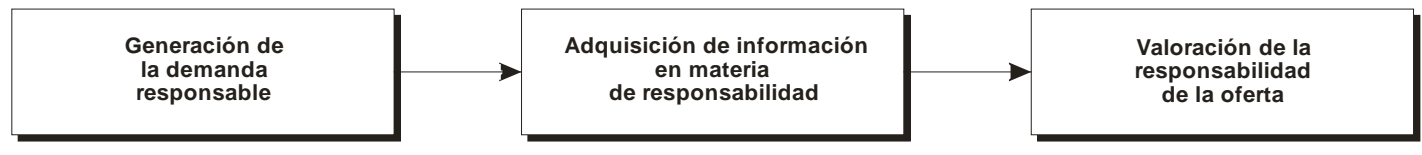

Fuente: Elaboración propia.

a) La fase de generación de la demanda responsable:

Con carácter general, la aparición de una demanda en el mercado es en sí misma un proceso que comienza con la constatación de un sentimiento de carencia por parte de los individuos, a lo que se añade una voluntad proactiva de satisfacción y disponibilidad de medios para hacerlo ${ }^{110}$. Esta secuencia no se halla exenta de un cierto grado de complejidad, pues son múltiples las variables internas y externas al individuo que ejercen su influencia. Entre ellas, la formación y experiencia en materia de responsabilidad, la disposición de informes de responsabilidad y de sostenibilidad, los datos facilitados por los medios de comunicación, etc.

\footnotetext{
109 Siguiendo el planteamiento de Öberseder et al. (2011) en cuanto a la posibilidad de estructurar jerárquicamente los factores que influyen en el proceso de compra responsable. Conforme a dicho planteamiento, el núcleo central de variables estaría en las etapas del proceso de pre-compra.

${ }^{110}$ De lo que se deduce la posibilidad de que existan necesidades no cubiertas por no haberse traducido en demanda, ya sea por falta de medios para satisfacer los correspondientes deseos, o incluso antes debido a la ausencia de una voluntad proactiva de los individuos. En otras palabras, porque éstos no quieran (falta de voluntad proactiva) y/o no puedan (falta de medios) satisfacerlas.
} 
Es precisamente la mayor influencia de algunos de estos condicionantes la que permite distinguir procesos de generación de demanda responsable (Figura 4.7). En este caso, y junto al reconocimiento en sí de la necesidad, se trataría de consumidores que ya perciben el carácter responsable que ha de tener su forma de satisfacción.

En tal sentido, debe destacarse el papel fundamental del autoconcepto o valores personales (obligación ética), así como de la percepción de eficacia en el sentido de que el consumidor piensa que conseguirá el objetivo marcado en cuanto a responsabilidad (como premiar o castigar determinados comportamientos empresariales) se sentirá más motivado a introducir en la demanda generada el matiz de responsabilidad ${ }^{111}$.

Bigné et al. (2005) también recalcan la influencia de los valores personales en cómo se percibe o se quiere satisfacer la necesidad. Junto a ellos, las dimensiones culturales pueden incluso llevar ya a buscar información, según la experiencia y conocimientos sobre el comportamiento responsable de las empresas, y la utilidad que el individuo espera obtener de su actuación (para sí y para otros). En consonancia con sus convicciones éticas y su umbral de acción (disposición y grado de actuación para apoyar una causa), algunos consumidores estarán dispuestos incluso a no transformar en deseo una necesidad, si con ello piensan que se puede dañar el medio ambiente, lesionar los derechos humanos, o generar cualquier otro problema (Valor 2010).

Figura 4.7. La generación de demanda responsable

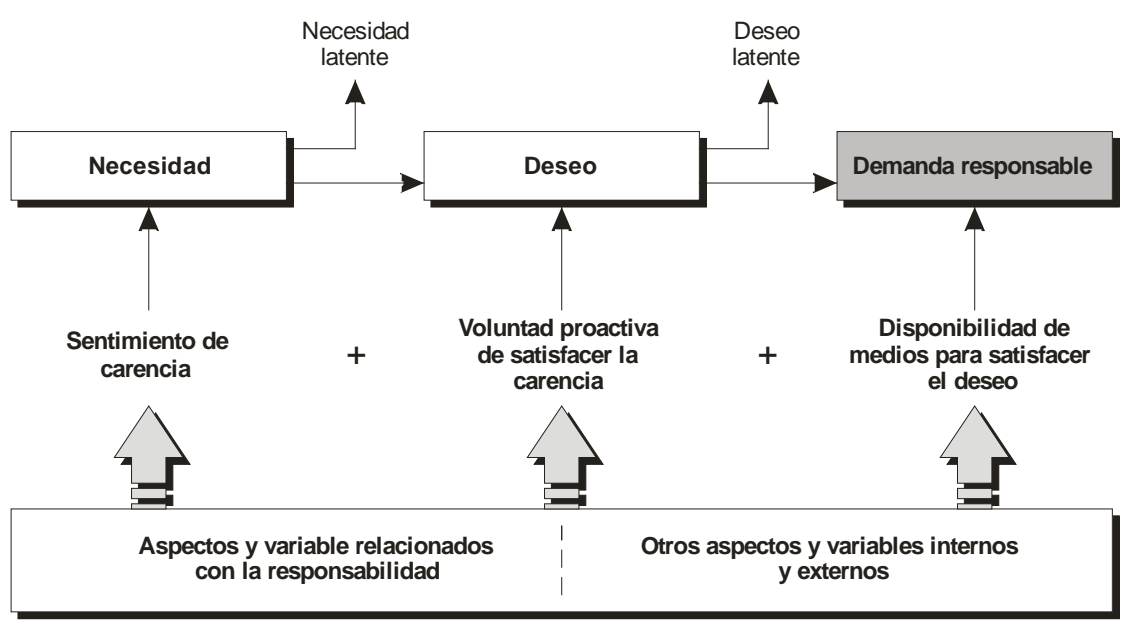

Fuente: Elaboración propia.

\footnotetext{
${ }^{111}$ Valor (2010) alude a ambos aspectos (autoconcepto o valores personales, y percepción de eficacia) como antecedentes de la compra responsable.
} 
Así las cosas, y de alguna manera, la generación de demanda responsable será también una generación de demanda sobre responsabilidad, en la medida en que los individuos perciban una diferencia entre la situación ideal y la realidad (Blackwell et al. 2006), así como el primero de los factores determinantes de hasta qué punto estarán dispuestos a buscar y tener en cuenta información sobre ofertas responsables.

b) La fase de adquisición de información en materia de responsabilidad:

La importancia que el consumidor conceda a los aspectos relacionados con la responsabilidad determinará directamente el deseo de incluir información al respecto entre la genéricamente recabada para sopesar posibilidades de satisfacer su necesidad. El carácter responsable de la segunda de las etapas del proceso de pre-compra responsable se basa en la evidencia de que cada día son más aquéllos que no sólo consideran el precio y la calidad como factores determinantes en sus decisiones de compra, sino también otros aspectos no económicos (García et al. 2011).

Como cualquier otro proceso de búsqueda de información (Blackwell et al. 2006), ésta puede hacerse a nivel interno (memoria y valoración de experiencias previas) o externo (recopilando datos de compañeros, la familia, los amigos, el mercado, etc.). Al tiempo, la búsqueda puede ser pasiva o activa. Bajo el primer supuesto, los individuos son receptivos a la información que les rodea, en tanto que al implicarse en una búsqueda activa recurren a la investigación, publicaciones, internet, prestan más atención a la publicidad, visitan establecimientos comerciales, etc.

En el caso de la compra responsable los consumidores suelen ser activos, por lo que, antes de actuar y elegir, exploran su interior y su entorno en busca de lo que quieren saber sobre el comportamiento de las entidades y/o las alternativas de compra para así sentirse en condiciones de tomar una decisión razonable. El proceso de búsqueda de información es crítico debido a varias dificultades que el individuo ha de afrontar, tales como (Valor 2010): i) la resistencia a iniciar la búsqueda, por entender que requiere un esfuerzo excesivo (razón por la que el esfuerzo y el tiempo dedicados a este cometido van a estar directamente relacionados con la obligación ética que sienta cada consumidor); ii) los problemas de acceso a los datos requeridos; y iii) la sobrecarga de información, resultando a veces difícil asimilar (y mucho más analizar) los datos encontrados, lo que puede llevar al consumidor a sentirse inerme y a pensar que no tiene capacidad para comprar de forma responsable. 
La presencia de alguna de esas circunstancias, y más aún la concurrencia de varias o todas, reduce la percepción de eficacia o confianza del individuo en sus propias posibilidades para lograr el éxito en el objetivo propuesto de disponer de la información adecuada. Tal sentimiento se puede paliar, poniendo a su disposición un amplio abanico de fuentes que aporten información veraz y simplificada. La percepción sobre la propia eficacia será cuando los datos no sólo provienen de los medios de comunicación, sino también de otras fuentes formales (como estudios e informes de organizaciones públicas o privadas) o informales (conocidos, amigos, etc.) y susceptibles de contrastación. Ello aumentará su predisposición a actuar, porque creen más fácil lograr el objetivo previsto.

Para que los consumidores puedan elegir de forma responsable será, pues, imprescindible que tengan información sobre las prácticas y los resultados sociales y medioambientales de las empresas, y para ello éstas deben revelar esa información. No obstante, y aunque cada vez son más las empresas que publican informes sociales o de sostenibilidad, la información “útil” para el consumidor es bastante escasa, tal y como se constata a la vista de la poca calidad de los contenidos, en términos de alcance, profundidad, inteligibilidad y fiabilidad (al no ser verificados, en muchas ocasiones, por terceras partes independientes).

En este sentido, el primer gran escollo es de accesibilidad (Valor 2010), ya sea porque no suele estar legislado el derecho a conocer los resultados del desempeño social y medioambiental de las empresas (motivo por el cual éstas deciden cuándo, dónde y hasta qué punto revelar información), o porque aun cuando las entidades puedan tener la obligación de enviar información a determinadas instituciones, a veces puede ocurrir que esa información no se hace pública ${ }^{112}$.

La información aportada debe ser, además, transparente, esto es, tener capacidad de satisfacer las expectativas de unos ciudadanos cada vez más exigentes con el papel social de las empresas (Navarro 2008, Aranguren et al. 2011). No ha de limitarse a proporcionar datos más o menos opacos sobre estados financieros, sino tratarse de información veraz y completa, comprensible e inteligente, pública y accesible.

\footnotetext{
112 Tal y como señala Valor (2010), y a pesar del desarrollo de los aspectos relacionados con la responsabilidad, el denominado reporting social es obligatorio tan solo en Bélgica, Francia y los Países Escandinavos. En otros casos hay limitaciones, tanto en cuanto al tipo de compañías que deben proporcionar la información como respecto a su alcance. De lo dicho en el Capítulo 2 se desprende que la mayoría de países han elaborado o suscrito regulaciones voluntarias que obligan sólo a quien lo desea a facilitar información en relación al gobierno corporativo, de carácter medioambiental o sobre riesgos laborales. Con todo, llama la atención que ningún país obligue a reportar sobre el cumplimiento y protección de los derechos humanos.
} 
A este respecto, Navarro (2008) sostiene que las empresas españolas parecen no estar comunicando correctamente sus políticas y acciones de responsabilidad a los ciudadanos-consumidores, puesto que existe una enorme distancia entre el contenido de los mensajes y el conocimiento de los individuos. A nivel global, Mohr et al. (2001) ya alertaban sobre este particular, haciendo hincapié en el creciente número de consumidores escépticos con las noticias sobre conductas o resultados responsables provenientes de las propias empresas, por ser éstas una fuente de información con muy baja credibilidad para los consumidores (Elliot et al. 1993, Becker-Olsen et al. 2006), quienes pueden percibirla como interesada y oportunista, y de ahí su poco poder de persuasión (Singh et al. 2008, García et al. 2012).

Swaen y Vanhamme (2005) sugerían, de hecho, que una misma información sobre el comportamiento responsable de las empresas resulta más creíble y tiene mayor impacto persuasivo en el consumidor cuando proviene de fuentes de información que éste percibe más cercanas e independientes, como pueden ser ONGs u organizaciones de consumidores. En cambio, si se utilizan medios que el consumidor considera “controlados” por la empresa, será menos considerada (García et al. 2012).

Otro argumento justificativo del escepticismo de los consumidores es el carácter unidireccional que en la gran mayoría de las ocasiones tienen los flujos de información, dando lugar a asimetrías, en el sentido de que las entidades pueden dar datos sobre sus logros y a la vez estar ocultando sus debilidades (Herranz 2010), hasta el punto de resultar incoherente lo que dicen y lo que hacen. La inversión en comunicación podría estar orientada a disminuir el impacto de sus irresponsabilidades, a modo de operación de lavado de imagen, pero ocultando datos relevantes que deberían conocer los compradores u otros grupos de interés.

Más aún, suponiendo que todas las entidades publicasen informes relevantes y verificados sobre su actuación, los consumidores deberían ser capaces de procesar y recordar toda esa información en el momento de tomar sus decisiones de consumo, lo que no es demasiado probable (Valor 2010).

En todo caso, y hoy por hoy, la falta de información sobre los atributos responsables de la oferta parece ser el obstáculo principal (Uusitalo y Oksanen 2004, CECU 2007 y 2010, Rokka y Uusitalo 2008), dando lugar a una nueva asimetría en el mercado, pues una parte (empresa) tiene más información que la otra (consumidor), que no la consigue o lo hace a un elevado coste (Carrero-Bosch y Valor 2012). 
No se trata, ni mucho menos, de un problema insalvable, siendo tres las posibles formas de corregir tal asimetría (Carrero-Bosch y Valor 2012): i) el envío directo de información al mercado desde la empresa (memorias, informes, notas de prensa, etc.); ii) recurrir a terceros evaluadores que posteriormente envíen la información a los mercados (informes corporativos elaborados por otras organizaciones); y iii) hacer llegar al mercado la información utilizando un etiquetado social.

Esta última forma puede entenderse como una combinación de las dos estrategias anteriores, puesto que supone la voluntad de la empresa de dar información y la participación de un agente tercero que verifique las afirmaciones de la empresa. Puede entenderse asimismo como una de las formas más eficaces de comunicación, dando a conocer de una forma simple y precisa al consumidor si una empresa cumple o no con determinados estándares o tiene o no un determinado desempeño (Valor 2010; Carrero-Bosch y Valor 2012). Sin embargo, el modo en que está actualmente implantado el sistema presenta tres importantes limitaciones, en lo tocante a su fragmentación ${ }^{113}$, falta de notoriedad (dificultad para comprender la información del etiquetado), y falta de credibilidad (desconfianza hacia los símbolos que reflejan la presencia de atributos de responsabilidad).

c) La fase de valoración de la responsabilidad de la oferta:

Fernández y Merino concluían en 2005 la escasez de datos sobre cómo y cuánto son valoradas las actuaciones responsables por los consumidores, hasta qué punto conocen su existencia (ya el contenido del término es bastante desconocido de por sí), y su disposición a pagar una prima por adquirir un producto ético, y ello aun cuando constataban una percepción social positiva de las actuaciones socialmente responsables, acompañada por una cierta disponibilidad a sustituir aquellos productos sin atributos sociales por otros funcionalmente idénticos o muy parecidos que sí los tengan.

A día de hoy, pese a que en los últimos años se han publicado algunos estudios sobre este particular, lo cierto es que no cabe hablar de resultados definitivos. Más allá de lo anterior, el modo en que dichas valoraciones pueden influir en la conducta empresarial sigue siendo poco conocido y analizado (Creyer y Ross 1997, Mohr et al. 2001, Sen y Bhattacharya 2001, Fernández y Merino 2005, García de los Salmones et al. 2005, Pérez et al. 2008), distando mucho de haber acuerdo en cuanto a conclusiones.

\footnotetext{
${ }^{113}$ Tan solo en Europa existen cerca de 240 etiquetas sociales diferentes que, sumadas a los códigos de conducta, llegan aproximadamente a 800 . No existe un enfoque integrado de etiquetado social.
} 
Así, varios estudios apuntan a que el consumidor valora positivamente a las entidades responsables, hasta llegar a modificar en consecuencia su conducta (Creyer y Ross 1997, Sen y Bhattacharya 2001, Bigné et al. 2005, Fernández y Merino 2005, Forética 2006, Bigné y Currás 2008). Otros sostienen que el cambio conductual sólo se da bajo ciertas circunstancias (Anderson y Cunningham 1972, Andreu et al. 2004), o que incluso si percibe la actuación responsable de la entidad, esto no va a ser un criterio que influya significativamente en las decisiones de compra (Carrigan 1997, Boulstridge y Carrigan 2000, Mohr et al. 2001, Bigné et al. 2005, Öberseder et al. 2011).

Al decidir, el consumidor elige entre el abanico de alternativas disponibles, y cualquier intento de explicar el porqué de dicha elección pasa por saber cómo se identifican las alternativas, cómo se deciden los criterios decisivos de valoración, y cómo se reducen la información y las opciones hasta resultar manejables (Solomon 2008), esto es, cómo se pasa de un conjunto evocado (todas las que ofrece el mercado) a un conjunto considerado (las realmente tenidas en cuenta) de alternativas.

Las opciones consideradas pueden ser valoradas tanto desde un punto de vista de utilidad económica o de mercado, como desde el punto de vista de la responsabilidad. El balance o peso relativo de unos u otros indicará hasta qué punto el consumidor está dispuesto a sacrificar su mero interés personal por otros aspectos o consideraciones.

Según Forética (2011), el primer grupo incluiría aspectos como precio, calidad, atención al cliente, o valor de marca, entre otros. En el segundo estarían los sociales, medioambientales, éticos y relacionados con cualquier otra faceta de la responsabilidad. Mediante unos y otros se llegaría a la concreción de las “buenas ofertas” y/o de las “buenas empresas”, en base a uno de tres niveles de valoración (Figura 4.8):

i) un nivel obligatorio, determinado por las exigencias básicas e ineludibles en cuanto a derechos humanos, igualdad, generación de empleo, trato al cliente..., cuya percepción tienen un fuerte impacto en la reputación de la entidad;

ii) un nivel exigible, incluyendo aspectos como la mejora del clima laboral, la conciliación de la vida personal y laboral, el respeto al medio ambiente, la atención a colectivos desfavorecidos, la transparencia, la ética en la gestión o la lucha contra el cambio climático; o

iii) un nivel deseable, añadiendo "un más allá” en términos de acción social, cooperación con ONGs, proyectos educativos, culturales o deportivos. 
Figura 4.8. La valoración de la responsabilidad de la oferta

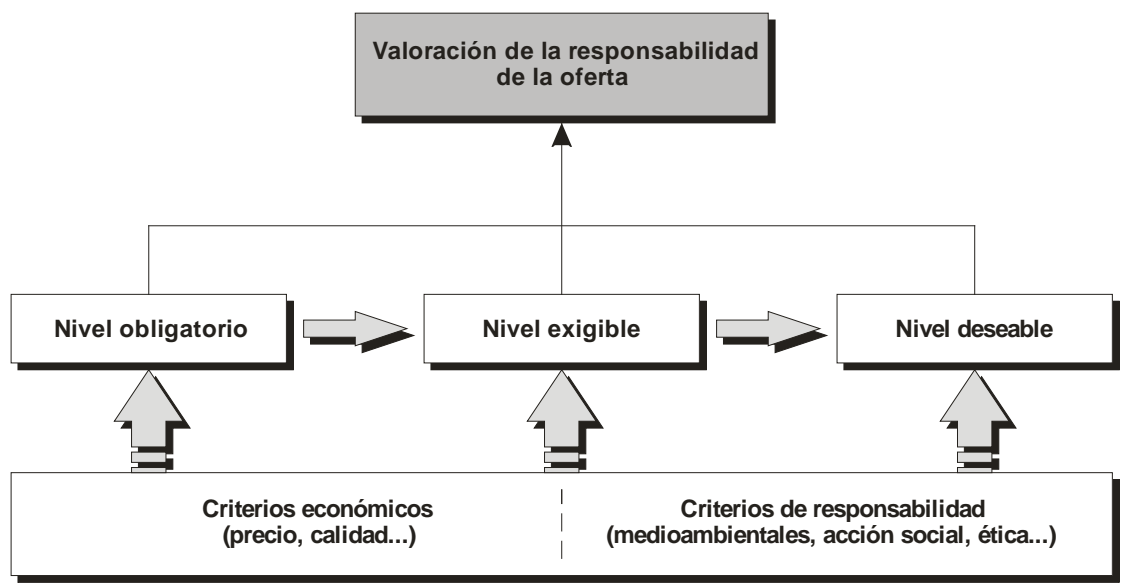

Fuente: Elaboración propia.

Tal y como indican Sen y Bhattacharya (2001), el papel de las reacciones del consumidor ante las prácticas responsables de las empresas es cada vez más crucial, pudiendo influir directa o indirectamente sobre sus intenciones de compra (Öberseder et al. 2011). Los efectos son indirectos cuando devienen del simple conocimiento de la entidad y sus esfuerzos en materia de responsabilidad, y directos cuando confían, están interesados y apoyan las iniciativas responsables de aquélla.

A modo de resumen, la Figura 4.9 refleja lo expuesto en cuanto a las distintas fases del proceso de pre-compra responsable, dándole continuidad en la subsecuente etapa, donde el consumidor decidirá o no efectuar la compra de alguno de los productos que se le ofrecen. Resultado de ello, experimentará sensaciones de utilidad / satisfacción (cumplimiento o superación de expectativas), o de no utilidad /insatisfacción (ya sea frustración ante la falta de una alternativa adecuada, o disconfirmación de expectativas), que en cualquier caso retroalimentarán el sistema como aprendizaje experiencial.

En todo caso, nunca debe perderse de vista la posibilidad de que se produzcan fallos o anomalías en el sistema, debidos a asimetrías de información (ya comentadas) o de poder (por ejemplo, cuando no se difunden abusos cometidos por grandes corporaciones con elevados presupuestos y capacidad para controlar los medios o difundir mensajes corporativos condicionantes de las decisiones del consumidor), unas y otras igualmente indeseables y potencialmente condicionantes (Valor 2010). 


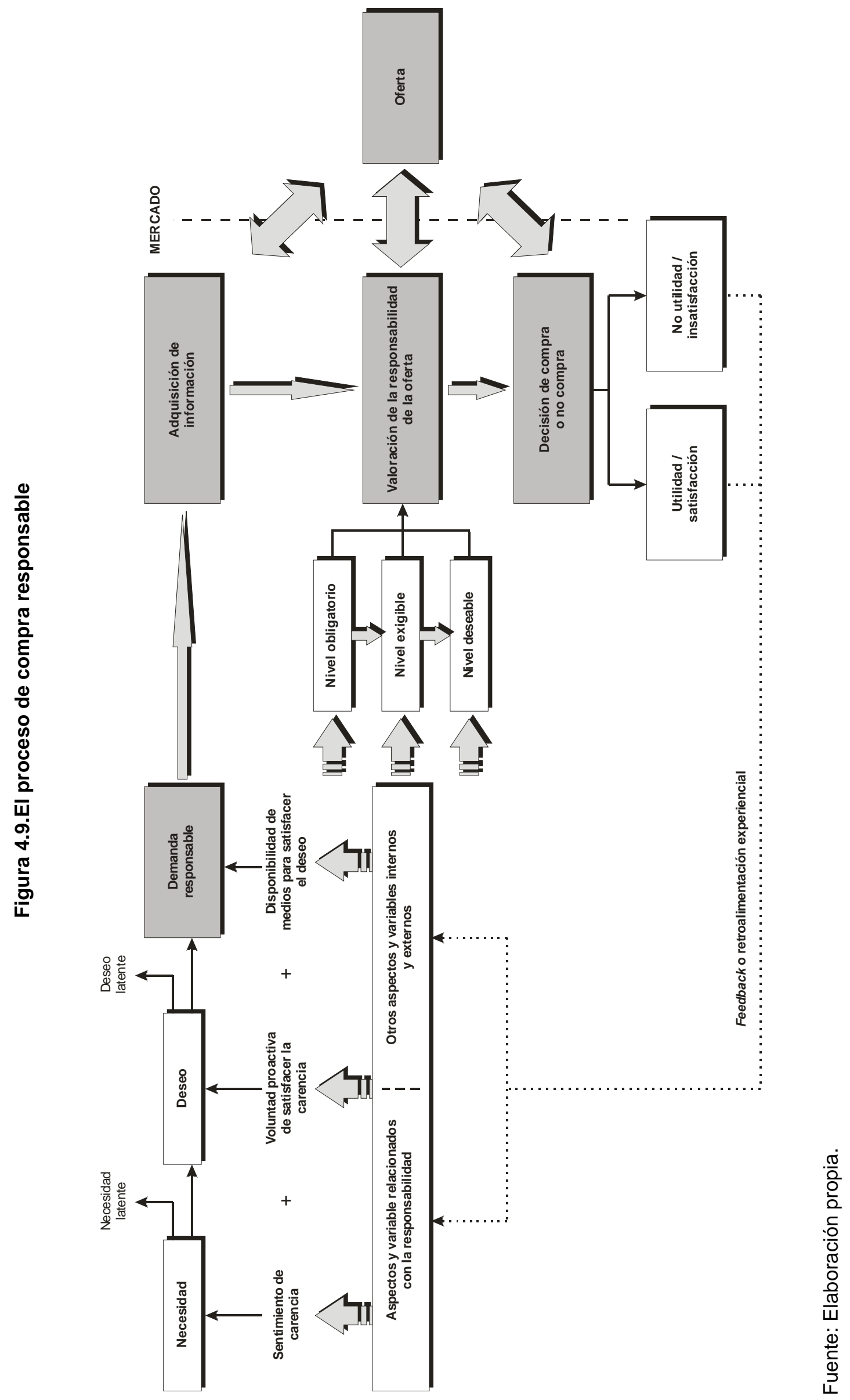




\subsection{La percepción de la responsabilidad por el consumidor}

Las asimetrías son, de hecho, uno de los condicionantes principales -si no el que más- de las divergencias en el análisis de las consecuencias y efectos sobre la conducta del consumidor de las actuaciones responsables o irresponsables de las empresas, justificando la necesidad de contar con nuevas teorías explicativas a este respecto (Marín y Rubio 2008).

Ya se han realizado algunos estudios tratando de arrojar algo de luz en cuanto a la opinión (percepción) y valoración de los comportamientos responsables de las distintas organizaciones y, más concretamente, de las empresas por parte de los consumidores (Pérez et al. 2008), concluyendo el papel clave de la responsabilidad en el proceso de construcción de la imagen corporativa (Alvarado y Schlesinger 2008). De ahí que los empresarios deberían ser conscientes en todo momento del impacto directo de sus acciones responsables en la reputación de sus negocios, estimulándoles a dedicar a ello recursos y esfuerzos, además de fortalecer los vínculos con sus consumidores para conseguir que éstos mejoren su grado de identificación con la organización.

Entre dichos estudios, y en España, cabe citar los de Bigné y sus colaboradores. Así, el llevado a cabo junto con Currás en 2008, a fin de contrastar el correspondiente modelo explicativo de la influencia de la imagen de RSC y de habilidad corporativa de la marca en la intención de compra, a través de la mayor o menor identificación del consumidor con la empresa ${ }^{114}$. El principal resultado es que la imagen de RSC sí influye en la intención de compra del individuo, pero de una forma indirecta, en función del grado de identificación del mismo con la empresa que ésta haya sido capaz de propiciar; entretanto, la imagen de habilidad corporativa (calidad, precio, disponibilidad del producto) influye directamente en esa misma intención de compra. La conclusión es que la RSC puede desempeñar un papel muy relevante en el comportamiento de compra de los sujetos, por ser un importante antecedente de la identificación consumidor-empresa.

Esto es, sin embargo, contradictorio con los de un estudio previo (Bigné et al. 2005) del comportamiento de compra de los jóvenes universitarios, en el que no se ponía de manifiesto ninguna relación significativa entre la RSC y el comportamiento de compra. La posición / percepción de este colectivo ante las prácticas responsables se

\footnotetext{
${ }^{114}$ Utilizando como referente para la investigación un producto de higiene personal, y más en concreto de la marca Dove, por ser una empresa que habitualmente desarrolla iniciativas responsables y asimismo reconocida a nivel global.
} 
revelaba aquí como neutral, lo que llevaba a los autores a recomendar la utilización de instrumentos de formación y comunicación para conectar con este público objetivo y con otros grupos de interés.

Otro estudio más reciente (Bigné et al. 2011) tuvo por finalidad contrastar un modelo explicativo de la influencia de las asociaciones de RSC con el valor percibido y la satisfacción del consumidor de servicios turísticos, en su doble dimensión cognitiva y afectiva (Figura 4.10) ${ }^{115}$. En él, dichas asociaciones, conforme los postulados de Brown y Dacin (1997:68), son “el reflejo del estatus y las actividades de una compañía respecto de sus obligaciones sociales percibidas”, esto es, la percepción de aspectos no económicos por los consumidores, concluyéndose su capacidad para mejorar tanto la satisfacción cognitiva como la afectiva, directa e indirectamente, a través del valor percibido.

En general, el análisis de estos y otros estudios permite apreciar cómo se ha pasado de analizar las dimensiones de la responsabilidad propuestas en el modelo de Carroll (Maignan 2001, García de los Salmones et al. 2005, Alvarado y Schlesinger 2008) a comprobar cómo esas asociaciones de responsabilidad pueden tener efectos en la intención de compra a través de la percepción que el consumidor tiene de la imagen de la entidad. De acuerdo con este enfoque de la percepción, el concepto que el consumidor tenga de la responsabilidad y los motivos que atribuye a las conductas responsables de las empresas serán dos variables fundamentales.

\section{Figura 4.10. Modelo de influencia de las asociaciones de RSC en el valor percibido y la satisfacción del consumidor}

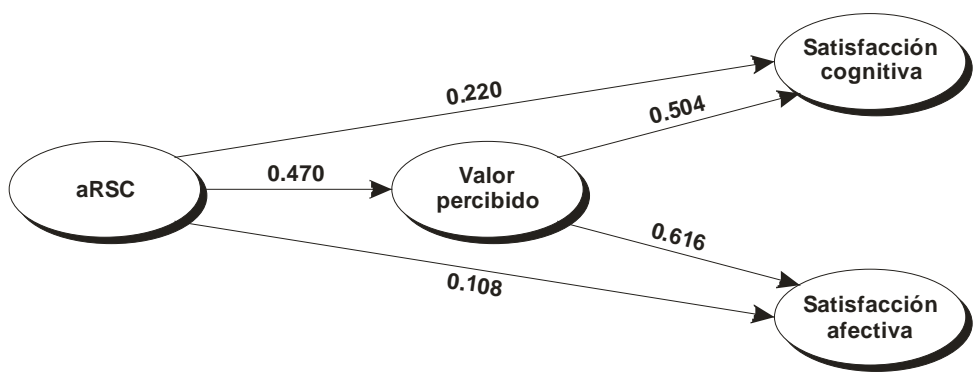

Fuente: Bigné et al. (2011).

\footnotetext{
${ }^{115}$ Para ello se realizaron 462 encuestas a ciudadanos tanto españoles como extranjeros y alojados en alguno de trece establecimientos hoteleros de la Comunidad Valenciana.
} 


\subsubsection{El concepto de responsabilidad desde el punto de vista del consumidor}

Sólo algunas de las propuestas modelizadoras de la responsabilidad organizativa han alcanzado una notoriedad relativamente significativa, utilizándose para identificar las dimensiones que definen dicho constructo desde la perspectiva del consumidor.

Entre éstas, destaca el modelo tridimensional inicialmente desarrollado por Carroll en 1979, y posteriormente refinado en 1991, con el propósito de servir de base conceptual clarificadora, sintetizando las dimensiones de la actuación responsable en un triple sentido: i) identificando sus categorías (económica, legal, ética y filantrópica) ${ }^{116}$; ii) los temas sociales de mayor relevancia (ambientalismo, discriminación, seguridad del producto, seguridad en el trabajo, consumerismo, accionistas...); iii) y caracterizando los tipos de respuesta (reactiva, defensiva, acomodativa y proactiva). Dicho modelo sería también revisado y ampliado por Wartick y Cochran (1985), y Wood (1991a), así como por el propio Carroll (1999), hasta llegar a un resultado final más estructurado.

Los trabajos basado en dicha aportación han estudiado las relaciones entre la actitud del consumidor hacia la empresa y sus productos, desde un punto de vista global y midiendo las categorías de responsabilidad económica, legal, ética y filantrópica (Maignan 2001, Maignan y Ferrell 2003, Bigné et al. 2005), centrándose en las preocupaciones filantrópicas de las organizaciones (Davis 1973, Karake 1998, Kok et al. 2001, Staples 2004), desde la perspectiva legal (McGuire 1963, Steiner 1972), conforme a un punto de vista ético (Kok et al. 2001, Lantos 2001, Staples 2004), o bien considerando las responsabilidades sociales y ecológicas (Roberts 1993, 1994, 1995, 1996, Mohr et al. 2001, Webb et al. 2008). Todo ello, estableciendo evidentes lazos entre los componentes de la responsabilidad y las teorías del desarrollo sostenible.

En particular, Alvarado y Schlesinger (2008), al estudiar la dimensionalidad de la RSE percibida y sus efectos sobre la imagen y la reputación, desde las dimensiones económica, ético-legal y discrecional propuestas en el modelo de Carroll, concluyen que, desde la perspectiva del consumidor, la imagen de la marca se ve influenciada directa y positivamente por los aspectos económicos, éticos y discrecionales de la responsabilidad, lo que proporciona soporte empírico a la idea de que los esfuerzos de las empresas en esta materia tienden a ser recompensados por los consumidores en términos de mejoras en cuanto a visibilidad, imagen y reputación de su oferta.

\footnotetext{
${ }^{116}$ Conforme a su propuesta piramidal, a la que se hacía alusión en el primer capítulo.
} 
Otros trabajos apuntan en la dirección de que la responsabilidad económica no estaría tan claramente vinculada con la percepción de las prácticas responsables, a diferencia de lo que ocurre con las dimensiones social y medioambiental. Pérez et al. (2008) justifican este argumento sobre la base de hallazgos previos (Aupperle, Carroll y Hatfield 1985; Maignan y Ferrell 2001; Bigné et al. 2005) en cuanto a la mayor importancia relativa de los aspectos legales, éticos y filantrópicos, o incluso la no percepción por los consumidores de los aspectos económicos como parte integrante de la responsabilidad (Brown y Dacin, 1977).

A partir de ahí, al analizar hasta qué punto las distintas dimensiones de la responsabilidad condicionan las decisiones del consumidor de servicios financieros, deciden no incluir la económica ${ }^{117}$. Su conclusión es que la imagen de una empresa (proclividad a recomendarla) para el consumidor deriva de la valoración global que éste haga del servicio y su satisfacción con el mismo, en tanto la intención de compra viene únicamente condicionada por la satisfacción con la empresa, teniendo la evaluación del servicio tan sólo un efecto indirecto.

Alvarado y Schlesinger (2008), al indagar sobre la forma en que las dimensiones de la responsabilidad son percibidas por el consumidor y las aparentes contradicciones con la teoría, plantean dos razones a la hora de proceder a su explicación. De acuerdo con estos autores, y en primer lugar, puede que el modelo tridimensional de Carroll no sea adecuado para aplicarlo desde la perspectiva del consumidor, lo que les lleva a sugerir la necesidad de contrastarlo empíricamente con otras aproximaciones teóricas. En segundo lugar, y al ser la viabilidad económica indisociable de la responsabilidad, su percepción es un índice formativo, debido a la alta dependencia del contexto.

Otro aspecto a resaltar, desde el punto de vista conceptual, es que, pese a sumir el modelo de Carroll que una organización no sólo debe responder ante sus propietarios o accionistas (teoría de los shareholders), sino también ante el resto de stakeholders (Frederick 1960, Jones 1980, Van Marrewijk 2003, Freeman, 2004), la mayoría de las investigaciones se han realizado bajo un enfoque directivo o gerencial, considerando de facto a este colectivo como único grupo de interés (Swaen y Maignan 2003, Bigné et al. 2011). Por el contrario, las aproximaciones desde la óptica de otros grupos de interés han sido marginales, y preocupante el olvido del punto de vista del consumidor.

\footnotetext{
${ }^{117}$ Aunque posteriormente señalan como limitación de la investigación el no haber incluido cuestiones objetivas y puramente económicas.
} 
Trabajos como los de Maignan y Ferrell (2001), Decker (2004), García de los Salmones et al. (2005), o Pérez y Rodríguez (2012) clasifican las acciones responsables atendiendo al criterio de los grupos de interés, para después centrarse en la percepción del consumidor. Más allá incluso, y conforme a las indicaciones del Libro Verde de la UE, es frecuente distinguir entre prácticas de carácter interno y externo (Unceta 2005). Las primeras tienen que ver con la forma en que las empresas ejecutan sus acciones de gobierno, hacen explícitos su compromisos con los problemas y el bienestar de los trabajadores, desarrollan mecanismos de participación y diálogo, o diseñan procedimientos para garantizar la seguridad de los trabajadores o fomentar su formación. Por el contrario, el carácter externo está vinculado a las actividades empresariales en las que se manifiesta la actitud de la entidad hacia la sociedad y otros agentes con los que se relaciona directa o indirectamente, así como a las diversas maneras por medio de las cuales expresa su contribución a las necesidades del entorno.

A nivel institucional, asociaciones como Forética han comenzado a reflejar en sus informes la perspectiva del consumidor, en este caso el consumidor español y desde 2004. El último de ellos refleja, por ejemplo, un aumento del grado de conocimiento o la notoriedad de la RSE, pues más del 50\% de los encuestados decían haber oído hablar de ella (Forética 2011). De acuerdo con ese mismo informe, debería ser algo prioritario para el 61\% de los individuos, y dos de las tres dimensiones del concepto, la social y la medioambiental ganaban terreno en la apreciación del consumidor, en detrimento de la económica y respecto a los datos previos de 2008.

No obstante, y pese a estos y otros resultados análogos que ponen de manifiesto la poca consciencia del consumidor sobre lo que es realmente la responsabilidad (Sen et al. 2006, Pomering y Dolnicar 2009), su conocimiento generalizado se incluye como supuesto inducido en la mayoría de estudios sobre la conducta de aquél (Öberseder et al. 2011). Con todo, el consumidor que es consciente de lo que es y de lo que implica suele serlo en gran medida, reflejándolo en actitudes positivas e intenciones de compra de productos responsables. Y hay incluso quien sostiene que, cuando menos, el concepto que en todo caso se irá formando sobe la actividad de las entidades va a afectar a sus intenciones de compra (Lee y Shin 2010) y va a ser uno de los factores directamente condicionantes de la posible necesidad de información al respecto. Tal autoconcepto podría ser así considerado como uno de los antecedentes que condicionan todo proceso de compra, y no sólo los de compra responsable (Valor 2010). 
En cualquier caso, el análisis de los estudios empíricos permite llegar a las mismas conclusiones que se desprendían del de las aportaciones teóricas, esto es, la coexistencia de una pluralidad de enfoques y aproximaciones, haciendo necesario, a los efectos aquí pretendidos, efectuar una serie de consideraciones con el fin de disponer de una base sólida sobre la que construir una batería de indicadores coherente con el punto de vista de los stakeholders y, más en concreto, de los consumidores.

Dichas consideraciones pueden sintetizarse en lo siguiente:

a) La teoría de los stakeholders es el marco conceptual más ampliamente utilizado para estudiar la responsabilidad empresarial, pudiendo considerarse una idea compartida en la mayoría de aportaciones conceptuales (Frederick 1960, Jones 1980, Phillips et al. 2003, Van Marrewijk 2003, Freeman 2004, Bigné et al. 2011).

b) Carroll (1979, 1991), autor de uno de los modelos que más han influido en la literatura especializada, sostiene que las cuestiones relacionadas con la responsabilidad ocupan al menos gran parte las relaciones de las empresas con sus stakeholders, siendo partidario de utilizar este término para referirse genéricamente y con propiedad a los grupos específicos con los que la empresa debe actuar en forma responsable, a diferencia de lo que ocurre con otros, como “social”, más vagos y menos específicos.

c) En este mismo sentido, y ya sea directa o indirectamente, la de los stakeholders es una de las referencias más frecuentes y recurrentes en la literatura académica y profesional $^{118}$, ratificando la fuerte presencia transversal del concepto en el cuerpo de teorías sobre la responsabilidad.

d) Entrando en mayor detalle, las guías y manuales de instituciones que promueven la responsabilidad dividen las prácticas empresariales en función de su relación con cada uno de sus principales stakeholders (accionistas, empleados, clientes, proveedores, comunidad, Administración, ONGs, etc.).

e) En consecuencia, queda descartada la idea de que la responsabilidad se asocia exclusivamente a comportamientos de apoyo social a desfavorecidos (Marín y Ruíz 2008), y suficientemente argumentada la de que las empresas deben proceder en este sentido conforme las demandas de sus grupos de interés, mediante las acciones responsables que supongan beneficios y obtengan respuesta positiva del consumidor.

\footnotetext{
${ }^{118}$ Conclusión a la que llega expresamente Dahlsrud (2008), tras analizar 37 definiciones de ambos ámbitos y determinar las cinco dimensiones comunes a ellas.
} 


\subsubsection{La percepción por el consumidor de la conducta empresarial responsable}

Todo apunta a que últimamente el papel desempeñado por la responsabilidad social en la estrategia empresarial oscila entre dos planteamientos, a veces confrontados o, incluso, antagónicos (Fundación ÉTNOR 2010). Puede usarse como argumento comercial, formando parte las correspondientes medidas de una estrategia empresarial más amplia en cuanto a diferenciación, posicionamiento o reputación corporativa, y percibiéndola como un activo o un recurso en la generación de valor. En otros casos se trata de un compromiso social, a modo de exigencia u obligación razonada adicional a la actividad económica propia de la entidad (como si la ésta viniese a asumir obligaciones propios de los poderes públicos o de las entidades de la sociedad civil).

No obstante, la relación entre ambas posibilidades no debe ser concebida como mutuamente excluyente. Las empresas implementan comportamientos responsables no sólo para cumplir sus obligaciones legales y responder a las demandas de sus diferentes grupos de interés sobre este particular, sino también en beneficio propio y a fin de lograr objetivos como incrementar su competitividad $^{119}$, o mayor rendimiento en los mercados de valores (Drumwright 1994, Waddocks y Smith 2000, Klein y Dawar 2004). En base a ello, es asumible la idea de que al público le puede importar menos lo que las empresas están haciendo que el por qué lo están haciendo (Gilbert y Malone 1995).

Distintas investigaciones llegan a la conclusión de que los consumidores no aceptan a ciegas las iniciativas responsables y no siempre las consideran sinceras. Se suelen mostrar escépticos si perciben que lo que busca la empresa es su propio interés (Webb y Mohr 1998, Porter y Kramer 2004, Luo y Bhattacharya 2006), y estarán dispuestos a castigarlas en caso de identificar una conducta social poco sincera (Brown y Dacin 1997, Creyer y Ross 1997, Barone et al. 2000, Ellen et al. 2000, Sen y Bhattacharya 2001, Becker-Olsen et al. 2006).

Tratando de explicar el modo en que los consumidores perciben los motivos que mueven a las empresas a actuar responsablemente, se han propuesto varios modelos. Entre los más simples, el de Becker-Olsen et al. (2006) caracteriza las conductas según se deban a fines estratégicos o sociales, y señala que los consumidores aprecian las motivaciones reactivas o proactivas, mejorando sus intenciones, creencias y actitudes. Por el contrario, el efecto es el inverso si los motivos atribuidos son sólo estratégicos.

\footnotetext{
119 De hecho, son muchas las empresas que dan a conocer sus prácticas éticas para diferenciar más y mejor sus productos, y así lograr una ventaja competitiva (Castaldo et al. 2009).
} 
Ello se contrapone, sin embargo, a los resultados obtenidos por Vázquez et al. $(2012 b)^{120}$, que apuntan a que tal influencia negativa puede llegar a no ser significativa, pues los consumidores tienden a realizar conductas de consumo responsable en sentido positivo y como medio para expresar valores personales, pero no así en sentido opuesto.

Más compleja es la propuesta de Ellen et al. (2006), cuyo modelo sostiene que los consumidores perciben los motivos que inducen a las empresas a actuar de forma responsable conforme a cuatro categorías:

i) en base a una orientación egoísta, para obtener un rendimiento o rentabilidad de la acción realizada, en lugar de llevarlas a cabo por su propia finalidad;

ii) de acuerdo con una orientación estratégica, tratando de lograr simultáneamente los objetivos de la empresa y los de la actuación responsable;

iii) en respuesta a las demandas de los stakeholders, y en función de la capacidad de presión de éstos;

y iv) en consonancia con motivos altruistas.

Partiendo de esa misma clasificación, Vlachos et al. (2009) postularon el efecto positivo de las actuaciones impulsadas por valores en la confianza de los consumidores, dando lugar a recomendaciones positivas y mayor fidelidad. Asimismo planteaban que el efecto sería negativo si la casusa de las actuaciones era atribuida a la acción de los stakeholders, a una orientación estratégica o a motivos de carácter egoístas.

Los resultados del correspondiente estudio revelaron que los efectos negativos atribuidos a comportamientos responsables pueden ser más profundos de lo reconocido hasta entonces, puesto que los consumidores cada vez se muestran más recelosos o cautos a la hora de atribuir motivaciones a las conductas responsables, lo cual influye en sus respuestas, tanto a nivel interno (confianza) como conductuales (compra y recomendación). En base a ello, se sugiere que la influencia de la percepción del comportamiento empresarial va a ser directa tanto en el concepto de responsabilidad empresarial que el consumidor tiene como referente en la toma de decisiones durante el proceso de pre-compra responsable, como con respecto a la utilidad esperada, en este caso como muestra probatoria de los resultados obtenidos a partir de su actuación (o de acuerdo con la magnitud de éstos y su percepción).

\footnotetext{
${ }^{120}$ En la línea de investigaciones previas (p.e. Vázquez et al. 2011, y Vázquez et al. 2012a).
} 


\subsection{Otros determinantes de la responsabilidad desde la óptica del consumidor}

La valoración que el consumidor hace de las ofertas responsables y, en general, las decisiones que toma a lo largo del correspondiente proceso no sólo se encuentran condicionadas por el significado conceptual del término en su aplicación a la empresa (desde una perspectiva cognitiva) y su evolución a lo largo del desarrollo secuencial. Existen también otros condicionantes directos, entre los que destacan, a nivel interno la utilidad esperada, y a nivel externo la influencia social.

\subsubsection{La utilidad esperada}

La satisfacción y el valor percibido son dos variables fundamentales en el estudio del comportamiento del consumidor (Bigné et al. 2011), si bien apenas han sido contrastadas empíricamente en la literatura que lo relaciona con la responsabilidad empresarial (Ravald y Grönroos 1996, Sánchez et al. 2007).

Algunos de estos escasos estudios se han basado en criterios económicos (Luo y Bhattacharya 2006), en ocasiones estableciendo una conexión entre la responsabilidad y el precio y la calidad del producto (Brown y Dacin 1997, Osterhus 1997). La mayoría, con todo, concluyen que el potencial de esa relación es limitado (Hoeffler y Keller 2002), por lo que no es esperable que el impacto de los programas de responsabilidad en el rendimiento de la entidad sea significativo (Green y Peloza 2011).

Otras aportaciones sostienen que todo acto de consumo proporciona, además de una utilidad económica o funcional, otro tipo de satisfacciones (Sheth et al. 1991, Green y Peloza 2011). De acuerdo con este planteamiento, la responsabilidad pasa a estar relacionada con la obtención de un valor emocional para el consumidor (sentirse bien con uno mismo, mejorar la imagen ante los demás al realizar este consumo) resultante de la adquisición de productos responsables o al castigar a aquellas empresas que son percibidas como irresponsables.

El consumo de productos responsables se encontraría motivado, en consecuencia, por las perspectivas de lograr una utilidad social (contribuir a causas sociales o medioambientales, apoyar a aquellas empresas comprometidas con la comunidad) y como mecanismo de expresión de una determinada identidad personal, permitiendo al sujeto solucionar ciertas necesidades de autodefinición a la vez que expresa socialmente una escala de valores (Sen y Bhattacharya 2001). 
Las decisiones de compra se orientarán más a determinados productos si se prevé que con su adquisición se conseguirán los objetivos propuestos en términos de utilidad, esto es, en función de la percepción de su potencial de utilidad (Yoon et al. 2006, Bigné et al. 2011) durante las fases de generación de demanda responsable y adquisición de información en materia de responsabilidad. Con posterioridad podrán traducirse en la intención de cambiar el comportamiento de las empresas, o en la de distinguirse positivamente frente a otros individuos mediante la adquisición y el uso de marcas socialmente responsables, proyectando una identidad personal basada en valores.

El nivel de intensidad con el que las expectativas de utilidad influirán de cara a la materialización de un determinado comportamiento de una u otra manera depende de la naturaleza y características de cada actividad. Conforme indica Bandura (1989), en aquellas ocasiones en las que todo apunta a que la calidad del rendimiento sea garantía suficiente de la consecución de ciertas recompensas, la utilidad esperada parece ser el principal factor determinante de la conducta del individuo, influyendo también sobre la representación de las propias expectativas de recompensa.

En cambio, cuando la relación entre las consecuencias esperadas y la calidad del rendimiento es dispersa, las expectativas de resultados pueden contribuir de manera independiente a la motivación y a la conducta.

A partir de dichos postulados este mismo autor procedió a identificar distintos tipos o categorías de recompensas susceptibles de ejercer su influencia sobre el comportamiento del consumidor. Así, cabría referirse a la anticipación de resultados físicos (esto es, la utilidad económica o funcional), resultados sociales (es decir, la obtención de reconocimiento o de aprobación), y resultados autoevaluativos (en términos de satisfacción personal). En particular, estos últimos son muy influyentes en las decisiones del consumidor, pues “algunas de las recompensas más valoradas residen en la satisfacción derivada del cumplimiento de estándares personales, más que en recompensas tangibles” (Bandura 1986:231).

De este modo, el potencial de la anticipación de autoevaluaciones positivas asociadas a la ejecución exitosa de tareas con vistas a reforzar la implicación en conductas futuras va a ser significativo, estimulando el desarrollo de conductas específicas y pudiendo aumentar el interés por ciertas decisiones para las que en un primer momento no había demasiada motivación extrínseca. 


\subsubsection{La influencia social}

Tal y como fue puesto de manifiesto en el apartado correspondiente al hacer referencia a la forma actual de interpretar el concepto de responsabilidad, éste varía con el tiempo y en función de las preocupaciones sociales de cada momento. Su aplicación depende de aspectos tales como las características de cada actividad, su dimensión o intensidad, o las características del contexto socioeconómico en el que opera la organización (Garmendia 2009). Una misma acción puede, por tanto, tener una cierta relevancia social en un momento y/o en un determinado contexto, pero esa misma relevancia puede ser mayor, menor o ninguna en otro marco diferente.

La propia y reciente ISO 26000 reconoce en el séptimo de sus capítulos la importancia del contexto social, recomendando a las organizaciones determinar, además de sus propias características, las del contexto en el que actúan, como paso previo a la implementación de políticas de responsabilidad. Para ello deben ser tenidos en cuenta toda una serie de aspectos, como son los rasgos más característicos de la entidad (tipo de organización, tamaño, sector...), la localización o localizaciones en las que opera (incluyendo el marco legal y el contexto económico, social y medioambiental), su historial en cuanto a actuaciones en materia de responsabilidad, la tipología de sus trabajadores o empleados, las organizaciones sectoriales en las que opera, su misión, su visión, sus valores, sus principios y sus códigos de conducta, los intereses y las expectativas de sus partes interesadas y de la sociedad, la estructura y naturaleza de su toma de decisiones, y la cadena de valor en la que se integra.

La alta dependencia del contextual de la responsabilidad (Jones 1980, Castillo 2001, Van Marrewijk 2003, Kakabadse et al 2005, Boxenbaum 2006) tiene que ver con el hecho de que su práctica es indisociable de la viabilidad económica (Alvarado y Schlesinger 2008), percibiéndose por el consumidor como un índice formativo y en continuo cambio, que requiere ser adaptado a las cambiantes relaciones económicas, sociales e institucionales de cada momento.

La influencia contextual estará, pues, presente en todas las fases del proceso de pre-compra y compra responsable, además de condicionar el comportamiento empresarial percibido por el consumidor.

En tal sentido, contextos de particulares dificultades económicas e incertidumbre como el actual (pérdida de empleos, reducción de ingresos...) tienen un impacto no sólo 
significativo sino decisivo en las decisiones que toma el consumidor en materia de responsabilidad (Green y Peloza 2011). De ahí la conveniencia de examinar su respuesta a los comportamientos responsables a través de un ciclo económico completo.

Más allá de lo anterior, el contexto no sólo es un factor condicionante de las valoraciones y percepciones propias de los individuos, sino también de sus relaciones con los individuos o grupos que más pueden influir en su comportamiento, y las percepciones y valoraciones de éstos (personas del entorno inmediato, medios de comunicación, etc.), determinando los resultados de muchas -si no de todas- las variables habitualmente consideradas en los intentos modelizadores (tanto las del proceso de intención de compra, como las de atribución de comportamiento empresarial y la utilidad esperada).

Y además, tampoco hay que olvidar que los individuos tienden a valorar más aquellas actividades congruentes con los aspectos más importantes de su identidad individual y apoyan las organizaciones que personifican esa identidad, entre otras razones porque tienen interés en mantener una imagen positiva y consistente de sí mismos, lo que les llevará a sentirse identificado con aquellas empresas que apoyan las mismas causas que ellos defienden (y probablemente sus entornos más próximos también), en términos de atributos comunes, de características similares o de valores compartidos (Dutton et al. 1994, Sen y Bhattacharya 2001, Marín y Ruíz 2008).

\subsection{Propuesta de un modelo de consideración y valoración de la responsabilidad en los procesos de intención de compra}

La evaluación de las iniciativas de responsabilidad de las empresas que hacen los consumidores es un proceso complejo y estructurado jerárquicamente (Öberseder et al. 2011).

En dicho proceso, los individuos distinguen entre un núcleo central (las etapas en sí del proceso de intención de compra) y otros factores periféricos que explican sus percepciones sobre los motivos que llevaron a las empresas a verse involucrarse en acciones de responsabilidad, y sus propios motivos de actuación, todo ello condicionado -según acaba de ser indicado- tanto exógena (influencia social) como endógenamente (utilidad esperada). 
Teniendo presente este propósito, son muchos los factores o aspectos a tener en cuenta, no sólo los pormenores de la generación de una demanda responsable y la consecuente búsqueda de información acerca de los correspondientes aspectos (Valor 2010), sino también en relación con los motivos que son atribuidos a la conducta responsable de las empresas (Becker-Olsen et al. 2006, Ellen et al. 2006, Vlachos et al. 2009), el modo en que la comprensión sobre las actividades de responsabilidad afecta a las intenciones de compra (Sen et al. 2006, Pomering y Dolnicar 2009, Lee y Shin 2010, Öberseder et al. 2011), el comportamiento de los consumidores inducido por la satisfacción y el valor percibido (Luo y Bhattacharya 2006, Bigné et al. 2011), y la influencia del entorno y asociada al interés por mantener una determinada imagen y/o sentirse identificado con algún grupo de referencia (Dutton et al. 1994, Sen y Bhattacharya 2001, Marín y Ruíz 2008).

Todo lo expuesto lleva a realizar la propuesta inicial de un modelo basado en el análisis de las interrelaciones establecidas entre una serie de variables determinantes o explicativas del componente valorativo de las ofertas responsables por parte del consumidor, en lo relativo al comportamiento de la empresa.

Dicha propuesta se fundamenta en el contenido de los apartados previos del capítulo, estructurándose en torno a las correspondientes hipótesis de investigación, conforme se indica a continuación:

- La adquisición de información sobre responsabilidad determina la valoración que hacen los consumidores en cuanto al grado de responsabilidad de los productos que les son ofertados.

Hipótesis 1: la adquisición de información sobre responsabilidad influye positiva y directamente sobre la valoración de la responsabilidad de la oferta

- La generación de la demanda responsable influye en el modo en que se plantea y tiene lugar la adquisición de información sobre los aspectos relacionados con la responsabilidad por parte del consumidor.

Hipótesis 2: la generación de la demanda responsable influye positiva y directamente en la adquisición de información sobre responsabilidad 
- El concepto que el consumidor tiene de la responsabilidad determina la forma en que se genera la demanda responsable.

Hipótesis 3: el concepto de responsabilidad influye positiva $y$ directamente sobre la generación de la demanda responsable

- La utilidad esperada determina la generación de la demanda responsable, así como la adquisición de información y la valoración de la responsabilidad de la oferta por parte del consumidor.

Hipótesis 4a: la utilidad esperada influye positiva y directamente sobre la valoración de la responsabilidad de la oferta

Hipótesis 4b: la utilidad esperada influye positiva y directamente en la adquisición de información sobre responsabilidad

Hipótesis 4c: la utilidad esperada influye positiva y directamente sobre la generación de la demanda responsable

- La forma en que se percibe la conducta empresarial influye en las expectativas de utilidad, así como en el concepto de responsabilidad de los consumidores.

Hipótesis 5a: el comportamiento empresarial percibido influye positiva y directamente sobre la utilidad esperada

Hipótesis 5b: el comportamiento empresarial percibido influye positiva y directamente sobre el concepto de responsabilidad

- El constructo influencia social (contexto) determina la percepción de la conducta empresarial por parte del consumidor, como sus expectativas de utilidad, la adquisición de información y su valoración de la responsabilidad de la oferta.

Hipótesis 6a: la influencia social incide positiva y directamente sobre el comportamiento empresarial percibido

Hipótesis 6b: la influencia social incide positiva y directamente sobre la utilidad esperada

Hipótesis 6c: la influencia social incide positiva y directamente en la adquisición de información sobre responsabilidad

Hipótesis 6d: la influencia social incide positiva y directamente sobre la valoración de la responsabilidad de la oferta 
Figura 4.11. Modelo teórico e hipótesis de investigación

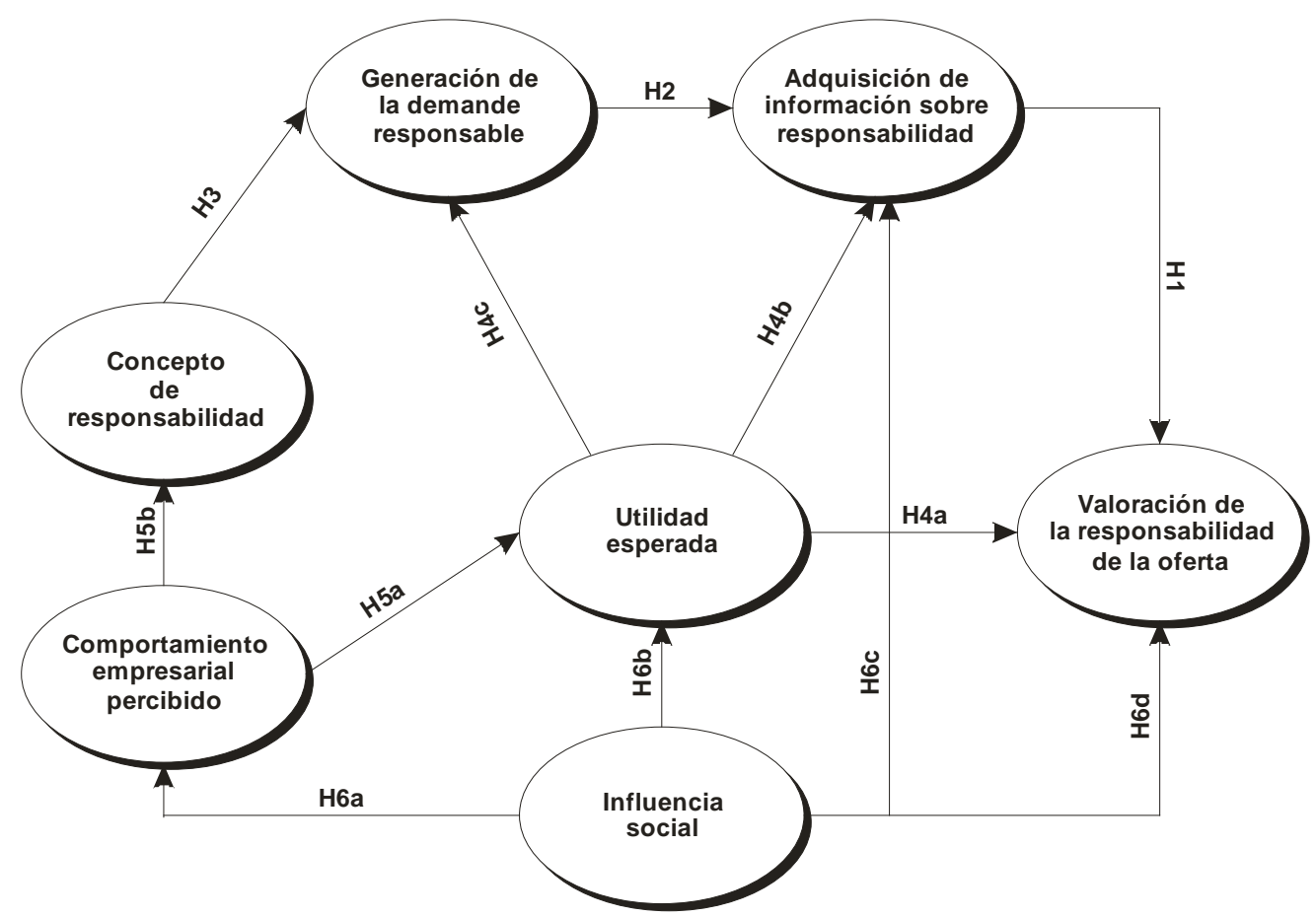

Fuente: Elaboración propia.

La Figura 4.11 permite ver gráficamente todas las relaciones e hipótesis planteadas en el modelo teórico.

A modo de resumen, y con carácter previo a la parte empírica del trabajo, cabe reiterar que todo él pretende contribuir a una mejor comprensión del proceso por el cual los consumidores integran sus percepciones sobre iniciativas responsables en sus criterios de compra, centrándose para ello en dos propósitos fundamentales:

i) Construir un modelo perceptivo útil para explicar cómo valoran los individuos la información sobre la responsabilidad de las organizaciones y cuál es la importancia de ese comportamiento de cara a incorporar el punto de vista del consumidor en los planteamientos de las empresas sobre este particular.

ii) Analizar, mediante dicho modelo conceptual, las variables determinantes en el proceso secuencial de intención de compra responsable (generación de la demanda de responsable, búsqueda y adquisición de información sobre responsabilidad y valoración 
de la responsabilidad de la oferta) y su influencia en los hábitos de consumo para tener en cuenta la inclusión de parámetros responsables en la actuación organizativa.

El Cuadro 4.4 refleja las doce hipótesis formuladas, agrupadas en seis grupos conforme al origen de su planteamiento. Cada uno de ellos hace referencia a la relación que puede tener una variable latente, ya sea independiente (como la influencia social) o dependiente (cualquiera, a excepción de la valoración de ofertas responsables) con las otras del modelo. Así, en el caso de los tres primeros grupos se plantea una única hipótesis para cada constructo, mientras que son tres las interrelaciones de la utilidad esperada y las correspondientes hipótesis, dos las del comportamiento empresarial percibido, y cuatro las de la influencia social, conformándose de este modo esta última como la variable latente con una mayor interacción con los demás constructos.

\section{Cuadro 4.4. Hipótesis para la investigación empírica}

\begin{tabular}{|c|c|}
\hline H1 & $\begin{array}{l}\text { La adquisición de información sobre responsabilidad influye positiva y directamente } \\
\text { sobre la valoración de la responsabilidad de la oferta }\end{array}$ \\
\hline $\mathrm{H} 2$ & $\begin{array}{l}\text { La generación de la demanda responsable influye positiva y directamente en la } \\
\text { adquisición de información sobre responsabilidad }\end{array}$ \\
\hline H3 & $\begin{array}{l}\text { El concepto de responsabilidad influye positiva y directamente sobre la generación de } \\
\text { la demanda responsable }\end{array}$ \\
\hline $\mathrm{H} 4 \mathrm{a}$ & $\begin{array}{l}\text { La utilidad esperada influye positiva y directamente sobre la valoración de la } \\
\text { responsabilidad de la oferta }\end{array}$ \\
\hline $\mathrm{H} 4 \mathrm{~b}$ & $\begin{array}{l}\text { La utilidad esperada influye positiva y directamente en la adquisición de información } \\
\text { sobre responsabilidad }\end{array}$ \\
\hline $\mathrm{H} 4 \mathrm{c}$ & $\begin{array}{l}\text { La utilidad esperada influye positiva y directamente sobre la generación de la } \\
\text { demanda responsable }\end{array}$ \\
\hline H5a & $\begin{array}{l}\text { El comportamiento empresarial percibido influye positiva y directamente sobre la } \\
\text { utilidad esperada }\end{array}$ \\
\hline $\mathrm{H} 5 \mathrm{~b}$ & $\begin{array}{l}\text { El comportamiento empresarial percibido influye positiva y directamente sobre el } \\
\text { concepto de responsabilidad }\end{array}$ \\
\hline H6a & $\begin{array}{l}\text { La influencia social incide positiva y directamente sobre el comportamiento } \\
\text { empresarial percibido }\end{array}$ \\
\hline H6b & La influencia social incide positiva y directamente sobre la utilidad esperada \\
\hline H6c & $\begin{array}{l}\text { La influencia social incide positiva y directamente en la adquisición de información } \\
\text { sobre responsabilidad }\end{array}$ \\
\hline H6d & $\begin{array}{l}\text { La influencia social incide positiva y directamente sobre la valoración de la } \\
\text { responsabilidad de la oferta }\end{array}$ \\
\hline
\end{tabular}

Fuente: Elaboración propia. 


\section{Capítulo 5}

Aspectos Metodológicos para La InVestigación

\section{EMPÍRICA}





\section{Capítulo 5. Aspectos Metodológicos para la InVestigación EMPÍRICA}

Como paso previo a la contrastación y validación o disconfirmación de las hipótesis planteadas en el modelo propuesto en el capítulo anterior sobre la percepción por parte del consumidor de la responsabilidad de las organizaciones empresariales, en el quinto capítulo del trabajo se procede a la descripción de los correspondiente aspectos metodológicos (en tanto los resultados darán contenido al capítulo siguiente).

Para ello, se comienza por hacer referencia a los criterios empleados en la selección de la muestra y a las características sociodemográficas de los encuestados. Tras ello se concreta el procedimiento seguido en la elaboración del cuestionario ad hoc utilizado para la recogida de datos, así como con las escalas de medida utilizadas a efectos de hacer posible la operativización de las variables del modelo. Por último, se comentan las técnicas estadísticas que fueron seleccionadas con vistas al análisis de los datos, en base a su naturaleza y alcance para dar cuenta del grado de cumplimiento de las hipótesis de partida.

En tal sentido, no debe perderse de vista el objetivo final de llegar a construir un modelo perceptivo útil y explicativo de las decisiones adoptadas en el proceso de precompra y compra responsable, concretando las variables determinantes.

\subsection{Descripción de la muestra}

Los datos necesarios para la validación del modelo fueron recabados mediante un estudio psicométrico de autoinforme llevado a cabo durante los cinco primeros meses de 2011 sobre una muestra representativa de individuos de la Provincia de León.

Al objeto de favorecer la posible comparación de los resultados obtenidos, así como la extrapolación de las conclusiones, la muestra fue planteada de modo que, por su tamaño y las características de sus integrantes, resultase suficientemente representativa de la población leonesa. 
De acuerdo con las cifras poblacionales del Instituto Nacional de Estadística, el número de habitantes de la Provincia a fecha 1 de enero de 2011 era de 480.309 personas. Conocida esta cifra, procedería calcular el tamaño muestral conforme a la fórmula siguiente:

$$
n=\frac{0.25 N}{(\alpha / z)^{2}(N-1)+0.25}
$$

donde:

$n$ es el tamaño muestral;

$N$ es el tamaño de la población total;

$\alpha$ es la probabilidad de error tipo 1 , siendo asumido en este caso un valor de $0.05( \pm 5 \%)$ asociado a un nivel de confianza del 95\%;

$z$ es el valor del número de unidades de desviación estándar para una prueba de dos colas con una zona de rechazo igual a $\alpha$, por tanto, 1.96 en este caso; $\mathrm{y}$

0.25 es el valor de $p^{2}$ que produce el máximo error estándar, esto es el correspondiente a los valores de $p=q=0.5$.

El valor del tamaño muestral obtenido a partir de la aplicación de la fórmula determinaba la conveniencia de utilizar una muestra de 383,85384 individuos. No obstante, y para evitar cualquier duda en cuanto a representatividad, se prefirió considerar la población como infinita y utilizar una muestra de 400 individuos.

Asimismo tratando de lograr el mayor grado posible de representatividad, los individuos fueron seleccionados aleatoriamente, y de acuerdo con un procedimiento de afijación proporcional por sexo y edad. De este modo, y tal y como se puede apreciar en el Gráfico 5.1, 185 de los entrevistados fueron varones (46,25\%) y las restantes 215 mujeres (53,75\%). Igualmente, de los 400 sujetos mayores de edad seleccionados, 120 se encontraban en el intervalo comprendido entre los 18 y los 35 años (30\%), y otros 120 tenían una edad en el tramo de 36 a 50 años (30\%), mientras que la edad de los 160 restantes estaba entre los 51 y 75 años (40\%).

Por último, y aunque se tuvo en cuenta este criterio, no se pudo lograr una distribución tan precisa en cuanto a nivel de estudios, en particular por el grado de dificultad que supone cumplir con los tres criterios (sexo, edad y nivel de estudios) a la hora de seleccionar los individuos muestrales. 


\section{Gráfico 5.1. Distribución de la muestra del estudio según las características de sexo, edad y nivel de estudios de los encuestados}

Sexo

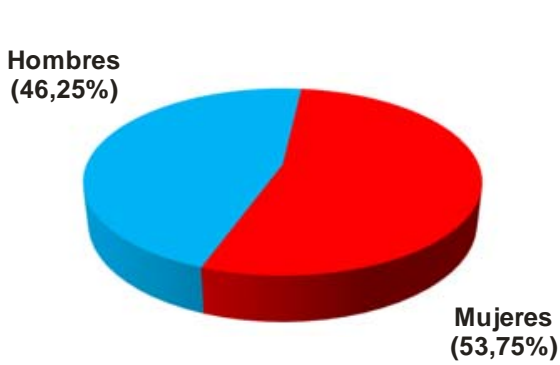

Edad

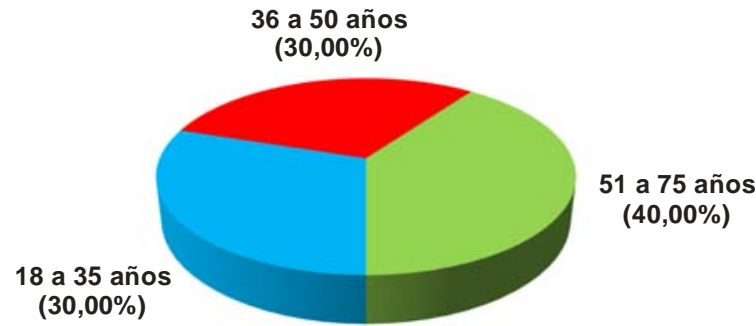

Formación Profesional $(24,25 \%)$

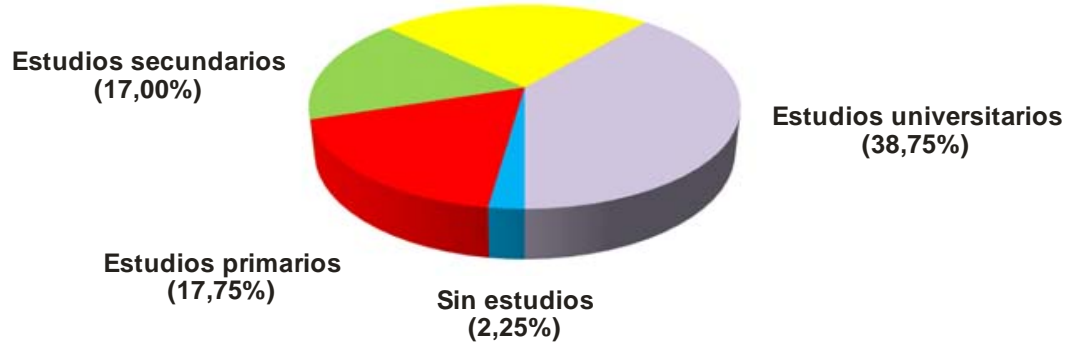

Nivel de Estudios

Base: Muestra poblacional del estudio (400).

En concreto, 9 individuos de la muestra carecían de estudios (2,25\%), 71 tenían estudios primarios (17,75\%), 68 tenían estudios secundarios (17\%), 97 habían realizado estudios de Formación Profesional (24,25\%), y 155 disponían de titulación universitaria (38,75\%). Tal distribución supone un ligero sesgo, precisamente hacia el último de dichos colectivos $\mathrm{y}$ en detrimento del primero o, lo que es lo mismo, una sobreapreciación del nivel de estudios general de la muestra con respecto a la población total.

Valorando esta situación, se estimó, no obstante, que no debería representar un inconveniente significativo, y más teniendo en cuenta que los niveles formativos y educativos de la población tienden a ser cada vez mayores. Además, cuanto más formado y educado está un individuo, mayor debería ser su capacidad de análisis y valoración con respecto a las diferentes cuestiones abordadas en el presente estudio. 


\subsection{Procedimiento de recogida de datos}

La recogida de datos tuvo lugar a partir de la administración de un cuestionario elaborado expresamente a los efectos de la presente investigación, en el que estaban incluidas varias escalas asociadas a las variables de interés. A continuación se comentan diferentes pormenores en cuanto a la construcción y administración de dicho cuestionario, así como con las escalas de medición de las variables.

\subsubsection{Construcción y administración del cuestionario}

El procedimiento para desarrollar los ítems a integrar en el modelo hipotetizado se llevó a cabo conforme a una aproximación deductiva (Hinkin 1995, Schwalb 2009), fundamentada en la definición operativa de los constructos teóricos a partir de una profunda revisión de la literatura especializada y de otros estudios similares, todo ello con el propósito de identificar indicadores específicos a partir de los que configurar el cuestionario.

En torno a este proceder, se siguió la secuencia de cinco pasos propuesta por Martínez (1995) para la construcción de escalas psicométricas:

i) identificación de la finalidad del test;

ii) especificación de las restricciones del instrumento;

iii) identificación de conductas observables representativas del constructo;

iv) preparación de los contenidos del test; y

v) especificación del formato de los ítems.

Así, y en primer lugar, la determinación de la finalidad con la que se elabora un cuestionario no sólo resulta necesaria para evitar desviaciones sobre el objetivo a lograr, sino que además proporciona el marco contextual adecuado para acometer la tarea de su diseño, siendo ésta inherente a la población a la que va destinada y a la potencial utilidad derivable de las puntuaciones obtenidas (Martínez 1995). En el caso que aquí nos ocupa, la composición de la muestra es conforme a las características de los individuos mayores de edad que forman parte de la sociedad (universo poblacional), y el propósito asignado a la investigación no es otro que elaborar un modelo útil de cara a la mejor explicación de las intenciones de compra responsable de los consumidores. 
En estrecha relación con lo anterior, al diseñar el instrumento de medida se trataron de anticipar posibles restricciones condicionantes de la recogida de datos a través del mismo. A tal efecto, y dada la viabilidad de acometer dicha tarea mediante administración colectiva en el contexto de grupos, se estimo oportuno acortar al máximo la longitud del cuestionario $\mathrm{y}$, en consecuencia, el tiempo requerido para responderlo. Mediante este proceder se trataba de minimizar la probabilidad de obtener respuestas erróneas debidas a los problemas de agotamiento y fatiga frecuentemente experimentados por los encuestados a causa del empleo de instrumentos y/o escalas demasiado largos (Anastasi 1976, Carmines y Zeller 1979).

A partir de dichas especificaciones, las fases tercera y cuarta del procedimiento dieron pie a una revisión concienzuda de la literatura relevante para identificar las dimensiones observables representativas de cada constructo incluido en el estudio, así como para concretarlas en forma de contenidos especificados en un conjunto de ítems vinculables a la medición de cada variable.

Por último, fue preciso tomar decisiones en cuanto al formato de los ítems y a las escalas de respuesta a los mismos. En dicho empeño fueron tenidas en cuenta diversas consideraciones, en un afán de reducir al máximo la probabilidad de ocurrencia de errores de medida sistemáticos asociados al método empleado (Fiske 1982, Bagozzi y Yi 1991).

Más concretamente, y siguiendo las recomendaciones de Podsakoff et al. (2003), para reducir los errores metodológicos en la administración de escalas de autoinforme cuando las variables objeto de estudio deben ser obtenidas de la misma fuente y no pueden ser medidas en distintos contextos temporales o espaciales, se procedió conforme a las siguientes especificaciones generales:

i) procurar la separación de las escalas, tratando de dar lugar a condiciones diferentes en la medición de las variables predictivas y en el criterio del modelo mediante el empleo de enunciados diferentes en las instrucciones de respuesta a cada una de ellas;

ii) incluir una aclaración general al comienzo del cuestionario en relación al anonimato y carácter subjetivo de los datos recabados, así como al tratamiento conjunto de los mismos, para así tener mayores garantías en cuanto a la honestidad de las respuestas y evitar la aprehensión a la evaluación; 
iii) diseñar cuidadosamente los ítems de las escalas, con una definición clara de términos ambiguos y no familiares, y redacción de enunciados simples, específicos y concisos, evitando conceptos vagos y sintaxis complicadas (Tourangeau et al. 2000);

iv) plantear los ítems en el polo positivo de cada constructo, evitando de este modo la utilización de negaciones y dobles negaciones, y a fin de minimizar la presencia de ítems invertidos, en tanto su empleo ha sido criticado en la literatura por reducir la validez de las respuestas del cuestionario (Schriesheim y Hill 1981), introducir errores sistemáticos en las escalas (Jackson et al. 1993), y dar lugar a factores artificiales de respuesta (Harvey et al.1985);

v) utilizar medidas cortas de cada constructo, con el propósito de reducir el tiempo de aplicación (Carmines y Zeller 1979) y minimizar posible errores de medida debidos a la fatiga (Anastasi 1976), en consonancia con lo ya mencionado al anticipar posibles restricciones a la hora de proceder a la recogida de datos; $y$

vi) emplear formatos tipo Likert en las escalas de respuesta empleadas, en términos de acuerdo/desacuerdo o gradación de respuesta, con 5 anclajes oscilantes entre un valor mínimo de 1 y uno máximo de 5 , a fin de resultar fácilmente comprensibles por los individuos encuestados, tal y como sugiere la literatura en cuanto al empleo de escalas impares (Hinkin 1995).

Construida la versión inicial del instrumento en base a dichas consideraciones, los ítems considerados fueron refinados en base a la opinión de dos expertos en la materia, a fin de mejorar su adecuación para la medición de las variables de interés. En idéntico sentido fue realizado un pretest con un reducido grupo de consumidores, a quienes se consultó acerca de la dificultad y comprensión del contenido de las escalas.

La versión definitiva del cuestionario fue administrada al total de la muestra seleccionada en la zona objeto de estudio, entre los meses de febrero y mayo de 2011, de forma personal y respetando los parámetros preestablecidos en cuanto a edad, sexo y nivel de estudios de los encuestados.

Los cuestionarios así cumplimentados fueron revisados previamente a su codificación y a la introducción de la información de las respuestas en una base de datos para su posterior tratamiento estadístico, eliminándose todos aquéllos que presentaban respuestas incompletas o sospechosas en base a patrones de tendencia de respuesta o predominio de puntuaciones extremas en los ítems. 


\subsubsection{Escalas de medición de las variables}

En el Anexo a este trabajo se muestran los ítems y las escalas que fueron empleados en la medición de las variables del estudio. En el cuestionario se procedió a su estructuración en cinco apartados, en base a su naturaleza y posición predictiva en el modelo teórico, distinguiéndose de este modo entre: i) variables sociodemográficas (encabezado); ii) variables perceptivas del consumidor (apartados I y II); iii) variables de decisión del consumidor (apartado III y parte del apartado IV); y iv) otros determinantes (parte restante del apartado IV).

a) Variables sociodemográficas:

La cabecera del cuestionario incluyó cuestiones orientadas a recabar datos de carácter sociodemográfico de los individuos muestrales. Se pedía así a los encuestados que indicasen su sexo (variable en sí misma categorizadora en cuanto a la distinción hombre vs. mujer), edad (en base a la cual los individuos fueron categorizados en tres grupos, entre 18 y 35, 36 y 50, y 51 y 75 años), y nivel de estudios (distinguiendo las cinco categorías de sin estudios, estudios primarios, estudios secundarios, formación profesional y universitarios), así como, en su caso, su profesión.

b) Variables perceptivas del consumidor:

La imagen que la compañía sea capaz de generar y el consumidor de apreciar define, bajo la perspectiva de la percepción, dos variables fundamentales, como son el concepto de responsabilidad y los motivos atribuidos al comportamiento responsable de las empresas. Por tal razón la primera parte del cuestionario tuvo por objeto la recogida de datos en torno a los aspectos definitorios, según el punto de vista del encuestado, de una empresa socialmente responsable. Para ello se utilizaron 12 ítems (I.1 a I.12), comprendiendo aspectos desde el cumplimiento estricto de las leyes a la colaboración abierta con instancias administrativas y ONGs, así como contemplando para el encuestado la posibilidad de especificar otros no explícitamente indicados.

Para cada ítem, los encuestados debían indicar su grado de identificación con los literales propuestos, señalando la correspondiente opción en una escala de respuesta tipo Likert de 1 (totalmente en desacuerdo) a 5 puntos (totalmente de acuerdo).

Por lo que respecta a las atribuciones, se buscaban los aspectos apreciados por los consumidores y que motivan el comportamiento responsable de las empresas (Becker-Olsen et al. 2006, Ellen et al. 2006, Vlachos et al. 2009). 
Para ello, en el segundo apartado del cuestionario se incluyeron 18 ítems (II.1 a II.18), a fin de reflejar la opinión de los individuos sobre las causas o motivos que pueden llevar a una empresa a comportarse de modo responsable. Algunos estaban más relacionados con pautas de actuación estratégicas (mejorar la reputación y crear buena imagen, darse a conocer, aumentar beneficios, retener y/o captar nuevos clientes, reducciones fiscales, imposición legal), y otros con razones de índole social (responder a las expectativas de la sociedad en general o de grupos de interés, devolver algo de lo que han recibido a la sociedad, interés por el bienestar social, o sentimiento moral de obligación), permitiendo al encuestado especificar otras opciones.

Al igual que previamente, se solicitaba a los encuestados que indicasen su grado de identificación marcando la opción correspondiente en una escala de respuesta tipo Likert de 1 (totalmente en desacuerdo) a 5 puntos (totalmente de acuerdo).

c) Variables decisionales del consumidor:

Fueron utilizados 11 ítems (III.1 a III.11) de cara a valorar la generación de la demanda responsable, tratando de reflejar la importancia en tal sentido que es otorgada por el consumidor a cada uno de los aspectos relacionados con la conducta responsable de las organizaciones. Más concretamente, en referencia a los compromisos de la empresa en el plano medioambiental, con los problemas sociales, la satisfacción de las expectativas de los clientes y de los empleados, la generación de beneficios para socios y accionistas, en las relaciones con proveedores y distribuidores, el respecto de la competencia, el desarrollo socioeconómico regional, los intereses de la comunidad, y la colaboración con entidades públicas y ONGs. Una vez más, se contemplaba también la posibilidad de que los encuestados señalasen otras opciones que no hubiesen sido específicamente consideradas.

En esta ocasión, lo solicitado a los participantes en el estudio fue que indicasen el grado de importancia atribuido a cada uno de los ítems propuestos a la hora de tomar sus decisiones de compra, marcando para ello la opción correspondiente en una escala de respuesta tipo Likert de 1 (nada importante) a 5 puntos (muy importante).

También en relación con el proceso de compra responsable, fueron incluidos otros 6 ítems en relación con la adquisición de información sobre responsabilidad (IV.1 a IV.6), ya fuese con carácter general, o de un modo particular, prestando atención a la publicidad, distintivos y sellos de calidad, o al propio conocimiento y experiencia. 
En relación a éstos, y al igual que ocurría con las dos primeras categorías, se solicitaba a los encuestados que indicasen su grado de identificación en una escala tipo Likert de 1 (totalmente en desacuerdo) a 5 puntos (totalmente de acuerdo).

Y asimismo se incluyeron 7 ítems más, relacionados con la valoración de la responsabilidad de la oferta (IV.7 a IV.13), en términos de conocimiento de conductas responsables e incorporación de las subsecuentes apreciaciones a la hora de tomar sus decisiones de compra. En concreto, refiriéndose a la importancia del hecho en sí de adquirir este tipo de productos, la calidad y la relación precio-calidad de los mismos, el carácter decisivo de cara a la compra, o propensión a llevar a cabo acciones, ya sea negativas (dejar de adquirir productos o marcas percibidas como no responsables), o positivas (disponibilidad a pagar más o realizar un mayor esfuerzo para adquirir un producto o una marca percibida como responsable).

Los encuestados también debían manifestar su grado de identificación con estos ítems, en una escala de respuesta tipo Likert de 1 (totalmente en desacuerdo) a 5 puntos (totalmente de acuerdo).

\section{d) Otros determinantes:}

Para completar el modelo se requería disponer de información sobre otras dos variables que asimismo influyen en la valoración de la responsabilidad de la oferta, como son la utilidad esperada y la influencia social.

En relación con la utilidad esperada se incluyeron 5 ítems (IV.15 a IV.19), solicitando a los encuestados que indicasen su grado de identificación con los mismos. Todos ellos se referían a aspectos internos, como eran el sentimiento de contribuir a causas sociales o medioambientales al adquirir productos responsables, estar apoyando a empresas comprometidas con la comunidad, o bien sentirse bien con uno mismo o percibir una mejora de la propia imagen frente a los demás.

Por su parte, los 4 ítems restantes del cuestionario se refieren a la influencia social (IV.14 y IV.20 a IV.22). Una vez más, se solicitó a los encuestados que indicasen su grado de identificación con las afirmaciones propuestas, y más concretamente en cuanto a que alguna persona de su entorno les hubiera sugerido adquirir productos responsables, haber notado una mayor implicación de las empresas en acciones de responsabilidad social, o considerarlo un tema cada vez más recurrente en los medios de comunicación o entre las personas del entorno inmediato. 


\subsection{Procedimiento de análisis de datos}

Una vez recabados los datos pertinentes, el modelo teórico de estudio fue sometido a prueba mediante una combinación de análisis factoriales, correlacionales, descriptivos, y predictivos, llevados a cabo a través los paquetes estadísticos SPSS 19.0 y SmartPLS 2.0, conforme a las indicaciones de Ringle et al. (2005). Las pruebas realizadas estuvieron en su conjunto dedicadas a comprobar la validez de medida y estructural del modelo y, con ello, el grado de cumplimiento de las hipótesis planteadas.

\subsubsection{Validación del instrumento de medida y análisis preliminares}

Los primeros análisis estadísticos que fueron llevado a cabo mediante diversas aplicaciones del programa SPSS 19.0 tuvieron por objeto comprobar la fiabilidad y la validez de las escalas empleadas en el estudio, a modo de precondiciones para después proceder a contrastaciones más detalladas sobre el alcance de las hipótesis del modelo.

En tales términos, la fiabilidad se refiere a la precisión con que un instrumento de medida arroja puntuaciones exentas de errores aleatorios (Kerlinger y Lee 2000), siendo considerada por los investigadores como una condición necesaria para que la medición sea válida (Peterson 1994).

La validez se refiere, por su parte, al grado en que un test "mide lo que pretende medir”, asociándose con el error sistemático (Carmines y Zeller 1979, Kerlinger y Lee 2000). En concreto, y para Malhotra (1997:298), es "el grado en el cual las diferencias en las calificaciones observadas de la escala reflejan las diferencias reales entre los objetos con respecto de la característica que se mide”.

Según argumentan Sánchez y Sarabia (1999), dado que las medidas en el ámbito de las Ciencias Sociales tienen diferentes propósitos, deben considerarse también diversos tipos de validez, lo cual lleva a distinguir generalmente cuatro facetas a tener en cuenta al valorar en qué medida una escala permite dar cuenta del constructo en relación con el cual fue diseñada (Grajales 1996): i) validez aparente o fiabilidad de las escalas; ii) validez de contenido; iii) validez de constructo o interna; y iv) validez de criterio o externa.

A continuación se indica la forma en la que fueron tenidos en cuenta cada uno de ellos en el presente estudio. 
a) Validez aparente o fiabilidad de las escalas:

La estimación de la fiabilidad de una escala integrada por dos o más ítems se basa en la determinación de la asociación entre las calificaciones obtenidas en diferentes aplicaciones de la misma -en distintos individuos o momentos temporales-, siendo buscada la consistencia de los resultados (Malhotra 1997).

Desde esta óptica, existen varios métodos para calcular la fiabilidad de una escala (Carmines y Zeller 1979, Nunnally y Bernstein 1994, Most y Zeidner 1995, Sánchez y Sarabia 1999), siendo los más frecuentes la estabilidad test-retest, el empleo de formas alternativas de la misma medida, y la consistencia interna. Los dos primeros implican, respectivamente, estimar el mismo constructo en la misma persona en dos momentos diferentes o mediante dos versiones alternativas de la prueba, resultando especialmente útiles en estudios longitudinales en los que el atributo a medir no cambia con el tiempo.

Dado el carácter transversal del presente estudio, el método más apropiado es la consistencia interna, la cual se utiliza para evaluar la confiabilidad de una escala en la que se suman varias partidas para formar una puntuación total, de forma que cada ítem mide algún aspecto del constructo. En tal sentido, el análisis de la consistencia interna permite estimar la homogeneidad de los ítems de la medida, o el grado en que aquéllos están correlacionados con la puntuación total. El índice más comúnmente aceptado a tal propósito es el coeficiente alpha de Cronbach $(\alpha)$, basado en el promedio de los coeficientes de correlación de Pearson $(r)$ entre todos los ítems de la escala si las puntuaciones de los mismos están estandarizadas, o como promedio de las varianzas si no lo están (Cronbach 1951). Los valores obtenidos por este procedimiento oscilan entre 0 y 1 , considerándose aceptables coeficientes por encima de 0,70 (Nunnally 1978), al tiempo que se recomienda proceder a eliminar aquéllos ítems que no contribuyan significativamente a dicho criterio.

b) Validez de contenido:

La validez de contenido remite a la adecuación de la medida para evaluar el dominio de interés, en alusión a la exhaustividad del procedimiento seguido para la elaboración de la escala (Peter y Churchill 1986) y a la representatividad proporcionada por los ítems seleccionados con respecto al universo de todos los posibles (De Vellis 1991). Con todo, el procedimiento para conseguir una medida válida a este nivel debe 
incluir una especificación correcta del dominio -partiendo de la información disponible-, una generación de ítems que agote dicho dominio, y una depuración de la escala (Churchill 1979).

A la vista de tal definición, puede afirmarse la inexistencia de un criterio ampliamente aceptado ni objetivo para valorar el nivel de validez de contenido de las medidas psicológicas, por cuanto que se trata de un concepto cualitativo dependiente en gran parte del juicio del investigador y/o del de otros expertos en el tema objeto de análisis (Kerlinger y Lee 2000). Por ello, "la validez de contenido por sí sola no es una medida suficiente de la validez de la escala; no obstante, ayuda en la interpretación de sentido común de las cualificaciones" (Malhotra 1997:306).

Partiendo de estas consideraciones, a efectos de verificación de la validez de contenido en el caso de este estudio se utilizó una aproximación deductiva en la generación de los ítems del cuestionario, teniendo como base la revisión en profundidad de la literatura y de otros instrumentos similares que permitieron desarrollar una definición teórica de los constructos empleada como guía en el desarrollo de los ítems. Posteriormente, los indicadores generados fueron refinados sometiéndolos al juicio crítico de investigadores expertos en la materia.

c) Validez de constructo o interna:

La validez de constructo o interna "es el concepto unificador que integra las consideraciones de validez de contenido y de criterio en un marco común para probar hipótesis acerca de las relaciones teóricamente relevantes" (Messick 1980:1015).

Según Cronbach y Meehl (1955), esta validez consiste en un análisis de la significación de las puntuaciones de los instrumentos de medida expresada en términos de los conceptos asumidos en su estimación. Por tanto, la validez de constructo busca garantizar la existencia de una dimensión subyacente y que dé significado a las puntuaciones de una escala (Kerlinger 1979) cuando se emplean medidas -tal es el caso- con múltiples ítems y con el propósito de hacer deducciones acerca de las conductas o atributos que pueden agruparse bajo la etiqueta de un constructo en particular.

Dado que es la más avanzada y difícil de determinar, su establecimiento implica tener en consideración otros dos subtipos de validez: discriminante y convergente. 
La validez discriminante hace referencia al hecho de que la escala permita medir un concepto efectivamente diferente de otro. Por tanto, cada escala de un cuestionario que pretenda estimar puntuaciones en múltiples variables ha de representar una dimensión independiente (Nunnally 1978), de forma que los ítems de escalas distintas deben correlacionar alto con el constructo que miden y bajo con otros constructos diferentes. La validez convergente, por su parte, permite conocer si una medida está sustancialmente relacionada con otras estimaciones del mismo constructo (Churchill 1979) y/o con otras variables con las que debería estar asociada por razones teóricas. Con todo, ambos tipos de validez aluden a una faceta vinculada a la fiabilidad de las medidas, por cuanto que, a mayor fiabilidad, mayor validez de constructo.

Entre los procedimientos más frecuentemente utilizados para la contrastación de la validez discriminante y convergente destaca el análisis factorial (Pérez et al. 2000, Moriano et al. 2006, Liñán y Chen 2009), acompañado de la revisión de la fiabilidad y las correlaciones entre las dimensiones identificadas por esta vía.

Conceptualmente, el análisis factorial presenta dos modalidades diferentes, una exploratoria y la otra confirmatoria. La diferencia más importante entre ambas radica en que el análisis factorial exploratorio es una técnica que, basada en los datos, intenta descubrir la estructura subyacente que éstos poseen, mientras que el análisis factorial confirmatorio se conduce principalmente por teorías sustantivas y por expectativas (Bollen 1989). En general, ambos tipos de procedimientos se corresponden con las dos grandes aproximaciones, inductiva y deductiva, que suelen ser asumidas en la definición de los constructos (Pérez-Gil et al. 2000).

La aproximación inductiva o exploratoria supone delimitar un número amplio de indicadores que supuestamente miden el dominio de interés para, seguidamente, buscar patrones de relación entre los mismos $\mathrm{y}$, a posteriori, proceder a definir las dimensiones conceptuales que representan. Por tanto, este enfoque trabaja desde las mediciones empíricas de los indicadores hacia la definición del constructo. Frente a ello, en la aproximación deductiva o confirmatoria el constructo está a priori insertado en una teoría que dirige su propia definición, señalando los comportamientos que podrían considerarse indicadores del mismo.

Así las cosas, se sigue un procedimiento inverso al exploratorio, a partir de la valoración de la correspondencia entre las características del concepto planteado y los datos obtenidos sobre éste a través de sus indicadores (Schmitt 1995). 
Considerando los pormenores del procedimiento seguido en la construcción del cuestionario que fue empleado para la recogida de datos en este trabajo, la aproximación considerada más apropiada en la validación de las escalas de medida y en el análisis de las relaciones entre las variables del modelo incluyó la combinación de una doble perspectiva exploratoria y confirmatoria en los análisis factoriales llevados a cabo. De un lado, pese a haber recurrido a una aproximación deductiva en la asignación de los indicadores a cada constructo a medir, las diferentes escalas fueron creadas ad hoc para los propósitos de la investigación, con lo que se empleó una técnica de análisis factorial exploratorio con la intención de comprobar si la estructura de factores resultante coincidía o no con la teorizada en el modelo de partida. Posteriormente, y mediante el empleo de procedimientos de análisis estructurales basados en la técnica de mínimos cuadrados parciales, se procedió de modo confirmatorio para establecer el funcionamiento de los indicadores asociados a los factores obtenidos en la predicción de relaciones entre éstos ${ }^{121}$.

Conforme a esta perspectiva metodológica, la utilidad del análisis factorial exploratorio reside en que permite la reducción de los datos y el refinamiento de los constructos (Ford et al. 1986), mediante la identificación del mínimo número posible de factores o componentes en los que agrupar los ítems de un cuestionario. Tal procedimiento abarca tres fases sucesivas (Pallant 2001): i) evaluación de la adecuación de los datos para el análisis factorial; ii) extracción de factores; y iii) rotación de factores e interpretación.

En primer lugar, el nivel de adecuación de los datos para ser sometidos a análisis factorial requiere tener en cuenta el tamaño de la muestra empleada, así como el grado de asociación entre las variables o ítems. En cuanto al primer aspecto, poco acuerdo hay entre los expertos acerca del tamaño ideal que debe alcanzar una muestra, si bien parece recomendable emplear el mayor número posible de observaciones (Stevens 1996, Tabachnick y Fidell 1996), dentro de una razón entre individuos e ítems de entre 5 y 10 a 1 (Nunnally 1978, Tabachnick y Fidell 1996).

Por lo que respecta a la intensidad de las relaciones entre los ítems a incluir en el análisis, Tabachnick y Fidell (1996) recomiendan una inspección previa de la matriz de correlaciones, siendo requerido el predominio de coeficientes $r$ por encima de 0,30 .

\footnotetext{
${ }^{121}$ Véase el apartado 5.3.2.
} 
A mayores de estas evidencias, dos índices estadísticos sirven de apoyo en la evaluación del potencial de los datos para ser agrupados en factores. El primero es el test de esfericidad propuesto por Barlett (1954), que debe resultar significativo a un nivel de $p<0,05$. El segundo es la medida Kaiser-Meyer-Ohlin (KMO) de adecuación de la muestra (Kaiser 1974), cuyos valores posibles oscilan entre 0 y 1, debiendo estar por encima de 0,60 para poder proceder al análisis (Tabachnick y Fidell 1996).

Una segunda fase implica la extracción de factores, mediante la determinación del mínimo número de combinaciones lineales entre ítems que permitan explicar la mayor parte posible de la variabilidad en el patrón de interrelaciones entre las variables resultantes. A tal fin, una de las técnicas factoriales más recomendadas por los expertos por su simpleza matemática y potencial para establecer la robustez psicométrica de las medidas es el análisis de componentes principales (Stevens 1996, Pallant 2001), el cual arroja una solución inicial sobre la estructura factorial de las dimensiones analizadas.

No obstante, la determinación del número de componentes que mejor describen la estructura de constructos subyacente a los datos requiere a menudo de una tarea interpretativa por parte del investigador, a la vista de las evidencias extraídas de la teoría. Para ello, dos técnicas asisten en la decisión sobre el número de factores a extraer de los datos, como son el criterio de Kaiser y el Test Scree de Catell (1966).

El criterio de Kaiser implica retener únicamente aquellos factores que lleven asociado un valor eigen superior a la unidad, estando referido dicho índice a la cantidad de varianza total explicada por el factor. Por su parte, el Test Scree de Catell arroja un gráfico de sedimentación (scree plot) en el que aparece representado el tamaño de los valores eigen (eje Y) de cada factor posible (eje X), a través de una curva que se torna en línea horizontal a medida que aumenta el número de factores. En la inspección del gráfico, Catell (1966) estableció la recomendación de retener los componentes que queden por debajo de dicho punto de inflexión, por cuanto que éstos son los que explican una mayor proporción de la varianza total.

Finalmente, la tercera fase del análisis implica rotar los factores mediante un procedimiento que, si bien no altera la solución inicial arrojada en la fase previa, ofrece una distribución de los ítems entre los componentes identificados que resulta más fácil de interpretar a partir de las cargas factoriales asociadas a cada indicador. Tales cargas factoriales representan la saturación específica de cada ítem en la predicción del constructo al que remiten, adquiriendo valores de correlación ítem-factor entre 0 y 1. 
En tal tarea, existen dos grandes aproximaciones de rotación que proporcionan, respectivamente, soluciones factoriales ortogonales -asumiéndose que los constructos subyacentes son independientes- $\mathrm{u}$ oblicuas -asumiéndose correlación entre constructos-. Con todo, Tabachnick y Fidell (1996) concluyen que el resultado de ambos enfoques metodológicos suele ser bastante similar, particularmente cuando existe un patrón claro de relaciones entre ítems, siendo más sencillo emplear rotaciones ortogonales de cara a la interpretación de los resultados. Dentro de tal aproximación ortogonal, existen a su vez diferentes técnicas de rotación, siendo el método de normalización Varimax el más comúnmente empleado por su capacidad para minimizar el número de indicadores con cargas factoriales altas en cada factor.

El resultado de tal procedimiento es lo que Thurstone (1947) ha denominado “estructura simple”, representativa de los constructos identificados a partir de los datos y de los ítems de la escala asociados a los mismos. La validez de los constructos resultantes queda entonces supeditada a la eliminación de aquellos ítems con cargas factoriales elevadas en más de una escala o con baja saturación en el componente al que remiten. A este último respecto, cuando los factores obtenidos van a ser posteriormente empleados con fines predictivos, algunos autores recomiendan desechar todos aquellos ítems con cargas factoriales inferiores a 0,50 (Barclay et al. 1995, Chin 1998a).

Siguiendo el procedimiento descrito en los párrafos precedentes, la validez de constructo de las escalas empleadas para los propósitos de la presente investigación fue contrastada mediante la realización de seis análisis factoriales exploratorios. El primero de ellos se refirió a las variables conceptuales relacionadas con una visión más distal o proximal de la empresa responsable, el segundo a las variables vinculadas a atribuciones del comportamiento empresarial, un tercero a las variables vinculadas con la generación de demanda responsable, el cuarto a las variables asociadas a las restantes fases del proceso de intención de compra responsable (adquisición de información de responsabilidad y valoración de ofertas responsables), y el quinto y el sexto a las variables relativas a la utilidad esperada y a la influencia social que inciden el citado proceso.

La naturaleza diferencial de estos grupos de variables en cuanto a definición y posición predictiva en el modelo teórico llevó a considerar la idoneidad de comprobar su estructura en análisis distintos, de cara a lograr una mayor precisión en la definición de los constructos subyacentes. 
En cualquier caso, los factores obtenidos fueron sometidos posteriormente a análisis de fiabilidad -mediante el índice alpha de Cronbach- y de correlación, buscándose evidencia acerca del nivel de asociación entre constructos del mismo y distinto nivel. A tal respecto, se esperaban correlaciones significativas entre todas las dimensiones, más altas entre puntuaciones de escalas del mismo grupo de especificidad (validez convergente) que de naturaleza diferente (validez discriminante).

Los resultados obtenidos fueron complementados con análisis descriptivos de las puntuaciones medias logradas por los participantes del estudio en las dimensiones identificadas, con el propósito de disponer de una primera aproximación en cuanto a cómo es percibida por el público la responsabilidad de las organizaciones y cuál es la importancia que se atribuye a esos comportamientos. Con un propósito similar se llevó a cabo un estudio de la distribución de frecuencias de las respuestas agregadas del público encuestado a partir de las escalas Likert de respuesta de 1 a 5 , previa categorización de las puntuaciones medias obtenidas en cada variable en los tres niveles de bajo (puntuaciones entre 1 y 2,33), intermedio (puntuaciones de 2,33 a 3,66), y alto (puntuaciones de 3,66 a 5).

d) Validez de criterio o externa:

La validez de criterio o externa, también conocida como validez nomológica, se considera la más importante en la construcción de una medida (Carmines y Zeller 1979, Clark y Watson 1995, Price 1997), por cuanto que remite al grado en que las relaciones empíricas entre variables estimadas con un determinado instrumento son consistentes con la teoría. Por tanto, su utilidad es la de determinar si las mediciones tomadas de un constructo se comportan según lo esperado con respecto a otras dimensiones con las que aquél está teóricamente relacionado.

En referencia a tal definición, investigar la validez de criterio de una medida implica tres fases sucesivas (Cronbach y Meehl 1955): i) especificar las relaciones teóricas entre conceptos; ii) examinar las relaciones empíricas entre las medidas de los conceptos; y iii) interpretar la evidencia empírica en términos de relaciones entre variables.

Para tal cometido, se suele distinguir entre dos aproximaciones alternativas en la contrastación de la validez de criterio de una medida, como son la predictiva y la concurrente. 
Por un lado, la validez predictiva se refiere al grado en que las puntuaciones de una variable independiente o predictora permiten pronosticar medidas de otra variable dependiente o criterio tomadas posteriormente. Por su parte, la validez concurrente remite al grado en que las puntuaciones de la variable independiente están asociadas con las de la variable dependiente cuando todas ellas son estimadas al mismo tiempo. Puesto que en este trabajo los datos de todas las variables fueron tomados en el mismo momento temporal para cada participante, los análisis llevados a cabo a este respecto estuvieron destinados a analizar la validez concurrente del instrumento de medición.

Diversos procedimientos estadísticos proporcionan evidencia sobre la validez de criterio asociada a una escala en mayor o menor profundidad, siendo los más usuales los análisis de correlación, regresión y varianza, y las técnicas de ecuaciones estructurales. Éstas últimas proporcionan la aproximación más precisa acerca de los vínculos predictivos o causales entre un conjunto de variables, siendo el método empleado prioritariamente en la contrastación de la validez concurrente en esta investigación, tal y como se detalla en el siguiente apartado.

\subsubsection{Validación del modelo predictivo}

Al amparo de las evidencias aportadas por los análisis preliminares descritos en los apartados precedentes, los análisis posteriores estuvieron dedicados a contrastar el ajuste del modelo propuesto y el grado de cumplimiento de las hipótesis recogidas en el mismo, así como el alcance de la fiabilidad y validez del instrumento de medida en el contexto concreto de las relaciones predictivas entre variables. Con este fin se empleó una técnica de modelos de ecuaciones estructurales (MEE) basada en el método de mínimos cuadrados parciales o PLS ${ }^{122}$, mediante el programa estadístico SmartPLS 2.0.

En este orden de cosas, cabe señalar que, de un modo particular en los últimos años, la utilización de modelos de ecuaciones estructurales se ha generalizado en la investigación (Gerow et al. 2010, Urbach y Alhelmann 2010, Roldán y Sánchez 2012), hasta el punto de convertirse en uno de los desarrollos recientes más importantes del análisis multivariante, siendo erigidos por Fornell (1982) como la segunda generación de métodos de análisis de datos. En tales términos, la característica común de las técnicas que se acogen bajo esta etiqueta es el reconocimiento metodológico de que la

\footnotetext{
${ }^{122}$ Acrónimo derivado de los términos en inglés Partial Least Squares.
} 
teoría científica implica tanto variables empíricas como abstractas, siendo el propósito de este tipo de modelos ayudar a vincular los datos con la teoría más allá de la asociación o descripción empírica, mediante la modelización sistemática y comprehensiva de relaciones entre múltiples constructos, independientes y dependientes, y de forma simultánea (Gerbins y Anderson 1998).

A tales efectos, el funcionamiento estadístico de los modelos de ecuaciones estructurales se fundamenta en la distinción entre varios tipos de variables. Por un lado, las variables latentes o factores aluden a constructos que no pueden ser observados ni, por tanto, tampoco medidos de una forma directa, debiendo ser inferidos a partir su operativización en conductas específicas representativas de los mismos. Por otro, las variables observadas o manifiestas representan tales conductas directamente medibles, sirviendo como indicadores del constructo subyacente al que teóricamente representan.

A su vez, las variables latentes pueden ser tanto exógenas como endógenas. Las variables exógenas actúan como variables independientes que causan fluctuaciones en los valores de otras variables latentes del modelo, mientras que su origen no es explicado por el efecto de ningún factor. Por su parte, las variables latentes endógenas actúan en el modelo como variables dependientes explicadas a partir de la influencia, directa o indirecta, de las variables exógenas y/o de otros constructos latentes de su misma naturaleza. Además, las variables observadas pueden adoptar la forma de indicadores reflexivos o formativos. Los primeros son desencadenados por el constructo latente, dado que “reflejan” una representación del mismo (Gerbins y Anderson 1998), mientras que los indicadores formativos causan la construcción latente, representando sumativamente las diferentes dimensiones de ésta (Campbell 1960, Thompson et al. 1995).

A partir de estas especificaciones, los modelos de ecuaciones estructurales surgieron de la unión de la perspectiva econométrica enfocada a la predicción, y la tradición psicométrica basada en la inferencia de variables latentes no observadas a partir de indicadores o variables manifiestas directamente observables (Chin 1998b). En tal sentido, son técnicas multivariantes que combinan aspectos de la regresión múltiple -examinando relaciones de dependencia- y del análisis factorial -representando constructos teóricos abstractos a partir de múltiples variables medibles- para estimar una serie de predicciones interrelacionadas simultáneamente (Fornell 1982, Barclay et al. 1995, Chin 1998b, Cepeda y Roldán 2004). 
Con todo, mediante esta técnica se puede llegar a estimar en un análisis único, sistemático e integrador del ajuste de dos modelos (Gefen et al. 2000): i) el modelo de medida, es decir, las cargas factoriales de las variables observadas (indicadores o ítems) con relación a sus correspondientes variables latentes (constructos), siendo contrastada la fiabilidad y validez de las mediciones empleadas; y ii) el modelo estructural, es decir, las relaciones de causalidad hipotetizadas entre un conjunto de variables latentes.

Si bien la difusión de los paquetes informáticos más populares ha conducido a que cuando se hable de tales análisis holísticos se piense en LISREL, AMOS o EQS, lo cierto es que en los últimos años la técnica PLS ha acrecentado su popularidad entre los investigadores en el campo de las Ciencias Sociales en virtud de las muchas ventajas que presenta, particularmente en lo relativo a las exigencias de distribución y tipo de las variables, y de tamaño de la muestra (Cepeda y Roldán 2004).

Dicho de manera sintética, ambas aproximaciones metodológicas difieren en que, mientras el resto de técnicas están basadas en el análisis de la covarianza (a partir de métodos de máxima verosimilitud -Maximun Likelihood, ML-, mínimos cuadrados generalizados -Generalized Least Squares, GLS-, etc.), PLS tiene como objetivo la predicción de las variables latentes a partir de la varianza, mediante la estimación de mínimos cuadrados ordinarios (Ordinary Least Squares, OLS) y el análisis de componentes principales. En cualquier caso, ambos enfoques presentan divergencias en cuanto a los objetivos de su análisis, las suposiciones estadísticas en las que se basan, y la naturaleza de los estadísticos de ajuste que proporcionan (ver Cuadro 5.1).

En términos concisos, el objetivo de los métodos basados en covarianzas es estimar los parámetros del modelo -es decir, las cargas factoriales de las variables observadas en las latentes y los caminos o paths de relación entre variables latentes-, de tal modo que sean minimizadas las discrepancias entre la matriz empírica inicial de datos de covarianzas y la matriz deducida a partir del modelo y de los parámetros estimados. Asimismo, este enfoque proporciona medidas de bondad de ajuste globales que informan acerca del grado con que el modelo hipotetizado representa los datos disponibles, buscando testar una teoría sólida en su conjunto.

Por lo tanto, de ahí que la aproximación basada en análisis de covarianzas se adapte a los propósitos de la investigación confirmatoria en la que se pretende encontrar parámetros invariantes estructurales que proporcionen una afinación de causalidad entre variables. 
Cuadro 5.1. Resumen comparativo entre PLS y los métodos basados en la covarianza

\begin{tabular}{|c|c|c|}
\hline Criterio & Métodos basados en la covarianza & PLS \\
\hline Objetivo & $\begin{array}{l}\text { Orientado a la estimación de } \\
\text { parámetros (análisis confirmatorio) }\end{array}$ & $\begin{array}{l}\text { Orientado a la predicción (análisis } \\
\text { exploratorio) }\end{array}$ \\
\hline Enfoque & Basado en covarianzas & Basado en la varianza \\
\hline Suposiciones & $\begin{array}{l}\text { Habitualmente, distribución normal } \\
\text { multivariada y observaciones } \\
\text { independientes (paramétricas) }\end{array}$ & $\begin{array}{l}\text { Especificación del predictor (no } \\
\text { paramétrica) }\end{array}$ \\
\hline $\begin{array}{l}\text { Estimación de } \\
\text { parámetros }\end{array}$ & Consistente & $\begin{array}{l}\text { Consistente a medida que se } \\
\text { incremente el número de indicadores } \\
\text { y aumenta la muestra (consistency at } \\
\text { large) }\end{array}$ \\
\hline $\begin{array}{l}\text { Puntuación de las } \\
\text { variables latentes }\end{array}$ & Indeterminada & Estimadas explícitamente \\
\hline $\begin{array}{c}\text { Relaciones } \\
\text { epistémicas entre las } \\
\text { variables latentes y } \\
\text { sus medidas }\end{array}$ & $\begin{array}{l}\text { Habitualmente, sólo con indicadores } \\
\text { reflexivos (constructo no observado } \\
\text { da lugar a lo que se observa) }\end{array}$ & $\begin{array}{l}\text { Pueden ser modeladas tanto en forma } \\
\text { reflexiva como formativa (constructo } \\
\text { teórico latente). }\end{array}$ \\
\hline Implicaciones & Óptimo para precisión de parámetros & Óptimo para precisión de predicción \\
\hline $\begin{array}{l}\text { Complejidad de } \\
\text { modelos }\end{array}$ & $\begin{array}{l}\text { Complejidad pequeña a moderada } \\
\text { (p.e. menos de } 100 \text { indicadores) }\end{array}$ & $\begin{array}{l}\text { Gran complejidad (p.e. } 100 \\
\text { constructos y } 1000 \text { indicadores) }\end{array}$ \\
\hline $\begin{array}{l}\text { Tamaño de la } \\
\text { muestra }\end{array}$ & $\begin{array}{l}\text { Basada idealmente en el poder de } \\
\text { análisis de un modelo específico. } \\
\text { Recomendaciones mínimas entre } \\
200 \text { y } 800 \text { casos }\end{array}$ & $\begin{array}{l}\text { Análisis de poder basado en la } \\
\text { proporción del modelo con el } \\
\text { número mayor de predictores. Las } \\
\text { recomendaciones mínimas están } \\
\text { entre } 30 \text { y } 100 \text { casos }\end{array}$ \\
\hline
\end{tabular}

Fuente: Adaptado de Cepeda y Roldán (2004).

Tal enfoque coincide con una modelización firme o rígida (Cepeda y Roldán 2004), el cual lleva asociadas varias limitaciones en torno a las suposiciones restrictivas requeridas con respecto a la teoría subyacente, las distribuciones de los datos y los niveles de medida de las variables, constituyendo lo que se define como un "sistema cerrado” (Falk y Miller 1992).

Dados tales requerimientos limitativos, la técnica PLS fue diseñada y después perfeccionada para reflejar las condiciones teóricas y empíricas de las Ciencias Sociales y del Comportamiento (Wold 1973, 1979, 1982 y 1985, Chin 1998a), en las que es habitual encontrarse con teorías no suficientemente asentadas en contextos de escasa información disponible (Wold 1979). En cualquier caso, PLS representa un tipo de 
análisis matemático y estadístico de datos correspondiente a lo que se conoce como una "modelización flexible" (Wold 1980), basada en la creación de relaciones predictivas lineales óptimas entre variables sin realizar suposiciones a niveles de medida, de distribuciones de los datos, y de tamaño muestral.

En palabras de Falk y Miller (1992:xi), “en un sentido de mínimos cuadrados, esto significa que dados los datos y el modelo, las variables independientes se vuelven las mejores variables predictoras posibles, y las variables dependientes se vuelven las mejores variables criterio o predichas", por cuanto se abandona la idea de causalidad que caracteriza la modelización firme, siendo reemplazada en cuanto que concepto por la de "predictibilidad", buscando llegar a estimar la probabilidad de un acontecimiento en función de la información disponible sobre otros acontecimientos cuando no se dan las condiciones de un sistema cerrado (Cepeda y Roldán 2004). Desde esta perspectiva, el objetivo perseguido por la modelización PLS es la predicción de variables dependientes intentando maximizar la varianza explicada $\left(R^{2}\right)$ de las mismas, de forma que las estimaciones de los parámetros estén basadas en la capacidad de minimizar las varianzas residuales de las variables endógenas. Para ello, PLS aplica una secuencia iterativa de OLS y regresión lineal múltiple, analizando un constructo en cada momento (Thompson et al. 1995, Chin 1998a).

Asimismo, y en comparación con los métodos basados en el análisis de la covarianza, PLS se adapta mejor a las aplicaciones exploratorias, predictivas y de desarrollo de la teoría (Wold 1979, Barclay et al. 1995, Chin et al. 2003, Cepeda y Roldán 2004, Chin 2010). Tal es el caso de la presente investigación, dado el objetivo perseguido de proponer un modelo explicativo del comportamiento del consumidor en el proceso pre-compra cuando éste considera criterios de responsabilidad, así como la consiguiente construcción de escalas ad hoc en la medición de las variables de interés.

Más aún, el modelado PLS reviste diversas ventajas que le convierten en una técnica adecuada para los fines aquí perseguidos. Para empezar, PLS es considerado un potente método de análisis (Chin et al. 2003) debido a sus mínimos requerimientos en relación con las escalas de medida de las variables, el tamaño muestral y las distribuciones residuales. Así, y con relación a las técnicas basadas en ajustes de covarianzas, PLS evita algunos de los problemas que aquéllas pueden ocasionar en términos de soluciones impropias o inadmisibles e indeterminación de factores, dado que las variables pueden ser estimadas por cualquier tipo de medición nominal, ordinal, 
de razón o de intervalos (Fornell y Bookstein 1982, Wold 1985). Al mismo tiempo, otra de las principales características de esta técnica es que, a diferencia del resto, no se basa en las asunciones de los análisis paramétricos, por cuanto se adapta especialmente bien al empleo de muestras pequeñas (Barclay et al. 1995) y a datos para los que no es fácil encontrar distribuciones normales (Thompson et al. 1995, Chin 1998a, Falk y Miller 1992).

Por otro lado, y atendiendo a la naturaleza de las relaciones entre los constructos teóricos y los datos empíricos, en tanto que los métodos modelos de ecuaciones estructurales basados en covarianzas están principalmente diseñados para operar con indicadores reflexivos, PLS permite operar también con medidas formativas. No obstante, y por lo que concierne a los vínculos direccionales entre constructos, una limitación de PLS es que sólo trabaja con relaciones recursivas (o sea, unidireccionales), mientras que otras técnicas admiten también relaciones no recursivas (o, lo que es lo mismo, bidireccionales).

A la vista de todos los pormenores que han sido comentados, seguidamente se procede a describir el procedimiento empleado en el presente estudio con el programa SmartPLS 2.0, en torno a las cuatro fases sucesivas implicadas en cualquier análisis relacionado con los modelos de ecuaciones estructurales: i) identificación del modelo; ii) evaluación del ajuste del modelo de medida; iii) evaluación del ajuste del modelo estructural; y iv) reespecificación del modelo.

\section{a) Identificación del modelo:}

Tal y como apuntaron Barclay et al. (1995), el primer paso que ha de dar el investigador en un estudio con PLS -al igual que con otras muchas técnicas de modelos de ecuaciones estructurales- es especificar tanto el modelo estructural de relaciones entre variables latentes exógenas y endógenas (modelo interno o inner model), como el modelo de medida representativo de las relaciones entre indicadores observados y constructos latentes (modelo externo u outer model). Para dicha tarea, resulta de una gran ayuda la realización de monogramas (Falk y Miller 1992), o diagramas de paso en la representación visual de las variables manifiestas y latentes, así como de las relaciones entre las mismas. En tal sentido, la Figura 5.1 ilustra un modelo genérico simple, utilizado como ejemplo en la descripción de los distintos elementos a tener en cuenta en esta primera fase de especificación del modelo. 
Figura 5.1. Diagrama de paso teórico genérico con constructos y medidas ${ }^{*}$

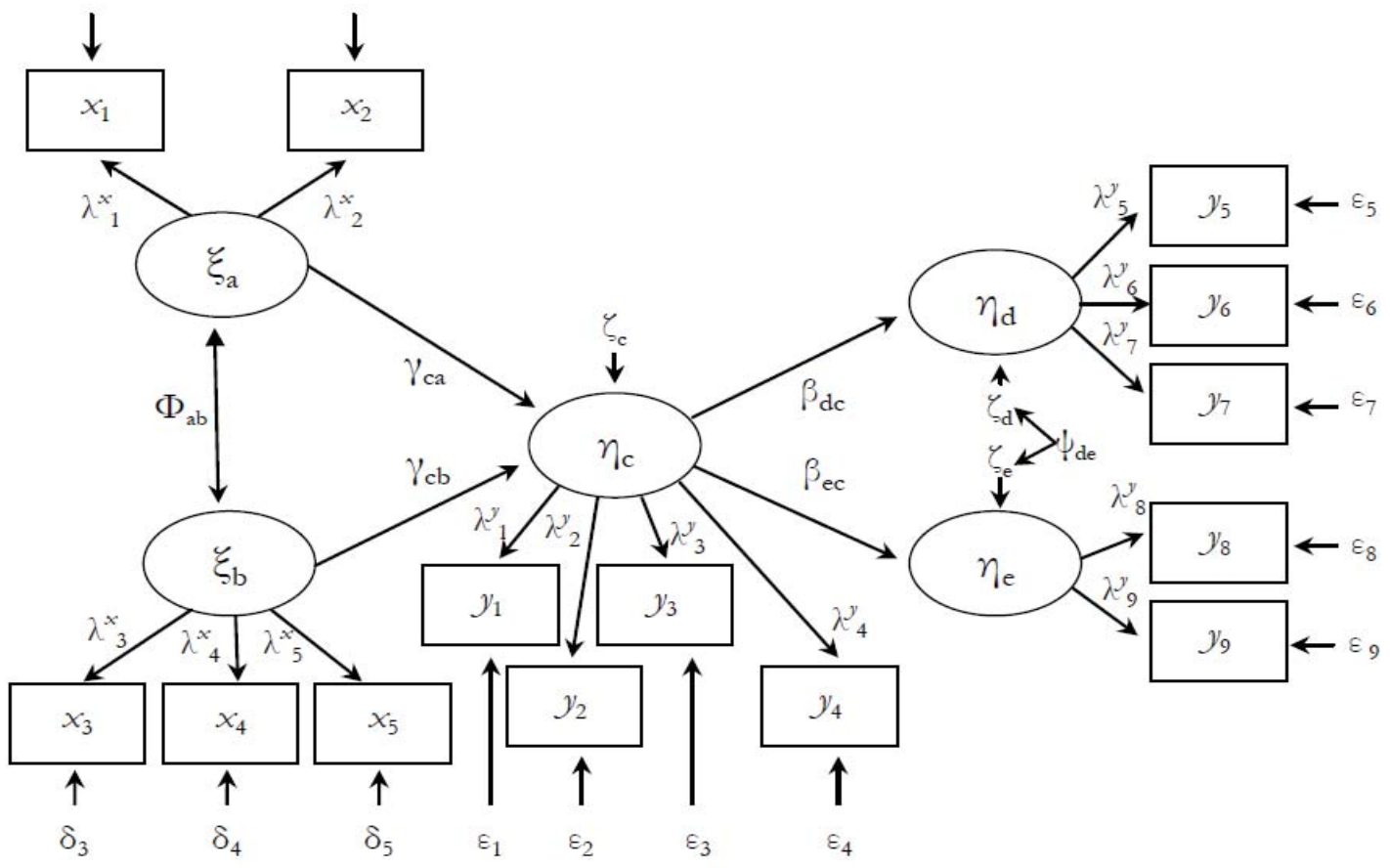

"Las variables latentes son expresadas por medio de indicadores reflexivos

Fuente: Adaptado de Gefen et al. (2000).

Tal y como puede observarse en dicha Figura, dentro de la aproximación metodológica PLS los constructos teóricos o variables latentes, ya sean exógenas o endógenas, son representados gráficamente en el interior elipses, mientras que las medidas o ítems correspondientes a los indicadores o variables observadas se simbolizan por medio de cuadros. Por su parte, las relaciones entre variables de cualquier naturaleza son visualizadas mediante flechas unidireccionales que pueden ser interpretadas como vínculos predictivos de la varianza de la dimensión a la que apuntan, por cuanto el esquema de flechas especifica las relaciones internas entre constructos, así como las relaciones externas entre cada variable latente y sus indicadores. A este último respecto, los ítems reflexivos son representados por medio de flechas que se alejan de las variables latentes -tal es el caso del ejemplo de la Figura y del modelo teórico de la presente investigación-, mientras que los ítems formativos son dibujados con una flecha dirigida hacia el constructo latente (Thompson et al. 1995, Chin 1998a). 
En torno al modelo estructural interno de vínculos predictivos entre variables latentes exógenas y endógenas, la terminología utilizada por las técnicas de modelado PLS contiene los siguientes elementos (Wold 1985, Falk y Miller 1992, Barclay et al. 1995, Gefen et al. 2000, Cepeda y Roldán 2004):

- construcciones latentes exógenas, denominadas xi o ksi $(\xi)$, dependiendo del diccionario usado;

- construcciones latentes endógenas, llamadas eta $(\eta)$;

- caminos, paths o flechas entre dos variables latentes $\xi$ y $\eta$, representados estadísticamente por los coeficientes gamma $(\gamma)$;

- caminos, paths o flechas de conexión entre dos variables latenteq, llamados $\operatorname{beta}(\beta)$;

- correlaciones entre dos variables exógenas, llamadas phi $(\Phi)$;

- errores de medida de las variables endógenas, representados como zeta $(\zeta)$; y

- correlaciones entre los errores de las variables endógenas, representadas por $\operatorname{psi}(\psi)$

Por su parte, el modelo de medida externo que aglutina las relaciones entre variables observadas (ítems o indicadores) y variables latentes queda especificado a través de:

- las variables $x$ e $y$, las cuales representan respectivamente las medidas de los constructos exógenos y endógenos, esto es, cada indicador $x$ se genera sobre una $\xi$, y cada indicador $y$ se asocia a una $\eta$;

- lambda $x\left(\lambda_{\mathrm{x}}\right)$, que representa el path o relación entre la variable observada $x \mathrm{y}$ su $\xi$, es decir, la carga factorial sobre la variable latente exógena;

- delta $(\delta)$, que representa el error asociado a la variable $x$, es decir, la parte de la varianza que no refleja la variable latente $\xi$

- lambda y $\left(\lambda_{\mathrm{y}}\right)$, que representa la relación entre la variable observada $y$ con respecto a su $\eta$, es decir, la carga factorial sobre la variable latente endgena ; $\mathrm{y}$

- epsilon (ع), que representa el error asociado a la variable $y$, es decir, la parte de la varianza que no refleja la variable latente $\eta$.

Atendiendo a tales especificaciones de nomenclatura, cada variable observada y latente puede ser igualmente expresada por medio de una ecuación matemática sumativa de los diferentes términos estadísticos vinculados a la misma. 
Por una parte, las medidas de las variables observadas o manifiestas asignadas a variables exógenas pueden ser inferidas a partir de la expresión:

$$
x=\lambda_{\mathrm{x}} \xi+\delta
$$

donde:

$x$ es un vector de $p x 1$ medidas observables de una variable exógena;

$\lambda_{\mathrm{x}}(\operatorname{lambda} x)$ representa una matriz pxn de coeficientes de regresión de $x$ con respecto a la variable latente $\xi(k s i)$, mostrando la relación entre $x$ $\mathrm{y} \xi ; \mathrm{y}$

$\delta($ delta $)$ es un vector $p x l$ de errores de medida de $x$.

Paralelamente, las medidas de las variables observadas vinculadas a variables endógenas quedan recogidas en la ecuación:

$$
y=\lambda_{\mathrm{y}} \eta+\varepsilon
$$

donde:

$y$ es un vector de qxl medidas observables de una variable endógena;

$\lambda_{\mathrm{y}}(\operatorname{lambda} y$ ) es una matriz qxn de coeficientes de regresión de $y$ con respecto a la variable latente $\eta(e t a)$, mostrando el vínculo de $y$ con $\eta$; y

$\varepsilon$ (epsilon) representa un vector $q x 1$ de errores de medida para la variable $y$.

Por otro lado, la ecuación del modelo estructural representativo de las relaciones predictivas entre variables latentes se presentaría en forma matricial abreviada para cada variable endógena $\eta$, de la siguiente forma:

$$
\mathrm{H}=\gamma \xi+\beta \eta+\zeta
$$

donde:

$\gamma$ (gamma) es una matriz de coeficientes de regresión mxn o de efectos de las variables latentes exógenas;

$\xi$ ( ksi) representa un vector de $m x l$ variables latentes exógenas;

$\beta$ (beta) es una matriz de coeficientes de regresión $n x m$ o de efectos de las variables latentes endógenas;

$\eta($ eta $)$ representa un vector de $n x l$ variables latentes endógenas; $\mathrm{y}$

$\zeta(z e t a)$ es un vector $m x l$ de errores de las ecuaciones.

Además, se asume que la matriß̧ no es singular, y que las matrices $\xi$ y $\zeta$ no están correlacionadas entre sí. 
Tal y como se detallará en el siguiente capítulo, la identificación del modelo de investigación se llevó a cabo en base a los elementos señalados. Se trata de un conjunto relativamente sencillo de regresiones simples y múltiples que puede ser extendido a relaciones predictivas más complejas, a medida que el algoritmo PLS toma segmentos de modelos aislados y aplica el mismo proceso hasta que converge el modelo completo. $\mathrm{Si}$ bien en el contexto de este procedimiento estadístico una de las principales limitaciones de PLS frente a otros modelos de ecuaciones estructurales es que no proporciona medidas de bondad de ajuste sólidas en relación a la capacidad explicativa del modelo respecto a las covarianzas de la muestra (Chin 1998a), existen dos técnicas no paramétricas de remuestreo, denominadas bootstrap y jackknife, las cuales permiten examinar la estabilidad de las estimaciones obtenidas.

Más concretamente, la metodología bootstrap trata el conjunto de datos original como si fuera una población total, generando a partir de ella $n$ conjuntos de muestras con el fin de obtener $n$ estimaciones de cada parámetro en el modelo PLS. A tal efecto, cada muestra es obtenida mediante un procedimiento de remuestreo con reemplazo del conjunto de datos original, normalmente hasta que el número de casos sea idéntico al conjunto muestral inicial (Chin 1998b). A través de tales operaciones estadísticas, bootstrap ofrece el cálculo del error estándar de los parámetros, así como un conjunto de valores para el estadístico $t$ de Student con $n$ - 1 grados de libertad, siendo $n$ el número de submuestras empleadas, asociados a las cargas factoriales del modelo de medida y a las relaciones path del modelo estructural.

Por su parte, jackknife es una técnica inferencial que permite testar la significación de las estimaciones de los parámetros a partir de datos en los que no se presupone una distribución normal (Chin 1998b). En términos generales, su operatividad estadística consiste en omitir un caso en cada período para luego estimar los parámetros del modelo sobre los casos restantes y, a continuación, reconstruir o predecir los valores omitidos usando los parámetros reestimados. En suma, y al igual que la metodología bootstrap, la técnica jackknife permite estimar el sesgo y el error estándar de los parámetros (Efron y Tibshirani 1993), así como obtener valores de la $t$ de Student con $n-1$ grados de libertad -siendo, de nuevo, $n$ el número de submuestras del procedimiento- que informan sobre la significación estadística de las estimaciones.

Con todo, y aunque en base al procedimiento descrito los parámetros de medida y estructurales sean estimados a la vez, un modelo PLS debe ser analizado e 
interpretado en dos etapas sucesivas (Barclay et al. 1995, Anderson y Gerbing 1988, Gefen et al. 2000):

i) Valoración de la validez y fiabilidad del modelo de medida (outer model), tratando de determinar si los conceptos teóricos están siendo estimados correctamente a través de las variables observadas, y habida cuenta del contexto específico de las relaciones planteadas entre constructos latentes.

ii) Valoración del modelo estructural (inner model), evaluando el peso y la magnitud de las relaciones entre las distintas variables latentes.

b) Evaluación del ajuste del modelo de medida:

Si bien los procedimientos de análisis factorial exploratorio y correlacional que han sido descritos fueron empleados en este estudio con el propósito de logar un primer acercamiento a la fiabilidad y validez de las escalas empleadas en la medición de las variables, lo cierto es que el procedimiento PLS posibilitó una aproximación más detallada a la utilidad del instrumento de medida en el contexto específico del modelo predictivo planteado.

A tal efecto, la evaluación del modelo de medida con PLS implica el análisis de la fiabilidad individual de los ítems, la consistencia interna o fiabilidad de las escalas, y la validez de constructo convergente y divergente (Cepeda y Roldán 2004). Ello supone, de acuerdo con Anderson y Gerbing (1988), una precondición para el posterior análisis de la validez predictiva del modelo estructural.

Mediante PLS, la fiabilidad individual de los ítems es valorada examinando las cargas factoriales estandarizadas $(\lambda)$, esto es, las correlaciones simples de las medidas o indicadores con sus respectivos constructos. Se procede, por tanto, mediante la aplicación de un análisis factorial confirmatorio, a garantizar el significado aportado por las variables observadas a las variables latentes (Barclay et al. 1995). En tal sentido, una de las reglas empíricas más difundidas señala que, para aceptar un indicador como integrante de un constructo, aquél ha de poseer una carga factorial igual o superior a 0,50 (Barclay et al. 1995, Chin 1998a y 1998b).

En este mismo orden de cosas, el concepto de "comunalidad" alude a la parte de la varianza de un indicador reflexivo explicada por el factor o constructo (Bollen 1989), equivaliendo al cuadrado de la correlación entre la variable observada y la latente $\left(\lambda^{2}\right)$, y siendo considerados aceptables valores superiores a 0,25 . Adicionalmente, y a modo de 
respaldo a las decisiones acerca de la retención o eliminación de ítems, las aplicaciones informáticas PLS permiten, a través del procedimiento bootstrap descrito anteriormente, la asignación de valores $t$ de Student a cada carga factorial, siendo asumidos niveles aceptables de significación $p<0,05$.

Comprobada la fiabilidad individual de los ítems, el análisis de la consistencia interna de las escalas permite determinar el nivel de rigurosidad con el que varios indicadores están midiendo la misma variable latente. Para llevar a cabo tal evaluación, los programas PLS arrojan dos indicadores: el tradicional coeficiente alpha de Cronbach ( $\alpha$ ) y la fiabilidad compuesta del constructo (Werts et al. 1974), representada como $\rho_{c}$, de acuerdo a la siguiente fórmula:

$$
\varrho_{c}=\frac{\text { Varianza del constructo }}{\text { Varianza del constructo }+ \text { Error de la varianza }}=\frac{\left(\sum \lambda_{\mathrm{i}}\right)^{2}}{\left(\sum \lambda_{\mathrm{i}}\right)^{2}+\sum_{\mathrm{i}} \mathrm{var}\left(\varepsilon_{\mathrm{i}}\right)}
$$

donde:

$\lambda_{\mathrm{i}}$ es la carga estandarizada del indicador $i$;

$\varepsilon_{\mathrm{i}}$ es el error de medida del indicador $i$; e

${ }_{\mathrm{i}} \operatorname{var}\left(\varepsilon_{\mathrm{i}}\right)$ es igual a $1-\lambda_{\mathrm{i}}^{2}$.

La fiabilidad compuesta es similar al alpha de Cronbach como medida de consistencia interna. La diferencia entre ambas radica en que la última presupone $a$ priori que cada indicador de un constructo contribuye de la misma forma, estando las cargas factoriales fijadas en la unidad (Barclay et al. 1995), mientras que la fiabilidad compuesta utiliza las cargas de los ítems tal como se dan en el modelo causal hipotetizado. Tal argumento ha sido el aducido por Fornell y Larcker (1981) para defender que la fiabilidad compuesta es una medida superior al alpha de Cronbach, por cuanto que es más general que ésta y no se ve influenciada por el número total de ítems de la escala. No obstante, la interpretación de ambos índices es bastante similar, considerándose aceptables valores de fiabilidad por encima de 0,70 en etapas tempranas de investigación (Nunnally 1978, Nunnally y Bernstein 1994, Barclay et al. 1995, Hair et al. 1998), lo que supone que el constructo explica al menos el $70 \%$ de la varianza total en los indicadores, frente al $30 \%$ atribuible al error.

Por lo que respecta a la evaluación de la validez convergente, el procedimiento PLS asume que los ítems que realmente miden el mismo constructo tendrán un ajuste significativo y estarán altamente correlacionados (Cepeda y Roldán 2004). Desde este 
postulado empírico, la validez convergente será calculada a partir de la medida de la varianza extraída media (Average Variance Extracted-AVE-), desarrollada por Fornell y Lacker (1981), la cual permite estimar la cantidad de varianza que un constructo obtiene de sus indicadores con relación a la cantidad de varianza debida al error de medida, de acuerdo a la ecuación:

$$
\operatorname{AVE}=\frac{\sum \lambda_{\mathrm{i}}^{2}}{\sum \lambda_{\mathrm{i}}^{2}+\sum_{\mathrm{i}} \operatorname{var}\left(\varepsilon_{\mathrm{i}}\right)}
$$

donde, de nuevo:

$\lambda_{\mathrm{i}}$ es la carga estandarizada del indicador $i$;

$\varepsilon_{\mathrm{i}}$ es el error de medida del indicador $i$; e

${ }_{\mathrm{i}} \operatorname{var}\left(\varepsilon_{\mathrm{i}}\right)$ es igual a $1-\lambda^{2}$.

Fornell y Larcker (1981) recomiendan que el valor AVE esté por encima de 0,50. Esto es así por cuanto ello viene a suponer que más del $50 \%$ de la varianza del constructo sería debida a los indicadores.

Para finalizar, la validez discriminante es evaluada en la interfaz PLS a partir de la verificación de que cada constructo comparte más varianza con sus medidas o indicadores que con otros constructos del modelo (Barclay et al. 1995).

En tales términos, es recomendable realizar una inspección de la matriz de correlaciones entre las variables latentes, reemplazando la diagonal por la raíz cuadrada de los valores AVE, los cuales deben ser superiores al resto de índices $r$ (Fornell y Lacker 1981).

c) Evaluación del ajuste del modelo estructural:

Una vez verificada la fiabilidad y validez del modelo de medida, el análisis PLS permite estimar los parámetros de ajuste del modelo estructural $\mathrm{y}$, con ello, informa sobre el grado de cumplimiento de las hipótesis de partita y la validez predictiva del modelo, en base a la respuesta a dos cuestiones fundamentales (Falk y Miller 1992), como son las relativas a: i) qué cantidad de la varianza de las variables endógenas es explicada por los constructos que las predicen; y ii) en qué medida las variables predictoras contribuyen a la varianza explicada de las variables endógenas.

Dos índices básicos proporcionan respuesta, respectivamente, a cada una de dichas preguntas: los estadísticos $R^{2}$ y los coeficientes path estandarizados $\gamma$ y $\beta$. 
El valor $R^{2}$ asociado a cada variable latente endógena expresa la cantidad de varianza del constructo que es explicada por el modelo, siendo interpretado de la misma manera que los obtenidos en un análisis de regresión múltiple. Falk y Miller (1992) señalan como criterio de ajuste del modelo que tal valor debería ser igual o superior a 0,10 (lo que supone una explicación del al menos el 10\% de la varianza), previniendo acerca de que las cifras inferiores de $R^{2}$, aún siendo estadísticamente significativas, proporcionan muy poca información sobre el poder predictivo de las relaciones planteadas como hipótesis en torno a dicha construcción latente (Cepeda y Roldán 2004).

En estrecha relación con el estadístico $R^{2}$, Wold (1982) sugirió el empleo del test Stone-Geisser (Stone 1974, Geisser 1974) de cara a la estimación del ajuste global del modelo en términos de relevancia predictiva. Básicamente, dicho test realiza una estimación jackknife a través del estadístico $Q^{2}$, el cual, aplicado para $i=1,2, \ldots, n$ casos y una regresión múltiple con $k$ regresiones se plantea como:

$$
Q^{2}=1-\frac{\sum_{\mathrm{n}}\left(\mathrm{Y}_{\mathrm{i}}-\sum \mathrm{X}_{\mathrm{ki}} \mathrm{b}_{\mathrm{k}(\mathrm{i})}\right)^{2}}{\sum_{\mathrm{n}}\left(\mathrm{Y}_{\mathrm{i}}-\mathrm{Y}_{\cdot_{(\mathrm{i})}}\right)^{2}}
$$

donde:

$b_{\mathrm{k}(\mathrm{i})}$ es el conjunto de coeficientes de la regresión obtenidos cuando es omitido el $i$-ésimo caso; e

$Y_{\text {.(i) }}$ es la media de la variable dependiente obtenida sin tener en cuenta los casos $i$-ésimos.

Con todo, el valor $Q^{2}$ así obtenido no es más que un análogo jackknife de la familia de los $R^{2}$ con dos propiedades básicas: i) puede incrementarse si alguna predicción inestable es eliminada de la ecuación; y ii) su valor puede tornarse negativo, indicando confusión o mala dirección del modelo planteado. Lo más normal, en todo caso, es recomendar que los valores de dicho estadístico sean positivos y superiores a 0,20 .

Los coeficientes $\gamma$ y $\beta$ representan, por su parte, los pesos de regresión estandarizados que relacionan, respectivamente, constructos latentes exógenos y endógenos y constructos latentes endógenos entre sí, debiendo ser interpretados del mismo modo que los coeficientes obtenidos en las regresiones tradicionales. Chin (1998a) propone que tales valores deberían alcanzar un mínimo de 0,20, e idealmente 
situarse por encima de 0,30. Ante la elevada exigencia de tal criterio, Falk y Miller (1992) han sugerido como alternativa una regla empírica menos restrictiva, según la cual una variable predictora debería explicar, al menos, el 1,5\% de la varianza en la variable latente dependiente. A tal respecto, estos mismos autores proponen que la proporción de varianza explicada en un constructo endógeno por otra variable latente viene dado por el valor absoluto de multiplicar el coeficiente de regresión por el correspondiente coeficiente $r$ de correlación entre ambos. De este modo, y por ejemplo, un valor $\gamma$ o $\beta=0,10$ requeriría un correspondiente coeficiente de correlación $r=0,15$ para satisfacer tal criterio. Adicionalmente, el procedimiento bootstrap vinculado al algoritmo PLS asigna valores $t$ de Student a los parámetros de regresión estimados, guiando la identificación de relaciones significativas de predicción entre variables.

Además de los efectos directos entre variables latentes reportados por los coeficientes $\gamma$ y $\beta$, la valońacidel alcance de las relaciones hipotetizadas entre constructos requiere también el análisis de las influencias indirectas producidas por mediación de una o más variables endógenas. En tal sentido, la estimación de efectos totales sobre una determinada variable latente endógenạ proviene de la multiplicación de los coeficientes $\gamma$ y $\beta$ predictivos de la misma, asociada a valores $t$ de Student significativos arrojados por la técnica bootstrap.

d) Reespecificación del modelo:

En los procesos de desarrollo de nuevas teorías, es habitual que las versiones iniciales de los modelos sometidos a análisis mediante ecuaciones estructurales no proporcionen un ajuste demasiado sólido. Por esta razón, los investigadores suelen recurrir a estrategias de modelización basadas en lo que se conoce como "desarrollo del modelo" o planteamiento de "modelos rivales", consistente en proponer una serie de reespecificaciones al planteamiento original y con el propósito de mejorar su nivel de ajuste, siempre respetando la relación con la teoría subyacente (Hair et al. 2005), las cuales actúan como explicaciones alternativas al modelo propuesto inicialmente.

En este orden de cosas, Robles (1996) ha resaltado la importancia de distinguir entre las dos categorías de relaciones teóricas y empíricas entre variables. Puesto que las primeras son inherentes al marco teórico de respaldo a las hipótesis planteadas y no pueden ser modificadas, están fuera de los límites de la reespecificación, la cual debe estar centrada en la reconsideración de los resultados empíricos obtenidos, particularmente en base al nivel de adecuación de los ítems empleados para medir los 
constructos, de cara a identificar un modelo refinado capaz de explicar una mayor proporción de la varianza en las dimensiones latentes endógenas.

En este sentido, la comparación entre modelos para la selección de la mejor alternativa se centra en la revisión de los parámetros de medida y estructurales obtenidos en cada caso, siendo el propósito el de garantizar la máxima correspondencia entre las variables observadas y los constructos latentes al tiempo que se obtiene la mayor evidencia posible de ajuste global a partir del valor de los estadísticos $R^{2}$ y $Q^{2}$.

Asimismo, los cambios en el indicador $R^{2}$ entre varios modelos alternativos permiten determinar si la influencia de una variable latente particular sobre un constructo dependiente tiene un impacto sustantivo (Chin 1998b), estando la importancia del efecto $\left(f^{2}\right)$ calculado de acuerdo a la fórmula:

$$
f^{2}=\frac{R_{\text {incluida }}^{2}-R_{\text {excluida }}^{2}}{1-R_{\text {incluida }}^{2}}
$$

donde:

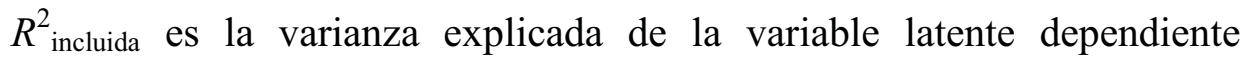
cuando la variable predictora es empleada en la ecuación estructural; y

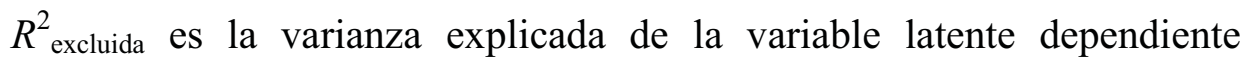
cuando la variable predictora es omitida en dicha ecuación estructural.

Los valores de $f^{2}$ oscilan entre 0 y 1 , pudiendo considerarse el nivel 0,02 como indicativo del tamaño pequeño del efecto de la variable independiente en el ámbito estructural, el nivel 0,15 como indicativo del tamaño mediano de dicho efecto, y el nivel 0,35 como indicativo del tamaño grande del mismo. 


\section{CApítulo 6}

\section{Resultados del Estudio Empírico}





\section{CAPÍTULO 6. RESULTADOS DEL ESTUDIO EMPÍRICO}

El proceso de validación de los modelos de medida y estructural hipotetizados fue llevado a cabo de acuerdo con la aproximación metodológica que fue especificada en el capítulo precedente. Conforme a ello se realizaron contrastes por medio de métodos estadísticos de análisis factorial, análisis descriptivos y de correlación entre variables, así como de análisis de ecuaciones estructurales basados en la técnica PLS. A lo largo de las páginas del presente capítulo se exponen los resultados obtenidos.

\subsection{Análisis factorial}

A fin de testar la validez de constructo de las escalas empleadas para medir las variables incluidas en el estudio empírico se comenzó por realizar seis análisis factoriales exploratorios con el programa SPSS 19.0. Dichos análisis fueron propuestos para constatar la estructura de las dimensiones del concepto de responsabilidad que tiene el consumidor, las atribuciones al comportamiento empresarial, la generación de demanda de responsabilidad, la valoración y la adquisición de esa información, la utilidad esperada y la influencia social, respectivamente.

De este modo, un primer análisis factorial estuvo dedicado a identificar los componentes subyacentes a los 12 ítems empleados en la medición de las variables que definen el concepto de empresa socialmente responsable para el consumidor (bloque I del cuestionario).

En el análisis de la adecuación de los datos para ser sometidos a factorización, la revisión de la matriz de correlaciones entre todos los indicadores desveló un predominio de valores $r$ superiores a 0,30. Asimismo, el índice KMO de adecuación de la muestra fue alto $(0,813)$, y el test de esfericidad de Barlett resultó significativo a un nivel de probabilidad de $p<0,001$.

Por su parte, el análisis de componentes principales llevado a cabo en la extracción de factores arrojó tres dimensiones con valores eigen superiores a la unidad, 
las cuales explicaron el $64,93 \%$ de la varianza total acumulada. No obstante, el gráfico de sedimentación mostró un claro punto de inflexión entre los componentes segundo y tercero, lo que llevó a considerar la extracción de dos factores como la estructura más apropiada por su mayor proximidad con el número de dimensiones esperadas a partir de la revisión teórica previa.

La rotación Varimax empleada a tal fin permitió confirmar, en términos generales, la existencia de dos factores acordes a la clasificación de las acciones de responsabilidad percibidas atendiendo al criterio de los grupos de interés (Maignan y Ferrell 2001, Decker 2004, García de los Salmones et al. 2005, Pérez y Rodríguez 2012), distinguiendo el consumidor las expectativas de los stakeholders por el grado de compromiso con la empresa (Maignan et al. 1999, Maignan y Ferrell 2003 y 2004, Maignan et al. 2005, Parmar et al. 2010, Hult et al 2011). En suma, los dos factores obtenidos permitieron explicar el 54,89\% de la varianza total acumulada.

El primer factor, denominado "concepto distal”, estuvo integrado por cinco ítems referidos a relaciones responsables entre la empresa y sus stakeholders indirectos, incluyendo el compromiso con el medio ambiente, la resolución de problemáticas sociales, el desarrollo socioeconómico regional, los intereses de la comunidad y la colaboración con administraciones y ONGs (stakeholders, pues, secundarios, sin obligación contractual con la compañía ni ejercer ninguna autoridad legal sobre ella). Dicho factor se asoció a una fiabilidad alta con un valor alpha de Cronbach de 0,860.

El segundo factor, denominado “concepto proximal”, alcanzó un valor alpha de Cronbach de 0,736 y quedó integrado por otros cinco indicadores relativos a las transacciones responsables de la empresa con sus stakeholders directos, como clientes, empleados, socios y accionistas, proveedores y distribuidores, y competidores (todos ellos stakeholders primarios, indispensables para la supervivencia de la entidad).

Todos los ítems mantuvieron cargas factoriales superiores a 0,50 en una única dimensión, lo que proporcionó evidencia sólida acerca de la validez discriminante de las escalas utilizadas (ver Tabla 6.1). Por su parte, el ítem referido al cumplimiento estricto de las leyes (I.1) manifestó una carga factorial en ambos constructos por debajo del criterio establecido de 0,50 y fue excluido de análisis posteriores. Esto venía a significar que los consumidores consideran comportamiento responsable lo que va más allá de la normativa y no así el estricto cumplimiento de las obligaciones legales. 
Tabla 6.1. Estructura factorial de las variables conceptuales

\begin{tabular}{ccc}
\hline Ítem $^{*}$ & Concepto distal & Concepto proximal \\
\hline I.2 & 0,739 & \\
I.3 & 0,751 & \\
I.9 & 0,776 & \\
I.10 & 0,830 & \\
I.11 & 0,795 & \\
I.4 & & 0,611 \\
I.5 & & 0,661 \\
I.6 & & 0,728 \\
I.7 & & 0,770 \\
I.8 & & 0,577 \\
\hline Fiabilidad $\alpha$ & 0,860 & 0,736 \\
\hline
\end{tabular}

*Véanse los literales en el Anexo.

En un segundo análisis factorial, se indagó acerca de la estructura de los componentes subyacentes a los 18 ítems propuestos para medir las variables vinculadas a las causas atribuidas a la realización de acciones responsables por parte de las empresas (bloque II del cuestionario).

Los datos resultaron, a priori, adecuados para ser sometidos al proceso factorial, apreciándose un claro predominio de correlaciones $r$ entre ítems superiores al mínimo de 0,30 . Por su parte, el índice KMO de adecuación de la muestra alcanzó un valor de 0,784, por encima del aceptable, y el test de esfericidad de Barlett resultó también significativo a un nivel $p<0,001$.

Al proceder a la extracción de factores, el análisis de componentes principales arrojó en este caso cinco dimensiones con valores eigen superiores a la unidad, las cuales explicaron el 62,37\% de la varianza total acumulada. Sin embargo, el gráfico de sedimentación mostró un punto de inflexión entre los componentes segundo y tercero, y por tanto se optó por la extracción de dos factores como la estructura más apropiada por su mayor proximidad con el número de dimensiones que caracterizan las conductas responsables de las empresas (Becker-Olsen et al. 2006), con atribuciones a motivos estratégicos o sociales.

En las atribuciones del comportamiento responsable de las empresas, aparecen dos factores, que agrupan los cuatro motivos de orientación egoísta, carácter estratégico, 
respuesta a la demanda de los stakeholders, y a causa de los propios valores. Tal distinción es tenida en cuenta por los consumidores cuando indican las causas que perciben que impulsan a las empresas a comportarse responsablemente, en consonancia con lo indicado por autores como Ellen et al. (2006), o Vlachos et al (2009).

La primera de dichas categorías se encuentra integrada por factores asociados a los intentos de obtener una rentabilidad de la explotación una causa, aprovechándola para alcanzar los objetivos de la empresa (mayores beneficios a partir de las mayores tasas de retención de clientes, colaboraciones beneficiosas, promociones, mejoras de reputación y de imagen, etc.). La segunda categoría puede considerarse análoga, añadiendo un componente de planificación a las acciones emprendidas.

El tercer grupo de motivos tiene que ver con la presión ejercida por los distintos grupos de stakeholders, en función tanto de sus expectativas como de su capacidad de influencia a la hora de plantear sus demandas. El tipo de actuaciones a las que darían lugar son similares a las de la cuarta categoría (para mejorar el bienestar de la sociedad, devolver a ésta parte de lo recibido de ella, etc.), si bien en este último caso la motivación es de carácter interno. En uno y otro caso (tercera y cuarta categoría de factores), se estaría hablando de un constructo integrado por aquellos comportamientos empresariales que pueden considerarse propiamente sociales.

Seguidamente, el método de normalización Varimax utilizado en la rotación de los factores confirmó, en términos generales, la correspondencia entre indicadores y constructos. Las cargas factoriales asociadas a los ítems retenidos para análisis subsiguientes superaron el valor de 0,50 y saturaron en una única dimensión, en apoyo a la validez discriminante de las escalas utilizadas (ver Tabla 6.2). En conjunto, los dos factores obtenidos explicaron el 40,63\% de la varianza total acumulada.

Consignando los resultados para cada dimensión particular, las variables de comportamiento empresarial estratégico y social conservaron la composición de ítems asociada a fiabilidades de 0,761 y 0,795, de acuerdo al índice alpha de Cronbach. Por un lado, se mantuvo para posteriores análisis el ítem II2 (obligación moral) con un valor de carga factorial muy próximo a 0,5; por otro, se eliminaron el II8 (aprovecharse de la colaboración con organizaciones no lucrativas) y el II11 (aumento de la credibilidad ante públicos objeto), ambos con cargas factoriales muy bajas y correspondientes a los factores de comportamiento empresarial estratégico y social, respectivamente. 
Tabla 6.2. Estructura factorial de las variables de comportamiento empresarial

\begin{tabular}{ccc}
\hline Ítem & $\begin{array}{c}\text { Comportamiento empresarial } \\
\text { con motivación estratégica }\end{array}$ & $\begin{array}{c}\text { Comportamiento empresarial } \\
\text { con motivación social }\end{array}$ \\
\hline II.1 & 0,519 & \\
II.3 & 0,753 & \\
II.4 & 0,573 & \\
II.5 & 0,665 & \\
II.7 & 0,733 & \\
\hline II.12 & 0,594 & 0,491 \\
II.2 & & 0,605 \\
II.10 & & 575 \\
II.13 & & 0,785 \\
II.14 & & 0,681 \\
II.15 & & 0,504 \\
II.16 & & 0,726 \\
II.17 & & 0,711 \\
\hline Fiabilidad $\alpha$ & 0,761 & 0,795 \\
\hline
\end{tabular}

\footnotetext{
*Véanse los literales en el Anexo.
}

El tercer análisis factorial fue para indagar la estructura de los 10 ítems propuestos para medir las variables vinculadas a la generación de la demanda responsable, en términos de las dimensiones de actuación empresarial (bloque III del cuestionario).

Los datos resultaron de nuevo, y a priori, adecuados para ser sometidos al proceso factorial, apreciándose un claro predominio de correlaciones $r$ entre ítems superiores al mínimo de 0,30. Por su parte, el índice KMO de adecuación de la muestra alcanzó un valor de 0,821, por encima del aceptable, y el test de esfericidad de Barlett resultó también significativo a un nivel $p<0,001$.

En la extracción de factores, el análisis de componentes principales arrojó en este caso tres dimensiones con valores eigen superiores a la unidad, explicando el $72,47 \%$ de la varianza total acumulada. Sin embargo, el gráfico de sedimentación mostró un punto de inflexión entre los componentes cuarto y quinto, lo que llevó a optar por la extracción de cuatro factores como la estructura más apropiada, por su mayor proximidad con el número de dimensiones acordes con las relaciones estructurales del modelo (dos factores del concepto de responsabilidad que se subdividen). 
En el análisis de la generación de la demanda responsable se extraen cuatro factores que vienen a perfilar los dos encontrados para el concepto de responsabilidad (distal y proximal). Por un lado, y en relación con el concepto distal de la responsabilidad, se denomina distal 1 al primer factor relacionado con la importancia que el consumidor atribuye a aspectos que se encuentran más alejados del centro de la actividad empresarial, pero con efectos más directos sobre el mismo (relacionado con demandas motivadas por los compromisos con el medioambiente o la resolución de problemas sociales). Por otro, un segundo factor, o distal 2, incluiría aspectos menos directos en cuanto a su alcance (como tener en cuenta el desarrollo socioeconómico regional y la implicación con los intereses de la comunidad).

Por otro lado, en un factor proximal 1 se enmarcan las preocupaciones de los stakeholders más relacionados con la esencia de la actividad empresarial (expectativas de clientes y empleados), y en otro proximal 2 los otros factores que también conforman el núcleo de esta actividad, pero que a los ojos de los consumidores no son tan próximos como los anteriores (objetivos de accionistas y relaciones con proveedores o con los distribuidores). Se aprecia asimismo que los consumidores no encuadran en ninguno de estos dos grupos ni las prácticas de juego limpio con la competencia, ni la colaboración abierta con administraciones o con ONGs.

El método de normalización Varimax utilizado en la rotación de los factores confirmó, en términos generales, la correspondencia esperada entre indicadores y constructos. Las cargas factoriales asociadas a los ítems que fueron retenidos de cara a la realización de los subsiguientes análisis superaron de nuevo el valor de 0,50 y saturaron en una única dimensión, en apoyo a la validez discriminante de las escalas utilizadas (ver Tabla 6.3). En conjunto, los dos factores obtenidos explicaron el 78,83\% de la varianza total acumulada.

Remitiendo a los resultados para cada dimensión particular, las variables de generación de demanda responsable, se asocian a fiabilidades de 0,845, de 0,828, de 0,727, y de 0,755, de acuerdo al índice alpha de Cronbach. Como resultado del análisis se descartó el ítem III7 (prácticas de juego limpio con la competencia) por tener una idéntica carga factorial $(0,586)$ para los factores distal 2 y proximal 2. El ítem III10 (colaboración abierta con administraciones y ONGs) fue asimismo eliminado por idéntico motivo y por tener unas cargas factoriales con los factores distal 1 y distal 2 de 0,565 y 0,573 , respectivamente. 
Tabla 6.3. Estructura factorial de las variables de generación de la demanda responsable

\begin{tabular}{lcccc}
\hline Ítem $^{*}$ & $\begin{array}{c}\text { Gen. demanda } \\
\text { resp. distal 1 }\end{array}$ & $\begin{array}{c}\text { Gen. demanda } \\
\text { resp. distal 2 }\end{array}$ & $\begin{array}{c}\text { G. dem. resp. } \\
\text { proximal 1 }\end{array}$ & $\begin{array}{c}\text { G. dem. resp. } \\
\text { proximal 1 }\end{array}$ \\
\hline III.1 & 0,854 & & \\
\hline III.2 & 0,806 & 0,837 & & \\
\hline III.8 & 0,826 & 0,784 & \\
\hline III.9 & & 0,822 & \\
\hdashline$I I I .3$ & & & 0,900 \\
III.4 & & & 0,847 \\
\hline III.5 & 0,828 & 0,727 & 0,755 \\
\hline III.6 & 0,845 & & \\
\hline Fiabilidad a & & & \\
\hline
\end{tabular}

${ }^{*}$ Véanse los literales en el Anexo.

Con el cuarto análisis factorial se averiguó en la estructura factorial de los 13 ítems presentados para la medición de las variables vinculadas los componentes del consumo derivados de criterios de responsabilidad social de las empresas (ítems 1 a 13 del bloque IV del cuestionario).

Los datos resultaron adecuados con vistas a ser sometidos al proceso factorial, apreciándose la casi totalidad de correlaciones $r$ entre ítems superiores al mínimo de 0,30. Por su parte, el índice KMO de adecuación de la muestra alcanzó un valor de 0,891, por encima del aceptable, y el test de esfericidad de Barlett resultó también significativo a un nivel $p<0,001$.

En la extracción de factores, el análisis de componentes principales arrojó en este caso dos dimensiones con valores eigen superiores a la unidad, las cuales explicaron el 59,11\% de la varianza total acumulada. El gráfico de sedimentación mostró la conveniencia de la extracción de esos dos factores como la estructura más apropiada.

El método de normalización Varimax utilizado en la rotación de los factores confirmó, en términos generales, la correspondencia esperada entre indicadores y constructos. De nuevo, las cargas factoriales asociadas a los ítems retenidos para análisis subsiguientes superaron en este caso el valor de 0,50 y saturaron en una única dimensión, en apoyo a la validez discriminante de las escalas utilizadas (ver Tabla 6.4). 
Tabla 6.4. Estructura factorial de las variables de componentes de consumo derivados de criterios de responsabilidad

\begin{tabular}{ccc}
\hline Ítem $^{*}$ & $\begin{array}{c}\text { Valoración de la } \\
\text { responsab. de la oferta }\end{array}$ & $\begin{array}{c}\text { Adquisición de información } \\
\text { sobre responsabilidad }\end{array}$ \\
\hline IV.1 & 0,683 & \\
IV.2 & 0,797 & \\
IV.3 & 0,729 & \\
IV.4 & 0,760 & 0,705 \\
\hline IV.7 & & 0,824 \\
IV.8 & & 0,806 \\
IV.9 & & 0,716 \\
IV.10 & 0,572 \\
IV.11 & & 0,706 \\
IV.12 & & 0,726 \\
IV.13 & & 0,897 \\
\hline Fiabilidad a & & \\
\hline
\end{tabular}

* Véanse los literales en el Anexo.

Este análisis factorial relacionado con las restantes fases del proceso de intención de compra responsable, arrojó como resultado los factores previstos. Uno, relacionado con la adquisición de información responsable (buscar información, fijarse en publicidad, distintivos o sellos, así como conocer productos y marcas responsables). El otro, de valoración de ofertas responsables (importancia de la compra de productos responsables, características en comparación con otros, importancia del criterio de responsabilidad, disposición a no consumir productos no responsables, o bien a pagar un sobreprecio o a dedicar más tiempo para adquirir los que sí lo sean).

Remitiendo a los resultados para cada dimensión particular, las variables de componentes del consumo derivados de criterios de responsabilidad social conservaron la composición de ítems esperada, asociándose a fiabilidades de 0,814 y 0,.897 de acuerdo al índice alpha de Cronbach.

En función de los resultados del análisis se excluyeron como indicadores del proceso de intención de compra, el haber tenido buenas experiencias con productos y marcas de empresas socialmente responsables (ítem IV5), así como tener productos y marcas de empresas responsables como referente para el consumo (ítem IV6), en ambos casos por tener cargas factoriales iguales para los dos componentes rotados. 
Con el quinto análisis factorial se indagó la estructura factorial de los 5 ítems presentados para la medición de las variables vinculadas a la utilidad esperada por valorar ofertas responsables de las empresas en la intención de compra (ítems 15 a 19 del bloque IV del cuestionario).

Los datos resultaron adecuados para ser sometidos al proceso factorial, apreciándose la casi totalidad de correlaciones $r$ entre ítems superiores al mínimo de 0,30. Por su parte, el índice KMO de adecuación de la muestra alcanzó un valor de 0,775, por encima del aceptable, y el test de esfericidad de Barlett resultó también significativo a un nivel $p<0,001$.

En la extracción de factores, el análisis de componentes principales arrojó en este caso una dimensión con valores eigen superiores a la unidad, la cual explicó el 59,35\% de la varianza total acumulada. El gráfico de sedimentación mostró la conveniencia de la extracción de ese factor como la estructura más apropiada.

Las cargas factoriales asociadas a los ítems retenidos para análisis subsiguientes superaron en este caso el valor de 0,50 y saturaron en una única dimensión, en apoyo a la validez discriminante de las escalas utilizadas (ver Tabla 6.5).

Por lo tanto, se constata cómo la utilidad esperada derivada de criterios de responsabilidad retiene en un único factor todos los ítems propuestos y relacionados con el convencimiento del individuo de que al consumir productos de empresas socialmente responsables éste contribuye a causas sociales, medioambientales, a apoyar a empresas comprometidas con la comunidad y/o a sentirse bien o a mejorar su imagen ante los demás, asociándose a una fiabilidad de 0,821 de acuerdo al alpha de Cronbach.

Tabla 6.5. Estructura factorial de las variables de la utilidad esperada

\begin{tabular}{cc}
\hline Ítem $^{*}$ & Utilidad esperada \\
\hline IV.15 & 0,832 \\
IV.16 & 0,865 \\
IV.17 & 0,843 \\
IV.18 & 0,719 \\
IV.19 & 0,547 \\
\hline Fiabilidad $\alpha$ & 0,821 \\
\hline
\end{tabular}

\footnotetext{
* Véanse los literales en el Anexo.
} 
Por último, con el sexto análisis factorial se profundizó en la estructura factorial de los 4 ítems presentados para la medición de las variables vinculadas influencia social en el consumo (ítems 14 y 20 a 22 del bloque IV del cuestionario).

Los datos resultaron adecuados para ser sometidos al proceso factorial, apreciándose la totalidad de correlaciones $r$ entre ítems superiores al mínimo de 0,30. Por su parte, el índice KMO de adecuación de la muestra alcanzó un valor de 0,716, por encima del aceptable, y el test de esfericidad de Barlett resultó también significativo a un nivel $p<0,001$.

En la extracción de factores, el análisis de componentes principales arrojó en este caso una dimensión con valores eigen superiores a la unidad, la cual explicó el 58,99\% de la varianza total acumulada. El gráfico de sedimentación mostró la conveniencia de la extracción de ese factor como la estructura más apropiada.

Las cargas factoriales asociadas a los ítems retenidos para análisis subsiguientes superaron en este caso el valor de 0,50 y saturaron en una única dimensión, en apoyo a la validez discriminante de las escalas utilizadas (ver Tabla 6.6).

Tal y como se puede apreciar, los resultados para la variable de influencia social en el consumo derivados de criterios de responsabilidad, agrupó en un solo factor todos los indicadores asociados con recomendaciones positivas para la adquisición de productos responsables, ya sea por el consejo de personas del entorno próximo, o por percibir las implicaciones de las empresas en acciones de responsabilidad, la recurrencia en los medios de comunicación o el debate sobre temas de responsabilidad en el entorno más próximo, asociándose a una fiabilidad de 0,767 de acuerdo al alpha de Cronbach.

Tabla 6.6. Estructura factorial de las variables de la influencia social

\begin{tabular}{cc}
\hline Ítem $^{*}$ & Influencia social \\
\hline IV.14 & 0,666 \\
IV.20 & 0,805 \\
IV.21 & 0,815 \\
IV.22 & 0,777 \\
\hline Fiabilidad a & 0,767 \\
\hline${ }^{*}$ Véanse los literales en el Anexo.
\end{tabular}




\subsection{Análisis correlacionales y descriptivos}

La Tabla 6.7 muestra los coeficientes de correlación $r$ entre las variables del estudio, así como las medias y desviaciones típicas de las puntuaciones en cada caso obtenidas, todo ello en base a las dimensiones factoriales previamente identificadas.

Como interpretación general, se puede decir que las variables conceptuales (distal y proximal) estaban débilmente asociadas (con correlaciones por debajo de 0,30) con aquellas variables para las que el modelo no establece una relación estructural directa, si bien resulta puntualmente significativa (utilidad esperada y adquisición de información sobre responsabilidad). No obstante, y en todo caso, guardan mayor correlación con los comportamientos empresariales (estratégicos y sociales) y con la generación de demanda, fundamentalmente la proximal 1 (relaciones directas ambas). Cabe, pues, afirmar que el sentido de la correlación es el esperado, lo que supone un primera evidencia acerca de la validez concurrente de las escalas de medida.

También se apreció una falta de correlación entre algunas de las variables del modelo, sugiriendo la posible refutación de alguna hipótesis de partida. La variable de conducta empresarial estratégica no apareció correlacionada con la influencia social y la utilidad esperada (valores respectivos de $r$ de 0,03 y de 0,13). Por otro lado, el comportamiento empresarial social sí tuvo una mayor correlación con la utilidad esperada $(r=0,33) \mathrm{y}$, en menor medida, con la influencia social $(r=0,25)$.

Tabla 6.7. Correlaciones, medias y desviaciones típicas (DT)

\begin{tabular}{|c|c|c|c|c|c|c|c|c|c|c|c|c|}
\hline Variables & 1 & 2 & 3 & 4 & 5 & 6 & 7 & 8 & 9 & 10 & 11 & 12 \\
\hline 1. Concepto distal & 1 & & & & & & & & & & & \\
\hline 2. Concepto proximal & $0,42^{* *}$ & 1 & & & & & & & & & & \\
\hline 3. Comp. empr. estratég. & $0,38^{* *}$ & $0,32^{\text {** }}$ & 1 & & & & & & & & & \\
\hline 4. Comp. empr. social & $0,19^{* *}$ & $0,39^{* *}$ & 0,06 & 1 & & & & & & & & \\
\hline 5. G. demanda distal 1 & $0,21^{\text {** }}$ & $0,25^{\text {** }}$ & $0,55^{\star \star}$ & $0,34^{* k}$ & 1 & & & & & & & \\
\hline 6. G. demanda distal 2 & $0,27^{* *}$ & $0,23^{\text {t* }}$ & $0,51^{\star \star}$ & $0,13^{\text {*k }}$ & $0,24^{* *}$ & 1 & & & & & & \\
\hline 7. G. demanda proxim. 1 & $0,41^{* *}$ & $0,39^{\text {t* }}$ & $0,18^{\star \star}$ & $0,38^{* *}$ & $0,21^{\text {*t }}$ & $0,16^{\text {t* }}$ & 1 & & & & & \\
\hline 8. G. demanda proxim. 2 & 0,00 & $0,30^{\text {t* }}$ & 0,00 & $0,47^{\text {th }}$ & $0,13^{\text {th }}$ & 0,09 & $0,32^{\text {** }}$ & 1 & & & & \\
\hline 9. Valorac. resp. oferta & $-0,03$ & $0,16^{\text {t* }}$ & $0,12^{*}$ & $0,32^{*+}$ & $-0,02$ & 0,05 & $0,21^{\text {t* }}$ & $0,41^{\star *}$ & 1 & & & \\
\hline 10. Adquis. inform. resp. & $0,17^{\text {t* }}$ & $0,19^{\text {t* }}$ & $0,14^{\star \star}$ & $0,22^{\text {t* }}$ & $0,16^{\text {t* }}$ & $0,17^{\text {t* }}$ & $0,29^{\text {t* }}$ & $0,27^{\star *}$ & $0,56^{\text {t* }}$ & 1 & & \\
\hline 11. Utilidad esperada & $0,26^{* *}$ & $0,21^{\text {t* }}$ & $0,13^{\star \star}$ & $0,33^{\text {t* }}$ & 0,00 & $0,19^{* *}$ & $0,26^{*}$ & $0,22^{\text {** }}$ & $0,57^{\text {t* }}$ & $0,52^{* *}$ & 1 & \\
\hline 12. Influencia social & 0,05 & $0,13^{\text {t* }}$ & 0,03 & $0,25^{* *}$ & $0,12^{*}$ & $0,14^{\text {t* }}$ & $0,22^{* *}$ & $0,28^{* *}$ & $0,64^{* *}$ & $0,61^{* *}$ & $0,57^{\text {t* }}$ & 1 \\
\hline Media & 3,78 & 3,60 & 3,87 & 3,36 & 3,56 & 3,75 & 3,61 & 3,30 & 2,99 & 3,25 & 3,37 & 3,2 \\
\hline DT & 0,753 & 0,664 & 0,581 & 0,615 & 0,728 & 0,722 & 0,849 & 0,966 & 0,883 & 0,826 & 0,782 & 0,82 \\
\hline
\end{tabular}


La falta de correlación de la variable de comportamiento empresarial estratégico con las variables de valoración y adquisición de información sobre responsabilidad (valores $r$ de 0,12 y 0,14), sugería el incumplimiento de algunas de las hipótesis del modelo conforme a las que se postulaba su influencia indirecta a través de las variables de conceptos o de utilidad esperada. Del mismo modo, la variable influencia social se mostró escasamente correlacionada con los conceptos distal y proximal (valores $r$ de 0,05 y 0,13), indicando también una influencia indirecta, como sugería el modelo. Lo mismo se puede decir de la falta de correlación entre las variables de adquisición y valoración de la información sobre responsabilidad y las de concepto distal y proximal.

Por otro lado, sin embargo, se puso de manifiesto una alta y significativa correlación entre otras variables, lo que venía a sugerir una alta expectativa de que se cumpliesen otras de las hipótesis propuestas en el modelo de partida, al haberse planteado un amplio abanico de interrelaciones. Concretamente, las variables de influencia social y de utilidad esperada estaban altamente correlacionadas con las de valoración y adquisición de información sobre responsabilidad (con unos valores $r$ comprendidos entre 0,52 y 0,64). Asimismo, también se apreció una alta correlación entre las variables relativas al concepto, al comportamiento y a la generación de la demanda responsable, evidenciando un importante número de interrelaciones, a la vez que quedando constatada una fuerte correspondencia entre estimaciones de constructos.

Los análisis de correlación se complementaron con otros descriptivos. En cuanto a las puntuaciones medias obtenidas para cada variable (parte inferior de la Tabla 6.7), teniendo en cuenta los valores extremos 1 y 5 atribuibles a cada ítem y la consecuente posición intermedia del valor 3 , lo primero que se puso de manifiesto a través de este nuevo procedimiento fue que la única variable cuya importancia era percibida por los encuestados ligeramente por debajo de dicho valor central fue la de valoración de la responsabilidad de la oferta (media de 2,99) en cuanto hábito de consumo que determina el modo en que se traducen aspectos de responsabilidad en compra efectiva.

En el otro extremo, los valores más altos de las medias correspondieron a las atribuciones otorgadas por los individuos al comportamiento estratégico de la empresa cuando trata de ser socialmente responsable $(3,87)$, al concepto distal que define a la empresa responsable $(3,78)$, así como la variable generación de demanda distal $2(3,72)$ como medida de la importancia dada a los aspectos relacionados con la responsabilidad y referidos al desarrollo socioeconómico regional y a los intereses de la comunidad. 
Por otra parte, la mayor dispersión de los datos se dio para las variables de generación de demanda proximal 2 (desviación típica de 0,966) y proximal $1(0,849)$, así como para la valoración de ofertas responsables $(0,883)$, en tanto los datos estaban más concentrados para el constructo comportamiento empresarial estratégico $(0,581)$, lo que reflejaba el criterio más uniforme del consumidor a la hora de atribuir a la empresa los motivos por los que se comporta o lleva a cabo acciones responsables.

El Gráfico 6.1 muestra la distribución de puntuaciones medias, de acuerdo a los tres niveles de bajo (valores de 1 a 2,33), intermedio (2,33 a 3,66), y alto (3,66 a 5). Predominan las puntuaciones altas para las variables de comportamiento empresarial estratégico (66,5\%), concepto distal (55,8\%) y generación de demanda distal 2 (53,8\%). Por contra, las variables de comportamiento empresarial social (63,3\%), adquisición de información sobre responsabilidad (59\%), generación de demanda distal 1 (55,1\%), utilidad esperada (54,5\%), y concepto proximal (51,5\%) son las que obtuvieron mayor número de valoraciones intermedias, predominando relativamente más las bajas para la valoración de la responsabilidad de la oferta (26,5\%), la generación de demanda proximal 2 (16,5\%) y la influencia social (14,7\%).

\section{Gráfico 6.1. Distribución de frecuencias para las variables del modelo}

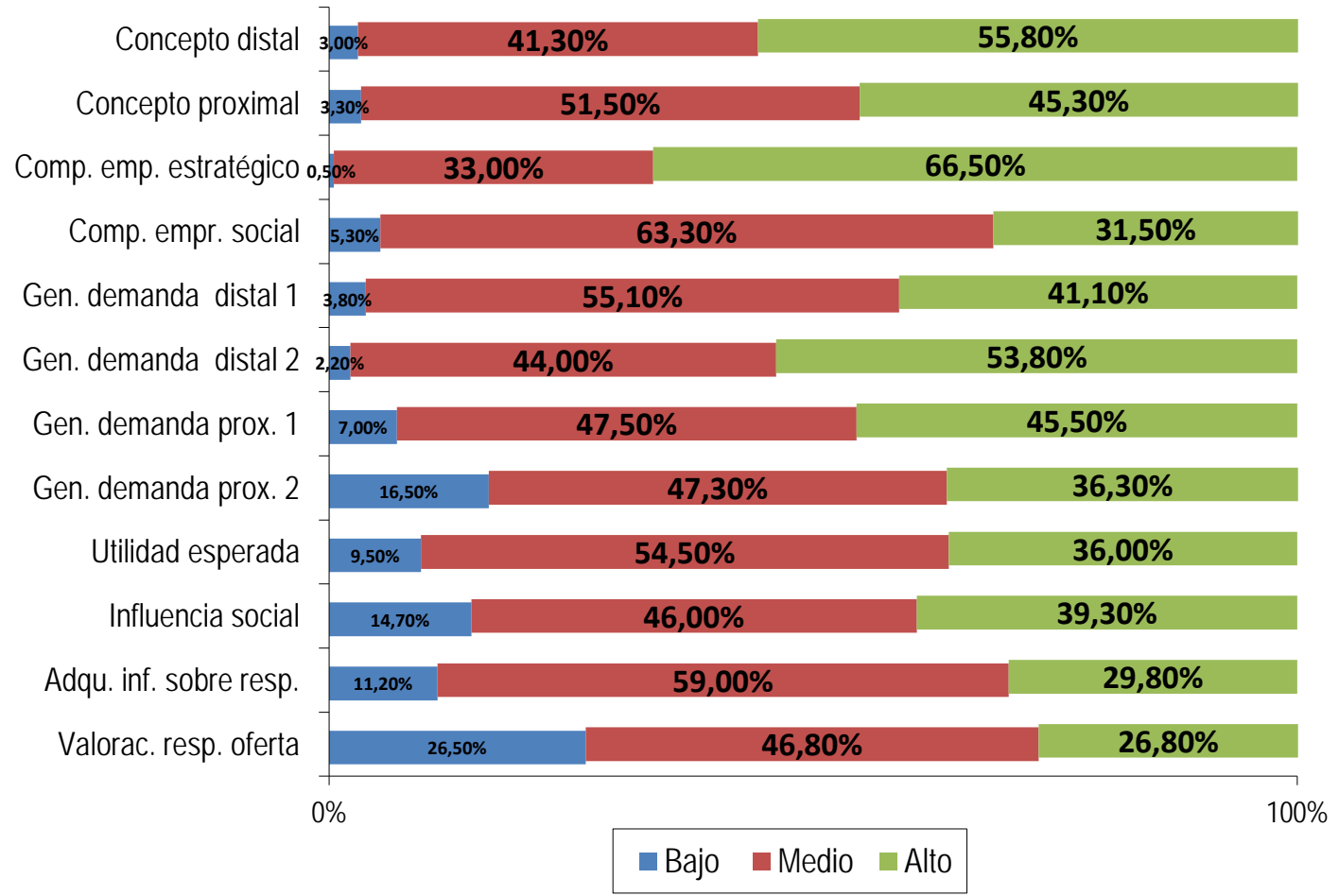


De estos datos preliminares sobre las opiniones del consumidor pudieron ya extraerse algunas conclusiones. Más en concreto:

- La mayor relación de las razones atribuidas por el consumidor a la conducta responsable de las empresas con motivos estratégicos que con los de índole social.

- La mayor caracterización de las empresas socialmente responsables en base a aspectos distales (medioambiente, problemas sociales, desarrollo regional, intereses de la comunidad, etc.), y no tanto por satisfacer expectativas y demandas de stakeholders proximales, concediendo una especial importancia a la implicación con el desarrollo socioeconómico regional y con los intereses de la comunidad (generación de demanda distal 2).

- La importancia del papel de la influencia social en el proceso de intención de compra como variable indicativa de las recomendaciones y el debate que tienen lugar en el entorno más próximo al consumidor, la apreciación de una mayor implicación por parte de las empresas o incluso, el tratamiento recurrente de aspectos relacionados con la responsabilidad en los medios de comunicación.

\subsection{Análisis predictivos con PLS}

En base a los resultados de los análisis descritos, se empleó la técnica de modelado estructural PLS en la comprobación del grado de cumplimiento de las hipótesis planteadas, mediante el programa estadístico SmartPLS 2.0. En este sentido, y siguiendo el procedimiento detallado en el capítulo precedente, los análisis llevados a cabo tuvieron por objeto evaluar el modelo de investigación a un doble nivel, de medida externa (outer model), y de estructura interna (inner model), procediendo a introducir las reespecificaciones oportunas de cara a lograr el mayor ajuste posible de los datos empíricos a la teoría. Seguidamente se describen los pasos seguidos de cara a lograr dicho propósito.

\subsubsection{Evaluación del modelo inicial (Modelo 1)}

El modelo inicial resulta de analizar el modelo teórico propuesto, incorporando las distintas dimensiones obtenidas en el análisis factorial y que afectan a tres constructos, como son el concepto de responsabilidad, la generación de la demanda responsable, y las motivaciones atribuidas a la conducta empresarial (Figura 6.1). 
Figura 6.1. Representación del modelo teórico (Modelo1)

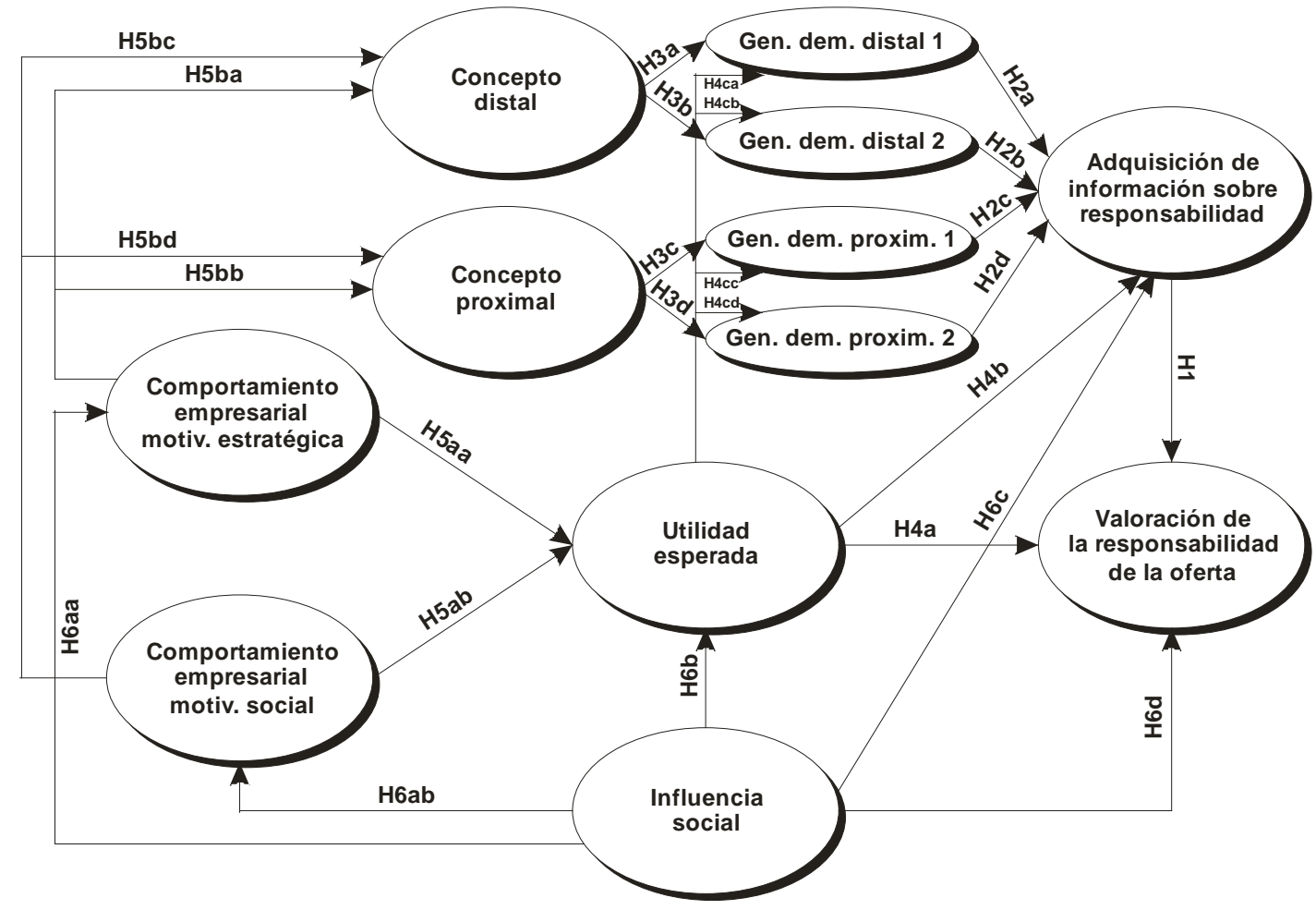

Fuente: Elaboración propia.

Más en concreto, el concepto de responsabilidad se desglosa en dos factores. El primero de ellos es el concepto distal (de responsabilidad), referido a aquellos aspectos que definen la empresa responsable en términos de actuaciones medioambientales o relacionadas con problemáticas sociales, contribución al desarrollo económico regional o a los intereses de la comunidad, así como la colaboración abierta con administraciones y ONGs. El segundo de los factores es el concepto proximal, obtenido en base a otros aspectos más relacionados con el núcleo de actividad de la entidad, tales como las expectativas de empresarios, clientes, accionistas o proveedores, e incluso el juego limpio con la competencia. Ambos constructos están relacionados con el concepto que tiene el consumidor de empresa responsable.

De modo análogo, el análisis factorial utilizado para describir la generación de la demanda responsable dio lugar a la distinción de cuatro factores. A la vista de los resultados se optó por denominarles distal 1 (agrupando los aspectos más alejados del 
centro de la actividad empresarial pero a su vez con efectos más directos), distal 2 (con alcance menos directo que los anteriores), proximal 1 (en relación con los stakeholders más vinculados con la esencia de la actividad empresarial) y proximal 2 (públicos objetivo que también están vinculados con el núcleo de actividad, pero que a los ojos de los consumidores no resultan tan próximos).

Por su parte, y en cuanto a las motivaciones atribuidas a la conducta empresarial, del análisis factorial se dedujo la conveniencia de agruparlas en dos categorías, una más relacionada con motivaciones estratégicas (en cuanto a obtención de beneficios, retención de clientes, colaboraciones beneficiosas, promoción, mejora de reputación e imagen), y la otra con motivos de índole social (bienestar de la sociedad, devolver algo de lo recibido, credibilidad, respuesta a las expectativas de los stakeholders).

La Figura 6.2 muestra el diagrama de paso del modelo de investigación y sometido a análisis PLS en referencia a las relaciones hipotetizadas entre las variables latentes del estudio.

Figura 6.2. Modelo de investigación sometido a PLS

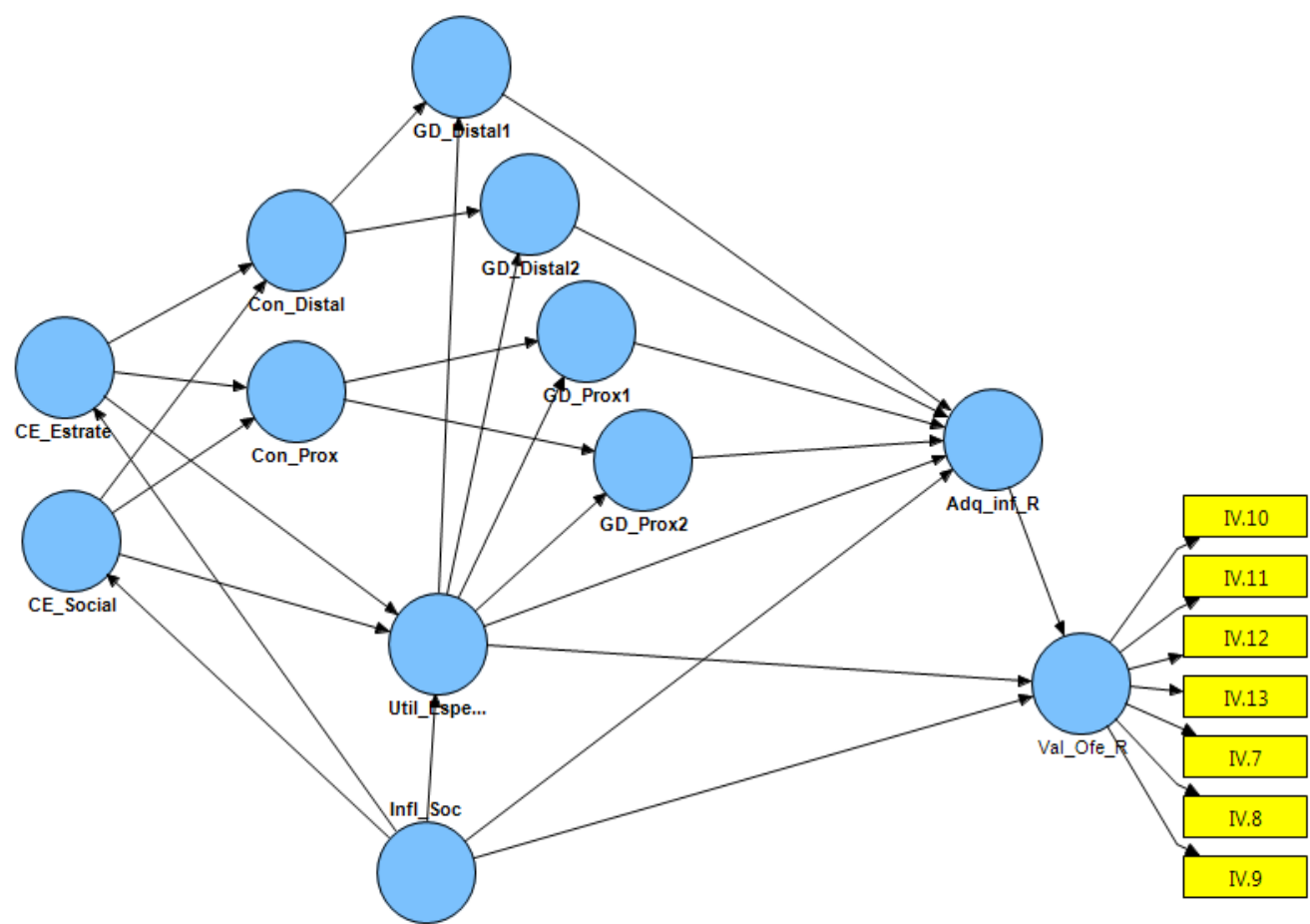

Fuente: Elaboración propia. 
En suma, dicho Modelo incluyó una variable latente exógena (6) la influencia social, la cual actúa como predictor general del resto de constructos considerados mediante caminos path $\gamma$. Por su parte, el conjunto de variables latentes enógenas $(\eta)$ está integrado por las seis variables del proceso decisional de pre-compra responsable, las cuatro variables de percepción de la responsabilidad, y la variable de utilidad esperada, encontrándose todas ellas interrelacionadas mediante vínculos predictivo $\$$. Asimismo se asumió que todas las variables latentes llevaban asociado su correspondiente error de medida $(\zeta)$.

Por razones de claridad en la representación gráfica, la Figura 6.2 no explicita las variables observadas empleadas en la medición de los constructos latentes, salvo en el caso de la referida a la valoración de la responsabilidad de la oferta, para la que sí se especifican sus indicadores (dada su importancia como variable endógena principal).

La representación del modelo de investigación corresponde, no obstante, a los ítems vinculados a cargas factoriales altas de acuerdo con los resultados del análisis factorial exploratorio previo: valoración de la responsabilidad de la oferta (siete indicadores), adquisición de información sobre responsabilidad (cuatro indicadores), generación de demanda distal 1 y 2 (dos indicadores cada una), generación de demanda proximal 1 y 2 (dos indicadores cada una), concepto distal (cinco indicadores), concepto proximal (cinco indicadores), comportamiento empresarial por motivación estratégica (ocho indicadores), comportamiento empresarial por motivación social (nueve indicadores), y utilidad esperada (cinco indicadores).

Todas las variables observadas adquirieron la forma de indicadores reflexivos de constructo endógeno $(y)$, vinculados a éstos mediante cargas factoriales $\lambda_{\mathrm{y}}, \mathrm{y}$ asociados a sus respectivos errores de medida $(\varepsilon)$

Por su parte, la variable latente exógena influencia social (cuatro indicadores) adquirió la forma de indicador reflexivo de constructo exógeno $(x)$, vinculado mediante cargas factoriales $\lambda_{\mathrm{x}}$, y asociado a su respectivo error de medida $(\delta)$.

Complementando la representación de la Figura 6.2, el Cuadro 6.1 resume las hipótesis de investigación previamente justificadas en la parte teórica del presente trabajo, una vez adaptadas al desglose de constructos consecuencia del análisis factorial exploratorio. 
Cuadro 6.1. Resumen de las hipótesis de investigación del Modelo 1

\begin{tabular}{|c|c|}
\hline H1 & $\begin{array}{l}\text { La adquisición de información sobre responsabilidad influye positiva y directamente } \\
\text { sobre la valoración de la responsabilidad de la oferta }\end{array}$ \\
\hline $\mathrm{H} 2 \mathrm{a}$ & $\begin{array}{l}\text { La generación de la demanda responsable distal } 1 \text { influye positiva y directamente en } \\
\text { la adquisición de información sobre responsabilidad }\end{array}$ \\
\hline H2b & $\begin{array}{l}\text { La generación de la demanda responsable distal } 2 \text { influye positiva y directamente en } \\
\text { la adquisición de información sobre responsabilidad }\end{array}$ \\
\hline $\mathrm{H} 2 \mathrm{c}$ & $\begin{array}{l}\text { La generación de la demanda responsable proximal } 1 \text { influye positiva y directamente } \\
\text { en la adquisición de información sobre responsabilidad }\end{array}$ \\
\hline H2d & $\begin{array}{l}\text { La generación de la demanda responsable proximal } 2 \text { influye positiva y directamente } \\
\text { en la adquisición de información sobre responsabilidad }\end{array}$ \\
\hline НЗа & $\begin{array}{l}\text { El concepto distal de responsabilidad influye positiva y directamente sobre la } \\
\text { generación de la demanda responsable distal } 1\end{array}$ \\
\hline H3b & $\begin{array}{l}\text { El concepto distal de responsabilidad influye positiva y directamente sobre la } \\
\text { generación de la demanda responsable distal } 2\end{array}$ \\
\hline НЗс & $\begin{array}{l}\text { El concepto proximal de responsabilidad distal influye positiva y directamente sobre } \\
\text { la generación de la demanda responsable proximal } 1\end{array}$ \\
\hline H3d & $\begin{array}{l}\text { El concepto proximal de responsabilidad distal influye positiva y directamente sobre } \\
\text { la generación de la demanda responsable proximal } 2\end{array}$ \\
\hline $\mathrm{H} 4 \mathrm{a}$ & $\begin{array}{l}\text { La utilidad esperada influye positiva y directamente sobre la valoración de la } \\
\text { responsabilidad de la oferta }\end{array}$ \\
\hline H4b & $\begin{array}{l}\text { La utilidad esperada influye positiva y directamente en la adquisición de información } \\
\text { sobre responsabilidad }\end{array}$ \\
\hline $\mathrm{H} 4 \mathrm{ca}$ & $\begin{array}{l}\text { La utilidad esperada influye positiva y directamente sobre la generación de la } \\
\text { demanda responsable distal } 1\end{array}$ \\
\hline $\mathrm{H} 4 \mathrm{cb}$ & $\begin{array}{l}\text { La utilidad esperada influye positiva y directamente sobre la generación de la } \\
\text { demanda responsable distal } 2\end{array}$ \\
\hline $\mathrm{H} 4 \mathrm{cc}$ & $\begin{array}{l}\text { La utilidad esperada influye positiva y directamente sobre la generación de la } \\
\text { demanda responsable proximal } 1\end{array}$ \\
\hline $\mathrm{H} 4 \mathrm{~cd}$ & $\begin{array}{l}\text { La utilidad esperada influye positiva y directamente sobre la generación de la } \\
\text { demanda responsable proximal } 2\end{array}$ \\
\hline Н5аa & $\begin{array}{l}\text { El comportamiento empresarial percibido con motivación estratégica influye positiva } \\
\text { y directamente sobre la utilidad esperada }\end{array}$ \\
\hline H5ab & $\begin{array}{l}\text { El comportamiento empresarial percibido con motivación social influye positiva y } \\
\text { directamente sobre la utilidad esperada }\end{array}$ \\
\hline H5ba & $\begin{array}{l}\text { El comportamiento empresarial percibido con motivación estratégica influye positiva } \\
\text { y directamente sobre el concepto de responsabilidad }\end{array}$ \\
\hline H5bb & $\begin{array}{l}\text { El comportamiento empresarial percibido con motivación estratégica influye positiva } \\
\text { y directamente sobre el concepto de responsabilidad }\end{array}$ \\
\hline H5bc & $\begin{array}{l}\text { El comportamiento empresarial percibido con motivación social influye positiva y } \\
\text { directamente sobre el concepto de responsabilidad }\end{array}$ \\
\hline H5bd & $\begin{array}{l}\text { El comportamiento empresarial percibido con motivación social influye positiva y } \\
\text { directamente sobre el concepto de responsabilidad }\end{array}$ \\
\hline
\end{tabular}


Cuadro 6.1. Resumen de las hipótesis de investigación del Modelo 1 (...continuación)

\begin{tabular}{|c|l|}
\hline H6aa & $\begin{array}{l}\text { La influencia social incide positiva y directamente sobre el comportamiento } \\
\text { empresarial percibido con motivación estratégica }\end{array}$ \\
H6ab & $\begin{array}{l}\text { La influencia social incide positiva y directamente sobre el comportamiento } \\
\text { empresarial percibido con motivación social }\end{array}$ \\
H6b & $\begin{array}{l}\text { La influencia social incide positiva y directamente sobre la utilidad esperada } \\
\text { La influencia social incide positiva y directamente en la adquisición de información } \\
\text { sobre responsabilidad } \\
\text { H6c }\end{array}$ \\
H6d & $\begin{array}{l}\text { La influencia social incide positiva y directamente sobre la valoración de la } \\
\text { responsabilidad de la oferta }\end{array}$ \\
\hline
\end{tabular}

Fuente: Elaboración propia.

Tal y como se puede apreciar, la hipótesis referida a la influencia de la generación de demanda responsable sobre la adquisición de información sobre responsabilidad (H2) divide ahora su influencia entre los cuatro factores encontrados (distal 1, distal 2, proximal 1 y proximal 2), de lo que resultan las correspondientes hipótesis (H2a, H2b, H2c y H2d). Del mismo modo, la hipótesis relativa a la influencia del concepto de responsabilidad en la generación de la demanda responsable (H3) se desglosa conforme al doble concepto (distal y proximal) y dichos cuatro factores, para dar lugar a cuatro hipótesis (H3a, H3b, H3c y H3d), en este último caso al igual que la hipótesis sobre la influencia de la utilidad esperada en la generación de la demanda responsable (H4c), dando lugar asimismo a cuatro hipótesis (4ca, 4cb, 4cc y 4cd).

Por lo que respecta a la hipótesis acerca de la influencia del comportamiento empresarial percibido sobre la utilidad esperada (H5a), ésta se subdivide como resultado de la doble motivación considerada para el comportamiento empresarial (H5aa y H5ab). Algo similar ocurre con la hipótesis sobre la influencia de ese mismo comportamiento en el concepto de responsabilidad, si bien aquí al considerarse un concepto distal y un concepto proximal, las nuevas hipótesis a las que se da lugar son más (h5ba, H5bb, H5bc y H5bd).

Finalmente, la hipótesis concerniente a la repercusión de la influencia social en el comportamiento empresarial percibido (H6a) queda subdividida como resultado de la posible doble motivación de dicho comportamiento, dando lugar a las correspondientes nuevas hipótesis (H6aa y H6ab). 
Todas las nuevas hipótesis, junto a las que se mantenían de la formulación inicial (H1, H4a, H4b, H6b, H6c y H6d) fueron puestas a prueba a través del modelado PLS. Las tablas 6.8, 6.9 y 6.10 resumen, respectivamente, los parámetros obtenidos en la evaluación del modelo de medida de las variables perceptivas (concepto y estrategias), las variables de decisión y las variables relativas a los otros determinantes de comportamiento del consumidor, proporcionando información acerca de la fiabilidad individual de los ítems, la consistencia interna de las escalas, y la validez de constructo -convergente y discriminante- en el contexto de relaciones predictivas hipotetizadas.

Tabla 6.8. Parámetros de medida de las variables perceptivas del consumidor (Modelo 1)

\begin{tabular}{|c|c|c|c|c|c|c|c|}
\hline Ítem/escala & $\begin{array}{c}\text { Carga } \\
\text { factorial }\end{array}$ & Comunalidad & $\begin{array}{c}\text { Error } \\
\text { estándar }\end{array}$ & $t$ & $\alpha$ & $\rho_{c}$ & AVE \\
\hline Concepto distal & & & & & 0,796 & 0,801 & 0,689 \\
\hline 1.2 & 0,810 & 0,657 & 0,050 & $15,99^{* k *}$ & & & \\
\hline 1.3 & 0,813 & 0,662 & 0,054 & $14,91^{\star \star \star}$ & & & \\
\hline 1.9 & 0,767 & 0,589 & 0,047 & $16,45^{\star k \star}$ & & & \\
\hline 1.10 & 0,580 & 0,001 & 0,117 & $4,93^{\star \star \star}$ & & & \\
\hline $\mathrm{I} .11$ & 0,797 & 0,637 & 0,047 & $16,75^{\star \star \star}$ & & & \\
\hline Concepto proximal & & & & & 0,076 & 0,264 & 0,205 \\
\hline 1.4 & $-0,009$ & 0,000 & 0,350 & 0,026 & & & \\
\hline 1.5 & 0,993 & 0,987 & 0,115 & $8,63^{* * k}$ & & & \\
\hline 1.6 & 0,007 & 0,000 & 0,2371 & 0,03 & & & \\
\hline 1.7 & 0,197 & 0,039 & 0,1016 & $1,93^{*}$ & & & \\
\hline 1.8 & 0,007 & 0,000 & 0,259 & 0,02 & & & \\
\hline Comp. emp. m. estr. & & & & & 0,207 & 0,450 & 0,212 \\
\hline II.1 & $-0,023$ & 0,001 & 0,247 & 0,09 & & & \\
\hline 11.3 & 0,096 & 0,010 & 0,314 & 0,31 & & & \\
\hline II.4 & $-0,223$ & 0,050 & 0,429 & 0,52 & & & \\
\hline II.5 & 0,146 & 0,021 & 0,168 & 0,87 & & & \\
\hline II.7 & 0,741 & 0,550 & 0,072 & $10,25^{\star * *}$ & & & \\
\hline 11.8 & 0,072 & 0,005 & 0,193 & 0,37 & & & \\
\hline II.9 & 0,733 & 0,539 & 0,109 & $6,72^{\text {k*k }}$ & & & \\
\hline II.12 & 0,724 & 0,525 & 0,094 & $7,67^{\text {k*k }}$ & & & \\
\hline Comp. emp. m. soc. & & & & & 0,470 & 0,624 & 0,226 \\
\hline II.2 & 0,065 & 0,004 & 0,202 & 0,32 & & & \\
\hline II.6 & 0,590 & 0,349 & 0,089 & $6,57^{\star \star \star}$ & & & \\
\hline II.10 & 0,741 & 0,337 & 0,072 & $10,25^{\star k \star}$ & & & \\
\hline II.11 & 0,505 & 0,255 & 0,150 & $3,35^{\star \star \star}$ & & & \\
\hline II.13 & 0,004 & 0,000 & 0,358 & 0,01 & & & \\
\hline II.14 & 0,160 & 0,026 & 0,251 & 0,63 & & & \\
\hline II.15 & 0,209 & 0,044 & 0,184 & 1,13 & & & \\
\hline II.16 & 0,611 & 0,374 & 0,116 & $5,27^{\star \star \star *}$ & & & \\
\hline II.17 & 0,806 & 0,650 & 0,075 & $10,63^{k \star k}$ & & & \\
\hline
\end{tabular}

${ }^{*} p<0,05 ;{ }^{* *} p<0,01 ;{ }^{* * *} p<0,001$ (199 grados de libertad). 
En cuanto a los resultados del análisis factorial confirmatorio para las variables perceptivas, las cargas factoriales estandarizadas $\lambda_{\mathrm{y}}$ ahora asociadas a los indicadores observados revelaron una estructura factorial menos consistente que la previamente encontrada mediante el análisis exploratorio. La Tabla 6.8 muestra la existencia de indicadores con cargas factoriales por encima del mínimo relevante de 0,50 (Barclay et al. 1995, Chin 1998a y 1998b) en poco más de la mitad de constructos analizados (14 de 27), todas ellas asociadas a valores $t$ de Student significativos de acuerdo a la técnica bootstrap aplicada con 200 submuestras de 100 casos cada una.

En función de tales resultados, las escalas con un mejor ajuste de medida correspondieron al concepto distal (teniendo significación estadística las cargas de todos sus indicadores), y al comportamiento empresarial con motivación social (5 cargas significativas de 9). Por contra, las escalas con un ajuste de medida más cuestionable fueron el comportamiento empresarial con motivación estratégica (con sólo 3 cargas significativas de un total de 8 ítems), y el concepto proximal (para el que una de las cinco cargas era significativa).

A su vez, la consistencia interna de las escalas perceptivas estimada mediante los índices alpha de Cronbach $(\alpha)$ y de fiabilidad compuesta $\left(\rho_{\mathrm{c}}\right)$ sólo superó el umbral aceptable de 0,70 en la medición del concepto distal. Por su parte, el índice AVE empleado en el análisis de la validez convergente a partir de la comparación de la varianza compartida entre cada constructo y sus indicadores con respecto al error de medida, estuvo por debajo del límite de 0,50 en todas las escalas, salvo en el concepto distal $(0,689)$. Frente a ello, y siguiendo la tendencia de resultados previos, el valor AVE obtenido resultó especialmente bajo en las demás escalas de concepto proximal, comportamiento empresarial con motivación estratégica y con motivación social, casos en los que se obtuvieron valores respectivos de 0,205, de 0,212 y de 0,226.

Con todo, los resultados derivados de la evaluación del modelo de medida de los factores perceptivos sugirió la conveniencia de proceder a la depuración de las variables utilizadas como indicadores en la estimación de los constructos, poniéndose en evidencia un escaso ajuste en varias de las dimensiones -particularmente, en la escala de concepto proximal-, lo cual podría comprometer seriamente el alcance de la validez predictiva del modelo estructural, así como las interpretaciones relativas al grado de cumplimiento de las hipótesis planteadas. 
Por lo que respecta a los resultados del análisis factorial para las variables decisionales del consumidor, la Tabla 6.9 muestra cómo las cargas $\lambda_{\text {y }}$ vinculadas a las mismas evidenciaron, de nuevo y en una proporción parecida (11 de 19), varios indicadores con parámetros por encima de 0,50 en los seis constructos analizados, vinculados a cifras de comunalidad superiores al mínimo de 0,25 y a valores $t$ de Student significativos de acuerdo con la técnica bootstrap. Las escalas con un mejor ajuste de medida correspondieron a la generación de demanda distal 1, la generación de demanda proximal 2 y la adquisición de información sobre responsabilidad (alcanzando significación estadística las cargas de todos sus indicadores), mientras que las escalas con un ajuste de medida más problemático fueron la valoración de la responsabilidad de la oferta (con sólo 2 cargas significativas de un total de 7 ítems), el concepto distal 2 y la generación de demanda proximal 1 (con una carga significativa de 2 en cada caso).

Tabla 6.9. Parámetros de medida de las variables de decisión del consumidor (Modelo 1)

\begin{tabular}{|c|c|c|c|c|c|c|c|}
\hline Ítem/escala & $\begin{array}{c}\text { Carga } \\
\text { factorial }\end{array}$ & Comunalidad & $\begin{array}{c}\text { Error } \\
\text { estándar }\end{array}$ & $t$ & $\alpha$ & $\rho_{c}$ & AVE \\
\hline Gen. dem. distal.1 & & & & & 0,846 & 0,928 & 0,867 \\
\hline III.1 & 0,931 & 0,868 & 0,017 & $52,89^{\star * *}$ & & & \\
\hline III.2 & 0,930 & 0,865 & 0,021 & $43,34^{\star \star \star}$ & & & \\
\hline Gen. dem. distal.2 & & & & & $-0,004$ & 0,642 & 0,499 \\
\hline III.8 & 0,450 & 0,203 & 0,320 & 1,40 & & & \\
\hline III.9 & 0,891 & 0,795 & 0,395 & $2,25^{*}$ & & & \\
\hline Gen. dem. prox. 1 & & & & & $-0,007$ & 0,494 & 0,500 \\
\hline III.3 & 1 & 1 & 0,083 & $12,03^{\star \star \star}$ & & & \\
\hline III.4 & $-0,011$ & 0,000 & 0,4875 & 0,02 & & & \\
\hline Gen.dem. prox. 2 & & & & & $-0,010$ & 0,653 & 0,497 \\
\hline III.5 & 0,844 & 0,712 & 0,389 & $2,16^{*}$ & & & \\
\hline III.6 & 0,531 & 0,283 & 0,544 & 0,97 & & & \\
\hline Adqu. inform. resp. & & & & & 0,796 & 0,867 & 0,622 \\
\hline IV.1 & 0,788 & 0,622 & 0,038 & $20,57^{\star \star \star}$ & & & \\
\hline IV.2 & 0,875 & 0,761 & 0,034 & $25,47^{\star \star \star}$ & & & \\
\hline IV.3 & 0,708 & 0,502 & 0,071 & $9,91^{\star \star k}$ & & & \\
\hline IV.4 & 0,777 & 0,605 & 0,056 & $13,75^{\star \star \star}$ & & & \\
\hline Valor. resp. oferta & & & & & 0,363 & 0,375 & 0,219 \\
\hline IV.7 & $-0,008$ & 0,000 & 0,285 & 0,02 & & & \\
\hline IV.8 & 0,015 & 0,000 & 0333 & 0,04 & & & \\
\hline IV.9 & 0,015 & 0,000 & 0,321 & 0,04 & & & \\
\hline IV.10 & 0,896 & 0,804 & 0,043 & $20,84^{\star \star \star *}$ & & & \\
\hline IV.11 & 0,016 & 0,000 & 0,242 & 0,06 & & & \\
\hline IV.12 & 0,023 & 0,001 & 0,298 & 0,07 & & & \\
\hline IV.13 & 0,854 & 0,729 & 0,045 & $18,79^{\star \star *}$ & & & \\
\hline
\end{tabular}

${ }^{*} p<0,05 ;{ }^{* *} p<0,01 ;{ }^{* * *} p<0,001$ (199 grados de libertad). 
Asimismo, las escalas de generación de demanda distal 1 y de adquisición de información sobre responsabilidad mostraron una consistencia interna aceptable, siendo sus índices $\rho_{\mathrm{c}}$ respectivos de 0,928 y 0,867 . Mientas tanto, los resultados para las otras escalas indicaron una baja fiabilidad, lo que venía a evidenciar el mal funcionamiento para el conjunto de los ítems empleados en su medición.

En lo que respecta a los índices AVE representativos de la validez convergente, tres variables de decisión del consumidor se situaron por encima del límite de 0,50 (0,867 para la generación de demanda distal 1, 0,622 para la adquisición de información sobre responsabilidad, y justo en el límite de 0,500 para la generación de demanda proximal 1). Cercanos al mínimo estuvieron los valores de las escalas de generación de demanda distal $2(0,499)$ y generación de demanda proximal $2(0,497)$, y especialmente bajo fue el de la escala de valoración de la responsabilidad de la oferta $(0,219)$. Estos valores también indicaban la necesidad de lograr un mejor ajuste del modelo.

En cuanto a los resultados referidos a los otros determinantes de la conducta del consumidor (Tabla 6.10), las cargas factoriales $\lambda_{\mathrm{y}}$ vinculadas a la variable endógena de utilidad observada mostraron 3 indicadores (de 5) con parámetros por encima de 0,50, con cifras de comunalidad superiores al mínimo de 0,25 y con valores $t$ de Student significativos de acuerdo con la técnica bootstrap. Entretanto, las cargas factoriales $\lambda_{\mathrm{x}}$ relacionadas con la variable exógena de influencia social sólo cumplían esos requisitos para un indicador.

Tabla 6.10. Parámetros de medida de las variables de otros determinantes (Modelo 1)

\begin{tabular}{|c|c|c|c|c|c|c|c|}
\hline Ítem/escala & $\begin{array}{c}\text { Carga } \\
\text { factorial }\end{array}$ & Comunalidad & $\begin{array}{c}\text { Error } \\
\text { estándar }\end{array}$ & $t$ & $\alpha$ & $\rho_{c}$ & AVE \\
\hline Utilidad esperada & & & & & 0,472 & 0,682 & 0,419 \\
\hline IV.15 & $-0,059$ & 0,004 & 0,406 & 0,14 & & & \\
\hline IV.16 & 0,843 & 0,711 & 0,074 & $11,29^{* * *}$ & & & \\
\hline IV.17 & 0,859 & 0,739 & 0,047 & $18,18^{\star \star \star}$ & & & \\
\hline IV.18 & 0,798 & 0,638 & 0,061 & $12,96^{* \star \star}$ & & & \\
\hline IV.19 & 0,058 & 0,003 & 0,279 & 0,20 & & & \\
\hline Influencia social & & & & & 0,045 & 0,383 & 0,256 \\
\hline IV.14 & 0,136 & 0,019 & 0,307 & 0,44 & & & \\
\hline IV.20 & 0,178 & 0,032 & 0,413 & 0,43 & & & \\
\hline IV.21 & 0,984 & 0,970 & 0,068 & $14,28^{* \star *}$ & & & \\
\hline IV.22 & 0,060 & 0,004 & 0,345 & 0,17 & & & \\
\hline
\end{tabular}


Por otro lado, ambos constructos demuestran una mala consistencia interna, proporcionando una baja fiabilidad, lo que evidenció el mal funcionamiento de los ítems empleados en su medición. En esta misma línea, los valores de los índices AVE representativos de la cantidad de varianza que el constructo obtiene de sus indicadores se situaron por debajo del límite de 0,50. Especialmente bajo fue el correspondiente a la escala de influencia social, donde la varianza explicada fue del $25.6 \%$, por debajo del 41,9\% en el caso de la utilidad esperada. Estas cifras señalaron la necesidad de depurar las medidas de cara a lograr un mejor ajuste del modelo y una mayor precisión estructural.

Un último aspecto en la evaluación del modelo de medida de las diferentes dimensiones perceptivas, de decisión y de otros determinantes, se centra en la comprobación de la validez discriminante de las escalas por medio de la inspección de la matriz de correlaciones entre las variables latentes, reemplazando la diagonal por la raíz cuadrada de los valores AVE (Tabla 6.11). En términos generales, tales índices estuvieron por encima de los coeficientes de correlación entre los constructos latentes tomados dos a dos, no detectándose grandes problemas en lo tocante a la validez discriminante de las escalas, salvo entre la valoración de la responsabilidad de la oferta y la utilidad esperada (con un índice de correlación de 0,49 superior a la raíz cuadrada de AVE de la primera variable), y entre la primera y la adquisición de información sobre responsabilidad (con un índice de correlación de 0,52 superior a la raíz cuadrada de AVE de la primera variable, cuyo valor era de 0,46 ).

Tabla 6.11 Matriz de correlaciones y raíz cuadrada de AVE (Modelo 1)*

\begin{tabular}{|c|c|c|c|c|c|c|c|c|c|c|c|c|}
\hline Variables & 1 & 2 & 3 & 4 & 5 & 6 & 7 & 8 & 9 & 10 & 11 & 12 \\
\hline 1. Adquis. inform. resp. & 0,78 & & & & & & & & & & & \\
\hline 2. Comp. empr. estratég. & 0,14 & 0,46 & & & & & & & & & & \\
\hline 3. Comp. empr. social & 0,20 & 0,15 & 0,47 & & & & & & & & & \\
\hline 4. Concepto distal & 0,18 & 0,33 & 0,24 & 0,71 & & & & & & & & \\
\hline 5. Concepto proximal & 0,09 & 0,06 & 0,06 & 0,08 & 0,45 & & & & & & & \\
\hline 6. G. demanda distal 1 & 0,33 & 0,26 & 0,17 & 0,59 & 0,09 & 0,93 & & & & & & \\
\hline 7. G. demanda distal 2 & $-0,05$ & 0,02 & $-0,04$ & 0,01 & 0,00 & 0,05 & 0,70 & & & & & \\
\hline 8. G. demanda proxim. 1 & 0,08 & 0,03 & 0,03 & 0,05 & 0,99 & 0,08 & 0,00 & 0,70 & & & & \\
\hline 9. G. demanda proxim. 2 & 0,08 & $-0,01$ & $-0,02$ & $-0,01$ & 0,00 & $-0,04$ & 0,00 & 0,00 & 0,70 & & & \\
\hline 10. Influencia social & 0,47 & 0,24 & 0,13 & 0,12 & 0,04 & 0,19 & $-0,03$ & 0,03 & $-0,01$ & 0,50 & & \\
\hline 11. Utilidad esperada & 0,50 & 0,23 & 0,29 & 0,27 & 0,08 & 0,31 & 0,04 & 0,05 & $-0,02$ & 0,36 & 0,64 & \\
\hline 12. Valorac. resp. oferta & 0,52 & $-0,04$ & 0,26 & 0,03 & 0,06 & 0,06 & $-0,04$ & 0,05 & 0,06 & 0,39 & 0,49 & 0,46 \\
\hline
\end{tabular}

* La raíz cuadrada de los valores AVE aparece para cada variable en la diagonal de la matriz. 
En suma, las limitaciones en términos de fiabilidad y validez del modelo de medida inicial apuntaron la necesidad de reespecificar las relaciones entre las variables observadas y latentes antes de someter a prueba un modelo estructural definitivo.

No obstante, la revisión de valores $R^{2}$ y $Q^{2}$ asociados a los constructos latentes y coeficientes de regresión entre variables exógenas y endógenas en este primer modelo ofreció una aproximación inicial al patrón predictivo interno (Tabla 6.12 y Figura 6.3).

Tabla 6.12. Índices de ajuste global del Modelo 1

\begin{tabular}{lcc}
\hline \multicolumn{1}{c}{ Variable } & $\boldsymbol{R}^{2}$ & $\mathbf{Q}^{2}$ \\
\hline Adquis. inform. resp. & 0,393 & 0,237 \\
Comp. empr. m. estratég. & 0,058 & 0,010 \\
Comp. empr. m. social & 0,018 & 0,002 \\
Concepto distal & 0,151 & 0,077 \\
Concepto proximal & 0,007 & 0,014 \\
G. demanda distal 1 & 0,383 & 0,320 \\
G. demanda distal 2 & 0,001 & $-0,009$ \\
G. demanda proxim. 1 & 0,986 & 0,014 \\
G. demanda proxim. 2 & 0,004 & $-0,005$ \\
Utilidad esperada & 0,212 & 0,082 \\
Valorac. resp. oferta & 0,365 & 0,052 \\
\hline
\end{tabular}

Figura 6.3. Ajuste global y coeficientes $\beta$ y y del Modelo ${ }^{*}$

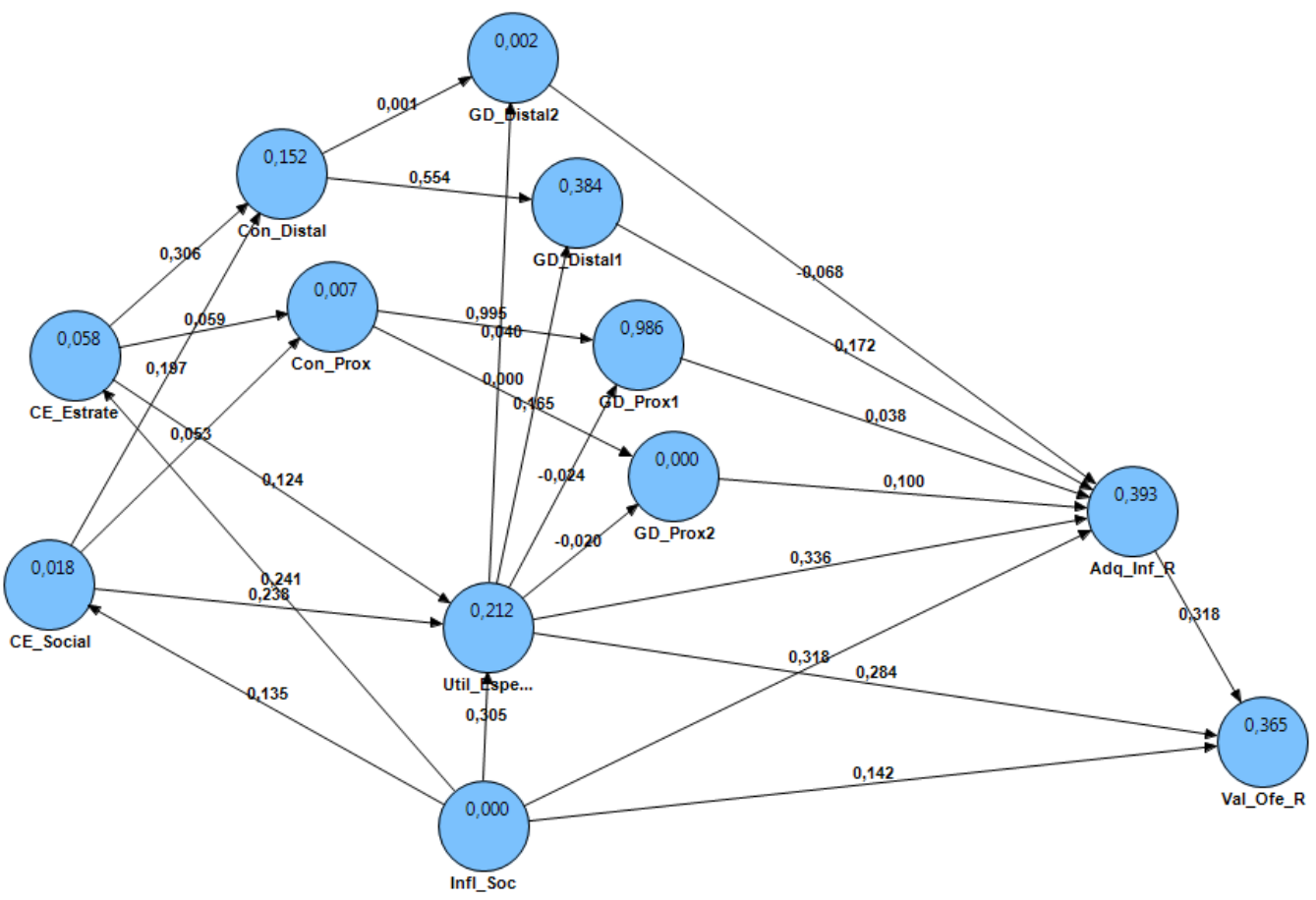

* Las flechas representan los coeficientes $\beta$ y y, mientras que en los c írculos el índice de ajuste global R2.

Fuente: Elaboración propia. 
Particularmente, los índices $R^{2}$ para todas las variables latentes endógenas se situaron por encima del nivel mínimo apropiado de 0,10 (Falk y Miller 1992) en seis de los once constructos analizados. Las relaciones predictivas entre variables permitieron explicar el 98,8\% de la varianza en la generación de demanda proximal 1, el 39,3\% en la adquisición de información sobre responsabilidad, el 38,3\% en la generación de demanda distal 1, el 36,5\% en la valoración de la responsabilidad de la oferta, el 21,2\% en la utilidad esperada, y el 15,1\% en el concepto distal, mientas que el poder predictivo de las otras variables fue notablemente bajo.

En estrecha relación con tal patrón predictivo, la estimación jackknife del ajuste global del modelo en términos de relevancia predictiva arrojó unos valores $Q^{2}$ bastante reducidos para todos los constructos latentes endógenos, superando el mínimo de 0,20 únicamente la generación de demanda distal $1(0,320)$ y la adquisición de información sobre responsabilidad $(0,237)$.

En términos más operativos, las Tablas 6.13 y 6.14 resumen los efectos directos y totales entre variables conforme a las hipótesis planteadas. En base a los valores $t$ de Student significativos a un nivel de $p<0,05$ de acuerdo al procedimiento bootstrap con 200 submuestras, se constató un efecto positivo directo de la adquisición de información sobre responsabilidad en la valoración de la oferta (Hipótesis 1), con un coeficiente estandarizado de regresión $\beta$ de 0,318 , asociado a un $16.86 \%$ de la varianza explicada.

La Hipótesis 2 relacionaba el constructo de generación de demanda considerada en sus diferentes dimensiones con la adquisición de información, no resultando una relación significativa, y destacando como más importante la varianza explicada (5,68\%) por la generación de demanda distal 1 (acciones relacionadas con el medioambiente y la problemática social).

Los conceptos proximal y distal también desempeñan un papel preponderante en el modelo inicial, explicando el 98,49\% de la varianza en la generación de demanda proximal 1 (Hipótesis 3c) y el 33,24\% en la generación de demanda distal 1 (Hipótesis 3a), con unos valores de los respectivos coeficientes $\beta$ de 0,995 y 0,554.

Por su parte, la utilidad esperada influye significativamente en la valoración de la responsabilidad (Hipótesis 4a), la adquisición de información (Hipótesis 4b) y la generación de demanda distal 1, explicando el 14,19\%, el 16,81\% y el 5,12\% de las respectivas varianzas, con valores de los coeficientes $\beta$ de 0,284, de 0,336 y de 0,165. 
Tabla 6.13. Efectos directos en el Modelo 1

\begin{tabular}{|c|c|c|c|c|c|c|}
\hline \multicolumn{7}{|c|}{ Efectos directos } \\
\hline & $\begin{array}{c}\text { Coeficiente } \\
(\boldsymbol{\beta} / \gamma)\end{array}$ & $\begin{array}{c}\text { Coef. de } \\
\text { correlación }\end{array}$ & $\begin{array}{l}\text { Varianza } \\
\text { explicada }\end{array}$ & $\begin{array}{c}\text { Error } \\
\text { estándar }\end{array}$ & $t$ & $p$ \\
\hline Adq_inf_R $\rightarrow$ Val_of_R & 0,318 & 0,53 & $16,86 \%$ & 0,122 & 2,61 & $* * *$ \\
\hline CE_Estrate $->$ Conc_distal & 0,306 & 0,34 & $10,40 \%$ & 0,087 & 3,53 & $* * \star x$ \\
\hline CE_Estrate -> Conc_prox & 0,059 & 0,07 & $0,41 \%$ & 0,102 & 0,58 & \\
\hline CE_Estrate -> Util_Esperada & 0,124 & 0,24 & $2,98 \%$ & 0,101 & 1,24 & \\
\hline CE_Social -> Conc_distal & 0,197 & 0,25 & $4,93 \%$ & 0,100 & 1,97 & * \\
\hline CE_Social -> Conc_prox & 0,053 & 0,06 & $0,32 \%$ & 0,103 & 0,51 & \\
\hline CE_Social -> Util_Esperada & 0,238 & 0,30 & $7,15 \%$ & 0,120 & 1,99 & * \\
\hline Conc_Distal -> GD_Distal1 & 0,554 & 0,60 & $33,24 \%$ & 0,083 & 6,69 & $* * x$ \\
\hline Conc_Distal -> GD_Distal2 & 0,001 & 0,01 & $0,00 \%$ & 0,161 & 0,01 & \\
\hline Conc_Prox -> GD_Prox1 & 0,995 & 0,99 & $98,49 \%$ & 0,194 & 5,14 & $* * x$ \\
\hline Conc_prox -> GD_Prox2 & 0,000 & 0,00 & $0,00 \%$ & 0,170 & 0,00 & \\
\hline GD_Distal1 -> Adq_inf_R & 0,172 & 0,33 & $5,68 \%$ & 0,106 & 1,62 & \\
\hline GD_Distal2 -> Adq_inf_R & $-0,068$ & $-0,05$ & $0,34 \%$ & 0,119 & 0,57 & \\
\hline GD_Prox1 -> Adq_inf_R & 0,038 & 0,08 & $0,30 \%$ & 0,090 & 0,42 & \\
\hline GD_Prox2 -> Adq_inf_R & 0,100 & 0,08 & $0,80 \%$ & 0,098 & 1,01 & \\
\hline Infl_Soc $>$ Adq_inf_R & 0,318 & 0,48 & $15,24 \%$ & 0,106 & 3,00 & $* * \star$ \\
\hline Infl_Soc $>$ CE_Estrate & 0,242 & 0,24 & $5,80 \%$ & 0,129 & 1,88 & * \\
\hline Infl_Soc -> CE_Social & 0,135 & 0,14 & $1,89 \%$ & 0,103 & 1,31 & \\
\hline Infl_Soc -> Util_Esperada & 0,305 & 0,37 & $11,27 \%$ & 0,111 & 2,75 & *** \\
\hline Infl_Soc -> Val_of_R & 0,142 & 0,40 & $5,68 \%$ & 0,159 & 0,89 & \\
\hline Util_Esperada $>>$ Adq_inf_R & 0,336 & 0,50 & $16,81 \%$ & 0,109 & 3,09 & $* * *$ \\
\hline Util_Esperada -> GD_Distal1 & 0,165 & 0,31 & $5,12 \%$ & 0,084 & 1,96 & * \\
\hline Util_Esperada -> GD_Distal2 & 0,040 & 0,04 & $0,16 \%$ & 0,104 & 0,39 & \\
\hline Util_Esperada -> GD_Prox1 & $-0,024$ & $-0,06$ & $0,14 \%$ & 0,120 & 0,20 & \\
\hline Util_Esperada -> GD_Prox2 & $-0,020$ & $-0,02$ & $0,04 \%$ & 0,131 & 0,16 & \\
\hline Util_Esperada $->$ Val_of_R & 0,284 & 0,50 & $14,19 \%$ & 0,128 & 2,22 & * \\
\hline
\end{tabular}

${ }^{*} p<0,05 ;{ }^{* *} p<0,01 ;{ }^{* * *} p<0,001$ (199 grados de libertad).

También resultó significativa la influencia del comportamiento empresarial con motivación social sobre el concepto distal (Hipótesis 5bc), explicando un 4,93\% de su varianza, y sobre la utilidad esperada (Hipótesis 5ab), con una explicación del 7,15\% de la misma. En estas relaciones los coeficientes $\beta$ que relacionan las variables latentes fueron, respectivamente, de 0,197 y 0,238.

Finalmente, se aprecia el efecto positivo que la influencia social tiene como variable latente exógena en el comportamiento empresarial con motivación estratégica (Hipótesis 6aa), con un coeficiente $\gamma$ de 0,242 y una varianza explicada del 5,80\%. Dicha variable también incidía sobre la utilidad esperada (Hipótesis 6b), con un coeficiente $\gamma$ de 0,305 y una varianza explicada del 11,27\%. Y determinaba igualmente la adquisición de información sobre responsabilidad (Hipótesis 6c), con un coeficiente $\gamma$ de 0,318 y llegando a explicar en este caso el 15,24\% de la varianza. 
Tabla 6.14. Efectos totales en el Modelo 1

\begin{tabular}{|c|c|c|c|c|c|c|}
\hline \multicolumn{7}{|c|}{ Efectos totales } \\
\hline & $\begin{array}{c}\text { Coeficiente } \\
(\beta / \gamma)\end{array}$ & $\begin{array}{l}\text { Coef. de } \\
\text { correlación }\end{array}$ & $\begin{array}{c}\text { Varianza } \\
\text { explicada }\end{array}$ & $\begin{array}{c}\text { Error } \\
\text { estándar }\end{array}$ & $t$ & $p$ \\
\hline Adq_inf_R $\rightarrow>$ Val_of_R & 0,318 & 0,53 & $16,86 \%$ & 0,122 & 2,61 & *** \\
\hline CE_Estrate -> Adq_inf_R & 0,076 & 0,14 & $1,06 \%$ & 0,038 & 2,02 & * \\
\hline CE_Estrate -> Conc_distal & 0,306 & 0,34 & $10,40 \%$ & 0,087 & 3,53 & $* *$ \\
\hline CE_Estrate -> Conc_prox & 0,059 & 0,07 & $0,41 \%$ & 0,102 & 0,58 & \\
\hline CE_Estrate -> GD_Distal1 & 0,190 & 0,27 & $5,13 \%$ & 0,058 & 3,26 & *** \\
\hline CE_Estrate -> GD_Distal2 & 0,005 & 0,25 & $0,13 \%$ & 0,076 & 0,07 & \\
\hline CE_Estrate -> GD_Prox1 & 0,056 & 0,03 & $0,17 \%$ & 0,055 & 1,01 & \\
\hline CE_Estrate -> GD_Prox2 & $-0,003$ & $-0,02$ & $0,01 \%$ & 0,067 & 0,04 & \\
\hline CE_Estrate -> Util_Esperada & 0,124 & 0,24 & $2,98 \%$ & 0,101 & 1,24 & \\
\hline CE_Estrate -> Val_of_R & 0,060 & 0,04 & $0,24 \%$ & 0,036 & 1,68 & * \\
\hline CE_Social -> Adq_inf_R & 0,106 & 0,21 & $2,23 \%$ & 0,045 & 2,35 & ** \\
\hline CE_Social -> Conc_distal & 0,197 & 0,25 & $4,93 \%$ & 0,100 & 1,97 & * \\
\hline CE_Social -> Conc_prox & 0,053 & 0,06 & $0,32 \%$ & 0,103 & 0,51 & \\
\hline CE_Social -> GD_Distal1 & 0,149 & 0,18 & $2,68 \%$ & 0,067 & 2,22 & * \\
\hline CE_Social -> GD_Distal2 & 0,010 & 0,04 & $0,04 \%$ & 0,063 & 0,15 & \\
\hline CE_Social -> GD_Prox1 & 0,047 & 0,03 & $0,14 \%$ & 0,058 & 0,82 & \\
\hline CE_Social -> GD_Prox2 & $-0,005$ & $-0,02$ & $0,01 \%$ & 0,082 & 0,06 & \\
\hline CE_Social -> Util_Esperada & 0,238 & 0,3 & $7,15 \%$ & 0,120 & 1,99 & * \\
\hline CE_Social -> Val_of_R & 0,102 & 0,27 & $2,74 \%$ & 0,059 & 1,71 & * \\
\hline Conc_distal -> Adq_inf_R & 0,095 & 0,18 & $1,72 \%$ & 0,053 & 1,79 & * \\
\hline Conc_distal -> GD_Distal1 & 0,554 & 0,6 & $33,24 \%$ & 0,083 & 6,69 & $* * *$ \\
\hline Conc_distal -> GD_Distal2 & 0,001 & 0,01 & $0,00 \%$ & 0,161 & 0,01 & \\
\hline Conc_distal -> Val_of_R & 0,030 & 0,04 & $0,12 \%$ & 0,017 & 1,78 & * \\
\hline Conc_prox -> Adq_inf_R & 0,038 & 0,1 & $0,38 \%$ & 0,044 & 0,86 & \\
\hline Conc_prox -> GD_Prox1 & 0,995 & 0,99 & $98,49 \%$ & 0,194 & 5,14 & $* * *$ \\
\hline Conc_prox -> GD_Prox2 & 0,000 & 0 & $0,00 \%$ & 0,170 & 0,00 & \\
\hline Conc_prox -> Val_of_R & 0,012 & 0,07 & $0,08 \%$ & 0,014 & 0,88 & \\
\hline GD_Distal1 -> Adq_inf_R & 0,172 & 0,33 & $5,68 \%$ & 0,106 & 1,62 & \\
\hline GD_Distal1 -> Val_of_R & 0,055 & 0,06 & $0,33 \%$ & 0,030 & 1,84 & * \\
\hline GD_Distal2 -> Adq_inf_R & $-0,068$ & $-0,05$ & $0,34 \%$ & 0,119 & 0,57 & \\
\hline GD_Distal2 -> Val_of_R & $-0,022$ & $-0,06$ & $0,13 \%$ & 0,034 & 0,64 & \\
\hline GD_Prox1 $>$ Adq_inf_R & 0,038 & 0,08 & $0,30 \%$ & 0,090 & 0,42 & \\
\hline GD_Prox1 -> Val_of_R & 0,012 & 0,05 & $0,06 \%$ & 0,024 & 0,51 & \\
\hline GD_Prox2 -> Adq̄_inf_R & 0,100 & 0,08 & $0,80 \%$ & 0,098 & 1,01 & \\
\hline GD_Prox2 -> Val_of_R & 0,032 & 0,07 & $0,22 \%$ & 0,033 & 0,97 & \\
\hline Infl_Soc $>$ Adq_inf_R & 0,460 & 0,48 & $22,07 \%$ & 0,077 & 5,94 & $* * *$ \\
\hline Infl_Soc $>$ CE_Estrate & 0,242 & 0,24 & $5,80 \%$ & 0,129 & 1,88 & * \\
\hline Infl_Soc -> CE_Social & 0,135 & 0,14 & $1,89 \%$ & 0,103 & 1,31 & \\
\hline Infl_Soc -> Conc_distal & 0,101 & 0,13 & $1,31 \%$ & 0,060 & 1,67 & * \\
\hline Infl_Soc -> Conc_prox & 0,022 & 0,05 & $0,11 \%$ & 0,061 & 0,35 & \\
\hline Infl_Soc -> GD_Distal1 & 0,116 & 0,19 & $2,21 \%$ & 0,059 & 1,96 & * \\
\hline Infl_Soc -> GD_Distal2 & 0,015 & 0,03 & $0,04 \%$ & 0,064 & 0,23 & \\
\hline Infl_Soc -> GD_Prox1 & 0,013 & 0,03 & $0,04 \%$ & 0,066 & 0,19 & \\
\hline Infl_Soc -> GD_Prox2 & $-0,007$ & $-0,01$ & $0,01 \%$ & 0,082 & 0,09 & \\
\hline Infl_Soc -> Util__Esperada & 0,367 & 0,37 & $13,58 \%$ & 0,097 & 3,79 & $* * *$ \\
\hline Infl_Soc -> Val_of_R & 0,392 & 0,4 & $15,69 \%$ & 0,096 & 4,07 & $* *$ \\
\hline Util_Esperada -> Adq_inf_R & 0,359 & 0,5 & $17,95 \%$ & 0,106 & 3,40 & $* * *$ \\
\hline Util_Esperada -> GD_Distal1 & 0,165 & 0,31 & $5,12 \%$ & 0,084 & 1,96 & * \\
\hline Util_Esperada -> GD_Distal2 & 0,040 & 0,04 & $0,16 \%$ & 0,104 & 0,39 & \\
\hline Util_Esperada -> GD_Prox1 & $-0,024$ & $-0,06$ & $0,14 \%$ & 0,120 & 0,20 & \\
\hline Util_Esperada -> GD_Prox2 & $-0,020$ & $-0,02$ & $0,04 \%$ & 0,131 & 0,16 & \\
\hline Util_Esperada -> Val_of_R & 0,398 & 0,50 & $19,90 \%$ & 0,139 & 2,86 & *** \\
\hline
\end{tabular}

${ }^{*} p<0,05 ;{ }^{* *} p<0,01 ;{ }^{* * *} p<0,001$ (199 grados de libertad). 
Todas las hipótesis enunciadas verifican la relación directa entre las variables latentes, pero además la relación entre cada una de las variables origen y el constructo valoración de ofertas responsables resulta ser asimismo estadísticamente significativa (según cabe apreciar en la Tabla 6.14, de efectos totales). Se trata de relaciones indirectas no hipotetizadas, donde destaca de una manera especial el efecto total entre la utilidad esperada y la valoración de la responsabilidad de la oferta, con una varianza explicada del 19,90\% y un coeficiente de 0,398. Igualmente es destacable la relación total entre la influencia social y la valoración de la responsabilidad de la oferta, siendo en este caso el valor del coeficiente que relaciona ambas variables latentes de 0,392 en tanto que la varianza quedaría explicada en un 15,69\%.

Si bien el resto de vínculos estructurales que fueron hipotetizados en el modelo no resultaron estadísticamente significativos de acuerdo con la técnica bootstrap, siguiendo el criterio de Falk y Miller (1992) sobre la relevancia predictiva de las variables explicativas de al menos un 1,5\% de la varianza en otros constructos latentes, algunas otras relaciones empíricas son de reseñar a partir de los datos recogidos en las Tablas 6.13 y 6.14 .

Así, y por un lado, se aprecia la ya comentada relación entre la generación de demanda distal 1 y la adquisición de información sobre responsabilidad, con el 5,68\% de la varianza explicada y un coeficiente $\beta$ no significativo de 0,72 (Hipótesis 2a). Ese mismo valor corresponde a la varianza explicada por las implicaciones entre la influencia social y el valor de la responsabilidad de la oferta, pero con un coeficiente $\beta$ de 0,142 (Hipótesis 6d), entre el comportamiento empresarial estratégico y la utilidad esperada (Hipótesis 5aa); con una explicación del 2,98\% de la varianza y un $\beta$ de 0,124; así como entre la influencia social y el comportamiento empresarial con motivación social (Hipótesis 6ab), que superaba el límite indicado (1,89\%), aunque el valor 0,135 de su coeficiente $\beta$ no era estadísticamente significativo.

El resto de hipótesis (2b, 2c, 2d, 3b, 3d, 4cb, 4cc, 4cd, 5bb,y 5bd) no cumplieron ninguna de las especificaciones establecidas para su verificación, siendo rechazadas junto a las indicadas en el párrafo anterior (2a, 5aa, 6ab, y 6d). En suma, respecto al modelo propuesto 12 hipótesis fueron verificadas, mientras que 14 fueron refutadas. A fin de poder apreciar con mayor claridad de los resultados estructurales obtenidos, en la Figura 6.4 se muestran con trazo más grueso las relaciones o hipótesis verificadas, y con línea discontinua las que fueron refutadas. 
Figura 6.4. Representación de las relaciones significativas del Modelo 1

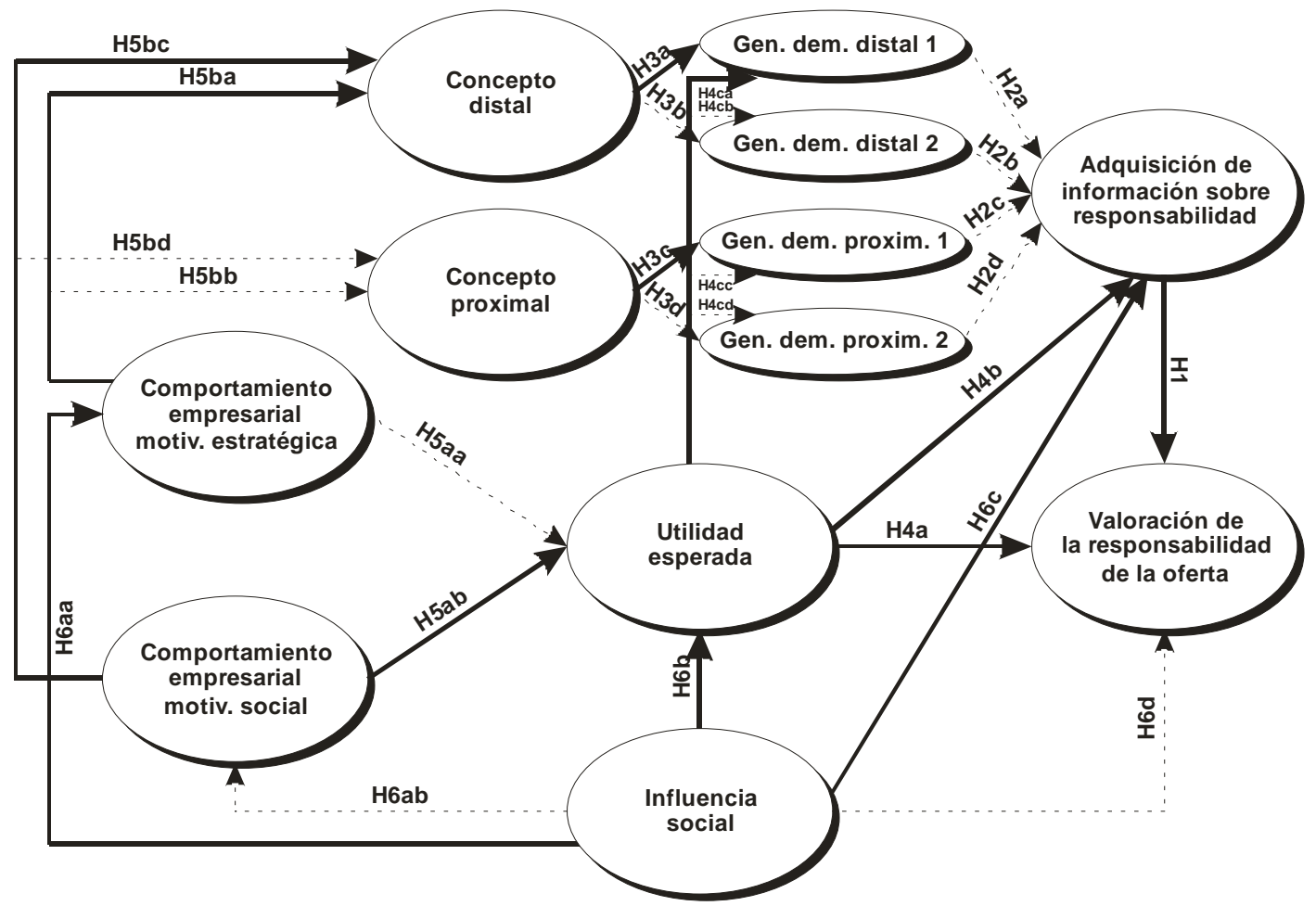

Fuente: Elaboración propia.

En conclusión, el escaso ajuste encontrado, y más a nivel de medición externa, justifica la necesidad de reespecificar el planteamiento inicial, atendiendo especialmente al nivel de adecuación de los ítems empleados para medir los constructos y a fin de lograr un mayor nivel de ajuste del modelo de medida como condición previa a la comprobación del ajuste del modelo estructural y sus hipótesis.

\subsubsection{Reespecificación del modelo de medida (Modelo 2)}

Respetando el patrón estructural hipotetizado en el Modelo 1 (Figura 6.1), en un segundo análisis se modificó el modelo interno de medida de las variables endógenas y la exógena, reteniendo únicamente los indicadores con cargas factoriales significativas de acuerdo con los resultados previos (Tablas 6.8, 6.9 y 6.10).

Así las cosas, y respecto a las dimensiones referidas a las perspectivas del consumidor, las escalas de medición de concepto distal pasaron a estar conformadas por 4 indicadores, el concepto proximal por 2, el comportamiento empresarial estratégico 
por 3 y el comportamiento empresarial social por 5 (parámetros todos ellos reflejados en la Tabla 6.15).

Por su parte, las variables de decisión del consumidor quedaron conformadas por 2 indicadores para la generación de demanda proximal 2 y distal 1, y uno solo en el caso de la distal 2 y la proximal 1. La adquisición de información mantuvo los 4 indicadores iniciales, y la valoración de la responsabilidad de la oferta pasó a tener 2 (Tabla 6.16).

En cuanto a los constructos de los otros determinantes, la utilidad esperada pasó a tener 3 indicadores, mientras que en el caso del constructo de la influencia social solamente se mantuvo uno de los 4 ítems inicialmente vinculados, con carga estandarizada asociada a un valor de la $t$ de Student significativo.

En el Modelo 2 reespecificado, y para las variables perceptivas del consumidor, prácticamente todas las cargas factoriales estandarizadas $\lambda_{\mathrm{y}}$ se situaron por encima de 0,50 (salvo en el caso del indicador I7), estando asociadas a valores $t$ de Student significativos $(p<0,05)$ de acuerdo a la técnica bootstrap aplicada con 200 submuestras de 100 casos cada una (Tabla 6.15).

Tabla 6.15. Parámetros de medida de las variables perceptivas del consumidor (Modelo 2)

\begin{tabular}{|c|c|c|c|c|c|c|c|}
\hline Ítem/escala & $\begin{array}{c}\text { Carga } \\
\text { factorial }\end{array}$ & Comunalidad & $\begin{array}{c}\text { Error } \\
\text { estándar }\end{array}$ & $t$ & $\alpha$ & $\rho_{c}$ & AVE \\
\hline $\begin{array}{l}\text { Concepto distal } \\
1.2\end{array}$ & 0813 & 0,660 & 0,039 & $200,61^{\star \star \star}$ & 0,809 & 0,875 & 0,638 \\
\hline $\begin{array}{l}1.2 \\
1.3\end{array}$ & $\begin{array}{l}0,813 \\
0,813\end{array}$ & 0,660 & 0,046 & $170,82^{* \star *}$ & & & \\
\hline 1.9 & 0,769 & 0,591 & 0,057 & $130,45^{* * *}$ & & & \\
\hline I.11 & 0,797 & 0,636 & 0,055 & $140,56^{\star \star \star}$ & & & \\
\hline Concepto proximal & & & & & 0,151 & 0,592 & 0,512 \\
\hline 1.5 & 0,994 & 0,987 & 0,112 & $80,90^{\star \star *}$ & & & \\
\hline 1.7 & 0,196 & 0,038 & 0,207 & $90,09^{\star \star \star}$ & & & \\
\hline Comp. emp. m. estr. & & & & & 0,611 & 0,794 & 0,562 \\
\hline II.7 & 0,751 & 0,564 & 0,083 & $90,09^{\star \star *}$ & & & \\
\hline$\| .9$ & 0,752 & 0,565 & 0,112 & $60,69^{* \star *}$ & & & \\
\hline II.12 & 0,747 & 0,559 & 0,086 & $80,66^{\star \star \star}$ & & & \\
\hline Comp. emp. m. soc. & & & & & 0,639 & 0,768 & 0,406 \\
\hline II.6 & 0,598 & 0,357 & 0,179 & $30,34^{\star \star \star}$ & & & \\
\hline II.10 & 0,594 & 0,353 & 0,179 & $30,32^{\star \star \star}$ & & & \\
\hline II.11 & 0,492 & 0,242 & 0,185 & $20,65^{\star \star \star}$ & & & \\
\hline II.16 & 0,631 & 0,398 & 0,205 & $30,08^{\star \star \star}$ & & & \\
\hline II.17 & 0,826 & 0,682 & 0,153 & $50,40^{\star \star \star}$ & & & \\
\hline
\end{tabular}

${ }^{*} p<0,05 ;{ }^{* *} p<0,01 ;{ }^{* * *} p<0,001$ (199 grados de libertad). 
Paralelamente, y en cuanto a los indicadores significativos, los valores de comunalidad superaron el mínimo establecido de 0,25 , de modo que los constructos latentes explicaron, en su conjunto, entre el 24,2\% (I11) y el 98,7\% (I5) de la varianza de sus respectivas variables observadas, quedando así constatada la fiabilidad individual de los indicadores seleccionados.

Si bien la consistencia interna de las escalas resultó buena para el concepto distal, para el concepto proximal fue reducida, tanto en términos del resultado obtenido con el índice alpha de Cronbach (con un valor de 0,151 o, lo que es lo mismo, muy por debajo del nivel aceptable), como respecto a lo sucedido con la fiabilidad compuesta (que no superó el mínimo de rigor exigible, al situarse en 0,592), lo que ponía de manifiesto un escaso nivel de rigurosidad en la medición de dicha variable latente.

Por otro lado, aunque las dos escalas de comportamiento empresarial (social y estratégico) no alcanzaron umbrales aceptables para sus valores del índice Alpha de Cronbach, la consistencia interna medida a través de la fiabilidad compuesta $\rho_{c}$, fue superada por las escalas empleadas para medir los dos constructos.

El índice AVE empleado en el análisis de la validez convergente adquirió valores aceptables y superiores a 0,50 en todas las escalas, con la única excepción de la correspondiente al comportamiento empresarial con motivación social, siendo en este caso la varianza que el constructo obtiene de sus indicadores del 40,6\% con respecto a la debida al error.

Por su parte, la Tabla 6.16, especifica que todas las cargas factoriales estandarizadas $\lambda_{\mathrm{y}}$ y $\lambda_{\mathrm{x}}$ se situaron por encima de 0,50 , estando asociadas a valores $t$ de Student significativos (a excepción claro está, de los constructos que mantenían un ítem). Los valores de comunalidad superaron todos ellos el mínimo establecido de 0,25.

A su vez, la consistencia interna de las escalas estimada mediante los índices alpha de Cronbach y de fiabilidad compuesta superó el umbral aceptable de 0,70 en prácticamente todos los casos, con la única excepción de la generación de demanda proximal 2, donde el valor $\alpha$ fue nulo y cuya fiabilidad compuesta se situó en 0,653 . Por otro lado, el índice AVE empleado en el análisis de la validez convergente adquirió valores aceptables superiores a 0,50 en todas las escalas, salvo en la generación de demanda proximal 2 (con un valor muy próximo, de 0,497), llegando a explicar el 86,70\% de la varianza en el caso de la generación de demanda distal 1. 
Tabla 6.16. Parámetros de medida de las variables de decisión del consumidor y de otros determinantes (Modelo 2)

\begin{tabular}{|c|c|c|c|c|c|c|c|}
\hline Ítem/escala & $\begin{array}{c}\text { Carga } \\
\text { factorial }\end{array}$ & Comunalidad & $\begin{array}{l}\text { Error } \\
\text { estándar }\end{array}$ & $t$ & $\alpha$ & $\rho_{c}$ & AVE \\
\hline Gen. dem.distal.1 & & & & & 0,846 & 0,928 & 0,867 \\
\hline III.1 & 0,932 & 0,868 & 0,019 & $50,35^{* * *}$ & & & \\
\hline III.2 & 0,930 & 0,866 & 0,019 & $49,14^{\star * *}$ & & & \\
\hline Gen. dem. distal 2 & & & & & --- & --- & --- \\
\hline III. $9^{* *+x+k}$ & --- & --- & --- & --- & & & \\
\hline Gen. dem. prox. 1 & & & & & --- & --- & --- \\
\hline III. $3^{\star * \star *}$ & --- & --- & --- & --- & & & \\
\hline Gen. dem. prox. 2 & & & & & 0,0 & 0,653 & 0,497 \\
\hline III.5 & 0,845 & 0,714 & 0,408 & $2,06^{*}$ & & & \\
\hline III.6 & 0,531 & 0,282 & 0,412 & 1,28 & & & \\
\hline Adqu. inform. resp. & & & & & 0,796 & 0,867 & 0,622 \\
\hline IV.1 & 0,789 & 0,623 & 0,043 & $18,57^{\text {k*k}}$ & & & \\
\hline IV.2 & 0,872 & 0,761 & 0,034 & $25,59^{* \star *}$ & & & \\
\hline IV.3 & 0,708 & 0,502 & 0,073 & $9,65^{\star \star k}$ & & & \\
\hline IV.4 & 0,778 & 0,605 & 0,051 & $15,17^{\star \star *}$ & & & \\
\hline Valor. resp. oferta & & & & & 0,700 & 0,868 & 0,768 \\
\hline IV.10 & 0,896 & 0,802 & 0,025 & $36,06^{\star \star *}$ & & & \\
\hline IV.13 & 0,857 & 0,734 & 0,044 & $19,69^{* \star *}$ & & & \\
\hline Utilidad esperada & & & & & 0,782 & 0,873 & 0,696 \\
\hline IV.16 & 0,844 & 0,713 & 0,045 & $18,69^{\text {k*k }}$ & & & \\
\hline IV.17 & 0,861 & 0,742 & 0,030 & $28,55^{\text {k*k }}$ & & & \\
\hline IV.18 & 0,798 & 0,636 & 0,046 & $17,363^{* * *}$ & & & \\
\hline Influencia social & & & & & --- & --- & --- \\
\hline IV.21 $21^{* \star * *}$ & --- & --- & --- & --- & & & \\
\hline
\end{tabular}

${ }^{*} p<0,05 ;{ }^{* *} p<0,01 ;{ }^{* * *} p<0,001$ (199 grados de libertad); ${ }^{* * * *}$ los parámetros de medida no han sido estudiados para los constructos medidos con un solo indicador.

Tabla 6.17 Matriz de correlaciones y raíz cuadrada de AVE (Modelo 2)*

\begin{tabular}{lrrrrrrrrrrrr}
\hline \multicolumn{1}{c}{ Variables } & $\mathbf{1}$ & $\mathbf{2}$ & $\mathbf{3}$ & $\mathbf{4}$ & $\mathbf{5}$ & $\mathbf{6}$ & $\mathbf{7}$ & $\mathbf{8}$ & $\mathbf{9}$ & $\mathbf{1 0}$ & $\mathbf{1 1}$ & $\mathbf{1 2}$ \\
\hline 1. Adquis. inform. resp. & $\mathbf{0 , 7 8}$ & & & & & & & & & & \\
2. Comp. empr. estratég. & 0,12 & $\mathbf{0 , 7 4}$ & & & & & & & & & \\
3. Comp. empr. social & 0,18 & 0,14 & $\mathbf{0 , 6 3}$ & & & & & & & & \\
4. Concepto distal & 0,17 & 0,33 & 0,23 & $\mathbf{0 , 7 9}$ & & & & & & & \\
5. Concepto proximal & 0,09 & 0,06 & 0,06 & 0,08 & $\mathbf{0 , 7 1}$ & & & & & & \\
6. G. demanda distal 1 & 0,33 & 0,25 & 0,18 & 0,59 & 0,09 & $\mathbf{0 , 9 3}$ & & & & & \\
7. G. demanda distal 2 & $-0,04$ & 0,02 & $-0,06$ & 0,00 & 0,00 & 0,10 & 1,00 & & & & \\
8. G. demanda proxim. 1 & 0,08 & 0,03 & 0,03 & 0,05 & 0,99 & 0,08 & 0,00 & 1,00 & & & \\
9. G. demanda proxim. 2 & 0,08 & $-0,01$ & $-0,02$ & $-0,01$ & 0,00 & $-0,04$ & 0,00 & 0,00 & $\mathbf{0 , 7 0}$ & & \\
10. Influencia social & 0,47 & 0,22 & 0,10 & 0,12 & 0,04 & 0,18 & $-0,02$ & 0,03 & $-0,01$ & 1,00 & \\
11. Utilidad esperada & 0,50 & 0,21 & 0,29 & 0,26 & 0,08 & 0,31 & 0,03 & 0,05 & $-0,02$ & 0,36 & $\mathbf{0}, 83$ \\
12. Valorac. resp. oferta & 0,52 & $-0,05$ & 0,25 & 0,03 & 0,06 & 0,06 & $-0,05$ & 0,05 & 0,06 & 0,39 & 0,49 & $\mathbf{0 , 8 7}$ \\
\hline
\end{tabular}

* La raíz cuadrada de los valores AVE aparece para cada variable en la diagonal de la matriz. 
En consonancia con el patrón de resultados descrito en los párrafos precedentes, la comprobación de la validez discriminante de las escalas comparando la raíz cuadrada de los valores AVE con respecto a los coeficientes de correlación entre variables (Tabla 6.17) no evidenció ningún problema, confirmando que cada constructo compartía más varianza con sus indicadores que con los otros constructos incluidos en el modelo.

En la Figura 6.5 se muestran con mayor claridad los indicadores asociados a cada constructo sometidos al análisis PLS de este segundo modelo.

Figura.6.5. Segunda versión del modelo sometido a PLS (Modelo 2)

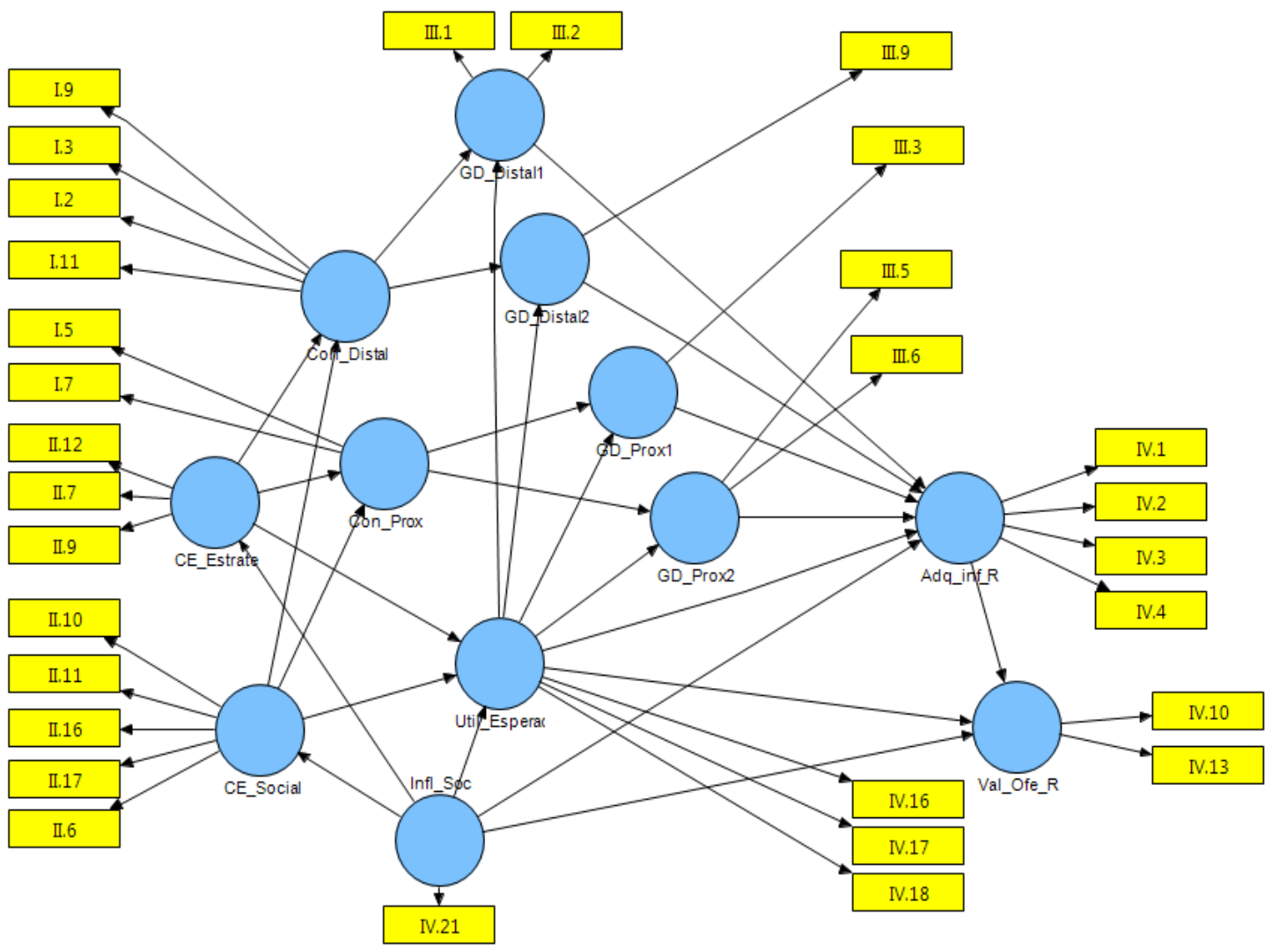

Fuente: Elaboración propia.

En cuanto a la dinámica estructural interna, los índices $R^{2}$ en la evaluación del ajuste del Modelo 2 en términos de predictibilidad global (Tabla 6.18) se situaron por encima del valor mínimo 0,10 para 6 de los 11 constructos endógenos analizados. En concreto, los efectos directos e indirectos resultantes permitieron dar cuenta del 98,66\% de la varianza en la generación de demanda proximal 1, del 39,47\% en la adquisición de 
información sobre responsabilidad, del 38,08\% en la generación de demanda distal 1, del 36,5\% en la valoración de la responsabilidad de la oferta, del 20,98\% en la utilidad esperada, y del 14.89\% en el concepto distal. El poder predictivo del modelo resultó sensiblemente bajo en cuanto a la explicación de la generación de demanda proximal 2, la generación de demanda distal 2, el comportamiento empresarial con motivación estratégica, el concepto proximal, y el comportamiento empresarial con motivación social.

En suma, y pese a que los valores $\mathrm{R}^{2}$ obtenidos no difirieren demasiado de los encontrados al poner a prueba del modelo inicial, las mejoras registradas en cuanto a la fiabilidad y a la validez de las variables observadas que fueron empleadas en la estimación de los constructos latentes vino a dotar de una mayor solidez al alcance de los resultados obtenidos en este segundo modelo en relación a las hipótesis de partida.

En esta misma línea, si bien los valores de los estadísticos $Q^{2}$ procedentes de la estimación jackknife del ajuste global del modelo fueron notablemente reducidos para todas las variables latentes endógenas en términos de relevancia predictiva, lo cierto es que mejoraron mucho con respecto al Modelo 1. Particularmente, el valor correspondiente a la valoración de la responsabilidad de la oferta, principal variable dependiente del modelo, pasó del 0,052 del modelo inicial a 0,269, superando así el mínimo exigible. En tales términos, el valor mínimo de 0,20 fue superado en el modelo reespecificado por la generación de demanda distal 1 (0,308), la valoración la responsabilidad de las ofertas $(0,269)$ y la adquisición de información sobre responsabilidad $(0,242)$.

Tabla 6.18. Índices de ajuste global del Modelo 2

\begin{tabular}{lcc}
\hline \multicolumn{1}{c}{ Variable } & $\boldsymbol{R}^{2}$ & $\mathbf{Q}^{2}$ \\
\hline Adquis. inform. resp. & 0,394 & 0,242 \\
Comp. empr. m. estratég. & 0,052 & 0,026 \\
Comp. empr. m. social & 0,011 & 0,002 \\
Concepto distal & 0,148 & 0,082 \\
Concepto proximal & 0,007 & 0,022 \\
G. demanda distal 1 & 0,380 & 0,308 \\
G. demanda distal 2 & 0,001 & $-0,002$ \\
G. demanda proxim. 1 & 0,986 & 0,044 \\
G. demanda proxim. 2 & 0,004 & $-0,002$ \\
Utilidad esperada & 0,209 & 0,131 \\
Valorac. resp. oferta & 0,365 & 0,269 \\
\hline
\end{tabular}


En términos de los pesos de regresión estandarizados, la Tabla 6.19 resume los efectos directos y la 6.20 los efectos totales entre variables exógenas y endógenas en relación a las hipótesis planteadas. La inspección de los valores de la $t$ de Student significativos a un nivel de $p<0,05$ de acuerdo al procedimiento bootstrap con 200 submuestras, evidenció un efecto positivo directo en los mismos términos que los descritos para el modelo inicial, confirmándose las mismas hipótesis, aunque con una variación poco significativa de los coeficientes que relacionan los constructos con cualquier otra variable latente endógena.

De este modo se puso de manifiesto el efecto positivo directo de la adquisición de información sobre responsabilidad en la valoración de la responsabilidad de la oferta (Hipótesis 1), con un coeficiente estandarizado de regresión $\beta$ de 0,320 , asociado a un 16,98\% de la varianza explicada.

Por su parte, el concepto proximal explicaba el 98,50\% del total de la varianza de la generación de demanda proximal 1 (Hipótesis 3c), y el concepto distal hacía otro tanto con el 33,24\% de la generación de demanda distal 1 (Hipótesis 3a), siendo los valores de los coeficientes $\beta$ respectivos de 0,995 y de 0,552 .

La utilidad esperada influía, a su vez y significativamente, en la valoración de la responsabilidad de la oferta (Hipótesis 4a), en la adquisición de información sobre responsabilidad (Hipótesis 4b), y en la generación de demanda distal 1, explicando respectivamente el 14,22\%, el 16,54\% y el 5,10\% de las correspondientes varianzas, con unos coeficientes $\beta$ de 0,284 , de 0,331 y de 0,165 .

La influencia del comportamiento empresarial con motivación social sobre el concepto distal resultaba significativa (Hipótesis 5bc), explicando un 4,65\% de su varianza. También lo resultaba su influencia sobre la utilidad esperada (Hipótesis 5ab), con una explicación del 7,48\% de la varianza. En estas relaciones, los coeficientes $\beta$ que relacionaban las variables latentes fueron, respectivamente, de 0,194 y 0,248.

La influencia social, como variable latente exógena, influía positivamente sobre el comportamiento empresarial estratégico (Hipótesis 6aa), con un coeficiente $\gamma$ de 0,228 y una varianza explicada del 5,24\%. También tenía influencia sobre la utilidad esperada (Hipótesis 6b), con un coeficiente $\gamma$ de 0,311 y una varianza explicada del 11,21\%. Determinaba igualmente la adquisición de información sobre responsabilidad (Hipótesis 6c), con un coeficiente $\gamma$ de 0,323 y explicando el 15,50\% de la varianza. 
Tabla 6.19. Efectos directos en el Modelo 2

\begin{tabular}{|c|c|c|c|c|c|c|}
\hline \multicolumn{7}{|c|}{ Efectos directos } \\
\hline & $\begin{array}{c}\text { Coeficiente } \\
(\boldsymbol{\beta} / \gamma)\end{array}$ & $\begin{array}{c}\text { Coef, de } \\
\text { correlación }\end{array}$ & $\begin{array}{c}\text { Varianza } \\
\text { explicada }\end{array}$ & $\begin{array}{c}\text { Error } \\
\text { estándar }\end{array}$ & $t$ & $p$ \\
\hline Adq_inf_R $->$ Val_of_R & 0,320 & 0,53 & $16,98 \%$ & 0,109 & 2,95 & $* * *$ \\
\hline CE_Estrate $->$ Conc_distal & 0,307 & 0,33 & $10,14 \%$ & 0,099 & 3,11 & $* * *$ \\
\hline CE_Estrate -> Conc_prox & 0,060 & 0,07 & $0,42 \%$ & 0,110 & 0,55 & \\
\hline CE_Estrate -> Util_Esperada & 0,106 & 0,21 & $2,23 \%$ & 0,087 & 1,22 & \\
\hline CE_Social $->$ Conc_distal & 0,194 & 0,24 & $4,65 \%$ & 0,102 & 1,91 & * \\
\hline CE_Social -> Conc_prox & 0,053 & 0,06 & $0,32 \%$ & 0,118 & 0,45 & \\
\hline CE_Social -> Util_Esperada & 0,249 & 0,3 & $7,48 \%$ & 0,110 & 2,28 & * \\
\hline Conc_Distal -> GD_Distal1 & 0,552 & 0,6 & $33,13 \%$ & 0,083 & 6,69 & $* \star *$ \\
\hline Conc_Distal -> GD_Distal2 & $-0,008$ & 0 & $0,00 \%$ & 0,215 & 0,04 & \\
\hline Conc_Prox -> GD_Prox1 & 0,995 & 0,99 & $98,50 \%$ & 0,304 & 3,28 & $* * *$ \\
\hline Conc_prox -> GD_Prox2 & 0,000 & 0,01 & $0,00 \%$ & 0,146 & 0,00 & \\
\hline GD_Distal1 $>$ - Adq̄_inf_R & 0,180 & 0,33 & $5,93 \%$ & 0,116 & 1,55 & \\
\hline GD_Distal2 -> Adq_inf_R & $-0,072$ & $-0,05$ & $0,36 \%$ & 0,170 & 0,42 & \\
\hline GD_Prox1 -> Adq_inf_R & 0,037 & 0,08 & $0,29 \%$ & 0,099 & 0,37 & \\
\hline GD_Prox2 ->Adq_inf_R & 0,100 & 0,08 & $0,80 \%$ & 0,111 & 0,89 & \\
\hline Infl_Soc $\rightarrow$ Adq_inf_êR & 0,323 & 0,48 & $15,50 \%$ & 0,093 & 3,46 & $* * *$ \\
\hline Infl_Soc $>$ CE_Estrate & 0,228 & 0,23 & $5,24 \%$ & 0,091 & 2,51 & ** \\
\hline Infl_Soc -> CE_Social & 0,107 & 0,11 & $1,18 \%$ & 0,121 & 0,89 & \\
\hline Infl_Soc -> Util_Esperada & 0,311 & 0,36 & $11,21 \%$ & 0,089 & 3,50 & $* * *$ \\
\hline Infl_Soc -> Val_of_R & 0,138 & 0,39 & $5,39 \%$ & 0,102 & 1,36 & \\
\hline Util_Esperada->Adq_inf_R & 0,331 & 0,5 & $16,54 \%$ & 0,103 & 3,22 & $* * *$ \\
\hline Util_Esperada -> GD_Distal1 & 0,165 & 0,31 & $5,10 \%$ & 0,078 & 2,11 & * \\
\hline Util_Esperada -> GD_Distal2 & 0,038 & 0,04 & $0,15 \%$ & 0,088 & 0,43 & \\
\hline Util_Esperada -> GD_Prox1 & $-0,023$ & 0,06 & $-0,14 \%$ & 0,123 & 0,19 & \\
\hline Util_Esperada -> GD_Prox2 & $-0,020$ & $-0,02$ & $0,04 \%$ & 0,123 & 0,16 & \\
\hline Util_Esperada -> Val_of_R & 0,284 & 0,50 & $14,22 \%$ & 0,122 & 2,32 & ** \\
\hline
\end{tabular}

${ }^{*} p<0,05 ;{ }^{* *} p<0,01 ;{ }^{* * *} p<0,001$ (199 grados de libertad).

La Tabla 6.20 refleja exclusivamente los efectos totales asociados a valores de la $t$ de Student significativos a un nivel de $p<0,05$ de acuerdo al procedimiento bootstrap, resaltándose relaciones indirectas entre variables latentes, lo que indica que, además de confirmarse un importante número de hipótesis (efectos directos), existían asimismo significativos efectos totales para constructos relacionados indirectamente.

Analizando el contenido de dicha tabla, es de destacar cómo se vio incrementada la influencia directa entre la utilidad esperada y la valoración de la responsabilidad de la oferta, siendo la varianza explicada del 19,91\% y el coeficiente de 0,398. Asimismo la del constructo influencia social sobre el de valoración de la responsabilidad de la oferta, en este caso siendo el valor del coeficiente que relaciona ambas variables latentes de 0,389 al tiempo que la explicación es de un 15,18\% de la varianza. 
Tabla 6.20. Efectos totales en el Modelo 2

\begin{tabular}{|c|c|c|c|c|c|c|}
\hline \multicolumn{7}{|c|}{ Efectos totales } \\
\hline & $\begin{array}{c}\text { Coeficiente } \\
(\beta / \gamma)\end{array}$ & $\begin{array}{l}\text { Coef, de } \\
\text { correlación }\end{array}$ & $\begin{array}{c}\text { Varianza } \\
\text { explicada }\end{array}$ & $\begin{array}{c}\text { Error } \\
\text { estándar }\end{array}$ & $t$ & $p$ \\
\hline Adq_inf_R -> Val_of_R & 0,320 & 0,53 & $16,98 \%$ & 0,109 & 2,95 & $* \star *$ \\
\hline CE_Estrate $->$ Adq_inf_R & 0,071 & 0,13 & $0,92 \%$ & 0,039 & 1,79 & * \\
\hline CE_Estrate -> Conc_distal & 0,307 & 0,33 & $10,14 \%$ & 0,099 & 3,11 & *** \\
\hline CE_Estrate -> GD_Distal1 & 0,187 & 0,13 & $2,43 \%$ & 0,062 & 3,02 & $* *$ \\
\hline CE_Social -> Adq_inf_R & 0,110 & 0,19 & $2,09 \%$ & 0,050 & 2,18 & * \\
\hline CE_Social -> GD_Distal1 & 0,148 & 0,18 & $2,66 \%$ & 0,067 & 2,21 & * \\
\hline CE_Social -> Util_Esperada & 0,249 & 0,30 & $7,48 \%$ & 0,110 & 2,28 & * \\
\hline CE_Social -> Val̄_of_R & 0,106 & 0,25 & $2,65 \%$ & 0,058 & 1,82 & * \\
\hline Conc_distal $->$ Adq_inf_R & 0,100 & 0,18 & $1,80 \%$ & 0,059 & 1,69 & * \\
\hline Conc_distal -> GD_Distal1 & 0,552 & 0,60 & $33,13 \%$ & 0,083 & 6,69 & $* \star *$ \\
\hline Conc_prox -> GD_Prox1 & 0,995 & 0,99 & $98,50 \%$ & 0,304 & 3,28 & $* \star \star$ \\
\hline Infl_Soc -> Adq_inf_R & 0,461 & 0,48 & $22,14 \%$ & 0,091 & 5,05 & $* * *$ \\
\hline Infl_Soc $->$ CE_Estrate & 0,228 & 0,23 & $5,24 \%$ & 0,091 & 2,51 & ** \\
\hline InfI_Soc $->$ Conc_Distal & 0,091 & 0,13 & $1,18 \%$ & 0,047 & 1,92 & * \\
\hline Infl_Soc -> GD_Distal1 & 0,110 & 0,18 & $1,98 \%$ & 0,043 & 2,58 & $* *$ \\
\hline Infl_Soc -> Util_Esperada & 0,362 & 0,36 & $13,05 \%$ & 0,088 & 4,14 & $* * *$ \\
\hline Infl_Soc -> Val_of_R & 0,389 & 0,39 & $15,18 \%$ & 0,088 & 4,43 & *** \\
\hline Util_Esperada -> Adq_inf_R & 0,355 & 0,50 & $17,74 \%$ & 0,091 & 3,92 & $* * *$ \\
\hline Util_Esperada -> Val_of_R & 0,398 & 0,50 & $19,91 \%$ & 0,114 & 3,49 & $* *$ \\
\hline
\end{tabular}

${ }^{*} p<0,05 ;{ }^{* *} p<0,01 ;{ }^{* * *} p<0,001$ (199 grados de libertad).

En consecuencia, los parámetros obtenidos mediante la técnica PLS para el Modelo 2 sustentan en mayor medida la fiabilidad y validez de la medición de las variables latentes a partir de la depuración de indicadores llevada a cabo, al tiempo que queda probada empíricamente la interrelación entre las dimensiones perceptivas y valorativas del consumidor cuando se consideran criterios responsables en el proceso de compra.

No obstante, los resultados obtenidos no permiten afirmar que se haya constatado un efecto significativo entre varios constructos del Modelo 2 (ver Figura 6.6), tal y como es el caso de la relación entre la generación de la demanda responsable en sus diferentes categorías y la adquisición de información sobre la materia. Del mismo modo, los diferentes conceptos de responsabilidad no parecen mantener una relación significativa con alguno de los tipos de generación de demanda responsable (distal 2 y proximal 2). También se aprecia la falta de relación entre las atribuciones a los comportamientos empresariales con el concepto responsabilidad proximal, así como del comportamiento empresarial estratégico con la utilidad esperada. 
Figura 6.6. Representación de las relaciones significativas del Modelo 2

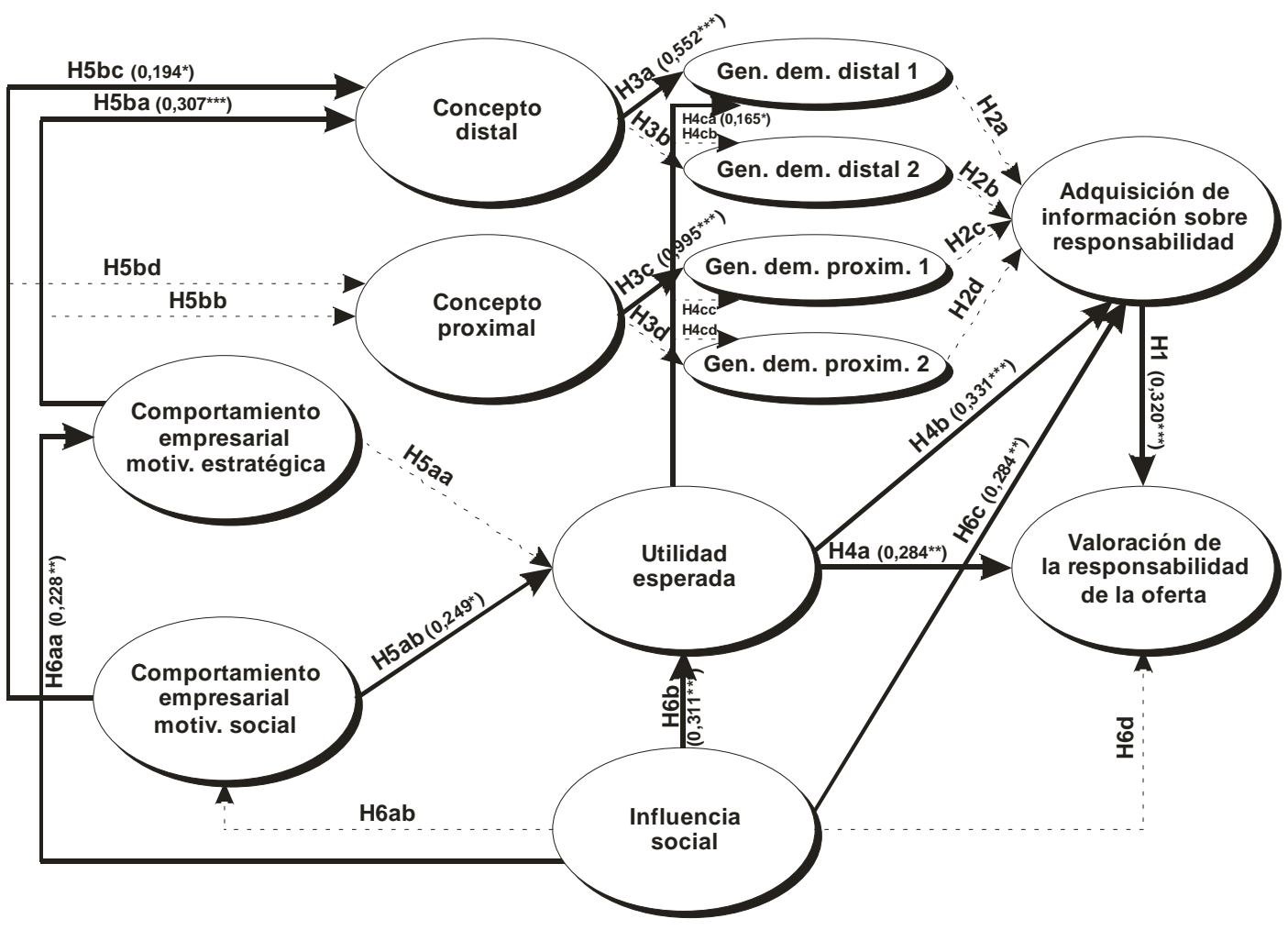

Fuente: Elaboración propia.

Asimismo cabe reseñar, por un lado, cómo se aprecia que la utilidad esperada no parecer mantener una relación significativa con ninguno de los tipos de generación de demanda responsable, salvo la distal 1. Por otro, cómo se pone de manifiesto que el constructo influencia social tampoco parece tenerlo con los distintos motivos atribuidos al comportamiento empresarial responsable o, de forma directa, con la valoración de la responsabilidad de la oferta.

A la vista de los resultados expuestos, no obstante, el Modelo 2 estructurado conforme a los términos descritos fue considerado como la mejor opción en cuanto a la contrastación empírica de las hipótesis previamente planteadas, dado que es sensible la mejora de su consistencia interna respecto a la formulación inicial (aunque contiene algunas deficiencias, ya descritas), en tanto que las relaciones estructurales mantienen la validez de aquél. En todo caso, y de cara a tratar de mejorar los resultados, se propuso un tercer modelo rival. 


\subsubsection{Reespecificación del modelo estructural (Modelo 3)}

El tercer modelo sometido a análisis PLS fue diseñado al objeto de profundizar en la sostenibilidad de la estructura predictiva representada en la Figura 6.7. Para ello se conservaron para cada constructo latente aquellos indicadores con cargas factoriales significativas en análisis previos. De la misma forma, se tuvieron en cuenta en esta nueva reespecificación del modelo las deficiencias estructurales apreciadas en las versiones anteriores, en los siguientes términos:

- Los problemas detectados en cuanto a tres de los cuatro componentes de la generación de la demanda responsable (distal 2, proximal 1 y proximal 2), en términos de baja fiabilidad y validez de constructo, así como la ausencia de efectos significativos de dichas variables en la predicción de la adquisición de información, llevaron a eliminarlas del modelo final, considerándose únicamente la generación de demanda distal 1 como dimensión válida y fiable de acuerdo con los análisis previos.

Figura.6.7. Tercera versión del modelo sometido a PLS (Modelo 3)

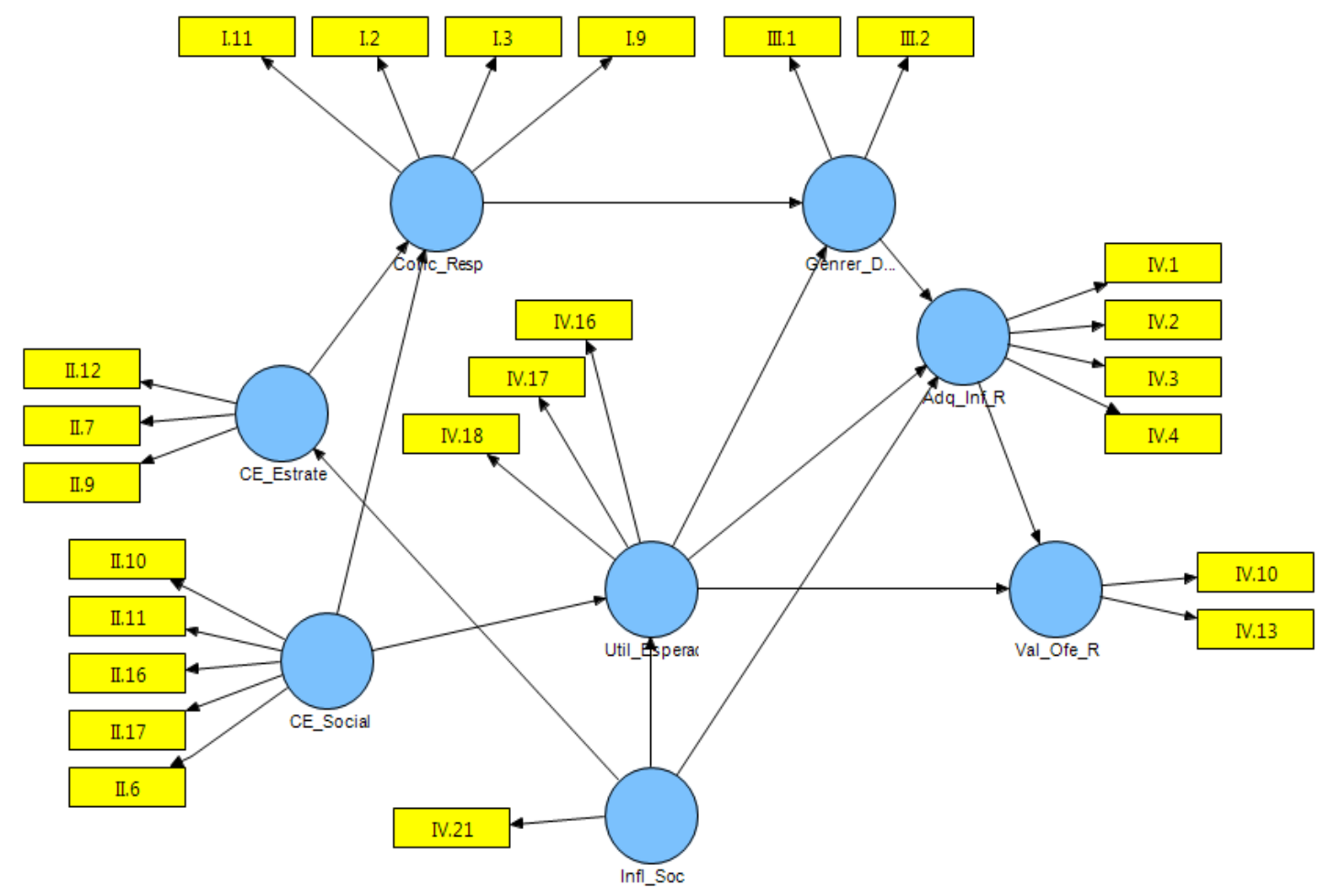

Fuente: Elaboración propia. 
- En la misma línea, la baja fiabilidad del constructo referido al concepto proximal de responsabilidad y su desconexión del resto del modelo como resultado de las atribuciones de motivación estratégica y social al comportamiento empresarial, llevó a descartarlo del modelo final, considerando sólo el concepto distal como determinante del proceso de intención de compra. A este respecto, cabe mencionar que la previa eliminación de las dimensiones de generación de demanda proximal 1 y 2, consideradas en versiones previas del modelo como resultados directos del concepto proximal, justificaba igualmente la eliminación de dicha variable.

- Pese a que la medición de la influencia social quedó conformada por un solo ítem (estando cuestionada, por tanto, su fiabilidad y su validez), la obtención de efectos directos significativos sobre la atribución de una motivación estratégica al comportamiento empresarial, la utilidad esperada, y la adquisición de información sobre responsabilidad, de acuerdo con lo hipotetizado inicialmente, llevó a conservarla como variable relevante del modelo estructural. No obstante, la ausencia de un efecto significativo de la influencia social sobre la atribución de una motivación social al comportamiento empresarial y la valoración de la responsabilidad de la oferta llevaron a eliminar dichas relaciones, para así poder proponer un modelo más depurado. Con todo, el constructo referente a la atribución de una motivación social al comportamiento empresarial quedó configurado como variable latente exógena en el Modelo 3.

- Por su parte, la ausencia de un efecto significativo la atribución de una motivación estratégica al comportamiento empresarial sobre la utilidad esperada llevó asimismo a eliminar dicha relación del modelo estructural. No obstante, la primera de dichas variables se mantuvo como variable latente endógena predicha a partir de la influencia social.

En suma, la reespecificación del modelo estructural estuvo fundamentada en la adaptación del modelo inicial a los cambios que fueron introducidos tanto en el proceso de medida (en términos de fiabilidad individual, consistencia interna de las escalas y validez de los constructos), como en la consideración de los argumentos precedentes, implicando como consecuencia una leve modificación de las relaciones estructurales de las hipótesis.

En aras de una mayor claridad expositiva, el Cuadro 6.2 muestra las hipótesis de investigación conforme el modelo estructural reespecificado. 
Cuadro 6.2. Resumen de las hipótesis de investigación del Modelo 3

\begin{tabular}{|c|c|}
\hline H1 & $\begin{array}{l}\text { La adquisición de información sobre responsabilidad influye positiva y directamente } \\
\text { sobre la valoración de la responsabilidad de la oferta }\end{array}$ \\
\hline $\mathrm{H} 2$ & $\begin{array}{l}\text { La generación de la demanda responsable (distal 1) influye positiva y directamente } \\
\text { en la adquisición de información sobre responsabilidad }\end{array}$ \\
\hline НЗа & $\begin{array}{l}\text { El concepto de responsabilidad (distal) influye positiva y directamente sobre la } \\
\text { generación de la demanda responsable }\end{array}$ \\
\hline $\mathrm{H} 4 \mathrm{a}$ & $\begin{array}{l}\text { La utilidad esperada influye positiva y directamente sobre la valoración de la } \\
\text { responsabilidad de la oferta }\end{array}$ \\
\hline $\mathrm{H} 4 \mathrm{~b}$ & $\begin{array}{l}\text { La utilidad esperada influye positiva y directamente en la adquisición de información } \\
\text { sobre responsabilidad }\end{array}$ \\
\hline $\mathrm{H} 4 \mathrm{c}$ & $\begin{array}{l}\text { La utilidad esperada influye positiva y directamente sobre la generación de la } \\
\text { demanda responsable }\end{array}$ \\
\hline H5a & $\begin{array}{l}\text { El comportamiento empresarial percibido con motivación social influye positiva y } \\
\text { directamente sobre la utilidad esperada }\end{array}$ \\
\hline H5ba & $\begin{array}{l}\text { El comportamiento empresarial percibido con motivación estratégica influye positiva } \\
\text { y directamente sobre el concepto de responsabilidad }\end{array}$ \\
\hline H5bb & $\begin{array}{l}\text { El comportamiento empresarial percibido con motivación social influye positiva y } \\
\text { directamente sobre el concepto de responsabilidad }\end{array}$ \\
\hline H6a & $\begin{array}{l}\text { La influencia social incide positiva y directamente sobre el comportamiento } \\
\text { empresarial percibido con motivación estratégica }\end{array}$ \\
\hline H6b & La influencia social incide positiva y directamente sobre la utilidad esperada \\
\hline H6c & $\begin{array}{l}\text { La influencia social incide positiva y directamente en la adquisición de información } \\
\text { sobre responsabilidad }\end{array}$ \\
\hline
\end{tabular}

Fuente: Elaboración propia.

Tras haber sometido esta nueva versión del modelo y las relaciones hipotetizadas entre las variables latentes del mismo a análisis PLS, se llegó a la conclusión de que dicho modelo de medida se mostraba válido y fiable, apreciándose para todos los ítems significatividad estadística de acuerdo a la técnica bootstrap, con cargas estandarizadas $\lambda_{\mathrm{y}}$ y $\lambda_{\mathrm{x}}$ superiores a 0,50 y valores de comunalidad por encima de 0,25, con la única excepción del valor de la carga factorial correspondiente al indicador II.11, muy próximo al nivel mínimo mencionado $(0,494)$. Los constructos latentes especificados explicaban, de este modo, entre el 36,8\% (II.16) y el 86,8\% (III.1) de la varianza de sus respectivas variables observadas.

Los resultados obtenidos para el total de las variables del Modelo 3 se presentan de forma sintética en la Tabla 6.21. 
Tabla 6.21. Parámetros de medida de las variables (Modelo 3)

\begin{tabular}{|c|c|c|c|c|c|c|c|}
\hline Ítem/escala & $\begin{array}{c}\text { Carga } \\
\text { factorial }\end{array}$ & Comunalidad & $\begin{array}{c}\text { Error } \\
\text { estándar }\end{array}$ & $t$ & $\alpha$ & $\rho_{c}$ & AVE \\
\hline Concepto de resp. & & & & & 0,810 & 0,975 & 0,637 \\
\hline 1.2 & 0,813 & 0,660 & 0,041 & $19.88^{\star \star \star}$ & & & \\
\hline 1.3 & 0,813 & 0,660 & 0,044 & $19.23^{\star \star \star}$ & & & \\
\hline 1.9 & 0,769 & 0,591 & 0,051 & $15.07^{\star \star \star}$ & & & \\
\hline I.11 & 0,797 & 0,636 & 0,060 & $12.23^{\star \star \star}$ & & & \\
\hline Comp. emp. m. estr. & & & & & 0,612 & 0,794 & 0,563 \\
\hline II.7 & 0,771 & 0,594 & 0,108 & $7,13^{* * *}$ & & & \\
\hline$\| .9$ & 0,736 & 0,542 & 0,115 & $6,38^{\star * *}$ & & & \\
\hline II.12 & 0,743 & 0,552 & 0,104 & $7,15^{* k *}$ & & & \\
\hline Comp. emp. m. soc. & & & & & 0,639 & 0,771 & 0,408 \\
\hline II.6 & 0,625 & 0,390 & 0,157 & $3,97^{\star \star \star}$ & & & \\
\hline II.10 & 0,617 & 0,380 & 0,190 & $3,41^{k \star k}$ & & & \\
\hline II.11 & 0,494 & 0,244 & 0,263 & $1,88^{*}$ & & & \\
\hline II.16 & 0,607 & 0,368 & 0,184 & $3,29^{\star * \star}$ & & & \\
\hline II.17 & 0,811 & 0,658 & 0,124 & $6,53^{\star \star \star}$ & & & \\
\hline Gen. de demanda & & & & & 0,847 & 0,929 & 0,867 \\
\hline III.1 & 0,932 & 0,868 & 0,017 & $54,74^{\star \star \star}$ & & & \\
\hline III.2 & 0,930 & 0,866 & 0,020 & $45,80^{* \star *}$ & & & \\
\hline Adqu. inform. resp. & & & & & 0,796 & 0,868 & 0,623 \\
\hline IV.1 & 0,787 & 0,619 & 0,045 & $17,44^{\star \star \star}$ & & & \\
\hline IV.2 & 0,871 & 0,759 & 0,038 & $23,14^{\star \star \star}$ & & & \\
\hline IV.3 & 0,713 & 0,508 & 0,073 & $9,84^{\star \star *}$ & & & \\
\hline IV.4 & 0,778 & 0,605 & 0,051 & $15,38^{\star \star \star}$ & & & \\
\hline Valor. resp. oferta & & & & & 0,699 & 0,869 & 0,768 \\
\hline IV.10 & 0,898 & 0,806 & 0,023 & $39,66^{* \star *}$ & & & \\
\hline IV.13 & 0,854 & 0,730 & 0,036 & $23,54^{\star \star \star}$ & & & \\
\hline Utilidad esperada & & & & & 0,783 & 0,873 & 0,697 \\
\hline IV.16 & 0,843 & 0,711 & 0,047 & $18,07^{\star \star k}$ & & & \\
\hline IV.17 & 0,861 & 0,741 & 0,039 & $22,22^{* k \star}$ & & & \\
\hline IV.18 & 0,799 & 0,638 & 0,047 & $17,10^{\text {k*k }}$ & & & \\
\hline Influencia social & & & & & --- & --- & --- \\
\hline IV. $21^{\star \star \star \star}$ & --- & --- & --- & --- & & & \\
\hline
\end{tabular}

La consistencia interna de las escalas, medida por el valor correspondiente al índice alpha de Cronbach superó el umbral aceptable de 0,70 en la mayoría de los casos, con las únicas excepciones del comportamiento empresarial, tanto con motivación estratégica como social (siendo sus valores respectivos de 0,612 y 0,639). En paralelo, el índice de fiabilidad compuesta sugería que el modelo resultaba válido y ampliamente aceptable para todas las escalas. 
En cuanto a la validez convergente, todos los índices AVE superaron el mínimo de 0,50 , salvo para el constructo de comportamiento empresarial estratégico $(0,408)$. Con todo, los constructos justificaban entre el 55,7\% (comportamiento empresarial estratégico) y el 86,7\% (generación de la demanda) de las respectivas varianza.

Asimismo se comprobó la validez discriminante de las distintas escalas mediante los resultados de la matriz de correlaciones entre las variables latentes, reemplazando la diagonal por la raíz cuadrada de los valores AVE (Tabla 6.22), lo cual reafirmó la solidez del modelo de medida, al comprobar que cada constructo compartía más varianza con sus indicadores que con otras variables latentes del mismo.

Una vez constatados esos resultados aceptables, restaba determinar la estimación del ajuste del modelo estructural mediante la comprobación del cumplimiento de las hipótesis de partida y la validez predictiva del modelo.

Para ello, se comprobó que todos los índices $R^{2}$ de predictibilidad global (Tabla 6.23) superaban el umbral aceptable de 0,10 en la predicción de todas las variables latentes endógenas, salvo la referida al comportamiento empresarial estratégico $(0,052)$. Los constructos que las predicen llegaron a explicar el 38,1\% de la varianza en el caso de la generación de la demanda, y el 37,9\% en el de la adquisición de información sobre responsabilidad. Por su parte, los valores de los estadísticos $Q^{2}$ proporcionados por la estimación jackknife mostraron un mal ajuste para tres constructos (comportamiento empresarial estratégico, concepto de responsabilidad, y utilidad esperada) mientras que la importancia predictiva se conservaba para las tres variables centrales del modelo, concretamente la generación de la demanda $(0,327)$, la valoración de la responsabilidad de la oferta $(0,254)$, y la adquisición de información sobre responsabilidad $(0,222)$.

Tabla 6.22. Matriz de correlaciones y raíz cuadrada de AVE (Modelo 3)*

\begin{tabular}{lcccccccc}
\hline \multicolumn{1}{c}{ Variables } & $\mathbf{1}$ & $\mathbf{2}$ & $\mathbf{3}$ & $\mathbf{4}$ & $\mathbf{5}$ & $\mathbf{6}$ & $\mathbf{7}$ & $\mathbf{8}$ \\
\hline 1. Adquisición Información Resp. & $\mathbf{0 , 7 9}$ & & & & & & & \\
2. Comp. Empr. Estratégico & 0,13 & $\mathbf{0 , 7 5}$ & & & & & & \\
3. Comp. Empr. Social & 0,19 & 0,13 & $\mathbf{0 , 6 4}$ & & & & & \\
4. Concepto de Responsabilidad & 0,18 & 0,34 & 0,24 & $\mathbf{0 , 8 0}$ & & & & \\
5. Generación de Demanda & 0,33 & 0,26 & 0,18 & 0,60 & 0,93 & & & \\
6. Influencia Social & 0,48 & 0,23 & 0,10 & 0,13 & 0,18 & 1,00 & & \\
7. Utilidad Esperada & 0,50 & 0,21 & 0,30 & 0,27 & 0,31 & 0,36 & 0,83 & \\
8. Valoración Ofertas Responsables & 0,53 & $-0,06$ & 0,26 & $-0,04$ & 0,06 & 0,39 & 0,50 & $\mathbf{0 , 8 8}$ \\
\hline
\end{tabular}

* La raíz cuadrada de los valores AVE aparece para cada variable en la diagonal de la matriz. 
Tabla 6.23. Índices de ajuste global del Modelo 3

\begin{tabular}{lcc}
\hline \multicolumn{1}{c}{ Variable } & $\boldsymbol{R}^{2}$ & $\boldsymbol{Q}^{2}$ \\
\hline Adquis. inform. resp. & 0,379 & 0,222 \\
Comp. empr. m. estratég. & 0,052 & 0,030 \\
Concepto responsabilidad & 0,150 & 0,094 \\
Generación demanda & 0,381 & 0,327 \\
Utilidad esperada & 0,201 & 0,139 \\
Valorac. resp. oferta & 0,351 & 0,254 \\
\hline
\end{tabular}

La Tabla 6.24 muestra los diferentes efectos directos existentes entre las variables latentes del modelo, a través del procedimiento bootstrap llevado a cabo con 200 submuestras. Los resultados obtenidos permiten confirman las siguientes relaciones hipotetizadas:

- La relación entre la adquisición de información sobre responsabilidad y la valoración de la responsabilidad de la oferta (Hipótesis 1) es estadísticamente significativa ( $t$ de Student). El criterio propuesto por Chin (1998a) se cumple, ya que el valor del parámetro $\beta$ es de 0,374 . Y también se cumple el criterio de Falk y Miller (1992), dado que la varianza explicada es del 19,82\%. Por tanto, y al satisfacer los tres criterios, la conclusión es que la hipótesis queda confirmada.

- La relación entre la generación de la demanda responsable (distal 1) y la adquisición de información sobre responsabilidad (Hipótesis 2) es estadísticamente significativa ( $t$ de Student), con un valor del parámetro $\beta$ de 0,170 y con una varianza explicada del 5,60\%. Por tanto, y al cumplirse dos de los criterios, entre los cuales se encuentra el de significatividad, la hipótesis queda confirmada.

- La relación entre el concepto de responsabilidad (distal) y la generación de la demanda responsable (Hipótesis 3a) es estadísticamente significativa ( $t$ de Student), con un valor del parámetro $\beta$ de 0,552 y con una varianza explicada del 33,14\%. Por tanto, y al cumplirse los tres criterios, la hipótesis queda confirmada.

- La relación entre la utilidad esperada y la valoración de la responsabilidad de la oferta (Hipótesis 4a) es estadísticamente significativa ( $t$ de Student), con un valor del parámetro $\beta$ de 0,309 y con una varianza explicada del 15,43\%. Por tanto, y al cumplirse los tres criterios, la hipótesis queda confirmada. 
Tabla 6.24. Efectos directos en el Modelo 3

\begin{tabular}{lccccccc}
\hline \multicolumn{7}{c}{ Efectos directos } \\
\hline & $\begin{array}{c}\text { Coeficiente } \\
(\boldsymbol{\beta} / \boldsymbol{\gamma})\end{array}$ & $\begin{array}{c}\text { Coef, de } \\
\text { correlación }\end{array}$ & $\begin{array}{c}\text { Varianza } \\
\text { explicada }\end{array}$ & $\begin{array}{c}\text { Error } \\
\text { estándar }\end{array}$ & $\boldsymbol{t}$ & $p$ \\
\hline Adq_Inf_R -> Val_Ofe_R & 0,374 & 0,53 & $19,82 \%$ & 0,089 & 4,213 & $*$ \\
CE_Estrate -> Conc_Resp & 0,311 & 0,34 & $10,57 \%$ & 0,099 & 3,154 & \\
CE_Social -> Conc_Resp & 0,195 & 0,24 & $4,68 \%$ & 0,123 & 1,589 & \\
CE_Social -> Util_Esperad & 0,265 & 0,30 & $7,95 \%$ & 0,098 & 2,695 & $*$ \\
Conc_Resp -> Gener_Demanda & 0,552 & 0,60 & $33,14 \%$ & 0,082 & 6,750 & $*$ \\
Gener_Demanda ->Adq_Inf_R & 0,170 & 0,33 & $5,60 \%$ & 0,089 & 1,905 & $*$ \\
Infl_Soc - $>$ Adq_Inf_R & 0,327 & 0,48 & $15,70 \%$ & 0,088 & 3,726 & $*$ \\
Infl_Soc - $>$ CE_Estrate & 0,227 & 0,23 & $5,22 \%$ & 0,103 & 2,197 & $*$ \\
Infl_Soc - $>$ Util_Esperad & 0,336 & 0,36 & $12,09 \%$ & 0,096 & 3,498 & $*$ \\
Util_Esperad -> Adq_Inf_R & 0,330 & 0,50 & $16,51 \%$ & 0,098 & 3,354 & $*$ \\
Util_Esperad -> Gener_Demanda & 0,164 & 0,31 & $5,10 \%$ & 0,081 & 2,021 & $*$ \\
Util_Esperad -> Val_Ofe_R & 0,309 & 0,50 & $15,43 \%$ & 0,105 & 2,936 & $*$ \\
\hline
\end{tabular}

${ }^{*} p<0,05 ;{ }^{* *} p<0,01 ;{ }^{* * *} p<0,001$ (199 grados de libertad).

- La relación entre la utilidad esperada y la adquisición de información sobre responsabilidad (Hipótesis 4b) es estadísticamente significativa ( $t$ de Student), con un valor del parámetro $\beta$ de 0,330 y con una varianza explicada del 16,51\%. Por tanto, y al cumplirse los tres criterios, la hipótesis queda confirmada.

- La relación entre la utilidad esperada y la generación de la demanda responsable (Hipótesis 4c) es estadísticamente significativa ( $t$ de Student), con un valor del parámetro $\beta$ de 0,164 y con una varianza explicada del 5,10\%. Por tanto, y al cumplirse dos de los criterios, entre los cuales se encuentra el de significatividad, la hipótesis queda confirmada.

- La relación entre el comportamiento empresarial percibido con motivación social y la utilidad esperada (Hipótesis 5a) es estadísticamente significativa ( $t$ de Student), con un valor del parámetro $\gamma$ de 0,330 y con una varianza explicada del 16,51\%. Por tanto, y al cumplirse los tres criterios, la hipótesis queda confirmada.

- La relación entre el comportamiento empresarial percibido con motivación estratégica y el concepto de responsabilidad (Hipótesis 5ba) es estadísticamente significativa ( $t$ de Student), con un valor del parámetro $\beta$ de 0,311 y con una varianza explicada del 10,57\%. Por tanto, y al cumplirse los tres criterios, la hipótesis queda confirmada. 
- La relación entre la influencia social y el comportamiento empresarial percibido con motivación estratégica (Hipótesis 6a) es estadísticamente significativa ( $t$ de Student), con un valor del parámetro $\gamma$ de 0,227 y con una varianza explicada del 5,22\%. Por tanto, y al cumplirse los tres criterios, la hipótesis queda confirmada.

- La relación entre la influencia social y la utilidad esperada (Hipótesis 6b) es estadísticamente significativa ( $t$ de Student), con un valor del parámetro $\gamma$ de 0,336 y con una varianza explicada del 12,09\%. Por tanto, y al cumplirse los tres criterios, la hipótesis queda confirmada.

- La relación entre la influencia social y la adquisición de información sobre responsabilidad (Hipótesis 6c) es estadísticamente significativa ( $t$ de Student), con un valor del parámetro $\gamma$ de 0,327 y con una varianza explicada del 15,70\%. Por tanto, y al cumplirse los tres criterios, la hipótesis queda confirmada.

Por el contrario, los resultados indican que la relación entre el comportamiento empresarial percibido con motivación social y el concepto de responsabilidad (Hipótesis $5 \mathrm{bb})$ no es estadísticamente significativa ( $t$ de Student). El criterio propuesto por Chin (1998a) tampoco se cumple, ya que el valor del parámetro $\gamma$ es de 0,195. Y aunque se cumple el criterio de Falk y Miller (1992), dado que la varianza explicada es del 4,68\%, dado que es el único y asimismo el menos restrictivo, la conclusión es que la hipótesis queda rechazada para un nivel de significación $p<0,05$.

En todo caso, cabe considerar que el criterio de Chin (1998a) prácticamente se cumple (pues se requiere un valor del parámetro $\beta$ o $\gamma>0$,20 y el valor aquí obtenido es de $\gamma=0,195)$, así como que marginalmente se podría aceptar esta última hipótesis en base a que la relación resulta estadísticamente significativa para un nivel $p<0,10$ (siendo el valor de la $t$ de Student de 1,589). De acuerdo con estas consideraciones, podría aceptarse la influencia directa y positiva del comportamiento empresarial percibido con motivación social sobre el concepto de responsabilidad.

Con todo, y aplicando las exigencias de forma rigurosa, se comprueba cómo se confirman 11 y tan sólo se rechaza 1 de las 12 hipótesis planteadas en el modelo con reespecificación estructural (Figura 8). En base a los valores del pesos de regresión estandarizado $(0,552)$ y de la varianza explicada $(33,14 \%)$ destaca en especial la relación entre el concepto de responsabilidad (distal) y la generación de la demanda responsable (Hipótesis 3a). 
Figura 6.8. Representación de las relaciones significativas del Modelo 3

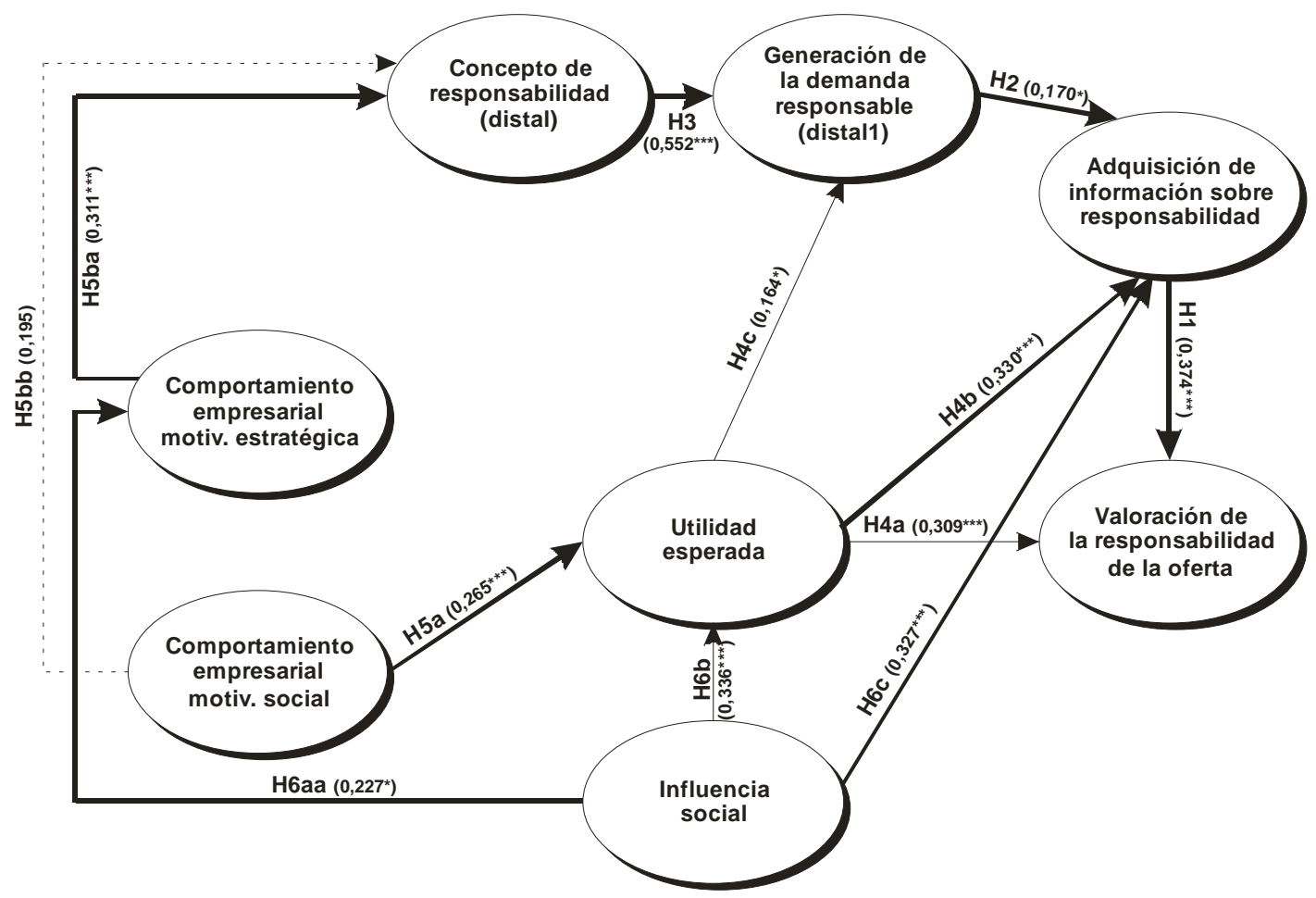

Fuente: Elaboración propia.

También resulta muy significativa la influencia de la adquisición de información sobre responsabilidad en la valoración de la responsabilidad de la oferta (Hipótesis 1), con un coeficiente de regresión estandarizado de 0,374 y una explicación del 19,82\% de la varianza. Junto con la anterior, esta hipótesis define la parte central del modelo, revelando y precisando las fases del proceso de compra, cuando el consumidor toma sus decisiones teniendo en cuenta criterios de responsabilidad.

Otra variable que tiene una influencia capital en los resultados del modelo es la utilidad esperada, particularmente por cuanto explica el 16,51\% de la varianza del constructo adquisición de información sobre responsabilidad, con un coeficiente de regresión estandarizado de 0,330 (Hipótesis 4b). Dicha variable tiene asimismo un peso importante en relación con la valoración de la responsabilidad de la oferta (Hipótesis 4a), ya que explica un $15,43 \%$ de su varianza, al tiempo que el valor del coeficiente de regresión estandarizado es de 0,309. 
En términos comparativos, el mayor ajuste estadístico del Modelo 3 -tanto a nivel de medida como estructural- hace de él la alternativa más adecuada para dar cuenta de las relaciones empíricas entre las variables del estudio. En tal sentido, los resultados del análisis PLS confirmaron una buena evaluación del modelo de medida, a través de la depuración practicada en las variables observadas, y una buena estimación en el ajuste del modelo estructural en lo que se refiere al cumplimiento de las hipótesis de partida (si bien no tanto en lo que se refiere a la validez predictiva del modelo).

Por otro lado, y de cara a ratificar los resultados obtenidos anteriormente, se procedió a analizar la importancia relativa atribuible a cada constructo en el modelo, de acuerdo con el estadístico $f^{2}$, el cual determina la importancia predictiva que tiene cada variable latente sobre las otras variables endógenas ${ }^{123}$, comparando la varianza explicada de la variable dependiente cuando la predictora es empleada u omitida ${ }^{124}$. A la vista de los resultados del estadístico $f^{2}$ (Tabla 6.25), en relación con este modelo cabe destacar distintos aspectos, todos muy relacionados con la confirmación de las hipótesis y que ponen de manifiesto lo que supondría un nuevo cambio estructural en el modelo:

- En primer lugar, el constructo adquisición de información tiene un efecto mediano sobre la valoración de la responsabilidad de la oferta $\left(f^{2}=0,16\right)$, mejorando la eficacia predictiva del modelo al estar especificada y confirmando la relación entre éste y su eficacia predictiva.

Tabla 6.25. Importancia atribuida a cada constructo del Modelo 3

\begin{tabular}{|c|c|c|c|c|c|c|c|}
\hline \multicolumn{8}{|c|}{ Estadístico f2 } \\
\hline Variables & 1. Ad_I_R & 2. CE_Est & 3. CE_Soc & 4. Conc_R & 5. G_Dem & 6. I_Social & 7. Util_Esp \\
\hline 1. Adq. inf. resp. & -.- & --- & --- & --- & 0,04 & 0,15 & 0,14 \\
\hline 2. C. emp. estrat. & --- & .-- & --- & --- & --- & 0,05 & --- \\
\hline 3. C. emp. soc. & --- & --- & --. & --- & --- & --- & --- \\
\hline 4. Concepto resp. & --- & 0,11 & 0,04 & .-- & --- & --- & --- \\
\hline 5. Gen. demanda & --- & --- & --- & 0,46 & -.. & --- & 0,04 \\
\hline 6. Influencia soc. & --- & --- & --- & --- & --- & -.. & --- \\
\hline 7. Utilidad esp. & --- & --- & 0,09 & --- & --- & 0,14 & -.- \\
\hline 8.Val. resp. oferta & 0,16 & --- & --- & --- & --- & --- & 0,11 \\
\hline
\end{tabular}

\footnotetext{
${ }^{123}$ Para calcular el estadístico $f^{2}$ se construyen tantos nuevos modelos como variables predictoras tiene el modelo sometido a análisis (en este caso, tantos como variables latentes, excepto para la valoración de la responsabilidad de la oferta), comprobando los nuevos coeficientes $R^{2}$ obtenidos al excluir el predictor con los $R^{2}$ previamente obtenidos para el modelo inicial.

${ }^{124}$ Procedimiento que carece de significado para constructos no relacionados directamente, pues en ese caso no se modifica el valor de $R^{2}$.
} 
- El efecto de la generación de la demanda (distal 1) en la adquisición de información es más bajo $\left(f^{2}=0,04\right)$, si bien aún con este valor reducido también aporta eficacia predictiva al modelo.

- El concepto de responsabilidad (distal) tiene un efecto grande (el que más en el modelo depurado, con un $f^{2}=0,46$ ) sobre la generación de la demanda (distal 1 ), lo que indica que mejoran sensiblemente las relaciones estructurales al incluir en el modelo el concepto que el consumidor tiene sobre la responsabilidad de las empresas.

- La utilidad esperada influye poco en la valoración de la responsabilidad $\left(f^{2}=\right.$ 0,11 ) y en la generación de la demanda $\left(f^{2}=0,04\right)$, y algo más en la adquisición de información $\left(f^{2}=0,14\right)$. Estos valores, aunque no muy altos, confirman las relaciones de la variable y su relevancia en las relaciones estructurales del modelo.

- El efecto del comportamiento empresarial estratégico en el concepto de responsabilidad es reducido $\left(f^{2}=0,11\right)$, aunque mejora la eficacia predictiva (con lo que se ratifica la relación).

- La influencia del comportamiento empresarial social en la utilidad esperada es pequeña $\left(f^{2}=0,09\right)$, aunque mayor que sobre el concepto de responsabilidad $\left(f^{2}=0,04\right)$. Con todo, se confirma su relación como variable predictora exógena en el primer caso (se verifica la relación estructural), aunque no así en el segundo (se había rechazado).

- A su vez, el efecto de la influencia social en la adquisición de información es mediano $\left(f^{2}=0,15\right)$, ligeramente inferior en la utilidad esperada $\left(f^{2}=0,14\right)$, y más reducido sobre el comportamiento empresarial estratégico $\left(f^{2}=0,05\right)$. En todo caso, esos valores confirman la necesidad de incluir el constructo en las relaciones estructurales del modelo y verifican las hipótesis relacionadas con esta variable latente exógena.

Los efectos totales entre variables latentes (Tabla 6.26) también reflejan algunos resultados interesantes. Entre los más relevantes están los efectos globales significativos (además de los ya descritos) entre los siguientes constructos:

- El comportamiento empresarial con motivación estratégica explica el 4,46\% de la varianza en la generación de la demanda responsable (distal 1).

- El comportamiento empresarial con motivación social explica el 3,23\% de la varianza de la valoración de la responsabilidad de la oferta, y el 2,73\% de la varianza de la generación de la demanda responsable (distal 1). 
Tabla 6.26. Efectos totales en el Modelo 3

\begin{tabular}{|c|c|c|c|c|c|c|}
\hline \multicolumn{7}{|c|}{ Efectos totales } \\
\hline & $\begin{array}{c}\text { Coeficiente } \\
(\beta / \gamma)\end{array}$ & $\begin{array}{l}\text { Coef, de } \\
\text { correlación }\end{array}$ & $\begin{array}{l}\text { Varianza } \\
\text { explicada }\end{array}$ & $\begin{array}{c}\text { Error } \\
\text { estándar }\end{array}$ & $t$ & $p$ \\
\hline Adq_Inf_R -> Val_Ofe_R & 0,374 & 0,53 & $19,82 \%$ & 0,089 & 4,213 & *** \\
\hline CE_Estrate $>$ - Adq_Inf_R & 0,029 & 0,13 & $0,38 \%$ & 0,018 & 1,617 & \\
\hline CE_Estrate $->$ Conc_Resp & 0,311 & 0,34 & $10,57 \%$ & 0,099 & 3,154 & $* * \star$ \\
\hline CE_Estrate $->$ Gener_Demanda & 0,172 & 0,26 & $4,46 \%$ & 0,056 & 3,081 & $* * *$ \\
\hline CE_Estrate -> Val_Ofe_R & 0,011 & 0,06 & $0,07 \%$ & 0,007 & 1,507 & \\
\hline CE_Social -> Adq_Inf_ēR & 0,113 & 0,19 & $2,15 \%$ & 0,046 & 2,443 & ** \\
\hline CE_Social -> Conc_Resp & 0,195 & 0,24 & $4,68 \%$ & 0,123 & 1,589 & \\
\hline CE_Social -> Genèr_Demanda & 0,151 & 0,18 & $2,73 \%$ & 0,074 & 2,041 & * \\
\hline CE_Social -> Util_Esperad & 0,265 & 0,30 & $7,95 \%$ & 0,098 & 2,695 & $* * *$ \\
\hline CE_Social -> Val_Ofe_R & 0,124 & 0,26 & $3,23 \%$ & 0,057 & 2,189 & * \\
\hline Conc_Resp -> Adq_Inf_R & 0,094 & 0,18 & $1,69 \%$ & 0,049 & 1,930 & * \\
\hline Conc_Resp -> Gener_Demanda & 0,552 & 0,60 & $33,14 \%$ & 0,082 & 6,750 & $* * *$ \\
\hline Conc_Resp -> Val_Ofe_R & 0,035 & 0,04 & $0,14 \%$ & 0,020 & 1,749 & * \\
\hline Gener_Demanda -> Adq__Inf_R & 0,170 & 0,33 & $5,60 \%$ & 0,089 & 1,905 & * \\
\hline Gener_Demanda -> Val_Ofe_R & 0,064 & 0,06 & $0,38 \%$ & 0,036 & 1,773 & * \\
\hline Infl_Sōc $>$ > Adq_Inf_R & 0,454 & 0,48 & $21,79 \%$ & 0,083 & 5,454 & $* * *$ \\
\hline Infl_Soc $->$ CE_Estrate & 0,227 & 0,23 & $5,22 \%$ & 0,103 & 2,197 & * \\
\hline Infl_Soc -> Conc_Resp & 0,071 & 0,13 & $0,92 \%$ & 0,041 & 1,720 & * \\
\hline Infl_Soc -> Gener_Demanda & 0,094 & 0,18 & $1,70 \%$ & 0,041 & 2,285 & * \\
\hline Infl_Soc -> Util_Esperad & 0,336 & 0,36 & $12,09 \%$ & 0,096 & 3,498 & $* * *$ \\
\hline Infl_Soc -> Val_Ofe_R & 0,273 & 0,39 & $10,66 \%$ & 0,066 & 4,143 & $* * *$ \\
\hline Util_Esperad ->Adq_Inf_R & 0,358 & 0,50 & $17,91 \%$ & 0,094 & 3,795 & $* * *$ \\
\hline Util_Esperad -> Gener_Demanda & 0,164 & 0,31 & $5,10 \%$ & 0,081 & 2,021 & * \\
\hline Util_Esperad -> Val_Ofe_R & 0,443 & 0,50 & $22,13 \%$ & 0,103 & 4,310 & $* * *$ \\
\hline
\end{tabular}

${ }^{*} p<0,05 ;{ }^{* *} p<0,01 ;{ }^{* * *} p<0,001$ (199 grados de libertad).

- Aunque la influencia social no tiene una incidencia directa significativa en la valoración de la responsabilidad de la oferta, globalmente sí es capaz de explicar el $10,66 \%$ de su varianza.

- Finalmente, el efecto de la utilidad esperada sobre la valoración de la responsabilidad de la oferta sí es directo y significativo, explicando el 15,43\% de su varianza. A nivel global, el efecto es aún mayor, llegando a explicar el 22,13\%, lo que indica una influencia que sólo es superada en el modelo por la relación directa entre el concepto de responsabilidad (distal) y la generación de la demanda responsable (distal 1), caso en el que el porcentaje de varianza explicada es del 33,14\%. 
ConClusiones y Consideraciones 



\section{CONCLUSIONES Y CONSIDERACIONES}

A partir del análisis del marco conceptual y de los resultados obtenidos en el proceso de validación del modelo propuesto, el contenido de las páginas siguientes tiene por objeto exponer las principales conclusiones derivadas del trabajo realizado, así como las implicaciones de éstas para la gestión, incluyendo ciertas consideraciones acerca de las limitaciones del estudio y las posibles líneas de investigación que quedan abiertas de cara al futuro.

De este modo, y por lo que respecta al análisis del marco teórico-conceptual, la contextualización desde el punto de vista de la praxis institucional y la evolución de la los planteamientos teórico-prácticos en cuanto al análisis de la percepción de los comportamientos responsables de las organizaciones desde la perspectiva del consumidor, la primera conclusión que cabe extraer es que la aceptación, confianza y respaldo de una entidad por parte de la sociedad depende no sólo de la generación de expectativas, sino sobre todo y en particular, del cumplimiento de éstas (ERSE 2010), y ello no sólo según el parecer de los propietarios, accionistas o shareholders, sino también de los trabajadores que demandan derechos sociales y económicos, de los clientes cuando exigen productos de calidad, y de un largo etcétera de públicos-objetivo o stakeholders internos y externos, incluyendo las comunidades en que las distintas entidades desarrollan sus actividades y una sociedad en su conjunto, cada día más preocupada por las cuestiones relacionadas con el desarrollo responsable y sostenible.

No obstante lo anterior, el análisis de los debates que a lo largo del tiempo han venido teniendo lugar en el ámbito académico, así como de los planteamientos y esfuerzos programáticos de diferentes instituciones con el propósito de consensuar una definición y dotar de contenido al término "responsabilidad", no permite sino concluir, pese a la creciente relevancia de las cuestiones consideradas, la ausencia aún en el momento presente de un concepto único y de generalizada aceptación, como tampoco hay una única línea de trabajo en el desarrollo del marco teórico que pueda llegar a respaldar un concepto de tales características en un futuro inmediato, ni tampoco existen 
unos métodos de medida y/o unos procedimientos empíricos estandarizados para la investigación (por ejemplo, y entre muchos, McWilliams et al. 2005, Garmendia 2009). Antes bien, la propia naturaleza del concepto, cuyo carácter pluridisciplinar, abierto y dinámico evoluciona con el tiempo, a la vez que depende de la cultura, ideología y de las costumbres de cada sociedad (Carroll 1979, Van Herpen et al. 2003, González 2005, Argandoña et al. 2011), proporciona por sí misma una clara explicación para la proliferación de enfoques y teorías que se han construido, y continúan construyéndose, en torno a la responsabilidad de las organizaciones.

En tal sentido, uno de los aspectos fundamentales que subyacen en los nuevos planteamientos sobre las conductas responsables pasa sin duda por la redefinición del papel que están llamadas a desempeñar unas organizaciones más vinculadas y comprometidas con los grupos de interés y con la sociedad, no sólo de forma esporádica y/o coyuntural, sino a largo plazo y de forma integral, respondiendo a demandas de diferente contenido y naturaleza en el marco de un entorno globalizado en el que, aparte de cumplir objetivos y asumir compromisos financieros, las entidades deben tener en cuenta las consecuencias sociales y medioambientales del desarrollos de su actividad, los requerimientos de consumidores e inversores responsables, los efectos en las comunidades y entornos en que actúan y, en definitiva, cuanto tiene que ver con un desarrollo responsable y sostenible. La justa contrapartida será el mayor grado de reconocimiento de su labor y su influencia en el desarrollo socioeconómico.

Es, precisamente, esta nueva concepción (consecuencia en parte de un cambio en el sistema de valores que impregnan la sociedad actual) la que determina la necesidad de profundizar en la relación empresa-sociedad por medio de un conocimiento integral (Garriga y Melé 2004), íntegro y recíproco, que incluye la consideración de múltiples grupos de interés cuya actuación es capaz de generar una gran presión sobre el entorno competitivo de la empresa (Bigné et al. 2005). Estos grupos de interés reaccionan ante las prácticas de responsabilidad social empresarial, siendo clave analizar de un modo particular las reacciones y conductas inducidas en los consumidores, por cuanto es evidente que ello tendrá significativas consecuencias sobre el desempeño y los resultados empresariales.

Así las cosas, cabe concluir que el diseño y puesta en práctica de programas y actuaciones de responsabilidad organizativa en la etapa más reciente no obedece tanto a 
un mandato o una regulación por parte de los poderes públicos, como a una mayor sensibilidad social y empresarial en relación con determinadas realidades que son objeto de especial preocupación: violaciones graves de los derechos fundamentales, el deterioro medioambiental, falta de condiciones elementales para una vida digna, etc. (Melgar 2009: 108).

Centrándonos ya en el análisis de los diferentes enfoques bajo los que ha sido planteado el estudio de la responsabilidad, puede constatarse cómo el marco conceptual más ampliamente utilizado es el de la teoría de los grupos de interés o stakeholders (Phillips et al. 2003, Bigné et al. 2011). No obstante, desde esta perspectiva mucho ha sido lo que se ha dicho sobre las obligaciones y responsabilidades de las entidades y sus directivos hacia otros stakeholders, pero muy poco de las obligaciones que bien pudieran tener tales stakeholders hacia la corporación (González 2001), y de ahí que una tarea muy importante y todavía por desarrollar consista en especificar de qué y por qué es responsable la empresa y no sólo ante quién tiene obligaciones o debe responder, lo cual implica la necesidad de disponer de criterios normativos y objetivos que permitan reflexionar sobre las responsabilidades de la empresa en un sentido amplio.

Ya sea partiendo de estos planteamientos, o de otros similares o alternativos, la producción científica sobre la responsabilidad de las entidades productivas ha dado lugar a una abundante literatura en el campo de la organización de empresas (Pérez 2011), en tanto resulta más escasa si se tienen en cuenta las aportaciones desde otras áreas científicas de empresa, desde otros ámbitos económicos, o desde otras disciplinas, y ello a pesar del evidente carácter multidisciplinar con que debe ser abordado su estudio. En todos los casos, y dada la variedad de aspectos que se recogen, así como la pluralidad de enfoques y planteamientos, se pone de manifiesto una clara fragmentación de la investigación en un sinfín de líneas de trabajo abiertas.

Entre tales líneas, el presente trabajo se ha centrado en las que analizan la relación de los consumidores con la responsabilidad, muy poco desarrolladas hasta época muy reciente. Llama, de hecho, poderosamente la atención (Andreu et al. 2004, Bigné et al. 2005) que hasta el año 2000 sean contados los trabajos que se centraban específicamente en estas reacciones del consumidor (Brown y Dacin 1997, Murray y Vogel 1997, Creyer y Ross 1997, Ellen et al. 2000), conforme ponen de manifiesto autores como Sen y Bhattacharya (2001) o, mucho más recientemente, Pérez (2011). No 
sólo esto, sino que aunque esta categoría de trabajos se ha visto dinamizada de una forma muy considerable en los últimos años, el número de investigaciones "palidece en comparación con otros estudios sobre responsabilidad" desarrollados en los diferentes ámbitos de las disciplinas empresariales (Alvarado 2008:106).

Ello, aunque la demanda de comportamientos socialmente responsables por parte de los ciudadanos y de organizaciones de la sociedad civil sea uno de los aspectos más significativos del escenario internacional de los últimos años (Doh y Guay 2006), y pese a la evidencia de las diferentes estrategias con que los distintos grupos o colectivos han buscado satisfacer sus demandas (García et al. 2011).

En este orden de cosas, de entre todas las posibles actuaciones encaminadas a demandar un comportamiento socialmente responsable a las empresas, el estudio se ha centrado en aquéllas que tienen una mayor justificación económica en cuanto a las relaciones que establecen los agentes económicos cuando toman sus decisiones, esto es, las vinculadas con dichas relaciones en el proceso de compra, analizando y concluyendo cómo el mercado y el poder de compra del consumidor sí pueden ser utilizados como elemento de expresión de las preocupaciones sociales, medioambientales y éticas de éste último hacia las entidades productivas.

Esto es así a pesar de que la teoría del mercado con libre elección respecto a la relación empresa-cliente, no está exenta de críticas (Weiss 1994), en buena parte derivadas de sus propias hipótesis (asimetrías de información y de poder). Cabe postular en este sentido que la materialización de unos planteamientos de responsabilidad compartida (también por parte del consumidor) plantea unos significativos niveles de dificultad en una sociedad como la actual, donde el mercado ofrece una gran diversidad de productos y de actividades, y los consumidores deberían conocer y tener información completa sobre todos ellos cuando toman cada una de sus múltiples decisiones de compra (Valor 2010).

Con todo, dada la pluralidad de aspectos relacionados con la responsabilidad organizativa que están conectados de una u otra forma con alguna de las distintas fases del proceso de compra, y tratando de eludir dichas limitaciones a la vez que de concretar específicamente el campo de estudio, éste se ha centrado en las etapas y procesos que tienen que ver con la intención de compra del consumidor, describiendo para ello la 
interacción entre la generación de demanda con la necesidad de obtener información sobre la conducta más o menos responsable de las ofertas del mercado y de las entidades que las realizan, materializándose en la búsqueda y recopilación efectiva de información también sobre estos aspectos, para su posterior valoración y repercusión en términos de mayor intención de compra hacia las ofertas socialmente responsables. Todo ello considerando las correspondientes variables como pilares centrales que describen el modelo propuesto de consideración y valoración de la responsabilidad en el proceso de intención de compra.

En tal sentido, y por una parte, se concluyó la necesidad de incluir en el modelo propuesto la perspectiva de la percepción, con dos variables fundamentales, como son el concepto de responsabilidad que tiene el consumidor y los motivos que éste atribuye a comportamientos responsables de las empresas. Tal es así porque, como se puede apreciar en la literatura, los estudios de la percepción del consumidor han derivado del previo análisis de las distintas dimensiones de la responsabilidad propuestas en el modelo de Carroll (1979 y 1991), al comprobar cómo esas asociaciones de responsabilidad pueden tener efectos en la intención de compra a través del proceso formación de la imagen que la compañía sea capaz de generar y el consumidor de apreciar.

Por otra parte, también se pudo constatar cómo el proceso no sólo está condicionado por la propia secuencia decisoria, el significado y las atribuciones en cuanto al comportamiento empresarial, sino también por otros factores que, de una manera directa, matizan la valoraciones de ofertas responsables, los cuales tienen que ver tanto con variables internas del individuo relacionadas con la utilidad esperada, como con otras variables externas a aquél y que determina la influencia social, motivo por el cual se incluyeron los citados constructos en el modelo propuesto de toma de decisiones del consumidor sobre la base de criterios de responsabilidad, analizando después las interrelaciones que pueden establecerse con las variables determinantes o explicativas del componente valorativo de las ofertas responsables por parte de aquél.

A tal fin, y desde un punto de vista práctico, se tuvo siempre presente el objetivo último del trabajo, esto es, construir un modelo perceptivo útil en la explicación del proceso secuencial de decisión de intención de compra, sobre la base la incorporación 
de criterios de responsabilidad por parte del consumidor, analizando las variables explicativas o determinantes que influyen en la valoración de las ofertas responsables.

Para ello se llevo a cabo un estudio psicométrico, a partir de una muestra representativa de la población, mediante la elaboración y la administración de un cuestionario, recogiendo datos primarios que hicieran operativas las variables estudiadas en el modelo. Para dicho propósito se emplearon las técnicas estadísticas de análisis factorial, descriptivo y de ecuaciones estructurales, dando cuenta del grado de cumplimiento de las hipótesis de partida.

En tal sentido, la realización de un análisis factorial exploratorio da una primera aproximación en cuanto a conclusiones, explicando la segmentación del concepto de responsabilidad en dos grupos (proximal y distal), a la vez que indica que los consumidores no encuadran el "cumplimiento estricto de las leyes" dentro del concepto. En las atribuciones al comportamiento responsable de las empresas aparecieron igualmente dos factores (estratégico y social), en tanto para la generación de demanda se extrajeron cuatro factores que vienen a perfilar los dos encontrados para el concepto de responsabilidad (distal -1 y $2-$ y proximal -1 y $2-$ ), si bien los consumidores no encajan dentro de ninguno de los grupos anteriores como motores de generación de demanda, las prácticas de juego limpio con la competencia y la colaboración abierta con administraciones y ONGs.

Dentro del análisis factorial, las restantes fases del proceso de intención de compra responsable arrojaron como resultado los factores previstos en el modelo inicial sobre adquisición de información sobre responsabilidad y valoración de la responsabilidad de la oferta, al igual que sucede con los otros determinantes (utilidad esperada e influencia social). Por el contrario, quedan fuera de consideración como indicadores del proceso de intención de compra el tener buenas experiencias con productos y marcas de empresas socialmente responsables, así como tener esas empresas como referencia en su consumo.

Sobre la base de las dimensiones factoriales identificadas, el análisis de correlaciones llevado a cabo permitió concluir un importante número de interrelaciones, probando una fuerte correspondencia entre estimaciones de constructos. Las conclusiones de dicho análisis se corroboran, además, con las de otros de naturaleza 
descriptiva, donde se constata la importancia por sus puntuaciones medias, destacando las atribuciones al comportamiento estratégico de la empresa cuando trata de ser socialmente responsable o al concepto distal que define la empresa responsable, mientras que la mayor dispersión de los datos corresponde a variables de generación de demanda (proximal 1 y proximal 2), así como a la valoración de la responsabilidad de la oferta. Entretanto, y por el contrario, los datos están más concentrados para el constructo comportamiento empresarial estratégico.

El modelo de medida inicial se basó en incorporar al modelo teórico propuesto las distintas dimensiones obtenidas en el análisis factorial, presentando en su validación limitaciones de fiabilidad y validez, junto con un escaso ajuste encontrado a nivel de medición externa, lo que apuntó la necesidad de reespecificar el planteamiento de partida, atendiendo especialmente al nivel de adecuación de los ítems empleados en la medición de los constructos, de cara a lograr un mayor ajuste del modelo de medida que sirviera como condición previa a la comprobación del ajuste del modelo estructural y las hipótesis recogidas en el mismo.

Un segundo modelo respetó el patrón estructural del inicial a la vez que se constataba la pertinencia de modificar el esquema interno de medida mediante alteraciones en la composición de indicadores vinculados a las variables latentes (reteniendo únicamente aquéllos indicadores con cargas factoriales significativas) para mejorar la consistencia interna del resultado final, mientras que las relaciones estructurales se mantenían la misma validez, concluyéndose de este modo que se trataba de una mejor opción frente a la primera alternativa en la contrastación empírica de las hipótesis previamente planteadas.

No obstante, para mejorar los resultados se propuso un tercer modelo rival. Con el fin de profundizar en la sostenibilidad de la estructura predictiva y conservando para cada constructo latente los indicadores con cargas factoriales significativas en análisis previos, dicho tercer modelo reespecificaba el anterior teniendo en cuenta sus deficiencias estructurales, basadas en:

- Eliminar tres variables de generación de la demanda responsable (distal 2, proximal 1 y proximal 2), por problemas detectados en términos de baja fiabilidad y validez de constructo, e inexistencia de un efecto significativo de dichas variables, 
considerándose únicamente la generación de demanda distal 1 como dimensión válida y fiable.

- Descartar el concepto proximal de responsabilidad, dada su baja fiabilidad y desconexión del resto del modelo (por un lado, las valoraciones recibidas de las atribuciones del comportamiento empresarial -tanto estratégico como social- y, por el otro, las causadas en la generación de demanda), considerándose únicamente el concepto distal como determinante o factor que influye en el proceso de intención de compra.

- Conservar el constructo influencia social (a pesar de la deficiencia de sus indicadores de medida), descartándose las relaciones sobre las percepciones de comportamiento empresarial social y la valoración de la responsabilidad de la oferta por falta de efecto significativo. A consecuencia de ello, el comportamiento empresarial social queda configurado como variable latente exógena en el modelo final. Además, la ausencia de un efecto significativo de las atribuciones del comportamiento empresarial estratégico sobre la utilidad esperada, llevó a eliminar dicha relación del modelo estructural.

El modelo de medida reespecificado resultó válido y fiable a partir de la revisión de los resultados, apreciando para todos los ítems significatividad estadística de acuerdo a la técnica bootstrap de PLS (cargas estandarizadas $\lambda_{\mathrm{y}}$ y $\lambda_{\mathrm{x}}$ superiores a 0,50). La consistencia interna de las escalas (alpha de Cronbach, índice de fiabilidad compuesta) fue válida en la práctica totalidad y ampliamente aceptable para todas las escalas, al igual que la validez convergente (índices AVE) y la validez discriminante, que reafirmó la solidez del modelo de medida al comprobar que cada constructo compartía más varianza con sus indicadores que con otras variables latentes del modelo.

Del análisis estructural del modelo reespecificado (respecto a los índices $R^{2}$ y $Q^{2}$ ) se concluye la falta de relevancia predictiva para tres constructos (comportamiento empresarial estratégico, concepto de responsabilidad y utilidad esperada) mientras que esta importancia predictiva se mantiene para las tres variables centrales del modelo, concretamente la generación de la demanda (distal 1), la adquisición de información sobre responsabilidad y la valoración de la responsabilidad de la oferta.

Por su parte, los efectos directos entre variables latentes (a través del procedimiento bootstrap) confirmaron todas las relaciones hipotetizadas, salvo la 
referida a la influencia directa y positiva del comportamiento empresarial social sobre el concepto de responsabilidad percibido (H5bb), puesto que, de los tres criterios propuestos para validar las hipótesis, sólo cumple el menos restrictivo (el de Falk y Miller 1992, con una varianza explicada del 4,68\%). No obstante, esta relación también podría aceptarse como marginalmente significativa.

Concretamente, se confirmaron relaciones directas significativas entre la adquisición de información sobre responsabilidad y la valoración de la responsabilidad de la oferta (H1); la generación de la demanda responsable y la adquisición de información sobre responsabilidad (H2); el concepto de responsabilidad (distal) y la generación de la demanda responsable -distal 1-(H3). La utilidad esperada se relaciona también positivamente con la valoración de la responsabilidad de la oferta (H4a), con la adquisición de información sobre responsabilidad (H4b) y con la generación de la demanda responsable -distal 1- (H4c). Del mismo modo, el comportamiento empresarial percibido con motivación social con la utilidad esperada (H5a), y el comportamiento empresarial percibido con motivación estratégica con el concepto de responsabilidad (H5ba). También la influencia social se relaciona positivamente con el comportamiento empresarial estratégico (H6a), con la utilidad esperada (H6b) y con la adquisición de información sobre responsabilidad (H6c).

De cara a ratificar los resultados obtenidos, se estudió la importancia relativa atribuible a cada constructo en el modelo (estadístico $f^{2}$ ) comparando la varianza explicada de la variable dependiente cuando la predictiva es empleada u omitida y concluyéndose que, si bien el predictor concepto de responsabilidad tiene el efecto más importante del modelo depurado sobre la generación de demanda de responsabilidad explicada como distal $1\left(f^{2}=0,46\right)$, todos los constructos aportan eficacia predictiva al modelo.

Por último, el alcance predictivo del modelo se pone de manifiesto no sólo a partir de los resultados en cuanto a vínculos directos que acaban de ser descritos, sino también por los otros efectos globales y que son significativos entre: el comportamiento empresarial estratégico y la generación de la demanda responsable -distal 1- (4,46\% de la varianza explicada); el comportamiento empresarial social con la valoración de la responsabilidad de la oferta (3,23\%), y con la generación de la demanda responsable distal 1- (2,73\%); y la utilidad esperada con la valoración de la responsabilidad de la oferta (que a nivel global amplia su efecto al 22,13\%). 


\section{Implicaciones teórico-prácticas:}

La no desdeñable solidez obtenida en respaldo al planteamiento inicial de un modelo perceptivo de la responsabilidad desde la perspectiva de la demanda aplicado al proceso decisorio del consumidor, cuando éste considera o tiene en cuenta criterios de responsabilidad, hace que las aportaciones del presente trabajo puedan ser reseñadas en tanto avance hacia propuestas teóricas e intervenciones prácticas más afinadas en la explicación y fomento del comportamiento responsable del consumidor.

De este modo, y comenzando por las implicaciones teóricas del estudio, se viene a demostrar que, en lo que atañe a su comportamiento, las organizaciones son responsables ante sí mismas de su propia gestión, pero también lo son ante terceros y más en concreto ante todos los grupos o colectivos que, ya sea de una forma directa o indirecta, inciden o son influidos por las actuaciones organizativas, lo cual significa que los resultados de las actividades de éstas se extienden a toda la sociedad.

Los distintos enfoques existentes (tanto académicos como de otras instituciones participantes en los debates) coinciden en cuanto a plantear discusiones teóricas e implementaciones prácticas de la responsabilidad, manteniendo una orientación más bien encaminada a la definición y medición del alcance que tiene la actividad desarrollada por la organización sobre sus públicos objetivo y el conjunto de la sociedad. Pero no es menos cierto que la empresa también pueden ser contemplada y valorada desde una óptica externa, por parte de consumidores, administraciones, comunidades, medios de comunicación o la propia sociedad, siendo éstos quienes delineen los contornos de una empresa responsable, planteando la responsabilidad desde el punto de vista de las colectividades con las que la entidad se relaciona o contextualizándola en el entorno en que ésta opera (Guibert 2007 y 2011).

En esta línea, teniendo en cuenta que la presión de los mercados de consumo es uno de los factores que más ha impulsado en los últimos años el número de contribuciones en la literatura sobre diferentes aspectos de la responsabilidad de las organizaciones, y cuando un número creciente de consumidores opta más que nunca por patrones y pautas de consumo responsable, el modelo planteando viene a arrojar luz sobre el proceso de intención de compra responsable, avanzando en la comprensión de las variables más significativas que lo explican y cómo están interrelacionadas. 
Por otro lado, y también como implicaciones prácticas derivadas de la investigación realizada, el estudio pone de manifiesto la importancia de la valoración y actuación subsecuente de los consumidores ante la información de que disponen sobre la forma de gestionar e implementar la responsabilidad en las empresas (y, por extensión, en otros tipos de organizaciones del ámbito público o de la Economía Social), lo cual resulta de interés no sólo para la propia empresa que en un momento dado pueda ser objeto de valoración, sino para otros agentes interesados en conocer estas opiniones y decisiones tomadas por el consumidor, así como, de un modo particular, sus consecuencias.

Comenzando por las empresas, el estudio demuestra que un desempeño por parte de éstas y que sea percibido y valorado por el consumidor como socialmente responsable influye en la valoración posterior que éste realiza de las ofertas de aquélla en términos de utilidad esperada, pero no tanto del concepto de responsabilidad que tiene dicho consumidor, entendido como la satisfacción de los intereses de los stakeholders secundarios (concepto distal). Sin embargo, cuando el comportamiento empresarial es atribuido a un motivo de índole estratégica, tal circunstancia también repercute en la valoración del consumidor, pero de una forma más indirecta (y, por tanto, menos importante), a través del concepto que tiene del comportamiento responsable (distal) y, sobre todo, en el proceso de decisión pre-compra responsable.

En este orden de cosas, es transcendental que la empresa fomente unas políticas de comunicación acerca de sus acciones y conductas responsables que resulten creíbles y sinceras, donde el consumidor no aprecie sólo motivos estratégicos, sino también aprecie los valores que han impulsado ese compromiso. Estas mismas implicaciones son igualmente útiles para organizaciones sectoriales y agrupaciones empresariales, puesto que sirven de apoyo empírico para impulsar políticas de promoción de responsabilidad entre sus asociados.

Del mismo modo cabe entender que tanto para legisladores, responsables públicos administrativos, interlocutores sociales como sindicatos, organizaciones de consumidores, ONGs y otras organizaciones, resulta de especial interés comprender el sesgado conocimiento que tiene hoy en día el consumidor del concepto de responsabilidad, al entender la empresa socialmente responsable desde un punto de vista distal (relacionado con actuaciones medioambientales, problemáticas sociales, 
contribución al desarrollo económico regional, intereses de la comunidad, así como la colaboración abierta con administraciones y ONGs), mientras que no identifica el concepto proximal que describe aspectos más relacionados con el núcleo de la actividad empresarial (expectativas de empresarios, clientes, accionistas, proveedores e incluso el juego limpio con la competencia).

Esta distorsión cognitiva del consumidor constituye en sí una llamada de atención, tanto a los responsables de las administraciones públicas (en el diseño de las políticas públicas), como a otros actores de la sociedad civil activamente interesados en que los consumidores adopten patrones de consumo más responsables, en todo caso para que se pongan los medios y se lleven a cabo los esfuerzos necesarios con los que transmitir un conocimiento más completo de lo que es y lo que significa el concepto de responsabilidad de las organizaciones, lo cual debe servir como base para la realización de campañas públicas de sensibilización y de información ciudadana.

Además de estar formados, si realmente se quieren trasladar al mercado las preocupaciones sociales de los consumidores, con la finalidad de fortalecer el argumento económico cuando toman sus decisiones de compra a favor de la responsabilidad, es importante que aquéllos dispongan de información no sólo sobre los productos ofertados y los resultados económicos de las empresas que los ofertan, sino también sobre el desempeño de dichas entidades en los restantes ámbitos de su responsabilidad, lo que favorecería en el proceso de compra la generación de demanda no sólo de actuaciones con el medioambiente o compromisos con problemas sociales (distal 1), tal y como sugieren los resultados obtenidos con el modelo propuesto, sino también con otros aspectos de gran transcendencia en el comportamiento responsable (expectativas de clientes, empleados, socios, accionistas, comunidad local...).

\section{Limitaciones y futuras líneas de investigación:}

El alcance de los resultados obtenidos en el estudio realizado, así como el incumplimiento de algunas de las hipótesis de partida, deben ser interpretados a la luz de ciertas limitaciones teóricas y metodológicas que dejan la puerta abierta a nuevos trabajos en este campo. 
De este modo, una primera debilidad del modelo de investigación desarrollado en páginas precedentes remite a la propia novedad del marco teórico empleado en la evaluación del comportamiento del consumidor como agente decisor en la elección de productos con base a criterios de responsabilidad, determinando el proceso tanto las propias decisiones como la influencia social percibida. En tal sentido, el escaso desarrollo teórico de algunas de las variables del modelo, particularmente en lo relativo a la utilidad esperada y a la influencia social, supeditan el alcance de las contribuciones atribuibles a este estudio al avance de nuevas investigaciones en el área que repliquen los resultados obtenidos o profundicen en el refinamiento de los constructos propuestos y de las relaciones entre los mismos en contextos específicos de comportamiento responsable del consumidor.

En relación con lo anterior, cabe asimismo puntualizar que la mayoría de las escalas empleadas en la medición de las variables del modelo fueron desarrolladas ad hoc para los propósitos de la presente investigación, siendo requerida su validación futura de cara a la contrastación de su utilidad más allá de los fines que les han sido asignados en este trabajo. A la espera de tales avances, y si bien los análisis estadísticos preliminares conducidos aportaron cierta evidencia de fiabilidad y validez del cuestionario empleado, la capacidad del modelo de medida propuesto para dar cuenta de las relaciones predictivas hipotetizadas entre variables queda supeditada a un considerable refinamiento de los indicadores inicialmente propuestos, habiendo derivado en la configuración de escalas integradas por pocos ítems, al tiempo que haciendo especialmente cuestionable la estimación del constructo "influencia social” a partir de un único enunciado, lo que invalida su consistencia interna. Con todo, el establecimiento de la robustez predictiva del modelo propuesto requiere igualmente de nuevos desarrollos psicométricos enfocados a la construcción de instrumentos de medida válidos y fiables basados en una mayor especificidad definicional de los constructos implicados.

En este mismo sentido, el modelo es incompleto por cuanto se circunscribe al estudio de la intención de compra responsable y resulta, pues, susceptible de ampliación para tener en cuenta todas las fases del proceso de decisión de compra. Para ello se deberían incluir no sólo la etapa de decisión de compra / no compra, sino también las posteriores a ésta, referidas a los resultados de la valoración posterior de la decisión 
adoptada y su utilidad, así como las repercusiones que tales resultados tienen en las nuevas decisiones del consumidor, donde su comportamiento incide de nuevo en los valores personales y en la percepción de eficacia de su actuación, lo cual no está exento de dificultades (como falta de alternativas en el mercado coherente con sus valores y expectativas, las restricciones presupuestarias, el sacrificio entre los criterios económicos y los no económicos). En todo caso, tal desarrollo permitiría disponer de un modelo más completo para su validación, por lo que encuentra plena justificación la idoneidad de ampliar el enfoque de investigación asumido en estas páginas con la inclusión de otros factores exógenos o endógenos con potencial para causar influencias directas o moderar muchas de las relaciones hipotetizadas entre variables, augurándose en tal línea de trabajo un avance más decisivo hacia la identificación de un proceso de decisión de compra responsable más completo y estructurado.

Por otro lado, y pese a la utilidad del diseño comparativo-transversal empleado en la comprensión del proceso de decisión precompra responsable en interacción con factores de nivel formativo, sector de actividad y contextuales, se requieren nuevos análisis longitudinales para dar cumplida y adecuada cuenta de la evolución de los procesos iniciales de valoración de ofertas responsables por parte del consumidor. Con base en dicho planteamiento queda reafirmada la pertinencia, o incluso necesidad, como propuesta de investigación futura, de disponer de una mayor cantidad de diseños longitudinales que den cabida criterios de valoración de ofertas responsables a lo largo del tiempo (variaciones cíclicas).

Otra limitación metodológica del estudio llevado a cabo se refiere al nivel de representatividad logrado en la muestra empleada en el estudio empírico. Tal es así por cuanto, si bien la muestra puede considerarse representativa, no es menos cierto que (según fue indicado en su momento), la dificultad para seleccionar los individuos siguiendo el criterio propuesto vino a suponer recabar la opinión de consumidores con niveles de formación ligeramente más altos que los de la población que quiere significar. En relación a esta cuestión, y pese a que no ha de pasar desapercibido el esfuerzo invertido en la selección de los participantes en la investigación a partir de un procedimiento de muestreo estratificado que permitió asegurar una composición muestral basada en la distribución real del consumidor por nivel de formación, la complejidad entrañada por el procedimiento metodológico de recogida de datos derivó 
en determinados casos muy puntuales hacia lo que cabría considerar recurso a muestras de conveniencia, a partir de la disponibilidad de colectivos sobre los que realizar la encuesta. De este modo, futuras investigaciones deberían contemplar el propósito de a procurar una mayor precisión mediante la selección aleatoria de individuos representativos, no sólo de los distintos niveles de formación, sino de otras características de la población, lográndose por esta vía un mayor alcance de los resultados obtenidos.

Siguiendo esta misma línea argumental, si bien la realización del estudio empírico en una zona geográfica con diferentes poblaciones pronostica una adecuada solidez de las conclusiones extraídas del mismo, se requieren estudios adicionales de cara a la generalización de los resultados a otras poblaciones nacionales o internacionales, dando cabida incluso a otros modelos de comportamiento responsable del consumidor con el propósito de ganar una mayor precisión en la identificación de los factores de influencia social, de utilidad esperada u otros que determinan la valoración de ofertas responsables por parte del consumidor.

Finalmente, y por lo que respecta a la metodología aplicada al análisis de los datos recabados, resulta imprescindible precisar que, si bien los procedimientos basados en los modelos de ecuaciones estructurales permiten evaluar el grado en que ciertos resultados empíricos son consistentes con el modelo teórico previamente hipotetizado, no proporcionan en absoluto evidencia de apoyo a la existencia de una única representación posible de la realidad a partir de los datos disponibles. Así las cosas, la naturaleza transversal del diseño empleado condiciona que las conclusiones avanzadas en el presente trabajo deban interpretarse más como evidencias de relaciones estadísticamente significativas entre variables, que como inferencias causales entre las mismas, siendo necesarias a tales efectos nuevas investigaciones basadas en diseños longitudinales y experimentales, las cuales hagan posible aislar el efecto de otro tipo de variables exógenas o endógenas que puedan interferir en el comportamiento responsable del consumidor. La realización de estudios o aplicaciones sobre productos concretos permitiría, asimismo, disponer de interesantes referentes para la comparación o contrastación de resultados. 
Bibliografía 



\section{BIBLIOGRAFÍA}

Abbott WF, Monsen RJ (1979) On the measurement of corporate social responsibility: self-reported disclosures as a method of measuring corporate social involvement. Academy of Management Journal 22(3):501-515

Ackerman RW (1973) How companies respond to social demands. Harvard Business Review 51(4):88-98

Ackerman RW, Bauer RA (1976) Corporate social responsiveness. Reston Publishing, Reston VA

Adams CA (1999) The nature and processes of corporate reporting on ethical issues. CIMA, London

Adams CA (2000) Ethical reporting: past and future. Management Accounting 78(2):48-50

Adams CA (2002) Internal organisational factors influencing corporate social and ethical reporting: beyond current theorising. Accounting, Auditing \& Accountability Journal 15(2):223-250

Adams CA, Harte G (2000) Making discrimination visible: the potential for social accounting. Accounting Forum 24(1): 56-79

Agle BR, Mitchell RK, Sonnenfeld JA (1999) Who matters to CEOs? An investigation of stakeholder attributes and salience, corporate performance, and CEO values. Academy of Management Journal 42(5):507-525

Alderson S, Kakabadse A (1994) Business ethics and Irish management: a crosscultural study. European Management Journal 12(4):432-441

Alvarado A (2008) Responsabilidad social empresarial percibida desde una perspectiva sostenicéntrica, y su influencia en la reputación de la empresa y en el comportamiento del turista. Tesis Doctoral. Universidad de Valencia

Alvarado A, Schlesinger MW (2008) Dimensionalidad de la responsabilidad social empresarial percibida y sus efectos sobre la imagen y la reputación: una aproximación desde el modelo de Carroll. Estudios gerenciales 24(108):37-59

Álvarez LI, Pedreira J (2007) La responsabilidad social de la mediana y gran empresa asturiana. Fundación Universidad de Oviedo, Oviedo

Álvarez LI, Pedreira J (2008) Responsabilidad social de la pequeña empresa asturiana. Fundación Universidad de Oviedo, Oviedo

Anastasi A (1976) Psychological testing (4a ed). Macmillan, New York

Anderson J, Gerbing D (1988) Structural equation modelling in practice: A review and recommended two step approach. Psychological Bulletin 103:285-309

Anderson WT, Cunningham WH (1972) The Socially Conscious Consumer. Journal of Marketing 36(3):23-31 
Andreasen AR (2009) Issues still unresolved when using commercial marketing ideas for promoting health, social development and environment. Conferencia inaugural del $8^{\text {th }}$ AIMPN/IAPNM International Congress on Public and Nonprofit Marketing, 17-19 de junio, Valencia

Andreu L, Beckmann S, Bigné E, Chumpitaz R, Swaen V. (2004) Corporate social responsibility in the eye of the beholder: the case of European business students. En: Proceedings of the $33^{\text {rd }}$ European Marketing Academy (EMAC) Conference. EMAC, Murcia, pp 1-7

Anshen M (1983) Changing the social contract: a role for business. En: Beauchamp TL, Bowie NE (eds) Ethical theory and business. Prentice-Hall, Englewood Cliffs, pp 97103

Aparicio J, Valdés B (2009) Sobre el concepto de responsabilidad social de las empresas. Un análisis europeo comparado. Cuadernos de Relaciones Laborales 27(1):53-75

Aragón C, Iturrioz C, Olarte F, Cappuyns K (2007) La responsabilidad social y la pyme en Gipuzkoa. En: Guibert JM (ed) Empresa y responsabilidad social en Gipuzkoa, Universidad de Deusto, San Sebastián, pp 177-309

Aragón J, Rocha F (2004) La responsabilidad social empresarial en España: una aproximación desde la perspectiva laboral. Ministerio de Trabajo y Asuntos Sociales, Madrid

Aragón J, Rocha F (2009) Los actores de responsabilidad social empresarial: el caso español. Cuadernos de Relaciones Laborales 27(1):147-167

Aranguren N, Ochoa E, Ochoa J (2011) Divulgación de la información sobre responsabilidad social corporativa. Un estudio sobre empresas guipuzcoanas. En: Guibert JM (coord) Gestión socialmente responsable. Universidad de Deusto, San Sebastián, pp 207-256

Araque RA, Montero MJ (2003) La responsabilidad social de la empresa en el ámbito del marketing: algunas reflexiones y propuestas. Papeles de Ética, Economía y Dirección 8:33-63

Arbuthnot J (1977) The roles of attitudinal and personality variables in the prediction of environment behaviour and knowledge. Environment and Behaviour 9(2):217-232

Archel P , Husillos J (2009) Últimos desarrollos sobre RSE en España: ¿un avance hacia la sostenibilidad? CIRIEC España, Revista de Economía Pública, Social y Cooperativa 65:59-84

Arenas D. (2006) Responsabilidad, Estrategia y Grupos de Interés. Harvard Deusto Marketing \&Ventas 77(6):34-39

Arens P, Brouthers KD (2001) Key stakeholder theory and state owned versus privatized firms. Management International Review 41(4):377-394

Argandoña A (1998) The stakeholder theory and the common good. Journal of Business Ethics 17(9):1093-1102

Argandoña A (2011) La ética y la toma de decisiones en la empresa. Universia Business Review 30(2):12-21

Argandoña A (2012) ¿Qué es y qué no es la responsabilidad social? Revista del Instituto de Estudios Económicos 1:1-14 
Argandoña A, Isea R (2011) ISO 26000, una guía para la responsabilidad social de las organizaciones. IESE Business School, Pamplona

Asociación Española de Contabilidad y Administración de Empresas (2004) Marco conceptual de la responsabilidad social corporativa. AECA, Madrid

Aupperle KE, Carroll AB, Hatfield JD (1985) An empirical investigation of the relationship between corporate social responsibility and profitability. Academy of Management Journal 28(2):446-463

Ayuso S, Mutis J (2010) El Pacto Mundial de las Naciones Unidas ¿una herramienta para asegurar la responsabilidad global de las empresas? Revista de Globalización, Competitividad y Gobernabilidad 4(2):28-39

Backman J (1975) Social responsibility and accountability. New York University Press, New York

Badal A (2005) Using interdisciplinary thinking to improve strategy formulation: a managerial perspective. International Journal of Management 22(3):365-375

Bagozzi RP, Yi Y (1991) Multitrait-multimethod matrices in consumer research. Journal of Consumer Research 17: 426-439

Baker MJ (2006) Editorial. Journal of Customer Behaviour 5(3) 197-200

Balaguer MR, Fernández MA, Muñoz MJ (2007) La responsabilidad social de la empresa. Relaciones entre la performance social, financiera y bursátil. Consellería d’Empresa, Universitat i Ciencia de la Generalitat de Valencia, Valencia

Bandura A (1986). Social foundations of thought and action: a social cognitive theory. Prentice Hall, Englewood Cliffs NJ

Bandura A (1989) Human agency in social cognitive theory. American Psychologist 44:1175-1184

Barclay D, Higgins C, Thompson R (1995) The Partial Least Squares (PLS) approach to causal modelling: personal computer adoption and use as an illustration. Technology Studies (2):285-309

Barlett M (1954) A note on the multiplying factors for various chi square approximations. Journal of the Royal Statistical Society 16(B):296-298

Barnard CI (1938) The functions of the executive. Harvard University Press, Cambridge MA

Baron D (2001) Private politics, corporate social responsibility and integrated strategy. Journal of Economics and Management Strategy 10:7-45

Barone MJ, Miyazaki, AD, Taylor KA (2000) The influence of cause-related marketing on consumer choice: does one good turn deserve another? Journal of Academic Marketing Science 28:248-262

Barone MJ, Norman AT, Miyazaki AD. (2007) Consumer response to retailer use of cause-related marketing: is more fit better? Journal of Retailing 83(4):437-445

Bebbington J (1997) Engagement, education and sustainability: a review essay on environmental accounting. Accounting, Auditing \& Accountability Journal 10(3):365-381 
Bebbington J, Gray RH, Owen DL (1999) Seeing the wood for the trees: taking the pulse of social and environmental accounting. Accounting, Auditing \& Accountability Journal 12(1):47-52

Becker-Olsen K Cudmore B, Hill R (2006) The impact of perceived corporate social responsibility on consumer behavior. Journal of Business Research 59(1):46-53

Beggs J, Lane I (1989) Corporate goal structures and business students: a comparative study of values. Journal of Business Ethics 8(6):471-478

Berens G, van Riel CBM, van Bruggen GH (2005) Corporate associations and consumer product responses: the moderating role of corporate brand dominance. Journal of Marketing 69 (3):35-48

Bestratén M, Pujol L (2004a) NTP 643. Responsabilidad social de las empresas (I): conceptos generales. Instituto Nacional de Seguridad e Higiene en el Trabajo, Madrid

Bestratén M, Pujol L (2004b) NTP 644. Responsabilidad social de las empresas (II): tipos de responsabilidades y plan de actuación. Instituto Nacional de Seguridad e Higiene en el Trabajo, Madrid

Bhattacharya CB, Korschun D, Sen S (2008) Strengthening stakeholder-company relationships through mutually beneficial corporate social responsibility initiatives. Journal of Business Ethics 85(2):257-272

Bhattacharya CB, Sen S (2003a) Consumer company identification: a framework for understanding consumers' relationships with companies. Journal of Marketing Research 67:76-88

Bhattacharya CB, Sen S (2003b) Doing better at doing good: when, why and how consumers respond to corporate social initiatives. California Management Review 47(1):9-24

Bigné E, Alvarado A, Aldás J, Currás R (2011) Efectos de la responsabilidad social corporativa percibida por el consumidor sobre el valor y satisfacción con el servicio. Revista Europea de Dirección y Economía de la Empresa 20 (4):139-160

Bigné E, Andreu L, Chumpitaz R, Swaen V (2005) Percepción de la responsabilidad social corporativa: un análisis cross-cultural, Universia Business Review 5:14-27

Bigné E, Andreu L, Chumpitaz R, Swaen V (2006). La influencia de la responsabilidad social corporativa en el comportamiento de compra de estudiantes universitarios. Esic Market 125:163-189

Bigné E, Currás R, (2008) ¿ ¿nfluye la imagen de responsabilidad social en la intención de compra? El papel de la identificación del consumidor con la empresa. Universia Business Review 19:10-23

Blackwell RD, Miniard PW, Engel JF (2006) Consumer behavior (6 $6^{\mathrm{a}}$ ed). Thomson Higher Education, Mason $\mathrm{OH}$

Bollen KA (1989) Structural equations with latent variables. Wiley, New York

Boulstridge E, Carrigan M (2000) Do consumers really care about corporate responsibility? highlighting the attitude-behavior gap. Journal of Communication Management 4:355-368 
Boush DM, Freistad M, Rose GM (1994) Adolescent skepticism toward TV advertising and knowledge of advertiser tactics. Journal of Consumer Research 21:165-175

Bowen HR (1953) Social responsibilities of the businessman. Harper \& Row, New York

Bowie N, Duska R (1990) Business ethics. Prentice Hall, Englewood Cliffs NJ

Bowman EH, Haire M (1975) A strategic posture toward corporate social responsibility. California Management Review 18(2):49-58

Boxenbaum E (2006) Corporate social responsibility as institutional hybrids. Journal of Business Strategies 23(1):45-63

Brammer S, Millington A, Rayton B (2007) The contribution of corporate social responsibility to organizational commitment. International Journal of Human Resource Management 18(10):1701-1719

Brammer S, Pavelin S (2004). Building a good reputation. European Management Journal 46(15):704-713

Brown T, Dacin P (1997) The company and the product: corporate associations and consumer product responses. Journal of Marketing 61(1):68-84

Bucholz RA (1987) The business/government/society relationship in management thought. En: Paul K (ed) Business environment and business ethics. The social, moral and political dimensions of management. Ballinger, Cambridge MA

Bucholz RA (1991) Corporate social responsibility and the good society: from economics to ecology. Business Horizons 34(4):19-31

Buil I, Martínez E, Montaner T (2012) La influencia de las acciones de marketing con causa en la actitud hacia la marca. Cuadernos de Economía y Dirección de la Empresa 15(2):84-93

Caballero I, Balaguer AI (2005a) NTP 647. Responsabilidad social de las empresas: Modelo SAI 8000 (Social Accountability). Instituto Nacional de Seguridad e Higiene en el Trabajo, Madrid

Caballero I, Balaguer AI (2005b) NTP 648. Responsabilidad social de las empresas. Modelo GRI. Instituto Nacional de Seguridad e Higiene en el Trabajo, Madrid

Caballero I, Balaguer AI (2006a) NTP 687. Responsabilidad social de las empresas. Modelo Balance Social de ANDI-OIT (I). Instituto Nacional de Seguridad e Higiene en el Trabajo, Madrid

Caballero I, Balaguer AI (2006b) NTP 688. Responsabilidad social de las empresas: modelo de balance social de ANDI-OIT. Indicadores (II). Instituto Nacional de Seguridad e Higiene en el Trabajo, Madrid

Cabero S, Cebollada J (1998) Modelos matemáticos de comportamiento del consumidor. Esic Market 101:21-33

Campbell CA (1992) A decision theory model for entrepreneurial acts. Entrepreneurship Theory and Practice 17(1):21-27

Campbell DT (1960) Recommendations for APA test standards regarding construct, trait, or discriminant validity. American Phychologist 15:253-267 
Campbell MC, Kirmani A (2000) Consumer's use of persuasion knowledge: the effects of accessibility and cognitive capacity on perceptions of an influence agent. Journal of Consumer Research 27:69-83

Cancino C, Morales M (2008) Responsabilidad Social Empresarial. Universidad de Chile, Santiago de Chile

Cantó N, Lozano JM (2009) The Spanish discourse on corporate social responsibility. Journal of Business Ethics 88(1):175-197

Carmines EG, Zeller RA (1979) Reliability and validity assessment. Sage, Newbury Park CA

Carneiro M (2004) La responsabilidad social corporativa interna: la "nueva frontera" de los recursos humanos. ESIC, Madrid

Carrero I, Valor C (2012) La relación del consumidor con el etiquetado responsable. Revista de Responsabilidad Social de la Empresa 10. Disponible en [http://www.fundacionluisvives.org/]. Consultado en junio de 2012

Carrigan M (1997) The great corporate give-away-can marketing do good for the 'dogooders'? European Business Journal 9(4):40-46

Carrigan M, Attalla A. (2001) The myth of the ethical consumer. Do ethics matter in purchase behaviour? Journal of Consumer Marketing 18(7):560-577

Carroll AB (1977) Managing corporate social responsibility. Little Brown, Boston MA

Carroll AB (1979) A three-dimensional conceptual model of corporate social performance. Academy of Management Review 4(4):497-505

Carroll AB (1983) Corporate social responsibility: will industry respond to cutbacks in social program funding? Vital Speeches of the Day 49:604-608

Carroll AB (1991) The pyramid of corporate social responsibility: toward the moral management of organizational stakeholders. Business Horizons 34(4):39-48

Carroll AB (1994) Social issues in management research: experts' views, analysis and commentary. Business \& Society 33(1):5-29

Carroll AB (1999) Corporate social responsibility. Evolution of a definitional construct. Business and Society 38(3):268-295.

Castaldo S, Perrini F (2004) Corporate social responsibility, trust management, and value creation. Trabajo presentado en el $20^{\text {th }}$ EGOS Colloquium, 1-3 de junio, Ljubljana

Castaldo S, Perrini F, Misani N, Tencati A (2009): The missing link between corporate social responsibility and consumer trust: the case of fair trade products. Journal of Business Ethics 84(1):1-15

Castillo AM (2001) El resurgir de la responsabilidad social de la empresa en los umbrales del siglo XXI. Universidad de Málaga, Málaga

Catell RB (1966) The scree test for number of factors. Multivariate Behavioral Research $1: 245-276$

CECU (2007) Los consumidores y la Responsabilidad Social Corporativa. CECU, Madrid 
CECU (2010) La opinión y valoración de los consumidores sobre la RSE en España. CECU, Madrid

Cepeda G, Roldán JL (2004) Aplicando en la práctica la técnica PLS en la Administración de Empresas. Comunicación presentada en el XIV Congreso Nacional de ACEDE, 19-21 de septiembre, Murcia

CERSE-GT.I (2011) El papel de la RSE ante la crisis económica: su contribución al nuevo modelo productivo, la competitividad y el desarrollo sostenible. Consejo Estatal de Responsabilidad Social de las Empresas, Madrid. Disponible en [http://empleo.gob.es/consejo_rse/]. Consultado en junio de 2012.

CERSE-GT.II (2011) Transparencia, comunicación y standards de los informes y memorias de sostenibilidad. Consejo Estatal de Responsabilidad Social de las Empresas, Madrid. Disponible en [http://empleo.gob.es/consejo_rse/]. Consultado en junio de 2012.

CERSE-GT.IIIa (2011) Consumo socialmente responsable. Consejo Estatal de Responsabilidad Social de las Empresas, Madrid. Disponible en [http://empleo.gob.es/consejo_rse/]. Consultado en junio de 2012.

CERSE-GT.IIIb (2011) Inversión socialmente responsable. Consejo Estatal de Responsabilidad Social de las Empresas, Madrid. Disponible en [http://empleo.gob.es/consejo_rse/]. Consultado en junio de 2012.

CERSE-GT.IV (2011) La RSE y la educación. Consejo Estatal de Responsabilidad Social de las Empresas, Madrid. Disponible en [http://empleo.gob.es/consejo_rse/]. Consultado en junio de 2012.

CERSE-GT.V (2011) Gestión de la diversidad, cohesión social y cooperación al desarrollo. Consejo Estatal de Responsabilidad Social de las Empresas, Madrid. Disponible en [http://empleo.gob.es/consejo_rse/]. Consultado en junio de 2012.

Chatfield C, Goodhart GJ (1973) A consumer purchasing model with erlang interpurchase times. Journal of the American Statistical Association 68:828-835

Chin WW (1998a) The partial least squares approach to structural equation modeling. En: George A (ed) Modern methods for business research. Laurence Erlbaum Associates, New Jersey, pp 295-336

Chin WW (1998b) Issues and opinion on structural equation modeling. Management Information Systems Quarterly 22(1):7-16

Chin WW (2010). How to write up and report PLS analyses. En: Esposito V, Chin WW, Henseler J, Wang $\mathrm{H}$ (eds) Handbook of partial least squares. Concepts, methods and applications. Springer-Verlag, Heidelberg, pp. 655-690

Chin WW, Marcolin BL, Newsted PR (2003) A partial least squares latent variable modeling approach for measuring interaction effects: Results from a Monte Carlo simulation study and an electronic mail emotion/adoption study. Information Systems Research 14:189-217

Chrisman JJ, How F, Robinson RB (1987) New venture development: The costs and benefits of public sector assistance. Journal of Business Venturing 2:315-328

Christmann P, Taylor G (2006). Firm self-regulation through international certifiable standards: determinants of symbolic versus substantive implementation. Journal of International Business Studies 37(6):863-878 
Churchill GA (1979) A paradigm for developing better measures of marketing constructs. Journal of Marketing Research 16:64-73

Clark JM (1939) Social control of business. McGraw-Hill, New York

Clark LA, Watson D (1995) Constructing validity: basic issues in objective scale development. Psychological Assessment 7:309-319

Clarkson MBE (1995) A stakeholder framework for analyzing and evaluating corporate social performance. Academy of Management Review 20(1):92-117

Clements R (1995). Complete Guide to ISO 14.000. Prentice Hall, Englewood Cliffs NJ

Cochran PL, Wood RA (1984) Corporate social responsibility and financial performance. Academy of Management Journal 27(1):42-56

Cohen J, Nacamuli C, Zadek S (2003) State of sustainability assurance 2003, Certified Accountants Educational Trust, London

Collins D (1996) How and why participatory management improves a company's social performance: four gainsharing case studies. Business \& Society 35(2):176-210

Comisión Europea (1993) Crecimiento, competitividad y empleo: Retos y pistas para entrar en el siglo XXI. Comisión Europea, Luxemburgo

Comisión Europea (2001a) Desarrollo sostenible en Europa para un mundo mejor: Estrategia de la Unión Europea para un desarrollo sostenible. COM (2001) 264 final. Comisión Europea, Bruselas. Disponible en [http://europa.eu/]. Consultado en junio de 2012

Comisión Europea (2001b) Libro Verde: fomentar un marco europeo para la responsabilidad social de las empresas. COM (2001) 366 final. Comisión Europea, Bruselas. Disponible en [http://europa.eu/]. Consultado en junio de 2012

Comisión Europea (2002a) Corporate social responsibility: a business contribution to sustainable development. COM (2002) 347 final. Comisión Europea, Bruselas. Disponible en [http://europa.eu/]. Consultado en junio de 2012

Comisión Europea (2002b) La responsabilidad social de las empresas: una contribución empresarial al desarrollo sostenible. COM (2002) 347 final. Comisión Europea, Bruselas. Disponible en [http://europa.eu/]. Consultado en junio de 2012

Comisión Europea (2005) Comunicación de la Comisión relativa a la revisión de la estrategia para un desarrollo sostenible. COM (2005) 658 final. Comisión Europea, Bruselas. Disponible en [http://europa.eu/]. Consultado en junio de 2012

Comisión Europea (2006) Poner en práctica la Asociación para el Crecimiento y el Empleo: hacer de Europa un polo de excelencia de la responsabilidad social de las empresas COM (2006) 136 final. Comisión Europea, Bruselas. Disponible en [http://europa.eu/]. Consultado en junio de 2012

Comisión Europea (2011) Estrategia Renovada de la UE para 2011-2014 sobre la responsabilidad social de las empresas. COM (2011) 681 final. Comisión Europea, Bruselas. Disponible en [http://europa.eu/]. Consultado en junio de 2012

Committee for Economic Development (1971) Social responsibilities of business corporations. CED, New York 
Congreso de los Diputados (2006) Informe de la Subcomisión para potenciar y promover la responsabilidad social de las empresas (Libro Blanco). Boletín Oficial de las Cortes Generales 423, de 31 de junio, 1-124

Cortina A (2003) Las tres edades de la ética empresarial. En: Cortina A (ed) Construir confianza. Ética de la empresa en la sociedad de la información y las comunicaciones. Trotta, Madrid, pp 17-38

Council on Economic Priorities Accreditation Agency CEPAA (1998) Guidance Document for Social Accountability 8000 (SA 8000). Disponible en [http://www.cepaa.org/]. Consultado en junio de 2012

Creyer EH, Ross WT (1997) The influence of firm behavior on purchase intention: do consumers really care about business ethics?, The Journal of Consumer Marketing 14(6):421-428

Cronbach LJ (1951) Coefficient alpha and the internal structure of tests. Psychometrika (16): 297-334

Cronbach LJ, Meehl PE (1955) Construct validity in psychological test. Psychological Bulletin 52:281-302

Cuervo A (2009) Responsabilidad social corporativa, gobierno de la empresa y stakeholders. En: Almagro JJ (ed) Responsabilidad social: una reflexión global sobre la RSE. Prentice Hall, Madrid, pp 39-50

Currás R (2007) Comunicación de la responsabilidad social corporativa: imagen e identificación con la empresa como antecedentes del comportamiento del consumidor. Tesis Doctoral. Universidad de Valencia

Dacin PA, Brown TJ (2006) Corporate branding, identity, and customer response. Journal of the Academy of Marketing Science 34(2):95-98

Dahlsrud A (2008) How corporate social responsibility is defined: an analysis of 37 definitions. Corporate Social Responsibility and Environmental Management 15:113

Dalton DR, Cosier RA (1982) The four faces of social responsibility. Business Horizons 25(3):19-27

Davenport K (2000) Corporate citizenship: a stakeholder approach for defining corporate social performance and identifying measures for assessing it. Business \& Society 39(2):210-219

Dávila MC (2012) Beneficios del voluntariado corporativo. Revista de Responsabilidad Social de la Empresa 10. Disponible en [http://www.fundacionluisvives.org/]. Consultado en junio de 2012

Davis K (1960) Can business afford to ignore social responsibilities? California Management Review 2(1):70-76

Davis K (1967) Understanding the social responsibility puzzle: what does the businessman owe to society? Business Horizons 10(4):45-50

Davis K (1973) The case for and against business assumption of social responsibilities. Academy of Management Journal 16(2):312-322

Davis K, Blomstrom RL (1966) Business and its environment. McGraw-Hill, New York 
De Bakker FGA, Groenewegen P, Den Hond F (2005). A bibliometric analysis of 30 years of research and theory on corporate social responsibility and corporate social performance. Business \& Society 44(3):283-317

De Bakker FGA, Groenewegen P, Den Hond F (2006). A research note on the use of bibliometrics to review the corporate social responsibility and corporate social performance literature. Business \& Society 45(1):7-19

De la Cruz C, Sasia PM, Guibert JM (2007) La responsabilidad social en Gipuzkoa: ¿por dónde empezar?. En: Guibert JM (coord) Empresa y Responsabilidad Social en Gipuzkoa. Universidad de Deusto, San Sebastián, pp 23-40

De la Cuesta M, Valor C (2003) Responsabilidad social de la empresa: concepto, medición y desarrollo en España. Boletín Económico de ICE 2755:7-19

De los Ríos A, Ruiz M, Tirado P, Carbonero M (2012) Una aproximación a la relación entre información sobre la responsabilidad social orientada al cliente y la reputación corporativa de las entidades financieras españolas. Cuadernos de Economía y Dirección de Empresas 15:130-140

De Vellis RF (1991) Scale development: theory and applications. Sage, Newbury Park CA

Decker OS (2004) Corporate social responsibility and structural change in financial services. Managerial Auditing Journal 19(6):712-728

Doh J, Guay Y (2006) Corporate social responsibility, public policy, and NGO activism in Europe and the United States: an institutional-stakeholder perspective. Journal of Management Studies 43(1):47-73

Domínguez N (2012) En tiempos de crisis las empresas sociales pueden ser más productivas y competitivas. Solidaridad Digital 07/05/2012. Disponible en [http://www.solidaridaddigital.es/]. Consultado en junio de 2012

Donaldson T (1989) The ethics of international business. Oxford University Press, New York

Drucker PF (1954) The practice of management. Harper \& Row, New York

Drucker PF (1984) The new meaning of corporate social responsibility. California Management Review 26(2):53-63

Drumwright ME (1994) Socially responsible organizational buying: environmental concern as a noneconomic buying criterion. Journal of Marketing 58(3):1-19

Dutton JE, Dukerich JM y Harquail CV (1994) Organizational images and member identification. Administrative Science Quarterly 39(2): 239-263

Eells R (1956) Corporate giving in a free society. Harper \& Row, New York

Eells R, Walton C (1961) Conceptual foundations of business. Irwin, Burr Ridge IL

Eells R, Walton C (1974) Conceptual foundations of business ( $3^{\mathrm{a}}$ ed). Irwin, Burr Ridge IL

Efron B, Tibshirani RJ (1993) An Introduction to the bootstrap. Chapman and Hall, New York

Eilbert H, Parket IR (1973) The current status of corporate social responsibility. Business Horizons 16(4):5-14 
Elkington J (1997) Cannibals with forks: the triple bottom line of $21^{\text {st }}$ century business. Capstone, Oxford MA

Ellen PS, Mohr LA, Webb DJ (2000) Charitable programs and the retailer: do they mix? Journal of Retailing 76(3):393-406

Ellen PS, Webb DJ, Mohr LA (2006) Building corporate associations: consumer attributions for corporate social responsibility programs. Journal of the Academy of Marketing Science 34(2):147-157

Elliot R, Eccles S, Hodgson M (1993) Re-coding gender representations: women, cleaning products, and advertising's 'new man'. International Journal of Research in Marketing 10(3): 311-324

Epstein EM (1987) The corporate social policy process: beyond business ethics, corporate social responsibility, and corporate social responsiveness. California Management Review 29(1):99-114

Esteban G, María J, Moneva JM, Rivero P (2005) Responsabilidad social corporativa. Aspectos jurídico-económicos. Universidad Jaume I, Castellón

European Multistakeholder Forum on CSR (2004) Final results \& recommendations. European Multistakeholder Forum on CSR, Bruselas. Disponible en [http://ec.europa.eu/]. Consultado en junio de 2012

Falk RF, Miller NB (1992) A primer for soft modelling. University of Akron Press, Akron $\mathrm{OH}$

Felber C (2012) La economía del bien común. Deusto, Bilbao

Fernández A, Martínez A (2003) ¿Es necesaria una regulación de la responsabilidad social en Europa? Boletín Económico de ICE 2775:33-45

Fernández D, Merino A (2005) ¿Existe disponibilidad a pagar por responsabilidad social corporativa? Percepción de los consumidores. Universia Business Review $7: 38-53$.

Fernández JJ (2012) De la condicionalidad social a los acuerdos marco internacionales sobre la evolución de la responsabilidad social empresarial. Aranzadi, Pamplona

Fernando M (2007) Corporate social responsibility in the wake of the Asian tsunami: a comparative case study of two Sri Lankan companies. European Management Journal 25(1):1-10

File KM, Prince RA (1998) Cause related marketing and corporate philanthropy in the privately held enterprise. Journal of Business Ethics 17(14):1529-1539

Fitch HG (1976) Achieving corporate social responsibility. Academy of Management Review 1(1):38-46

Folkes VS, Kamins MA (1999) Effects of information about firms' ethical and unethical actions on consumer's attitudes. Journal of Consumer Psychology 8(3):243-259

Fombrun C. (1996): Reputation: realizing value from the corporate image. Harvard Business School Press, Cambridge MA

Ford JK, MacCallum RC, Tait M (1986) The application of exploratory factor analysis in applied psychology: a critical review and analysis. Personnel Psychology 39:291-314 
Forética (2006) Evolución de la Responsabilidad Social de las Empresas en España 2006. Forética, Madrid

Forética (2011) Evolución de la Responsabilidad Social de las Empresas en España 2011, Forética, Madrid

Fornell C (1982) A second generation of multivariate analysis: an overview. En: Fornell $\mathrm{C}$ (ed) A second generation of multivariate analysis (vol 1). Praeger, New York, pp $1-21$

Fornell C, Bookstein FL (1982) A comparative analysis of two structural equation models: Lisrel and PLS applied to market data. En C. Fornell (ed.), A second generation of multivariate analysis (vol 1). Praeger, New York, pp 289-324

Fornell C, Larcker DF (1981) Evaluating structural equation models with unobservable variables and measurement error. Journal of Marketing Research 18:39-50

Foro de Expertos de RSE (2007a) Documento del Foro de Expertos de RSE: I, II y III Sesión de trabajo. Definición y ámbito de la RSE. Foro de Expertos de RSE, Madrid. Disponible en [http://empleo.gob.es/es/sec_trabajo/]. Consultado en junio de 2012

Foro de Expertos de RSE (2007b) Documento del Foro de Expertos de RSE: IV Sesión de trabajo. El informe de RSE como motor de la responsabilidad social. Foro de Expertos de RSE, Madrid. Disponible en [http://empleo.gob.es/es/sec_trabajo/]. Consultado en junio de 2012

Foro de Expertos de RSE (2007c) Documento del Foro de Expertos de RSE: V Sesión de trabajo. El desarrollo de la responsabilidad social de las empresas en España. Foro de Expertos de RSE, Madrid. Disponible en [http://empleo.gob.es/es/sec_trabajo/]. Consultado en junio de 2012

Foro de Expertos de RSE (2007d) Documento del Foro de Expertos de RSE: VI Sesión de trabajo. Las políticas de fomento y desarrollo de la responsabilidad social de las empresas en España. Foro de Expertos de RSE, Madrid. Disponible en [http://empleo.gob.es/es/sec_trabajo/]. Consultado en junio de 2012

Frederick WC (1960) The growing concern over business responsibility. California Management Review 2(4):54-61

Frederick WC (1986) Toward CSR3: why ethical analysis is indispensable and unavoidable in corporate affairs. California Management Review 8(2):126-141

Frederick WC (1987) Theories of corporate social performance. En: Sethi SP, Falbe CM (eds) Business and society: dimensions of conflict and co-operation. Lexington Books, Lexington KY, pp 142-161

Frederick WC (1994) From CSR1 to CSR2: the maturing of business and society thought. Business and Society 33(2):150-164

Freeman RE (1984) Strategic management: a stakeholder approach. Pitman, Boston MA

Freeman RE (2004) The Stakeholder Approach Revisited. Zeitschrift für Wirtschaftsund Unternehmensethik 5 (3):220-241

Freeman RE, Gilbert DR (1992) Business, ethics and society: a critical agenda. Business and Society 31(1):9-17 
Freeman RE, Harrison J, Wicks A, Parmar B, de Colle S (2010) Stakeholder Theory: The State of the Art, Cambridge University Press, Cambridge MA

Freeman RE, Reed DL (1983) Stockholders and stakeholder: a new perspective on corporate governance. California Management Review 25(3):88-106

Friedman M (1962) Capitalism and freedom. University of Chicago Press, Chicago IL

Friedman M (1999) Consumer boycotts. Effecting change through the marketplace and the media. Routledge, New York

Fuentes F, Núñez J, Veroz R (2005) Alternativas de cumplimiento de responsabilidad social corporativa en gestión de recursos humanos. Universia Business Review (7):68-89

Fundación Étnor (2007) ERSE-Observatorio de Ética y Responsabilidad Social de la Empresa 2007. Fundación Étnor, Valencia

Fundación Étnor (2010): ERSE-Observatorio de Ética y Responsabilidad Social de la Empresa 2010. Fundación Étnor, Valencia

Fundación Luis Vives (2011) Cuaderno de conclusiones del Primer Foro de Investigación y Debate sobre la Responsabilidad Social de las Empresas. Innovación y competitividad a través de la RSE. Fundación Luis Vives, Madrid

Galán MM (2011) Variables que influyen en la actitud hacia el marketing con causa y determinantes de la satisfacción y la lealtad en la compra solidaria. Tesis Doctoral. Universidad de Extremadura.

Galán MM, Galera C, Valero V (2002) El marketing con causa. Un análisis de su evolución y su situación en España. En: Vázquez JL, Placer JL (eds) I Jornadas Internacionales de Marketing Público y No Lucrativo. Universidad de León, León, pp 333-345

Gandz J, Hayes N (1988) Teaching business ethics. Journal of Business Ethics 7:657669

García de los Salmones MM, Herrero A, Rodriguez I (2005) Influence of corporate social responsibility on loyalty and valuation of services. Journal of Business Ethics (61):369-385

García I, Gibaja J, Mujika A (2007) Opinión del consumidor guipuzcoano sobre la responsabilidad social corporativa. En: Guibert JM (coord) Empresa y Responsabilidad Social en Gipuzkoa. Universidad de Deusto, San Sebastián, pp $137-172$

García I, Gibaja J, Mujika A. (2011) Activismo y participación ciudadana a favor del comportamiento empresarial socialmente responsable. El caso de Gipuzkoa. En: Guibert JM (coord) Gestión socialmente responsable. Universidad de Deusto, San Sebastián, pp 259-339

García I, Gibaja JJ, Mujika A (2012) Credibilidad de las fuentes de información sobre responsabilidad social corporativa. Revista de Responsabilidad Social de la Empresa 10. Disponible en [http://www.fundacionluisvives.org/]. Consultado en junio de 2012

Garmendia JA (2009) Qué quiere decir y para qué sirve la responsabilidad social corporativa. En: Almagro JJ (ed) Responsabilidad social. Una reflexión global sobre la RSE. Prentice Hall, Madrid, pp 3-13 
Garriga E, Melé C (2004) Corporate social responsibility theories: mapping the territory. Journal of Business Ethics 53:51-71

Gefen D, Rigdon EE, Straub DW (2011) An updated and extension to SEM guidelines for administrative and social science research. Management Information Systems Quarterly 35(2):iii-xiv

Gefen D, Straub DW (2005) A practical guide to factorial validity using PLS-Graph: tutorial and annotated example. Communications of the Association for Information Systems 16:91-109

Gefen D, Straub DW, Boudreau M (2000) Structural equation modeling techniques and regression: guidelines for research practice. Communications of the Association for Information System 7(7):1-78

Geisser S (1974) A predictive approach to the random effects model. Biometrica 61:101-107

Gerbins D, Anderson JC (1998) An updated paradigm for scale development incorporating unidimensionality and its assessment. Journal of Marketing Research 25:186-192

Gerow JE, Grover V, Roberts N, Thatcher JB (2010). The diffusion of second generation statistical techniques in Information Systems research from 1990-2008. Journal of Information Technology Theory and Application 11(4):5-28

Gilbert DT, Malone PS (1995) The correspondence bias. Psychological Bulletin 117(1):21-38

Global Reporting Initiative (2002) Guía para la elaboración de memorias de sostenibilidad. Disponible en [http://www.globalreporting.org/]. Consultado en junio de 2012.

Global Reporting Initiative (2006) Guía para la elaboración de memorias de sostenibilidad. Disponible en [http://www.globalreporting.org/]. Consultado en junio de 2012.

Godfrey PC (2005) The relationship between corporate philanthropy and shareholder wealth: a risk management perspective. Academy of Management Review 30(4):777-798

González AM, Negueruela M, Dávila MC (2008) Voluntariado apoyado por la empresa: guía para entidades de acción social. Dirección General de Voluntariado y Promoción Social de la Comunidad de Madrid, Madrid

González, L. (2005): Aproximaciones a la definición y el contenido de la Responsabilidad Corporativa. Disponible en [http://www.a3net.net/rsc/]. Consultado en junio de 2012.

Grajales T (1996) Conceptos básicos para la investigación social. Publicaciones Universidad de Montemorelos, Nuevo León

Gray RH (1998) Imagination, a bowl of petunias and social accounting. Critical Perspectives on Accounting 9(2):205-216

Gray RH (2000) Current developments and trends in social and environmental auditing, reporting and attestation: a review and comment. International Journal of Auditing 4(3):247-268 
Gray RH (2001) Thirty years of social accounting, reporting and auditing: what (if anything) have we learnt? Business Ethics: A European Review 10(1):9-15

Gray RH (2002) The social accounting project and accounting organizations and society: privileging engagement, imagination, new accountings and pragmatism over critique? Accounting, Organizations and Society 27(7):687-708

Gray RH, Bebbington KJ, Walters D, Thomson I (1995) The greening of enterprise: an exploration of the (non) role of environmental accounting and environmental accountants in organisational change. Critical Perspectives on Accounting 6(3):211239

Gray RH, Dey C, Owen DL, Evans R, Zadek S (1997) Struggling with the praxis of social accounting: stakeholders, accountability, audits and procedures. Accounting, Auditing \& Accountability Journal 10(3):325-364

Gray RH, Owen DL, Adams CA (1996) Accounting and accountability: changes and challenges in corporate social and environmental reporting. Prentice Hall, London

Gray RH, Owen DL, Maunders KT (1987) Corporate social reporting: accounting and accountability. Prentice Hall, London

Gray RH, Owen DL, Maunders KT (1988) Corporate social reporting: emerging trends in accountability and the social contract. Accounting, Auditing \& Accountability Journal 1(1):6-20

Green T, Peloza J (2011) How does corporate social responsibility create value for consumers? Journal of Consumer Marketing 28(1):48-56

Greening DW, Gray B (1994).Testing a model of organizational response to social and political issues. Academy of Management Journal 37(3): 467-498

Griffin JJ, Mahon JF (1997) The corporate social performance and corporate financial performance debate: twenty-five years of incomparable research. Business \& Society 36:5-31

Guibert JM (coord) (2007) Empresa y Responsabilidad Social en Gipuzkoa. Universidad de Deusto, San Sebastián

Guibert JM (coord) (2011) Gestión socialmente responsable. Universidad de Deusto, San Sebastián

Hair JF, Anderson RE, Tatham RL, Black WC (1998) Multivariate data analysis (5 ed). Prentice Hall, London

Hair JF, Anderson RE, Tatham RL, Black WC (2005) Análisis multivariante de datos ( $5^{\mathrm{a}}$ ed). Pearson Prentice Hall, México DF

Handelman JM, Arnold SJ (1999) The role of marketing actions with a social dimension: appeals to the institutional environment. Journal of Marketing 63(3):3348

Harte G, Owen DL (1987) Fighting de-industrialisation: the role of local government social audits. Accounting, Organizations and Society 12(2):123-42

Harvey RJ, Billings RS, Nilan KJ (1985) Confirmatory factor analysis of the job diagnostic survey: good news and bad news. Journal of Applied Psychology 70:461-468 
Hathaway JW (1990) Students teach business lesson. Business and Society Review 95:58-61

Heald M (1957) Management's responsibility to society: the growth of an idea. Business History Review 31(4): 375-384

Heald M (1970) The social responsibilities of business: company and community, 19001960. Case Western Reserve University Press, Cleveland OH

Heras I (2011) ¿Qué fue de la isomanía? ISO 9000, ISO 14000 y otros metaestándares en perspectiva. Universia Business Review (29):66-79

Herranz JM (2010) La comunicación de la responsabilidad social: una forma de participación ciudadana. Sociedad y Utopía. Revista de Ciencias Sociales 35:201218

Hildebrand D, Sen S, Bhattacharya CB (2011) Corporate social responsibilty: a corporate marketing perspective. European Journal of Marketing 45(9):1353-1364

Hinkin TR (1995) A review of scale development practices in the study of organizations. Journal of Management 21: 967-988

Hoeffler S, Keller KL (2002) Building brand equity through corporate societal marketing. Journal of Public Policy \& Marketing 21(2):78-89

Holmes SL (1976) Executive perceptions of corporate social responsibility. Business Horizons 19(3):34-40

Hult GT, Mena J, Ferrell OC, Ferrell L (2011) Stakeholder marketing: a definition and conceptual framework. American Mathematical Society Review 1:44-65

Husted BW, Allen DB (2006). Corporate social responsibility in the multinational enterprise: strategic and institutional approaches. Journal of International Business Studies 37(6):838-849

Ibisate A (2011) Estudio multisectorial sobre el estado de la responsabilidad corporativa de la gran empresa en España. Club de Excelencia en Sostenibilidad, Madrid. Disponible en [http://www.clubsostenibilidad.org/]. Consultado en junio de 2012

Ibrahim NA, Angelidis JP, Howard DP (2006) Corporate social responsibility: a comparative analysis of perceptions of practicing accountants and accounting students. Journal of Business Ethics 66(2-3):157-167

Institute of Social and Ethical AccountAbility ISEAA (2008) AA1000 AccountAbility Principles Standard 2008. Disponible en [http://www.accountability.org/]. Consultado en junio de 2012

Ioannis I, Serafeim G (2011) The consequences of mandatory corporate sustainability reporting. Working Paper 11/100. Harvard Business School, Harvard MA

Jackson PR, Wall TD, Martin R, Davids K (1993) New measures of job control, cognitive demand, and production responsibility. Journal of Applied Psychology, 78:753-762

Johnson HL (1971) Business in contemporary society: framework and issues. Wadsworth, Belmont CA

Jones D. (1997): Good works, good business. USA Today, Abril $25^{\text {th }}: 1 \mathrm{~B}-2 \mathrm{~B}$ 
Jones MT (1996) Missing the forest for the trees: a critique of the social responsibility concept and discourse. Business and Society 35(1):7-41

Jones MT (1999) The institutional determinants of social responsibility. Journal of Business Ethics 20:163-179

Jones TM (1980) Corporate social responsibility revisited, redefined. California Management Review 22(3):59-67

Jones TM (1983) An integrative framework for research in business and society: a step toward the elusive paradigm? Academy of Management Review 8(4):559-564

Jones TM (1995). Instrumental stakeholder theory: A synthesis of ethics and economics. Academy of Management Review 20(2):404-437

Kaiser HF (1974) An index of factorial simplicity. Psychometrika 39:31-36

Kakabadse NK, Rozuel C, Lee-Davies L (2005) Corporate social responsibility and stakeholder approach: a conceptual review. International Journal of Business Governance and Ethics 4(1) 277-302

Karake ZA (1998) An examination of the impact of organizational downsizing and discrimination activities on corporate social responsibility as measured by a company’s reputation index. Management Decision 36(3):206-216

Kerlinger FN (1979) Enfoque conceptual de la investigación del comportamiento. Interamericana, México DF

Kerlinger FN, Lee HB (2000) Foundations of behavioral research (4 ${ }^{\mathrm{a}}$ ed). Harcourt College Publishers, Fort Worth TX

Klassen RD, McLaughlin CP (1996) The impact of environmental management on firm performance. Management Science 42(8):1199-1214

Klein J, Dawar H (2004) Corporate social responsibility and consumers' attributions and brand evaluations in a product-harm crisis. International. Journal of Research in Marketing 21:203-217

Knox S (2004) Corporate social responsibility: moving beyond investment towards measuring outcomes. European Management Journal 22(5):508-516

Kok K, Farrow A, Veldkamp A, Verburg PH (2001) A method and application of multiscale validation in spatial land use models. Agriculture, Ecosystems and Environment 85:223-238

Kolk A, Pinkse J (2006) Stakeholder mismanagement and corporate social responsibility crises. European Management Journal 24(1):59-72

Kolk A, Van Tulder R (2002) The effectiveness of self-regulation: corporate codes of conduct and child labour. European Management Journal 20(3):260-271

Kolk A, Van Tulder R (2004) Ethics in international business: multinational approaches to child labor. Journal of World Business 39(1):49-60

Kotler P (1989) Dirección de mercadotecnia. Análisis, planificación y control. Diana, México DF

Kotler P, Lee N (2005) Corporate Social Responsibility: doing the most good for your company and your cause. John Wiley \& Sons, New Jersey 
Kotler P, Levy S (1969) Broadening the concept of Marketing. Journal of Marketing 33(1):10-15

Kotler P, Zaltman G (1971) Social marketing: an approach to planned social change. Journal of Marketing 35(3):3-12

Kreps TJ (1940) Measurement of the social performance of business. An investigation of concentration of economic power for the temporary National Economic Committee. US Government Printing Office, Washington DC

Lafferty BA, Goldsmith RE (1999) Corporate credibility's role in consumers' attitudes and purchase intentions when a high versus a low credibility endorser is used in the ad. Journal of Business Research 44(2):109-116

Lambin JJ (1995) Marketing estratégico ( $3^{\mathrm{a}}$ ed). McGraw-Hill, Madrid

Lantos GP (2001) The boundaries of strategic corporate social responsibility. Journal of Consumer Marketing 18(7):595-632

Larrinaga C, Bebbington J (2001) Accounting change or institutional appropriation? A case study of the implementation of environmental accounting. Critical Perspectives on Accounting 12(3):269-292

Larrinaga C, Carrasco F, Caro FJ, Correa C, Páez JM (2001) The role of environmental accounting in organizational change: an exploration of Spanish companies. Accounting, Auditing \& Accountability Journal 14(2):213-239

Lee K, Shin D (2010) Consumers' responses to CSR activities: the linkage between increased awareness and purchase intention. Public Relations Review 36:193-195

Lilien GL, Kotler P, Moorthy KS (1992) Marketing models. Prentice Hall, New Jersey

Liñán F, Chen Y (2009) Development and cross-cultural application of a specific instrument to measure entrepreneurial intentions. Entrepreneurship Theory and Practice 33: 593-617

Litz RA (1996) A resource based view of the socially responsible firm: stakeholder interdependence, ethical awareness and issue responsiveness as strategic assets. Journal of Business Ethics 15(12):1355-1363

Lizcano JL (2003) Responsabilidad social corporativa y confianza en las organizaciones. Una aproximación al cuadro de mando para la responsabilidad social (CMRS) Papeles de Ética, Economía y Dirección 8:1-25

Lizcano JL, Nieto P (2006) La responsabilidad en el capitalismo futuro. Competencia, gasto público y comportamiento social de las empresas. Universia Business Review $10: 10-23$

Lorca P, García J (2004) The relation between firm survival and the achievement of balance among its stakeholders: an analysis. International Journal of Management 21(1):93-99

Loredo E, Suárez E (1998) Corporate governance in Europe: is convergence desirable? International Journal of Management 15(4):525-532

Lorge S (1999) Consumers care about causes. cornering the market. Sales \& Marketing Management 151(6):47

Lozano JM (2006) De la responsabilidad social de la empresa (RSE) a la empresa responsable y sostenible (ERS). Papeles de Economía Española 108:40-60 
Lozano JM (2009) La empresa ciudadana como empresa responsable y sostenible. Trotta, Madrid

Lozano JM, Albareda L, Ysa T, Roscher H, Marcuccio M (2005) Los gobiernos y la responsabilidad social de las empresas. Políticas públicas más allá de la regulación y la voluntariedad. Granica, Barcelona

Luo X, Bhattacharya CB (2006) Corporate Social responsibility, customer satisfaction, and market value. Journal of Marketing 70(4):1-18

Luthy MR, Toner Schrader J, Padgett BL (2003) Corporate social responsibility and ethics in the principles of marketing course: one institution's journey. Academy of Marketing Studies Journal 7(1):45-60

Maignan I (2001) Consumers' perceptions of corporate social responsibilities: a crosscultural comparison. Journal of Business Ethics 30(1):57-72

Maignan I, Ferrell OC (2000) Measuring corporate citizenship in two countries: the case of the United States and France. Journal of Business Ethics 23:283-297

Maignan I, Ferrell OC (2001) Corporate citizen as a marketing instrument. concepts, evidence and research directions. European Journal of Marketing 35(3/4)457-484

Maignan I, Ferrell OC (2003) Nature of corporate responsibilities: perspectives from American, French, and German consumers. Journal of Business Research 56(1):5567

Maignan I, Ferrell OC (2004) Corporate social responsibility and marketing: an integrative framework. Journal of the Academy of Marketing Science 32(1):3-19

Maignan I, Ferrell OC, Ferrell L (2005) A stakeholder model for implementing social responsibility in marketing. European Journal of Marketing 39(9/10):956-977

Maignan I, Ferrell OC, Hult G (1999) Corporate citizenship: cultural antecedents and business benefits. Jounal of the Academy of Marketing Science 27(4):455-469

Maignan I, Hillebrand B, McAlister D (2002) Managing socially-responsible buying: how to integrate non-economic criteria into the purchasing process. European Management Journal 20(6):641-648

Maignan I, Ralston DA (2002) Corporate social responsibility in Europe and the U.S.: insights from businesses' selfpresentations. Journal of International Business Studies 33(3):497-514

Mair J, Martí I (2006) Social entrepreneurship research: a source of explanation, prediction, and delight. Journal of World Business 41(1):36-44

Malhotra NK (1997) Investigación de Mercados. Un enfoque práctico. Prentice Hall, México DF

Manne HG, Wallich HC (1972) The modern corporation and social responsibility. American Enterprise Institute for Public Policy Research, Washington DC

Marín JL, Abenza M, Agramonte R (2008) La percepción de los murcianos sobre la responsabilidad social empresarial. Colegio de Economistas de la Región de Murcia, Murcia

Marín JL, Rubio A (2008) ¿Moda o factor competitivo? Un estudio empírico de la responsabilidad social corporativa en Pyme. Información Comercial Española. Revista de Economía 842:177-193 
Marín JL, Rubio A, Ruiz S (2009) The role of identity salience in the effects of corporate social responsibility on consumer behavior. Journal of Business Ethics 84:65-78

Marín JL, Ruiz S (2007) 'I need you too!' corporate identity attractiveness for consumers and the role of social responsibility. Journal of Business Ethics 71:245260

Marín JL, Ruiz S (2008) La evaluación de la empresa por el consumidor. Cuadernos de Economía y Dirección de la Empresa 35:91-112

Marín M (2012) Responsabilidad social corporativa y realpolitik. En: Alonso JA (coord) La empresa en tiempos de cambio: la RSC y los negocios inclusivos. Fundación Carolina, Madrid, pp 273-286

Martínez R (1995) Psicometría: Teoría de los test psicológicos y educativos Síntesis, Madrid

Maslow AH (1954) Motivation and personality. Harper \& Row, New York

Mathews MR (1993) Socially Responsible Accounting. Chapman Hall, London

McGee J (1998) Commentary on 'corporate strategies and environmental regulations: an organizing framework' by A,M. Rugman and A. Verbeke. Strategic Management Journal 19: 377-387

McGuire JB, Sundgren A, Schneeweis T (1988). Corporate social responsibility and firm financial performance. Academy of Management Journal 31(4):854-872

McGuire JW (1963) Business and society. McGraw-Hill, New York

McWilliams A, Siegel D (2001) Corporate social responsibility: a theory of the firm perspective. Academy of Management Review 26(1):117-127

McWilliams A, Siegel D, Wright P (2005) Corporate social responsibility: strategic implications. Rensselaer Working Papers in Economics 0506. Rensselaer Polytechnic Institute, Troy NY

Medawar C (1976) The social audit: a political view. Accounting, Organizations and Society 1(4):389-394

Melé D (2004) Corporate social responsability in Spain: an overwiew. IESE Business School Working Paper 543. IESE Business School-Universidad de Navarra, Pamplona

Melgar M (2009) Competitividad y responsabilidad social, un debate en la CEOE. En: Almagro JJ (ed) Responsabilidad social. Una reflexión global sobre la RSE. Prentice Hall, Madrid, pp 99-109

Mesa de Diálogo Social (2007) La responsabilidad social de las empresas. Diálogo social. Ministerio de Trabajo y Asuntos Sociales, Madrid. Disponible en [http://empleo.gob.es/es/sec_trabajo/]. Consultado en junio de 2012

Messick S (1980) Test validity and ethics of assessment. American Psychologist 35:1012-1027

Mintzberg $\mathrm{H}$ (1983) The case for corporate social responsibility. The Journal of Business Strategy 4(2):3-15 
Mitchell R, Agle B, Wood D. (1997) Toward a theory of stakeholder identification and salience: defining the principle of who and what really counts. The Academy of Management Review 22(4):853-886

Mitnick B (1995) Systematics and CSR: the theory and processes of normative referencing. Business and Society 34(1):5-34

Mohr LA, Webb DJ (2005) The effects of corporate social responsibility and price on consumer responses. The Journal of Consumer Affairs 39(1):121-147

Mohr LA, Webb DJ, Harris KE (2001) Do consumers expect companies to be socially responsible? The impact of corporate social responsibility on buying behavior. The Journal of Consumer Affairs 35(1):45-72

Moneva JM (2005) Información sobre responsabilidad social corporativa: situación y tendencias. Revista Asturiana de Economía 34:43-67

Moriano JA, Palací FJ, Morales JF (2006) Adaptation and validation of the entrepreneurial self-efficacy scale in Spain. Revista de Psicología Social 21:51-64

Morimoto R, Ash J, Hope C (2005) Corporate social responsibility audit: from theory to practice. Journal of Business Ethics 62(4):315-325

Moskowitz MR (1972) Choosing socially responsible stocks. Business and Society Review 1:71-75

Moskowitz MR (1975) Profiles in corporate social responsibility. Business and Society Review 13:29-42

Most RB, Zeidner M (1995) Constructing personality and intelligence instruments: Methods and instruments. En: Saklofse DH, Zeidner $M$ (eds) International handbook of personality and intelligence. Plenum Press, New York, pp 475-503

Muller A (2006) Global versus local CSR strategies. European Management Journal 24(2/3):189-198

Murphy PE (1994) European managers' views on corporate ethics. Business Ethics: A European Review 3(3):137-144

Murphy PE (1995) Top managers' views on corporate ethics. Irish Marketing Review 8:61-72

Murray K, Vogel CM (1997) Using a hierarchy-of-effects approach to gauge the effectiveness of corporate social responsibility to generate goodwill toward the firm: financial versus nonfinancial impacts. Journal of Business Research 38(2):141-160

Navarro F (2008) Responsabilidad social corporativa: teoría y práctica. Esic, Madrid

Nieto M, Fernández R (2004) Responsabilidad social corporativa: la última innovación en management. Universia Business Review 1(1):28-39

Nunnally JC (1978) Psychometric Theory. McGraw-Hill, New York

Nunnally JC, Bernstein IH (1994) Psychometric theory ( $3^{\mathrm{a}}$ ed). McGraw-Hill, New York

O’Dwyer B (2001) The legitimacy of accountants' participation in social and ethical accounting, auditing and reporting. Business Ethics: A European Review 10(1):27-39 
Öberseder M, Schlegelmilch BB, Gruber V (2011) "Why don’t consumers care about CSR": a qualitative study exploring the role of CSR in consumption decisions. Journal of Business Ethics 104:449-460

Osterhus TL (1997) Pro-social consumer influence strategies: when and how do they work? Journal of Marketing 61(4):16-29

Owen DL (1996) A critical perspective on the development of European environmental accounting and reporting. En: Hibbett C, Blokdisk (eds) Environmental accounting and sustainable development. Limperg Instituut, Amsterdam

Owen DL, Gray RH, Bebbington J (1997) Green accounting: cosmetic irrelevance or radical agenda for change? Asia Pacific Journal of Accounting 4(2):175-198

Owen DL, Swift T (2001) Social accounting, reporting and auditing: beyond the rhetoric? Business Ethics: A European Review 10(1):4-8

Owen DL, Swift T, Humphrey C, Bowerman M (2000) The new social audits: accountability, managerial capture or the agenda of social champions? European Accounting Review 9(1):81-98

Owen DL, Swift T, Hunt K (2001) Questioning the role of stakeholder engagement in social and ethical accounting, auditing and reporting. Accounting Forum 25(3):264282

Page G, Fearn H (2005) Corporate reputation: what do consumers really care about? Journal of Advertising Research 45(3):305-313

Pallant J (2001) SPSS survival manual. A step by step guide to data analysis using SPSS. UK Open University Press, Berkshire

Parboteeah KP, Cullen JB, Lim L (2004) Formal volunteering: a cross-national test. Journal of World Business 39(4):431-441

Parlamento Europeo (2000) Consejo Europeo de Lisboa 23 y 24 de marzo 2000. Conclusiones de la Presidencia. Parlamento Europeo, Bruselas. Disponible en [http://europarl.europa.eu/]. Consultado en junio de 2012

Parlamento Europeo (2006) Informe sobre la responsabilidad social de las empresas: una nueva asociación. 2006/2133 (INI). Parlamento Europeo, Bruselas. Disponible en [http://europarl.europa.eu/]. Consultado en junio de 2012

Parmar BL, Freeman RE, Harrison JS, Wicks AC, Purnell L, De Colle S (2010) Stakeholder theory: the state of the art. The Academy of Management Annals 4(1):403-445

Penelas A, Galera C, Galán MM, Valero V (2012) Marketing solidario. El marketing en las organizaciones no lucrativas. Pirámide, Madrid

Peredo AM, McLean M (2006) Social entrepreneurship: a critical review of the concept. Journal of World Business 41(1), 56-65

Pérez A (2011) Estudio de la imagen de responsabilidad social corporativa: formación e integración en el comportamiento de usuarios de servicios financieros. Tesis Doctoral. Universidad de Cantabria

Pérez A, García de los Salmones MM, Rodríguez I (2008) Las dimensiones de la responsabilidad social de las empresas como determinantes de las intenciones de comportamiento del consumidor. Revista Asturiana de Economía 41:127-146 
Pérez A, Rodríguez I (2012) La imagen de responsabilidad social corporativa en un contexto de crisis económica: el caso del sector financiero en España. Universia Business Review 33:14-28

Pérez JA, Chacón S, Moreno R (2000) Validez de constructo: el uso del análisis factorial exploratorio-confirmatorio para obtener evidencias de validez. Psicothema 12:442-446

Pérez M, Martínez A (2003) The development of university spin-offs: early dynamics of technology transfer and networking. Technovation 23:823-831

Perrini F (2005) Building a European portrait of corporate social responsibility reporting. European Management Journal 23 (6):611-627

Peter JP, Churchill GA (1986) Relationship among research design choices and psychometric properties of rating scales: a meta-analysis. Journal of Marketing Research 23:1-10

Peterson RA (1994) A meta-analysis of Cronbach's coefficient alpha. Journal of Consumer Research 21(2):381-91

Phillips R, Freeman RE, Wicks AC (2003) What stakeholder theory is not. Business Ethics Quarterly 13(4):479-502

Podsakoff PM, MacKenzie SB, Lee J, Podsakoff NP (2003) Common method biases in behavioral research: a critical review of the literature and recommended remedies. The Journal of Applied Psychology 88:879-903

Pomering A, Dolnicar S (2009) Assessing the prerequisite of successful CSR implementation: Are consumers aware of CSR initiatives? Journal of Business Ethics 85:285-301

Porter ME, Kramer MR (2004): Strategy and society: the link between competitive advantage and corporate social responsibility, Harvard Business Review 84(12): 512

Porter ME, Kramer MR (2011) Created shared value. Harvard Business Review 89(1/2):62-77

Post JE (1978a) Corporate behavior and social change. Prentice Hall, Reston VA

Post JE (1978b) Research on patterns of corporate response to social change. En: Preston LE (ed) Research in corporate social performance and policy (vol 1). JAI Press, Greenwich CT, pp 89-112

Power M (1991) Auditing and environmental expertise: between protest and professionalization. Accounting, Auditing \& Accountability Journal 4(3):30-42

Preston LE (1975) Corporation and society. The search for a paradigma. Journal of Economic Literature 13(2):434-453

Preston LE (1978) Research in corporate social performance and policy (vol 1). JAI Press, Greenwich CT

Preston LE, Post JE (1975) Private management and public policy: the principle of public responsibility. Prentice Hall, Englewood Cliffs NJ

Price JL (1997) Handbook of organizational measurement. International Journal of Manpower 18:305-558 
Puxty AG (1986) Social accounting as immanent legitimation: a critique of a technicist ideology. Advances in Public Interest Accounting 1:95-111

Puxty AG (1991) Social accountability and universal pragmatics. Advances in Public Interest Accounting 4:35-45

Ravald A, Grönroos C (1996) The value concept and relationship marketing. European Journal of Marketing 30(2):19-30

Reece JW (2001) Business and the civil society: the missing dialectic. Thunderbird International Business Review 43(5):651-667

Reyes LE, Pinillos MJ, Martín ML (2005) La responsabilidad social corporativa: ¿una moda o un nuevo planteamiento de dirección empresarial. Comunicación presentada en el XIV Congreso Nacional de ACEDE, 10-12 de septiembre, Valencia

Reynaud E, Egri CP, Ralston DA, Danis W, Starkus A, Dabic M, Wangenheim F, Dalgic T, Castro FB, Potocan VV, Kavoossi M, Molteni M, Girson I, Elenkov D, Pla J, Maignan I, Weber M, Wallace A (2007) The differences in values between managers of the European founding countries, the new members and the applicant countries: societal orientation or financial orientation? European Management Journal 25(2):132-145

Ringle CM, Wende S, Will A (2005) SmartPLS 2.0 (beta). University of Hamburg, Hamburg

Roberts JA (1993) Sex differences in socially responsible consumers' behavior. Psychological Reports 73:139-148

Roberts JA (1995) Profiling levels of socially responsible consumer behavior: a cluster analytic approach and its implications for marketing. Journal of Marketing Theory and Practice 3(4):97-117

Roberts JA (1996) Green consumers in the 1990s: profile and implications for advertising. Journal of Business Research 36:217-231

Roberts RW (1992) Determinants of corporate social responsibility disclosure, Accounting, Organizations and Society 17(6):595-612

Robles J (1996) Confirmation bias in structural equation modeling. Structural Equation Modeling 3(4):307-322

Rodríguez A (2008) Análisis de los modelos de responsabilidad social corporativa. Primera aproximación a un modelo desde la economía social andaluza. Trabajo presentado en las XI Jornadas de Investigadores en Economía Social y Cooperativa, 25-27 de octubre, Santiago de Compostela

Rodríguez-Piñero M (2006) Una nueva iniciativa comunitaria sobre responsabilidad social de las empresas. Relaciones Laborales 4:119-127

Rokka J, Uusitalo L (2008) Preference for green packaging in consumer product choices - Do consumers care? International Journal of Consumer Studies 32(5): 516-525

Roldán JL, Sánchez MJ (2012) Variance-based structural equation modeling: guidelines for using partial least squares in information systems. En: Mora M, Gelman O, Steenkamp A, Raisinghani MS (eds) Research methodologies, innovations and philosophies in software systems engineering and information systems. IGI Global, Hershey PA, pp 193-221 
Samuelson PA (1971) Love that corporation. Mountain Bell Magazine Spring:24

Sánchez J, Moliner MA, Callarisa L, Rodríguez RM (2007) Relationship quality of an establishment and perceived value of a purchase. The Service Industries Journal 27(2):151-174

Sánchez M, Sarabia FJ (1999) Validez y fiabilidad de escalas. En: Sarabia FJ (coord.) Metodología para la investigación en marketing y dirección de empresas. Pirámide, Madrid, pp 363-393

Santesmases M (2012) Marketing. Conceptos y estrategias (6ª ed). Pirámide, Madrid

Schmitt FF (1995) Truth: a primer. Westviw Press, Boulder CO

Schriesheim CA, Hill K (1981). Controlling acquiescence response bias by item reversal: The effect on questionnaire validity. Educational and Psychological Measurement 41:1101-1114

Schuler DA, Cording M (2006) A corporate social performance. Corporate financial performance behavioral model for consumers. Academy of Management Review 31(3):540-558

Schwalb M (2009) Un estudio de la valoración del consumidor limeño sobre la Responsabilidad Social del Marketing. Tesis Doctoral. Universidad de Deusto

Selekman B (1959) A moral philosophy for business. McGraw-Hill, New York

Sen S, Bhattacharya CB (2001) Does doing good always lead to doing better? consumer reactions to corporate social responsibility. Journal of Marketing Research 38(2):225-243

Sen S, Bhattacharya CB, Korschun D (2006) The role of corporate social responsibility in strengthening multiple stakeholder relationships: a field experiment. Journal of the Academy of Marketing Science 34(2):158-166

Sethi SP (1975) Dimensions of corporate social performance: an analytic framework. California Management Review 17:58-64

Sethi SP (1979). A conceptual framework for environmental analysis of social issues and evaluation of business response patterns. Academy of Management Review 4(1):63-74

Shapiro BP (1973) Marketing for nonprofit organizations. Harvard Business Review 51(5):123-132

Shaw B, Post FR (1993) A moral basis for corporate philanthropy. Journal of Business Ethics 12(10):745-751

Shepard JM, Betz M, O’Connell L (1997) The proactive corporation: its nature and causes. Journal of Business Ethics 16:1001-1010

Sheth JN, Newman BI, Gross BL (1991) Why we buy what we buy: a theory of consumption values. Journal of Business Research 22(2):159-170

Sichar G (2003) La empresa socialmente responsable. Fundación Cideal, Madrid

Simerly RL (2000) A theoretical examination of the relationship between chief executive officers and corporate social performance. International Journal of Management 17(2):218-223 
Singh J, García de los Salmones MM, Rodriguez I (2008) Understanding corporate social responsibility and product perceptions in consumer markets: a cross-cultural evaluation. Journal of Business Ethics 80:597-611

Smith D, Skalnik J, Skalnik P (1999) Ethical behavior of marketing managers and MBA students. Teaching Business Ethics 3(4):321-335

Solomon MR (2008) Comportamiento del consumidor (7 ${ }^{\mathrm{a}}$ ed). Pearson, Madrid

Solomon RC (1992) Ethics and excellence. Oxford University Press, New York

Sorribas C (2007) Historic evolution of cause-related marketing programmes. Does a "perfect" CRM program exist? International Review on Public and Nonprofit Marketing 4(1/2):149-158

Speed R, Thompson P (2000) Determinants of sports sponsorship response. Journal of Academic Marketing Science 28:226-238

Spicer BH (1978) Investors, corporate social performance and information disclosure: an empirical study. Accounting Review 53(1):94-111

Staples L (2004) Social action groups. En: Garvin C, Gutiérrez L (eds) Handbook of social work with groups. Guilford Publications, New York, pp. 344-359

Steiner GA (1971) Business and society. Random House, New York

Steiner GA (1972) Social policies for business. California Management Review 15(2):17-24

Stevens G (1984) Ethical inclinations of tomorrow's citizens: actions speak louder? Journal of Business Education 59:147-152

Stevens J (1996) Applied multivariate statistics for the social sciences ( $3^{\mathrm{a}}$ ed). Lawrence Erlbaum, Mahwah NJ

Stohs JH, Brannick T (1999) Codes and conduct: predictors of Irish managers' ethical reasoning. Journal of Business Ethics 22(4):311-326

Stone CD (1975) Where the Law ends. Harper \& Row, New York

Stone M (1974) Cross-validatory choice and assessment of statistical predictions. Journal of the Royal Statistical Society 36:111-133

Strand R (1983) A systems paradigm of organizational adaptations to the social environment. Academy of Management Review 8:90-96

Stuart H (2002) Employee identification with the corporate identity. International Studies of Management \& Organization 32(3):28-44

Sullivan J (1999) What are the functions of corporate home pages? Journal of World Business 34(2):193-210

Swaen V, Maignan I. (2003) Organizational citizenship and corporate citizenship: two constructs, one research theme? En: Sheb LT, Pelton L, Ferrell OC (eds.) Business rites, writs and responsibilities: readings on ethics and social impact management (vol 1). Michael J. Coles College of Business, Kennesaw GA, pp 107-134

Swaen V, Vanhamme J (2005) The use of corporate social responsibility arguments in communication campaigns : does source credibility matter?. Advances in Consumer Research 32:590-591 
Swanson DL (1995) Addressing a theoretical problem by reorienting the corporate social performance model. Academy of Management Review 20:43-64

Székely F, Knirsch M (2005) Responsible leadership and corporate social responsibility: metrics for sustainable performance. European Management Journal 23(6):628-647

Tabachnick BG, Fidell LS (1996) Using multivariate statistics ( $3^{\mathrm{a}}$ ed). Harper Collins, New York

Tascón R (2008) Aspectos jurídico-laborales de la responsabilidad social corporativa. Centro de Estudios Financieros, Madrid

Thompson RD, Barclay, DW, Higgins CA (1995) The partial least squares approach to causal modeling: personal computer adoption and use as an illustration. Technology Studies 2(2):284-324

Thurstone LL (1947) Multiple factor analysis. Chicago University Press, Chicago IL

Tinker AM, Lehman C, Neimark M (1991) Falling down the hole in the middle of the road: political quietism in corporate social reporting. Accounting, Auditing \& Accountability Journal 4(1):28-54

Tixier M (2003) Soft vs. hard approach in communicating on corporate social responsibility. Thunderbird International Business Review 45(1):71-91

Torres A, Bijmolt T, Tribó JA, Verhoef P (2012) Generating global brand equity through corporate responsibility to key stakeholders. International Journal of Research in Marketing 29(1):13-24

Tourangeau R, Rips LJ, Rasinski K (2000) The psychology of survey response. Cambridge University Press, Cambridge MA

Truño J (2007) La responsabilidad social corporativa: aproximación cuantitativa a la gestión de un activo intangible. Trabajo de investigación. Universidad Autonoma de Barcelona

Tschirhart M (2005) Employee volunteer programs. En: Brudney JL (ed.) Emerging areas of volunteering. Association for Research on Nonprofit Organizations and Voluntary Action, Indianapolis IN, pp 13-29

Tully S (2012) International corporate legal responsibility. Kluwer Law International, London

Turban DB, Greening DW (1997) Corporate social performance and organizational attractiveness to prospective employees. Academy of Management Journal 40(3):658-672

Tuzzolino F, Armandi BR (1981) A need-hierarchy framework for assessing corporate social responsibility. Academy of Management Review 6:21-28

Unceta A (2005) Empresas socialmente responsables en el escenario económico global. Aproximación a la noción de responsabilidad social corporativa. Politika: Revista de Ciencias Sociales 1:121-128

Unceta A, Gurrutxaga G (2005) Responsabilidad social corporativa en el País Vasco. Paradox, Bilbao 
Urbach N, Ahlemann F (2010) Structural equation modeling in information systems research using partial least squares. Journal of Information Technology Theory and Application 11(2):5-40

Uusitalo O, Oksanen R (2004) Ethical consumerism: a view from Finland. International Journal of Consumer Studies 28(3):214-221

Vaaland T, Heide M (2005) Corporate social responsiveness: exploring the dynamics of "bad episodes". European Management Journal 23(5):495-506

Vaaland T, Heide M, Gronhaug K (2008) Corporate social responsibility: investigating theory and research in the marketing context. European Journal of Marketing 42(9/10):927-953

Valor C (2006). Percepción de la responsabilidad social de la empresa y hábitos de consumo de los consumidores españoles. Distribución y Consumo sept-oct: 84-94

Valor C (coord) (2010) Relaciones con la Sociedad. Netbiblo, La Coruña

Van Herpen E, Pennings J, Meulenberg M (2003) Consumer's evaluations of socially responsible activities in retailing. Marketing and Consumer Behavior Group Working Paper. Universidad de Wageningen

Van Liere KD, Dunlap R. (1980) The social bases of environment concern: a review of hypothesis, explanations and empirical evidence. Public Opinion Quarterly 4:181197

Van Marrewijk M (2003). Concepts and definitions of CSR and corporate sustainability: between agency and communion. Journal of Business Ethics 44 (2/3):95-105

Varadarajan PR, Menon A (1988) Cause-related marketing: a coalignment of marketing strategy and corporate philanthropy. Journal of Marketing 52(3):58-74

Vázquez JL, Lanero A, Alves H, Gutiérrez P, García MP (2011) An analysis of the reasons attributed by Spanish undergraduates to CSR in organizations and its implications for consumer behavior. Ponencia presentada en el $22^{\text {nd }}$ CROMAR Congress, 6-8 de octubre, Pula

Vázquez JL, Lanero A, García MP (2012a) Corporate social responsibility and consumer goodwill: is it a matter of credibility? En: Proceedings of the $41^{\text {st }}$ Annual Conference of the European Marketing Academy. EMAC, Lisboa.

Vázquez JL, Lanero A, García MP, García J (2012b). Altruism or strategy? A study of attributions of responsibility in business and its impact on the consumer decision making process. Ponencia presentada en el $11^{\text {th }}$ International Congress on Public and Non-Profit Marketing, 14-15 de junio, Vilnius

Viñuales V, Eguiagaray JM (dirs) (2006) Anuario sobre responsabilidad social empresarial en España 2006. Fundación Ecología y Desarrollo y Fundación Alternativas, Zaragoza

Vlachos PA, Tsamakos A, Vrechopoulos AP, Avramidis PK (2009) Corporate social responsibility: attributions, loyalty, and the mediating role of trust. Journal of the Academy of Marketing Science 37:170-180

Votaw D (1973) Genius becomes rare. En: Votaw D, Sethi SP (eds) The corporate dilemma. Prentice-Hall, Englewood Cliffs NJ, pp 11-45 
Waddock SA, Graves SB (1997) The corporate social performance-financial performance link. Strategic Management Journal 18:303-319

Waddock SA, Smith N (2000) Corporate social responsibility audits: doing well by doing good. Sloan Management Review 41(2):75-83

Waldman DA, De Luque M, Washburn N, House RJ, Adetoun B, Barrasa A, Bobina M, Bodur M, Chen YJ, Debbarma S, Dorfman P, Dzuvichu RR, Evcimen I, Fu P, Grachev M, Duarte RG, Gupta V, Den Hartog DN, De Hoogh AHB, Howell J (2006) Cultural and leadership predictors of corporate social responsibility values of top management: a GLOBE study of 15 countries. Journal of International Business Studies 37(6):823-837

Walton CC (1967) Corporate social responsibilities. Wadsworth, Belmont CA

Wartick SL, Cochran PL (1985) The evolution of the corporate social performance model. Academy of Management Review 10(4):758-769

Webb DJ, Mohr LA (1998) A typology of consumer responses to cause-related marketing: from skeptics to socially concerned. Journal of Public Policy Marketing $17: 226-238$

Webb DJ, Mohr LA, Harris K (2008) A re-examination of socially responsible consumption and its measurement. Journal of Business Research 61(2):91-98

Weerawardena J, Mort GS (2006) Investigating social entrepreneurship: a multidimensional model. Journal of World Business 41(1):21-35

Weiss J (1994) Business Ethics. A managerial stakeholder approach. Wadsworth Publishing Company, Belmont CA

Werts CE, Linn RL, Jöreskog KG (1974) Interclass reliability estimates: testing structural assumptions. Educational and Psychological Measurement 34:25-33

Wold H (1973) Nonlinear iterative partial least squares (NIPALS) modeling: some current developments. En: Krishnaiah PR (ed) Multivariate Analysis: II. Proceedings of an International Symposium on Multivariate Analysis. Academic Press, New York, pp 383-407

Wold H (1979) Model construction and evaluation when theoretical knowledge is scarce: an example of the use of partial least squares. Cahiers du Département D’Économétrie. Université de Genève, Genève

Wold H (1980) Soft modeling: Intermediate between traditional model building and data analysis. Mathematical Statistics 6: 333-346

Wold H (1982) Systems under indirect observation using PLS. En: Fornell C (ed) A second generation of multivariate analysis. Praeger Publishers, New York, pp 325347

Wold H (1985) Systems analysis by partial least squares. En: Nijkamp P, Leitner H, Wrigley $\mathrm{N}$ (eds) Measuring the unmeasurable. Martinus Nijhoff Publishers, Dordrecht, pp. 221-251

Wood DJ (1991a) Toward improving corporate social performance. Business Horizons 34(4):66-73

Wood DJ (1991b) Corporate social performance revisited. Academy of Management Review 16(4):691-718 
Wood DJ, Jones RE, (1995) Stakeholder mismatching: a theoretical problem in empirical research on corporate social performance. International Journal of Organizational Analysis 3(3):229-267

Yoon Y, Gürhan-Canli Z, Bozok B (2006) Drawing inferences about others on the basis of corporate associations: Journal of the Academy of Marketing 34(2):167-173

Zadek S, Raynard P (2004) The future of sustainability assurance, Certified Accountants Educational Trust, London

Zenisek TJ (1979) Corporate social responsibility: a reconceptualization based on organizational literature. Academy of Management Review 4:359-368 
ANEXo

Cuestionario Empleado en la Recogida de Datos 

universidad deleón

\section{Encuesta sobre percepción de la responsabilidad de las empresas por parte del consumidor 2011}

Datos personales:

Encuestador:

Sexo: Hombre $\square$ Mujer $\square$

Nivel de estudios: Sin estudios $\square$ Secundarios $\square$

Profesión
Edad:

Estudios Primarios $\square \quad$ Estudios

Formación Profesional $\square$

Para conocer su opinión sobre diferentes cuestiones relacionadas con la actividad socialmente responsable de las empresas, le agradeceríamos unos minutos de su tiempo para contestar a unas cuestiones. Los datos recopilados serán tratados de forma agregada y anónima.

I) En primer lugar, indique cuáles de los siguientes aspectos definen, desde su punto de vista, a una "empresa socialmente responsable":

( 1 = "totalmente en desacuerdo"; 2 = "en desacuerdo"; 3 = "indiferente"; 4 = "de acuerdo"; 5 = "totalmente de acuerdo")

1) Cumplimiento estricto de las leyes

2) Actuaciones comprometidas con el medio ambiente

3) Compromiso con la resolución de problemáticas sociales

4) Satisfacción de las expectativas de los clientes

5) Satisfacción de las expectativas de los empleados

6) Generación del máximo beneficio para socios y accionistas

7) Compromiso ético en las relaciones con proveedores y distribuidores

8) Prácticas de juego limpio con la competencia

9) Contribución al desarrollo socioeconómico regional

10) Implicación en los intereses de la comunidad

11) Colaboración abierta con administraciones y ONGs

12) Otros (especificar):

II)Exprese también su opinión sobre las causas/motivos que llevan a las empresas a comportarse de un modo "socialmente responsable":

( 1 = "totalmente en desacuerdo"; 2 = "en desacuerdo"; 3 = "indiferente"; 4 = "de acuerdo"; 5 = "totalmente de acuerdo")

1) Por imposición legal

2) Porque se sienten moralmente obligadas

\begin{tabular}{lllll}
1 & 2 & 3 & 4 & 5 \\
1 & 2 & 3 & 4 & 5 \\
1 & 2 & 3 & 4 & 5 \\
1 & 2 & 3 & 4 & 5 \\
1 & 2 & 3 & 4 & 5 \\
1 & 2 & 3 & 4 & 5 \\
1 & 2 & 3 & 4 & 5 \\
1 & 2 & 3 & 4 & 5 \\
1 & 2 & 3 & 4 & 5 \\
1 & 2 & 3 & 4 & 5 \\
1 & 2 & 3 & 4 & 5 \\
1 & 2 & 3 & 4 & 5 \\
1 & 2 & 3 & 4 & 5 \\
1 & 2 & 3 & 4 & 5 \\
1 & 2 & 3 & 4 & 5 \\
1 & 2 & 3 & 4 & 5 \\
1 & 2 & 3 & 4 & 5 \\
1 & 2 & 3 & 4 & 5 \\
\hline
\end{tabular}

3) Porque se benefician de reducciones fiscales

4) Porque así consiguen retener /captar nuevos clientes

5) Para sacar provecho de preocupaciones sociales en beneficio propio

6) Porque se interesan por el bienestar de la sociedad

$\begin{array}{ll}1 & 2 \\ 1 & 2 \\ 1 & 2 \\ 1 & 2 \\ 1 & 2 \\ 1 & 2\end{array}$

2
2
2
2
2
2
2

$\begin{array}{lll}3 & 4 & 5 \\ 3 & 4 & 5 \\ 3 & 4 & 5 \\ 3 & 4 & 5 \\ 3 & 4 & 5 \\ 3 & 4 & 5 \\ 3 & 4 & 5 \\ 3 & 4 & 5 \\ 3 & 4 & 5 \\ 3 & 4 & 5 \\ 3 & 4 & 5 \\ 3 & 4 & 5\end{array}$

7) Para aumentar sus beneficios

8) Para aprovecharse de la colaboración con organizaciones no lucrativas

9) Por un tema de publicidad, para darse a conocer

10) Porque quieren devolver algo a la sociedad

11) Para aumentar su credibilidad ante sus públicos objetivo

12) Para mejorar su reputación y crear buena imagen

13) Para responder a las expectativas de los empleados

14) Para responder a las expectativas de los consumidores

15) Para responder a las expectativas de socios y accionistas

16) Para responder a las expectativas de proveedores y distribuidores

17) Para responder a las expectativas de la sociedad en general

18) Otros (especificar): 


\section{III) A continuación, valore la importancia que otorga a los siguientes aspectos relacionados con la responsabilidad de las empresas cuando elige productos o marcas en sus compras:}

( 1 = "nada importante"; 2 = "poco importante"; 3 = "indiferente"; 4 = "algo importante"; 5 = "muy importante")

\begin{tabular}{llllll}
\hline 1) Actuaciones comprometidas con el medio ambiente & 1 & 2 & 3 & 4 & 5 \\
\hline 2) Compromiso con la resolución de problemáticas sociales & 1 & 2 & 3 & 4 & 5 \\
3) Preocupación por satisfacer las expectativas de los clientes & 1 & 2 & 3 & 4 & 5 \\
\hline 4) Preocupación por satisfacer las expectativas de los empleados & 1 & 2 & 3 & 4 & 5 \\
5) Generación del máximo beneficio para socios y accionistas & 1 & 2 & 3 & 4 & 5 \\
6) Compromiso ético en las relaciones con proveedores y & 1 & 2 & 3 & 4 & 5 \\
distribuidores & 1 & 2 & 3 & 4 & 5 \\
7) Prácticas de juego limpio con la competencia & 1 & 2 & 3 & 4 & 5 \\
8) Contribución al desarrollo socioeconómico regional & 1 & 2 & 3 & 4 & 5 \\
9) Implicación en los intereses de la comunidad & 1 & 2 & 3 & 4 & 5 \\
10) Colaboración abierta con administraciones y ONGs & 1 & 2 & 3 & 4 & 5 \\
\hline 11) Otros (especificar): & & & & &
\end{tabular}

IV) Por último, señale su acuerdo/desacuerdo con los siguientes enunciados relativos a sus hábitos de consumo a partir de criterios de responsabilidad de las empresas:

( 1 = "totalmente en desacuerdo"; 2 = "en desacuerdo"; 3 = "indiferente"; 4 = "de acuerdo"; 5 = "totalmente de acuerdo")

1) A menudo, busco información sobre productos y marcas de empresas socialmente responsables $\quad \begin{array}{llllll}1 & 2 & 3 & 4 & 5\end{array}$

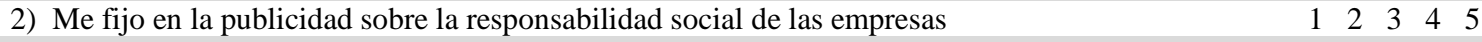

3) Cuando voy de compras, me fijo en los distintivos y sellos de calidad de los productos $\quad \begin{array}{lllll}1 & 2 & 3 & 4 & 5\end{array}$

4) Conozco productos y marcas de empresas socialmente responsables $\quad \begin{array}{llll}1 & 2 & 4 & 5\end{array}$

5) He tenido buenas experiencias con productos y marcas de empresas socialmente responsables $\quad \begin{array}{llllll}1 & 2 & 3 & 4 & 5\end{array}$

6) Tengo como referencia productos y marcas de empresas responsables que siempre consumo $\quad \begin{array}{llllll}1 & 2 & 3 & 4 & 5\end{array}$

7) Comprar productos de empresas socialmente responsables es importante para mí $\quad \begin{array}{lllll}1 & 2 & 3 & 4 & 5\end{array}$

8) En mi opinión, los productos de empresas socialmente responsables son de mejor calidad $\quad \begin{array}{lllll}1 & 2 & 3 & 4 & 5\end{array}$

9) Creo que los productos de empresas socialmente responsables tienen mejor relación $\quad \begin{array}{lllll}1 & 2 & 3 & 4 & 5\end{array}$ calidad/precio

10) La responsabilidad social es un criterio decisivo para mí cuando dudo entre varios productos $\quad \begin{array}{lllll}1 & 2 & 3 & 4 & 5\end{array}$

11) He dejado de consumir ciertas marcas o productos por considerar que la empresa no era $\quad \begin{array}{lllll}1 & 2 & 3 & 4 & 5\end{array}$ responsable

12) Estoy dispuesto a pagar un precio superior por productos de empresas socialmente $\quad$\begin{tabular}{lllll}
\hline & 24
\end{tabular} responsables

13) Estoy dispuesto a realizar un mayor esfuerzo de compra (tiempo, desplazamiento) para adquirir un producto de una empresa socialmente responsable

14) Algunas personas de mi entorno me han recomendado adquirir productos de empresas responsables

15) Consumiendo productos de empresas socialmente responsables contribuyo a causas sociales

16) Consumiendo productos de empresas socialmente responsables contribuyo a causas medioambientales

17) Consumir productos de responsabilidad social me permite apoyar a empresas comprometidas con la comunidad

18) Consumir productos de empresas socialmente responsables me hace sentir bien conmigo mismo

19) Consumir productos de empresas socialmente responsables mejora mi imagen ante los demás

20) En los últimos años he notado una mayor implicación de las empresas en acciones de responsabilidad social

21) La responsabilidad social es un tema cada vez más recurrente en los medios de comunicación

22) Percibo que las personas de mi entorno hablan a menudo sobre temas de responsabilidad social 
RÉsumé et ConClusions 



\section{RÉSUMÉ}

Le dynamisme des marchés chaque fois plus grandissant et l'activité économique en général ont accentué le souci de tout type d’entités de conserver leur réputation ainsi que de démontrer leur implication avec la demande et les changements sociaux. Les entreprises privées sont également conscientes du besoin de répondre aux inquiétudes d'autres publics cibles, au-delà de leurs investisseurs et de leurs clients, en concevant leur activité d’une façon plus vaste et intégratrice.

Certains aspects comme la compréhension des besoins des clients, la collaboration avec des causes d'intérêt social, les relations avec les fournisseurs et les distributeurs qui assureront des conditions adéquates, le commerce équitable, la conscience environnementale et le développement durable, l'intégration professionnel des handicapés et d'autres collectifs difficiles à employer, la conciliation de la vie familiale et professionnelle, la sécurité dans le travail entre autres, constituent maintes exemples des aspects les plus importants aux yeux des entités, publiques et privées, convaincues que l'amélioration de l'environnement social à travers leurs actions devrait leur permettre d'atteindre leurs objectifs.

Il est évident que l'acceptation, la confiance et le soutien d'une organisation par la société dépend de l'accomplissement des attentes (ERSE 2010), non seulement de la part de ses propriétaires mais aussi de la part des travailleurs qui demandent des droits sociaux et économiques, de la part des clients lorsqu’ils exigent des produits de qualité, de la part des communautés et d’une société en général soucieuse d'un développement plus durable.

La réflexion sur la responsabilité des organisations (notamment des entreprises) “a joué un rôle fondamental durant le siècle dernier, d'une façon plus ou moins intermittente, dans divers débats, aussi bien dans le monde académique que dans le monde organisationnel” (Unceta 2005:122). Des affaires comme celles d'Enron, de Worldcom, d'Andersen.... “où le seul et unique objectif de l'activité des entités était la 
rentabilité immédiate, remettent sur le tapis et d'une façon bien visible, que l'éthique est indispensable dans le monde de l'entreprise” (Cortina 2003:34).

Le débat dépasse le cadre académique et professionnel, pour se matérialiser au fur et à mesure à travers le temps en un ensemble d'initiatives qui ont pris corps à la fin du siècle dernier et au début de l'actuel. Le Pacte Mondial des Nations Unies propose un débat entre les entreprises privées et publiques, les gouvernements, les organisations du travail, les ONG et d'autres agents de la société civile sur le besoin d'adopter une série de mesures qui auront pour but de favoriser une économie globale, responsable et durable à échelle internationale. C'est dans ce contexte que la Commission de la Communauté Européenne a présenté à Bruxelles un Livre Vert (2001), afin d'entamer une vaste discussion sur le développement des comportements responsables à l'intérieur des organisations européennes et à travers le monde qui aura pour but d'encourager un cadre européen de responsabilité sociale des entreprises.

Ce projet prétend contribuer au développement de la connaissance scientifique sur le comportement responsable des entités productives. Il s'agira d'orienter l'analyse depuis la perspective de la demande, en observant comment sera perçue la responsabilité des organisations et les implications que la confirmation ou la désapprobation subséquente des attentes pourront avoir sur leurs futures lignes de conduite, pendant que les entités seront plus ou moins soucieuses d'inclure dans leurs plans stratégiques les appréciations de ceux qui se verront affectés en dernier ressort, que ce soit de manière directe ou indirecte, par leurs comportements.

En effet, les différentes approches, aussi bien celles des académiciens que des diverses institutions qui ont participé aux débats, à la diffusion théorique et à la mise en œuvre pratique de la responsabilité assumable et imputable aux organisations, ont généralement maintenu un chemin qui les a menés à définir et à mesurer la portée que l'activité développée par l’organisation a sur la société. Néanmoins, on peut également contempler l'organisation depuis l'extérieur en tant que citoyens-consommateurs, en tant qu'administration, en tant que communauté, en tant que réseaux sociaux, en tant qu'université, en tant qu'environnement qui pourra tracer et envisager les responsabilités de celle-ci vues depuis la société dans laquelle elle développe son activité (De la Cruz et al. 2007). 
Bien que ces dernières années de nombreuses publications qui abordent la manière dont le consommateur perçoit ce comportement responsable sont parues, ce phénomène n’est pas encore suffisamment connu ni analysé (Creyer et Ross 1997; Mohr et al. 2001; Sen y Bhattacharya 2001; García de los Salmones et al. 2005; Fernández et Merino 2005; Pérez et al. 2008) et, bien sûr, peu de conclusions définitives ont été tirées qui permettraient d'expliquer de quelle façon peut être définie la perception des demandeurs des produits et les services des organisations qui mèneront à bien des conduites responsables, et comment ces appréciations pourront-elles avoir une incidence essentielle sur un comportement plus responsable de celles-ci.

Diverses travaux (Fernández et Merino 2005) démontrent que le consommateur évalue positivement l'organisation quand elle agit de façon responsable et modifie même son propre comportement (Creyer et Ross 1997; Sen et Bhattacharya 2001; Bigne et al. 2005; Fernández et Merino 2005; Forética 2006; Bigne et Curras 2008). Or, d'autres travaux contredisent cette conclusion lorsqu'ils s'aperçoivent que certains comportements responsables n’ont été modifiés que dans des circonstances déterminées (Anderson et Cunningham 1972; Andreu et al. 2004). Des études diverses maintiennent également que, même si le consommateur remarque un comportement responsable, celui-ci ne sera pas un critère qui aura une influence significative et, moins encore, définitive, sur ses décisions d’achat (Carrigan 1997; Boulstridge et Carrigan 2000).

C'est justement cette divergence qui se produit lorsqu'on analyse les conséquences et les effets d'une conduite plus ou moins responsable de l'organisation sur les comportements du consommateur (qui pourront d'ailleurs être conditionnés par le manque de consensus sur la définition et les variantes déterminantes de la responsabilité). C’est pour cette raison qu'il semble nécessaire de compter sur de nouvelles théories qui apporteront des explications plus précises quant aux perceptions et aux évaluations. (Martín et Rubio 2008).

Dans leur travail, Alvarado et Schlesinger (2008), concluent que la responsabilité joue un rôle clé dans le processus de formation de l'image et, par conséquent, les chefs d'entreprises doivent savoir que leurs comportements auront un impact direct sur la réputation que les consommateurs attribueront à leur affaire. Tout ceci doit motiver les entreprises et tout type d'organisations à consacrer des efforts et 
des ressources pour renforcer les liens avec leurs consommateurs afin de faire en sorte que ceux-ci atteignent un degré majeur d’identification avec cette même organisation.

D’autre part, la perception sociale est une des dimensions les moins explorées de la responsabilité des organisations, c’est la raison pour laquelle de nouvelles études sont nécessaires afin de mettre en relief la manière dont les différents publics-cibles les évaluent et comment ceux-ci réagissent face à la façon de gérer et de mettre en œuvre les actions qui leur sont demandées. En effet, cette réflexion s'avère très intéressante non seulement pour l'entité, mais aussi pour les différents agents qui voudront prendre connaissance de ces opinions et de leurs conséquences (Valor 2006).

Donc, et en premier lieu, cela doit intéresser les entreprises parce qu'elles doivent prendre conscience de l'opinion du public en ce qui concerne leur comportement. En effet, il s'agit d’une information qui leur sera d'une utilité essentielle puisqu'elle leur permettra d'orienter leurs priorités et de définir des objectifs en se fondant sur les résultats observés et, en outre, cela leur permettra de favoriser le dialogue avec la société dans l’intérêt de tous.

Ceci est également utile pour les organisations sectorielles et les groupes d'entreprises étant donné que, grâce à ces travaux, ils pourraient compter sur des résultats et sur des évaluations qui leur serviront de soutien empirique tout en impulsant des politiques qui vont promouvoir la responsabilité parmi leurs associés.

Il semble spécialement important pour les législateurs et pour les administrations publiques de savoir ce que demandent les citoyens de l'État et vers où sont orientées leurs demandes à l'entreprise. Ils connaitront ainsi davantage de données ainsi que des évaluations qui pourront guider la réalisation des politiques publiques.

Ce projet est également intéressant aux yeux des interlocuteurs sociaux, comme, par exemple, les syndicats, les organisations de consommateurs, les ONG et les organisations environnementales qui ont besoin d'obtenir des informations qui leur serviront de base afin qu'ils puissent mener à bien des campagnes publiques de sensibilisation et d'information citoyenne.

Donc, il semble capital que de nombreux agents connaissent les informations qui émanent des citoyens, non seulement en ce qui concerne les résultats économiques mais 
aussi dans d'autres domaines de responsabilité de l'entreprise quand il s'agit de prendre leurs décisions d'achat et d'investissement. Cependant, au-delà de l'information (Valor 2006), il faut que le citoyen soit formé à tous ces aspects s’il veut réellement exprimer ses préoccupations sociales au marché dans le but de renforcer l'argument économique en faveur de la responsabilité.

C'est dans ce sens que nous pouvons dire que le but de cette thèse est de contribuer à clarifier le concept de la responsabilité des organisations, aussi bien depuis la perspective des argumentations académiques qui ont été l'objet de controverses pendant les dernières décennies, que depuis la contextualisation que ce concept pose d'un point de vue normatif et règlementaire, qui met en relief la pratique institutionnel du terme pour, ensuite, axer cette étude sur la perception que le consommateur se fait du comportement responsable de l'entreprise. C'est pourquoi nous présenterons et analyserons un modèle qui permettra de mettre en ordre les variables déterminantes de la vision particulière du consommateur en ce qui concerne la responsabilité à laquelle peut arriver une organisation. Plus concrètement, nous essayerons d'atteindre les objectifs suivants:

(i) Réaliser une analyse historico-économique de l'évolution du concept de responsabilité des organisations.

(ii) Contextualiser la responsabilité depuis la pratique institutionnelle qui conditionne ou impose le cadre normatif et règlementaire.

(iii) Connaître la vision ou la perspective du consommateur envers le comportement responsable qu'adoptent ou que doivent adopter les entités.

(iv) Identifier les déterminants de la perception responsable du consommateur grâce au dessin d'un modèle conceptuel qui sera utile, d'une part, pour expliquer de quelle manière le public perçoit la responsabilité des organisations et quelle est l'importance qu'il accorde à ce comportement puis, d'autre part, pour analyser les variables qui déterminent l'évaluation et l'acquisition des informations de responsabilité du côté de l’organisation.

En vue d'atteindre l'objectif général ainsi que les objectifs spécifiques, le schéma que nous suivrons sera celui qui est détaillé ci-dessous. 
Dans le premier chapitre, nous mènerons à bien une évaluation et une analyse critique des points de vue pluriels qui ont contemplé peu à peu la responsabilité des organisations. Nous réviserons les antécédents scientifiques depuis la perspective historico-économique sur laquelle était fondée leur étude afin d’aborder la position la plus étendue possible quant à ce sujet.

Ensuite, dans le second et dans le troisième chapitre, nous identifierons les différentes approches règlementaires et normatives qui ont essayé de délimiter la responsabilité des organisations, en faisant référence aux fonctions que doivent exercer les Administrations Publiques, à la description de l'environnement normatif puisqu'il s’agit d'un élément additionnel que les organisations doivent prendre en compte, non seulement nationalement ou supranationalement, mais aussi à une échelle internationale. En effet, l'environnement normatif est sujet à débats dans tous les domaines entre les entreprises privées et publiques, les gouvernements, les organisations du travail, les ONG et diverses agents de la société civile, au sein de laquelle on met sans cesse en évidence le besoin d'adopter une série de mesures dans le but de favoriser une économie globale, responsable et durable. Par conséquent, nous mettrons l'accent sur les aspects normatifs mais également sur tous les aspects qui, quelque part, ont eu une influence sur ce type de régulations et sur les comportements responsables de la part des organisations.

Nous mènerons à bien cette étude en nous appuyant sur la certitude que, ces dernières années, un des facteurs qui a le plus stimulé le développement de la responsabilité sociale est la pression des marchés de consommation (Nieto et Fernández 2004), où un nombre croissant de consommateurs choisit une consommation plus responsable, cherche des produits écologiques ou élaborés selon des critères de responsabilité. C’est dans ce sens que, dans le quatrième chapitre, nous explorons des approches qui supposent une perspective ou un regard de l'extérieur vers les entités, en faisant le schéma d'un nouveau point de vue à travers lequel les décisions du consommateur peuvent être expliquées comme une forme de comprendre et d'évaluer le comportement des organisations d'entreprises. C'est pourquoi nous examinerons les différentes variables qui servent de fondement au modèle d'étude.

La partie empirique de cette Thèse est structurée en trois chapitres au long desquels nous ferons une référence succincte au procédé employé puis évoquerons les 
résultats obtenus et les conclusions dérivées de l'étude. À cet effet, nous proposons un modèle théorique à travers lequel il sera possible d'avancer dans la recherche sur la responsabilité perçue durant les étapes diverses du processus d'intention d'achat du consommateur. En effet, nous étudions la relation séquentielle établie entre la génération de demande de responsabilité avec l'acquisition, l’information et l'évaluation d'offres responsables, selon les étapes qui décrivent le noyau central du modèle, celui-ci est complété, en premier lieu, par une analyse du rôle déterminant des motifs attribués à la responsabilité de l'entreprise ainsi que le concept de responsabilité perçu par le consommateur pour, en second lieu, intégrer d'autres déterminants qui ont également une influence sur le processus d'intention d'achat responsable, telles que l'utilité attendue et l'influence sociale.

La section de conclusions qui succède la liste de références bibliographiques, aussi bien dans la partie théorique que dans la partie empirique du travail, inclue aussi des considérations quant aux limitations de celui-ci. Elle propose également des relations en vue à de futures recherches qui dériveront de cette Thèse. 


\section{CONCLUSIONS}

A partir de l'analyse du cadre conceptuel et des resultats obtenus lors du processus de validation du modèle proposé, le contenu des pages suivantes a pour but d’exposer les conclusions principales dégagées par le travail réalisé et ce que celles-ci impliquent pour la gestion. Nous incluerons également des réflexions concernant les limites de cette étude et les possibles lignes de recherches qui pourront être suivies dans le futur.

Ainsi, et en ce qui concerne l'analyse du cadre théorique et conceptuel, la mise en contexte depuis la perspective de la praxis institutionnelle et l'évolution des approches théoriques et pratiques quant à l'analyse de la perception des comportements responsables des organisations depuis la perspective du consommateur, la première conclusion que nous devons tirer est celle que l'acceptation, la confiance et le soutien de la société à une entreprise dépend non seulement des attentes générées, mais surtout et particulièrement de l'accomplissement de celles-ci (ERSE 2010). En effet, ce soutien ne dépend pas uniquement de l'opinion des propriétaires, actionnaires ou shareholders, il est aussi tributaire des travailleurs qui sont à la demande de droits sociaux et économiques, des clients quand ceux-ci exigent des produits de qualité, et d'un bien long etcétéra de publics-cibles ou stakeholders internes et externes qui inclut les communautés dans lesquelles les entités développent leurs activités et une société dans son ensemble, chaque fois plus soucieuse des questions qui touchent de près le développement responsable et durable.

À l'instar de ce que nous citons précédemment, l'analyse des débats qui ont eu lieu au fil du temps dans les milieux académiques ainsi que les approches et les efforts programmatiques réalisés par différentes institutions dans le but de trouver une définition commune et de doter d'un contenu le terme "responsabilité", ne permet que de conclure, malgré l'importance croissante des questions abordées, l'absence, aujourd'hui encore, d'un concept unique et généralement accepté. Nous ne trouverons pas non plus, dans un futur immédiat, une seule ligne de travail dans le développement 
du cadre théorique qui puisse arriver à soutenir un concept revêtant de telles caractéristiques. Il n’existe pas non plus des méthodes de mesure et/où des procédés empiriques standardisés pour la recherche (par exemple, et parmi tant d'autres, Mc Williams et al. 2005; Garmendia 2009). Certes, la propre nature du concept dont le caractère pluridisciplinaire, ouvert et dynamique, évolue avec le temps et qui dépend à la fois de la culture, de l'idéologie et des habitudes de chaque société (Carroll 1979; Van Herpen et al. 2003; González 2005; Argandoña et al. 2011), donne en-soi une explication claire quant à la prolifération des approches et des théories qui ont été construites, et qui sont encore en construction, en ce qui concerne la responsabilité des organistions.

Ainsi et dans ce sens, un des aspects fondamentaux et sous-jacent de ces nouvelles approches sur les conduites responsables passe sans doute par la redéfinition du rôle que des organisations à chaque fois plus engagées, liées avec les groupes d'intérêt et la société seront amenées à jouer. Celles-ci ne sauraient jouer ce rôle non seulement de façon sporadique et/ou conjoncturelle mais bel et bien à long terme et de manière intégrale, en répondant à des demandes de nature et contenu différents dans le cadre d'un environnement global dans lequel, outre l'atteinte des objectifs et le fait d'assumer des compromis financiers, les entités doivent prendre en compte les conséquences sociales et environnementales du développement dans leur activité, les requêtes des consommateurs et des investisseurs responsables, les effets au sein des communautés et environnements dans lesquels elles agissent et, en définitive, la place qu’occupera le développement responsable et durable. Un degré majeur de la reconnaissance de leur travail et de leur influence sur le développement socioéconomique représentera une juste contrepartie.

C’est précisément cette nouvelle conception (en partie la conséquence d’un nouveau système de valeurs imprégnant la société actuelle) celle qui détermine le besoin le d’approfondir la relation entreprise-société à travers une connaissance intégrale (Garriga et Melé 2004), intègre et réciproque, qui inclut la prise en considération de divers groupes d'intérêt dont les agissements sont capables d'engendrer une grande pression sur l'environnement concurrentiel de l'entreprise (Bigné et al. 2005). Ces groupes d’intérêt réagissent face aux pratiques de responsabilité sociale et imprésariale. Il est donc fondamental d'analyser plus particulièrement les réactions et les conduites 
induites aux consommateurs puisqu'il est évident que cela aura des conséquences significatives sur le travail et les résultats des entreprises.

C'est pourquoi nous pouvons conclure que la conception et la mise en pratique de programmes et d'actions de responsabilité organisationnelle sur une période plus récente n’obéit pas seulement à un mandat ou à une régulation des pouvoirs publics mais aussi à une sensibilité sociale et imprésariale plus développée en rapport avec des réalités déterminées qui font l’objet d’une préoccupation spéciale : graves violations des droits fondamentaux, détérioration environnementale, manque de conditions élémentaires pour une vie digne, etc. (Melgar 2009: 108).

Si nous portons une attention particulière aux différentes approches qui ont abordé l'étude de la responsabilité, on peut observer comment le cadre conceptuel utilisé le plus souvent est celui de la théorie des groupes d'intérêt ou stakeholders (Phillips et al. 2003, Bigné et al. 2011). Or, beaucoup de choses ont été dites depuis cette perspective sur les obligations et les responsabilités des entités et de leurs cadres envers d'autres stakeholders, mais très peu quant à la responsabilité que pourraient avoir ces stakeholders à l'égard de la corporation (González 2001), c’est pourquoi une tâche essentielle et encore à développer consiste à déterminer en quoi et pourquoi l'entreprise est-elle responsable et non seulement devant qui a-t-elle des obligations ou doit-elle répondre, ce qui implique la nécessité de disposer de critères normatifs et d’objectifs qui permettent d'aborder une réflexion sur les responsabilités de l'entreprise dans un sens plus large.

Que l'on parte de ces approches ou que l'on parte d'autres alternatives, la production scientifique concernant la responsabilité des entités productives a donné lieu à une littérature prolixe au sujet de l'organisation des entreprises (Pérez 2011) qui devient bien plus rare si l'on tient compte des apports provenant d'autres domaines scientifiques d'entreprise, d'autres environnements économiques, ou d'autres disciplines, malgré l'évident caractère pluridisciplinaire à partir duquel on doit aborder cette étude. Dans tous les cas et, étant donnée la diversité des aspects recueillis ainsi que la pluralité des approches et des perspectives, une claire fragmentation de la recherche en une infinité de lignes de travail ouvertes est mise en relief. 
Parmi toutes ces lignes, ce travail s'est concentré sur celles qui analysent la relation des consommateurs avec la responsabilité, très peu développées jusqu'à présent. Il est d'ailleurs interpellant (Andreu et al. 2004; Bigné et al. 2005) que, jusqu'en 2000, si peu de travaux se soient spécifiquement concentrés sur ce type de réactions de la part des consommateurs (Brown et Dacin 1997; Murray et Vogel 1997; Creyer et Ross 1997; Ellen et al. 2000), comme le soulignent des auteurs tels que Sen et Bhattacharya (2001) ou, beaucoup plus récemment, Pérez (2011). Même si cette catégorie de travaux a été considérablement stimulée ces dernières années, le nombre de recherches "pâli si on le compare à d'autres études sur la responsabilité" développées dans différents secteurs des disciplines imprésariales (Alvarado 2008:106).

Malgré que la demande de comportements socialement responsables de la part des citoyens et des organisations de la société civile est un des aspects les plus significatifs de la scène internationale de ces dernières années (Doh et Guay 2006), et que l'évidence des différentes stratégies avec lesquelles les différents groupes ou collectifs ont cherché à satisfaire leurs demandes (García et al. 2011).

Dans cet ordre des choses, parmi tous les agissements possibles destinés à demander un comportement social responsable aux entreprises, ce travail a été particulièrement orienté vers celles qui ont une majeure justification économique selon les relations que les agents économiques établissent lorsqu’ils prennent leurs décisions. C'est-à-dire, celles qui sont liées à ces relations lors du processus d'achat, en analysant et en concluant comment le marché et le pouvoir d'achat du consommateur peuvent effectivement être utilisés comme un élément d'expression des préoccupations sociales, environnementales et éthiques de ce dernier envers les entités productives.

Il en est ainsi malgré que la théorie du marché de libre choix à l'égard de la relation entreprise-client ne soit pas exempte de critique (Weiss 1994), qui émanent en partie de leurs propres hypothèses (asymétries d'information et de pouvoir). C'est pourquoi nous pouvons donc nous demander si la matérialisation des approches de responsabilité partagée (également par le consommateur) pose des degrés de difficultés significatifs dans une société comme celle de nos jours, où le marché offre une grande diversité de produits et d'activités, où les consommateurs devraient connaître et avoir des informations complètes sur l'intégralité de ceux-ci lorsqu'ils prennent chacune de leurs multiples décisions d’achat (Valor 2010). 
Ainsi, étant donnée la pluralité des aspects en relation avec la responsabilité organisationnelle qui sont connectés d'une manière ou d'une autre aux différentes phases du processus d'achat, et en essayant d'éluder ces limites tout en concrétisant clairement le domaine d'étude. Celle-ci s’est concentrée sur les étapes et les processus qui ont un rapport avec les intentions d'achat du consommateur, en décrivant pour cela l'interaction entre la génération de la demande et le besoin d'obtenir des informations sur la conduite plus ou moins responsable des offres de marché et des entités qui les réalisent, en se matérialisant à travers la recherche et la recompilation effective d'informations qui touchera aussi à ces aspects, pour ensuite pouvoir évaluer et observer la répercussion traduite par une intention d'achat croissante envers les offres socialement responsables. En outre, il faudra prendre en considération toutes les variables correspondantes en tant que piliers centraux qui permettent de décrire le modèle proposé de considération et d'évaluation de la responsabilité ans le processus d'intention d'achat.

C’est dans ce sens, en premier lieu, que nous en avons conclu le besoin d'inclure dans le modèle proposé la perspective de la perception, avec deux variables fondamentales, tels que le sont le concept de la responsabilité attribué au consommateur et les motifs que celui-ci attribue aux comportements responsables des entreprises. Il en est ainsi puisque, comme on peut l'apprécier dans la littérature, les études de la perception du consommateur sont les dérivés de l'analyse préalable de différentes dimensions de la responsabilité proposées dans le modèle de Carroll (1979 et 1991), lorsqu'il a pu constater comment ces associations de responsabilité ont eu des effets sur l'intention d'achat à travers le processus de formation de l'image que la compagnie est capable d'engendrer et que le consommateur est capable d'apprécier.

En second lieu, nous avons également pu constater comment le processus n’est pas uniquement conditionné à la propre séquence décisionnelle, au sens et aux attributions correspondantes au comportement de l'entreprise, mais aussi à d'autres séquences lesquelles, d'une manière directe, nuancent les valeurs d'offres responsables qui sont en rapport aussi bien avec les variables internes de l'individu liées à l'utilité attendue qu'avec d'autres variables externes à ce comportement qui déterminent l'influence sociale. C’est la raison pour laquelle nous avons incorporé les éléments de construction cités dans le modèle proposé de prise de décisions du consommateur fondés sur des critères de responsabilité, en analysant ensuite les interrelations qui 
peuvent être établies avec les variables déterminantes ou explicatives du composant évaluateur des offres responsables.

En effet, et d'un point de vue pratique, nous n'avons jamais perdu de vue l'objectif ultime de ce travail : construire un modèle perceptif utile dans l'explication du processus séquentiel de décision d’intention d’achat, fondé sur l'incorporation de critères de responsabilité de la part du consommateur, en analysant les variables explicatives ou déterminantes qui ont de l'influence sur l'évaluation des offres responsables.

Par conséquent, nous avons mené à bien une étude psychométrique à partir d'un échantillon représentatif de la population, ’pa travers l'élaboration et l'administration d’un questionnaire, en recueillant des données élémentaires qui pourraient rendre opérationnelles les variables étudiées dans ce modèle. Dans ce but que nous avons employé des techniques statistiques d'analyse factorielle, descriptive, et d'équations structurelles, en rendant compte du degré d’accomplissement de l’hypothèse de départ.

Par conséquent, la réalisation d’une analyse factorielle exploratrice nous fournit une première approche concernant les conclusions, qui explique la segmentation du concept de responsabilité en deux groupes (proximal et distal), tout en indiquant que les consommateurs n’entrent pas dans le "strict respect des lois" à l'intérieur du concept. En outre, deux facteurs (stratégique et social), ont fait leur apparition dans les attributions au comportement responsable des entreprises, tandis que quatre facteurs ont été extraits pour la génération de la demande qui viennent parfaire les deux précédents déjà trouvés quant au concept de la responsabilité (distal -1 et 2- et proximal -1et 2-), par conséquent, les consommateurs ne rentrent plus dans aucun groupe antérieur en tant que moteur de génération de la demande, de fair play à l'égard de la concurrence et de la collaboration ouverte avec les administrations et les O.N.G.

À l'intérieur de l'analyse factorielle, les phases restantes du processus d’intention d'achat responsable ont dégagé, comme résultat, les facteurs prévus dans le modèle initial sur l'acquisition de l'information responsable et l'évaluation des offres responsables; il en est de même en ce qui concerne d'autres facteurs déterminants (utilité attendue et l'influence sociale). Par contre, le fait d'avoir vécues des expériences positives avec des produits et des marques d'entreprises socialement responsables et que 
celles-ci soient une référence en matière de consommation n’est plus considéré comme un indicateur du processus d'intention d'achat.

En se fondant sur les dimensions factorielles identifiées, nnous avons mené à bien une analyse des corrélations qui a permis de dégager un nombre important d'interactions qui démontre une forte correspondance entre les estimations des construtions. En outre, les conclusions de cette analyse sont comparées à d'autres ayant une nature plus descriptives, dont on constate l'importance grâce à leurs notes moyennes, tout en soulignant les attributions du comportement stratégique de l'entreprise lorsqu'il s'agit d'être socialement responsable ou du concept distal qui définit l'entreprise responsable tandis qu'une dispersion majeure des données correspond aux variables de génération de demande (proximal 1 et proximal 2) et à l'évaluation des offres responsables. Par contre, les données concernant la construction comportement imprésarial stratégique sont plus concentrées.

Le modèle de mesure initial est fondé sur l'incorporation de différentes dimensions obtenues lors de l'analyse factorielle au modèle théorique proposé , en présentant, durant sa validation, les limites de fiabilité et de validité ainsi qu’un léger ajustement décelé au niveau de la mesure externe qui a mis en relief le besoin de déterminer à nouveau l'approche de départ en portant une attention particulière au degré d'adéquation des items employés pendant la mesure des constructions, afin d'arriver à un ajustement plus précis du modèle de mesure qui servirait de condition préalable à la vérification des ajustements du modèle structurel et des hypothèses recueillies à l’intérieur de celui-ci.

Un second modèle a respecté le patron structurel du modèle initial au même moment où nous constations la modification pertinente du schéma interne de mesure à travers des altérations dans la compositions des indicateurs liés aux variables latentes (ne retenant que les indicateurs avec des charges factorielles significatives) afin d'améliorer la consistance interne du résultat final alors que les relations structurelles ont conservé la même validité et nous ont ainsi permis de conclure qu’il s'agissait d'une meilleure option si on la compare à la première alternative lors de la corroboration empirique des hypothèses posées préalablement. 
Néanmoins, dans le but d'améliorer les résultats, nous avons proposé un troisième modèle rival. Il s’agissait d'approfondir la viabilité de la structure prédictive et de conserver pour chaque construction latente les indicateurs ayant des charges factorielles significatives dans l'analyse préalable. Ce troisième modèle réajuste le précédent en tenant compte de ses défaillances structurelles, basées sur:

- L’élimination de trois variables de génération de demande de responsabilité (distal 2, proximal 1 et proximal 2), puisque nous avons détecté des problèmes en termes de fiabilité mineure, de validité de la construction et de l'inexistence d'un effet significatif de ces variables. Seule a été considéré la génération de demande 1 en tant que dimension valide et fiable.

- La suppression du modèle proximal de responsabilité étant donné qu’il était peu fiable et qu'il était déconnecté du reste du modèle (d’un côté, de par les évaluations reçues des attributions du comportement imprésarial- aussi bien stratégique que socialet, de l'autre, celles qui ont affectées la génération de demande), en prenant uniquement en considération le concept distal en tant que déterminant ou facteur ayant une influence sur le processus d'intention d'achat.

- La conservation de la construction influence sociale (malgré la défaillance de ses indicateurs de mesure), en écartant les relations concernant les perceptions du comportement imprésarial social et l'évaluation des offres responsables par manque d'effet significatif. C’est pourquoi le comportement imprésarial social est configuré comme une variable latente exogène dans le modèle final. De plus, l'absence d'un effet significatif des attributions au comportement imprésarial stratégique sur l'utilité attendue nous a conduit à éliminer celle-ci du modèle structurel.

À partir de la révision des résultats, le modèle de mesure réajusté s’est avéré valide et fiable. Nous avons pu apprécier pour tous les items une signification statistique en accord avec la technique bootstrap de PLS (charges standardisées $\lambda_{\mathrm{y}}$ et $\lambda_{\mathrm{x}}$ supérieures à 0,50). La consistance interne des échelles (Coefficient Alpha de Cronbach, indice de fidélité composée) a été validée dans sa quasi-totalité et amplement acceptable pour toutes les échelles, telles que la validité convergente (indices AVE) et la validité discriminante, qui a réaffirmé la solidité du modèle de mesure en vérifiant que chaque 
construction partageait plus de variance avec ses indicateurs qu'avec d'autres variables latentes du modèle.

Nous pouvons dégager de l'analyse structurelle du modèle réajusté (en ce qui concerne les indices $R^{2}$ et $Q^{2}$ ) le manque d'importance prédictive pour ces trois construction (comportement stratégique de l'entreprise, concept de responsabilité et utilité attendue) alors que cette importance prédictive est maintenue pour les trois variables centrales du modèle, concrètement la génération de demande (distal 1), l'acquisition d’information responsable et l'évaluation des offres responsables.

Pour leur part, les effets directs entre les variables latentes (à travers le procédé bootstrap) ont confirmé toutes les relations mises en hypothèse, exceptée celle qui fait référence à l'influence directe et positive du comportement social de l'entreprise sur le concept de responsabilité perçu (H5bb), puisque, parmi les trois critères proposés pour valider les hypothèses, il ne remplit que le moins restrictif (celui de Falk et Miller 1992, avec une variance expliquée de $4.68 \%$ ). Nonobstant, cette relation pourrait également être acceptée en tant que marginalement significative.

En effet, nous avons concrètement confirmé des relations directes significatives entre l'acquisition d'information de responsabilité et l'évaluation des offres responsables (H1); la génération de demande de responsabilité et l'acquisition d’information de responsabilité (H2); le concept de responsabilité (distal) et la génération de demande de responsabilité -distal 1- (H3). L'utilité attendue établit également une relation positive avec l'évaluation des offres responsables (H4a), avec l'acquisition d'information de responsabilité (H4b) et avec la génération de demande de responsabilité -distal 1- (H4c). Il en est de même pour le comportement social de l'entreprise perçu avec l'utilité attendue perçue (h5a), et le comportement stratégique de l'entreprise perçu avec le concept de responsabilité (H5ba). L’influence sociale établit aussi une relation positive avec le comportement stratégique de l'entreprise (H6a), avec l'utilité attendue (H6b) et avec l'acquisition d’information de responsabilité (H6c).

Afin de réaffirmer les résultats obtenus, nous avons étudié l’importance relative attribuable à chaque construction dans le modèle (statistique $f^{2}$ ) en comparant la variance expliquée de la variable liée quand la prédictive est employée ou omise. Nous sommes arrivés à la conclusion que, même si le prédicteur du concept de responsabilité 
a l'effet le plus important du modèle épuré sur la génération de demande de responsabilité expliquée en tant que distal 1 ( $\left.\mathrm{f}^{2}=0,46\right)$, toutes les constructions apportent une efficacité prédictive au modèle.

Finalement, la portée prédictive du modèle se fait évidente non seulement à partir des résultats concernant les liens directs que nous venons de décrire, mais également grâce à d'autres effets globaux et significatifs entre : le comportement stratégique de l'entreprise et la génération de demande de responsabilité -distal 1(4,46\% de la variance expliquée); le comportement social de l'entreprise avec l'évaluation des offres responsables (3,23\%), et avec la génération de demande de responsabilité -distal 1- (2,73\%); et l'utilité attendue avec l'évaluation d’offres responsables ( laquelle, globalement, augmente son effet à 22,13\%).

\section{Implications théorico-pratiques:}

La solidité obtenue n'est pas négligeable et soutient l'approche de départ d'un modèle perceptif de la responsabilité depuis la perspective de la demande appliqué au processus décisionnel du consommateur quand celui-ci considère ou prend en considération des critères de responsabilité. Cette solidité fait en sorte que les apports de ce travail puissent être considérés comme un progrès vers des propositions théoriques et des interventions pratiques davantage ciblées sur l'explication et la promotion du comportement responsable du consommateur.

C’est ainsi que, si nous commençons par les implications théoriques de cette étude, nous pouvons démontrer que, en ce qui concerne leur comportement, les organisations sont responsables face à elles-mêmes de leur propre gestion, mais elles le sont également face aux tiers et plus concrètement face à tous les groupes ou collectifs qui, que ce soit de façon directe ou indirecte, ont une influence ou sont influencés par les agissements des organisations. Cela veut dire que les résultats des activités de cellesci s’étendent sur toute la société.

Les différentes approches existantes (aussi bien académiques qu’émises par des institutions qui participent aux débats) coïncident sur le fait de projeter des discussions théoriques et des mises en œuvre pratiques de la responsabilité tout en maintenant une 
orientation plutôt dirigée vers la définition et la mesure de la portée que l'activité développée par l’organisation peut avoir sur les publics cible et l'ensemble de la société. Or, il est certain que l'entreprise et également être contemplée et évaluée depuis une optique externe, de la part des consommateurs, des administrations, des communautés, des médias ou de la propre société. Ce sont eux qui délimiteront et traceront les contours d'une entreprise responsable, lorsqu'ils poseront la responsabilité depuis le point de vue des collectivités avec lesquelles l'entité est en relation ou en la mettant en contexte dans l'environnement dans lequel celle-ci agit (Guibert 2007 et 2011).

Si nous suivons cette ligne, en considérant que la pression des marchés de consommation est un des facteurs qui, ces dernières années, a fortement stimulé le nombre de contributions des écrits sur divers aspects de la responsabilité des organisations et, lorsqu'un nombre croissant de consommateurs opte plus que jamais pour des patrons et des critères de consommation responsable, le modèle proposé fait lumière sur le processus d'intention d'achat responsable et permet une évolution quant à la compréhension des variables les plus significatives qui l'expliquent et de quelles manières celles-ci sont en interrelation.

D’autre part, et également en tant qu’implications pratiques dérivées de la recherche réalisée, cette étude fait apparaître l'importance de l'évaluation et de l'agissement subséquent des consommateurs face à l'information dont ils disposent sur la manière de gérer et d'implémenter la responsabilité des entreprises (et par extension de divers types d'organisations dans le domaine public ou de l’Économie Sociale). Ceci pourrait s’avérer intéressant non seulement pour la propre entreprise laquelle, à un moment donné, pourra être l'objet d’une évaluation, mais aussi pour maints agents qui souhaiteraient connaître ces avis et ces décisions prises par le consommateur ainsi que, plus particulièrement, leurs conséquences.

Si l'on commence par les entreprises, l'étude démontre qu'un effort de leur part, perçu et évalué par le consommateur en tant que socialement responsable, a une influence sur la valorisation postérieure que celui-ci réalise sur les offres émises par les entreprises en termes d'utilité attendue mais pas autant sur le concept de responsabilité dont fait preuve ce consommateur, considéré comme satisfaction des intérêts des stakeholders secondaire (concept distal). Néanmoins, quand le comportement de l'entreprise est attribué à une raison de caractère stratégique, cette circonstance a aussi 
une répercussion sur l'évaluation du consommateur, mais d'une forme indirecte (et, par conséquent, moins importante), à travers le concept qu'il se fait du comportement (distal) et, surtout, dans le processus de décision de préachat responsable.

Dans cet ordre des choses, il semble fondamental que l'entreprise encourage des politiques de communication sur ses agissements et conduites responsables qui s'avèreront crédibles et sincères, ou le consommateur puisse apprécier des valeurs qui ont favorisé cet engagement au-delà des motifs stratégiques. Ces implications sont aussi utiles pour des organisations sectorielles et des groupes d'entreprises puisqu'elles servent de soutien empirique pour encourager des politiques de promotion responsable parmi leurs associés.

C’est pourquoi il faut également comprendre que, tant pour les législateurs, les responsables publics administratifs, les interlocuteurs sociaux que pour les syndicats, organisations de consommateurs, O.N.G et diverses organisations, il est particulièrement intéressant d'arriver à comprendre la connaissance partielle du concept de responsabilité que le consommateur possède actuellement, en arrivant à comprendre l'entreprise socialement responsable d'un point de vue distal ( en rapport avec des agissements environnementaux, des problématiques sociales, la contribution au développement économique et régional, les intérêts de la communauté, ainsi que la collaboration ouverte avec des administrations et des O.N.G), alors qu'il n’identifie pas le concept proximal qui décrit des aspects plus en relation avec le noyau de l'activité des entreprises (attentes des entrepreneurs, des clients, des actionnaires, des fournisseurs voire du fair play avec la concurrence).

Cette distorsion cognitive du consommateur constitue en soi un avertissement, aussi bien aux responsables des administrations publiques (dans la conception des politiques publiques), qu'à différents acteurs de la société civile qui sont hautement intéressés par l'adoption de patrons de consommation plus responsables de la part des consommateurs ou, en tout cas, pour que l'on y investisse des moyens et que l'on fasse les efforts nécessaires pour transmettre une connaissance plus complète de ce qu'est et de ce que veut dire le concept de responsabilité des organisations. Voici ce qui doit servir de socle afin de réaliser des campagnes publiques de sensibilisation et d'information citoyenne. 
Au-delà de la formation, si l'on veut réellement transférer les préoccupations sociales des consommateurs au marché, dans le but de renforcer l'argument économique lorsque ceux-ci prennent leurs décisions d’achat en faveur de la responsabilité, il est important que ceux qui disposent d'informations non seulement sur les produits offerts et les résultats économiques des entreprises qui les offrent, mais aussi sur l'effort fourni par ces entités quant aux domaines restants de leur responsabilité, ce qui favoriserait lors du processus d'achat la génération de demande non seulement d'actions à l'égard de l'environnement ou des engagements sur les problèmes sociaux (distal 1), tels que les résultats obtenus grâce au modèle proposé le suggèrent, mais aussi divers aspects ayant une grande transcendance sur le comportement responsable (attentes des clients, employés, partenaires, actionnaires, communauté local...).

\section{Limites et futures lignes de recherche:}

La portée des résultats obtenus dans l'étude réalisée et les hypothèses de départ non réalisées doivent être interprétées à la lumière de certaines limites théoriques et méthodologiques qui laissent la porte ouvertes à de nouveaux travaux dans ce domaine.

Ainsi, une première faiblesse du modèle de recherche développé dans les pages précédentes nous renvoie à la propre nouveauté du cadre théorique employé dans l'évaluation du comportement du consommateur en tant qu'agent décisionnaire lors du choix des produits fondé sur des critères de responsabilité, en déterminant aussi bien le processus de ces décisions que l'influence sociale perçue. Dans ce sens, le développement insuffisant de certaines variables du modèle, particulièrement ayant trait à l'utilité attendue et à l'influence sociale, soumettent la portée des contributions attribuables à cette étude aux progrès de recherches plus récentes dans la zone où les résultats auront une réplique ou auront approfondi l'affinement des constructions proposées et des relations entre ces contextes spécifiques de comportement responsable du consommateur.

En effet, il faut donc préciser que la plupart des échelles employées dans la mesure des variables du modèle ont été développé ad hoc pour atteindre les buts de cette recherche ; leur future validation est nécessaire pour contraster leur utilité au-delà des objectifs qui leur ont été assignés dans ce travail. Dans l'attente de ces progrès et, 
même si les analyses statistiques préliminaires réalisées ont tout de même apporté une preuve quant à la fiabilité et à la validité du questionnaire employé, la capacité du modèle de mesure proposé pour rendre compte des relations prédictives mises en hypothèse entre les variables est soumises à un affinement des indicateurs initialement proposés, tout en ayant dérivé vers la configuration des échelles intégrées à cause de quelques items et, en même temps, rendant spécialement questionnable l’estimation de la construction "influence sociale" à partir d'un seul énoncé, ce qui invalide sa consistance interne. Donc, pour établir la robustesse prédictive du modèle proposé nous avons besoin de nouveaux développements psychométriques dirigés à la construction d'instruments de mesure valides et fiables fondés sur une plus grande spécificité définitionnelle des constructions impliquées.

Dans ce sens, le modèle est incomplet car il se limite à l'étude de l'intention d’achat responsable et il s'avère donc susceptible d’être développé afin de prendre en compte toutes les phases du processus de décision d'achat. C’est pourquoi on devrait inclure non seulement l'étape de décision d'achat / non achat, mais aussi les étapes postérieures à celles-ci, en relation avec les résultats de l'évaluation postérieure de la décision adoptée et de son utilité, ainsi que les répercussions que de tels résultats pourront avoir sur les nouvelles décisions du consommateur, où son comportement aura de nouveau une incidence sur les valeurs personnelles et sur la perception de l'efficacité de son agissement, ce qui n’est pas exempt de difficultés (comme le manque d’alternatives sur le marché cohérent avec leurs valeurs et leurs attentes, les restrictions budgétaires, le sacrifice parmi les critères économiques et ceux qui ne le sont pas). En tout cas, un tel développement nous permettrait de disposer d'un modèle plus complet pour sa validation, c'est pourquoi l'ampliation de l'approche de la recherche assumée dans ces pages est entièrement appropriée, en incluant d'autres facteurs exogènes ou endogènes ayant suffisamment de potentiel pour causer des influences directes ou modérer beaucoup de relations mises en hypothèses entre variables. Cette ligne de travail nous laisserait présager un progrès décisif vers l'identification d'un processus de décision d'achat responsable plus complet et structuré.

D’autre part, et malgré l'utilité de la conception comparative-transversale employée dans la compréhension du processus de décision préachat responsable en interaction avec les facteurs de niveau formatif, secteur d'activité et contextuels, nous avons besoin de nouvelles analyses longitudinales pour rendre compte des processus 
initiaux d'évaluation d'offres responsables de la part du consommateur de façon claire et adéquate. En nous fondant sur cette approche nous réaffirmons la pertinence, voire le besoin, en tant que proposition d'une future recherche, de disposer d'une plus quantité plus élevée de conception longitudinales qui puissent, au fur et à mesure, accueillir davantage de critères d'évaluation d'offres responsables (variations cycliques).

Une autre limite méthodologique de l'étude menée à bien fait référence au niveau de représentativité atteint dans l'échantillon employé dans l'étude empirique. Même si l'échantillon peut être considérée représentatif, il n’en est pas moins sûr que (comme nous l'avons déjà indiqué), la difficulté de la sélection des individus en suivant le critère proposé a finalement supposé l'obtention de l'opinion des consommateurs ayant des niveaux de formation légèrement plus élevé que ceux de la population qu’il souhaite représenter. Par rapport à cette question, et bien que l'effort investi dans la sélection des participants à la recherche à partir d'un procédé d’échantillonnage stratifié qui a permis d'assurer une composition d'échantillons fondée sur la distribution réelle du consommateur par niveau de formation ne saurait passer inaperçu, la complexité entraînée par le processus méthodologique de récolte de données a dérivé dans certains cas très ponctuels vers ce que nous pourrions considérer comme un recours à des échantillons de convenance, à partir de la disponibilité de collectif sur lesquels réaliser une enquête. Par conséquent, de futures recherches devraient considérer l’objectif de fournir une précision majeure via une sélection aléatoire d’individus représentatifs, non seulement de différents niveaux de formation, mais aussi à partir d'autres caractéristiques de la population, en arrivant ainsi une plus grande portée des résultats obtenus.

Si nous suivons cette même ligne argumentaire, même si la réalisation d'une étude empirique dans une zone géographique ayant des populations diverses pronostique une solidité adéquate des conclusions dégagées de cette étude, nous avons besoin d'études complémentaires concernant la généralisation des résultats à d'autres populations nationales ou internationales, permettant même d'accueillir d'autres modèles de comportement responsable du consommateur dans le but de gagner une plus grande précision dans l'identification des facteurs d'influence sociale, d'utilité attendue ou autres qui déterminent l'évaluation des offres responsables de la part du consommateur. 
Finalement, et en ce qui concerne la méthodologie appliquée à l'analyse des données recueillies, il s’avère nécessaire de préciser que, même si les procédés fondés sur les modèles d'équation structurelles permettent d'évaluer le degré dans lesquels certains résultats empiriques sont consistants avec le modèle théorique préalablement posé en hypothèse, ils ne fournissent absolument pas une preuve de soutien à l'existence d'une seule représentation possible de la réalité à partir des données disponibles. Par conséquent, la nature transversale de la conception employée fait que les conclusions avancées dans ce travail doivent être interprétées plus comme des preuves de relations statistiquement significatives entre variables, que comme des inférences causales entre celles-ci. Il est donc nécessaire d'effectuer de nouvelles recherches fondées sur les conceptions longitudinales et expérimentales qui permettront d'isoler l'effet d'autres types de variables exogènes ou endogènes qui puissent interférer avec le comportement responsable du consommateur. Ainsi, la réalisation d'études ou d'applications sur des produits concrets permettrait de disposer de référents intéressants pour la comparaison ou la mise en contraste de résultats. 